\title{
LA COMPETENCIA TRIBUTARIA VERTICAL ENTRE NIVELES DE GOBIERNO
}

\author{
Darío Alejandro Rossignolo \\ TESIS DOCTORAL \\ DOCTORADO EN ECONOMIA \\ FACULTAD DE CIENCIAS ECONOMICAS \\ UNIVERSIDAD NACIONAL DE LA PLATA
}

DIRECTOR DE TESIS: Dr. Gonzalo Fernández

La Plata, Diciembre 2013 
A mis padres Ricardo y Ana, y mis hermanos Adrián y Vanina por su permanente apoyo 


\section{Agradecimientos}

Quisiera agradecer en primer lugar a mi tutor, el Dr. Gonzalo Fernández, con quien he discutido largamente los desarrollos y conclusiones de la tesis, por su tiempo y dedicación.

Esta tesis se ha enriquecido sustancialmente a partir de las sucesivas presentaciones realizadas en los seminarios de Doctorado, en las 44as. Jornadas Internacionales de Finanzas Públicas (JIFP) de la Universidad Nacional de Córdoba, y en las XLV y XLVI Reuniones Anuales de la Asociación Argentina de Economía Política (AAEP).

En relación con los primeros, quisiera agradecer especialmente al Dr. Walter Cont por sus agudas y esclarecedoras observaciones, los que han resultado de enorme importancia para orientar el desarrollo y la elaboración de las temáticas presentadas, y a los Dres. Alberto Porto, Irene Brambilla, y Leonardo Gasparini, cuyas sugerencias pertinentes han sido de gran utilidad.

En lo que refiere a las JIFP y a las Reuniones Anuales de la AAEP, quisiera dejar expresa constancia de mi gratitud hacia el Lic. Néstor Grión, del IERAL, quien a partir de la presentación de una versión preliminar de los capítulos 2 y 3 de este trabajo contribuyó de manera sustancial a la elaboración de los ejemplos numéricos presentados en esta tesis, y al Dr. Horacio Piffano, con quien también he intercambiado opiniones, sobre todo en lo referente al capítulo 1 , por su permanente interés.

Desearía adicionalmente agradecer a la Dra. María Lorena Garegnani, por su predisposición para la lectura y consecuentes sugerencias para el mejoramiento del capítulo 4 de esta tesis.

Tanto en los seminarios como en las jornadas mencionadas, la tesis se ha nutrido de comentarios y observaciones realizados por los Dres. Martín Besfamille, Ernesto Rezk, Diego Fernández Felices, Sebastián Freille, Daniel Heymann y Guido Porto, a quienes también agradezco.

En última instancia, quiero subrayar mi gratitud al Dr. Juan Carlos Gómez Sabaini, quien ha sido quien ha incentivado mi interés por las cuestiones relacionadas con las Finanzas Públicas en general, y por los efectos económicos de la tributación en particular.

Los errores que aún subsistieran son de mi entera responsabilidad. 


\section{Indice}

I. Introducción $\quad 7$

\section{Capítulo 1. Una reseña de antecedentes teóricos y empíricos 9}

1. Introducción 9

2. Aspectos conceptuales 11

3. Antecedentes teóricos 16

3.1. Fijación de alícuotas por parte de los gobiernos federal y subnacionales $\quad 17$

$\begin{array}{ll}\text { 3.1.1. Gobiernos con instrumentos limitados } & 17\end{array}$

3.1.2. Gobiernos con acceso a transferencias $\quad 21$

3.1.3. Competencia tributaria horizontal y vertical 23

3.2. Provisión de bienes públicos $\quad 26$

3.2.1. Gobiernos con instrumentos limitados $\quad 29$

3.2.2. Gobiernos con acceso a transferencias 34

3.2.3. Competencia tributaria horizontal y vertical 38

4. Antecedentes empíricos 46

4.1. Estimaciones internacionales 46

4.2. Estimaciones para el caso argentino $\quad 51$

5. Síntesis y conclusiones 54

III. Capítulo 2. Un modelo sobre externalidades tributarias verticales en impuestos sobre los consumos 57

1. Introducción 57

2. Planteamiento del modelo 59

3. Políticas impositivas de los distintos gobiernos 61

3.1. Política impositiva del gobierno unificado con impuestos de suma fija 61

3.2. Política impositiva del gobierno unificado con impuestos selectivos sobre bienes 63

4. Política impositiva descentralizada con impuestos selectivos sobre bienes 66

$\begin{array}{ll}\text { 4.1. Caso base } & 67\end{array}$

4.1.1. Políticas impositivas de los estados $\quad 67$

$\begin{array}{ll}\text { 4.1.2. Políticas impositivas del gobierno federal } & 70\end{array}$

4.1.3. Comparación entre los resultados de los niveles de gasto y tasas impositivas $\quad 73$

4.2. Caso en que ambos niveles de gobierno ignoran mutuamente la restricción $\begin{array}{ll}\text { presupuestaria del otro nivel. } & 78\end{array}$

4.2.1.Políticas impositivas de los estados $\quad 79$

4.2.2. Políticas impositivas del gobierno federal 81

4.2.3. Comparación entre los resultados de los niveles de gasto y tasas impositivas $\quad 82$

4.3. Caso en que ambos niveles de gobierno consideran en su totalidad a la restricción $\begin{array}{ll}\text { presupuestaria del otro nivel } & 84\end{array}$

$\begin{array}{ll}\text { 4.3.1.Políticas impositivas de los estados } & 84\end{array}$

4.3.2. Políticas impositivas del gobierno federal 86

4.3.3. Comparación entre los resultados de los niveles de gasto y tasas impositivas $\quad 88$

4.4. Caso en que el gobierno federal considera la restricción presupuestaria del gobierno $\begin{array}{lr}\text { provincial pero no a la inversa } & 89\end{array}$

4.4.1.Políticas impositivas de los estados $\quad 89$

4.4.2. Políticas impositivas del gobierno federal 91

4.4.3. Comparación entre los resultados de los niveles de gasto y tasas impositivas $\quad 93$

5. Un ejemplo numérico 93 
5.1. Impuestos de suma fija 98

5.2. Impuesto distorsivo 100

5.2.1. Caso de gobierno unificado 100

5.2.2. Caso de gobierno descentralizado con ambos gobiernos "miopes" 102

5.2.3. Caso de gobierno descentralizado en donde ambos gobiernos consideran la restricción presupuestaria del otro nivel de gobierno 104

5.2.4. Caso en que el gobierno federal considera la restricción presupuestaria de las provincias pero éstas son "miopes" 107

5.3. Simulaciones 110

6. Conclusiones 112

7. Anexo 115

IV. Capítulo 3. La deducción de impuestos en tributos sobre los consumos en un modelo con externalidades tributarias verticales 118

1. Introducción 118

2. Planteamiento del modelo 121

3. Deducción sobre precios 121

3.1. Caso base 122

3.1.1.Políticas impositivas de los estados 122

3.1.2. Políticas impositivas del gobierno federal 123

3.2. Caso en que el gobierno federal considera la restricción presupuestaria del gobierno $\begin{array}{lr}\text { provincial pero no a la inversa } & 124\end{array}$

3.2.1.Políticas impositivas de los gobiernos provinciales 125

3.2.2. Políticas impositivas del gobierno federal 126

3.3. Caso en que ambos niveles de gobierno ignoran mutuamente la restricción $\begin{array}{ll}\text { presupuestaria del otro nivel. } & 127\end{array}$

$\begin{array}{lr}\text { 3.3.1.Políticas impositivas de los estados } & 128\end{array}$

3.3.2. Políticas impositivas del gobierno federal 128

3.4. Caso en que ambos gobiernos consideran la restricción presupuestaria del gobierno $\begin{array}{ll}\text { otro nivel de gobierno } & 129\end{array}$

$\begin{array}{ll}\text { 3.4.1.Políticas impositivas de los estados } & 129\end{array}$

3.4.2. Políticas impositivas del gobierno federal 130

4. Un ejemplo numérico 131

4.1. Caso de gobierno descentralizado con ambos gobiernos "miopes" 132

4.2. Caso de gobierno descentralizado en donde ambos gobiernos consideran la restricción presupuestaria del otro nivel de gobierno 134

4.3. Caso en que el gobierno federal considera la restricción presupuestaria de las

provincias pero éstas son "miopes" 137

$\begin{array}{lr}\text { 4.4. Simulaciones } & 140 \\ \text { 5. Conclusiones } & 146\end{array}$

5. Conclusiones 146

V. Capítulo 4. Una estimación empírica sobre externalidades verticales en impuestos sobre los consumos en Argentina $\quad 148$

$\begin{array}{lll}\text { 1. Introducción } & 148\end{array}$

2. Antecedentes de estudios sobre la temática 149

3. Marco normativo y cuantitativo 151

3.1. Impuesto al Valor Agregado 152

3.1.1. Síntesis normativa $\quad 152$

3.1.2. Evolución histórica 153

3.2. Impuesto sobre los Ingresos Brutos Provinciales 156

3.2.1. Síntesis normativa 156 
3.2.2. Evolución histórica 157

3.3. Análisis cuantitativo 159

4. Aspectos teóricos 161

4.1. Modelo sin competencia horizontal 161

4.2. Modelo con competencia tributaria horizontal 166

5. Metodología empleada para el análisis $\quad 170$

5.1. Variables dependientes relevantes $\quad 170$

$\begin{array}{lr}\text { 5.2. Estrategia empírica } & 179\end{array}$

6. Presentación de los resultados 183

7. Síntesis de los resultados de las estimaciones 201

8. Conclusiones 204

9. Anexo estadístico 207

VI. Referencias bibliográficas 224 


\section{Introducción}

La teoría del "federalismo fiscal" analiza la estructura vertical del sector público y las interrelaciones que existen entre los diferentes niveles de gobierno. Considerando que los mismos están vinculados de manera horizontal y mantienen una coordinación vertical para el recaudo de los recursos y la producción y el suministro de los bienes públicos, la teoría se ha ocupado de analizar las múltiples interrelaciones que acontecen entre los diferentes niveles de gobierno.

Para analizar la asignación de funciones entre niveles de gobierno se ha utilizado la división tripartita de funciones básicas de la política fiscal propuesta por Musgrave: estabilización económica, redistribución del ingreso y asignación de recursos y provisión de bienes.

Existe un amplio consenso de que las dos primeras funciones se prestan con más eficiencia a nivel nacional, mientras que la tercera es la que ha concentrado mayor cantidad de argumentos a favor de la descentralización, en razón de poder determinar con la mayor precisión el nivel para la provisión y consumo de los bienes públicos. Como esta función tiene que ver con el suministro y financiamiento de bienes públicos, no es fácil determinar el nivel de gobierno que debe cumplirla, máxime cuando son las características y naturaleza de los bienes públicos las que llevan a que existan niveles de gobierno.

Cuando distintos gobiernos, del mismo nivel o de niveles superpuestos, comparten la misma base imponible, se genera un efecto de competencia tributaria: los gobiernos compiten entre sí por la recaudación impositiva. Si los gobiernos son del mismo nivel jurisdiccional, se genera competencia horizontal; si fueran benevolentes, el resultado, según la literatura, es una subprovisión de bienes públicos locales, en relación con el óptimo social global dado que la competencia se corporiza en la baja de tasas impositivas ("race to the bottom") con el fin de capturar base imponible. Si, por el contrario, los gobiernos fueran leviatánicos (Brennan y Buchanan), la competencia aporta una "disciplina fiscal” (“domar al leviatán”) que impide a los gobiernos enrolarse en políticas expansivas en lo que refiere al tamaño de su sector público.

Adicionalmente a lo comentado, existe otro efecto de la competencia horizontal, que está dado por la "externalidad horizontal": el cambio en la base imponible de la otra jurisdicción cuando la primera modifica sus variables impositivas. Esta externalidad, como el caso anterior, concluye con subprovisión de bienes públicos por parte de las jurisdicciones subnacionales; la competencia tributaria, a diferencia de las conclusiones de Brennan y 
Buchanan, genera resultados subóptimos, dado que cada gobierno no considera el efecto de la externalidad al variar sus tasas impositivas.

Sin embargo, la esencia del federalismo radica en la existencia de jurisdicciones superpuestas. Esto también tiene efectos sobre niveles de imposición y de gasto público; el hecho de que uno de los niveles varíe sus tasas impositivas afecta la base imponible compartida. Esta "externalidad vertical" puede generar provisión excesiva de bienes públicos y tasas de impuestos ineficientemente elevadas, considerando el óptimo social.

El objetivo de este trabajo de tesis consiste en analizar en particular el caso de las "externalidades verticales" en la imposición, es decir, el efecto sobre niveles de tasas y provisión de bienes públicos, por un lado, y la reacción de las tasas impositivas de uno de los gobiernos cuando el otro varía sus alícuotas impositivas.

La tesis se estructura de la siguiente manera. En el Capítulo 1 se desarrolla una extensa y detallada revisión de la literatura sobre la temática. En el Capítulo 2 se presenta un modelo sobre externalidades tributarias verticales, en donde emergen distintos resultados sobre niveles de tasas y provisión de bienes públicos en relación con distintos supuestos sobre el comportamiento de los gobiernos, mientras que en el Capítulo 3 se presenta una política específica para morigerar el efecto de las externalidades, dada por la deducción de impuestos. En el Capítulo 4 se presenta un modelo empírico para analizar la reacción de la política impositiva de uno de los gobiernos cuando el otro varía su tasa de impuestos, en particular para el caso de Argentina, en donde coexisten el Impuesto al Valor Agregado federal y el Impuesto sobre los Ingresos Brutos provincial. 


\section{Capítulo 1. Una reseña de antecedentes teóricos y empíricos}

\section{Introducción}

La literatura moderna sobre "tax competition" comienza con el propósito de comprender los potenciales problemas de eficiencia relacionados con la competencia por capital, llevadas a cabo por los gobiernos locales.

Estos modelos desarrollados por Wilson (1986) y Zodrow y Mieszkowski (1986) estaban basados en el análisis de Oates (1972), el cual mencionaba que "In an attempt to keep taxes low to attract business investment, local officials may hold spending below those levels for which marginal benefits equal marginal cost". Los modelos mencionados comparten la característica esencial de que representan a situaciones en las que los gobiernos locales fijan impuestos en forma no cooperativa, o independiente, en un proceso mediante el cual los gobiernos "compiten" por una base imponible móvil.

Si bien los mismos estaban destinados inicialmente a la competencia por capital, más tarde los análisis fueron ampliados para incluir competencia por impuestos a los bienes de consumo, o competencia para atraer firmas de gran tamaño.

La descripción anterior, sin embargo, encierra un proceso más amplio, dado que el hecho de competir por bases imponibles móviles lleva a variaciones en la recaudación. Una definición más abarcativa de "tax competition", en consecuencia, incluye al proceso de determinación de impuestos, también en forma no cooperativa por parte de gobiernos independientes ${ }^{1}$, en el cual la política impositiva llevada a cabo por cada uno de los gobiernos afecta la base imponible, y, consecuentemente, el nivel de recaudación tributaria de los demás gobiernos.

La fuente básica de la ineficiencia en estos modelos es la existencia de "externalidades interregionales", en donde las acciones que uno de los gobiernos toma, ya sea para mejorar el bienestar de sus residentes, en el caso de gobiernos benevolentes, o para incrementar la recaudación tributaria, en el caso de gobiernos leviatánicos, llevan a reducciones en los niveles de bienestar o de ingresos tributarios por parte de los demás gobiernos. En la literatura de "tax competition", esta externalidad se denomina "externalidad fiscal" o "externalidad tributaria".

\footnotetext{
1 "Independiente" refiere aquí al hecho de que cada gobierno tiene la potestad de fijar las alícuotas tributarias y definir bases imponibles.

2 Otro tipo de externalidad, según Wilson (1999), es la "externalidad pecuniaria" que existe cuando las regiones son lo suficientemente grandes como para afectar los precios de los factores o de los productos que enfrentan
} 
En gobiernos del mismo nivel, la ineficiencia se denomina "externalidad tributaria horizontal". Las discusiones sobre externalidades fiscales horizontales provenientes de competencia por impuestos han sido analizadas en forma abundante por la literatura. Esto corresponde al efecto de una disminución de la base imponible que provocan los impuestos aplicados sobre bases móviles en una jurisdicción, debido a la migración de la base hacia otra región con menores alícuotas, lo que conlleva un incremento en la base de la otra jurisdicción. En este sentido, la región bajo análisis tenderá a gravar a la base móvil con una alícuota demasiado baja ("race to the bottom"), lo que le hará proveer una cantidad subóptima de bienes públicos. Con el fin de compensar las consecuencias de las externalidades horizontales, el gobierno federal, mediante un sistema de transferencias apropiado, intentará llevar a la economía al nivel unitario, es decir, al nivel elegido por un policymaker benevolente con perfecto acceso a la misma información a la cual acceden los estados.

Por otro lado, sin embargo, desde la óptica de los modelos de "public choice", Brennan y Buchanan (1980) asumen que el gobierno puede tener comportamiento leviatánico, maximizando su propio tamaño. En ese caso, la competencia tributaria interjurisdiccional previene a los agentes del sector público local de incrementar los impuestos de manera excesiva para no expulsar base imponible. La competencia proporciona una forma de "disciplinar" a los gobiernos subnacionales.

La esencia del federalismo reside en la existencia de distintos niveles de gobierno. Es por ello que, adicionalmente a la anterior, existe otro tipo de externalidad, la "externalidad vertical", que proviene de la financiación concurrente, a partir del hecho de gravar la misma fuente de imposición por parte de diferentes niveles de gobierno. El efecto sobre la base imponible del otro gobierno implica una variación en la recaudación impositiva, y otro impacto adicional, el cual implica afectar el nivel de provisión de bienes públicos que el estado afectado puede proveer; una disminución en la recaudación de impuestos provocados por el aumento de la alícuota del otro nivel hará que el gobierno afectado reduzca su provisión de bienes públicos.

Cabe consignar que, de acuerdo a los diferentes arreglos institucionales existentes en cada país, la externalidad vertical mencionada puede darse desde el gobierno federal hacia los

otras regiones. Estas externalidades llevan a políticas ineficientes a través de las regiones, causando una asignación ineficiente de factores de producción. Las mismas no permiten determinar si los niveles de gastos públicos o de impuestos resultan elevados o bajos en el agregado. En este trabajo se hará referencia solamente a las externalidades fiscales, con énfasis en las tributarias. 
estados ("top-down externality") o desde los estados hacia el gobierno federal ("bottom-up externality”) $)^{3}$.

Sin embargo, la externalidad horizontal, debida a la movilidad de las bases imponibles y operando en forma conjunta con la vertical, hace que la colocación de la alícuota impacte en la recaudación de impuestos del resto de los estados, y en la recaudación del gobierno federal debido a la variación en la demanda del bien, con lo cual el costo social marginal de los fondos públicos difiere del costo marginal que enfrentan los estados de ignorar estos efectos. Si la externalidad horizontal es positiva (aumento de la base imponible de los demás estados) la vertical es negativa y reduce la recaudación del impuesto federal.

El efecto que genera la "externalidad vertical" puede evaluarse desde dos puntos de vista: en primer lugar, el objetivo es establecer si la alícuota tributaria resultante es óptima o no en función de los bienes públicos que deben proveerse si se pretende maximizar la utilidad social, y en segundo, cuál es la reacción de uno de los niveles de gobierno cuando el otro incrementa su presión tributaria para evaluar el grado de reacción de la política impositiva provincial ante un incremento del impuesto nacional que grava la misma base que las provincias.

El presente capítulo se configura de la siguiente manera: en la sección 2 se plantean los aspectos conceptuales que definen las externalidades verticales, mientras que en la sección 3 se lleva a cabo la revisión de la literatura teórica. En la sección 4 se realiza la revisión de la literatura empírica, para concluir en la sección 5.

\section{Aspectos conceptuales}

Como fuera expresado con anterioridad, la teoría del federalismo fiscal analiza la estructura vertical del sector público y las interrelaciones que existen entre los diferentes niveles de gobierno, teniendo en consideración que están vinculados de manera horizontal y mantienen una coordinación vertical para el recaudo de los recursos y la producción y el suministro de bienes públicos.

En relación con lo anterior, la forma de distribuir los poderes de imposición entre los distintos niveles de gobierno se suele dividir convencionalmente en dos: la "separación de fuentes" y la “concurrencia en las fuentes de imposición". Esto implica, en el primer caso, que los distintos

\footnotetext{
${ }^{3}$ Wrede (1996)
} 
niveles de gobierno deban adoptar formas de imposición diferentes, mientras que la segunda implica que las formas de imposición pueden ser similares.

El concepto de "concurrencia en la fuente de imposición" no refiere exclusivamente al mecanismo de coparticipación de la recaudación de impuestos a través de los distintos niveles de gobierno, sino que el término significa la situación en donde distintos niveles de gobierno ejercen algún grado de discrecionalidad en la determinación de alícuotas nominales o efectivas sobre la misma base imponible ${ }^{4}$.

En los Estados Unidos, por ejemplo, los impuestos a la renta personal y empresarial están compartidos por el gobierno federal y por los estados. En Canadá y en Rusia, ocurre algo similar; en todos los países mencionados los distintos niveles de gobierno ejercen algún poder de decisión sobre tasas o bases imponibles.

En el caso de impuestos sobre los consumos, Brasil, por ejemplo, tiene un impuesto general sobre los consumos a nivel estadual (ICMS), y un impuesto específico sobre los consumos a nivel nacional (IPI). Mientras tanto, Canadá posee a nivel federal un impuesto general sobre los consumos (Goods and Services Tax - GST-), mientras las provincias (excluyendo Alberta) poseen un impuesto a las ventas minoristas (Retail Sales Tax-RST-)

En el caso argentino, por ejemplo, si bien el hecho imponible para el caso del Impuesto al Valor Agregado nacional y para el Impuesto a los Ingresos Brutos provincial está definido en forma diferente, la base imponible de ambos tiene grandes similitudes.

Lo anteriormente expresado implica que existen relaciones entre los tributos federales y estaduales; la existencia de un margen de discrecionalidad es lo que da origen a la posible existencia de externalidad.

Debe distinguirse, sin embargo, entre dos grados de concurrencia: la concurrencia "formal" y la concurrencia "efectiva"; a los fines de las implicancias de la política tributaria, es la concurrencia efectiva la que tiene efectos. Para poder diferenciar entre ambas debe llevarse a cabo un detallado análisis de las normativas tributarias y de los mecanismos de asignación de potestades tributarias para cada nivel jurisdiccional y sus efectos económicos, considerando movilidad de factores de producción. Es razonable concluir que la concurrencia formal subestima a la concurrencia efectiva ${ }^{5}$.

\footnotetext{
${ }^{4}$ Keen (1998)

${ }^{5}$ De acuerdo al ejemplo citado en Keen (1998), si solamente los estados pueden colocar un impuesto general a las ventas, mientras que sólo el gobierno federal puede colocar un impuesto proporcional sobre los salarios,
} 
Un ejemplo del efecto generado por la externalidad tributaria vertical puede verse en la figura subsiguiente $^{6}$. Se supone inicialmente el caso en el que los gobiernos nacional y subnacional establecen un impuesto al consumo unitarios de $\tau_{f}$ y $\tau_{i}$, respectivamente, sobre el bien $X$, el cual posee una curva de oferta infinitamente elástica $S$ y enfrenta una curva de demanda $D$. Inicialmente, el impuesto subnacional es $\tau_{1 i}$, el impuesto total es $\tau=\tau_{1 i}+\tau_{f}$ y el precio del bien es $q_{1}$.

El gobierno nacional recauda la suma de las áreas $c+e$, mientras que el gobierno provincial recauda la suma de las áreas $b+d$. Si el gobierno subnacional incrementa su alícuota a $\tau_{2 i}$, el precio del bien se incrementa a $q_{2}$; la recaudación del gobierno subnacional será más alta si el área $a$ es mayor que el área $d$, mientras que la recaudación del impuesto federal declinará de acuerdo al área $e$ dado que la base imponible se verá reducida de $x_{1}$ a $x_{2}$

\section{Gráfico 1}

\section{La externalidad tributaria vertical cuando existe superposición de bases imponibles}

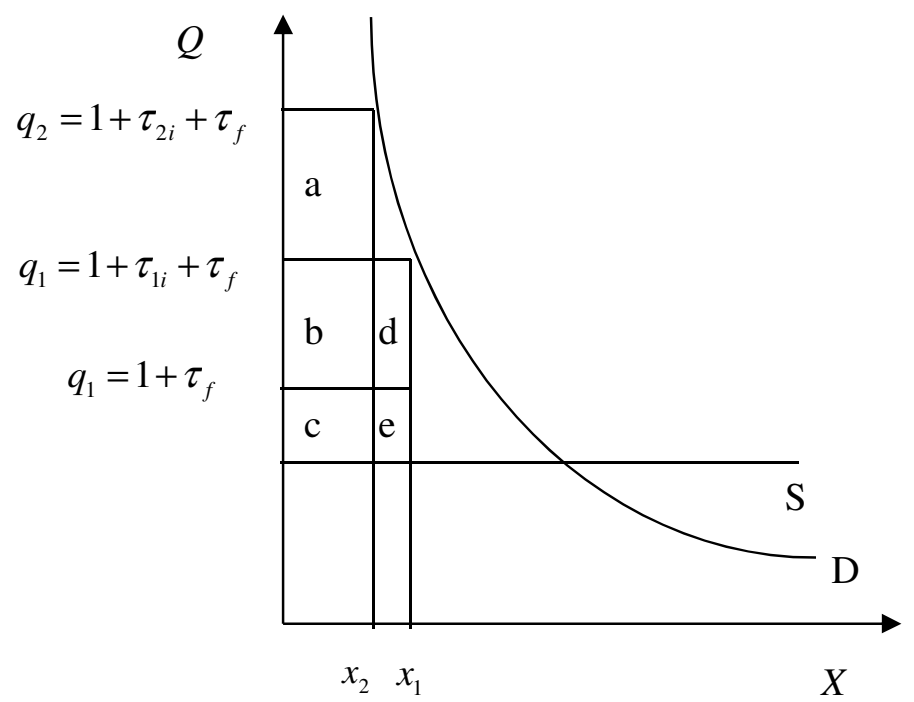

Fuente: Dahlby y Wilson (2003), Keen (1998)

Es posible, sin embargo, que la disminución en la recaudación del gobierno nacional sea mayor que el incremento generado en la recaudación del gobierno provincial, con lo cual la recaudación total bajo la tasa impositiva $\tau=\tau_{2 i}+\tau_{f}$ sea menor que en el caso inicial; de esta manera los gobiernos estarían operando en la parte decreciente de la curva de Laffer; la

siendo éstos los únicos impuestos existentes en la economía, no existe concurrencia formal. Sin embargo, con mercados de capitales perfectos, ambos impuestos son equivalentes, con lo cual la concurrencia efectiva es completa; con mercados de capitales imperfectos, permanece aún un cierto grado de concurrencia efectiva.

${ }^{6}$ Dahlby y Wilson (2003) 
recaudación total aumenta si la elasticidad precio de la demanda es menor que la unidad ${ }^{7}$. Sin embargo, aunque estuvieran operando en la parte creciente de la curva de Laffer, el gobierno subnacional estará subestimando el costo marginal de los fondos públicos (la carga que soporta el sector privado cuando el gobierno incrementa en una unidad monetaria adicional su recaudación impositiva) provenientes de esta base imponible al no considerar el efecto del impuesto federal, lo cual lo lleva a establecer alícuotas demasiado elevadas ${ }^{8}$.

La existencia de concurrencia afecta, como quedara expresado, las bases imponibles de los distintos niveles gubernamentales. Cuando los gobiernos deciden sobre la variación de sus alícuotas impositivas, igualan el efecto que el incremento de los impuestos genera en el bienestar de los individuos, es decir, el denominado "costo marginal de los fondos públicos", en el caso de gobiernos benevolentes, o el efecto sobre la recaudación, en el caso de gobiernos leviatánicos, con el beneficio marginal de la provisión del bien público o con la utilidad marginal de la renta, en el caso de bienes privados.

El problema es que cada gobierno, al colocar sus alícuotas, solamente considera el efecto de sus propios impuestos sobre el bienestar de los individuos, ignorando, en mayor o menor medida, como se verá más adelante, el efecto de los impuestos de la otra jurisdicción. Es decir que el "costo marginal social de los fondos públicos", que incluye a los impuestos de ambas jurisdicciones y constituyen el precio que realmente enfrenta el consumidor, en impuestos sobre los consumos, excede al "costo marginal de los fondos públicos" que cada gobierno advierte, con lo cual la caída en la base imponible es mayor a la que cada gobierno aprecia.

En equilibrio, la alícuota combinada de ambos niveles gubernamentales tiende a ser más alta que el valor óptimo; la existencia de competencia tributaria horizontal reduce la posibilidad de establecer alícuotas elevadas para las subjurisdicciones dependiendo de la movilidad de la base imponible.

Un efecto adicional a considerar está dado por la existencia de transferencias, particularmente las que tienen relación con las bases imponibles de cada jurisdicción o con el esfuerzo tributario de cada jurisdicción. En el caso de Canadá, por ejemplo ${ }^{9}$, se compensa a los gobiernos cuya base imponible per cápita es inferior a la base standard. Estas transferencias pueden alterar los incentivos fiscales de los gobiernos que las reciben, dado que sus propias políticas pueden alterar las magnitudes de las transferencias a recibir.

\footnotetext{
${ }^{7}$ Porto (2004)

${ }^{8}$ El crecimiento de la tasa provoca una pérdida de eficiencia mayor que el triángulo de Harberger (Porto (2004))

${ }^{9}$ Dahlby (2001)
} 
En consecuencia, el alcance de las externalidades horizontales depende de varios factores, entre los cuales pueden mencionarse a los supuestos sobre el comportamiento de los gobiernos (esto es, si son benevolentes o leviatánicos; si actúan bajo el supuesto de equilibrio de Nash o en modelos de líderes y seguidores); de si los impuestos gravan a la oferta o a la demanda; de si los bienes públicos que se proveen son residenciales o mejoran la productividad, del tipo de bienes que provee cada nivel de gobierno, etc.

En síntesis, los efectos a considerar al momento de analizar el impacto de la concurrencia en la fuente de imposición sobre los sistemas tributarios nacionales y subnacionales se agrupan en las siguientes dos grandes vertientes, de acuerdo a Keen $(1998)^{10}$ :

a) Cuál es la respuesta de los impuestos de un nivel jurisdiccional (estados) ante la variación en las tasas impositivas del otro nivel (nacional) que afecta a la misma base imponible: esto es, un mayor impuesto nacional lleva a los gobiernos subnacionales a un aumento de sus propios impuestos o a una disminución de los mismos.

b) Si a partir de la existencia de externalidades, y las reacciones de los diferentes gobiernos ante las variaciones en las políticas tributarias de los demás, lograr establecer si la alícuota tributaria resultante es óptima o no en función de los bienes públicos que deben proveerse si se pretende maximizar la utilidad social.

Combinadas con las anteriores, surgen las siguientes alternativas:

c) Cuál es el nivel de tasas de impuestos que la existencia de concurrencia en la fuente de imposición genera: significa el hecho de establecer si el hecho de compartir la base imponible lleva a alícuotas demasiado elevadas.

d) La determinación de si la existencia de transferencias intergubernamentales afectan en alguna manera la fijación de alícuotas por parte de los gobiernos subnacionales receptores de las mencionadas transferencias, particularmente considerando los casos en que las transferencias están en función de las mismas bases imponibles.

Como ejemplos de las alternativas mencionadas pueden citarse los trabajos de Esteller-Moré y Solé-Ollé para Canadá y Estados Unidos (1999 y 2001), Keen (1998), Devereux et al (2007), y Esteller Moré y Rizzo (2011) entre otras, para la alternativa a), en las que el propósito es el de evaluar el grado de reacción de la política impositiva provincial ante un

\footnotetext{
${ }^{10}$ Keen (1998) menciona la elección óptima entre bases imponibles para atribuir a cada nivel jurisdiccional, pero se considera que esta alternativa hace referencia a un sistema de fuentes separadas en lugar de uno de concurrencia.
} 
incremento del impuesto nacional que grava la misma base que las provincias, mientras que para la b) pueden mencionarse, las contribuciones de Vigneault y Boadway (1996), Boadway, Marchand y Vigneault (1998), Hoyt (2001) y Dahlby y Wilson (2003), entre otras.

En relación con las alternativas c) y d), las mismas se hallan comprendidas en las alternativas a) y b) ya mencionadas; puede explicitarse que la alternativa b) ha sido desarrollada con el fin de lograr aproximar a una especificación que permita el testeo empírico de esta temática y es incluida en varios casos en el análisis de la alternativa a), particularmente en los cuales se consideran modelos de líderes y seguidores. En lo sucesivo se explicitarán los distintos desarrollos teóricos y empíricos existentes en la literatura sobre esta temática.

\section{3. $\underline{\text { Antecedentes teóricos }}$}

Como quedara expresado en los apartados anteriores, la existencia de concurrencia en la fuente de imposición, en organizaciones institucionales de carácter federal, genera ineficiencias. Las mismas están en relación con los distintos supuestos sobre el comportamiento del gobierno federal, resultando ser características comunes a las alternativas a), b), c) y d) mencionadas anteriormente, y dependen de lo siguiente:

• Gobiernos "benevolentes" o "no benevolentes" (“leviatánicos”)

- Limitaciones en los instrumentos de política

- Modelos de "movidas simultáneas" (Nash) o modelos de líderes y seguidores (Stackelberg)

- Asimetrías informativas

Los modelos sobre "tax competition" comienzan con la determinación de la función objetivo del gobierno. Si el supuesto es que sean gobiernos benevolentes, los mismos maximizarán una función objetivo que contiene una función de utilidad indirecta del agente representativo, si, por el contrario, se los considerara como gobiernos no benevolentes, los mismos maximizarán la recaudación impositiva, o el superávit presupuestario.

Debe considerarse también si los gobiernos federales tienen a su disposición un mecanismo de transferencias, que les permita compensar, desde el gobierno federal hacia los niveles inferiores de gobierno, posibles ineficiencias relacionadas con la superposición de bases imponibles. 
Adicionalmente, es importante diferenciar, en combinación con el punto anterior, si ambos niveles de gobierno toman decisiones simultáneas (configurando un equilibrio de Nash) o si, dado el tamaño relativo de ambos niveles, puede pensarse que el gobierno federal "mueva primero", mientras que los estados deben reaccionar ante las decisiones del gobierno federal.

Puede considerarse como un caso adicional la situación en que ambos gobiernos son "miopes", en el sentido en que ignoran el efecto que sus decisiones de incremento de impuestos genera sobre la restricción presupuestaria del otro nivel, dado que se reduce la base imponible de éste y consecuentemente disminuye su capacidad de provisión de bienes públicos.

Un último punto se relaciona con las asimetrías informativas. Puede pensarse que los estados tengan algún tipo de ventajas informacionales al tener una relación más cercana con los contribuyentes de su territorio en relación con el gobierno federal, sin embargo, éste puede compensar esta asimetría con mayores tecnologías o la existencia de economías de escala correspondientes a la función de recaudación ${ }^{11}$.

\subsection{Fijación de alícuotas por parte de los gobiernos federal y subnacionales}

Los trabajos se sustentan en una estimación de la reacción de las alícuotas de los gobiernos subnacionales ante una variación en la tasa del gobierno federal. A continuación se presentará el marco teórico de análisis sobre esta temática, diferenciando los estudios realizados en función de si los gobiernos tienen limitaciones en el uso de herramientas de política (existencia de transferencias), y considerando adicionalmente la existencia de competencia tributaria horizontal.

\subsubsection{Gobiernos con instrumentos limitados}

En este apartado se hará referencia a los casos en donde los gobiernos no disponen de transferencias entre distintos niveles. El resto de esta sección presenta el marco teórico de análisis, siguiendo a Besley y Rosen (1998), Keen (1998) y Esteller-Moré y Solé-Ollé (2001 y 2002).

Se supone inicialmente que ambos niveles de gobierno graven la misma base imponible. Se trata de un impuesto indirecto, y se supone que los estados son idénticos, que están

\footnotetext{
${ }^{11}$ Un ejemplo de estos trabajos puede verse en Touya (2009), en donde se introducen diferentes mecanismos de imposición para testear la robustez de los análisis tradicionales. En el trabajo se propone un modelo en donde operan simultáneamente interacciones fiscales horizontales y verticales, existiendo incertidumbre sobre la base imponible (el capital a invertir); emerge como resultado un excesivo nivel de imposición en comparación con un marco de gobierno unificado.
} 
compuestos por un solo consumidor y que la base es inmóvil. Estos últimos supuestos no permiten la existencia de cuestiones de equidad ni la competencia horizontal entre jurisdicciones.

Uno de los primeros trabajos en analizar estas cuestiones es el de Besley y Rosen (1998), el cual estudia, con aplicaciones al caso del impuesto a los cigarrillos y a los combustibles en los Estados Unidos, cuál es la reacción de los impuestos provinciales ante un incremento en la alícuota impositiva del gobierno federal.

El trabajo mencionado considera un gobierno subnacional benevolente que maximiza una función de utilidad social dada por $W^{R}\left(q_{1 R}, \ldots \ldots, q_{N R}\right)$, donde $q_{j R}=p_{j R}+t_{j R}+t_{j F}$ es el precio post impuestos de los $\mathrm{n}$ bienes; $t_{j R}$ es la tasa impositiva del gobierno subnacional $R$ y $t_{j F}$ es la tasa impositiva del gobierno nacional, con $p_{j R}$ precios antes de impuestos. Las cantidades demandadas de los bienes consumidos en el estado $r$ están dadas por el vector $X_{R}=\left(X_{1 R}, \ldots . . X_{N R}\right)$, asumiendo que existe una restricción presupuestaria a nivel provincial que implica que $\sum_{j=1}^{N} t_{j R} X_{j R} \geq R_{R}$, la recaudación generada por los impuestos subnacionales debe alcanzar un determinado nivel.

Al caracterizar al gobierno nacional como un líder de Stackelberg debido a su magnitud, el trabajo se concentra en calcular la reacción de los gobiernos provinciales ante un aumento en la alícuota impositiva del gobierno nacional que grava la misma base imponible. Los resultados pueden caracterizarse desde cuatro puntos de vista:

- Revenue effect: si el gobierno federal incrementa la tasa, incrementando el precio del bien y reduciendo su demanda, el gobierno subnacional ya no puede cumplimentar su propia restricción presupuestaria con lo cual debe incrementar los impuestos

- Deadweight loss effect: si los gobiernos evalúan el costo en bienestar asociado a la colocación de distintos impuestos, siendo que la desutilidad marginal del impuesto crece con la tasa, se define en consecuencia una tasa ad valorem "deseada" relacionada con el precio post impuestos del bien, $t_{j R} / q_{j R}$. Si el gobierno nacional incrementa sus impuestos, incrementa el denominador de la expresión anterior y lleva al gobierno subnacional a incrementar la tasa en con el fin de volver al ratio deseado.

Si el gobierno regional es benevolente, maximiza la función de utilidad indirecta del agente representativo. El nivel de la tasa colocada por el gobierno regional, con demandas 
independientes y elasticidad precio de la demanda constante, se obtiene la fórmula de la inversa de la elasticidad para la determinación de la tasa de impuestos

- Sustitución de impuestos y efectos complementarios: con demandas no separables es esperable que existan relaciones entre impuestos que los hagan complementarios o sustitutos, con lo cual en este caso el efecto de reacción del impuesto provincial no puede predecirse a priori

- Expenditure effects: es posible responder ante un aumento en la tasa del impuesto nacional reduciendo el nivel de gasto provincial, dado que la recaudación es ahora inferior y no puede financiar el mismo nivel de gasto; en este caso no hay una respuesta uniforme del gobierno provincial.

Keen (1998), en un marco más general, y Esteller-Moré y Solé-Ollé (2001 y 2002), con el objeto de realizar una estimación empírica para el caso del impuesto a la renta de Canadá, presentan una formulación teórica que abarca las explicitaciones realizadas anteriormente por Besley y Rosen (1998), dado que a diferencia del caso anterior, incorporan la provisión de un bien público federal y otro estadual, los que incluyen dentro de la función de utilidad del agente representativo. Se presentará aquí una versión de los trabajos que comprende a ambas.

Dado que se supone que ambos niveles de gobierno toman como dados la tasa impositiva y el nivel de gasto de la otra jurisdicción, se comportan como Nash. El supuesto de que ambos niveles de gobierno toman como dadas las consecuencias de sus decisiones sobre el otro nivel de gobierno no es obvio; no todos los niveles colocan sus alícuotas lejos del óptimo social. El gobierno federal puede actuar como un líder de Stackelberg, considerando el efecto que sus acciones tendrán sobre los demás gobiernos ${ }^{12}$.

Ambos niveles son benevolentes, es decir, maximizan la función de utilidad indirecta del agente representativo, sujeta a sus respectivas restricciones presupuestarias. El precio que enfrenta el consumidor es $q=1+t_{R}+t_{F}$, siendo $t_{R}$ la tasa provincial, $t_{F}$ la tasa nacional, mientras que el precio para el productor ha sido normalizado a 1. Entretanto, B es la base imponible, $g$ es el bien público regional y $G$ es el bien público nacional, siendo sus utilidades respectivas $h(g)$ y $H(G)$, ambas cóncavas y siendo $h_{g} \geq 0 \geq h_{g g}$; la función de utilidad es

\footnotetext{
${ }^{12}$ En este caso el gobierno federal podría, mediante un sistema de transferencias apropiado, compensar a los gobiernos subnacionales y obtener el nivel de impuestos socialmente óptimo; se esperaría que la reacción del gobierno federal fuera menor de comportarse como líder de Stackelberg.
} 
separable entre bienes públicos y privados. El problema para el gobierno regional es, en consecuencia, el siguiente

$$
\operatorname{Max}_{t_{R}} V(q)+h(g)+H(g) \text { sujeto a } t_{R} B=g
$$

En el óptimo, el gobierno regional iguala el beneficio marginal de la provisión del bien público y el costo marginal de los fondos públicos $(R M C P F)$, lo que implica la pérdida del contribuyente ante el aumento de una unidad en la recaudación tributaria. Cada vez que el gobierno federal eleva la presión tributaria (a través de $q$ ), el gobierno subnacional actúa para rebalancear la expresión anterior. Ahora los impuestos provinciales financian la provisión del bien público local, y aparecen dos efectos:

- en primer lugar, el mayor precio del bien reduce su demanda y la pérdida de bienestar asociada al incremento del impuesto local (“deadweight loss effect”);

- en segunda instancia la contracción de la base genera una caída en la provisión del bien público local; esto hace más atractivo el incremento en el impuesto provincial para aumentar la provisión del bien público ("expenditure effect").

Ambos efectos van en la dirección de provocar un aumento de los impuestos subnacionales ante un incremento de los nacionales, esto es, los vuelve complementarios ${ }^{13}$.

En el caso de un gobierno subnacional con comportamiento leviatánico, el mismo solamente maximiza la recaudación tributaria $\operatorname{Max}_{t R} R_{t R}=t_{R} x(q)$. A partir de las condiciones de primer orden, se obtiene entonces la fórmula de la inversa de la elasticidad para la determinación de la tasa de impuestos. Esto implica tener en cuenta dos efectos:

- el efecto del lado del gasto, que requiere un aumento de la alícuota regional para mantener constantes los ingresos públicos y consecuentemente los gastos públicos (revenue effect o expenditure effect),

- y el efecto de pérdida de bienestar, que implica que el gobierno eleva las tasas para mantener la presión tributaria (cociente entre alícuota y precio del bien) constante. (deadweight loss effect)

En definitiva, el efecto final depende de la consideración sobre la elasticidad-precio de la demanda del bien gravado. Si la misma es constante, un aumento en los impuestos nacionales

\footnotetext{
${ }^{13}$ Analíticamente, el resultado anterior se expresa a partir de diferenciar totalmente las condiciones pe primer orden, lo que determina la función de reacción del gobierno regional en relación a la tasa fijada por el gobierno federal.
} 
eleva el precio del bien y el gobierno subnacional elevará el impuesto para mantener constante la igualdad anterior $\left(d t_{R} / d t_{F}>0\right)$. Si la curva de demanda fuera lineal, un aumento de los impuestos federales genera una reducción de los impuestos provinciales $\left(d t_{R} / d t_{F}<0\right)$ (se reduce el cociente $q / \varepsilon$ ), mientras que si fuera igual a cero, la reacción sería igual a cero $\left(d t_{R} / d t_{F}=0\right)$. Es condición necesaria y suficiente para un aumento de los impuestos provinciales la log convexidad de la curva de demanda del bien gravado.

Si se considerara el caso en que los gobiernos tienen en cuenta el efecto de sus acciones sobre la restricción presupuestaria y el nivel de provisión del bien público por parte del otro gobierno $^{14}$ (es decir, los gobiernos no son "miopes"); el problema del gobierno regional se vuelve:

$$
\operatorname{Max}_{t_{R}} V\left(1+t_{R}+t_{F}\right)+h(g)+H(g) \text { sujeto a } t_{R} B=g \quad G=G\left(B\left(t_{F}\right)\right) t_{F} \bar{\Xi} t^{-} F
$$

En comparación con el caso anterior, el costo marginal del gobierno subnacional es menor, con lo que la tasa es menor, lo que se debe a que el gobierno regional considera la disminución en el nivel de provisión del bien público por parte del gobierno nacional cuando la tasa del gobierno subnacional varía, con excepción del caso en que el nivel de provisión del bien nacional sea elevado $\left(H_{G} \rightarrow 0\right)$ con lo que la expresión es igual a la anterior.

La reacción del gobierno subnacional ante la variación de la tasa federal determina dos efectos de diferente signo:

- el primer efecto muestra cómo el gobierno regional internaliza parte de la pérdida de bienestar causada en el gobierno federal, lo que lleva a una reacción inversa

- el segundo refleja el hecho de que ahora el gobierno regional otorga una menor pérdida de utilidad a la disminución en la provisión del bien público nacional, lo que lleva a una reacción mayor, efecto que se ve incrementado cuando el bien público nacional es relativamente más valuado que el provincial (cuanto más alto es $H_{G} / h_{g}$ ).

Sin embargo, como el segundo efecto depende de las derivadas segundas $\left(H_{G G}\right)$, se espera que el primer efecto domine, con lo cual la reacción sería menor que en el caso básico.

\subsubsection{Gobiernos con acceso a transferencias}

\footnotetext{
${ }^{14}$ Esteller-Moré y Solé-Ollé (2002)
} 
Existen varios sistemas de transferencias financieras. El más difundido es el mecanismo de coparticipación, según el cual niveles generalmente inferiores participan en la recaudación de tributos que recaudan los niveles superiores en una manera determinada.

Los sistemas varían entre numerosos regímenes, desde atar la participación de cada jurisdicción a la recaudación generada para cada impuesto en particular, como la generalización, considerando a todos los gravámenes dentro de la masa coparticipable.

Otra forma son las asignaciones directas de presupuesto, en donde los ingresos de sectores inferiores no dependen del monto de recaudación. Este mecanismo se denomina específicamente transferencias, constituyendo asignaciones de fondos condicionadas o no condicionadas $^{15}$.

Las primeras pueden ser utilizadas libremente por quien las recibe y no están sujetas a ningún condicionamiento, mientras que los requerimientos involucrados en las segundas pueden ser variables. Pueden referirse no sólo a los bienes públicos que se proveen con esos fondos, sino también a su propio sistema tributario, estando condicionados al propio esfuerzo tributario de la jurisdicción.

Tanto el régimen de transferencias como el de coparticipación comparten el problema de dimensionar el monto de las transferencias. Más allá de los planteamientos teóricos mencionados, los parámetros son resultado de la negociación teniendo en cuenta antecedentes históricos.

Dahlby (2001) ${ }^{16}$ y Esteller-Moré y Solé-Ollé (2002) ${ }^{17}$ analizan el efecto de las transferencias sobre la función de reacción del gobierno subnacional para el caso de Canadá. El sistema de transferencias mencionado consiste en una compensación que el gobierno federal hace a los gobiernos subnacionales en función de la insuficiencia de base imponible en relación a un nivel standard fijado para cinco estados; la transferencia de igualación surge de multiplicar la referida diferencia de base imponible por la alícuota promedio standard, siendo la fórmula la que se muestra a continuación, en donde puede verse que la transferencia no es de suma cero, es decir, sólo se realiza para aquellos casos en los que existe deficiencia de base imponible.

$E=\bar{t}(\bar{B}-B)$, iff $\bar{B} \geq B \quad$ y $E=0$, iff $\bar{B} \leq B$

\footnotetext{
${ }^{15}$ Macón (1998)

${ }^{16}$ Dahlby (2001)

${ }^{17}$ Esteller-Moré y Solé-Ollé (2001)
} 
El problema para el gobierno provincial es ahora

$$
\operatorname{Max}_{t_{R}} V\left(1+t_{R}+t_{F}\right)+h(g)+H(g) \text { sujeto a } t_{R} B+\bar{t}(\bar{B}-B)=g
$$

La transferencia de igualación hace emerger dos efectos:

- Deadweight loss effect, que incentiva al gobierno subnacional a incrementar su alícuota.

Dado que el $R M C P F$ es ahora menor (la tasa ad valorem disminuye de $t_{R} / q$ a $\left(t_{R}-\bar{t}\right) / q$. La razón para este hecho es que una tasa mayor, si bien disminuye la base, da derecho a recibir una transferencia más alta

- Expenditure effect: los recursos provenientes de la transferencia de igualación se transfieren a los residentes, con lo cual se reduce la carga tributaria regional

Comparando con la expresión que surge del caso inicial sin transferencias, puede advertirse que la tasa promedio $\bar{t}$ reduce la pendiente de la función de reacción; el efecto contrario es generado por la recaudación de fuente propia $\bar{t}(B \tilde{-B})$ la que, al ser menor que uno genera un efecto creciente en la pendiente. Sin embargo, dado que este último efecto depende nuevamente de las valoraciones marginales de segundo orden $h_{g g}$; de ser ésta reducida la reacción de los impuestos provinciales será menor que en el primer caso.

\subsubsection{Competencia tributaria horizontal y vertical}

Es interesante evaluar en qué medida estos resultados se modifican al incluir competencia tributaria horizontal entre estados. Devereux, Lockwood y Redoano (2007) presentan un modelo general, que incluye como casos particulares a los anteriormente comentados, a la par de incluir también como casos especiales a los modelos presentados en la literatura mencionada inicialmente en relación con los efectos de las externalidades verticales en el nivel de provisión de bienes públicos.

Si bien se conoce en forma teórica el hecho de que las externalidades horizontales mitigan en alguna forma los niveles de imposición alcanzados con las externalidades verticales, para aproximarlos a los niveles socialmente óptimos, este modelo resulta ser un avance muy importante a los fines de vincular ambos tipos de efectos de manera formal y mostrar de manera explícita los umbrales a partir del momento en que uno de los efectos se vuelve más significativo que el otro. 
El modelo presentado plantea la existencia de dos estados $i=1,2$, cada uno de los cuales grava con un impuesto específico tipo origen al consumo de determinado bien, al igual que el gobierno federal. Se asume que el precio al productor está fijo en ambos estados, con lo cual el precio al consumidor es en el estado $i q_{i}=p_{i}+t_{i}+T$. El consumidor de cada estado, que habita a una distancia $d$ de la frontera con el otro estado, puede adquirir el bien en su propio estado abonando $q_{i}$, o cruzar la frontera y abonar $q_{j}$ más los costos de transporte asociados, los que se especifican $c_{i}(x, d)=c_{i} d$, independientes de $x$.

El residente maximiza la función de utilidad indirecta $V(q)=\max \{u(x)-q x\}$, derivando la demanda individual del bien gravado cuando el precio es $q: x(q)=\arg \max \{u(x)-q x\}$. La decisión de adquirir el bien en el otro estado se determina en función de si el precio es menor $q_{i}>q_{j}$ y la distancia a la que se encuentra de la frontera es $\frac{1}{c_{i}}\left(v\left(q_{j}\right)-v\left(q_{i}\right)\right)=d_{i}$ o menor.

En consecuencia, si el costo de adquirir en el otro estado es prohibitivo, no hay externalidades tributarias horizontales.

La base imponible en el estado $i$ es $X_{i}=X\left(q_{i}\right) s_{i}\left(q_{i}, q_{j}\right)$, donde $s_{i}\left(q_{i}, q_{j}\right)$ es la cantidad de compradores en $i$, y $\quad s_{i}\left(q_{j}, q_{i}\right)=n_{i}-\rho_{i}\left(v\left(q_{j}\right)-v\left(q_{i}\right)\right) \quad$ si $\quad q_{i} \geq q_{j}$, y $s_{i}\left(q_{j}, q_{i}\right)=n_{i}+\rho_{i}\left(v\left(q_{j}\right)-v\left(q_{i}\right)\right)$ si $q_{i} \leq q_{j}$ donde $\rho_{i}=\phi_{i} / c_{i}$ mide la respuesta de los compradores en el otro estado a las diferencias en los impuestos; si $q_{i}=q_{j}$, no hay compras en el otro estado; si $q_{i}>q_{j}$, hay compras en $j$ por parte de los residentes en $i$, mientras que si $q_{i}<q_{j}$, hay compras en $i$ por parte de los residentes de $j$; la base imponible en consecuencia se reduce o se amplía en función de las compras de los residentes de los otros estados (principio de destino).

Se asume que los estados maximizan la función de recaudación $R_{i}\left(t_{1}, t_{2}\right)=t_{i} X_{i}\left(t_{i}+T, t_{j}+T\right)$, es decir, son leviatánicos, donde $q_{i}=t_{i i}+T_{i}$ (los precios al productor de los bienes están normalizados a cero); se origina entonces la función de reacción de los impuestos del estado $i$, $t_{i}=r_{i}\left(t_{j}, T\right)$ con $t_{j}$ dado y $T$ fijos.

Si los estados y el gobierno federal actúan Nash, se definen los impuestos de equilibrio a partir de la condición de primer orden; en términos ad valorem, la tasa impositiva elegida es inversamente proporcional a la elasticidad de la base imponible, 
La elasticidad agregada de la demanda puede escribirse como la suma de dos elasticidades, $-\frac{q_{i}}{X_{i}} \frac{\partial X_{i}}{\partial q_{i}}=\varepsilon_{i}+\sigma_{i}$, donde $\varepsilon_{i}$ es la elasticidad de la demanda por el bien vendido en $i$, y $\sigma_{i}$ es la elasticidad del número de compradores en $i$ con respecto al precio del bien $q_{i}$.

El valor de esta elasticidad depende de los precios relativos de los estados (versión simétrica y asimétrica del modelo, representadas por los casos $q_{i}=q_{j}$ y $q_{i}>q_{j}$, respectivamente). El impuesto óptimo que surge del equilibrio de Nash es $\hat{t}=q /(\varepsilon+\sigma)$ para el caso de simetría; a mayor $\rho$ se intensifica la competencia tributaria horizontal e $i$ disminuye, mientras que a mayor $n$, disminuyen las compras interestaduales.

La derivación de las pendientes de las funciones de reacción de cada estado ante las variaciones en las tasas impositivas del gobierno federal determina varias conclusiones a considerar:

- Si el costo de transporte es prohibitivo, es decir, $c_{i}=\infty$, no existen compras al otro lado de la frontera, entonces las funciones de reacción implican que el estado $i$ no reacciona ante variaciones en la tasa del estado j, mientras que la reacción de la tasa del estado i ante variaciones en la tasa del impuesto federal puede ser positiva o negativa, dependiendo de la curvatura de la función de demanda del bien (si es lineal la reacción es negativa, mientras que si es isoelástica, la reacción es positiva).

- Si la función de demanda es inelástica, $x_{i}(q)=\bar{x}$, asumiendo la existencia de compras interestaduales, la base imponible es ahora $X_{i}\left(q_{i}, q_{j}\right)=n_{i} \bar{x}+\rho_{i}\left(q_{j}-q_{i}\right) \bar{x}^{2}$. Las funciones de reacción determinan que, en el caso de demanda inelástica, los estados no reaccionan ante las variaciones de las tasas federales, mientras que la reacción es de 0,5 cuando el otro estado aumenta sus tasas.

- Para el caso general en donde existen compras interestaduales y demanda elástica, si bien no puede predecirse el signo de la reacción vertical, puede establecerse que la reacción horizontal es positiva $\frac{\partial t_{1}}{\partial t_{2}}>0 y \frac{\partial t_{2}}{\partial t_{1}}>0$, lo que es robusto aún ante la existencia de potenciales asimetrías entre los estados.

- Reexpresando las pendientes de las funciones de reacción, en función de las elasticidades relativas se evidencia, para el caso de simetría entre los estados, la existencia de relaciones 
entre las competencias tributarias verticales y horizontales: un incremento en la competencia tributaria horizontal (un aumento de $\sigma$ ) hace más probable que la pendiente vertical sea positiva. La proporción relativa de las funciones de reacción verticales y horizontales depende de la curvatura de la función de demanda $\frac{\partial t_{i} / \partial t_{j}}{\partial t_{i} / \partial T}=\frac{\sigma^{2}}{\varepsilon(\sigma-\varepsilon-\eta)}$, donde $\eta=\frac{q x^{\prime \prime}}{x^{\prime}}$

- Sin embargo, pese a la existencia de estimaciones empíricas de $\varepsilon$ y $\sigma$, resulta muy dificultoso establecer valores a priori de las funciones de reacción por dependerse de estimaciones de la curvatura de la función de demanda. Salvo para los casos extremos de costos prohibitivos y demanda inelástica, es probable que las pendientes de las funciones de reacción, verticales y horizontales, sean distintas de cero y las pendientes de las funciones de reacción horizontales sean positivas.

\subsection{Provisión de bienes públicos}

Existe una gran variedad de trabajos que analizan el impacto de las políticas tributarias de los gobiernos federales sobre los niveles de provisión óptima de los bienes públicos de los gobiernos subnacionales. Sin embargo, la mayor parte de los mismos se centran en el análisis de las políticas tributarias relacionadas con impuestos sobre ingresos o patrimonios, siendo más restringida la variedad de trabajos relacionados con impuestos sobre los consumos.

El trabajo de Gordon (1983) es uno de los primeros en plantear en forma sistemática los tipos de externalidades que una unidad de gobierno puede crear a los no residentes a través tanto de sus decisiones de gasto público como de imposición, considerando en forma conjunta a los impuestos sobre los consumos y sobre los ingresos de los factores de producción. Si esta unidad de gobierno subnacional actúa teniendo en cuenta sólo los intereses de sus residentes, ignorando las externalidades generadas, el bienestar global requiere que las mismas sean consideradas. En el mismo trabajo se analizan también brevemente las acciones que el gobierno central puede realizar a los fines de reducir los costos de las mencionadas decisiones descentralizadas.

Gordon asume que existe un número finito de comunidades, las que configuran un sistema de gobierno federal con gobierno central y subnacionales. En cada comunidad existen empresas e individuos; las empresas pueden contratar factores y colocar su producción en otras comunidades, con costos de transporte, los que hacen variar los precios de bienes y factores entre comunidades. 
Cada unidad de gobierno coloca impuestos sobre cada factor de producción empleado y cada bien que se vende en la comunidad (impuestos en la fuente y de origen) y produce bienes públicos; las comunidades eligen su provisión de bienes y alícuotas de impuestos óptimos. En consecuencia existe un precio recibido por la firma por su producto y un precio pagado por el consumidor por cada bien y un precio pagado por el factor por la empresa y el ingreso recibido como factor de producción por cada individuo; la diferencia entre los primeros configuran el impuesto para la firma, mientras que la brecha entre los segundos es el impuesto al consumo.

Las firmas eligen un vector de outputs y un vector de inputs, en donde éstos pueden ser contratados en la propia comunidad, pero los bienes pueden ser vendidos en toda la nación. En relación con los individuos, existe un número finito de tipos de individuos que maximizan una función de utilidad compuesta por los precios que enfrentan, la dotación del factor de producción y la disponibilidad de bienes públicos; enfrentan un vector de precios después de impuestos y un vector de precios de factores antes de impuestos.

En relación con los gobiernos locales, los ingresos tributarios de los mismos están compuestos por la recaudación de impuestos sobre los factores $(t)$ y sobre los productos $(s), T_{k}=s_{k} Y_{k}+t_{k} x_{k}$, con $Y$, output, y $x$, factores; esta recaudación es utilizada para adquirir un vector de factores de producción en la comunidad $k$. La función de producción para los bienes públicos es $g_{k}(Q, b)=0$. Dado que los impuestos disponibles son distorsionantes, cada nivel de gobierno enfrenta un problema de second best que consiste en generar la mayor recaudación posible con el mínimo costo de bienestar.

Cada nivel de gobierno actúa para maximizar una función de utilidad tipo Bentham $V$ en donde se tienen en cuenta sólo a los propios residentes de cada estado (con ponderación $\omega$ ); dado que las decisiones pueden afectar a los no residentes, las externalidades aparecen a partir de la toma de decisiones descentralizada.

Se analiza inicialmente la toma de decisiones coordinada entre los niveles de gobierno con el fin de comparar con los resultados del análisis descentralizado. El gobierno coordinado elige los vectores de impuestos $t$ y $s$ y el vector de bienes públicos $Q$, para maximizar la siguiente expresión, donde $\mu$ y $\gamma$ son los multiplicadores de los recursos y del gasto público:

$\operatorname{Max}_{t_{* *}, s_{* *}, b_{* *}, Q_{* *}} \sum_{i} \varpi_{i} \sum_{k} u^{i k} V^{i k}+\mu\left[\sum_{k}\left(s_{*_{k}} Y_{*_{k}}+t_{*_{k}} x_{*_{k}}-v_{*_{k}} b_{*_{k}}\right)\right]+\sum \gamma_{k} g_{k}$ 
A partir de la comparación con la toma de decisiones en forma descentralizada, en la cual cada gobierno toma como dada la decisión del otro gobierno, el objetivo de cada gobierno es maximizar la suma ponderada de la utilidad de sus propios residentes, sujeta a la restricción presupuestaria de balance y a la función de producción del gasto, es decir:

$\left.\operatorname{Max}_{t_{t_{i}, s_{*},}, b_{*_{i}}, Q_{*_{i}}} \sum_{i} \varpi_{i} u^{i i} V^{i i}+\mu \mid s_{*_{i}} Y_{*_{i}}+t_{*_{i}} x_{*_{i}}-v_{*_{i}} b_{*_{i}}\right]+\gamma_{i} g_{i}$

Los efectos sobre otras unidades de gobierno son ignorados, con lo cual cada gobierno maximiza en forma simultánea tomando como dadas las decisiones de los demás gobiernos.

A partir del análisis de las condiciones de primer orden para ambos casos, la decisión coordinada y la no coordinada, puede verse que en el segundo aparecen diferencias debido al hecho de no tomar en cuenta el efecto sobre los no residentes. Para el caso de los efectos directos de los cambios de política, se ignora la pérdida de utilidad de los no residentes por el pago de impuestos. Lo propio ocurre con la valoración de los bienes públicos locales para los no residentes.

Además de los efectos distributivos y los cambios en la congestión en la comunidad correspondiente, se capturan los efectos en la recaudación de impuestos de los cambios de política; en el caso centralizado, se tienen en cuenta los efectos en la recaudación total, mientras que en el caso descentralizado, sólo los efectos en la recaudación de cada comunidad son los que se analizan, lo cual ocurre sólo en el caso en que las elasticidades precio cruzadas sean cero.

A partir del análisis mencionado surgen distintos tipos de externalidades, a saber: los no residentes pagan parte de los impuestos y reciben beneficios de la provisión del bien público, la recaudación de impuestos en otras comunidades pueden experimentar variaciones debido a las externalidades generadas en la actividad económica, costos de provisión de bienes públicos en otras localidades pueden variar, como así también los precios de factores y productos. El trabajo enuncia distintas maneras en las que el gobierno federal puede minimizar las distorsiones, apelando a mecanismos de provisión centralizada de bienes públicos, transferencias condicionadas, mecanismos de coparticipación de impuestos, o regulación federal de bases imponibles a nivel subnacional.

Sin embargo, el trabajo de Gordon no considera las externalidades verticales generadas por la superposición de bases imponibles. Los trabajos más recientes sobre esta temática le otorgan un rol más trascendente al gobierno federal; la fortaleza básica de la misma parte del 
reconocimiento que el gobierno federal es un actor relevante con sus propios objetivos en un juego con gobiernos de nivel inferior. El gobierno federal pasa ahora a tener una participación relevante en la provisión de bienes públicos propios y el financiamiento de los mismos a través de recaudar impuestos sobre la base imponible compartida con los gobiernos subnacionales. A continuación se explicitarán algunas de las contribuciones más relevantes.

\subsubsection{Gobiernos con instrumentos limitados}

La literatura sobre esta temática ha tenido un desarrollo importante en los últimos años. Se sintetizarán algunas de las contribuciones, para desarrollar con mayor detalle un modelo sobre imposición a los consumos presentado por Hoyt (2001).

Kothenburger (2002) y Vigneault y Boadway (1996), para impuestos al capital o a los beneficios de sociedades, analizan las maneras en que la interacción entre impuestos federales y provinciales puede crear distorsiones en los niveles y tipos de impuestos y analizan alternativas en las que las distorsiones pueden ser reducidas o eliminadas.

Mientras tanto, con impuestos sobre salarios, Boadway, Marchand y Vigneault (1998) desarrollan un modelo en el que los estados implementan un impuesto progresivo lineal y proveen un bien público. La externalidad fiscal vertical genera un incentivo para incrementar la progresividad de los impuestos estaduales; el gobierno federal implementa sus propios impuestos progresivos y realiza transferencias a los estados; el gobierno federal puede anular la externalidad vertical con políticas apropiadas y la imposición redistributiva puede ser descentralizada a los estados

En impuestos sobre los patrimonios, Fernández (2004) analiza el caso de dos jurisdicciones superpuestas (un distrito escolar y una ciudad) cuando uno de ellos (la ciudad) utiliza TIF ("tax increment financing”) para financiar un aumento en la provisión del bien público que provee. Si se asume equilibrio de Nash, se genera una cantidad subóptima del bien público provisto por el distrito, mientras que en el caso en el que el distrito es líder, el resultado depende en forma inversa del nivel de provisión del bien público del otro nivel jurisdiccional.

El trabajo de Hoyt (2001), para impuestos sobre los consumos, presenta distintos escenarios. Inicialmente realiza el análisis de la provisión centralizada de bienes públicos y de recaudación de impuestos, en donde llega a la condición de óptimo de second best de Atkinson y Stiglitz para la tributación de bienes de consumo. El modelo asume la existencia de $n$ estados idénticos, cada uno con un individuo representativo. Existe un factor de 
producción trabajo, utilizado en la producción de dos bienes de consumo privados, $x_{1}$ y $x_{2}$, ambos normales; una unidad de trabajo produce una unidad de bienes privados.

Adicionalmente se proveen dos bienes públicos, uno nacional provisto uniformemente a todos los estados en un nivel $g_{f}$, y otro estadual, provisto por cada estado a sus habitantes $i=1, \ldots \ldots \ldots n$ a un nivel $g_{i}$; una unidad de trabajo produce una unidad de bienes públicos por habitante o una unidad de bien privado. Existen dos bienes privados, $x_{1} \mathrm{y} x_{2}, \mathrm{y}$ un tercer bien, el ocio $x_{3}$, numerario. La función de utilidad para un residente del estado $i$ es $U\left(X\left(x_{1 i}, x_{2 i}, x_{3 i}\right), g_{i}, g_{f}\right)$ es separable, donde $x_{i j}$ es el consumo del bien $x_{j}$ por el residente del estado $i$, no afectando el nivel de los gastos públicos la demanda de bienes privados.

Los precios son normalizados a 1 , el precio de una unidad de trabajo, mientras que $t_{j i}$ y $t_{j f}$ son las alícuotas impositivas del estado y el gobierno federal, respectivamente, sobre el bien $j$. El precio post impuestos del bien $x_{j}$ en el estado $i$ es $q=1+\tau_{j i}+\tau_{j f}$, con $q_{i}=\left(q_{1 i}, q_{2 i}\right)$ denotando el vector de precios en el estado i. La función de utilidad indirecta es $V\left(q_{i}, g_{i}, g_{f}\right)$ para el residente del estado i.

Es importante destacar que se asume que el residente del estado $i$ sólo adquiere los bienes en su propio estado, con lo cual no hay impacto de cambios en los impuestos del estado $i$ en los ingresos de otros estados, lo que implica la inexistencia de externalidades horizontales. El mencionado efecto también se obtiene a partir del supuesto de colocar impuestos de destino.

Con el fin de establecer un marco de referencia para el accionar del sector público en relación con las políticas descentralizadas, se asume inicialmente la existencia de un gobierno unificado que fija las alícuotas tributarias con la potestad de gravar la base imponible en forma total y proveer bienes públicos a nivel federal y subnacional.

En el análisis del gobierno unificado, se asume que el mismo puede gravar la totalidad de la base imponible, lo que también se asume para el caso en que la estructura de gobierno federal implique que ambos gravan la misma base y ambos toman como dadas las decisiones en relación con la determinación de alícuotas tributarias del otro nivel jurisdiccional. En consecuencia, el problema para el gobierno unificado es:

$$
\operatorname{Max}_{\tau_{11}, \ldots . ., \tau_{1 n} ; \tau_{21}, \ldots \ldots . ., \tau_{2 n} ; g_{1,}, \ldots \ldots ., g_{n} ; g_{f}} \sum_{i=1}^{n} V\left(q_{i}, g_{i}, g_{f}\right) \text { s. t. } \sum_{i=1}^{n}\left(\tau_{1 i} x_{1 i}\left(q_{i}\right)+\tau_{21} x_{2 i}\left(q_{i}\right)\right)=\sum_{i=1}^{n}\left(g_{i}+g_{f}\right)
$$


Se demuestra que en cada estado la cantidad provista de bien público local y la del nacional en cada estado deben ser iguales. Dado que los residentes de los estados son iguales y cada residente tiene igual ponderación en la función de bienestar del gobierno unificado, las alícuotas son iguales para todos los estados y las mismas se expresan $\tau_{1}^{*}$ y $\tau_{2}^{*}$, omitiendo el subíndice del estado. En términos de elasticidades, expresando $\tilde{\tau}_{j}=\tau_{j} / q_{j}$, resulta, para $j=1,2, \overline{\tau_{1}^{*}} \eta_{j 1}+\overline{\tau_{2}^{*}} \eta_{j 2}=\theta^{*}$, donde $\theta^{*}=\left[\frac{\alpha}{\lambda}+\sum_{k=1}^{2} \tau_{k}^{*} \frac{\partial x_{k}}{\partial y}-1\right]<0$. De esta manera se determina la regla de imposición óptima sobre los bienes de Diamond y Mirrlees o Atkinson y Stiglitz. Ahora la utilidad marginal de la renta difiere del costo marginal de los fondos públicos.

De acuerdo con Atkinson y Stern, y descomponiendo la ecuación anterior, la igualdad se convierte en la ecuación subsiguiente, lo que permite apreciar la distorsión en términos de la diferencia entre la utilidad marginal de la renta $(\alpha)$ y el costo marginal de los fondos públicos $(\lambda): \frac{\alpha}{\lambda}=1+\overline{\tau_{1}^{*}} \eta_{j 1}+\overline{\tau_{2}^{*}} \eta_{j 2}-\sum_{k=1}^{2} \tau_{k}^{*} \frac{\partial x_{k}}{\partial y}$

Las alícuotas impositivas y los niveles de gasto público del gobierno unificado constituyen las políticas de second best de maximización del bienestar. El término $\eta_{j k}$ es la elasticidad precio compensada de la demanda del bien $j$ con respecto al precio del bien $k$. La ecuación determina que el set óptimo de alícuotas implica que el ratio de carga excedente marginal de los impuestos a recaudación marginal debe ser igual para todos los bienes en todos los estados. El set de tasas que maximizan el bienestar social es, en función de $\theta^{*}$, el siguiente: $\overline{\tau_{j}^{*}}\left(\theta^{*}\right)=\left(\frac{\eta_{k k}-\eta_{j k}}{\eta_{11} \eta_{22}-\eta_{12} \eta_{21}}\right) \theta^{*}$

En el caso del gobierno descentralizado, con bases imponibles idénticas para ambos niveles de gobierno, el hecho de considerar de manera diferenciada a los individuos de todos los estados (gobierno federal) o de sólo el estado propio (gobierno local) hace surgir diferencias en relación con las alícuotas tributarias óptimas explicitadas anteriormente, a partir de las cuales puede generarse un nivel de imposición que lleve a los estados a proveer un nivel de bien público que difiera del gobierno federal.

Se consideran las políticas de los gobiernos federal y estaduales en forma independiente, eligiendo sus alícuotas en un juego con un equilibrio de Nash en las tasas impositivas; cada gobierno toma como dadas las alícuotas fijadas por el otro nivel jurisdiccional. Cada 
gobierno, sin embargo, tiene en cuenta los cambios en la recaudación impositiva del otro nivel jurisdiccional (es decir, no son "miopes") pero asumen que no hay cambios en las políticas impositivas del otro nivel como resultado de sus propias decisiones. Se asume que ambos gobiernos tienen bases imponibles idénticas, es decir, ambos gravan los mismos bienes.

En este equilibrio de Nash el estado $i$ elige sus alícuotas $\tau_{1 i}$ y $\tau_{2 i}$ dadas las alícuotas federales y las tasas de los otros estados para resolver el siguiente problema, considerando la restricción presupuestaria para el gobierno $i$ y para el gobierno federal:

$\operatorname{Max}_{\tau_{1 i}, \tau_{2 i} ; g_{i,}} V\left(q_{i}, g_{i}, g_{f}\right)$ s.t. $\tau_{1 i} x_{1 i}\left(q_{i}\right)+\tau_{21} x_{21}\left(q_{i}\right)=g_{i} \mathrm{y} \sum_{j=1}^{n}\left(\tau_{1 f} x_{1 f}\left(q_{i}\right)+\tau_{2 f} x_{2 f}\left(q_{i}\right)\right)=n g_{f}$

En la condición de primer orden para la determinación de la alícuota del estado $i$ para el bien $j$ se aprecia el impacto de la misma sobre el precio del bien y sobre la recaudación necesaria para financiar la provisión del bien público local $g_{i}$ además del efecto sobre la recaudación del gobierno federal, lo que reduce el nivel de provisión del bien público federal $g_{f}$. Sin embargo, dado que el estado $i$ sólo considera el impacto del incremento de su tasa impositiva en la recaudación del gobierno federal, y en la provisión del bien público federal en su propio estado y no considera la disminución en la provisión del bien público federal en el resto de los estados; para los residentes del resto de los estados, se genera una externalidad fiscal vertical. Los gobiernos estaduales consideran el impacto de las políticas impositivas en la recaudación del gobierno federal, la que depende de la cantidad de estados y de la tasa marginal de sustitución entre los bienes provistos por el sector público estadual y federal; la influencia es menor a mayor cantidad de estados y mayor tasa marginal de sustitución entre ambos bienes.

El gobierno federal maximiza la utilidad agregada en los estados, aunque sólo financia bienes públicos federales. Influye indirectamente en el nivel de provisión de bienes públicos locales a partir de afectar las bases imponibles de los estados. En consecuencia, el problema del gobierno federal es, tomando como dadas las tasas de los estados:

$$
\operatorname{Max}_{\tau_{1 f}, \tau_{2 f}, g_{f}} \sum_{i=1}^{n} V\left(q_{i}, g_{i}\left(\tau_{1 f}, \tau_{2 f}\right), g_{f}\right) \text { s.t. } \sum_{i=1}^{n}\left(\tau_{1 f} x_{1 i}\left(q_{i}\right)+\tau_{2 f} x_{2 i}\left(q_{i}\right)\right)=n g_{f}
$$

Comparando los niveles de gasto público del gobierno federal y de los estados, a partir de las condiciones de primer orden para las maximizaciones de cada gobierno en relación a su 
propia alícuota tributaria ${ }^{18}$, se llega a una subprovisión del bien público federal, con lo cual el gasto público en los gobiernos estaduales es muy alto en relación con el bien público federal.

En consecuencia, los estados colocan tasas impositivas demasiado elevadas como consecuencia de la externalidad vertical; el nivel de provisión de gasto propio es muy elevado; el gobierno federal intenta compensar esta externalidad a partir de reducir sus propios impuestos y gastos propios. La tasa combinada del gobierno federal y de los estados es superior a la del gobierno unificado ${ }^{19}$, y el nivel de gasto público combinado es también más alto que el del gobierno centralizado.

Los mecanismos anteriores procuraban utilizar la política tributaria por parte del gobierno federal para incrementar el nivel de provisión del bien público. Sin embargo, si bien lo consiguen en parte, lo hacen a expensas de alcanzar niveles de gasto e imposición demasiado elevados.

Si las bases imponibles difieren en parte, el gobierno federal puede compensar mediante la recaudación de impuestos provenientes de la base que no comparte la pérdida anterior y lograr acercarse al óptimo a partir de considerar a todos los individuos en su función de utilidad. Las externalidades fiscales son endógenas y reflejan las decisiones de política del gobierno federal. En ausencia de transferencias, el gobierno federal colocará alícuotas de manera tal que el costo marginal de un incremento en las tasas de los estados sea la misma para todos los estados.

En este caso, el gobierno federal puede gravar $x_{1}$ y $x_{2}$, mientras que el estadual sólo $x_{1}$, configurando el caso de superposición parcial en la fuente de imposición. Cada estado ahora maximiza la función indirecta de utilidad, sujeta a la restricción presupuestaria propia y a la del gobierno federal aunque sólo gravando uno de los bienes:

$\operatorname{Max}_{\tau_{\tau_{1} ;} ; g_{i,}} V\left(q_{i}, g_{i}, g_{f}\right)$ s.t. $\tau_{1 i} x_{1 i}\left(q_{i}\right)=g_{i}$ y $\sum_{j=1}^{n}\left(\tau_{1 f} x_{1 f}\left(q_{i}\right)+\tau_{2 f} x_{2 f}\left(q_{i}\right)\right)=n g_{f}$

En el caso de bases imponibles idénticas, los estados generaban un nivel de imposición demasiado elevado, lo que generaba una externalidad negativa en el gobierno federal que determinaba sobreproducción de su propio bien público en relación con el federal. En el caso de bases imponibles limitadas, sin embargo, puede ahora generarse una subprovisión del bien

\footnotetext{
${ }^{18}$ Hoyt (2001)

${ }^{19}$ Wilson (2005)
} 
público de los estados, dado que la recaudación generada por la base imponible que no es compartida puede compensar la pérdida de recaudación generada en la base compartida.

Adicionalmente, el costo marginal social de los fondos públicos es mayor en el caso de los estados, por lo limitado de la base imponible, aún teniendo en cuenta el hecho de la externalidad negativa generada por los gobiernos subnacionales al aumentar su propia alícuota sobre la base compartida y el bien público del estado siga siendo subprovisto.

El gobierno federal varía sus políticas impositivas de acuerdo a si el bien público subnacional está sobre o subprovisto con el fin de alcanzar una tasa cercana a la óptima para ambos bienes e influir en la recaudación de impuestos de los estados. La tasa que grava $x_{1}$ (base compartida) será más alta que la de $x_{2}$ si la tasa marginal de sustitución entre los bienes públicos locales y los federales es menor que uno y viceversa, de acuerdo a las tasas relativas que maximizan el bienestar social, pudiendo inclusive subsidiar al bien si $M R S_{s f}>1$ y $x_{1}$ y $x_{2}$ son complementarios.

Adicionalmente, la externalidad puede ser una elección del gobierno federal, al incrementar la recaudación generada en el bien gravado mediante un aumento de la alícuota si el bien público estadual está subprovisto en relación al federal. En general, no se puede extraer una conclusión determinante sobre las tasas del gobierno subnacional cuando estos sólo manejan un limitado set de instrumentos. En algunos casos, inclusive, el gobierno federal debe subsidiar el bien gravado por los estados para compensar parcialmente los impuestos ineficientemente elevados.

\subsubsection{Gobiernos con acceso a transferencias}

En el caso de la existencia de transferencias, en Hoyt (2001) se lleva a cabo el análisis con el fin de determinar aquéllas que aseguren un nivel eficiente de gasto en bienes públicos federales y estaduales. La existencia de transferencias reduce las distorsiones generadas por los impuestos independientemente de la amplitud de la base imponible de los estados.

En un resultado conocido en la mayoría de los estudios sobre esta temática, se demuestra que la posibilidad de acceder a transferencias permite minimizar las distorsiones generadas por las bases imponibles concurrentes, aún cuando existe superposición parcial. Hoyt (2001), por ejemplo, determina las transferencias de igualación necesarias para asegurar una combinación eficiente de gasto público federal y estadual. 
En forma similar a los casos anteriores, el problema para el gobierno federal ahora es elegir las tasas impositivas, las transferencias de ingresos hacia o desde los gobiernos subnacionales y una transferencia de suma fija. El mismo está dado por lo siguiente, en donde los bienes $x_{1}$ y $x_{2}$ están gravados por ambos gobiernos, y se adiciona un bien $x_{3}$, sólo gravado por el gobierno federal, y en donde $q$ es el vector de precios:

$$
\begin{aligned}
& \operatorname{Max}_{\tau_{1 f}, \tau_{2 f}, \tau_{3 f}, m_{1}, m_{2}} \sum_{i=1}^{n} V\left(\underline{q}, g_{i}, g_{f}\right) \text { s.t. }\left(1+m_{1}\right) \tau_{1 i} x_{1 i}(\underline{q})+\left(1+m_{2}\right) \tau_{2 i} x_{2 i}(\underline{q})+S_{i}-g_{i}=0 \mathrm{y} \\
& \sum_{i=1}^{n}\left(\left(\tau_{1 f}-\tau_{1 i} m_{1}\right) x_{1 i}(\underline{q})+\left(\tau_{2 f}-\tau_{2 i} m_{2}\right) x_{2 i}(\underline{q})+\tau_{3 f} x_{3 i}(\underline{q})-S_{i}-g_{f}\right)=0
\end{aligned}
$$

El problema para el gobierno subnacional es el siguiente:

$$
\begin{aligned}
& \operatorname{Max}_{\tau_{1 i}, \tau_{2 i}} V\left(\underline{q}, g_{i}, g_{f}\right) \text { s.t. }\left(1+m_{1}\right) \tau_{1 i} x_{1 i}(\underline{q})+\left(1+m_{2}\right) \tau_{2 i} x_{2 i}(\underline{q})+S_{i}-g_{i}=0 \mathrm{y} \\
& \frac{1}{n} \sum_{j=1}^{n}\left(\left(\tau_{1 f}-\tau_{1 j} m_{1}\right) x_{1 j}(\underline{q})+\left(\tau_{2 f}-\tau_{2 j} m_{2}\right) x_{2 j}(\underline{q})+\tau_{3 f} x_{3 j}(\underline{q})-S_{j}\right)=g_{f}
\end{aligned}
$$

A partir de las condiciones de primer orden y de la regla óptima del gobierno federal, se logra derivar la conclusión de que las políticas impositivas y de transferencias óptimas $\left(S, m_{1}, m_{2}\right)$ del gobierno federal deben ser tales que la tasa marginal de sustitución entre los bienes provistos por ambos niveles de gobierno sea igual a uno $\left(M R S_{s f}=1\right)$, lo que implica igual nivel de bienes públicos para ambos gobiernos, y que ninguno de los estados genere una externalidad tributaria.

Esto significa que el gobierno federal puede compensar mediante el mecanismo de transferencias las externalidades que generan los gobiernos subnacionales en la base imponible del gobierno federal

Las alícuotas combinadas del gobierno federal y de los gobiernos provinciales son óptimas. Dado el impuesto del gobierno subnacional, el gobierno federal controla el impuesto total sobre cada bien a través de la elección apropiada del impuesto propio, como gobierno benevolente, el objetivo es minimizar la carga excedente total, integrada por la suma de ambas tasas.

El gobierno federal puede en consecuencia reasignar la recaudación tributaria entre los dos niveles de gobierno mediante transferencias de suma fija, o compensatorias. No puede, sin embargo, alterar las decisiones sobre tasas de los gobiernos subnacionales pero sí compensar las ineficiencias mediante una elección apropiada de tasas y transferencias. 
De acuerdo con Hoyt (2001) si en lugar de suponer un juego en equilibrio de Nash se asimilara a un análisis en donde el gobierno federal es líder de Stackelberg, en el contexto en que exista la posibilidad de apelar al mecanismo de transferencias no hay ganancias por parte del gobierno federal de mover primero. En el caso de instrumentos limitados, es decir, en organizaciones institucionales en las cuales no pueda hacerse uso de transferencias, el gobierno federal puede, al mover primero, influenciar las tasas impositivas de los estados y los niveles de provisión de bienes públicos, con lo cual el gobierno federal no colocará tasas para maximizar el bienestar social.

Hoyt (2001) también menciona el caso de estados heterogéneos. Como en el caso de estados idénticos, la política impositiva del gobierno federal depende de las tasas de los estados y la provisión relativa del bien público federal y del estado. Sin embargo, a diferencia del caso de estados idénticos, la tasa combinada federal y provincial no serán iguales a las determinadas por el gobierno unificado; con bases imponibles idénticas, los bienes públicos de los estados están provistos en exceso en relación al bien público federal al igual que en el caso de estados idénticos.

Para que las externalidades verticales resulten negativas, debe producirse una reducción de la base imponible del otro gobierno cuando uno de ellos incrementa su alícuota tributaria. Dahlby y Wilson (2003) presentan un modelo en donde las externalidades verticales pueden ser positivas, sin considerar externalidades horizontales. En el mismo muestran que un incremento en el impuesto salarial estadual puede incrementar la recaudación de impuestos del gobierno federal si éste impone una tasa ad valorem en los salarios y la demanda de trabajo es inelástica (ver gráfico 2).

En el modelo tanto el gobierno federal como los estados gravan salarios y beneficios, a las tasas ad valorem $T$ y $t$, y proporcionales $U$ y $u$, respectivamente, siendo $\tau=T+t$ y $1=U+u$ las tasas totales. Los estados proveen dos bienes públicos, uno es un bien de consumo $c$ que se introduce en la función de utilidad indirecta del agente representativo $V\left(w_{n}\right)+B(c)$, mientras que el otro es un bien público $g$ que incrementa la productividad, por lo cual se incorpora en la función de producción de las empresas $X=F(L, g)$, en donde $X$ es el producto y $L$ es el insumo trabajo (las productividades marginales son decrecientes).

Los beneficios son $\pi=F(L, g)-w L$ y la demanda de trabajo está determinada por la condición de maximización de beneficios $w=F_{L}$ y donde $\varepsilon=F_{L} /\left(L F_{L L}\right)<0$ es la elasticidad 
de la demanda de trabajo. La oferta de trabajo en cada estado es una función no decreciente del salario neto, $L\left(w_{n}\right)$, y la elasticidad de la oferta de trabajo es $\eta=\left(\partial L / \partial w_{n}\right) /\left(\partial w_{n} / L\right) \geq 0$

La recaudación tributaria de ambos niveles de gobierno, que utilizan para financiar los gastos públicos propios, es $R_{s}=t w L+u \pi$, y $R_{F}=T w L+U \pi$, respectivamente, para los estados y para el gobierno federal. La externalidad vertical aparece (en este caso, "bottom-up externality", desde los estados hacia el gobierno federal) cuando el cambio en la tasa provincial afecta la recaudación impositiva del gobierno federal.

\section{Gráfico 2}

El efecto en la recaudación tributaria federal de un incremento en la tasa impositiva del gobierno provincial sobre el salario de los empleados

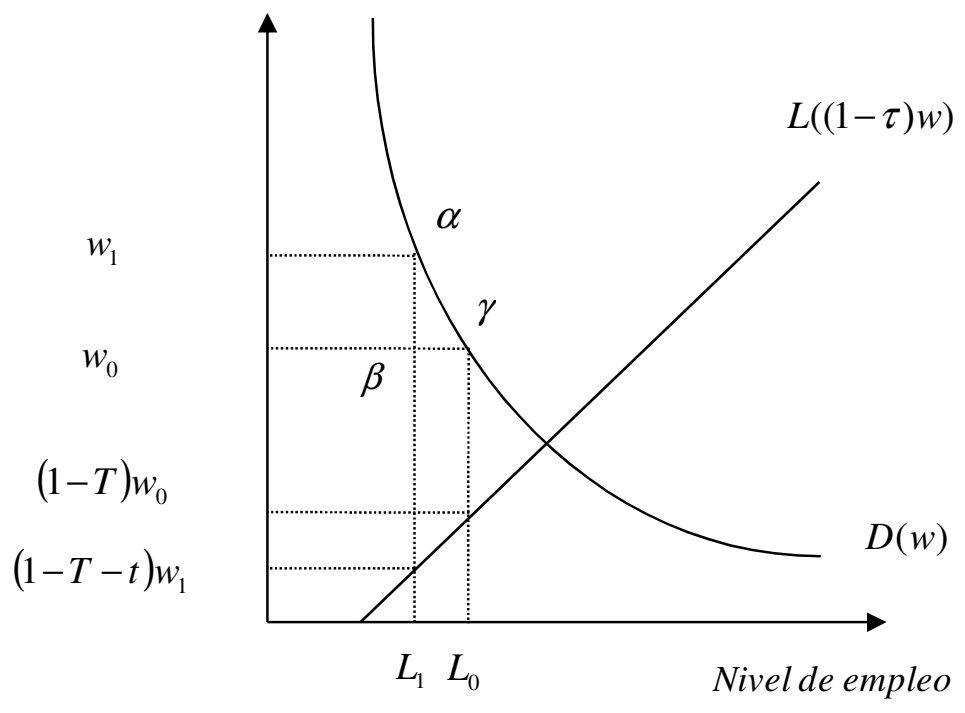

Fuente: Dahlby y Wilson (2003)

Los efectos de los cambios de $\tau$ en $w$ y en $\pi$ se derivan a partir de diferenciar totalmente la condición de maximización de beneficios y la función de oferta de trabajo, y pueden verse adicionalmente en el gráfico que se expone a continuación. Inicialmente, el equilibrio está en $\gamma$, en donde la base imponible es $w_{0} L_{0}$; cuando la provincia introduce un impuesto de $t$, el cambio en la base imponible del impuesto sobre salarios está dado por la diferencia entre las áreas $w_{1} \alpha \beta w_{0}$ y $L_{1} \beta L_{0}$, mientras que la base imponible del impuesto sobre los beneficios declina en $w_{1} \alpha \beta w_{0}$. Si la demanda de trabajo es suficientemente inelástica, y la tasa impositiva federal sobre salarios es mayor que la tasa sobre beneficios $\left(T / U>(1+\varepsilon)^{-1}>1\right)$, 
la recaudación federal total se incrementará cuando los estados aumenten la tasa sobre los salarios $^{20}$.

\subsubsection{Competencia tributaria horizontal y vertical}

Resulta interesante profundizar el análisis para incluir la posibilidad de que exista, adicionalmente a la competencia vertical, la horizontal. Keen y Kotsogiannis (2002 a, 2002 b), en este marco, utilizan un marco analítico de impuestos sobre el capital para analizar dos cuestiones relevantes: en primer lugar, si el nivel de la tasa combinada que surge de la superposición de bases imponibles es demasiado elevado, y en segundo, analizan los efectos de la intensificación de la competencia tributaria en sistemas caracterizados por la presencia de externalidades horizontales y verticales.

En el modelo existen $N$ estados idénticos. La producción en cada estado está dada por la función $F\left(K_{j}\right)$, donde $K_{j}$ es el capital, móvil entre estados hasta igualar el retorno post impuestos $\rho$. Cada estado coloca un impuesto $t_{j}$ al capital. El gobierno federal coloca un impuesto unitario $T$ al capital en cada jurisdicción; la tasa impositiva consolidada en el estado $j$ es $\tau_{j} \equiv t_{j}+T$. La condición de arbitraje $F^{\prime}\left(K_{j}\right)=\rho+\tau_{j}$ define la demanda por capital en el estado $j$ como $K_{j}=K\left(\rho+\tau_{j}\right)$ con $K^{\prime}=1 / F^{\prime \prime}<0$. Las rentas obtenidas por las firmas en el estado $j, \pi \equiv F\left(K_{j}\right)-F^{\prime}\left(K_{j}\right) K_{j}$, son gravadas por el gobierno subnacional a la tasa exógena $\theta$ y no están gravadas por el gobierno federal.

El consumidor representativo responde a la función de utilidad $U\left(C_{1}, C_{2}, g, G\right)=u\left(C_{1}\right)+C_{2}+H(g, G)$, en donde $C_{i}$ son los consumos en el período $i$, y $g$ у $G$ son los bienes públicos "residenciales" provistos por ambos niveles de gobierno; la función de utilidad es separable. La maximización de la utilidad genera una curva de oferta de ahorro $S=S(\rho)$

Cada consumidor en el estado $j$ posee una dotación $e$ de ingresos del primer período; en el segundo, recibe el principal y el interés en los ahorros del primer período, además de las rentas después de impuestos obtenidas en su jurisdicción. La función de utilidad indirecta es

$U(\rho, \tau, g, G) \equiv u(e-S(\rho))+(1+\rho) S(\rho)+(1-\theta) \pi(\rho+\tau)+H(g, G)$

\footnotetext{
${ }^{20}$ Dahlby y Wilson (2003) demuestran que, si el impuesto sobre salarios recae sobre los empleadores, la externalidad es negativa, porque caen tanto la base imponible del impuesto sobre salarios como la del impuesto sobre los beneficios.
} 
El retorno neto $\rho$ está definido, en el equilibrio simétrico en donde todos los estados colocan la misma alícuota, por $p^{\prime}(\tau)=N \frac{\partial \rho}{\partial \tau_{j}}=\frac{K^{\prime}(\rho+\tau)}{S^{\prime}(\rho)-K^{\prime}(\rho+\tau)}$

Los gobiernos son benevolentes; maximizan el bienestar de sus residentes decidiendo simultáneamente, en un equilibrio de Nash, sobre sus tasas impositivas, sin posibilidad de acceder a transferencias. Las recaudaciones de ambos niveles son las siguientes, en donde el gobierno federal distribuye igualitariamente lo recaudado entre los $N$ estados: $g_{j}=t_{j} K\left(\rho+\tau_{j}\right)+\theta \pi\left(\rho+\tau_{j}\right)$, para cada estado, y $G=\frac{1}{N} \sum_{i=1}^{N} T K\left(\rho+\tau_{j}\right)=T S(\rho)$, para el gobierno federal.

El estado $j$ maximiza la siguiente función de bienestar, eligiendo su alícuota óptima tomando como dadas las tasas de los otros estados y la del gobierno federal.

$W_{j}\left(\tau_{j}, \vec{\tau}\right) \equiv U\left|\rho(\vec{\tau}), \tau_{j}, t_{j} K\left(\rho(\vec{\tau})+\tau_{j}\right)+\theta \pi\left(\rho(\vec{\tau})+\tau_{j}\right), T S(\rho(\vec{\tau}))\right| . \quad$ El $\quad$ gobierno $\quad$ federal maximiza la función de bienestar $W(\tau, \vec{\tau}) \equiv U \mid \rho(\vec{\tau}), \tau, t K(\rho(\vec{\tau})+\tau)+\theta \pi(\rho(\vec{\tau})+\tau), T S(\rho(\vec{\tau})))$; Las ineficiencias a partir de las decisiones de imposición por parte de los estados, luego de escribir la función de bienestar social en equilibrio de simetría (misma tasa para todos los estados) y de diferenciar con respecto a la tasa impositiva común, evaluando en el equilibrio simétrico resulta:

$W_{t}\left(t^{*}, T^{*}\right)=\left[H_{g} t^{*} K^{\prime}+\theta K\left(1-H_{g}\right)+\frac{H_{G}}{N} T^{*} N S^{\prime}\right]\left(1-\frac{1}{N}\right) p^{\prime}$

Los primeros dos términos capturan las externalidades horizontales provenientes de la movilidad del capital debida a los impuestos entre los estados, afectando la recaudación tributaria proveniente del impuesto al capital $t$ y el impuesto sobre los beneficios $\theta$. El tercer término refleja la externalidad vertical, proveniente de cambios en la base imponible del impuesto federal, $S$.

Keen y Kotsogiannis (2002 a) establecen condiciones para las cuales las externalidades horizontales dominan a las verticales, con lo cual la tasa impositiva del estado es demasiado baja $\left(W_{t}\left(t^{*}, T^{*}\right)>0\right)$, y a la inversa, es decir, aquellas para las cuales la externalidad vertical domina a la horizontal, con lo cual la alícuota es demasiado alta $\left(W_{t}\left(t^{*}, T^{*}\right)<0\right)$. 
Cuando las rentas no están gravadas $(\theta=0)$, la externalidad horizontal domina a la vertical si la oferta de ahorro es independiente de la tasa de interés neta; la externalidad vertical domina a la horizontal si la respuesta del ahorro a la variación del tipo de interés es más alta que la de la demanda de capital. En el caso en que las rentas estén gravadas $(\theta=1)$, la externalidad horizontal domina a la vertical.

Si el gobierno federal actuara como líder de Stackelberg, dado que anticipa la respuesta de su propio impuesto sobre el nivel de la tasa impositiva de equilibrio de los estados, se desviará de la regla $W_{T}=0$ para inducir a los estados a variar su tasa de equilibrio. De acuerdo con Keen y Kotsogiannis (2002 a), esto puede provocar que los impuestos federales sean demasiado elevados.

Lo anterior depende de dos factores: en primer lugar, de si la externalidad vertical o la externalidad horizontal resultan ser dominantes en la fijación de alícuotas; en segundo, de si los impuestos federales y los estaduales son sustitutos o complementarios estratégicos. Por ejemplo, si la externalidad horizontal es la que domina, lo que determina tasas demasiado bajas a nivel de los estados, el gobierno federal va a colocar su tasa de modo tal de inducir a una tasa más alta a nivel de los estados; si ambos impuestos son complementarios, la tasa será más alta que el valor óptimo, si son sustitutos, la tasa será más baja que el valor óptimo. La externalidad vertical, en consecuencia, es una decisión de política por parte del gobierno federal.

Keen y Kotsogiannis (2002 b) consideran luego el efecto de un incremento en la competencia tributaria horizontal, aproximada mediante el incremento en la cantidad de estados $N$. Si tanto el gobierno federal como los estados actúan Nash, y cada estado aumenta su tasa menos que una relación de uno a uno en respuesta a un aumento de la tasa de los otros estados, el aumento de la cantidad de estados (mayor competencia) lleva a la disminución en el bienestar de la sociedad.

Esto implica, por ejemplo, que si los impuestos de los estados tienden a ser demasiado elevados debido a una externalidad vertical dominante, un aumento en la cantidad de estados llevará a incrementar aún más las tasas; si los impuestos eran demasiado bajos en función de una externalidad horizontal dominante, el aumento de la competencia tributaria llevará a las alícuotas a un valor aún más reducido.

El modelo de Hoyt (2001) para impuestos sobre los consumos mencionado anteriormente es, sin embargo, de competencia perfecta. Es válido mencionar cómo se modifican las 
conclusiones ante cambios en este supuesto. Karakosta y Kotsogiannis (2006) analizan un modelo de "imperfect commodity tax competition" en un sistema federal en donde las externalidades fiscales aparecen horizontal y verticalmente. El impuesto sobre los consumos aparece bajo principio de destino o de origen, pudiendo ser específicos o ad valorem, en gobiernos benevolentes. Los autores encuentran que, independientemente del principio y del tipo de impuesto, la tasa del impuesto provincial es demasiado baja, a partir de una situación de equilibrio, si los consumidores le otorgan una valoración más alta al bien público local en relación con el federal.

En los trabajos mencionados, se aprecia la posibilidad de que las tasas impositivas resulten elevadas, en función de que, en el caso de una externalidad vertical negativa dominante, una reducción de la misma genere mejoras en el bienestar de la comunidad. Wrede (1996) y Keen y Kotsogiannis (2003) analizan la posibilidad de que las tasas puedan resultar tan elevadas que acaben en el lado decreciente de la curva de Laffer.

Para ello, consideran la existencia de gobiernos leviatánicos, que maximizan la recaudación tributaria. La coexistencia de externalidades verticales y horizontales es analizada por Wrede (1996) en el siguiente cuadro, donde $R$ es la recaudación total, $t_{F}$ es el impuesto federal y $t_{i}$ es el impuesto provincial.

De acuerdo con Wrede (1996), si los efectos totales son negativos, a partir de un equilibrio de Nash, una reducción en la tasa impositiva del gobierno federal y/o en la tasa impositiva de los estados lleva a un incremento en la recaudación impositiva total. Un resumen de los efectos mencionados puede apreciarse en el Cuadro 1.

\section{Cuadro 1}

Los signos de los efectos totales en un equilibrio de Nash

\begin{tabular}{|c|c|c|}
\hline & \multicolumn{1}{|c|}{$\begin{array}{c}\text { Externalidad vertical positiva } \\
\text { A }\end{array}$} & $\begin{array}{c}\text { Externalidad vertical negativa } \\
\text { B }\end{array}$ \\
\hline $\begin{array}{c}\text { Externalidad } \\
\text { horizontal } \\
\text { positiva } \\
\mathbf{C}\end{array}$ & $\frac{\partial\left[R+\sum_{i=1}^{n} R_{i}\right]}{\partial t_{i}}>0, \frac{\partial\left[R+\sum_{i=1}^{n} R_{i}\right]}{\partial t_{F}}>$ & $\frac{\partial\left[R+\sum_{i=1}^{n} R_{i}\right]}{\partial t_{i}}>=<0, \frac{\partial\left[R+\sum_{i=1}^{n} R_{i}\right]}{\partial t_{F}}<0$ \\
\hline $\begin{array}{c}\text { Externalidad } \\
\text { horizontal } \\
\text { negativa } \\
\mathbf{D}\end{array}$ & $\frac{\partial\left[R+\sum_{i=1}^{n} R_{i}\right]}{\partial t_{i}}>=<0, \frac{\partial\left[R+\sum_{i=1}^{n} R_{i}\right]}{\partial t_{F}}$ & $\frac{\partial\left[R+\sum_{i=1}^{n} R_{i}\right]}{\partial t_{i}}<0, \frac{\partial\left[R+\sum_{i=1}^{n} R_{i}\right]}{\partial t_{F}}<0$ \\
\hline
\end{tabular}

Fuente: Wrede (1996) 
Si las externalidades verticales y horizontales tienen signos opuestos, el impacto de la reducción de alícuotas en la recaudación impositiva total es ambiguo. Sin embargo, si la externalidad vertical desde los estados al gobierno federal ("bottom-up externality") excede a la externalidad horizontal, el efecto sobre la recaudación total está determinado por el signo de la externalidad vertical.

Si todos los efectos fueran negativos, la economía terminará en el lado decreciente de la curva de Laffer (intersección de la fila D y la columna B del cuadro 1); Keen y Kotsogiannis (2003) y Wrede (1996) muestran que también puede acabar en el lado decreciente de la curva de Laffer considerando situaciones más usuales, como el caso de externalidades horizontales positivas y verticales negativas (intersección de la fila $\mathrm{C}$ y la columna $\mathrm{B}$ del cuadro 1); en este caso, sólo puede incrementarse la recaudación total a través de una reducción de la tasa del estado si las externalidades verticales exceden a las horizontales.

Keen y Kotsogiannis (2003) especifican el caso de gobiernos leviatánicos en un modelo similar al expuesto anteriormente. Ahora las rentas en el estado $i$ están gravadas a la tasa $x_{i} \mathrm{y}$ a la tasa $\chi$ por el gobierno federal. La recaudación impositiva, utilizada para financiar los gastos públicos de cada nivel de gobierno $g_{i}$ y $G$, para cada nivel de gobierno, está dada, respectivamente para cada estado y para el gobierno federal, por: $r_{i}=t_{i} K\left(\rho+\tau_{i}\right)+x_{i} \pi\left(\rho+\tau_{i}\right)$ y $R=\frac{1}{N} \sum_{i=1}^{N}\left[T K\left(\rho+\tau_{i}\right)+\chi \pi\left(\rho+\tau_{i}\right)\right]$.

La recaudación impositiva del estado $i$ en equilibrio es $r_{t}\left(t^{*}, T^{*}\right)=K+\left(t * K^{\prime}-x K\right)\left(1+p^{\prime}\right)=\frac{-K p^{\prime}(N-1)}{N+p^{\prime}} \geq 0$, implicando que, si la tasa federal permanece constante, cada estado incrementaría su recaudación aumentando la alícuota (externalidad horizontal).

Es importante apreciar como varía la recaudación federal y provincial cuando el gobierno federal cambia la alícuota impositiva (externalidad vertical). Las dos externalidades apuntan en direcciones opuestas: la externalidad vertical, hacia tasas impositivas altas; la horizontal, hacia tasas bajas; ambas externalidades están operando a nivel de los estados. Para analizar cuál prevalece, sumando los cambios en la recaudación generados por las externalidades verticales y horizontales resulta que la externalidad vertical domina a la horizontal. En consecuencia, la recaudación consolidada crece con una reducción en la tasa federal, la tasa 
impositiva de los estados o la tasa combinada $\tau=t+T$; la economía se encuentra en la parte decreciente de la curva de Laffer en un equilibrio no cooperativo.

En los trabajos expuestos hasta aquí, se asume que los bienes públicos provistos por los gobiernos son residenciales, lo que asegura separabilidad en la función de producción y en la función de utilidad del agente representativo. Existe una literatura más reciente que ahonda en la determinación del efecto que la provisión de bienes públicos de distinto tipo genera en la externalidades interjurisdiccionales, generando externalidades verticales, pero por el lado del gasto público; si los gastos públicos alteran las demandas privadas, pueden generar "vertical expenditure externalities"

Dado que el objetivo de este trabajo es el análisis de tax competition, se hará solamente referencia a algunas contribuciones relacionadas con la provisión de bienes públicos sobre la recaudación tributaria ${ }^{21}$.

Madiès (2004) profundiza el análisis de Keen y Kotsogiannis (2002 a y b), con gobiernos benevolentes, asumiendo que los estados proveen un bien público industrial que incrementa la productividad de firmas localizadas en su propia jurisdicción, mientras que gobierno federal provee un bien público residencial al individuo representativo de cada estado.

La producción en el estado $i$ puede escribirse como función del capital en $i, K_{i}$ y el bien público industrial $g_{i F}: Y_{i}=F\left(K_{i}, g_{i F}\right)$. La condición de arbitraje se vuelve ahora $F_{K}\left(K_{i}, g_{i F}\right)-\tau_{i}=p$, mientras que la demanda de capital es $K_{i}=K_{i}\left(p+\tau_{i}, g_{i F}\right)$. Las rentas en el estado i, gravadas sólo por el estado, resultan ser $\pi_{i} \equiv F\left(K_{i}, g_{i F}\right)-F_{K}\left(K_{i}, g_{i F}\right) K_{i}$, todas incluyendo el bien público industrial.

El bien público industrial también está incluido en la función de utilidad y en las funciones de recaudación tributaria de ambos niveles de gobierno, que utilizan para financiar su propio gasto público. Las mismas son las siguientes:

$$
\begin{aligned}
& U\left(\rho, \tau, g_{F}, G\right) \equiv u(e-S(\rho))+(1+\rho) S(\rho)+(1-\theta) \pi\left(\rho+\tau, g_{F}\right)+H(G), \\
& G=\frac{1}{N} \sum_{i=1}^{N} T K\left(\rho+\tau_{i}, g_{i F}\right)=T S(\rho) \text { y } g_{i F}=t_{i} K_{i}\left(\rho+\tau_{i}, g_{i F}\right)+\theta \pi\left(\rho+\tau_{i}, g_{i F}\right)
\end{aligned}
$$

\footnotetext{
${ }^{21}$ Dahlby y Wilson (2003), en el trabajo ya mencionado, muestran si un incremento de la provisión del bien público que aumenta la productividad aumenta los ingresos fiscales federales, esto llevará a provisión en defecto del bien público por parte de los gobiernos provinciales.
} 
El retorno neto $\rho$ está definido, en el equilibrio simétrico en donde todos los estados colocan la misma alícuota, por $p^{\prime}(\tau)=N \frac{\partial \rho}{\partial \tau_{j}}=\frac{K^{\prime}(\rho+\tau)+K K^{\prime \prime}}{S^{\prime}\left(1-t K^{\prime \prime}-\theta F_{g_{F}}\right)-K^{\prime}(\rho+\tau)}$

El aumento en la provisión del bien público industrial genera un 'fiscal feed-back effect'. Manteniendo el costo del capital constante, una mayor provisión del bien público industrial lleva a un aumento de la base del impuesto al capital y a un aumento en la recaudación del impuesto al capital y a la renta. Esto genera un trade off entre dos externalidades horizontales: por un lado, una tasa más alta en uno de los estados lleva a una emigración de capital hacia otros estados; por el otro, una alícuota más elevada puede inducir a una mayor provisión del bien público estadual y un influjo de capital que afecta a los demás estados.

El efecto de un incremento coordinado de los impuestos de los estados puede verse en la ecuación siguiente.

$$
W_{t}\left(t^{*}, T^{*}\right)=\rho^{\prime}\left(1-\frac{1}{N}\right)\left[\theta K\left(1-\frac{F_{g_{F}}}{1-t^{*} K_{2}-\theta F_{g_{F}}}\right)+\frac{F_{g_{F}} t * K_{1}}{1-t^{*} K_{2}-\theta F_{g_{F}}}+H_{G} T^{*} S^{\prime}\right]
$$

Pueden identificarse tres efectos: el primero es el resultado de la externalidad horizontal que surge a partir del efecto en el consumo privado y en la recaudación tributaria de la imposición sobre el capital; el segundo captura el efecto de la movilidad del capital inducido por los impuestos sobre el consumo privado y sobre las rentas que están incorporadas en la función de utilidad del agente representativo, constituyendo otra externalidad horizontal.

El tercer efecto es la externalidad vertical ("bottom up externality") que resulta de la concurrencia en la fuente de imposición y proviene del hecho de que los estados sólo toman en cuenta el efecto de sus políticas en la recaudación federal y por ende en el nivel de provisión de bienes públicos federales en su propio estado.

Considerando ambas externalidades en conjunto, Madiès (2004) demuestra que en presencia de bienes públicos industriales, una externalidad vertical dominante puede resultar en tasas impositivas a nivel de los estados demasiado bajas, y, bajo determinadas condiciones, las externalidades verticales y horizontales pueden apuntar en la misma dirección hacia tasas demasiado bajas o demasiado altas.

Wrede (2000), en el caso de gobiernos leviatánicos, extiende su modelo anterior (Wrede (1996)) adicionando bienes públicos provistos por el gobierno federal y los estados, siendo éstos sustitutos perfectos que consisten en infraestructura, educación, etc., los que ayudan a 
incrementar la base imponible. Al igual que Keen y Kotsogiannis (2003), y Wrede (1996), concluye que una reducción en las tasas federales, estaduales o ambas, a partir de una situación de equilibrio simétrico de Nash (impuestos iguales para todos los estados), generan un incremento en la recaudación de impuestos (tasas demasiado altas, llevando a la economía del lado decreciente de la curva de Laffer), pero adiciona el efecto sobre el gasto.

A partir de un equilibrio simétrico de Nash (gastos iguales para todos los estados), un incremento pequeño del gasto de cada estado y/o un incremento en el gasto federal llevan a un mayor superávit presupuestario en presencia de superposición perfecta de bases imponibles, debido a que un mayor gasto genera un aumento en la base imponible y en consecuencia aumenta la recaudación impositiva (la economía está del lado decreciente de la curva de Laffer). Los resultados anteriores pueden apreciarse en el gráfico 3 subsiguiente.

\section{Gráfico 3}

\section{Las curvas de Laffer de impuestos y gastos públicos}
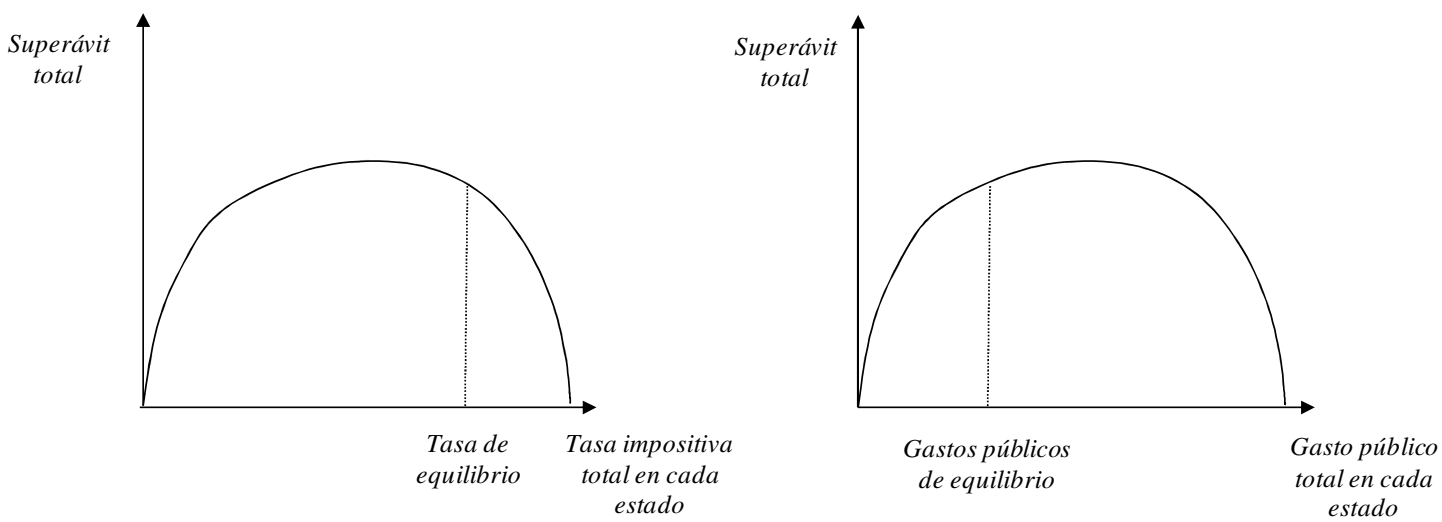

Fuente: Wrede (2000)

Martínez-López (2005) asume que el gobierno federal provee un bien público de consumo y los estados financian la provisión de insumos que afectan positivamente la productividad laboral; ambos niveles de gobierno utilizan impuestos al trabajo y a las rentas económicas como base imponible con limitaciones de instrumentos, esto es, el gobierno federal no tiene la posibilidad de apelar al mecanismo de transferencias ${ }^{22}$.

En concordancia con la literatura sobre esta temática, se llega al resultado de que el signo de la externalidad vertical depende del efecto sobre la base imponible del bien público que mejora la productividad, dado que incrementa la base imponible de ambos niveles de gobierno. Adicionalmente, la productividad marginal del insumo provisto por el sector

\footnotetext{
${ }^{22}$ Janeba y Wilson (2009) modelizan la división optima de bienes públicos entre el gobierno federal y los gobiernos regionales en una economía con competencia tributaria interregional.
} 
público, la sensibilidad de la tasa salarial al insumo provisto por el sector público y la elasticidad de la oferta de trabajo a la tasa impositiva del gobierno federal determinan el signo y la magnitud de la externalidad vertical.

En última instancia, y también en línea con la literatura sobre el tema, la imposibilidad de utilizar el mecanismo de transferencias impide al gobierno federal alcanzar el óptimo del gobierno unitario, aunque el mismo actúe como líder de Stackelberg.

\section{Antecedentes empíricos}

En función de lo comentado en la sección anterior, no existe una determinación teórica concluyente sobre la reacción de los impuestos provinciales, con lo cual la misma depende de las estimaciones empíricas. El propósito de esta sección es el de establecer los lineamientos utilizados para el análisis empírico. Inicialmente se hará referencia a estimaciones internacionales, para luego mencionar algunas contribuciones para el caso argentino.

\subsection{Estimaciones internacionales}

A continuación se describirán algunas estimaciones realizadas para los trabajos internacionales; el objetivo es el de estimar la pendiente de la función de reacción del gobierno provincial. En el cuadro 2 se presentan los resultados, en forma sintética, de los estudios.

Besley y Rosen (1998) estiman la reacción de los impuestos estaduales específicos a los cigarrillos y a la gasolina en Estados Unidos para el período 1975-1989. La ecuación a estimar es $t_{j s t}=\alpha_{s} \times \beta T_{j t}+\gamma X_{t}+\delta Z_{j s t}+\varepsilon_{j s t}$, donde $t_{j s t}$ es la tasa específica por estado y por bien y $T_{j t}$ es la tasa federal, e incluyen como variables dependientes a:

- variables macroeconómicas: la tasa de desocupación nacional y el producto bruto doméstico

- variables económicas estaduales y demográficas: población, ingreso per cápita, tasa de desocupación del estado, proporción de población menor a 17 y mayor a 65

- variables de índole política del estado: partido político del gobernador y composición del órgano legislativo

- variables fiscales federales: además de la tasa del impuesto específico, impuestos generales sobre los consumos, presión tributaria federal sobre los estados, transferencias verticales.

- variables dicotómicas por cada estado $\alpha_{s}$ 
Como resultado de las estimaciones obtienen una respuesta positiva de los impuestos estaduales ante un incremento de los impuestos específicos nacionales; en el caso de los cigarrillos, un $10 \%$ de aumento en la tasa federal induce un 2,8\% de aumento en la tasa del estado; para la gasolina, un $10 \%$ de aumento en la tasa federal induce un $4,1 \%$ de aumento en la tasa del estado.

Sin embargo, no todas las reacciones observadas en la conducta de los gobiernos jurisdiccionales ante incrementos en las tasas de los demás se deben a externalidades tributarias. Por ejemplo, si el gobierno subnacional deduce el monto de impuesto nacional, o lo que es equivalente, percibe el impuesto propio sobre el total de la base excluyendo los impuestos nacionales, tiende a una alícuota más alta que en el caso de no deducibilidad por reducir el costo marginal de los fondos públicos.

Existe otro tipo de reacción que puede asimilarse a la externalidad fiscal que se relaciona con la denominada ilusión fiscal. Esto hace referencia a que incrementos automáticos en los recursos tributarios de los estados no son compensados con políticas discrecionales por parte de los mismos, sino que se comportan en forma pasiva ${ }^{23}$.

Esteller-Moré y Solé-Ollé (2001) ${ }^{24}$, para el caso del impuesto personal a la renta nacional y los impuestos generales a las ventas estaduales en Estados Unidos en el período 1987-1996 eligen como variable dependiente a los impuestos estaduales dado que al existir múltiples estados, el gobierno federal no reacciona ante la variación en la alícuota de impuestos de uno de ellos, sino probablemente de una suma ponderada de ellos, lo que, según plantean los autores, elimina la posible endogeneidad de la tasa federal.

La ecuación utilizada es la siguiente, donde $t_{i t}$ e $t_{F i t}$ representan el impuesto provincial y el impuesto nacional por año y provincia, respectivamente y DRec tiene en cuenta el efecto de la deducibilidad de los impuestos nacionales o estaduales en el cálculo de la base imponible:

$t_{i t}=\alpha_{1} \times t_{F i t}+\alpha_{2} \times \sum_{j \neq i} \omega_{i j} \times t_{j t}+\alpha_{3} \times\left(t_{F i t} \times D \operatorname{Re} c_{i}\right)+\sum_{k} \alpha_{k} Z_{k, i t}+\alpha_{0, i}+\varepsilon_{i t}$

El resto de las variables incluidas en la ecuación son las tasas fijadas por los estados próximos denominada $t_{j t}$ y un vector de variables de control simbolizadas en $Z_{k}$. La primera de las variables refiere a la competencia tributaria horizontal entre jurisdicciones; la misma es

\footnotetext{
${ }^{23}$ La explicitación sigue a Esteller-Moré y Solé-Ollé (2002) op. cit.

${ }^{24}$ Los mismos autores realizan una estimación de características similares a la aquí comentada para el caso de Canadá (2002)
} 
evaluada a partir de promediar a las alícuotas de las provincias que limitan con cada una con una ponderación de 1 , mientras que 0 a las restantes.

La existencia de externalidades tributarias horizontales en la imposición es incorporada en el modelo a partir de incluir las tasas impositivas de los estados limítrofes en forma ponderada, suponiendo $\omega i j=1$ si los estados son limítrofes y $\omega i j=0$, si no lo son.

Las provincias con mayor nivel de ingreso tenderán a demandar mayores bienes públicos y tolerarán mayores impuestos; por otro lado, dado que ante un aumento del ingreso el mismo nivel de recaudación puede alcanzarse con una alícuota menor, el efecto del nivel de renta sobre la alícuota es incierto. Se incluyen el producto bruto geográfico y su cuadrado de cada jurisdicción como proxy del ingreso de cada provincia.

Del mismo modo, las transferencias que perciben los gobiernos subnacionales por parte del gobierno central pueden tener alguna influencia sobre el nivel de los impuestos provinciales y su reacción ante un incremento de los nacionales y reducen el costo marginal de los fondos públicos.

Se incluyen como variables de costos las proporciones de población que utilizan los servicios públicos en forma más intensiva (mayores de 65 y menores de 14, por provincia y por año), además de la cantidad total de habitantes, su cuadrado y la densidad de población. Adicionalmente, se incluyen dos variables dummy de índole política, de acuerdo a la afinidad o no con el partido político del gobierno federal.

Los resultados empíricos muestran que un punto de incremento en los impuestos federales generan una reacción de 0.1 puntos en el impuesto estadual a la renta, y de 0.22 al considerar impuesto a la renta y a las ventas en forma conjunta.

Para poder discriminar la existencia de ilusión fiscal se realiza una evaluación sobre si las bases imponibles de los estados conforman en forma completa o no a la base del impuesto nacional; la existencia de significatividad en esta variable estaría indicando la existencia de una reacción de la provincia que la diferencia del concepto de ilusión fiscal. La ecuación a estimar es la siguiente, en donde DNC (mayor o menor coincidencia en el alcance de la base imponible) es la variable que procura identificar la existencia de ilusión fiscal; si el coeficiente es cercano a cero, la hipótesis de ilusión fiscal desplaza a la de existencia de externalidades.

$$
t_{i t}=\alpha_{11} \times\left(t_{F i t} \times D N C_{i t}\right)+\alpha_{12} \times t_{F i t}+\alpha_{2} \times \sum_{j \neq i} \omega_{i j} \times t_{j t}+\sum_{k} \alpha_{k} Z_{k, i t}+\alpha_{0, i}+\varepsilon_{i t}
$$


Los resultados en este caso arrojan que la reacción es mayor en el caso de los estados cuya definición de base imponible es más próxima a la del impuesto nacional, la que es inclusive contemporánea, a diferencia del caso en que existen diferencias en el alcance de la base imponible, en cuyo caso la reacción es desfasada. En consecuencia, la reacción atribuible a la externalidad vertical sólo representa la mitad de la misma, mientras que el resto es explicado por la existencia de ilusión fiscal.

Devereux et. al. (2007) realiza sus estimaciones para el caso de los impuestos específicos sobre cigarrillos y gasolina para Estados Unidos en el período 1977-1997. En relación con el trabajo de Besley y Rosen (1998), encuentran que aquél no incluía las externalidades horizontales en su análisis e incluyen en sus estimaciones variables para considerar el efecto de las mismas.

La ecuación del modelo es $t_{i s}=\alpha_{i}+\sum_{j \neq i} \beta_{i j} t_{j s}+\gamma T_{s}+\delta^{\prime} Y_{i s}+\phi^{\prime} Z_{s}+\varepsilon_{i s}$, donde $Y_{i}$ es un vector de variables de control estaduales y $Z$ es el vector de variables federales. Para realizar la estimación se lleva a cabo una ponderación de los impuestos de los otros estados, $t_{-i, s}=\sum_{j \neq i} \varpi_{i j} t_{j s}$ con lo cual la ecuación a estimar es la siguiente: $t_{i s}=\alpha_{i}+\sum_{j \neq i} \beta_{i j} t_{-i, s}+\gamma T_{s}+\delta^{\prime} Y_{i s}+\phi^{\prime} Z_{s}+\varepsilon_{i s}$

Se consideran tres mecanismos de ponderación:

- uniforme, es decir, aquel en el cual todos los estados tienen la misma ponderación;

- estados limítrofes: sólo considera a los estados vecinos

- estados limítrofes ponderados: asigna mayor participación a los estados vecinos más poblados

Debido a la posible endogeneidad de los impuestos estaduales y federales se utilizan variables instrumentales, con lo cual la ecuación a estimar es: $t_{i s}=\alpha_{i}+\theta t_{i, s-1}+\beta_{i-i, s}+\gamma T_{s}+\delta^{\prime} Y_{i s}+\phi^{\prime} Z_{s}+\varepsilon_{i s}$

Se utilizan las tasas impositivas en términos reales, dado que se observa que las nominales varían en una reducida medida. Se incluyen, como variables de control, variables económicas federales (GDP, tasa de desocupación y el índice de precios al consumidor), la producción doméstica del bien gravado en cada estado, variables económicas estaduales (ingreso per cápita, desocupación, transferencias federales y alícuota de impuesto a la renta), variables 
demográficas de los estados (población y proporciones de menores y mayores) y variables de índole política (partido político del gobernador y composición de los poderes legislativos).

Los resultados muestran que la tasa federal tiene un efecto positivo en la tasa estadual, elevando los impuestos específicos a los cigarrillos en 0,28 por cada punto porcentual de incremento en los impuestos federales.

\section{Cuadro 2}

Síntesis de estudios teóricos y empíricos sobre externalidades tributarias verticales

\begin{tabular}{|c|c|c|}
\hline Autores & Impuestos considerados & Resultados \\
\hline $\begin{array}{l}\text { Besley, T.J. y Rosen, H.S. } \\
\text { (1998): Journal of Public } \\
\text { Economics }\end{array}$ & $\begin{array}{l}\text { Gasolina y cigarrillos en } \\
\text { Estados Unidos 1975-1989 }\end{array}$ & $\begin{array}{l}\text { Un } 10 \% \text { de aumento en la tasa federal } \\
\text { induce un } 2,8 \% \text { de aumento en la tasa } \\
\text { del estado para cigarrillos; para la } \\
\text { gasolina, un } 10 \% \text { de aumento en la tasa } \\
\text { federal induce un } 4,1 \% \text { de aumento en } \\
\text { la tasa del estado. }\end{array}$ \\
\hline $\begin{array}{l}\text { Dahlby, B. (2001), paper } \\
\text { presented at the } \\
\text { AIMS/MEI/FCPP Conference }\end{array}$ & $\begin{array}{l}\text { Impuesto a la renta en } \\
\text { Canadá }\end{array}$ & $\begin{array}{l}\text { El grado de reacción de los impuestos } \\
\text { subnacionales depende de varios } \\
\text { factores }\end{array}$ \\
\hline $\begin{array}{l}\text { Esteller-Moré A. y Solé-Ollé, } \\
\text { A. (2001), Regional Science } \\
\text { y Urban Economics }\end{array}$ & $\begin{array}{l}\text { Impuestos a las renta } \\
\text { personal y generales a los } \\
\text { consumos en Estados } \\
\text { Unidos } 1987-1996\end{array}$ & $\begin{array}{l}\text { Un } 1 \% \text { de aumento del impuesto federal } \\
\text { a la renta genera un } 0,1 \% \text { de aumento } \\
\text { en los impuestos a la renta de los } \\
\text { estados y un } 0,22 \% \text { considerando en } \\
\text { forma conjunta renta y consumos }\end{array}$ \\
\hline $\begin{array}{l}\text { Esteller-Moré, A. y Solé-Ollé, } \\
\text { A (2002), International Tax } \\
\text { and Public Finance }\end{array}$ & $\begin{array}{l}\text { Impuesto a la renta } \\
\text { personal en Canadá 1982- } \\
1996\end{array}$ & $\begin{array}{l}\text { Un } 1 \% \text { de aumento del impuesto federal } \\
\text { a la renta genera un } 0,14 \% \text { de aumento } \\
\text { en los impuestos a la renta de los } \\
\text { estados con transferencias y un } 0,16 \% \\
\text { considerando los que no las reciben }\end{array}$ \\
\hline $\begin{array}{l}\text { Boadway, R. y M. Hayashi } \\
\text { (2002), Canadian Journal of } \\
\text { Economics }\end{array}$ & $\begin{array}{l}\text { Impuesto a la renta de } \\
\text { sociedades en Canadá } \\
1963-1996\end{array}$ & $\begin{array}{l}\text { Los impuestos provinciales disminuyen } \\
\text { cuando aumenta la alícuota federal; el } \\
\text { efecto varía por provincia }\end{array}$ \\
\hline $\begin{array}{l}\text { Devereux, M.P., Lockwood } \\
\text { B. y Redoano M. (2007), } \\
\text { Journal of Public Economics }\end{array}$ & $\begin{array}{l}\text { Gasolina y cigarrillos en } \\
\text { Estados Unidos 1977-1997 }\end{array}$ & $\begin{array}{l}\text { En cigarrillos, baja reacción vertical y } \\
\text { elevada reacción horizontal; en } \\
\text { gasolina, elevada reacción vertical y } \\
\text { baja reacción horizontal, no } \\
\text { significativos }\end{array}$ \\
\hline $\begin{array}{l}\text { Fredriksson y Mamun } \\
\text { (2008) Journal of Urban } \\
\text { Economics }\end{array}$ & $\begin{array}{l}\text { Cigarrillos en Estados } \\
\text { Unidos 1975-2001 }\end{array}$ & Reacción positiva y no significativa \\
\hline $\begin{array}{l}\text { Rizzo, Leonzio (2008), } \\
\text { MPRA Paper }\end{array}$ & $\begin{array}{l}\text { Impuesto a los cigarrillos } \\
\text { en Canadá y Estados } \\
\text { Unidos 1984-1994 }\end{array}$ & $\begin{array}{l}\text { Reacción positiva de los impuestos } \\
\text { regionales ante un aumento en el } \\
\text { impuesto federal }\end{array}$ \\
\hline $\begin{array}{l}\text { Esteller Moré A. y Rizzo, L. } \\
\text { (2011): National Tax Journal }\end{array}$ & $\begin{array}{l}\text { Gasolina y cigarrillos en } \\
\text { Estados Unidos 1975-2006 }\end{array}$ & $\begin{array}{l}\text { Aumento de los impuestos } \\
\text { subnacionales para gasolina y } \\
\text { reducción para el caso de los cigarrillos, } \\
\text { no significativos }\end{array}$ \\
\hline
\end{tabular}

Fuente: elaboración propia

Para corregir los errores de especificación, se adiciona la variable dependiente rezagada y la existencia de competencia tributaria horizontal introduciendo el promedio ponderado de las tasas de los otros estados; esto último reduce la significatividad de la pendiente de la función 
de reacción ante cambios en los impuestos nacionales aunque la de las tasas en los otros estados resulta significativa; esto es evidencia de competencia horizontal.

Los resultados para el caso de los cigarrillos concuerdan con la teoría; dado que la demanda de cigarrillos es relativamente inelástica, un aumento en la tasa federal no tiene efectos significativos en la respuesta de los gobiernos estaduales. En el caso de la gasolina, el coeficiente asociado a la tasa federal es significativo, no siéndolo el de las tasas de los otros estados, con lo cual la evidencia asociada a la externalidad horizontal es reducida.

Existe en consecuencia evidencia robusta de competencia horizontal en el caso de los impuestos a los cigarrillos, pero no para los impuestos a la gasolina. En este último caso, hay mayor evidencia de una respuesta ante variaciones de la tasa federal.

\subsection{Estimaciones para el caso argentino}

Para el caso argentino, Porto y Di Gresia (2007) cuantifican el impacto de las políticas llevadas a cabo por el gobierno federal sobre el superávit presupuestario de las provincias. Las mismas incluyen a:

- Transferencia de servicios hacia las provincias, sin contrapartida de financiamiento.

- Transferencias de cajas previsionales desde las provincias hacia la nación.

- Modificaciones del esquema de coparticipación establecido por la Ley 23.548.

- Aumento de la importancia de las transferencias de recursos hacia las provincias por la vía del presupuesto nacional.

Algunas de estas políticas mejoran el resultado financiero de las provincias, como, la transferencia de cajas previsionales deficitarias a la nación, y las transferencias presupuestarias desde nación, mientras que otras empeoran fiscalmente a las provincias como la transferencia de servicios y las modificaciones al esquema de coparticipación.

A continuación los autores llevan a cabo una cuantificación para determinar el efecto neto de las políticas públicas nacionales sobre la determinación de la evolución del resultado fiscal provincial; el resultado se reproduce en el cuadro 3. No se cuantifican sin embargo los efectos de la política tributaria nacional sobre los recursos tributarios provinciales (transferencias y recursos propios), que afectan fuentes tributarias provinciales (bases imponibles y alícuotas).

De acuerdo con Porto y Di Gresia (2007), en términos de valor presente, en el período 19832006 el conjunto de provincias muestra un déficit contable acumulado equivalente al 12,3\% 
del PIB del 2006;7 si se corrige por el efecto de políticas nacionales, el resultado se transforma en un superávit acumulado equivalente al 9,1\% del PIB de 2006. El componente exógeno del resultado financiero de las provincias es equivalente al 21,4\% del PIB de 2006.

La introducción de los Derechos de Exportación, a partir de 2002, a nivel del gobierno federal, significa un claro caso de externalidad tributaria vertical, dado que los mismos reducen la base imponible de impuestos provinciales, a la par de otros nacionales. Nogués y Porto (2007) llevan a cabo un ejercicio contrafáctico, que consiste en el cálculo de los recursos incrementales en los demás tributos que la eliminación de los Derechos de Exportación generarían, evaluando solamente la parte de la recaudación correspondiente a la cadena agroindustrial (los resultados se muestran en el cuadro 4).

\section{Cuadro 3}

Impacto de políticas nacionales sobre el superávit financiero provincial (en porcentaje del PBI)

\begin{tabular}{|c|c|c|c|c|c|c|c|c|c|}
\hline \multirow[b]{3}{*}{ Año } & \multirow{3}{*}{$\begin{array}{l}\text { Ingre- } \\
\text { sos }\end{array}$} & \multirow[b]{3}{*}{ Gastos } & \multirow{3}{*}{$\begin{array}{c}\text { Result } \\
\text { financ } \\
\text { iero }\end{array}$} & \multicolumn{5}{|c|}{$\begin{array}{l}\text { Políticas nacionales que afectaron la situación } \\
\text { fiscal provincial }\end{array}$} & \multirow{3}{*}{$\begin{array}{c}\text { Resulta } \\
\text { do } \\
\text { financie } \\
\text { ro sin } \\
\text { impacto } \\
\text { de } \\
\text { políticas } \\
\text { nacional } \\
\text { es }\end{array}$} \\
\hline & & & & \multicolumn{2}{|c|}{$\begin{array}{c}\text { Transferencia } \\
\text { s de gasto }\end{array}$} & \multirow{2}{*}{$\begin{array}{l}\text { Modif } \\
\text { de la } \\
\text { copart } \\
\text { icipa- } \\
\text { ción }\end{array}$} & \multirow{2}{*}{$\begin{array}{c}\text { Transf } \\
\text { desde } \\
\text { Presup } \\
\text { Nacion } \\
\text { al }\end{array}$} & \multirow[b]{2}{*}{$\begin{array}{l}\text { Impacto } \\
\text { fiscal sin } \\
\text { políticas } \\
\text { nacionales }\end{array}$} & \\
\hline & & & & $\begin{array}{l}\text { Servi } \\
\text { cios }\end{array}$ & $\begin{array}{l}\text { Cajas } \\
\text { previ- } \\
\text { sional } \\
\text { es }\end{array}$ & & & & \\
\hline & 1 & 2 & $3=1-2$ & 4 & 5 & 6 & 7 & $8=4+5+6+7$ & $9=3+5$ \\
\hline 1983 & $7.1 \%$ & $6.9 \%$ & $0.2 \%$ & & & & $-2.5 \%$ & $-2.5 \%$ & $-2.3 \%$ \\
\hline 1984 & $6.8 \%$ & $7.7 \%$ & $-0.9 \%$ & & & & $-1.8 \%$ & $-1.8 \%$ & $-2.7 \%$ \\
\hline 1985 & $7.7 \%$ & $8.1 \%$ & $-0.4 \%$ & & & & $-0.2 \%$ & $-0.2 \%$ & $-0.7 \%$ \\
\hline 1986 & $8.8 \%$ & $9.2 \%$ & $-0.5 \%$ & & & & $-0.4 \%$ & $-0.4 \%$ & $-0.9 \%$ \\
\hline 1987 & $7.5 \%$ & $9.6 \%$ & $-2.1 \%$ & & & & $-0.6 \%$ & $-0.6 \%$ & $-2.7 \%$ \\
\hline 1988 & $7.3 \%$ & $8.7 \%$ & $-1.4 \%$ & & & & $-0.1 \%$ & $-0.1 \%$ & $-1.5 \%$ \\
\hline 1989 & $7.4 \%$ & $8.4 \%$ & $-1.0 \%$ & & & $0.2 \%$ & $-0.1 \%$ & $0.1 \%$ & $-1.0 \%$ \\
\hline 1990 & $6.9 \%$ & $8.5 \%$ & $-1.6 \%$ & & & $0.5 \%$ & $-0.1 \%$ & $0.4 \%$ & $-1.2 \%$ \\
\hline 1991 & $8.2 \%$ & $9.0 \%$ & $-0.8 \%$ & & & $0.6 \%$ & $-0.1 \%$ & $0.4 \%$ & $-0.4 \%$ \\
\hline 1992 & $9.6 \%$ & $9.9 \%$ & $-0.3 \%$ & $0.7 \%$ & & $0.8 \%$ & $-0.2 \%$ & $1.2 \%$ & $1.0 \%$ \\
\hline 1993 & $10.8 \%$ & $11.5 \%$ & $-0.8 \%$ & $0.7 \%$ & & $0.9 \%$ & $-0.3 \%$ & $1.3 \%$ & $0.6 \%$ \\
\hline 1994 & $10.6 \%$ & $11.5 \%$ & $-0.8 \%$ & $0.7 \%$ & & $1.0 \%$ & $-0.3 \%$ & $1.5 \%$ & $0.6 \%$ \\
\hline 1995 & $10.4 \%$ & $11.6 \%$ & $-1.3 \%$ & $0.7 \%$ & & $1.2 \%$ & $-0.4 \%$ & $1.6 \%$ & $0.3 \%$ \\
\hline 1996 & $10.7 \%$ & $11.1 \%$ & $-0.4 \%$ & $0.7 \%$ & & $1.2 \%$ & $-0.4 \%$ & $1.5 \%$ & $1.0 \%$ \\
\hline 1997 & $11.1 \%$ & $11.2 \%$ & $0.0 \%$ & $0.7 \%$ & $-0.4 \%$ & $1.3 \%$ & $-0.4 \%$ & & $1.2 \%$ \\
\hline 1998 & $11.1 \%$ & $11.7 \%$ & $-0.7 \%$ & $0.8 \%$ & $-0.4 \%$ & $1.5 \%$ & $-0.4 \%$ & $1.4 \%$ & $0.8 \%$ \\
\hline 1999 & $11.4 \%$ & $12.8 \%$ & $-1.5 \%$ & $0.9 \%$ & $-0.4 \%$ & $1.5 \%$ & $-0.4 \%$ & $1.6 \%$ & $0.1 \%$ \\
\hline 2000 & $11.5 \%$ & $12.6 \%$ & $-1.2 \%$ & $0.9 \%$ & $-0.4 \%$ & $1.9 \%$ & $-0.5 \%$ & $1.9 \%$ & $0.7 \%$ \\
\hline 2001 & $11.2 \%$ & $13.6 \%$ & $-2.4 \%$ & $1.0 \%$ & $-0.4 \%$ & $1.8 \%$ & $-0.4 \%$ & $2.0 \%$ & $-0.4 \%$ \\
\hline 2002 & $10.4 \%$ & $10.9 \%$ & $-0.5 \%$ & $0.8 \%$ & $-0.2 \%$ & $1.7 \%$ & $-0.7 \%$ & $1.6 \%$ & $1.1 \%$ \\
\hline 2003 & $11.4 \%$ & $10.9 \%$ & $0.4 \%$ & $0.7 \%$ & $-0.3 \%$ & $2.5 \%$ & $-0.6 \%$ & $2.3 \%$ & $2.7 \%$ \\
\hline 2004 & $12.9 \%$ & $11.8 \%$ & $1.1 \%$ & $0.8 \%$ & $-0.2 \%$ & $2.9 \%$ & $-0.8 \%$ & $2.6 \%$ & $3.7 \%$ \\
\hline 2005 & $13.4 \%$ & $13.1 \%$ & $0.3 \%$ & $0.8 \%$ & $-0.2 \%$ & $2.9 \%$ & $-0.9 \%$ & $2.6 \%$ & $2.9 \%$ \\
\hline 2006 & $13.5 \%$ & $13.4 \%$ & $0.1 \%$ & $0.9 \%$ & $-0.2 \%$ & $2.9 \%$ & $-0.8 \%$ & $2.8 \%$ & $2.9 \%$ \\
\hline
\end{tabular}

Fuente: Porto y Di Gresia (2007) 
El efecto total de la eliminación de los derechos de exportación se compone de las siguientes partes, de acuerdo al trabajo analizado:

- Efecto directo, es la pérdida de recaudación del gobierno por la eliminación de las retenciones a las exportaciones.

- Efecto indirecto 1, es la recaudación que se obtiene sobre los ingresos adicionales del sector privado por la eliminación de las retenciones. Este efecto puede desagregarse en el producido por los mayores ingresos de las exportaciones que genera la eliminación de las retenciones (efecto indirecto 1.a) y el producido por la eliminación del subsidio al consumo final interno de los bienes exportables (efecto indirecto 1.b).

- Efecto indirecto 2, es la recaudación generada por el incremento de ingresos privados debida a la expansión de producción. Esta mayor producción generará un mayor nivel de recaudación.

Si se eliminaran las retenciones, la pérdida fiscal, luego de completados todos los efectos, sería de 2,2 mil millones de pesos. Sin embargo, las provincias recuperan alrededor de 2,7 mil millones de pesos, con lo cual ésta sería una representación aproximada de la magnitud de la externalidad tributaria generada por los Derechos de Exportación sobre los recursos tributarios de las provincias.

Estos efectos, según Nogués y Porto (2007), no son simultáneos. Al evaluar el impacto recaudatorio presentado en la sección anterior debe tenerse en cuenta especialmente el sendero temporal de los distintos efectos:

- El efecto directo de pérdida de recaudación es instantáneo; se pierden ingresos fiscales por más de 8 mil millones de pesos.

- El efecto indirecto 1.a debería ser también instantáneo.

- El efecto indirecto 1.b se encuentra más separado temporalmente, debido a los incrementos de precios internos, producto de la eliminación del subsidio

- El efecto indirecto 2 refleja un impacto de mediano plazo asociado a las decisiones de producción. 


\section{Cuadro 4}

Efecto tributario consolidado de la eliminación total de las retenciones Año 2006. En millones de pesos corrientes

\begin{tabular}{|c|c|c|c|c|}
\hline Efectos & Observación & $\begin{array}{c}\text { Monto } \\
\text { consolidado }\end{array}$ & Nación & $\begin{array}{c}\text { Provin } \\
\text { cias }\end{array}$ \\
\hline Efecto directo & Sobre derechos de exportación & $-8,167$ & $-8,167$ & \\
\hline Efecto indirecto 1.a & $\begin{array}{l}\text { Sobre Impuesto a las Ganancias } \\
\text { Sobre Impuesto a los Bienes } \\
\text { Personales } \\
\text { Sobre Impuesto Inmobiliario Rural } \\
\text { Sobre resto de presión impositiva }\end{array}$ & $\begin{array}{c}2,238 \\
13 \\
205 \\
1,122\end{array}$ & $\begin{array}{c}1,169 \\
5 \\
632\end{array}$ & $\begin{array}{c}1,069 \\
8 \\
205 \\
490\end{array}$ \\
\hline & Total & 3,578 & 1,806 & 1,772 \\
\hline Efecto indirecto 1.b & $\begin{array}{l}\text { Sobre subsidio al consumo final } \\
\text { interno multiplicado por presión } \\
\text { impositiva promedio }\end{array}$ & 1,803 & 1,057 & 746 \\
\hline Efecto indirecto 2 & Considerando alternativa mínima & 628 & 368 & 260 \\
\hline Consolidado & & $-2,157$ & $-4,935$ & 2,778 \\
\hline
\end{tabular}

Fuente: Elaboración propia en base a Nogués y Porto (2007)

\section{Síntesis y conclusiones}

Los estudios sobre competencia tributaria vertical entre jurisdicciones de distinto nivel surgen a partir de características de los sistemas federales, los que, en mayor o menor medida, plantean esta problemática desde las atribuciones de potestades jurisdiccionales, debidas a la superposición de las bases tributarias. En el caso de Canadá y Estados Unidos, por ejemplo, la superposición está dada por los impuestos sobre la renta nacional, en donde los estados difieren entre sí en función de la concordancia total o no en la definición de la base imponible y aún la posibilidad de establecer sobretasas sobre las alícuotas nacionales en sus propios estados.

En el caso de la Argentina, si bien la concurrencia está dada por el mandato constitucional, no existe un grado de concordancia entre los tributos que gravan la misma base imponible, con lo cual ésta se encuentra gravada de manera diferente.

En el caso de superposición de poderes de imposición entre gobiernos de distinto nivel se generan externalidades verticales cuando un nivel jurisdiccional eleva su alícuota para incrementar su recaudación, generando una disminución en la base imponible del otro nivel, implicando una menor provisión del bien público de la otra jurisdicción.

Desde el punto de vista del nivel de provisión de bienes públicos del gobierno federal y de los estados, el análisis de la literatura existente determina que el efecto final depende de varios 
factores, en particular, por ejemplo, de la cantidad de instrumentos que el gobierno federal tiene a disposición, de si puede considerarse como un líder de Stackelberg o de si ambos niveles actúan en equilibrio de Nash o de si ambos gobiernos son benevolentes, en el sentido de que maximizan la función de bienestar social del agente representativo o leviatánicos, si maximizan su propia recaudación o su superávit presupuestario.

Si el gobierno federal no puede recurrir a transferencias, bajo equilibrio de Nash, se demuestra que, en el caso de gobiernos benevolentes no "miopes", los estados colocan tasas que son superiores a las del gobierno federal, y proveen bienes públicos en una cantidad mayor a la del gobierno federal; la sumatoria de ambas tasas y de ambos niveles de bienes públicos generan niveles mayores a los que resultarían de un gobierno unificado, el óptimo de second best de la imposición indirecta. Este resultado es robusto inclusive ante una especificación de gobierno federal como líder de Stackelberg.

Cuando las bases imponibles son idénticas, en el modelo se demuestra que el gobierno federal subprovee el bien público, lo que hace que se aleje de la regla del second best del gobierno unificado, que implica cantidades de bienes público locales y federales en cada estado iguales. Este resultado se debe a que el gobierno federal considera la disminución en el nivel de provisión del bien público local evaluando por igual a todos los estados, mientras que los gobiernos locales sólo tienen en cuenta el gasto del gobierno federal en el propio estado.

Sin embargo, si las bases imponibles difieren en parte, con el gobierno federal gravando más bienes que los estados, éste puede compensar parte de la recaudación que deja de percibir por efecto de la externalidad vertical. El gobierno federal varía sus políticas impositivas de acuerdo a si el bien público subnacional está sobre o subprovisto con el fin de alcanzar una tasa cercana a la óptima para ambos bienes e influir en la recaudación de impuestos de los estados; la externalidad pasa a ser una decisión de política.

En gobiernos leviatánicos, entretanto, estas tasas y niveles de gastos públicos pueden ser inclusive demasiado elevados, tanto como para caer del lado decreciente de la curva de Laffer, para los impuestos, y creciente, para el caso de los gastos.

Si los gobiernos tuvieran la posibilidad de acceder u otorgar transferencias, es un resultado conocido que las mismas permiten minimizar las distorsiones generadas por las bases imponibles concurrentes, pudiendo determinarse las transferencias de igualación necesarias para asegurar una combinación eficiente de gasto público federal y estadual. 
Cuando se consideran en forma conjunta a la competencia vertical y horizontal, las conclusiones dependen de las diferencias en las bases imponibles federales y provinciales y de sus respectivas elasticidades, entre otros aspectos, para determinar cuál efecto domina en gobiernos benevolentes. En gobiernos leviatánicos, entretanto, puede demostrarse que domina la externalidad vertical, lo que implica que una baja de tasas mejora el bienestar.

Si los bienes públicos provistos por los estados y el gobierno federal no son sustitutos, y si los estados proveen bienes públicos que mejoran la productividad mientras que el gobierno federal provee bienes públicos residenciales, considerando ambas externalidades en conjunto puede demostrarse que una externalidad vertical dominante puede resultar en tasas impositivas a nivel de los estados demasiado bajas.

En cuanto al análisis sobre la función de reacción, no existe una determinación teórica concluyente sobre la reacción de los impuestos provinciales, con lo cual depende de las estimaciones empíricas. La evidencia encontrada sugiere que existe en general una reacción positiva de los impuestos provinciales ante cambios en la presión tributaria nacional, aunque no puede identificarse si esa reacción es debida al efecto de la externalidad o a un efecto de ilusión fiscal. 


\section{Capítulo 2. Un modelo sobre externalidades tributarias verticales en impuestos sobre los consumos}

\section{Introducción}

La literatura sobre "federalismo fiscal" distingue entre dos tipos de externalidades interjurisdiccionales originadas por la tributación: las externalidades horizontales y las externalidades verticales.

Las externalidades fiscales horizontales provenientes de competencia por impuestos han sido analizadas en forma abundante por la literatura. Esto corresponde al efecto de una disminución de la base imponible que provocan los impuestos aplicados sobre bases móviles en una jurisdicción, debido a la migración de la base hacia otra región con menores alícuotas, lo que conlleva un incremento en la base de la otra jurisdicción. En este sentido, la región bajo análisis tenderá a gravar a la base móvil con una alícuota demasiado baja, lo que le hará proveer una cantidad subóptima de bienes públicos.

La externalidad vertical, entretanto, proviene de la financiación concurrente, a partir del hecho de que diferentes niveles de gobierno (provincias o estados y gobiernos locales, o gobierno federal y gobiernos subnacionales) graven la misma fuente de imposición superponiendo sus poderes tributarios.

Sin embargo, la externalidad horizontal debida a la movilidad de las bases imponibles hace que la colocación de la alícuota impacte en la recaudación de impuestos del resto de los estados, y en la recaudación del gobierno federal debido a la reducción en la demanda del bien $^{25}$, con lo cual el costo social marginal de los fondos públicos difiere del costo marginal que enfrentan los estados al ignorar estos efectos. Si la externalidad horizontal es positiva (aumento de la base imponible de los demás estados) la vertical es negativa y reduce la recaudación del impuesto federal.

Los distintos trabajos existentes se han concentrado, inicialmente, en la determinación teórica de las externalidades verticales, y pueden clasificarse en dos grandes grupos. En primer lugar, los que buscan determinar cuál es la respuesta de los impuestos de un nivel jurisdiccional (estados) ante la variación en las tasas impositivas del otro nivel (nacional) que afecta a la misma base imponible, mientras que también la literatura se ha nutrido de trabajos que intentan evaluar si a partir de la existencia de externalidades, y las reacciones de los diferentes

\footnotetext{
${ }^{25}$ Con bienes normales y elasticidad precio de la demanda inferior a la unidad.
} 
gobiernos ante las variaciones en las políticas tributarias de los demás, la alícuota tributaria resultante es óptima o no en función de los bienes públicos que deben proveerse si se pretende maximizar la utilidad social.

El modelo que se desarrollará en este trabajo se inscribe en la segunda de las alternativas referidas. Se explicitará el modelo del trabajo de Hoyt (2001), para impuestos sobre los consumos, para luego determinar la sensibilidad de los resultados ante cambios en los supuestos estipulados inicialmente en el modelo. El valor agregado de este trabajo consiste en que en el mismo se plantean, desarrollan y calculan explícitamente los resultados de alícuotas y niveles de gasto público para todas las alternativas.

En primer lugar se considera el caso en el cual el gobierno federal grava la base imponible con un impuesto selectivo sobre los bienes, situación en la cual se alcanza el nivel de alícuotas de second best para la obtención de la máxima recaudación con el mínimo costo de eficiencia (minimización de la carga excedente de la imposición), constituyéndose éste en el benchmark con el cual se compararán los resultados de las distintas alternativas a analizar. Los resultados de estos cálculos se compararán con los que surgen de colocar un impuesto de suma fija con el cual el gobierno centralizado financie la provisión del bien público federal y estaduales.

En segunda instancia, en bases imponibles idénticas, se analizan los efectos de la toma de decisiones descentralizada; los resultados varían en función de los distintos supuestos sobre cómo consideran los gobiernos a las restricciones presupuestarias del otro nivel. Dado que cada estado sólo toma en cuenta los efectos de sus políticas sobre su propia restricción presupuestaria (igualando el costo marginal al beneficio marginal de los fondos públicos), y la restricción presupuestaria del gobierno federal y el gasto público de éste en su jurisdicción, a diferencia del gobierno federal, que considera a la provisión de su propio bien público en todos los estados por igual, la alícuota resultante será subóptima dado que el gobierno federal subprovee el bien público en relación a los estados, generándose externalidad vertical. Los resultados deben compararse con los que surgen, en primer lugar, con el costo marginal social de los fondos públicos (que considera la carga tributaria total) y las restricciones presupuestarias de ambos niveles de gobierno.

El supuesto de que ambos niveles de gobierno toman como dadas las consecuencias de sus decisiones sobre el otro nivel de gobierno en función de la recaudación impositiva y el nivel de gasto público, comportándose en equilibrio de Nash, no es sin embargo obvio; no todos los niveles colocan sus alícuotas lejos del óptimo social. El gobierno federal podría actuar como 
un líder de Stackelberg, considerando el efecto que sus acciones tendrán sobre los demás gobiernos $^{26}$.

Dado que en un resultado conocido en la mayoría de los estudios sobre esta temática, se demuestra que la posibilidad de acceder a transferencias permite minimizar las distorsiones generadas por las bases imponibles concurrentes, aún cuando existe superposición parcial, en este trabajo sólo se hará referencia a las políticas tributarias de los gobiernos asumiendo que los mismos no tienen acceso a mecanismos de transferencias.

El presente estudio se configura de la siguiente manera: en la sección 2 se plantea el modelo, desarrollado en base al trabajo de Hoyt (2001), para determinar la política del gobierno unificado en la sección 3. En la sección 4 se deriva la política descentralizada, en forma separada para los estados y el gobierno federal, para cada uno de los distintos supuestos sobre funciones objetivo de los gobiernos. En la sección 5 se presenta un ejemplo numérico que permitirá analizar la sensibilidad de los resultados ante cambios en los supuestos de las funciones de los gobiernos. Se concluye en la sección 6 , determinándose que el modelo de Hoyt es un caso particular cuyos resultados varían en relación con los distintos supuestos que se adopten.

\section{Planteamiento del modelo}

El modelo presentado por Hoyt (2001) asume la existencia de $n$ estados idénticos, cada uno con un individuo representativo. Se proveen dos bienes públicos, uno nacional provisto uniformemente a todos los estados en un nivel $g_{f}$, y otro estadual, provisto por cada estado a sus habitantes $i=1, \ldots \ldots \ldots n$ a un nivel $g_{i}$; una unidad de trabajo produce una unidad de bienes públicos por habitante o una unidad de bien privado. A diferencia del modelo original, en este caso existe un bien privado, $x$, y un segundo bien, el ocio $l$. La función de utilidad para un residente del estado $i$ es $U\left(X\left(x_{i}, l_{i}\right), g_{i}, g_{f}\right)$ separable $^{27}$, donde $x_{i}$ es el consumo del bien por el residente del estado $i$, no afectando el nivel de los gastos públicos la demanda de bienes privados. Se asume que los bienes son normales y que los gastos públicos ${ }^{28}$ son estrictamente positivos, no existiendo relación entre ambos bienes públicos para el individuo representativo.

\footnotetext{
${ }^{26}$ Keen (1998), Besley y Rosen (1996), Boadway, Marchand y Vigneault (1998), entre otros, asumen que el gobierno federal se comporta como líder de Stackelberg

${ }^{27}$ En el Anexo se desarrolla la maximización del consumidor

${ }^{28}$ Se asume que el gasto público hace referencia a un gasto en bienes de consumo
} 
Los precios son normalizados a 1 , el precio de una unidad de trabajo, mientras que $t_{i}$ y $t_{f}$ son las alícuotas impositivas ad valorem del estado y el gobierno federal, respectivamente, sobre el bien privado gravado (el ocio no está gravado). El precio post impuestos del bien $x$ en el estado $i$ es $q=1+\tau_{i}+\tau_{f}$, con $q_{i}=\left(q_{i}\right)$ denotando el vector de precios en el estado $i$. La función de utilidad indirecta es $V\left(q_{i}, g_{i}, g_{f}\right)$ para el residente del estado $i$. Se asume que las derivadas parciales de la función indirecta de utilidad con relación a los gastos públicos $\operatorname{son} V^{\prime}\left(g_{i}\right)>0, V^{\prime \prime}\left(g_{i}\right)<0, V^{\prime}\left(g_{f}\right)>0, V^{\prime \prime}\left(g_{f}\right)<0$, y que las utilidades marginales del gasto público del gobierno federal ${ }^{29}$ y del gasto del gobierno subnacional son iguales entre sí.

Es importante destacar que se asume que el residente del estado $i$ sólo adquiere los bienes en su propio estado, con lo cual no hay impacto de cambios en los impuestos del estado $i$ en los ingresos de otros estados, implicando de esta manera la inexistencia de externalidades horizontales.

Con el fin de establecer un marco de referencia para el accionar del sector público en relación con las políticas descentralizadas, se asume inicialmente la existencia de un gobierno federal unificado que recauda impuestos en todo el territorio de la federación para financiar la provisión de bienes públicos federales y subnacionales, en cada estado. Se desarrollará inicialmente el caso en el que el gobierno unificado coloca un impuesto de suma fija para financiar la provisión de los bienes públicos en ambos niveles, para luego determinar el caso en que el gobierno federal fija las alícuotas tributarias de un impuesto selectivo sobre bienes, siempre bajo el supuesto de que el gobierno unificado detenta la potestad de gravar la base imponible en forma total y proveer bienes públicos a nivel federal y subnacional.

En el análisis del gobierno federal unificado, se asume que el mismo puede gravar la totalidad de la base imponible, lo que también se asume para el caso en que la estructura de gobierno federal implique que ambos gravan la misma base y ambos toman como dadas las decisiones en relación con la determinación de alícuotas tributarias del otro nivel jurisdiccional.

En una segunda instancia se analizará el caso del gobierno descentralizado. Se asume que los gobiernos tienen potestad para fijar alícuotas impositivas y niveles de provisión de bienes públicos en función de maximizar la utilidad del individuo representativo de cada estado, sujeta a la restricción presupuestaria recaudatoria. El efecto diferenciador de los resultados radica en la determinación sobre cuáles son los supuestos sobre los que se basan las distintas

\footnotetext{
${ }^{29}$ En lo sucesivo se considerarán como sinónimos gobierno federal y gobierno nacional, con lo cual ambos términos se utilizarán en forma indistinta.
} 
formas en que los gobiernos consideran, dentro de la determinación de sus gastos e impuestos óptimos, a la restricción presupuestaria de los demás niveles de gobierno cuando deciden fijar sus tasas impositivas. Este efecto determinará la magnitud de la externalidad vertical.

En lo sucesivo, se plantearán los resultados para los gobiernos federal y subnacional para cada uno de los supuestos analizados; cabe consignar que en todos los casos los resultados incluirán los niveles de gasto público alcanzados y las alícuotas impositivas determinadas por cada nivel de gobierno.

\section{Políticas impositivas de los distintos gobiernos}

En este apartado se analizarán los resultados de aplicar distintas políticas impositivas para financiar el gasto público. Inicialmente se evaluará el caso de un impuesto de suma fija para el gobierno federal unificado, para luego utilizar imposición selectiva sobre bienes para el caso del gobierno centralizado y descentralizado. Cabe consignar que cada gobierno tiene en cuenta los cambios en la recaudación impositiva del otro nivel jurisdiccional cuando varía su nivel de gasto público.

Con el propósito de establecer un marco de referencia para el accionar del sector público en relación con las políticas descentralizadas con impuestos selectivos, se asume la existencia de un gobierno unificado que fija las alícuotas tributarias con la potestad de gravar la base imponible en forma total y proveer bienes públicos a nivel federal y subnacional.

\subsection{Política impositiva del gobierno unificado con impuestos de suma fija}

Si inicialmente se asume el caso de un gobierno unificado ${ }^{30}$ el mismo puede colocar niveles de impuestos y de provisión de gasto únicos para ambos estados. Considerando inicialmente el caso de lump sum taxes, a diferencia del modelo de Hoyt (2001), $T_{i}$ son los impuestos establecidos por el gobierno unificado con los que financia bienes públicos provinciales y federales para cada estado. En consecuencia el problema para el gobierno unificado es:

Maximizar $\sum_{i=1}^{n} U\left(X\left(x_{i}, z_{i}\right), g_{i}, g_{f}\right)$ s.t. $\sum_{i=1}^{n} T_{i}=\sum_{i=1}^{n}\left(g_{i}+g_{f}\right)$

$T_{1}, \ldots . ., T_{n} ; g_{1, \ldots \ldots ., g_{n}} ; g_{f}$

\footnotetext{
${ }^{30}$ En lo sucesivo se utilizarán como sinónimos gobierno centralizado y gobierno unificado, y “estados” y "provincias".
} 
Las condiciones de primer orden para las alícuotas impositivas y para los bienes públicos son las siguientes, donde $L_{u}$ denota la función de Lagrange para el gobierno unificado; $M U_{i}$ y $M U_{f}$ son las utilidades marginales indirectas del consumo del bien público respectivo, y $\lambda$ es el costo marginal de los fondos públicos

$$
\begin{aligned}
& L_{u}=\sum_{i=1}^{n} U\left(X\left(x_{i}, z_{i}\right), g_{i}, g_{f}\right)+\lambda\left[\sum_{i=1}^{n} T_{i}-\sum_{i=1}^{n}\left(g_{i}+g_{f}\right)\right] \\
& \frac{\partial L_{u}}{\partial T_{i}}=-\frac{\partial U}{\partial x}+\lambda n=0 \quad i=1, \ldots \ldots \ldots . . n(2) \\
& \frac{\partial L_{u}}{\partial g_{i}}=\frac{\partial V}{\partial g_{i}}-\lambda=0 \quad(3) \quad i=1, \ldots \ldots \ldots . . . n \\
& \frac{\partial L_{u}}{\partial g_{f}}=\sum_{i=1}^{n} \frac{\partial V}{\partial g_{f}}-n \lambda=0 \text { (4) } \\
& \frac{\partial L_{u}}{\partial \lambda}=\sum_{i=1}^{n} T_{i}-\sum_{i=1}^{n}\left(g_{i}+g_{f}\right)=0
\end{aligned}
$$

A partir de las condiciones de primer orden (2), (3) y (4) puede establecerse:

$$
\frac{\partial U}{\partial x}=\frac{\partial U}{\partial g_{i}}=\frac{\partial U}{\partial g_{f}}=\lambda(5), \text { y } M U_{i}=M U_{i f}=\lambda(6)
$$

En consecuencia se iguala la utilidad marginal del gasto público de cada uno de los estados con la utilidad marginal del gasto público federal en cada uno de los estados, al costo marginal de los fondos públicos $\lambda$. En consecuencia, el resultado del gobierno unificado sugiere que el gobierno provee el mismo nivel de gasto público local y nacional en cada uno de los estados, en el nivel de first best dado por la imposición de suma fija. De la condición de primer orden (2), surge $^{31}$ :

$\alpha=\lambda(7)$

En el óptimo de first best, se iguala la utilidad marginal privada de la renta $\alpha$ con el costo marginal de los fondos públicos, y por la ecuación (6), a la utilidad marginal del gasto público de los estados y federal en cada estado, resultando entonces niveles iguales de gasto público. Este será el benchmark con el cual se comparará el resto de los resultados del modelo, tanto para el gobierno unificado como para la política descentralizada.

\footnotetext{
${ }^{31}$ Ver Anexo para la deducción de la utilidad marginal privada de la renta.
} 


\subsection{Política impositiva del gobierno unificado con impuestos selectivos sobre bienes}

Con el fin de analizar instrumentos impositivos más aproximados a los utilizados en la práctica habitual de las administraciones tributarias, se analizarán en lo sucesivo los efectos de los impuestos selectivos sobre bienes. En consecuencia, el problema para el gobierno unificado es:

Maximizar $\sum_{i=1}^{n} V\left(q_{i}, g_{i}, g_{f}\right)$ s.t. $\sum_{i=1}^{n}\left(\tau_{i} x_{i}\left(q_{i}\right)\right)=\sum_{i=1}^{n}\left(g_{i}+g_{f}\right)$

$\tau_{1}, \ldots \ldots, \tau_{n} ; g_{1}, \ldots \ldots ., g_{n} ; g_{f}$

Las condiciones de primer orden para las alícuotas impositivas y para los bienes públicos son las siguientes, donde $L_{u}$ denota la función para el gobierno unificado, y $M U_{i}$ y $M U_{f}$ son las utilidades marginales indirectas del consumo del bien público respectivo:

$$
\begin{aligned}
& L_{u}=\sum_{i=1}^{n} V\left(q_{i}, g_{i}, g_{f}\right)+\lambda\left[\sum_{i=1}^{n}\left(\tau_{i} x_{i}\left(q_{i}\right)\right)-\sum_{i=1}^{n}\left(g_{i}+g_{f}\right)\right] \\
& \frac{\partial L_{u}}{\partial \tau_{i}}=\frac{\partial V_{i}}{\partial q_{i}}+\lambda\left(x_{i}+\tau_{i} \frac{\partial x_{i}}{\partial q_{i}}\right)=0 \quad i=1, \ldots \ldots \ldots . . n(9) \\
& \frac{\partial L_{u}}{\partial g_{i}}=\frac{\partial V}{\partial g_{i}}-\lambda=0 \\
& \frac{\partial L_{u}}{\partial g_{f}}=\sum_{i=1}^{n} \frac{\partial V}{\partial g_{f}}-n \lambda=0
\end{aligned}
$$

De las condiciones de primer orden (10) y (11) puede establecerse:

$$
\sum_{i=1}^{n} M U_{i}=\sum_{i=1}^{n} M U_{i f}=n \lambda \mathrm{y} M U_{i}=M U_{i f}=\lambda(12)
$$

A partir de la ecuación (9), y utilizando la identidad de Roy y la descomposición de Slutzky, surge:

$$
\begin{aligned}
& \frac{\partial L_{u}}{\partial \tau_{i}}=-\alpha x_{i}+\lambda\left(x_{i}+\tau_{i} \frac{\partial h_{i}}{\partial q_{i}}-x_{i} \frac{\partial x_{i}}{\partial y}\right)=0(13), \text { y reordenando } \\
& \lambda \tau_{i} \frac{\partial h_{i}}{\partial q_{i}}=\lambda x_{i}\left(\frac{\alpha}{\lambda}-1+\tau_{i} \frac{\partial x_{i}}{\partial y}\right)(14)
\end{aligned}
$$


Dado que los residentes de los estados son iguales y cada residente tiene igual ponderación en la función de bienestar del gobierno unificado, las alícuotas son iguales para todos los estados y las mismas se expresan $\tau^{*}$, omitiendo el subíndice del estado. En términos de elasticidades, expresando $\bar{\tau}=\tau / q$ (15) y partiendo de (14), resulta,

$\overline{\tau^{*}} \eta=\theta^{*}$ (16), donde $\theta^{*}=\left[\frac{\alpha}{\lambda}+\tau^{*} \frac{\partial x}{\partial y}-1\right]<0$,

De esta manera se determina la regla de imposición óptima sobre los bienes de Diamond y Mirrlees $^{32}$ o Atkinson y Stiglitz ${ }^{33}$. Ahora, de acuerdo con Hoyt (2001), la utilidad marginal de la renta difiere del costo marginal de los fondos públicos.

Las alícuotas impositivas y los niveles de gasto público del gobierno unificado constituyen las políticas de second best de maximización del bienestar. El término $\eta$ es la elasticidad precio compensada de la demanda del bien; la ecuación determina que el set óptimo de alícuotas implica que el ratio de carga excedente marginal de los impuestos a recaudación marginal debe ser igual en todos los estados.

De acuerdo con Atkinson y Stern (1974), y descomponiendo la ecuación (17) anterior, la igualdad se convierte en la ecuación subsiguiente, lo que permite apreciar la distorsión en términos de la diferencia entre la utilidad marginal de la renta $(\alpha)$ y el costo marginal de los fondos públicos $(\lambda)$ :

$$
\frac{\alpha}{\lambda}=1+\overline{\tau^{*}} \eta-\tau^{*} \frac{\partial x}{\partial y}(18)
$$

El efecto distorsivo determinado por la carga excedente de la imposición (efecto sustitución), sumado al efecto ingreso determinan que, en el caso de imposición distorsionante, la utilidad marginal de la renta resulte inferior al costo marginal de los fondos públicos, en contraposición a lo que ocurre con un impuesto de suma fija en donde ambos son iguales ${ }^{34}$. Esto determina, adicionalmente, consideraciones sobre el nivel de los bienes públicos provistos bajo imposición distorsionante.

\footnotetext{
${ }^{32}$ Diamond y Mirlees (1971)

${ }^{33}$ Atkinson y Stiglitz (1980)

${ }^{34}$ Dados los supuestos iniciales, en donde el bien privado es normal, y el ocio no está subsidiado, se anula la posibilidad que plantean Atkinson y Stiglitz en función de que la utilidad marginal privada de la renta pudiera resultar superior al costo marginal de los fondos públicos.
} 
Proposición 1 (Atkinson y Stern): En el caso de imposición selectiva, el gobierno unificado provee un nivel de gasto público que es inferior, y subóptimo, al que resulta de la imposición de suma fija.

A partir de las condiciones de primer orden, puede establecerse la siguiente igualdad, en la cual puede apreciarse que el costo marginal de los fondos públicos, igual a la utilidad marginal del gasto público en la región $i$, e igual al gasto público nacional en la región $i$, es mayor a la utilidad marginal privada de la renta $(\alpha)^{35}$ :

$\frac{\alpha}{1+\frac{\tau_{i}}{x_{i}} \frac{\partial x_{i}}{\partial q_{i}}}=\lambda=M U_{i}=M U_{i f}$

Este es el óptimo de second best que difiere del first best también en términos de niveles de gasto público financiados con impuestos de suma fija. En consecuencia, el costo marginal de los fondos públicos bajo un impuesto de suma fija (igual a la utilidad marginal privada de la renta) es menor que bajo impuestos específicos sobre los consumos.

Lo anteriormente expresado puede verse en el siguiente gráfico, en donde $g_{C T}$ representa al gasto público correspondiente a un impuesto especifico, y $g_{L T}$ corresponde al gasto público bajo un impuesto de suma fija. En el caso del gobierno unificado, en consecuencia, sólo se aprecia el efecto de la distorsión generado por el impuesto sobre los consumos ${ }^{36}$.

En relación con los niveles de gasto público de cada nivel de gobierno, en ambos casos se demuestra que en cada estado la cantidad provista de bien público local y la del nacional en cada estado deben ser iguales (ecuaciones (6) y (12)), sin embargo, ambos niveles son inferiores en el caso de los impuestos selectivos en relación con el impuesto de suma fija.

\footnotetext{
${ }^{35}$ Se asume que $\alpha$, la utilidad marginal de la renta, es constante.

${ }^{36}$ Cabe aquí, al igual que en Atkinson y Stiglitz, o Atkinson y Stern, prevenir sobre la generalización de estos resultados, dado que los mismos dependen de las formas funcionales postuladas para la especificación de las preferencias.
} 


\section{Gráfico 1}

\section{Los niveles de provisión de bienes públicos con impuestos de suma fija y distorsivos}

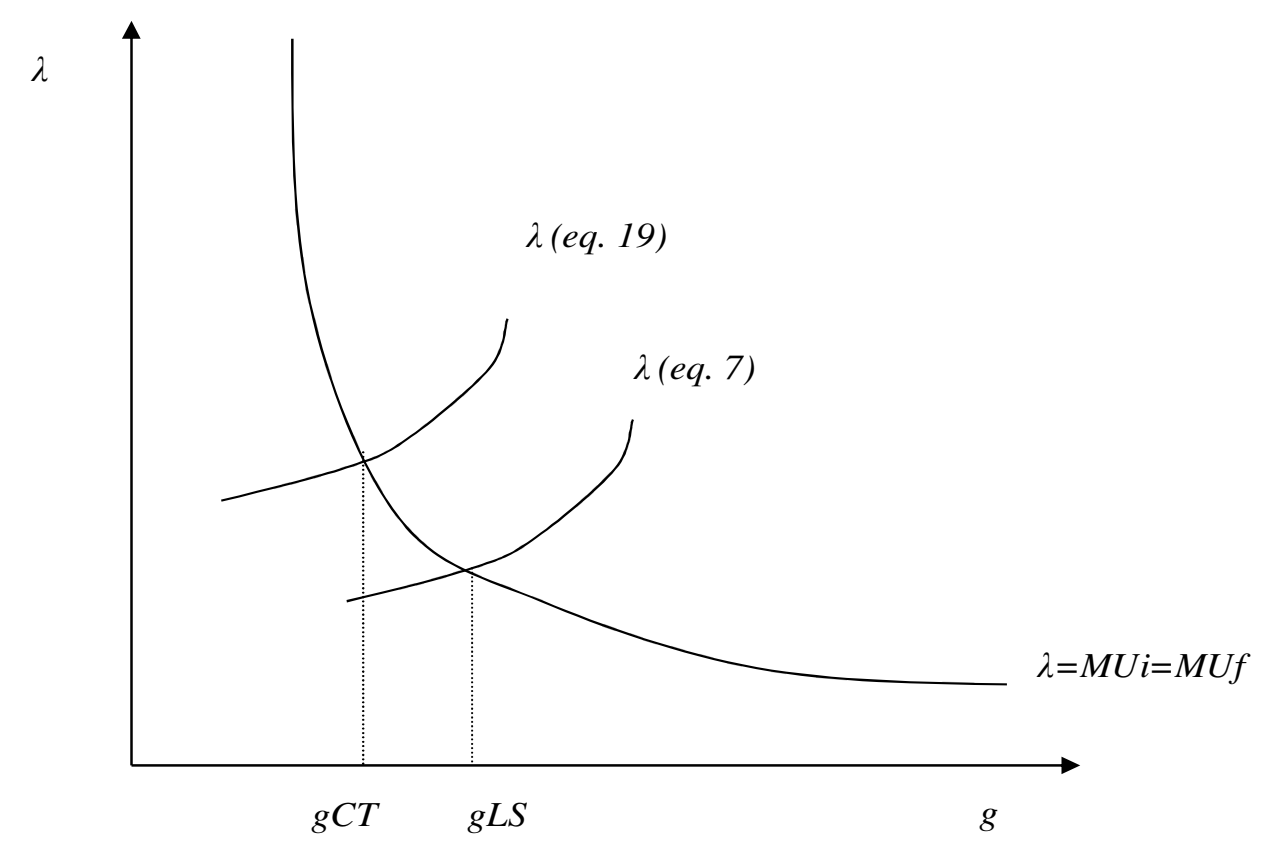

\section{Política impositiva descentralizada con impuestos selectivos sobre bienes}

En los países federales, sin embargo, ambos niveles de gobierno tienen discrecionalidad sobre la fijación de alícuotas y niveles de gasto público, tanto el gobierno federal como los gobiernos subnacionales constituyen actores relevantes con sus propios objetivos. El gobierno federal tiene una participación relevante en la provisión de bienes públicos propios y el financiamiento de los mismos a través de recaudar impuestos sobre la base imponible compartida con los gobiernos subnacionales. Estos últimos, entretanto, presentan características similares en relación con el comportamiento sobre gastos y recursos propios.

Se consideran las políticas de los gobiernos federal y estaduales en forma independiente, eligiendo sus alícuotas en un juego con un equilibrio de Nash en las tasas impositivas; cada gobierno toma como dadas las alícuotas fijadas por el otro nivel jurisdiccional. Cada gobierno, sin embargo, tiene en cuenta los cambios en la recaudación impositiva del otro nivel jurisdiccional pero asumen que no hay cambios en las políticas impositivas del otro nivel como resultado de sus propias decisiones. Se asume que ambos gobiernos tienen bases imponibles idénticas.

Pese a la existencia de múltiples estados y un solo gobierno federal, los que llevarían a analizar en primer lugar el caso en el que el gobierno federal actúa como líder de Stackelberg, la hipótesis de interacción entre los gobiernos subnacionales es verificable en varias 
circunstancias $^{37}$. En Canadá, por ejemplo, alrededor del $40 \%$ de la recaudación tributaria proviene de Ontario, lo que haría suponer que este estado pudiera poseer características de líder en relación con el gobierno federal.

\subsection{Caso base}

En el análisis a realizar a continuación, se asume que ambos gobiernos tienen en cuenta el efecto que el aumento de sus tasas impositivas genera en la recaudación tributaria del otro gobierno al reducirles las bases imponibles respectivas, lo que les lleva a proveer un menor nivel de bienes públicos. De acuerdo con Hoyt (2001), la diferencia entre ambos niveles de gobierno radica en que el gobierno federal considera el impacto del aumento de sus tasas en la recaudación tributaria de todos los estados por igual, mientras que cada uno de los estados sólo pondera, en la función de utilidad del individuo representativo, a la disminución del gasto público del gobierno federal en su propia jurisdicción, sin evaluar lo que acontece en el resto de los estados.

Lo anterior implica que al gobierno federal le interesa el bienestar en toda la nación, con lo cual, y dado que la carga excedente de la imposición selectiva está compuesta por la suma de las tasas federal y de los estados, tratará de minimizar el exceso de gravamen total y la externalidad tributaria vertical dada la manera en que los estados evalúan el impacto de sus políticas impositivas. Como ambos evalúan de forma distinta el impacto de sus políticas, ahora ambos pueden llevar a cabo niveles de gasto público diferentes, con lo cual las utilidades marginales del gasto público federal en cada estado, y del provisto por cada estado, serán distintas.

\subsubsection{Políticas impositivas de los estados}

En este equilibrio de Nash el estado $i$ elige sus alícuotas $\tau_{i}$ dadas las alícuotas federales y las tasas de los otros estados para resolver el siguiente problema, considerando la restricción presupuestaria para el gobierno $i$ y para el gobierno federal:

Maximizar $V\left(q_{i}, g_{i}, g_{f}\right)$ s.t. $\tau_{i} x_{i}\left(q_{i}\right)=g_{i} \sum_{i=1}^{n}\left(\tau_{f} x_{i}\left(q_{i}\right)\right)=n g_{f}$ $\tau_{i} ; g_{i,}$

Las condiciones de primer orden son, para la alícuota $\tau_{i}$ y para el gasto público propio $g_{i}$, y a partir del lagrangiano $L$ las siguientes:

\footnotetext{
${ }^{37}$ La presente sección sigue a Keen (1998)
} 


$$
\begin{aligned}
& \frac{\partial L_{i}}{\partial \tau_{i}}=\frac{\partial V_{i}}{\partial q_{i}}+\lambda_{i}\left(x_{i}+\tau_{i} \frac{\partial x_{i}}{\partial q_{i}}\right)+\frac{1}{n} \frac{\partial V_{i}}{\partial g_{f}}\left(\tau_{f} \frac{\partial x_{i}}{\partial q_{i}}\right)=0 \\
& \frac{\partial L}{\partial g_{i}}=\frac{\partial V_{i}}{\partial g_{i}}-\lambda_{i}=0
\end{aligned}
$$

En la condición de primer orden para la determinación de la alícuota del estado $i$ para el bien se aprecia el impacto de la misma sobre el precio del bien y sobre la recaudación necesaria para financiar la provisión del bien público $g_{i}$ además del efecto sobre la recaudación del gobierno federal, lo que reduce el nivel de provisión del bien público federal $g_{f}$. Para los residentes del resto de los estados, la externalidad fiscal vertical está dada por: $\sum_{j \neq i}\left(\frac{\partial V_{i}}{\partial g_{f}}\right)\left(\tau_{f}\left(\frac{\partial x_{i}}{\partial q_{i}}\right)\right)$

A partir de las condiciones de primer orden se determina el nivel de gasto público de los estados; de acuerdo con Atkinson y Stern, debe igualarse el costo marginal con el beneficio marginal de los fondos públicos.

Para determinar el nivel de gasto público en el caso descentralizado, para cada estado, se le adiciona el efecto de la externalidad, es decir, la pérdida de recaudación que genera en el gobierno federal un aumento de la alícuota tributaria propia que le permite financiar una menor cantidad de gasto público federal dividido en los $n$ estados el cual resulta:

$$
\frac{\alpha-\frac{1}{n} \frac{\partial V}{\partial g_{f}}\left[\frac{\tau_{f}}{x_{i}} \frac{\partial x_{i}}{\partial q_{i}}\right]}{1+\frac{\tau_{i}}{x_{i}} \frac{\partial x_{i}}{\partial q_{i}}}=\lambda_{i}=M U_{i}(23)
$$

El término que acompaña a la utilidad marginal privada de la renta $(\alpha)$ es la externalidad vertical, lo que incrementa el beneficio marginal del gasto público en el estado.

Sin embargo, cada estado tomará decisiones erróneas en relación con su nivel de gasto y de alícuotas tributarias si el costo marginal de los fondos públicos que advierte difiere del costo marginal social de los fondos públicos.

El óptimo social global, para cada estado, surge de encontrar los valores de $g_{i}$ y $\tau_{i}$ que maximizan el bienestar social agregado $W=V\left(q_{i}, g_{i}, g_{f}\right)$, en donde se incluyen las restricciones presupuestarias de ambos gobiernos, y en donde $\lambda_{i}$ es el multiplicador que puede 
ser interpretado como el costo marginal social total de obtener una unidad adicional de recaudación tributaria para el gobierno provincial.

Maximizar $V\left(q_{i}, g_{i}, g_{f}\right)$ s.t. $\tau_{i} x_{i}\left(q_{i}\right)=g_{i} \sum_{i=1}^{n}\left(\tau_{f} x_{i}\left(q_{i}\right)\right)=n g_{f}$

$g_{i}, \tau_{i}$

Las condiciones de primer orden son, para la alícuota $\tau_{i}$ y para el gasto público propio $g_{i}$, y a partir del lagrangiano $L$ las siguientes:

$$
\begin{aligned}
& L=V\left(q_{i}, g_{i}, g_{f}\right)+\lambda_{i}\left(\tau_{i} x_{i}\left(q_{i}\right)-g_{i}+\sum_{i=1}^{n}\left(\tau_{f} x_{i}\left(q_{i}\right)-g_{f}\right)\right) \\
& \frac{\partial L_{i}}{\partial \tau_{i}}=\frac{\partial V_{i}}{\partial q_{i}}+\lambda_{i}\left(x_{i}+\tau_{i} \frac{\partial x_{i}}{\partial q_{i}}+\tau_{f} \frac{\partial x_{i}}{\partial q_{i}}\right)+\frac{1}{n} \frac{\partial V_{i}}{\partial g_{f}}\left(\tau_{f} \frac{\partial x_{i}}{\partial q_{i}}\right)=0 \\
& \frac{\partial L}{\partial g_{i}}=\frac{\partial V_{i}}{\partial g_{i}}-\lambda_{i}=0
\end{aligned}
$$

A partir de las condiciones de primer orden, determinadas en relación a las alícuotas impositivas y los niveles de gasto público de los estados, puede determinarse la condición siguiente, que es la que surge al considerar las restricciones presupuestarias del otro nivel de gobierno para el gobierno subnacional, resultando ser éste el costo marginal social:

$$
\frac{\alpha-\frac{1}{n} \frac{\partial V}{\partial g_{f}}\left[\frac{\tau_{f}}{x_{i}} \frac{\partial x_{i}}{\partial q_{i}}\right]}{1+\frac{\tau_{i}}{x_{i}} \frac{\partial x_{i}}{\partial q_{i}}+\frac{\tau_{f}}{x_{i}} \frac{\partial x_{i}}{\partial q_{i}}}=\lambda_{i}
$$

Para el cálculo de las tasas impositivas, a partir de la ecuación (20), empleando la identidad de Roy, la ecuación de Slutzky, y las ecuaciones (10) y (11), donde $s$ es el subíndice para los estados en equilibrio, surge:

$-\alpha x+M U_{s}\left(x+\tau_{s}\left(\frac{\partial h}{\partial q}-x \frac{\partial x}{\partial y}\right)\right)+\frac{1}{n} M U_{f}\left(\tau_{f}\left(\frac{\partial h}{\partial q}-x \frac{\partial x}{\partial y}\right)\right)=0(27)$

Dividiendo por $M U_{f}$, y considerando $M R S_{s f}=\frac{M U_{s}}{M U_{f}}$, tasa marginal de sustitución entre el bien público del estado y el bien público federal: 


$$
\frac{-\alpha x_{i}}{M U_{f}}+M R S_{s f}\left(x_{i}+\tau_{s}\left(\frac{\partial h_{s}}{\partial q_{i}}-x_{i} \frac{\partial x_{i}}{\partial y}\right)\right)=-\frac{1}{n}\left(\tau_{f}\left(\frac{\partial h}{\partial q}-x_{i} \frac{\partial x_{i}}{\partial y}\right)\right)
$$

Distribuyendo y despejando,

$M R S_{s f} \tau_{s} \frac{\partial h_{s}}{\partial q_{s}}+\frac{1}{n} \tau_{f} \frac{\partial h_{s}}{\partial q_{s}}=\frac{\alpha x_{i}}{M U_{f}}-M R S_{s f} x_{i}+M R S_{s f} \tau_{s} x_{i} \frac{\partial x_{i}}{\partial y}+\frac{1}{n} \tau_{f} x_{i} \frac{\partial x_{i}}{\partial y}$

Reagrupando términos

$M R S_{s f} \tau_{s}+\frac{1}{n} \tau_{f} \frac{\partial h_{s}}{\partial q_{i}}=x_{i}\left(\frac{\alpha}{M U_{f}}-M R S_{s f}+\left(M R S_{s f} \tau_{s}+\frac{1}{n} \tau_{f}\right) \frac{\partial x_{i}}{\partial y}\right)(30)$

Reexpresando los resultados anteriores en términos de regla fiscal, el resultado es

$$
\left(\tau_{s}+\frac{1}{n M R S_{s f}} \tau_{f}\right) \eta=\frac{\theta_{s}}{M R S_{s f}}
$$

Reagrupando,

$$
\left(\tau_{s} \eta\right)+\frac{1}{n M R S_{s f}}\left(\tau_{f} \eta\right)=\frac{\theta_{s}}{M R S_{s f}}(32)
$$

donde $\theta_{s}=x_{i}\left(\frac{\alpha}{M U_{f}}+\left(M R S_{s f} \tau_{s}+\frac{1}{n} \tau_{f}\right) \frac{\partial x_{i}}{\partial y}-M R S_{s f}\right)$

Los gobiernos estaduales consideran el impacto de las políticas impositivas en la recaudación del gobierno federal, la que depende de la cantidad de estados y de la tasa marginal de sustitución entre los bienes provistos por el sector público estadual y federal; la influencia de la tasa del gobierno federal en el nivel de tasa fijado por el estado es menor a mayor cantidad de estados y mayor tasa marginal de sustitución entre ambos bienes.

\subsubsection{Políticas impositivas del gobierno federal}

El gobierno federal maximiza la utilidad agregada en los estados, aunque sólo financia bienes públicos federales. Influye indirectamente en el nivel de provisión de bienes públicos locales a partir de afectar las bases imponibles de los estados. En consecuencia, el problema del gobierno federal es, tomando como dadas las tasas de los estados:

Maximizar $\sum_{i=1}^{n} V\left(q_{i}, g_{i}, g_{f}\right)$ s.t. $\sum_{i=1}^{n}\left(\tau_{f} x_{i}\left(q_{i}\right)\right)=n g_{f} \mathrm{y} \sum_{i=1}^{n} \tau_{i} x_{i}\left(q_{i}\right)=g_{i}$ $\tau_{f}, g_{f}$ 
donde las condiciones de primer orden son, con respecto a la tasa y al gasto público del gobierno federal:

$\frac{\partial L}{\partial \tau_{f}}=\sum_{i=1}^{n}\left(\frac{\partial V}{\partial q_{i}}+\frac{\partial V}{\partial g_{i}} \sum_{i=1}^{n} \tau_{i} \frac{\partial x_{i}}{\partial q_{i}}\right)+\lambda_{f} \sum_{i=1}^{n}\left(x_{i}+\tau_{f} \frac{\partial x_{i}}{\partial q_{i}}\right)=0$,

$\frac{\partial L}{\partial g_{f}}=\frac{\partial V}{\partial g_{f}}-\lambda_{f}=0$

También para el caso descentralizado, se determina el nivel de gasto público del gobierno federal. En comparación con el caso del gobierno unificado, se le adiciona el efecto de la externalidad, es decir, la pérdida de recaudación que genera en el gobierno subnacional un aumento de la alícuota tributaria propia que le permite financiar una menor cantidad de gasto público de los estados. En consecuencia el costo marginal de los fondos públicos del gobierno federal en el gobierno descentralizado es menor que en el caso unificado, lo que indica también mayor nivel de gasto público.

$$
\frac{\alpha-\frac{\partial V}{\partial g_{i}}\left[\frac{\tau_{i}}{x_{i}} \frac{\partial x_{k}}{\partial q_{i}}\right]}{1+\frac{t_{f}}{x_{i}} \frac{\partial x_{i}}{\partial q_{i}}}=\lambda_{f}=M U_{f}(36)
$$

El óptimo social global para el gobierno federal, surge de encontrar los valores de $g_{f} \mathrm{y} \tau_{f}$ que maximizan el bienestar social agregado $W=\sum_{i=1}^{n} V\left(q_{i}, g_{i}, g_{f}\right)$, en donde se incluyen las restricciones presupuestarias de ambos gobiernos, y en donde $\lambda_{f}$ es el multiplicador que puede ser interpretado como el costo marginal social total de obtener una unidad adicional de recaudación tributaria para el gobierno federal.

Maximizar $\sum_{i=1}^{n} V\left(q_{i}, g_{i}, g_{f}\right)$ s.t. $\sum_{i=1}^{n}\left(\tau_{f} x_{i}\left(q_{i}\right)\right)=n g_{f} \mathrm{y} \sum_{i=1}^{n} \tau_{i} x_{i}\left(q_{i}\right)=g_{i}$

$\tau_{f}, g_{f}$

Las condiciones de primer orden son, para la alícuota $\tau_{f}$ y para el gasto público federal a partir del lagrangiano $L$ las siguientes:

$L=\sum_{i=1}^{n} V\left(q_{i}, g_{i}, g_{f}\right)+\lambda_{f} \sum_{i=1}^{n}\left(\tau_{i} x_{i}\left(q_{i}\right)-g_{i}+\tau_{f} x_{i}\left(q_{i}\right)-n g_{f}\right)$ 


$$
\begin{aligned}
\frac{\partial L_{i}}{\partial \tau_{f}} & =\sum_{i=1}^{n} \frac{\partial V_{i}}{\partial q_{i}}+\lambda_{f} \sum_{i=1}^{n}\left(x_{i}+\tau_{i} \frac{\partial x_{i}}{\partial q_{i}}+\tau_{f} \frac{\partial x_{i}}{\partial q_{i}}\right)+\sum_{i=1}^{n} \frac{\partial V_{i}}{\partial g_{i}}\left(\tau_{i} \frac{\partial x_{i}}{\partial q_{i}}\right)=0 \\
\frac{\partial L}{\partial g_{f}} & =\frac{\partial V_{i}}{\partial g_{f}}-\lambda_{f}=0
\end{aligned}
$$

A partir de las condiciones de primer orden, determinadas en relación a las alícuotas impositivas y los niveles de gasto público de los estados, puede determinarse la condición siguiente, que determina, para el gobierno federal, el costo marginal social:

$$
\frac{\alpha-\frac{\partial V}{\partial g_{i}}\left[\frac{\tau_{i}}{x_{i}} \frac{\partial x_{k}}{\partial q_{i}}\right]}{1+\frac{\tau_{i}}{x_{i}} \frac{\partial x_{i}}{\partial q_{i}}+\frac{\tau_{f}}{x_{i}} \frac{\partial x_{i}}{\partial q_{i}}}=\lambda_{f}
$$

Para el cálculo de las tasas, a partir de utilizar la identidad de Roy, la ecuación de Slutzky, y la simetría de la matriz de Slutzky:

$$
\frac{-n \alpha x_{i}}{M U_{f}}+\frac{n M U_{s}}{M U_{f}}\left(\tau_{s}\left(\frac{\partial h_{i}}{\partial q_{i}}-x_{i} \frac{\partial x_{i}}{\partial y}\right)\right)+\frac{n M U_{f}}{M U_{f}}\left(\tau_{f}\left(\frac{\partial h_{i}}{\partial q_{i}}-x_{i} \frac{\partial x_{i}}{\partial y}\right)\right)=0 \text { (40) }
$$

Distribuyendo y despejando,

$$
\frac{\alpha x_{i}}{M U_{f}}+M R S_{s f} \tau_{s} x_{i} \frac{\partial x_{i}}{\partial y}+\tau_{f} x_{i} \frac{\partial x_{i}}{\partial y}=M R S_{s f} \tau_{s} \frac{\partial h_{i}}{\partial q_{i}}-\tau_{f} x_{i} \frac{\partial h_{i}}{\partial q_{i}}(41)
$$

Reagrupando términos,

$$
x_{i}\left(\frac{\alpha}{M U_{f}}+\left(M R S_{s f} \tau_{s}+\tau_{f}\right) \frac{\partial x_{i}}{\partial y}\right)=\left(M R S_{s f} \tau_{s}+\tau_{f}\right) \frac{\partial h_{i}}{\partial q_{i}}(42)
$$

Resolviendo, para las alícuotas óptimas, es:

$\left(M R S_{s f} \tau_{s}+\tau_{f}\right) \eta=\theta_{f}$

Reagrupando,

$$
M R S_{s f}\left(\tau_{s} \eta\right)+\left(\tau_{f} \eta\right)=\theta_{f}
$$

Donde

$$
\theta_{f}=x_{i}\left(\frac{\alpha}{M U_{f}}+\left(M R S_{s f} \tau_{s}+\tau_{f}\right) \frac{\partial x_{i}}{\partial y}-1\right)
$$




\subsubsection{Comparación entre los resultados de los niveles de gasto y tasas impositivas}

A partir del análisis establecido en los apartados anteriores puede efectuarse una comparación entre los niveles de gasto público y de tasas impositivas entre ambos niveles de gobierno.

Adaptando el trabajo de Atkinson y Stern (1974) a la evaluación de las políticas de los gobiernos unificado y combinado de la descentralización, la misma puede analizarse desde dos puntos de vista. En primer lugar, como quedara comentado; estableciendo las alícuotas relativas y el impacto sobre la eficiencia de la imposición distorsiva, en relación con la carga excedente generada por la concurrencia en la fuente de imposición y en segundo lugar, en función de los niveles de bienes públicos provistos por ambas alternativas

Al comparar el resultado del gobierno federal unificado con el del gobierno descentralizado en el caso en que ambos consideran el impacto en la restricción presupuestaria del otro nivel cuando ejecutan sus políticas impositivas, de las ecuaciones anteriores puede verse lo siguiente.

En primer lugar, dado que se asume que los estados advierten el impacto de sus políticas sobre los gastos del gobierno federal en su jurisdicción y no en el resto de la nación, el costo marginal de los fondos públicos que advierten difiere del costo marginal social de los fondos públicos, lo que puede apreciarse al comparar las ecuaciones (23) y (26).

En consecuencia, los estados toman decisiones erróneas en relación con los niveles de gasto público que proveen y de tasas impositivas que colocan, dado que el costo marginal de los fondos públicos que advierten difiere del costo marginal social de los fondos públicos. Como el primero es inferior al segundo, el nivel subnacional de gobierno, que sólo observa el costo marginal de los fondos públicos $\mathrm{y}$ no el social, fija niveles de gasto elevados $\mathrm{y}$, consecuentemente, tasas impositivas también demasiado elevadas, para financiar estos niveles de gasto, en relación a las que resultarían del bienestar agregado.

El gobierno federal, entretanto, también fija niveles de gasto altos y, consecuentemente, coloca tasas demasiado elevadas, para financiar los mencionados gastos, en relación a las que resultarían del bienestar agregado, lo que puede apreciarse al comparar las ecuaciones (36) y (39). Sin embargo, al gobierno federal le importa el óptimo social global, con lo cual coloca una tasa menor para tratar de corregir el sesgo en el costo marginal de provisión de bienes públicos percibido por los gobiernos subnacionales.

El gobierno federal, dado que no puede recurrir al mecanismo de transferencias, intenta compensar parcialmente la externalidad al reducir las tasas impositivas y el gasto público para 
alejarse, lo menos posible, del óptimo social global. Comparando, en consecuencia, los niveles de gasto público del gobierno federal y de los estados, puede establecerse lo siguiente:

Proposición 2: En el caso descentralizado, el gasto del gobierno subnacional es mayor que el gasto del gobierno federal en cada estado.

Este es el resultado que obtiene Hoyt (2001). Comparando los niveles de gasto público del gobierno federal y de los estados, del análisis de los costos marginales de los fondos públicos puede verse que el del gobierno federal es mayor, y consecuentemente, el nivel de gasto público es menor que el de los estados, dado que la reducción en el gasto del gobierno subnacional cuando el gobierno federal aumenta su alícuota es mayor que la reducción en el gasto federal en cada estado cuando el gobierno del estado aumenta su alícuota ${ }^{38}$.

Dado que los estados no consideran en su totalidad el costo de la reducción en la recaudación del gobierno federal que resulta de sus incrementos de alícuotas, porque sólo consideran el impacto que sus políticas generan en la restricción presupuestaria del gobierno federal afectando la utilidad de sus propios residentes, esto podría tener implicancias sobre los niveles de gasto relativos.

En lo que concierne a los niveles de gasto público, se efectuará adicionalmente la comparación entre el gasto del gobierno unificado en los estados y el gasto que surge del caso descentralizado. La determinación de la ineficiencia que surge al comparar el nivel del gasto público agregado entre el gobierno unificado y el descentralizado puede advertirse al evaluar la optimización del gobierno descentralizado en su conjunto y compararla con la del gobierno unificado. Sin embargo, para realizar este análisis es necesario evaluar los niveles de las tasas impositivas, el que se presenta a continuación.

A partir de la comparación de estas ecuaciones entre sí y con las resultantes, en función de las alícuotas, de la optimización del gobierno unificado ((16) y (17)), y adicionando las determinaciones de los niveles de gastos públicos, pueden extraerse las siguientes conclusiones, que ayudan a distinguir los resultados en función de niveles de gastos y alícuotas planteados anteriormente.

Proposición 3 (Hoyt): En términos relativos, la tasa impositiva de los estados es mayor que la del gobierno federal.

\footnotetext{
${ }^{38}$ La demostración que realiza Hoyt (2001) sobre este punto se presenta en el Anexo.
} 
De la comparación de las ecuaciones en las que se determinan las tasas del gobierno federal y de los estados, que se muestran a continuación, siendo la (32) y (33) para los estados, y la (44) y (45) para el gobierno federal, se aprecia que a mayor cantidad de estados la tasa de éstos será mayor, dado que ponderan en menor medida la política del gobierno federal al fijar sus tasas propias ${ }^{39}$.

$$
\begin{aligned}
& \left(\tau_{s} \eta\right)+\frac{1}{n M R S_{s f}}\left(\tau_{f} \eta\right)=\frac{\theta_{s}}{M R S_{s f}}(32), \quad \text { donde } \theta_{s}=x\left(\frac{\alpha}{M U_{f}}+\left(M R S_{s f} \tau_{s}+\frac{1}{n} \tau_{f}\right) \frac{\partial x}{\partial y}-M R S_{s f}\right) \\
& \mathrm{y} M R S_{s f}\left(\tau_{s} \eta\right)+\left(\tau_{f} \eta\right)=\theta_{f}(44), \text { donde } \theta_{f}=x\left(\frac{\alpha}{M U_{f}}+\left(M R S_{s f} \tau_{s}+\tau_{f}\right) \frac{\partial x}{\partial y}-1\right)
\end{aligned}
$$

Proposición 4: La alícuota del gobierno unificado es mayor que la del gobierno federal descentralizado y que la del gobierno subnacional, mientras que las alícuotas agregadas del gobierno descentralizado resultan ser mayores que las del gobierno unificado.

En el desarrollo del cálculo de la tasa impositiva del gobierno unificado, en donde el mismo financia el gasto público estadual y el federal en cada estado, se demuestra que la misma es la siguiente,

$\overline{\tau^{*}} \eta=\theta^{*}(16)$ en donde $\theta^{*}=\left[\frac{\alpha}{\lambda}+\tau^{*} \frac{\partial x}{\partial y}-1\right]<0$

Para el gobierno unificado, el efecto sobre el nivel de gasto está dado solamente por la imposición distorsiva, no existiendo externalidades interjurisdiccionales.

En el caso del gobierno descentralizado, cada uno financia su propio bien público pero considera el nivel de provisión del bien público del otro nivel. Partiendo de las alícuotas establecidas en ambos niveles, ecuaciones (32) y (44), tomando como dada la del otro nivel, se obtiene, para el gobierno federal:

$M R S_{s f}\left(\overline{\tau_{s}} \eta\right)+\overline{\tau_{f}} \eta=\theta_{f}(46)$

Insertando la ecuación (32) en la (44),

$$
-\frac{1}{n M R S_{s f}}\left(\overline{\tau_{f}} \eta\right)+\frac{\theta_{s}}{M R S_{s f}}=\frac{1}{M R S_{s f}}\left(\theta_{f}-\overline{\tau_{f}} \eta\right)
$$

\footnotetext{
${ }^{39}$ En forma rigurosa, las tasas son endógenas y dependen de los niveles de gasto público determinados. Si, como se verá inmediatamente, el gasto público del gobierno provincial es mayor que el del gobierno federal, las tasas de las provincias son mayores que las del gobierno federal.
} 


\section{Reagrupando}

$$
\overline{\tau_{f}} \eta=\overline{\theta_{f}} \text { (48), donde } \overline{\theta_{f}}=\left(\theta_{f}-\theta_{s}\right)\left(1-\frac{1}{n}\right)^{-1}
$$

Mediante una metodología idéntica se arriba al resultado para el gobierno subnacional, en donde las tasas son

$$
\overline{\tau_{s}} \eta=\overline{\theta_{s}},(50), \text { con } \overline{\theta_{s}}=\frac{1}{M R S_{s f}}\left(\theta_{s}-\frac{1}{n} \theta_{f}\right)\left(1-\frac{1}{n}\right)^{-1}
$$

La alícuota combinada de ambos gobiernos sigue una regla similar a la del gobierno unificado, con la diferencia de que en este caso la misma se encuentra ponderada por la tasa marginal de sustitución entre el bien público estadual y el federal (ecuaciones (28) y (36)). Las alícuotas combinadas resultantes son:

$$
\left(\overline{\tau_{s}}+\overline{\tau_{f}}\right) \eta=\left(\overline{\theta_{s}}+\overline{\theta_{f}}\right)(52)
$$

En consecuencia, como fuera planteado en la Proposición 4, a partir de la comparación de los resultados de las alícuotas del gobierno unificado con las tasas del gobierno descentralizado, puede apreciarse lo siguiente. En primer lugar, la alícuota del gobierno unificado es mayor que la del gobierno federal descentralizado y que la del gobierno subnacional $\left(\theta^{*}>\overline{\theta_{f}} \mathrm{y} \theta^{*}>\bar{\theta}_{i}\right),^{40} \mathrm{y}$ en segundo, las alícuotas agregadas del gobierno descentralizado resultan ser mayores que las del gobierno unificado dado que $\theta^{*}<\bar{\theta}_{f}+\bar{\theta}_{s}{ }^{41}$, lo que puede advertirse en la ecuación subsiguiente.

$\left(\overline{\theta_{f}}+\overline{\theta_{s}}\right)=x_{i}\left[\frac{\alpha}{\lambda_{i}}+\left(\tau_{i}+\tau_{f}\right) \frac{\partial x}{\partial y}+\left(1-\frac{1}{n}\right)^{-1}\left(M R S_{i f}+\frac{1}{n M R S_{i f}}-1\right)\right]$

Esta expresión es más negativa cuanto mayor sea la tasa marginal de sustitución entre el gasto público de cada estado y mayor sea la cantidad de estados. En el caso trivial, con $n=1$ y con niveles de gasto público iguales $\left(M R S_{s f}=1\right)$, se alcanzan las tasas del gobierno unificado.

En consecuencia, la financiación distorsiva y la financiación concurrente generan dos distorsiones:

\footnotetext{
${ }^{40}$ En valor absoluto, es decir, más negativo

${ }^{41}$ En valor absoluto, es decir, menos negativo
} 
- la fijación de los niveles de alícuotas depende de la carga excedente de la imposición distorsiva, que se genera en toda la nación, y lleva a que una menor tasa genere una menor distorsión,

- y la externalidad tributaria, que lleva a que una mayor tasa genere un mayor efecto sobre los niveles de provisión de bienes públicos de la otra jurisdicción.

El gobierno federal, en el caso descentralizado, al considerar a todos los estados y la tasa impositiva total, es quien procura minimizar la distorsión que provoca una tasa elevada colocada por los gobiernos subnacionales, Existe un trade off entre la minimización de la carga excedente y el efecto de la externalidad; dado que los estados colocan una tasa elevada, el gobierno federal coloca una tasa más baja para reducir la carga excedente total y el efecto de la externalidad.

En consecuencia, en relación con la comparación de las tasas entre el gobierno federal y de los estados, ambos en el caso descentralizado, dado que $\theta_{i}>\theta_{f}{ }^{42}$ y $\bar{\theta}_{i}>\bar{\theta}_{f}{ }^{43}$ la tasa del gobierno subnacional es mayor que la del federal, y la suma de ambas es superior a la del gobierno unificado. Esto implica que los estados coloquen tasas que son superiores a las que se necesitarían para llevar a una asignación eficiente de los fondos públicos, lo que provocará consecuencias sobre los niveles de provisión relativos de los bienes públicos de cada nivel de gobierno.

Proposición 5: El gasto público del gobierno descentralizado es mayor al del gobierno centralizado; el nivel de gasto de cada estado es superior al que el gobierno unificado determina para cada estado

Para el gobierno unificado, partiendo de la condición de primer orden (9) y utilizando la identidad de Roy, se arriba a la siguiente expresión, que establece la divergencia entre el costo marginal de los fondos públicos, el beneficio marginal del bien público, y la utilidad marginal privada de la renta en donde las cantidades de bien público estadual y nacional en los estados son iguales:

$$
\frac{\alpha}{1+\frac{\tau_{i}}{x_{i}} \frac{\partial x_{i}}{\partial q_{i}}}=\lambda=M U_{i}=M U_{i f}
$$

\footnotetext{
${ }^{42}$ En valor absoluto, es decir, más negativo

${ }^{43}$ En valor absoluto, es decir, más negativo
} 
Para determinar el nivel de gasto público en el caso descentralizado, para el gasto de los estados, en comparación con el caso del gobierno unificado, se le adiciona el efecto de la externalidad, es decir, la pérdida de recaudación que genera en el gobierno federal un aumento de la alícuota tributaria propia que le permite financiar una menor cantidad de gasto público federal dividido en los $n$ estados. En consecuencia el costo marginal de los fondos públicos en el estado para el gobierno descentralizado es menor que en el caso unificado, lo que indica mayor nivel de gasto público.

$$
\frac{\alpha-\frac{1}{n} \frac{\partial V}{\partial g_{f}}\left[\frac{\tau_{f}}{x_{i}} \frac{\partial x_{i}}{\partial q_{i}}\right]}{1+\frac{\tau_{i}}{x_{i}} \frac{\partial x_{i}}{\partial q_{i}}+\frac{\tau_{f}}{x_{i}} \frac{\partial x_{i}}{\partial q_{i}}}=\lambda_{i}(26)
$$

En consecuencia, la descentralización, a partir de la externalidad generada por la tributación concurrente y el hecho de considerar la restricción presupuestaria del otro nivel jurisdiccional genera un nivel de gasto público mayor de los estados y nacional en los estados del que resultaría del equilibrio del gobierno unificado para el estado y el gobierno federal en el estado, respectivamente, con lo cual el gasto público agregado es mayor. El gobierno centralizado está, en cierta forma, internalizando la externalidad para producir un nivel menor de gasto público al intentar reducir el problema de superposición de bases imponibles colocando una menor tasa.

En consecuencia, la externalidad genera dos resultados subóptimos. El primero tiene que ver con el nivel de provisión del gasto, tanto federal en el estado como local: surge que ambos son superiores al nivel determinado en el gobierno unificado. El segundo es el relativo: el nivel de gasto federal en cada estado es inferior al de los estados. Si los gastos son mayores en comparación con la solución centralizada, la necesidad de recaudación es mayor y las tasas son mayores.

Como el gobierno federal tiene en cuenta el óptimo social global, postulando una función de utilidad social para el agregado, procurará reducir sus tasas y fijar niveles de gasto menores a los de los estados para minimizar el impacto de la externalidad.

\subsection{Caso en que ambos niveles de gobierno ignoran mutuamente la restricción presupuestaria del otro nivel.}

Se considera a continuación el caso de los gobiernos "miopes", es decir, las instancias en que los gobiernos ignoran la restricción presupuestaria del otro nivel. Este es el supuesto que 
presentan Dahlby, Mintz y Wilson (2000) para el caso de los gobiernos provinciales, basándose en que, si existen $n$ gobiernos provinciales idénticos, una provincia soportará sólo una proporción de $1 / n$ del costo de la reducción de la recaudación del gobierno federal causada por sus decisiones fiscales.

Se asume que $n$ es lo suficientemente grande como para que una provincia pueda ignorar el impacto de sus decisiones fiscales sobre la restricción presupuestaria del gobierno federal cuando toma sus decisiones fiscales. Se asumirá un supuesto idéntico para el caso del gobierno federal como marco de referencia.

\subsubsection{Políticas impositivas de los estados}

El gobierno del estado maximiza la utilidad del agente representativo, y sólo financia sus propios bienes públicos. Ahora el gobierno subnacional ignora su impacto en el nivel de provisión de bienes públicos federales en la función de utilidad del agente representativo, a diferencia del modelo de Hoyt (2001); en consecuencia, el problema del gobierno local es, tomando como dadas las tasas de los estados, el siguiente:

Maximizar $V\left(q_{i}, g_{i}, g_{f}\right)$ s.t. $\tau_{i} x_{i}\left(q_{i}\right)=g_{i}$ $\tau_{i}, g_{i}$

donde las condiciones de primer orden son, con respecto a la tasa del gobierno estadual:

$$
\begin{aligned}
& \frac{\partial L}{\partial \tau_{i}}=\frac{\partial V}{\partial q_{i}}+\lambda_{i}\left[x_{i}+\tau_{i} \frac{\partial x_{i}}{\partial q_{i}}\right]=0,(54) \\
& \frac{\partial L}{\partial g_{i}}=\frac{\partial V}{\partial g_{i}}-\lambda_{i}=0
\end{aligned}
$$

A partir de la ecuación (57), y reordenando, surge:

$\frac{\partial V}{\partial q_{i}}=-\lambda_{i}\left[x_{i}+\tau_{i} \frac{\partial x_{i}}{\partial q_{i}}\right](56)$, y utilizando la identidad de Roy y la descomposición de Slutzky, se obtiene el nivel de gasto público en el caso del nivel subnacional de gobierno, a partir de las condiciones de primer orden (53) y (54):

$$
\frac{\alpha}{1+\frac{\tau_{i}}{x_{i}} \frac{\partial x_{i}}{\partial q_{i}}}=\lambda_{i}=M U_{i}
$$


El óptimo social global, para cada estado, surge de encontrar los valores de $g_{i}$ y $\tau_{i}$ que maximizan el bienestar social agregado $W=V\left(q_{i}, g_{i}, g_{f}\right)$, en donde se incluyen las restricciones presupuestarias de ambos gobiernos, y en donde $\lambda_{i}$ es el multiplicador que puede ser interpretado como el costo marginal social total de obtener una unidad adicional de recaudación tributaria para el gobierno provincial.

Maximizar $V\left(q_{i}, g_{i}, g_{f}\right)$ s.t. $\tau_{i} x_{i}\left(q_{i}\right)=g_{i} \sum_{i=1}^{n}\left(\tau_{f} x_{i}\left(q_{i}\right)\right)=n g_{f}$

$g_{i} \mathrm{y} \tau_{i}$

Las condiciones de primer orden son, para la alícuota $\tau_{i}$ y para el gasto público propio $g_{i}$, y a partir del lagrangiano $L$ las siguientes:

$$
\begin{aligned}
& L=V\left(q_{i}, g_{i}, g_{f}\right)+\lambda_{i}\left(\tau_{i} x_{i}\left(q_{i}\right)-g_{i}+\sum_{i=1}^{n}\left(\tau_{f} x_{i}\left(q_{i}\right)-g_{f}\right)\right) \\
& \frac{\partial L_{i}}{\partial \tau_{i}}=\frac{\partial V_{i}}{\partial q_{i}}+\lambda_{i}\left(x_{i}+\tau_{i} \frac{\partial x_{i}}{\partial q_{i}}+\tau_{f} \frac{\partial x_{i}}{\partial q_{i}}\right)=0 \\
& \frac{\partial L}{\partial g_{i}}=\frac{\partial V_{i}}{\partial g_{i}}-\lambda_{i}=0
\end{aligned}
$$

A partir de las condiciones de primer orden, determinadas en relación a las alícuotas impositivas y los niveles de gasto público de los estados, puede determinarse la condición siguiente, que es la que surge al considerar las restricciones presupuestarias del otro nivel de gobierno para el gobierno subnacional, resultando ser éste el costo marginal social:

$$
\frac{\alpha}{1+\frac{\tau_{i}}{x_{i}} \frac{\partial x_{i}}{\partial q_{i}}+\frac{\tau_{f}}{x_{i}} \frac{\partial x_{i}}{\partial q_{i}}}=\lambda_{i}(60)
$$

En consecuencia, los estados toman decisiones erróneas en relación con los niveles de gasto público que proveen y de tasas impositivas que colocan, dado que el costo marginal de los fondos públicos que advierten difiere del costo marginal social de los fondos públicos. Como el primero es inferior al segundo, el nivel subnacional de gobierno, que sólo observa el costo marginal de los fondos públicos y no el social, fija niveles de gasto elevados y tasas impositivas también demasiado elevadas en relación a las que resultarían del bienestar agregado. 
De una manera similar a la expuesta al momento de calcular las tasas impositivas en los casos anteriores, se determina que las alícuotas resultantes son, en términos de elasticidades,

$\overline{\tau_{s}} \eta=\theta_{s}{ }^{\prime \prime} \quad(61)$, donde $\theta_{s}{ }^{\prime \prime}=\left[\frac{\alpha}{\lambda_{i}}+\tau_{i} \frac{\partial x}{\partial y}-1\right]<0(62)$

\subsubsection{Políticas impositivas del gobierno federal}

El gobierno federal maximiza la utilidad agregada en los estados, aunque sólo financia bienes públicos federales. Si el gobierno federal ignora su impacto en el nivel de provisión de bienes públicos locales en la función de utilidad del agente representativo, a diferencia del modelo de Hoyt, el problema del gobierno federal, tomando como dadas las tasas de los estados, es:

Maximizar $\sum_{i=1}^{n} V\left(q_{i}, g_{i}, g_{f}\right)$ s.t. $\sum_{i=1}^{n}\left(\tau_{f} x_{i}\left(q_{i}\right)\right)=n g_{f}$

$\tau_{f}, g_{f}$

donde las condiciones de primer orden son, con respecto a la tasa del gobierno federal:

$$
\begin{aligned}
& \frac{\partial L}{\partial t_{f}}=\sum_{i=1}^{n}\left(\frac{\partial V}{\partial q_{i}}\right)+\lambda_{f} \sum_{i=1}^{n}\left(x_{i}+\tau_{f} \frac{\partial x_{i}}{\partial q_{i}}\right)=0,(63) \\
& \frac{\partial L}{\partial g_{f}}=\frac{\partial V}{\partial g_{f}}-\lambda_{f}=0
\end{aligned}
$$

A partir de la ecuación (59), y utilizando la identidad de Roy y la descomposición de Slutzky, surge:

$$
\begin{aligned}
& \frac{\partial L}{\partial \tau_{f}}=-\alpha x_{i}+\lambda_{f}\left(x_{i}+\tau_{f} \frac{\partial h_{i}}{\partial q_{i}}-x_{i} \frac{\partial x_{i}}{\partial y}\right)=0 \text { (65), y reordenando } \\
& \lambda_{f} \tau_{f} \frac{\partial h_{i}}{\partial q_{i}}=\lambda_{f} x_{i}\left(\frac{\alpha}{\lambda}-1+\tau_{f} \frac{\partial x_{i}}{\partial y}\right)(66)
\end{aligned}
$$

En lo que respecta al nivel de gasto público en el caso del nivel federal de gobierno, a partir de las condiciones de primer orden (59) y (60), se obtiene:

$\frac{\alpha}{1+\frac{\tau_{f}}{x_{i}} \frac{\partial x_{i}}{\partial q_{i}}}=\lambda_{f}=M U_{f}(67)$ 
El óptimo social global para el gobierno federal, surge de encontrar los valores de $g_{f}$ y $\tau_{f}$ que maximizan el bienestar social agregado $W=\sum_{i=1}^{n} V\left(q_{i}, g_{i}, g_{f}\right)$, en donde se incluyen las restricciones presupuestarias de ambos gobiernos, y en donde $\lambda_{f}$ es el multiplicador que puede ser interpretado como el costo marginal social total de obtener una unidad adicional de recaudación tributaria para el gobierno federal.

Maximizar $\sum_{i=1}^{n} V\left(q_{i}, g_{i}, g_{f}\right)$ s.t. $\sum_{i=1}^{n}\left(\tau_{f} x_{i}\left(q_{i}\right)\right)=n g_{f} \sum_{i=1}^{n} \tau_{i} x_{i}\left(q_{i}\right)=g_{i}$

$\tau_{f}, g_{f}$

Las condiciones de primer orden son, para la alícuota $\tau_{f}$ y para el gasto público federal a partir del lagrangiano $L$ las siguientes:

$$
\begin{aligned}
& L=\sum_{i=1}^{n} V\left(q_{i}, g_{i}, g_{f}\right)+\lambda_{f} \sum_{i=1}^{n}\left(\tau_{i} x_{i}\left(q_{i}\right)-g_{i}+\tau_{f} x_{i}\left(q_{i}\right)-n g_{f}\right) \\
& \frac{\partial L_{i}}{\partial \tau_{i}}=\frac{\partial V_{i}}{\partial q_{i}}+\lambda_{f}\left(x_{i}+\tau_{i} \frac{\partial x_{i}}{\partial q_{i}}+\tau_{f} \frac{\partial x_{i}}{\partial q_{i}}\right)=0 \\
& \frac{\partial L}{\partial g_{f}}=\frac{\partial V_{i}}{\partial g_{f}}-\lambda_{f}=0
\end{aligned}
$$

A partir de las condiciones de primer orden, determinadas en relación a las alícuotas impositivas y los niveles de gasto público de los estados, puede determinarse la condición siguiente, que determina, para el gobierno federal, el siguiente costo marginal social.

$$
\frac{\alpha}{1+\frac{\tau_{i}}{x_{i}} \frac{\partial x_{i}}{\partial q_{i}}+\frac{\tau_{f}}{x_{i}} \frac{\partial x_{i}}{\partial q_{i}}}=\lambda_{f}
$$

\subsubsection{Comparación entre los resultados de los niveles de gasto y tasas impositivas}

Es importante comparar los niveles de gasto público que surgen de las optimizaciones de cada nivel de gobierno, con el óptimo social global, si ambos gobiernos actuaran ignorando el efecto de sus propias políticas respecto a los niveles de gasto del otro gobierno. El objetivo es comparar el costo marginal de los fondos públicos que aprecia cada nivel de gobierno con el costo marginal social; cada gobierno toma decisiones que lo alejan del costo marginal social si las decisiones sobre alícuotas impositivas afectan la base imponible del otro nivel. 
A diferencia del caso base, en donde el gobierno federal procuraba fijar sus tasas impositivas y niveles de gasto público teniendo en cuenta el óptimo social, en este caso ambos gobiernos son "miopes". En consecuencia, ambos niveles de gobierno colocan tasas demasiado elevadas en relación a las que resultarían del bienestar agregado.

Proposición 6: En el caso en que cada gobierno ignora la restricción presupuestaria del otro (gobiernos “miopes"), los niveles de gasto público que se obtienen son elevados, inclusive más altos que en el caso en que sí las tomaban en cuenta (caso base).

Comparando las ecuaciones (23) y (36) del caso base con las ecuaciones (60) y (67), en ambos casos los costos marginales de los fondos públicos ((60) y (67)) son mayores a los costos marginales de los fondos públicos que advierte cada gobierno ((23) y (36)), con lo que ambos gobiernos generan, al ignorar mutuamente las restricciones presupuestarias, niveles de gasto ineficientemente altos, y aún más elevados que en el caso base.

En relación con las tasas de ambos gobiernos cuando no tienen en cuenta las restricciones presupuestarias de los otros, la agregación de los resultados se lleva a cabo de manera idéntica al caso anterior y, siguiendo una regla similar a la del gobierno unificado, se llega a:

$$
\begin{aligned}
& {\overline{\tau_{f}}}^{*}=\tau^{*}\left(\overline{\theta_{f}^{*}}\right) \quad(64) ; \quad \bar{\tau}_{s}^{*}=\tau^{*}\left({\overline{\theta_{s}}}^{*}\right) \quad(71) \text { mientras que las alícuotas agregadas son } \\
& {\overline{\tau_{f}}}^{*}+{\overline{\tau_{s}}}^{*}=\tau^{*}\left({\overline{\theta_{f}}}^{*}+{\overline{\theta_{s}}}^{*}\right)(72)
\end{aligned}
$$

Los niveles de las tasas impositivas para el gobierno federal y los estados son los siguientes.

$$
\begin{gathered}
\tau_{f} \eta=\theta_{f}^{*}(67), \operatorname{con} \theta_{f}^{*}=\left[\frac{\alpha}{\lambda_{f}}+\tau_{f} \frac{\partial x_{i}}{\partial y}-1\right](73), \mathrm{y} \\
\tau_{s} \eta=\theta_{s}^{*}(69), \text { con } \theta_{s}^{*}=\left[\frac{\alpha}{\lambda_{s}}+\tau_{s} \frac{\partial x}{\partial y}-1\right]
\end{gathered}
$$

Proposición 7: Al comparar las alícuotas y los niveles de provisión del gobierno descentralizado cuando consideran o no las restricciones presupuestarias de los otros niveles, puede verse que las alícuotas tributarias del gobierno federal y de los estados son mayores en el caso en que no consideran el efecto de sus politicas sobre el otro nivel (caso de “miopía”) que cuando sí lo hacen.

Esto se produce debido al hecho de que desaparece, en el costo marginal de los fondos públicos percibido por cada nivel de gobierno, el efecto de la externalidad (sólo hay un efecto 
de carga excedente de la imposición); cada gobierno no puede afectar el nivel de provisión de bienes públicos de la otra jurisdicción mediante la fijación de alícuotas, en consecuencia el gasto que fijan es elevado.

El hecho de ignorar la externalidad en el nivel de gasto público del otro gobierno hace que los niveles combinados de ambas resulten ser mayores que las alícuotas del caso en que las consideran. Lo mismo ocurre con los niveles del gasto público, los cuales, tanto para el caso de los estados, como para el gobierno federal en cada estado y el agregado, son mayores que en el caso de no considerar a los otros gobiernos.

La regla de maximización del bienestar social es la del gobierno unificado donde los niveles de gasto público son iguales. Si ambos ignoraran el efecto del gasto público del otro nivel en la función de utilidad indirecta del agente representativo, y el consecuente efecto en la restricción presupuestaria del otro nivel cuando modifica las tasas propias, se genera exceso de gasto y alícuotas demasiado elevadas en relación al óptimo social.

\subsection{Caso en que ambos niveles de gobierno consideran en su totalidad a la restricción presupuestaria del otro nivel}

Se considera a continuación, a modo de referencia, el caso extremo en que los gobiernos consideran en su totalidad la restricción presupuestaria del otro nivel. Este supuesto modifica el caso descentralizado inicial en la forma en que los estados internalizan el impacto de sus políticas en el nivel federal de gobierno, y el nivel de gastos públicos que el nivel superior lleva a cabo en el resto de la federación.

Este es el caso que podría denominarse “'óptimo social del gobierno descentralizado"; implicando que cada gobierno debería tener en cuenta al aplicar tasas impositivas y niveles de gasto público, para el caso trivial en el que existe un solo estado provincial y un estado federal.

\subsubsection{Políticas impositivas de los estados}

El gobierno del estado maximiza la utilidad del agente representativo, y sólo financia sus propios bienes públicos. Ahora el gobierno subnacional considera en forma completa el impacto de sus políticas sobre la restricción presupuestaria del gobierno federal, y la disminución en el nivel de provisión de bienes públicos federales en el resto de los estados en la función de utilidad del agente representativo, a diferencia del modelo de Hoyt (2001). 
En consecuencia, el problema del gobierno local es, tomando como dadas las tasas de los estados, el siguiente:

Maximizar $V\left(q_{i}, g_{i}, g_{f}\right)$ s.t. $\tau_{i} x_{i}\left(q_{i}\right)=g_{i} y \sum_{i=1}^{n}\left(\tau_{f} x_{i}\left(q_{i}\right)\right)=g_{f}$

$\tau_{i}, g_{i}$

donde las condiciones de primer orden son, con respecto a la tasa del gobierno estadual:

$$
\begin{aligned}
& \frac{\partial L}{\partial \tau_{i}}=\frac{\partial V}{\partial q_{i}}+\lambda_{i}\left[x_{i}+\tau_{i} \frac{\partial x_{i}}{\partial q_{i}}\right]+\frac{\partial V}{\partial g_{f}}\left(\tau_{f} \frac{\partial x_{i}}{\partial q_{i}}\right)=0,(75) \\
& \frac{\partial L}{\partial g_{i}}=\frac{\partial V}{\partial g_{i}}-\lambda_{i}=0
\end{aligned}
$$

A partir de la ecuación (75), surge, reordenando:

$\frac{\partial V}{\partial q_{i}}=-\lambda_{i}\left[x_{i}+\tau_{i} \frac{\partial x_{i}}{\partial q_{i}}\right]+\frac{\partial V}{\partial g_{f}}\left(\tau_{f} \frac{\partial x_{i}}{\partial q_{i}}\right)(77)$, y utilizando la identidad de Roy y la descomposición de Slutzky, surge la igualdad entre el costo marginal de los fondos públicos y el beneficio marginal de los gastos públicos, que determina el nivel de provisión del bien público.

$$
\frac{\alpha-\frac{\partial V}{\partial g_{f}}\left(\frac{\tau_{f}}{x_{i}} \frac{\partial x_{i}}{\partial q_{i}}\right)}{1+\frac{\tau_{i}}{x_{i}} \frac{\partial x_{i}}{\partial q_{i}}}=\lambda_{i}(78)
$$

El óptimo social global, para cada estado, surge de encontrar los valores de $g_{i}$ y $\tau_{i}$ que maximizan el bienestar social agregado $W=V\left(q_{i}, g_{i}, g_{f}\right)$, en donde se incluyen las restricciones presupuestarias de ambos gobiernos, y en donde $\lambda_{i}$ es el multiplicador que puede ser interpretado como el costo marginal social total de obtener una unidad adicional de recaudación tributaria para el gobierno provincial.

Maximizar $V\left(q_{i}, g_{i}, g_{f}\right)$ s.t. $\tau_{i} x_{i}\left(q_{i}\right)=g_{i}$ y $\sum_{i=1}^{n}\left(\tau_{f} x_{i}\left(q_{i}\right)\right)=g_{f}$

$g_{i} \mathrm{y} \tau_{i}$

Las condiciones de primer orden son, para la alícuota $\tau_{i}$ y para el gasto público propio $g_{i}$, y a partir del lagrangiano $L$ las siguientes: 


$$
\begin{aligned}
& L=V\left(q_{i}, g_{i}, g_{f}\right)+\lambda_{i}\left(\tau_{i} x_{i}\left(q_{i}\right)-g_{i}+\sum_{i=1}^{n}\left(\tau_{f} x_{i}\left(q_{i}\right)-g_{f}\right)\right) \\
& \frac{\partial L_{i}}{\partial \tau_{i}}=\frac{\partial V_{i}}{\partial q_{i}}+\lambda_{i}\left(x_{i}+\tau_{i} \frac{\partial x_{i}}{\partial q_{i}}+\tau_{f} \frac{\partial x_{i}}{\partial q_{i}}\right)+\frac{\partial V_{i}}{\partial g_{f}}\left(\tau_{f} \frac{\partial x_{i}}{\partial q_{i}}\right)=0 \\
& \frac{\partial L}{\partial g_{i}}=\frac{\partial V_{i}}{\partial g_{i}}-\lambda_{i}=0
\end{aligned}
$$

A partir de las condiciones de primer orden, determinadas en relación a las alícuotas impositivas y los niveles de gasto público de los estados, puede determinarse la condición siguiente, que es la que surge al considerar las restricciones presupuestarias del otro nivel de gobierno para el gobierno subnacional, resultando ser éste el costo marginal social:

$$
\frac{\alpha-\frac{\partial V}{\partial g_{f}}\left[\frac{\tau_{f}}{x_{i}} \frac{\partial x_{i}}{\partial q_{i}}\right]}{1+\frac{\tau_{i}}{x_{i}} \frac{\partial x_{i}}{\partial q_{i}}+\frac{\tau_{f}}{x_{i}} \frac{\partial x_{i}}{\partial q_{i}}}=\lambda_{i}
$$

A diferencia de los casos anteriores, aquí los estados tienen en cuenta el costo marginal social al colocar sus tasas impositivas y fijar niveles de gasto público.

\subsubsection{Políticas impositivas del gobierno federal}

El gobierno federal maximiza la utilidad agregada en los estados, aunque sólo financia bienes públicos federales. Al igual que en el modelo de Hoyt, el gobierno federal reconoce su impacto en el nivel de provisión de bienes públicos locales en la función de utilidad del agente representativo. El problema del gobierno federal es, tomando como dadas las tasas de los estados, el siguiente:

Maximizar $\sum_{i=1}^{n} V\left(q_{i}, g_{i}, g_{f}\right)$ s.t. $\sum_{i=1}^{n}\left(\tau_{f} x_{i}\left(q_{i}\right)\right)=n g_{f} y \sum_{i=1}^{n} \tau_{i} x_{i}\left(q_{i}\right)=n g_{i}$ $\tau_{f}, g_{f}$

donde las condiciones de primer orden son, con respecto a la tasa del gobierno federal:

$$
\begin{aligned}
& \frac{\partial L}{\partial \tau_{f}}=\sum_{i=1}^{n}\left(\frac{\partial V}{\partial q_{i}}\right)+\lambda_{f} \sum_{i=1}^{n}\left(x_{i}+\tau_{f} \frac{\partial x_{i}}{\partial q_{i}}\right)+\sum_{i=1}^{n}\left(\frac{\partial V}{\partial g_{i}} \tau_{i} \frac{\partial x_{i}}{\partial q_{i}}\right)=0 \\
& \frac{\partial L}{\partial g_{f}}=\frac{\partial V}{\partial g_{f}}-\lambda_{f}=0
\end{aligned}
$$

A partir de la ecuación (82), reordenando, surge: 


$$
\frac{\partial V}{\partial q_{i}}=-\lambda_{f}\left[x_{i}+\tau_{f} \frac{\partial x_{i}}{\partial q_{i}}\right]+\frac{\partial V}{\partial g_{i}}\left(\tau_{i} \frac{\partial x_{i}}{\partial q_{i}}\right)(84),
$$

Utilizando la identidad de Roy y la descomposición de Slutzky, emerge la igualdad entre el costo marginal de los fondos públicos y el beneficio marginal de los gastos públicos, que determina el nivel de provisión del bien público.

$$
\frac{\alpha-\frac{\partial V}{\partial g_{i}}\left(\frac{\tau_{i}}{x_{i}} \frac{\partial x_{i}}{\partial q_{i}}\right)}{1+\frac{\tau_{f}}{x_{i}} \frac{\partial x_{i}}{\partial q_{i}}}=\lambda_{f}(85)
$$

El óptimo social global para el gobierno federal, surge de encontrar los valores de $g_{f} \mathrm{y} \tau_{f}$ que maximizan el bienestar social agregado $W=\sum_{i=1}^{n} V\left(q_{i}, g_{i}, g_{f}\right)$, en donde se incluyen las restricciones presupuestarias de ambos gobiernos, y en donde $\lambda_{f}$ es el multiplicador que puede ser interpretado como el costo marginal social total de obtener una unidad adicional de recaudación tributaria para el gobierno federal.

Maximizar $\sum_{i=1}^{n} V\left(q_{i}, g_{i}, g_{f}\right)$ s.t. $\sum_{i=1}^{n}\left(\tau_{f} x_{i}\left(q_{i}\right)\right)=n g_{f} \mathrm{y} \sum_{i=1}^{n} \tau_{i} x_{i}\left(q_{i}\right)=g_{i}$ $\tau_{f}, g_{f}$

Las condiciones de primer orden son, para la alícuota $\tau_{f}$ y para el gasto público federal a partir del lagrangiano $L$ las siguientes:

$$
\begin{aligned}
& L=\sum_{i=1}^{n} V\left(q_{i}, g_{i}, g_{f}\right)+\lambda_{f} \sum_{i=1}^{n}\left(\tau_{i} x_{i}\left(q_{i}\right)-g_{i}+\tau_{f} x_{i}\left(q_{i}\right)-n g_{f}\right) \\
& \frac{\partial L_{i}}{\partial \tau_{i}}=\frac{\partial V_{i}}{\partial q_{i}}+\lambda_{f}\left(x_{i}+\tau_{i} \frac{\partial x_{i}}{\partial q_{i}}+\tau_{f} \frac{\partial x_{i}}{\partial q_{i}}\right)+\frac{\partial V_{i}}{\partial g_{i}}\left(\tau_{i} \frac{\partial x_{i}}{\partial q_{i}}\right)=0 \\
& \frac{\partial L}{\partial g_{f}}=\frac{\partial V_{i}}{\partial g_{f}}-\lambda_{f}=0
\end{aligned}
$$

A partir de las condiciones de primer orden, determinadas en relación a las alícuotas impositivas y los niveles de gasto público de los estados, puede determinarse la condición siguiente, que determina, para el gobierno federal, el siguiente costo marginal social. 


$$
\frac{\alpha-\frac{\partial V}{\partial g_{i}}\left[\frac{\tau_{i}}{x_{i}} \frac{\partial x_{k}}{\partial q_{i}}\right]}{1+\frac{\tau_{i}}{x_{i}} \frac{\partial x_{i}}{\partial q_{i}}+\frac{\tau_{f}}{x_{i}} \frac{\partial x_{i}}{\partial q_{i}}}=\lambda_{f}
$$

El gobierno federal, al igual que en los casos anteriores, también tiene en cuenta el costo marginal social de los fondos públicos al fijar tasas impositivas y niveles de gasto público.

\subsubsection{Comparación entre los resultados de los niveles de gasto y tasas impositivas}

Ambos niveles de gobierno internalizan totalmente sus decisiones de tasas impositivas sobre el nivel de gasto del otro gobierno. Dado que lo óptimo en este caso consiste en la igualación de las tasas marginales de sustitución, con lo cual los gastos públicos son iguales ${ }^{44}$, ambos gobiernos intentarán colocar tasas lo suficientemente bajas como para desplazar el gasto del otro gobierno en la menor proporción posible. En el óptimo social global, los niveles de gasto público, y por consiguiente, las tasas impositivas, de ambos gobiernos, son iguales (surge de la comparación entre las ecuaciones (74) y (78)).

Proposición 8: En el caso en que ambos gobiernos consideran de la misma manera la restricción presupuestaria del otro, el "óptimo social global del gobierno descentralizado"; los niveles de gasto público que se obtienen son más bajos que en los casos en que los gobiernos no consideran las restricciones presupuestarias de los otros niveles de gobierno. Estos resultados coinciden con los del gobierno unificado para el caso trivial en el que existe un solo estado subnacional y un estado federal.

Si los estados no incorporan el efecto completo de sus políticas en la restricción presupuestaria del gobierno federal, generarán niveles de gasto ineficientemente elevados en comparación con el gasto del "óptimo social global”.

La cuestión relevante a considerar es la comparación con el costo marginal social. Al ignorar el efecto sobre los demás niveles de gobierno, no aprecian la caída en la base imponible que deviene de incrementar las tasas propias, dado que en el precio están incluidas ambas tasas. Esto hace que la reducción en la base imponible sea mayor que la que advierten, con lo cual, para compensar esa disminución, colocan tasas más altas.

Esta disminución en las bases genera una caída en la recaudación del otro nivel que no es considerada en el caso de gobiernos miopes, lo cual incentiva a la colocación de tasas altas.

\footnotetext{
${ }^{44}$ La demostración se presenta en el Anexo al presente capítulo.
} 
De la comparación de los resultados anteriores con los que surgen del gobierno unificado (ecuación (19)), puede advertirse los gobiernos, individualmente, generan niveles de gasto público ineficientemente elevados al ignorar las restricciones presupuestarias del otro gobierno.

Cabe consignar que la distorsión (el mayor nivel de bienes públicos provistos por el gobierno de los estados) depende de la cantidad de estados $n$; como se expusiera en el caso base, a mayor cantidad de estados, mayor provisión de bienes públicos a nivel subnacional (ecuación (63)); en consecuencia la externalidad es función de la cantidad de estados.

La externalidad hace que los estados coloquen tasas mayores que el gobierno federal porque perciben un costo marginal de los fondos públicos menor al costo marginal social de los fondos públicos, y el costo marginal de los fondos públicos para los estados es menor que el del gobierno federal en el caso en el que éstos no evalúen de la misma manera a la restricción presupuestaria del gobierno federal.

\subsection{Caso en que el gobierno federal considera la restricción presupuestaria del gobierno provincial pero no a la inversa}

Se considera a continuación el caso en que los gobiernos provinciales ignoran la restricción presupuestaria del otro nivel, mientras que el gobierno federal considera el nivel de gasto público de los gobiernos subnacionales. El gobierno federal, al considerar a todas las provincias, mantiene el rol de internalizador de externalidades generadas por la superposición de bases imponibles. Es decir que el gobierno provincial es "miope", pero el gobierno federal no lo es.

Este es el supuesto que presentan Dahlby, Mintz y Wilson (2000), basándose en que, si existen $n$ gobiernos provinciales idénticos, y $n$ es lo suficientemente grande, una provincia pueda ignorar el impacto de sus decisiones fiscales sobre la restricción presupuestaria del gobierno federal cuando toma sus decisiones fiscales dado que soportará sólo una proporción de $1 / n$ del costo de la reducción de la recaudación del gobierno federal causada por sus decisiones fiscales.

\subsubsection{Políticas impositivas de los estados}

El gobierno del estado maximiza la utilidad del agente representativo, y sólo financia sus propios bienes públicos. Ahora el gobierno subnacional ignora su impacto en el nivel de 
provisión de bienes públicos federales en la función de utilidad del agente representativo, a diferencia del modelo de Hoyt (2001); en consecuencia, el problema del gobierno local es:

Maximizar $V\left(q_{i}, g_{i}, g_{f}\right)$ s.t. $\tau_{i} x_{i}\left(q_{i}\right)=g_{i}$

$\tau_{i}, g_{i}$

donde las condiciones de primer orden son, con respecto a la tasa del gobierno estadual:

$$
\begin{aligned}
& \frac{\partial L_{i}}{\partial \tau_{i}}=\frac{\partial V}{\partial q_{i}}+\lambda_{i}\left[x_{i}+\tau_{i} \frac{\partial x_{i}}{\partial q_{i}}\right]=0,(89) \\
& \frac{\partial L_{i}}{\partial g_{i}}=\frac{\partial V}{\partial g_{i}}-\lambda_{i}=0
\end{aligned}
$$

A partir de las condiciones de primer orden, y reordenando, surge:

$\frac{\partial V}{\partial q_{i}}=-\lambda_{i}\left[x_{i}+\tau_{i} \frac{\partial x_{i}}{\partial q_{i}}\right](91)$, y utilizando la identidad de Roy y la descomposición de Slutzky, se obtiene el nivel de gasto público en el caso del nivel subnacional de gobierno, a partir de las condiciones de primer orden (89) y (90):

$\frac{\alpha}{1+\frac{\tau_{i}}{x_{i}} \frac{\partial x_{i}}{\partial q_{i}}}=\lambda_{i}=M U_{i}(92)$

El óptimo social global, para cada estado, surge de encontrar los valores de $g_{i}$ y $\tau_{i}$ que maximizan el bienestar social agregado $W=V\left(q_{i}, g_{i}, g_{f}\right)$, en donde se incluyen las restricciones presupuestarias de ambos gobiernos, y en donde $\lambda_{i}$ es el multiplicador que puede ser interpretado como el costo marginal social total de obtener una unidad adicional de recaudación tributaria para el gobierno provincial.

Maximizar $V\left(q_{i}, g_{i}, g_{f}\right)$ s.t. $\tau_{i} x_{i}\left(q_{i}\right)=g_{i} \sum_{i=1}^{n}\left(\tau_{f} x_{i}\left(q_{i}\right)\right)=n g_{f}$

$g_{i} \mathrm{y} \tau_{i}$

Las condiciones de primer orden son, para la alícuota $\tau_{i}$ y para el gasto público propio $g_{i}$, y a partir del lagrangiano $L$ las siguientes:

$$
L=V\left(q_{i}, g_{i}, g_{f}\right)+\lambda_{i}\left(\tau_{i} x_{i}\left(q_{i}\right)-g_{i}+\sum_{i=1}^{n}\left(\tau_{f} x_{i}\left(q_{i}\right)-g_{f}\right)\right)
$$




$$
\begin{aligned}
& \frac{\partial L_{i}}{\partial \tau_{i}}=\frac{\partial V_{i}}{\partial q_{i}}+\lambda_{i}\left(x_{i}+\tau_{i} \frac{\partial x_{i}}{\partial q_{i}}+\tau_{f} \frac{\partial x_{i}}{\partial q_{i}}\right)=0 \\
& \frac{\partial L}{\partial g_{i}}=\frac{\partial V_{i}}{\partial g_{i}}-\lambda_{i}=0
\end{aligned}
$$

A partir de las condiciones de primer orden, determinadas en relación a las alícuotas impositivas y los niveles de gasto público de los estados, puede determinarse la condición siguiente, que es la que surge al considerar las restricciones presupuestarias del otro nivel de gobierno para el gobierno subnacional, resultando ser éste el costo marginal social:

$$
\frac{\alpha}{1+\frac{\tau_{i}}{x_{i}} \frac{\partial x_{i}}{\partial q_{i}}+\frac{\tau_{f}}{x_{i}} \frac{\partial x_{i}}{\partial q_{i}}}=\lambda_{i}
$$

Los estados toman decisiones erróneas en relación con los niveles de gasto público que proveen y de tasas impositivas que colocan, dado que el costo marginal de los fondos públicos que advierten difiere del costo marginal social de los fondos públicos. El nivel subnacional de gobierno sólo observa el costo marginal de los fondos públicos y no el social; como el primero es inferior al segundo, fija niveles de gasto elevados y tasas impositivas también demasiado elevadas en relación a las que resultarían del bienestar agregado.

Las alícuotas resultantes son, en consecuencia, en términos de elasticidades,

$\overline{\tau_{s}} \eta=\theta_{s}{ }^{\prime \prime \prime}$ (96), donde $\theta_{s}{ }^{\prime \prime \prime}=\left[\frac{\alpha}{\lambda_{s}}+\tau_{s} \frac{\partial x}{\partial y}-1\right]<0(97)$

\subsubsection{Políticas impositivas del gobierno federal}

El gobierno federal maximiza la utilidad agregada en los estados, aunque sólo financia bienes públicos federales. Si el gobierno federal ignora su impacto en el nivel de provisión de bienes públicos locales en la función de utilidad del agente representativo, a diferencia del modelo de Hoyt, el problema del gobierno federal es, tomando como dadas las tasas de los estados, el siguiente:

Maximizar $\sum_{i=1}^{n} V\left(q_{i}, g_{i}, g_{f}\right)$ s.t. $\sum_{i=1}^{n}\left(\tau_{f} x_{i}\left(q_{i}\right)\right)=n g_{f} \mathrm{y} \sum_{i=1}^{n} \tau_{i} x_{i}\left(q_{i}\right)=g_{i}$ $\tau_{f}, g_{f}$

donde las condiciones de primer orden son, con respecto a la tasa del gobierno federal: 


$$
\begin{aligned}
& \frac{\partial L}{\partial \tau_{f}}=\sum_{i=1}^{n}\left(\frac{\partial V}{\partial q_{i}}+\frac{\partial V}{\partial g_{i}} \tau_{i} \frac{\partial x_{i}}{\partial q_{i}}\right)+\lambda_{f} \sum_{i=1}^{n}\left(x_{i}+\tau_{f} \frac{\partial x_{i}}{\partial q_{i}}\right)=0,(98) \\
& \frac{\partial L_{f}}{\partial g_{f}}=\frac{\partial V}{\partial g_{f}}-\lambda_{f}=0
\end{aligned}
$$

A partir de las condiciones de primer orden, y reordenando, surge:

$\frac{\partial V}{\partial q_{i}}=-\lambda_{f}\left[x_{i}+\tau_{f} \frac{\partial x_{i}}{\partial q_{i}}\right]+\frac{\partial V}{\partial g_{i}} \tau_{i} \frac{\partial x_{i}}{\partial q_{i}}(100), \quad$ y utilizando la identidad de Roy y la descomposición de Slutzky, se obtiene el nivel de gasto público en el caso del nivel federal de gobierno

$$
\frac{\alpha-\frac{\partial V}{\partial g_{i}}\left[\frac{\tau_{i}}{x_{i}} \frac{\partial x_{k}}{\partial q_{i}}\right]}{1+\frac{\tau_{f}}{x_{i}} \frac{\partial x_{i}}{\partial q_{i}}}=\lambda_{f}{ }^{\prime \prime \prime}=M U_{f}(101)
$$

El óptimo social global para el gobierno federal, surge de encontrar los valores de $g_{f} \mathrm{y} \tau_{f}$ que maximizan el bienestar social agregado $W=\sum_{i=1}^{n} V\left(q_{i}, g_{i}, g_{f}\right)$, en donde se incluyen las restricciones presupuestarias de ambos gobiernos, y en donde $\lambda_{f}$ es el multiplicador (costo marginal social total de obtener una unidad adicional de recaudación tributaria para el gobierno federal)

Maximizar $\sum_{i=1}^{n} V\left(q_{i}, g_{i}, g_{f}\right)$ s.t. $\sum_{i=1}^{n}\left(\tau_{f} x_{i}\left(q_{i}\right)\right)=n g_{f} \mathrm{y} \sum_{i=1}^{n} \tau_{i} x_{i}\left(q_{i}\right)=g_{i}$

$\tau_{f}, g_{f}$

Las condiciones de primer orden son, para la alícuota $\tau_{f}$ y para el gasto público federal a partir del lagrangiano $L$ las siguientes:

$$
\begin{aligned}
& L=\sum_{i=1}^{n} V\left(q_{i}, g_{i}, g_{f}\right)+\lambda_{f} \sum_{i=1}^{n}\left(\tau_{i} x_{i}\left(q_{i}\right)-g_{i}+\tau_{f} x_{i}\left(q_{i}\right)-n g_{f}\right) \\
& \frac{\partial L_{i}}{\partial \tau_{i}}=\frac{\partial V_{i}}{\partial q_{i}}+\lambda_{f}\left(x_{i}+\tau_{i} \frac{\partial x_{i}}{\partial q_{i}}+\tau_{f} \frac{\partial x_{i}}{\partial q_{i}}\right)+\frac{\partial V_{i}}{\partial g_{i}}\left(\tau_{i} \frac{\partial x_{i}}{\partial q_{i}}\right)=0 \\
& \frac{\partial L}{\partial g_{f}}=\frac{\partial V_{i}}{\partial g_{f}}-\lambda_{f}=0
\end{aligned}
$$


A partir de las condiciones de primer orden, determinadas en relación a las alícuotas impositivas y los niveles de gasto público de los estados, puede determinarse la condición siguiente, que determina, para el gobierno federal, el siguiente costo marginal social.

$$
\frac{\alpha-\frac{\partial V}{\partial g_{i}}\left[\frac{\tau_{i}}{x_{i}} \frac{\partial x_{k}}{\partial q_{i}}\right]}{1+\frac{\tau_{i}}{x_{i}} \frac{\partial x_{i}}{\partial q_{i}}+\frac{\tau_{f}}{x_{i}} \frac{\partial x_{i}}{\partial q_{i}}}=\lambda_{f}
$$

Ambos niveles de gobierno colocan tasas demasiado elevadas en relación a las que resultarían del bienestar agregado; dado que al gobierno federal le importa el óptimo social global, cual coloca una tasa menor para tratar de corregir el sesgo en el costo marginal de provisión de bienes públicos percibido por los gobiernos subnacionales.

\subsubsection{Comparación entre los resultados de los niveles de gasto y tasas impositivas}

Es importante comparar los niveles de gasto público que surgen de las optimizaciones de cada nivel de gobierno, con el óptimo social global; el objetivo es comparar el costo marginal de los fondos públicos que aprecia cada nivel de gobierno con el costo marginal social; cada gobierno toma decisiones que lo alejan del costo marginal social si las decisiones sobre alícuotas impositivas afectan la base imponible del otro nivel.

Proposición 9: En el caso en que el gobierno del estado ignora la restricción presupuestaria del gobierno federal, pero éste sí tiene en cuenta la restricción presupuestaria de las provincias, los niveles de gasto público que se obtienen son más elevados que en el caso descentralizado inicial, pero en menor medida que en el caso de gobiernos "miopes".

Lo anteriormente expresado puede advertirse a partir de la comparación de las ecuaciones (92) y (99), con las ecuaciones (23) y (36), para el caso "base”, y las ecuaciones (57) y (67), para el caso de gobiernos que no incorporan la restricción presupuestaria del otro nivel cuando llevan a cabo sus políticas de impuestos y gastos.

\section{Un ejemplo numérico}

Se presentará a continuación un ejemplo numérico que permita dimensionar los distintos casos analizados. 
El consumidor representativo maximiza la función de utilidad directa $U(x, l)$ sujeta a su restricción presupuestaria. Se plantea una función de utilidad de la manera siguiente: $U=a * \ln (x)+b * \ln l$

Mientras que la restricción presupuestaria resulta

$w T=p x+w l$

A partir del Lagrangiano, surgen las condiciones de primer orden, con $w=1, p=1$ y con tiempo total disponible $T=1$, y donde $\alpha$ representa la utilidad marginal privada de la renta.

$$
\begin{aligned}
& L=a^{*} \ln (x)+b^{*} \ln l+\alpha(w T-p x-w l) \\
& \frac{\partial L}{\partial x}=\frac{a}{x}-\alpha=0 \\
& \frac{\partial L}{\partial l}=\frac{b}{l}-\alpha=0 \\
& \frac{\partial L}{\partial \alpha}=1-x-l=0
\end{aligned}
$$

Resultan las siguientes soluciones: $x=\frac{a}{a+b} ; l=\frac{b}{a+b} ; \alpha=a+b$

Si, $a+b=1$, las soluciones resultan $x=a, l=b$ y $\alpha=1$

Se introducen luego dos impuestos, un impuesto específico sobre el consumo, que afecta al precio del bien, y adicionalmente, un impuesto de suma fija $T$; el precio después de impuestos es ahora $q=1+\tau$ Ambos serán utilizados por el gobierno para financiar sus gastos públicos, de la manera que se expondrá más adelante. La restricción presupuestaria es ahora $w \bar{T}=(p+\tau) x+w l+T$

A partir del Lagrangiano, surgen las condiciones de primer orden, con $w=1, p=1$ y con tiempo total disponible $T=1$, y donde $\alpha$ representa la utilidad marginal privada de la renta.

$$
\begin{aligned}
& L=a * \ln (x)+b^{*} \ln l+\alpha[1-(1+\tau) x-l-T] \\
& \frac{\partial L}{\partial x}=\frac{a}{x}-(1+\tau) \alpha=0 \\
& \frac{\partial L}{\partial l}=\frac{b}{l}-\alpha=0 \\
& \frac{\partial L}{\partial \alpha}=1-(1+\tau) x-l-T=0
\end{aligned}
$$

De las condiciones de primer orden, resulta 


$$
\begin{aligned}
& \frac{a}{x(1+\tau)}=\alpha \\
& \frac{b}{l}=\alpha \\
& x=\frac{1-l-T}{1+\tau}
\end{aligned}
$$

Por lo tanto

$$
l=\frac{b}{a} x(1+\tau)
$$

Si $\tau=0$, es decir, sólo hubiese un impuesto de suma fija, reemplazando resultan las siguientes soluciones: $x=\frac{a}{a+b}(1-T) ; l=\frac{b}{a+b}(1-T) ; \alpha=\frac{a+b}{1-T}$

$\mathrm{Si}$, por el contrario, sólo hubiera un impuesto específico $(T=0)$, resultaría

$$
x=\frac{a}{a+b} \frac{1}{1+\tau} ; l=\frac{b}{a+b} ; \alpha=a+b
$$

El paso siguiente consiste en incorporar un bien público en la función de utilidad del agente representativo, que demanda bienes privados y públicos. Este bien público es financiado por el gobierno en parte con impuestos de suma fija y en parte con un impuesto específico sobre el bien de consumo ${ }^{45}$.

La tecnología de producción implica que $c=1-l_{c}, g=1-\lg$ es decir que una unidad de trabajo produce una unidad de bien de consumo, una unidad de gasto público federal y una unidad de gasto público provincial, con $l=l_{c}+l_{g}$.

Reemplazando las demandas del bien de consumo y de ocio en la función de utilidad, se plantea la función de utilidad indirecta. En primer lugar se asumirá que el gasto público es sólo financiado con un impuesto de suma fija.

El gobierno maximiza la función indirecta de utilidad, con $a+b+c=1$, sujeta a la restricción presupuestaria:

$$
V=a * \ln \left(\frac{a(1-T)}{a+b}\right)+b * \ln \left(\frac{b(1-T)}{a+b}\right)+c * \ln (g)
$$

\section{Sujeta a $T=g$}

El lagrangiano es $L=a * \ln \left(\frac{a(1-T)}{a+b}\right)+b * \ln \left(\frac{b(1-T)}{a+b}\right)+c \ln g+\lambda[T-g]$

\section{Las condiciones de primer orden son:}

\footnotetext{
${ }^{45}$ Atkinson y Stiglitz
} 


$$
\begin{aligned}
& \frac{\partial L}{\partial T}=-\frac{a}{1-T}-\frac{b}{1-T}+\lambda=0 \\
& \frac{\partial L}{\partial g}=\frac{c}{g}-\lambda=0 \\
& \frac{\partial L}{\partial \lambda}=T-g=0
\end{aligned}
$$

Despejando,

$$
\frac{a+b}{1-T}=\lambda
$$

En consecuencia, en el caso de impuestos de suma fija, $\alpha=\lambda$, la utilidad marginal de la renta es igual al costo marginal de los fondos públicos.

De las condiciones de primer orden, y la restricción presupuestaria del sector público,

$$
\frac{c}{T}=\frac{a+b}{1-T}
$$

Con lo que $T=g=c$

$\mathrm{Si}$, en lugar de un impuesto de suma fija, el gasto público fuera financiado con un impuesto específico $(T=0)$, la función indirecta de utilidad sería:

$$
V(q, g)=a * \ln \left(\frac{a}{a+b} \frac{1}{1+t}\right)+b * \ln \left(\frac{b}{a+b}\right)+c * \ln (g)
$$

El gobierno elige los niveles de gasto público y la tasa impositiva para maximizar la función de utilidad indirecta del agente representativo, sujeta a la restricción presupuestaria de financiamiento del gasto público: $\tau x=g$

El lagrangiano es $L=a * \ln \left(\frac{a}{a+b} \frac{1}{1+\tau}\right)+b * \ln \left(\frac{b}{a+b}\right)+c \ln g+\lambda[\tau x-g]$

Las condiciones de primer orden son:

$$
\begin{aligned}
& \frac{\partial L}{\partial \tau}=\frac{-a}{1+\tau}+\lambda\left(x+\tau \frac{\partial x}{\partial q} \frac{\partial q}{\partial \tau}\right)=0 \\
& \frac{\partial L}{\partial g}=\frac{c}{g}-\lambda=0 \\
& \frac{\partial L}{\partial \lambda}=\tau x-g=0
\end{aligned}
$$

Reemplazando e igualando, resulta 


$$
\begin{aligned}
& \frac{\partial L}{\partial g}=\frac{c}{\tau x-g}-\lambda=0 \\
& \frac{c}{\tau\left(\frac{a}{a+b} \frac{1}{1+\tau}\right)-g}=\frac{c}{g}
\end{aligned}
$$

Con lo cual, el costo marginal de los fondos públicos $\lambda$ resulta:

$$
\lambda=\frac{c(a+b)(1+\tau)}{a \tau}
$$

Despejando y reemplazando en la primera de las condiciones de primer orden, resulta, después de varias operaciones algebraicas:

$$
\frac{-a}{1+\tau}+\frac{c(a+b)(1+\tau)}{a \tau}\left(\frac{a}{a+b} \frac{1}{1+\tau}-\tau \frac{a}{a+b} \frac{1}{(1+\tau)^{2}}\right)=0 \text {, con lo cual } \tau=\frac{c}{a}
$$

Los niveles de gasto público surgen de reemplazar en la ecuación de la condición de primer orden:

$\tau x-g=0$

A partir de las respectivas restricciones presupuestarias, los niveles de gasto público resultan:

$$
g=\left(\frac{c}{a}\right)\left(\frac{a}{a+b} \frac{1}{1+\frac{c}{a}}\right)=\frac{a c}{(a+b)(a+c)}
$$

El costo marginal de los fondos públicos resulta:

$$
\lambda=\frac{c}{\tau x}=\frac{c(a+b)(a+c)}{c a}
$$

En consecuencia, en el caso de impuestos específicos, $\alpha<\lambda$; la utilidad marginal de la renta es menor al costo marginal de los fondos públicos.

En los próximos apartados se introduce la estructura de gobiernos superpuestos. Inicialmente se plantea el caso de un gobierno unificado, que utiliza impuestos de suma fija o específicos, según corresponda, para financiar la provisión de bienes públicos provinciales y federales en cada estado. 
A partir de lo anterior puede obtenerse la función de utilidad indirecta, reemplazando $V=a * \ln (x)+b * \ln (l)+c * \ln \left(g_{i}\right)+c * \ln \left(g_{f}\right)$

En donde $a+b+2 c=1$. La tecnología de producción implica que $c=1-l_{c}, g_{i}=1-\lg _{i}, g_{f}=1-\lg _{f}$ es decir que una unidad de trabajo produce una unidad de bien de consumo, una unidad de gasto público federal y una unidad de gasto público provincial, con $l=l_{c}+l_{g i} l_{g}$.

Los casos mencionados se presentarán a continuación.

\subsection{Impuestos de suma fija}

Se introduce en una segunda instancia al sector público; dos gobiernos que realizan gastos y recaudan impuestos de suma fija. Reemplazando, la función de utilidad indirecta resulta:

$$
V=a * \ln \left[\frac{a(1-T)}{a+b}\right]+b * \ln \left[\frac{b(1-T)}{a+b}\right]+c * \ln \left(g_{i}\right)+c * \ln \left(g_{f}\right)
$$

La anterior es la función de utilidad indirecta del individuo representativo a maximizar, con $T_{i,} g_{i} \quad y g_{f}$ como variables de control, sujeta a la restricción presupuestaria:

$T_{i}=g_{i}+g_{f}$

El correspondiente lagrangiano es

$$
L=a * \ln \left[\frac{a(1-T)}{a+b}\right]+b * \ln \left[\frac{b(1-T)}{a+b}\right]+c * \ln \left(g_{i}\right)+c * \ln \left(g_{f}\right)+\lambda\left[T_{i}-g_{i}-g_{f}\right]
$$

Las condiciones de primer orden serían:

$$
\begin{aligned}
& \frac{\partial L}{\partial T_{i}}=-\frac{a}{1-T_{i}}-\frac{b}{1-T_{i}}+\lambda=0 \\
& \frac{\partial L}{\partial g_{i}}=\frac{c}{g_{i}}-\lambda=0 \\
& \frac{\partial L}{\partial g_{f}}=\frac{c}{g_{f}}-\lambda=0 \\
& \frac{\partial L}{\partial \lambda}=T_{i}-g_{i}-g_{f}=0
\end{aligned}
$$

A partir de las condiciones de primer orden, surge:

$$
\frac{c}{g_{f}}=\frac{c}{g_{i}}=\lambda
$$


Por lo tanto, $g_{i}=g_{f}$

Adicionalmente,

$\frac{a+b}{1-T_{i}}=\lambda$

Reemplazando,

$\frac{a+b}{1-g_{i}-g_{f}}=\lambda$

Resulta

$\frac{a+b}{1-2 g_{i}}=\frac{c}{g_{i}}$

Con lo cual

$T_{i}=\frac{2 c}{a+b+2 c}$

Siendo

$g_{i}=\frac{c}{a+b+2 c}=g_{f}$

El costo marginal de los fondos públicos $\lambda$ es:

$$
\lambda=\frac{a+b}{1-\frac{2 c}{a+b+2 c}}=a+b+2 c
$$

Los valores para $x, l$ y $\alpha$ son los siguientes:

$$
\begin{aligned}
& x=\frac{a\left(1-T_{i}\right)}{a+b}=\frac{a}{a+b+2 c} \\
& l=\frac{b\left(1-T_{i}\right)}{a+b}=\frac{b}{a+b+2 c} \\
& \alpha=\frac{a+b}{1-T_{i}}=a+b+2 c
\end{aligned}
$$


Si $a+b+2 c=1$, surgen los resultados de equilibrio, $T_{i}=2 c ; x=a ; l=b ; g_{i}=c ; g_{f}=c$, y la utilidad marginal de la renta $\alpha$ es igual al costo marginal de los fondos públicos $\lambda$ y ambos son iguales a uno.

\subsection{Impuesto distorsivo}

Se analizarán en lo sucesivo los efectos de los impuestos selectivos sobre bienes. El problema para el individuo representativo es el siguiente, en donde $q=1+\tau_{i}+\tau_{f}$

Maximizar $a * \ln (x)+b * \ln l$ s.t. $w T=q x+w l$

$x, l$

De las condiciones de primer orden, con $w=1, p=1$ y con tiempo total disponible $T=1$

$$
\begin{aligned}
& \frac{\partial L}{\partial x}=\frac{a}{x}-q \lambda=0 \\
& \frac{\partial L}{\partial l}=\frac{b}{l}-\lambda=0 \\
& \frac{\partial L}{\partial \lambda}=1-q x-l=0
\end{aligned}
$$

Resultan las siguientes soluciones

$$
\begin{aligned}
& x=\frac{a}{a+b} \frac{1}{q} \\
& l=\frac{b}{a+b}
\end{aligned}
$$

A continuación se analizarán los casos del gobierno unificado, del gobierno descentralizado en donde ambos niveles de gobierno ignoran la restricción presupuestaria del otro nivel (caso de "miopía"), el caso en donde ambos consideran la restricción presupuestaria del otro nivel de gobierno, y adicionalmente, el caso intermedio, en donde el gobierno federal considera la restricción de los gobiernos subnacionales pero éstos ignoran la del gobierno federal.

\subsubsection{Caso de gobierno unificado}

En primer lugar, se analiza el gobierno centralizado. Esto implica que el nivel federal de gobierno coloca una tasa impositiva para financiar la provisión de dos bienes públicos en cada estado, uno nacional y otro provincial. El problema para el gobierno centralizado parte de maximizar la función de utilidad indirecta del agente representativo, sujeta a la restricción presupuestaria del financiamiento de los gastos públicos de ambos niveles de gobierno 
Maximizar $a \ln \left(\frac{a}{a+b} \frac{1}{q}\right)+b \ln \left(\frac{b}{a+b}\right)+c \ln g_{i}+c \ln g_{f}$

$\tau_{i}, g_{i}$

s.t. $\tau_{i} x=g_{i}+g_{f}$

Las condiciones de primer orden para las alícuotas impositivas y para los bienes públicos son las siguientes, donde $L$ denota la función de Lagrange:

$$
\begin{aligned}
& L_{u}=a \ln \left(\frac{a}{a+b} \frac{1}{q}\right)+b \ln \left(\frac{b}{a+b}\right)+c \ln g_{i}+c \ln g_{f}+\lambda\left(\tau_{i} x-g_{i}-g_{f}\right) \\
& \frac{\partial L}{\partial \tau_{i}}=\frac{-a}{1+\tau_{i}}+\lambda\left(x+\tau_{i} \frac{\partial x}{\partial q} \frac{\partial q}{\partial \tau_{i}}\right)=0 \\
& \frac{\partial L}{\partial g_{i}}=\frac{c}{g_{i}}-\lambda=0 \\
& \frac{\partial L}{\partial g_{f}}=\frac{c}{g_{f}}-\lambda=0 \\
& \frac{\partial L}{\partial \lambda}=\tau_{i} x_{i}-g_{i}-g_{f}=0
\end{aligned}
$$

Reemplazando e igualando, resulta

$$
\begin{gathered}
\frac{\partial L}{\partial g_{f}}=\frac{c}{\tau_{i} x-g_{i}}-\lambda=0 \\
\frac{c}{\tau_{i}\left(\frac{a}{a+b} \frac{1}{1+\tau_{i}}\right)-g_{i}}=\frac{c}{g_{i}}
\end{gathered}
$$

Con lo cual, el costo marginal de los fondos públicos $\lambda$ resulta:

$$
\lambda=\frac{2 c(a+b)\left(1+\tau_{i}\right)}{a \tau_{i}}
$$

Despejando y reemplazando en la primera de las condiciones de primer orden, resulta, después de varias operaciones algebraicas:

$$
\frac{-a}{1+\tau_{i}}+\frac{2 c(a+b)\left(1+\tau_{i}\right)}{a \tau_{i}}\left(\frac{a}{a+b} \frac{1}{1+\tau_{i}}-\tau_{i} \frac{a}{a+b} \frac{1}{\left(1+\tau_{i}\right)^{2}}\right)=0, \text { con lo cual } \tau_{i}=\frac{2 c}{a}
$$


Los niveles de gasto público surgen de reemplazar en la ecuación de la condición de primer orden con relación al multiplicador:

$\tau_{i} x-g_{i}-g_{f}=0$

A partir de las respectivas restricciones presupuestarias, los niveles de gasto público resultan:

$g_{f}=\left(\frac{2 c}{a}\right)\left(\frac{a}{a+b} \frac{1}{1+\frac{2 c}{a}}\right)-\left(\frac{a c}{(a+b)(a-2 c)}\right)=\frac{a c}{(a+b)(a+2 c)}=g_{i}$

\subsubsection{Caso de gobierno descentralizado con ambos gobiernos "miopes"}

Para el caso del gobierno descentralizado, se presentará inicialmente el caso de ambos gobiernos "miopes", en el sentido de que ignoran la restricción presupuestaria del otro nivel de gobierno. Para los estados, la función de utilidad del agente representativo a maximizar es:

Maximizar $a \ln \left(\frac{a}{a+b} \frac{1}{q}\right)+b \ln \left(\frac{b}{a+b}\right)+c \ln g_{i}$

$\tau_{i}, g_{i}$

s.t. $\tau_{i} x=g_{i}$

El lagrangiano correspondiente es el siguiente:

$$
L=a \ln \left(\frac{a}{a+b} \frac{1}{q}\right)+b \ln \left(\frac{b}{a+b}\right)+c \ln g_{i}+\lambda\left(\tau_{i} x-g_{i}\right)
$$

Las siguientes son las condiciones de primer orden

$$
\begin{aligned}
& \frac{\partial L}{\partial \tau_{i}}=\frac{-a}{1+\tau_{i}+\tau_{f}}+\lambda\left(x+\tau_{i} \frac{\partial x}{\partial q} \frac{\partial q}{\partial \tau_{i}}\right)=0 \\
& \frac{\partial L}{\partial g_{i}}=\frac{c}{g_{i}}-\lambda=0
\end{aligned}
$$

Despejando en las condiciones de primer orden en relación con los gastos, resulta:

$$
\begin{aligned}
& \frac{\partial L}{\partial g_{i}}=\frac{c}{\tau_{i} x}-\lambda=0 \\
& \frac{\partial L}{\partial g_{i}}=\frac{c(a+b)\left(1+\tau_{i}+\tau_{f}\right)}{a \tau_{f}}=\lambda
\end{aligned}
$$


Reemplazando y despejando, en la condición de primer orden, relacionado con el impuesto provincial, resulta:

$\frac{-a}{1+\tau_{i}+\tau_{f}}+\frac{c(a+b)\left(1+\tau_{i}+\tau_{f}\right)}{a \tau_{i}}\left(\frac{a}{a+b} \frac{1}{1+\tau_{i}+\tau_{f}}-\tau_{i} \frac{a}{a+b} \frac{1}{\left(1+\tau_{i}+\tau_{f}\right)^{2}}\right)=0$

Luego de varias operaciones algebraicas, resulta,

$\frac{1}{1+\tau_{i}+\tau_{f}}=\frac{c}{a \tau_{i}}\left(1-\tau_{i} \frac{1}{\left(1+\tau_{i}+\tau_{f}\right)}\right)=0$

En consecuencia, la tasa impositiva de los estados depende de la del gobierno federal, con lo cual, para calcular los niveles de impuestos y gastos debe resolverse el problema del gobierno federal

$\tau_{i}=\frac{c+c \tau_{f}}{a}$

Para el caso del gobierno federal, la función de utilidad del agente a maximizar es:

Maximizar $a \ln \left(\frac{a}{a+b} \frac{1}{q}\right)+b \ln \left(\frac{b}{a+b}\right)+c \ln g_{f}$

$\tau_{f}, g_{f}$

s.t. $\tau_{f} x=g_{f}$

El lagrangiano correspondiente es el siguiente:

$L=a \ln \left(\frac{a}{a+b} \frac{1}{q}\right)+b \ln \left(\frac{b}{a+b}\right)+c \ln g_{f}+\lambda\left(\tau_{f} x-g_{f}\right)$

Las siguientes son las condiciones de primer orden

$$
\begin{aligned}
& \frac{\partial L}{\partial \tau_{f}}=\frac{-a}{1+\tau_{i}+\tau_{f}}+\lambda\left(x+\tau_{f} \frac{\partial x}{\partial q} \frac{\partial q}{\partial \tau_{f}}\right)=0 \\
& \frac{\partial L}{\partial g_{f}}=\frac{c}{g_{f}}-\lambda=0
\end{aligned}
$$

Despejando en las condiciones de primer orden en relación con los gastos, resulta:

$$
\frac{\partial L}{\partial g_{f}}=\frac{c}{\tau_{f} x}-\lambda=0
$$


$\frac{\partial L}{\partial g_{f}}=\frac{c(a+b)\left(1+\tau_{i}+\tau_{f}\right)}{a \tau_{f}}=\lambda$

Reemplazando y despejando, en la condición de primer orden, relacionado con el impuesto federal, resulta:

$\frac{-a}{1+\tau_{i}+\tau_{f}}+\frac{c(a+b)\left(1+\tau_{i}+\tau_{f}\right)}{a \tau_{i}}\left(\frac{a}{a+b} \frac{1}{1+\tau_{i}+\tau_{f}}-\tau_{i} \frac{a}{a+b} \frac{1}{\left(1+\tau_{i}+\tau_{f}\right)^{2}}\right)=0$

Luego de varias operaciones algebraicas, resulta,

$\frac{1}{1+\tau_{i}+\tau_{f}}=\frac{c}{a \tau_{f}}\left(1-\tau_{f} \frac{1}{\left(1+\tau_{i}+\tau_{f}\right)}\right)=0$

En consecuencia, la tasa impositiva del gobierno federal depende de la de los estados,

$\tau_{f}=\frac{c+c \tau_{i}}{a}$

Reemplazando esta ecuación en la tasa de los estados, resultan las tasas de ambos gobiernos,

$\tau_{i}=\frac{c}{a-c}=\tau_{f}$

Los respectivos niveles de gasto público resultan de reemplazar en las respectivas restricciones presupuestarias partiendo de las tasas impositivas calculadas en el paso anterior.

Para el caso de los estados, es $\tau_{i} x=g_{i}$

Sustituyendo en la expresión anterior, resulta ser

$\tau_{i} \frac{1}{1+\tau+\tau_{f}}=g_{i}$

Con lo cual los niveles de gasto público, dado que el gobierno federal resuelve un problema idéntico, resultan ser los siguientes:

$g_{i}=\frac{a c}{(a+b)(a+c)}=g_{f}$

\subsubsection{Caso de gobierno descentralizado en donde ambos gobiernos consideran la} restricción presupuestaria del otro nivel de gobierno

Se plantea a continuación el caso de los gobiernos no miopes. Como fuera expuesto en el texto, existe una diferencia en la manera en que los gobiernos perciben la restricción 
presupuestaria del otro nivel de gobierno; el nivel provincial percibe la reducción del gasto público federal sólo en su propia jurisdicción, mientras que el nivel federal pondera en su totalidad al gasto público de los gobiernos subnacionales. El problema para los estados es:

Maximizar $a \ln \left(\frac{a}{a+b} \frac{1}{q}\right)+b \ln \left(\frac{b}{a+b}\right)+c \ln g_{i}+c \ln g_{f}$

$\tau_{i}, g_{i}$

s.t. $\tau_{i} x=g_{i} \frac{1}{n} \tau_{f} x=g_{f}$

Reemplazando, el lagrangiano resulta:

$L=a \ln \left(\frac{a}{a+b} \frac{1}{1+\tau_{i}+\tau_{f}}\right)+b \ln \left(\frac{b}{a+b}\right)+c \ln g_{i}+c \ln \left(\frac{1}{n} \tau_{f} x\right)+\lambda\left(\tau_{i} x-g_{i}\right)$

Las siguientes son las condiciones de primer orden

$$
\begin{aligned}
& \frac{\partial L}{\partial \tau_{i}}=\frac{-a}{1+\tau_{i}+\tau_{f}}-\frac{c}{n} \frac{1}{1+\tau_{i}+\tau_{f}}+\lambda\left(x+\tau_{i} \frac{\partial x}{\partial q} \frac{\partial q}{\partial \tau_{i}}\right)=0 \\
& \frac{\partial L}{\partial \tau_{i}}=\frac{n a+c}{n\left(1+\tau_{i}+\tau_{f}\right)}=\lambda\left(\frac{a}{a+b} \frac{1}{1+\tau_{i}+\tau_{f}}+\tau_{i}\left(\frac{-a}{a+b} \frac{1}{\left(1+\tau_{i}+\tau_{f}\right)^{2}}\right)\right)=0 \\
& \frac{\partial L}{\partial g_{i}}=\frac{c}{g_{i}}-\lambda=0
\end{aligned}
$$

Despejando en las condiciones de primer orden en relación con los gastos, resulta:

$$
\begin{aligned}
& \frac{\partial L}{\partial g_{i}}=\frac{c}{\tau_{i} x}-\lambda=0 \\
& \frac{\partial L}{\partial g_{i}}=\frac{c\left(1+\tau_{i}+\tau_{f}\right)}{a \tau_{i}}=\lambda
\end{aligned}
$$

Reemplazando y despejando, en la condición de primer orden relacionada con el impuesto provincial, resulta:

$$
\frac{n a+c}{n\left(1+\tau_{i}+\tau_{f}\right)}=\frac{c(a+b)\left(1+\tau_{i}+\tau_{f}\right)}{a \tau_{i}}\left(\frac{a}{a+b} \frac{1}{1+\tau_{i}+\tau_{f}}-\tau_{i} \frac{a}{a+b} \frac{1}{\left(1+\tau_{i}+\tau_{f}\right)^{2}}\right)=0
$$


$\frac{n a+c}{n\left(1+\tau_{i}+\tau_{f}\right)}=\frac{c}{\tau_{i}}\left(1-\tau_{i} \frac{1}{\left(1+\tau_{i}+\tau_{f}\right)}\right)=0$

Las tasas impositivas resultan ser las siguientes, teniendo en cuenta que para el caso del gasto público, al depender la tasa de la federal, no existe solución analítica ${ }^{46}$, y se calcula a partir de la restricción presupuestaria del gobierno subnacional. $\tau_{i} x=g_{i}$

$\tau_{i}=\frac{n c\left(1+\tau_{f}\right)}{n a+c}$

El problema para el gobierno federal es el siguiente,

Maximizar $a \ln \left(\frac{a}{a+b} \frac{1}{q}\right)+b \ln \left(\frac{b}{a+b}\right)+c \ln g_{i}+c \ln g_{f}$

$\tau_{f}, g_{f}$

s.t. $\tau_{i} x=g_{i} \quad \tau_{f} x=g_{f}$

Reemplazando, el lagrangiano resulta:

$L=a \ln \left(\frac{a}{a+b} \frac{1}{1+\tau_{i}+\tau_{f}}\right)+b \ln \left(\frac{b}{a+b}\right)+c \ln g_{f}+c \ln \left(\tau_{i} x\right)+\lambda\left(\tau_{f} x-g_{f}\right)$

Las siguientes son las condiciones de primer orden

$$
\begin{aligned}
& \frac{\partial L}{\partial \tau_{f}}=-\left(\frac{a+c}{1+\tau_{i}+\tau_{f}}\right)+\lambda\left(x+\tau_{f} \frac{\partial x}{\partial q} \frac{\partial q}{\partial \tau_{i}}\right)=0 \\
& \frac{\partial L}{\partial \tau_{f}}=\left(\frac{a+c}{\left(1+\tau_{i}+\tau_{f}\right)}\right)=\lambda\left(\frac{a}{a+b} \frac{1}{1+\tau_{i}+\tau_{f}}+\tau_{f}\left(\frac{-a}{a+b} \frac{1}{\left(1+\tau_{i}+\tau_{f}\right)^{2}}\right)\right)=0 \\
& \frac{\partial L}{\partial g_{f}}=\frac{c}{g_{f}}-\lambda=0
\end{aligned}
$$

Despejando en las condiciones de primer orden en relación con los gastos, resulta:

$$
\frac{\partial L}{\partial g_{f}}=\frac{c}{\tau_{f} x}-\lambda=0
$$

\footnotetext{
${ }^{46}$ Para el cálculo de las tasas y los niveles de gasto público, tanto para el caso del gobierno federal como para el provincial en los casos en que no existe solución analítica se utilizó el programa Matlab 2010.
} 


$$
\frac{\partial L}{\partial g_{f}}=\frac{c\left(1+\tau_{i}+\tau_{f}\right)}{a \tau_{f}}=\lambda
$$

Reemplazando y despejando, en la condición de primer orden del impuesto federal, resulta:

$$
\begin{aligned}
& -\frac{(a+c)}{1+\tau_{i}+\tau_{f}}=\frac{c(a+b)\left(1+\tau_{i}+\tau_{f}\right)}{a \tau_{f}}\left(\frac{a}{a+b} \frac{1}{1+\tau_{i}+\tau_{f}}-\tau_{f} \frac{a}{a+b} \frac{1}{\left(1+\tau_{i}+\tau_{f}\right)^{2}}\right)=0 \\
& \frac{a+c}{\left(1+\tau_{i}+\tau_{f}\right)}=\frac{c}{\tau_{f}}\left(1-\tau_{f} \frac{1}{\left(1+\tau_{i}+\tau_{f}\right)}\right)=0
\end{aligned}
$$

Las tasas impositivas resultan ser las siguientes, teniendo en cuenta que para el caso del gasto público, al depender la tasa de la provincial, no existe solución analítica, y se calcula a partir de la restricción presupuestaria del gobierno federal $\tau_{f} x=g_{f}$

$$
\tau_{f}=\frac{c\left(1+\tau_{i}\right)}{a+c}
$$

En el caso en que la cantidad de estados $n$ sea igual a uno $(n=1)$ los resultados anteriores en cuanto a alícuotas y niveles de gastos públicos son los siguientes:

$$
\begin{aligned}
& \tau_{f}=\frac{c}{a}=\tau_{i} \\
& g_{f}=\frac{c a}{(a+b)(a+2 c)}=g_{i}
\end{aligned}
$$

\subsubsection{Caso en que el gobierno federal considera la restricción presupuestaria de las}

\section{provincias pero éstas son "miopes"}

Se plantea a continuación el caso del gobierno provincial "miope" con gobierno federal teniendo en cuenta la restricción presupuestaria de los gobiernos subnacionales. El problema para los estados es el siguiente

Maximizar $a \ln \left(\frac{a}{a+b} \frac{1}{q}\right)+b \ln \left(\frac{b}{a+b}\right)+c \ln g_{i}+c \ln g_{f}$

$\tau_{i}, g_{i}$

s.t. $\tau_{i} x=g_{i} \quad \tau_{f} x=g_{f}$

El lagrangiano correspondiente es el siguiente: 


$$
L=a \ln \left(\frac{a}{a+b} \frac{1}{q}\right)+b \ln \left(\frac{b}{a+b}\right)+c \ln g_{i}+\lambda\left(\tau_{i} x+\tau_{f} x-g_{i}-g_{f}\right)
$$

Las siguientes son las condiciones de primer orden

$$
\begin{aligned}
& \frac{\partial L}{\partial \tau_{i}}=\frac{-a}{1+\tau_{i}+\tau_{f}}+\lambda\left(x+\tau_{i} \frac{\partial x}{\partial q} \frac{\partial q}{\partial \tau_{i}}\right)=0 \\
& \frac{\partial L}{\partial \tau_{i}}=\frac{-a}{1+\tau_{i}+\tau_{f}}+\lambda\left(x+\tau_{f} \frac{\partial x}{\partial q} \frac{\partial q}{\partial \tau_{i}}\right)=0 \\
& \frac{\partial L}{\partial g_{i}}=\frac{c}{g_{i}}-\lambda=0 \\
& \frac{\partial L}{\partial g_{f}}=\frac{c}{g_{f}}-\lambda=0
\end{aligned}
$$

Despejando en las condiciones de primer orden en relación con los gastos, resulta: $g_{i}=g_{f}$

$$
\begin{aligned}
& \frac{\partial L}{\partial g_{i}}=\frac{c}{\tau_{i} x}-\lambda=0 \\
& \frac{\partial L}{\partial g_{i}}=\frac{c(a+b)\left(1+\tau_{i}+\tau_{f}\right)}{a \tau_{i}}=\lambda
\end{aligned}
$$

Reemplazando y despejando, en la condición de primer orden, relacionado con el impuesto provincial, resulta:

$$
\frac{-a}{1+\tau_{i}+\tau_{f}}+\frac{c(a+b)\left(1+\tau_{i}+\tau_{f}\right)}{a \tau_{i}}\left(\frac{a}{a+b} \frac{1}{1+\tau_{i}+\tau_{f}}-\tau_{i} \frac{a}{a+b} \frac{1}{\left(1+\tau_{i}+\tau_{f}\right)^{2}}\right)=0
$$

Las tasas impositivas y los niveles de gasto público resultan ser los siguientes:

$$
\tau_{i}=\frac{c}{a-c} g_{i}=\frac{a c}{(a+b)(a+c)}
$$

El problema para el gobierno federal es el siguiente,

Maximizar $a \ln \left(\frac{a}{a+b} \frac{1}{q}\right)+b \ln \left(\frac{b}{a+b}\right)+c \ln g_{i}+c \ln g_{f}$

$\tau_{f}, g_{f}$

s.t. $\tau_{i} x=g_{i} \quad \tau_{f} x=g_{f}$ 
Reemplazando, el lagrangiano resulta:

$$
L=a \ln \left(\frac{a}{a+b} \frac{1}{1+\tau_{i}+\tau_{f}}\right)+b \ln \left(\frac{b}{a+b}\right)+c \ln g_{f}+c \ln \left(\tau_{i} x\right)+\lambda\left(\tau_{f} x-g_{f}\right)
$$

Las siguientes son las condiciones de primer orden

$$
\begin{aligned}
& \frac{\partial L}{\partial \tau_{f}}=-\left(\frac{a+c}{1+\tau_{i}+\tau_{f}}\right)+\lambda\left(x+\tau_{f} \frac{\partial x}{\partial q} \frac{\partial q}{\partial \tau_{i}}\right)=0 \\
& \frac{\partial L}{\partial \tau_{f}}=\left(\frac{a+c}{\left(1+\tau_{i}+\tau_{f}\right)}\right)=\lambda\left(\frac{a}{a+b} \frac{1}{1+\tau_{i}+\tau_{f}}+\tau_{f}\left(\frac{-a}{a+b} \frac{1}{\left(1+\tau_{i}+\tau_{f}\right)^{2}}\right)\right)=0 \\
& \frac{\partial L}{\partial g_{f}}=\frac{c}{g_{f}}-\lambda=0
\end{aligned}
$$

Despejando en las condiciones de primer orden en relación con los gastos, resulta:

$$
\begin{gathered}
\frac{\partial L}{\partial g_{f}}=\frac{c}{\tau_{f} x}-\lambda=0 \\
\frac{\partial L}{\partial g_{f}}=\frac{c\left(1+\tau_{i}+\tau_{f}\right)}{a \tau_{f}}=\lambda
\end{gathered}
$$

Reemplazando y despejando, en la condición de primer orden, relacionado con el impuesto federal, resulta:

$$
\begin{aligned}
& -\frac{(a+c)}{1+\tau_{i}+\tau_{f}}=\frac{c(a+b)\left(1+\tau_{i}+\tau_{f}\right)}{a \tau_{f}}\left(\frac{a}{a+b} \frac{1}{1+\tau_{i}+\tau_{f}}-\tau_{f} \frac{a}{a+b} \frac{1}{\left(1+\tau_{i}+\tau_{f}\right)^{2}}\right)=0 \\
& \frac{a+c}{\left(1+\tau_{i}+\tau_{f}\right)}=\frac{c}{\tau_{f}}\left(1-\tau_{f} \frac{1}{\left(1+\tau_{i}+\tau_{f}\right)}\right)=0
\end{aligned}
$$

Las tasas impositivas resultan ser las siguientes, teniendo en cuenta que para el caso del gasto público, al depender la tasa de la provincial, no existe solución analítica.

$$
\tau_{f}=\frac{c\left(1+\tau_{i}\right)}{a+c}
$$

Los niveles de gasto público se calculan a partir de reemplazar las tasas obtenidas en los cálculos anteriores en la restricción presupuestaria de cada gobierno. 


\subsection{Simulaciones}

Para la simulación numérica, se establecen los siguientes valores de los parámetros en la función de utilidad: $a=0.4 ; b=0.5 ; c=(1-a-b) / 2$. Los resultados que se presentan a continuación presentan las simulaciones sobre variación de cantidad de estados, la misma se fija inicialmente en $n=1$, para luego incrementarlos a $n=10$ y $n=10000000$.

\section{Cuadro 1}

Síntesis de resultados

\begin{tabular}{|c|c|c|c|c|c|c|c|}
\hline & \multicolumn{2}{|c|}{ Centralizado } & \multirow{2}{*}{\multicolumn{5}{|c|}{$\frac{\text { Descentralizado Distorsivo }}{\text { No deducibilidad }}$}} \\
\hline & \multirow[b]{2}{*}{ Lump Sum } & \multirow{2}{*}{$\begin{array}{l}\text { Distorsivo } \\
\text { unificado }\end{array}$} & & & & & \\
\hline & & & Miope & $\begin{array}{c}\text { Miope I y no } \\
\text { miope F }\end{array}$ & \multicolumn{3}{|c|}{ No miopes } \\
\hline $\begin{array}{l}\text { Estados } \\
\text { Deducibilidad }\end{array}$ & $\begin{array}{l}1 \\
0\end{array}$ & $\begin{array}{l}1 \\
0\end{array}$ & $\begin{array}{l}1 \\
0\end{array}$ & $\begin{array}{l}1 \\
0\end{array}$ & $\begin{array}{l}1 \\
0\end{array}$ & $\begin{array}{c}10 \\
0\end{array}$ & $\begin{array}{c}10000000 \\
0\end{array}$ \\
\hline $\mathbf{x}$ & 0.400 & 0.356 & 0.346 & 0.351 & 0.356 & 0.351 & 0.351 \\
\hline I & 0.500 & 0.556 & 0.556 & 0.556 & 0.556 & 0.556 & 0.556 \\
\hline ti & $10.00 \%$ & $25.00 \%$ & $14.29 \%$ & $14.08 \%$ & $12.50 \%$ & $13.91 \%$ & $14.08 \%$ \\
\hline tF & $0.00 \%$ & $0.00 \%$ & $14.29 \%$ & $12.68 \%$ & $12.50 \%$ & $12.66 \%$ & $12.68 \%$ \\
\hline tFd & $0.00 \%$ & $0.00 \%$ & $14.29 \%$ & $12.68 \%$ & $12.50 \%$ & $12.66 \%$ & $12.68 \%$ \\
\hline ti+tf & $10.00 \%$ & $25.00 \%$ & $28.57 \%$ & $26.76 \%$ & $25.00 \%$ & $26.56 \%$ & $26.76 \%$ \\
\hline gi & 0.050 & 0.044 & 0.049 & 0.049 & 0.044 & 0.049 & 0.049 \\
\hline gF & 0.050 & 0.044 & 0.049 & 0.044 & 0.044 & 0.044 & 0.044 \\
\hline$g i+g f$ & 0.100 & 0.089 & 0.099 & 0.094 & 0.089 & 0.093 & 0.094 \\
\hline $\mathbf{u}$ & -1.013 & -1.019 & -1.020 & -1.019 & -1.019 & -1.019 & -1.019 \\
\hline
\end{tabular}

En los gráficos subsiguientes se presenta la evolución de los valores de las tasas y de los niveles de gastos públicos para las distintas alternativas. Allí puede apreciarse que la descentralización incrementa las alícuotas y los niveles de gasto público; el hecho de apreciar la restricción presupuestaria del gobierno federal de distinta manera que la forma en la que el gobierno federal aprecia la restricción presupuestaria de los estados hace que éstos coloquen tasas impositivas y fijen niveles de gasto público mayores a los del propio gobierno federal.

En términos agregados, los niveles de tasas impositivas y de gasto público son más elevados en el caso en que los gobiernos son miopes; las tasas y los gastos de los estados se hacen más elevados a medida que aumenta el número de gobiernos subnacionales. 


\section{Gráfico 2}

Evolución de las tasas impositivas para distintas alternativas

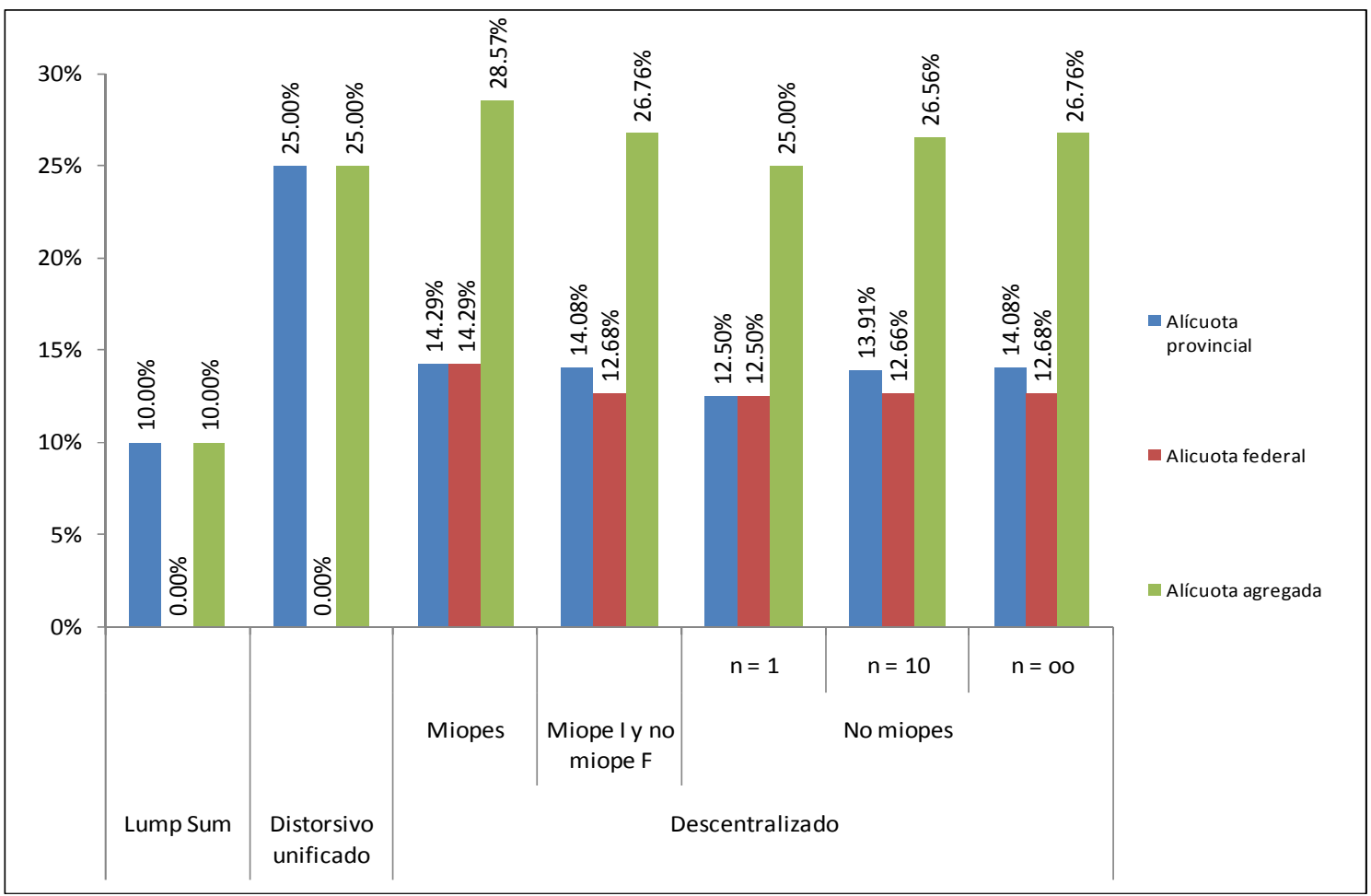

\section{Gráfico 3}

Evolución de los niveles de gasto público para distintas alternativas

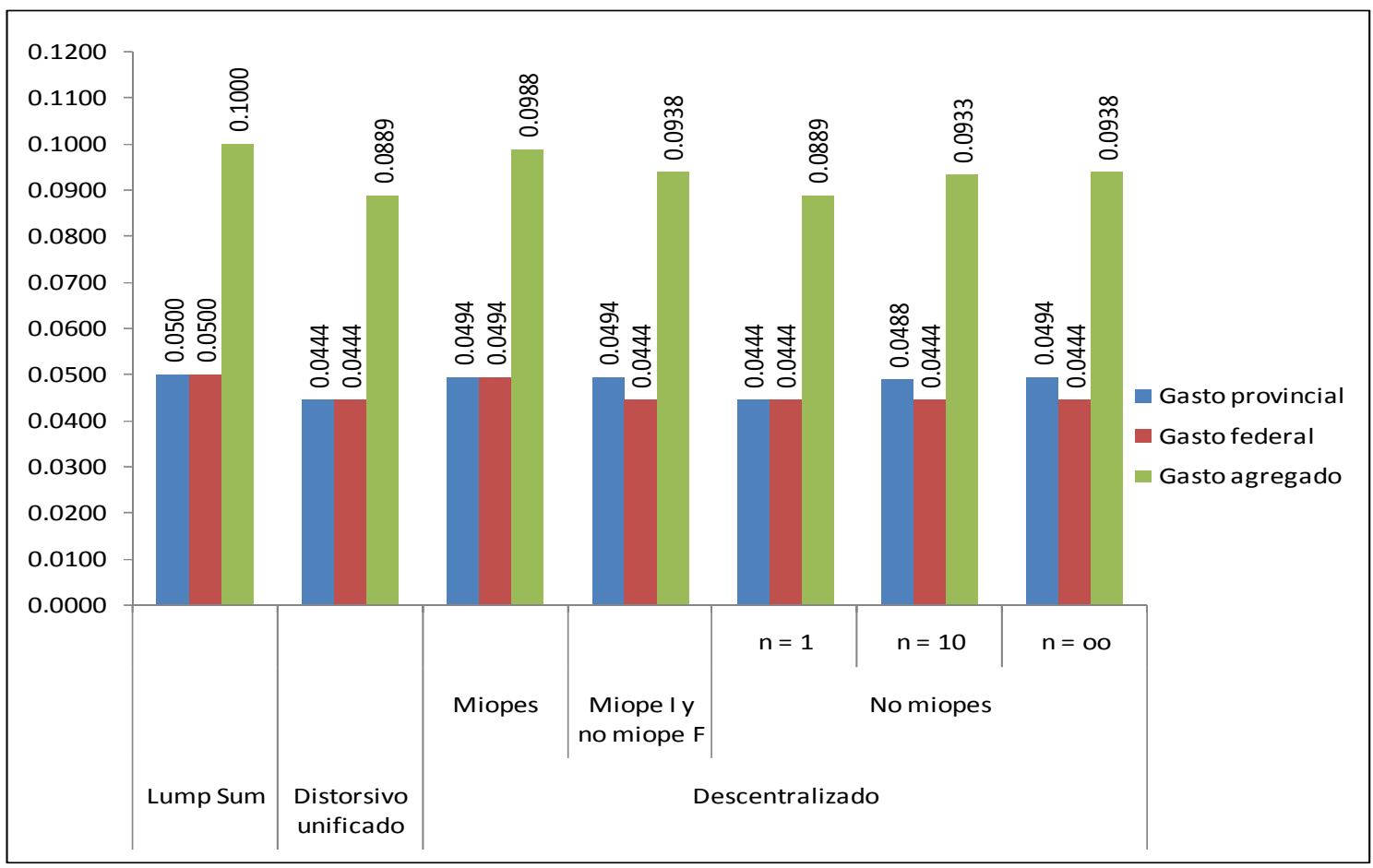




\section{Conclusiones}

Los estudios sobre externalidades tributarias verticales entre jurisdicciones de distinto nivel surgen a partir de la existencia del solapamiento de las bases tributarias, es decir, de la existencia de concurrencia en las fuentes de imposición. Esta es una característica de los sistemas federales, los que, en mayor o menor medida, plantean esta problemática desde las atribuciones de potestades jurisdiccionales.

En el caso de la Argentina, si bien la concurrencia está dada por el mandato constitucional, no existe un grado de concordancia entre los tributos que gravan la misma base imponible, con lo cual ésta se encuentra gravada de manera diferente.

En el trabajo se plantea un modelo en el cual existen dos niveles jurisdiccionales, uno federal y $n$ estados, en los cuales ambos comparten poderes de imposición sobre la misma base imponible en impuestos sobre los consumos en un equilibrio de Nash en tasas impositivas, en donde ambos gobiernos consideran el efecto de sus políticas tributarias sobre el nivel de provisión del bien público provisto por la otra jurisdicción.

En el caso de superposición de poderes de imposición entre gobiernos de distinto nivel se generan externalidades verticales cuando un nivel jurisdiccional eleva su alícuota para incrementar su recaudación, generando una disminución en la base imponible del otro nivel, implicando una menor provisión del bien público de la otra jurisdicción.

Cuando las bases imponibles son idénticas, en el modelo se demuestra que los gobiernos subnacionales proveen cantidades excesivas de bienes públicos, lo que hace que se aleje de la regla del second best del gobierno unificado, que implica cantidades de bienes públicos locales y federales en cada estado iguales. Este resultado se debe a que el gobierno federal considera la disminución en el nivel de provisión del bien público local evaluando por igual a todos los estados, mientras que los gobiernos locales sólo tienen en cuenta el gasto del gobierno federal en el propio estado, de acuerdo a uno de los supuestos adoptados.

Se originan en consecuencia dos problemas: uno referido al nivel de cada gasto en relación con el del gobierno unificado, y otro en términos relativos: el gasto federal en el estado es inferior al del gobierno local.

Se analiza adicionalmente el efecto en los niveles de gasto e impuestos de ignorar las restricciones presupuestarias de las otras jurisdicciones, lo cual genera un nivel de gasto y de impuestos más elevado que el de los casos anteriores. 
Lo expresado anteriormente puede apreciarse en el gráfico 4 (que presenta el caso descentralizado con $n>1$ ), en el cual se presentan los resultados a modo ilustrativo, en los términos de Atkinson y Stern. Las curvas crecientes presentan los costos marginales de los fondos públicos para cada nivel de gobierno de acuerdo a los distintos supuestos sobre cómo consideran las restricciones presupuestarias de los otros niveles jurisdiccionales.

El gasto del gobierno unificado resulta ser el menor, en donde son iguales el gasto federal y el provincial; la descentralización incrementa el gasto, en mayor medida para el gobierno subnacional, lo cual está en relación con la manera en que considera a la restricción presupuestaria del gobierno federal en relación con el impacto de sus políticas impositivas sobre la recaudación del otro gobierno.

\section{Gráfico 4}

\section{Los niveles de provisión de bienes públicos del gobierno federal y los estados bajo} imposición distorsionante

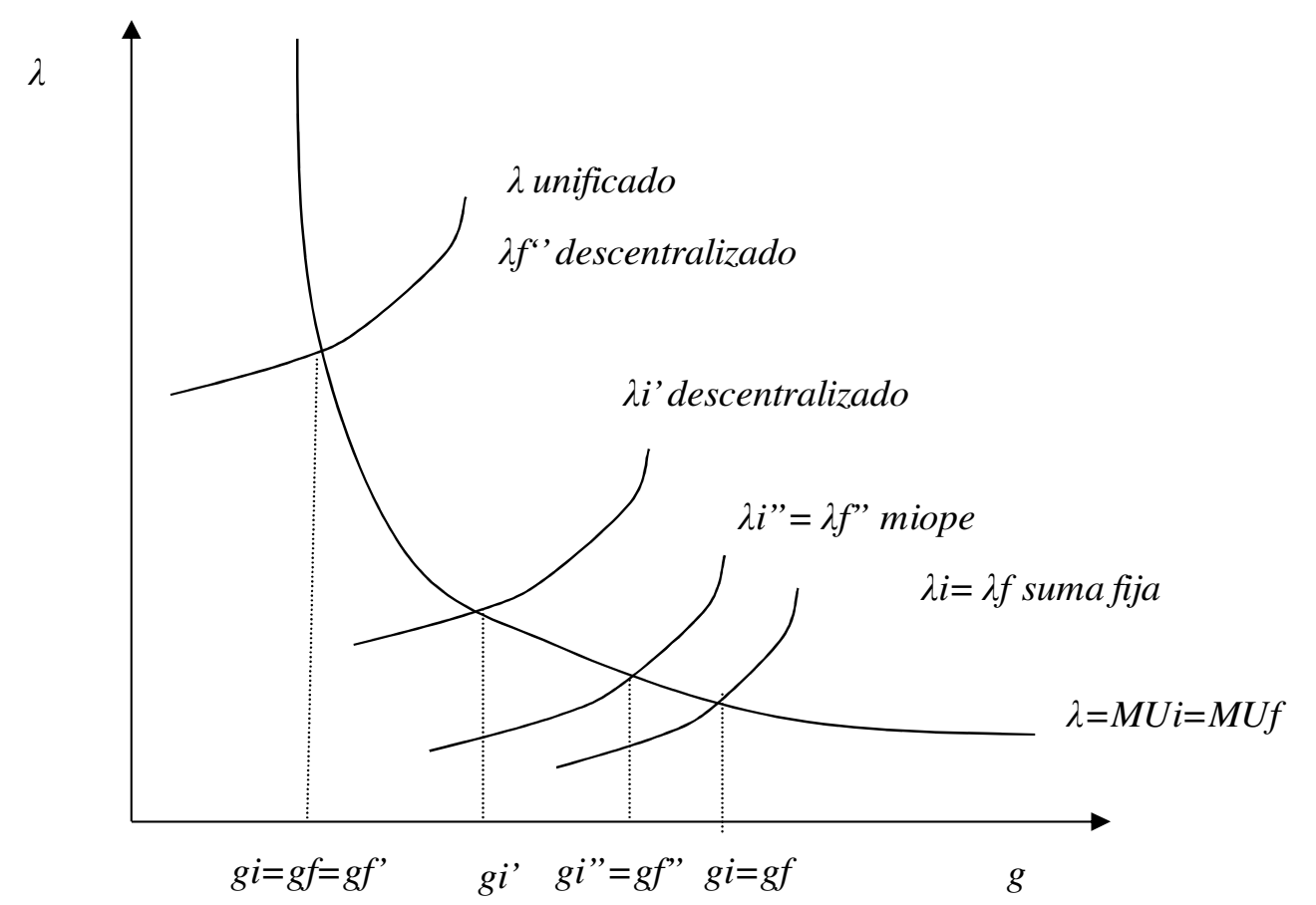

El impuesto distorsivo, junto con la concurrencia de fuentes de imposición, genera varios efectos. Por un lado, existe el efecto distorsionante del impuesto selectivo, que aleja los niveles de gasto del óptimo de impuestos de suma fija; por el otro, aparece el impacto de la externalidad provocada por la superposición de base imponible.

Si el efecto inicial del impuesto distorsivo era el de llevar a un nivel de gasto bajo, ahora la externalidad compensa, en cierta manera y de acuerdo a las distintas hipótesis sobre cómo 
aprecian los gobiernos las restricciones presupuestarias del otro nivel, los niveles de gasto público, incrementándolos ${ }^{47}$.

En consecuencia, el modelo presentado en Hoyt (2001) es sólo un caso particular de un modelo más general, en donde los resultados varían en función de los distintos supuestos que se adopten en relación con los tipos de impuestos, y consideraciones sobre el grado en que cada nivel de gobierno tiene en cuenta el efecto que sus políticas generan sobre el nivel de recaudación tributaria del otro nivel.

\footnotetext{
${ }^{47}$ Esto no puede, sin embargo, considerarse óptimo, o de menor ineficiencia, porque la misma debería medirse en relación con el instrumento tributario del que se dispone.
} 


\section{7. $\underline{\text { Anexo }}$}

\section{Optimización del consumidor}

El consumidor representativo maximiza su función de utilidad, eligiendo sus niveles de consumo del bien privado y ocio, sujeta a la restricción presupuestaria

Maximizar $U(x, l)$ s.t.: $w T=p x+w l$

A partir del Lagrangiano, surgen las condiciones de primer orden, con $w=1, p=1$ y con tiempo total disponible $T=1$, y siendo $\alpha$ la utilidad marginal privada de la renta.

$$
\begin{aligned}
& L=U(x, l)+\alpha(w T-p x-w l) \\
& \frac{\partial L}{\partial x}=\frac{\partial U}{\partial x}-\alpha=0 \\
& \frac{\partial L}{\partial l}=\frac{\partial U}{\partial l}-\alpha=0 \\
& \frac{\partial L}{\partial \alpha}=1-x-l=0
\end{aligned}
$$

En consecuencia, $\frac{\partial U}{\partial x}=\frac{\partial U}{\partial l}=\alpha$

\section{Niveles relativos de gasto público federal y estadual para el caso del gobierno}

\section{descentralizado}

Otra manera de evaluar este resultado puede verse, de acuerdo con Hoyt (2001), a partir de las condiciones de primer orden para las maximizaciones de cada gobierno en relación a su propia alícuota tributaria:

$$
\begin{gathered}
\frac{\partial L_{i}}{\partial \tau_{i}}=\frac{\partial V}{\partial q_{i}}+\lambda_{i}\left(x_{i}+\tau_{i} \frac{\partial x_{i}}{\partial q_{i}}\right)+\frac{1}{n} \frac{\partial V}{\partial g_{f}}\left(\tau_{f} \frac{\partial x_{i}}{\partial q_{i}}\right)=0,(105), \mathrm{y} \\
\frac{\partial L_{f}}{\partial \tau_{f}}=\sum_{i=1}^{n}\left(\frac{\partial V}{\partial q_{i}}+\frac{\partial V}{\partial g_{i}} \frac{\partial x_{i}}{\partial q_{i}}\right)+\lambda_{f} \sum_{i=1}^{n}\left(x+\tau_{f} \frac{\partial x_{i}}{\partial q_{i}}\right)=0 \text { (106) }
\end{gathered}
$$

Igualando ambas condiciones de primer orden,

$$
\frac{\partial V}{\partial q_{i}}+M U_{s}\left(x+\tau_{s} \frac{\partial x_{i}}{\partial q_{i}}\right)+\frac{1}{n} M U_{f}\left(\tau_{f} \frac{\partial x_{i}}{\partial q_{i}}\right)=\frac{\partial V}{\partial q_{i}}+M U_{s} \tau_{s} \frac{\partial x_{i}}{\partial q_{i}}+M U_{f} \sum_{i=1}^{n}\left(x_{i}+\sum_{i=1}^{n} \tau_{f} \frac{\partial x_{i}}{\partial q_{i}}\right)
$$

Aplicando la identidad de Roy y la descomposición de Slutzky, surge 
$M U_{s} x+M U_{s} \tau_{s} \frac{\partial x_{i}}{\partial q_{i}}+\frac{1}{n} M U_{f} \tau_{f} \frac{\partial x_{i}}{\partial q_{i}}=M U_{s} \tau_{s} \frac{\partial x_{i}}{\partial q_{i}}+M U_{f} x_{i}+M U_{f} \tau_{f} \frac{\partial x_{i}}{\partial q_{i}}(107)$

Despejando las ecuaciones anteriores, se llega a

$\left(M R S_{s f}-1\right) x_{i}=\left(1-\frac{1}{n}\right) t_{f} \frac{\partial x_{i}}{\partial q_{i}}(108)$

En la igualdad anterior, si el término de la derecha de la igualdad es negativo, el de la izquierda también lo es, con lo cual el gasto público en los gobiernos estaduales es muy alto en relación con el bien público federal. En consecuencia, si $M R S_{s f}<1$, existe subprovisión del bien público federal.

Si ambos niveles de gobierno consideraran a las restricciones presupuestarias del otro nivel de la misma manera, los resultados serían los siguientes. A partir de las condiciones de primer orden para las maximizaciones de cada gobierno en relación a su propia alícuota tributaria:

$$
\begin{gathered}
\frac{\partial L_{i}}{\partial \tau_{i}}=\frac{\partial V}{\partial q_{i}}+\lambda_{i}\left(x_{i}+\tau_{i} \frac{\partial x_{i}}{\partial q_{i}}\right)+\frac{\partial V}{\partial g_{f}}\left(\tau_{f} \frac{\partial x_{i}}{\partial q_{i}}\right)=0,(109), \mathrm{y} \\
\frac{\partial L_{f}}{\partial \tau_{f}}=\sum_{i=1}^{n}\left(\frac{\partial V}{\partial q_{i}}+\frac{\partial V}{\partial g_{i}} \frac{\partial x_{i}}{\partial q_{i}}\right)+\lambda_{f} \sum_{i=1}^{n}\left(x+\tau_{f} \frac{\partial x_{i}}{\partial q_{i}}\right)=0
\end{gathered}
$$

Igualando ambas condiciones de primer orden,

$$
\frac{\partial V}{\partial q_{i}}+M U_{s}\left(x+\tau_{s} \frac{\partial x_{i}}{\partial q_{i}}\right)+M U_{f}\left(\tau_{f} \frac{\partial x_{i}}{\partial q_{i}}\right)=\frac{\partial V}{\partial q_{i}}+M U_{s} \tau_{s} \frac{\partial x_{i}}{\partial q_{i}}+M U_{f} \sum_{i=1}^{n}\left(x_{i}+\sum_{i=1}^{n} \tau_{f} \frac{\partial x_{i}}{\partial q_{i}}\right)
$$

Aplicando la identidad de Roy y la descomposición de Slutzky, surge

$$
M U_{s} x+M U_{s} \tau_{s} \frac{\partial x_{i}}{\partial q_{i}}+M U_{f} \tau_{f} \frac{\partial x_{i}}{\partial q_{i}}=M U_{s} \tau_{s} \frac{\partial x_{i}}{\partial q_{i}}+M U_{f} x_{i}+M U_{f} \tau_{f} \frac{\partial x_{i}}{\partial q_{i}}(112)
$$

Despejando las ecuaciones anteriores, se llega a

$$
\left(M U_{s}-M U_{f}\right) x_{i}=0(113)
$$

Lo anterior implica que $M U_{s}=M U_{f}$, y los niveles de gasto público serían iguales.

\section{Niveles relativos de gasto público federal y estadual para el caso del gobierno} descentralizado en el que se ignoran las restricciones presupuestarias 
A partir de las condiciones de primer orden para las maximizaciones de cada gobierno en relación a su propia alícuota tributaria:

$$
\begin{gathered}
\frac{\partial L_{i}}{\partial \tau_{i}}=\frac{\partial V}{\partial q_{i}}+\lambda_{i}\left(x_{i}+\tau_{i} \frac{\partial x_{i}}{\partial q_{i}}\right)=0,(114), \mathrm{y} \\
\frac{\partial L_{f}}{\partial \tau_{f}}=\sum_{i=1}^{n}\left(\frac{\partial V}{\partial q_{i}}\right)+\lambda_{f} \sum_{i=1}^{n}\left(x+\tau_{f} \frac{\partial x_{i}}{\partial q_{i}}\right)=0
\end{gathered}
$$

Igualando ambas condiciones de primer orden,

$$
\frac{\partial V}{\partial q_{i}}+M U_{s}\left(x+\tau_{s} \frac{\partial x_{i}}{\partial q_{i}}\right)=\frac{\partial V}{\partial q_{i}}+M U_{f} \sum_{i=1}^{n}\left(x_{i}+\sum_{i=1}^{n} \tau_{f} \frac{\partial x_{i}}{\partial q_{i}}\right)
$$

Aplicando la identidad de Roy y la descomposición de Slutzky, surge

$$
M U_{s} x+M U_{s} \tau_{s} \frac{\partial x_{i}}{\partial q_{i}}=M U_{f} x_{i}+M U_{f} \tau_{f} \frac{\partial x_{i}}{\partial q_{i}}(117)
$$

Despejando las ecuaciones anteriores, se llega a

$$
\left(M U_{s}-M U_{f}\right) x_{i}=\left(M U_{s} \tau_{s}-M U_{f} \tau_{f}\right) \frac{\partial x_{i}}{\partial q_{i}}
$$

Si las utilidades marginales de la provisión de ambos bienes públicos son iguales (dado que los dos ponderan de la misma manera al gasto del otro nivel -no lo consideran-, no hay razón para que sean distintas), los niveles de provisión de bienes públicos serán iguales. 


\section{Capítulo 3. La deducción de impuestos en tributos sobre los consumos en un modelo con externalidades tributarias verticales}

\section{Introducción}

La existencia de externalidades tributarias implica niveles de provisión de bienes públicos y de colocación de alícuotas tributarias que son ineficientes en relación con el óptimo de second best de gobierno centralizado. Esto fue demostrado en el capítulo anterior, en donde pudo apreciarse que en términos generales, dado que ambos gobiernos no consideran todo el impacto de sus políticas sobre la restricción presupuestaria del otro nivel jurisdiccional, el costo marginal de los fondos públicos difiere del costo marginal social y los niveles de gasto son demasiado elevados.

Adicionalmente, puede aparecer una cuestión de gasto relativo: el bien público federal se provea en un nivel inferior en relación con el bien público estadual dado que los estados no consideran el efecto completo de un cambio en las políticas impositivas sobre la recaudación tributaria de los restantes estados, mientras que el gobierno federal evalúa a todos los estados por igual.

Dado que se asume que el gobierno federal procura acercarse a niveles de gasto eficientes, considerando el óptimo social global, y, como fuera expuesto en el capítulo anterior, los niveles de gasto ineficientes debidos a la externalidad se generan a partir de que el gobierno provincial no internaliza completamente el efecto de sus decisiones fiscales sobre la restricción presupuestaria del gobierno federal, será éste último quien aplicará instrumentos fiscales con el fin de aproximar al gasto provincial a un nivel más eficiente, es decir, para "corregir la externalidad".

Una alternativa institucional a esto se plantea a partir de establecer la deducibilidad de los impuestos del otro nivel jurisdiccional para reducir el grado de externalidad generada por la política impositiva del mismo.

La deducción de impuestos provinciales sobre las ganancias empresariales, como recursos de regalías, nóminas salariales e impuestos sobre el capital, han constituido una importante fuente de discusión en cuanto a las políticas tributarias en Canadá ${ }^{48}$; el tratamiento tributario de las regalías provinciales sobre minería, petróleo y gas generó discusiones que fueron

\footnotetext{
${ }^{48}$ La presente sección sigue a Dahlby, Mintz y Wilson (2000), op. cit.
} 
parcialmente resueltas a partir del otorgamiento de compensaciones relacionadas con la posibilidad de deducir el impuesto provincial en relación con la obligación tributaria nacional.

El hecho de permitir esta deducibilidad, y del atractivo que esta deducibilidad generaba en función de los impuestos provinciales en relación con los nacionales, hizo que el gobierno federal procurara limitar la franquicia para no ver disminuida su recaudación. Adicionalmente, en el caso de los Estados Unidos, se realizaron distintas estimaciones econométricas, como Feldstein y Metcalf (1987), y Metcalf (1991), para evaluar el impacto de la eliminación de las deducibilidad de los impuestos estaduales en el impuesto a la renta federal.

La deducibilidad de impuestos no está exenta de controversias. En Dahlby, Mintz y Wilson (2000) se hace referencia al hecho de que existen autores (McLure, Vigneault y Boadway) que sostienen que los impuestos del otro nivel jurisdiccional no deberían ser deducibles porque la deducción reduce el costo de los fondos públicos para el propio estado, creando una externalidad fiscal vertical dado que la reducción en la recaudación del gobierno federal que sobrevendría es soportada por todos los habitantes, no sólo por los de propio estado que aumenta la tasa.

En el trabajo mencionado se argumenta que otros autores (Kesselman) postulan que, en el caso de impuestos sobre la nómina salarial pagados por los empleadores, si los mismos son trasladados a los salarios, la deducibilidad completa no afectará a la recaudación del impuesto federal a las ganancias empresariales, con lo cual se anula el efecto de la externalidad vertical.

Keen (1998), Esteller-Moré y Solé-Ollé (2002) y Dahlby, Mintz y Wilson (2000), para el caso de los impuestos a las ganancias empresariales en Canadá puntualizan, por ejemplo, el caso de la deducibilidad del impuesto nacional contra el provincial, que vuelve más probable un aumento de los impuestos provinciales. Si se considera al precio que enfrenta el consumidor $q=\left[1=\tau_{i}+\tau_{f}\left(1-\tau_{i}\right)\right\rfloor$, con impuestos ad valorem, un efecto del incremento en el impuesto nacional es la reducción en el incremento en el precio que enfrenta el consumidor debido a un aumento en el impuesto provincial, lo que reduce simultáneamente la pérdida de bienestar del consumidor y la disminución de la recaudación provincial debida a una caída en la demanda.

La formulación anterior refiere a la deducibilidad de la obligación tributaria del estado en relación con la del gobierno federal. Adicionalmente, en algunos estados de los Estados 
Unidos existe la posibilidad de deducibilidad recíproca. De acuerdo a Esteller-Moré y SoléOllé, las mismas se expresan de la siguiente manera:

Deducibilidad: $q=1+\tau_{i}+\tau_{f} *\left(1-\tau_{i}\right)$

Deducibilidad recíproca: $q=\frac{1+\tau_{f}\left(1-\tau_{i}\right)+\tau_{s}\left(1-\tau_{f}\right)}{1-\tau_{i} \tau_{f}}$

En ambos casos, la obligación tributaria resultante es inferior al caso de no deducibilidad, aunque en el caso de la deducibilidad recíproca, la disminución es mayor debido a los efectos de segunda vuelta que se reflejan en el denominador de la expresión (2).

De acuerdo con la literatura sobre esta temática, la especificación de la deducibilidad se desarrollará de acuerdo a Keen (1998), en los cuales la deducción implica una disminución del precio del bien, al poder descontar del mismo la alícuota del otro nivel jurisdiccional.

Por ejemplo, en el caso argentino, en donde coexisten el Impuesto al Valor Agregado nacional y el Impuesto sobre Ingresos Brutos provincial, el segundo está contenido en la base imponible del primero, con lo cual un aumento de la tasa de Ingresos Brutos afecta la base imponible del IVA. La deducción se implementaría, en este caso, mediante una disminución de la cuantía de la tasa de IIBB que se incluye dentro de la base imponible del IVA.

Otra alternativa, en relación con arreglos institucionales vigentes en distintas economías ${ }^{49}$, y que no se desarrollará en este trabajo, resulta en la posibilidad que plantea el gobierno federal de deducir (o "devolver") el monto de impuestos pagados en el nivel subnacional para la determinación de la obligación tributaria del gobierno federal. Esto reduciría, en principio, la recaudación del gobierno federal en la base imponible compartida: una aplicación de esta variante a nivel local por parte del gobierno nacional generaría menor nivel de gasto público en el nivel subnacional.

Este capítulo se desarrollará de la siguiente manera. En la segunda parte, se efectuará la presentación del modelo, para luego, en una tercera parte, analizar los efectos de deducibilidad sobre precios para los distintos casos sobre la forma en que los gobiernos consideran a la restricción presupuestaria del otro nivel. Los resultados de estas políticas se compararán, en términos de niveles de gastos, con los generados en el capítulo anterior. En el cuarto apartado se presenta un ejemplo numérico, mientras que en el quinto se presentan las conclusiones.

\footnotetext{
${ }^{49}$ Flochel, L., y Madiès, T. (2002), Wrede, M. (2000); Madiès, T. (2008) y Dahlby, Mintz y Wilson (2000)
} 


\section{Planteamiento del modelo}

Para el análisis de los efectos de las externalidades, se continúa con el modelo presentado en el capítulo anterior, y que fuera desarrollado por Hoyt (2001), por lo cual no se repetirá aquí ${ }^{50}$.

Se asume que el residente del estado $i$ sólo adquiere los bienes en su propio estado, con lo cual no hay impacto de cambios en los impuestos del estado $i$ en los ingresos de otros estados, lo que determina la ausencia de externalidades horizontales.

Se plantearán los resultados para los gobiernos federal y subnacional para cada uno de los supuestos analizados; cabe consignar que en todos los casos los resultados incluirán los niveles de gasto público alcanzados ${ }^{51}$.

\section{Deducción sobre precios}

Este caso implica el hecho en el cual la deducción significa una disminución del precio del bien, al poder descontar del mismo la alícuota del otro nivel jurisdiccional. Esta alternativa resulta ser el análogo a la determinación de si la base imponible del impuesto federal incluye al impuesto provincial o viceversa; en consecuencia la obligación tributaria se determinaría después del impuesto provincial o antes del mismo.

En el caso argentino, por ejemplo, el impuesto provincial a los Ingresos Brutos, pertenece al tipo de tributos en cascada, en tanto grava el ingreso bruto sin deducción del impuesto ya pagado y acumulado sobre las compras ${ }^{52}$. Para determinar el monto imponible se excluye del precio el débito fiscal del IVA y los impuestos internos que gravan la actividad o producto. Sin embargo, el IVA nacional incluye al impuesto sobre los Ingresos Brutos como un costo y aplica la alícuota sobre el precio incluyendo el impuesto sobre los Ingresos Brutos.

En el presente modelo se asume que $h$ es la fracción del impuesto provincial que es deducible en la determinación de la obligación tributaria federal. El gobierno federal puede imponer deducibilidad total, con $h=1$, deducibilidad parcial $(0<h<1)$, no deducibilidad, deducibilidad negativa, por medio de la cual impone una sobretasa a la recaudación del gobierno provincial, o aún valores de $h$ superiores a 1 . La formulación correspondiente es $q=1+\tau_{i}+\tau_{f} *\left(1-h \tau_{i}\right)$

\footnotetext{
${ }^{50}$ Ver Capítulo 2

${ }^{51}$ El cálculo de las tasas impositivas se presenta en la sección del ejemplo numérico.

${ }^{52}$ La descripción normativa sigue a Santiere, J., Gómez Sabaini, J. C. y Rossignolo, D. (2000) op. cit.
} 


\subsection{Caso base}

En el caso base, el gobierno federal considera el impacto del aumento de sus tasas en la recaudación tributaria de todos los estados por igual, mientras que cada uno de los estados sólo pondera, en la función de utilidad del individuo representativo, a la disminución del gasto público del gobierno federal en su propia jurisdicción, sin evaluar lo que acontece en el resto de los estados.

\subsubsection{Políticas impositivas de los estados}

En este equilibrio de Nash el estado $i$ elige sus alícuotas $\tau_{i}$ dadas las alícuotas federales y las tasas de los otros estados para resolver el siguiente problema, considerando la restricción presupuestaria para el gobierno $i$ y para el gobierno federal:

Maximizar $V\left(q_{i}, g_{i}, g_{f}\right)$ s.t. $\tau_{i} x_{i}\left(q_{i}\right)=g_{i} \sum_{i=1}^{n}\left(\tau_{f} x_{i}\left(q_{i}\right)\right)=n g_{f}$ $\tau_{i} ; g_{i}$

Las condiciones de primer orden son, para la alícuota $\tau_{i}$ y para el gasto público propio $g_{i}$, y a partir del lagrangiano $L$ las siguientes:

$$
\begin{aligned}
& \frac{\partial L}{\partial \tau_{i}}=\frac{\partial V_{i}}{\partial q_{i}}\left(1-h \tau_{f}\right)+\lambda_{i}\left(x_{i}+\tau_{i} \frac{\partial x_{i}}{\partial q_{i}}\left(1-h \tau_{f}\right)\right)+\frac{1}{n} \frac{\partial V_{i}}{\partial g_{f}}\left(1-h \tau_{f}\right)\left(\tau_{f} \frac{\partial x_{i}}{\partial q_{i}}\right)=0 \\
& \frac{\partial L}{\partial g_{i}}=\frac{\partial V_{i}}{\partial g_{i}}-\lambda_{i}=0
\end{aligned}
$$

En la condición de primer orden para la determinación de la alícuota del estado $i$ para el bien se aprecia el impacto de la misma sobre el precio del bien y sobre la recaudación necesaria para financiar la provisión del bien público $g_{i}$ además del efecto sobre la recaudación del gobierno federal, lo que reduce el nivel de provisión del bien público federal $g_{f}$.

Los gobiernos estaduales consideran el impacto de las políticas impositivas en la recaudación del gobierno federal, la que depende de la cantidad de estados y de la tasa marginal de sustitución entre los bienes provistos por el sector público estadual y federal; la influencia de la tasa del gobierno federal en el nivel de tasa fijado por el estado es menor a mayor cantidad de estados y mayor tasa marginal de sustitución entre ambos bienes. 
Para determinar el nivel de gasto público de los estados, se iguala el costo marginal con el beneficio marginal de los fondos públicos. A partir de las condiciones de primer orden, se determina el costo marginal de los fondos públicos:

$$
\frac{\left(\alpha-\frac{1}{n} \frac{\partial V}{\partial g_{f}}\left[\frac{\tau_{f}}{x} \frac{\partial x}{\partial q}\right]\right)\left(1-h \tau_{f}\right)}{1+\frac{\tau_{i}}{x} \frac{\partial x}{\partial q}\left(1-h \tau_{f}\right)}=\lambda_{i}=M U_{i} \text { (5) }
$$

\subsubsection{Políticas impositivas del gobierno federal}

El gobierno federal maximiza la utilidad agregada en los estados, aunque sólo financia bienes públicos federales. Influye indirectamente en el nivel de provisión de bienes públicos locales a partir de afectar las bases imponibles de los estados. En consecuencia, el problema del gobierno federal es, tomando como dadas las tasas de los estados:

Maximizar $\sum_{i=1}^{n} V\left(q_{i}, g_{i}, g_{f}\right)$ s.t. $\sum_{i=1}^{n}\left(\tau_{f}\left(1-h \tau_{i}\right) x_{i}\left(q_{i}\right)\right)=n g_{f}$ y $\sum_{i=1}^{n} \tau_{i} x(q)=g_{i}$ $\tau_{f}, g_{f}$

donde las condiciones de primer orden son, con respecto a la tasa del gobierno federal:

$$
\begin{aligned}
& \frac{\partial L}{\partial t_{f}}=\left(\frac{\partial V}{\partial q}\left(1-h \tau_{i}\right)+\frac{\partial V}{\partial g_{i}} \frac{\partial x}{\partial q} \tau_{i}\left(1-h \tau_{i}\right)\right)+\lambda_{f}\left(\left(1-h \tau_{i}\right) x+\tau_{f}\left(1-h \tau_{i}\right) \frac{\partial x}{\partial q}\right)=0,(6) \\
& \frac{\partial L}{\partial g_{f}}=\frac{\partial V}{\partial g_{f}}-\lambda_{f}=0
\end{aligned}
$$

Para determinar el nivel de gasto público del gobierno federal, se iguala el costo marginal con el beneficio marginal de los fondos públicos. A partir de las condiciones de primer orden, se determina el costo marginal de los fondos públicos:

$$
\frac{\alpha-\frac{\partial V}{\partial g_{i}}\left[\frac{\tau_{i}}{x} \frac{\partial x}{\partial q}\right]}{1+\frac{\tau_{f}}{x} \frac{\partial x}{\partial q}\left(1-h \tau_{i}\right)}=\lambda_{f}=M U_{f}
$$

A partir de la comparación de ambos costos marginales de los fondos públicos, puede apreciarse ahora que la posibilidad de establecer deducción de impuestos le permite al gobierno federal variar el nivel de gasto propio y de los estados. Sin embargo, para 
incrementar el gasto propio, y reducir el gasto de los estados, la deducción debe ser negativa, es decir que debe colocar una sobretasa al impuesto provincial.

Gráficamente, y siguiendo a Atkinson y Stern, podría visualizarse de la siguiente manera, en donde la curva de pendiente negativa muestra la demanda por bienes públicos y las de pendiente positiva las ofertas, implicando mayores niveles de provisión de bienes públicos para el gobierno federal y disminuyendo la provisión del bien público del estado en relación al caso de no deducibilidad. La introducción de este mecanismo para el gobierno federal incrementa ligeramente el nivel de provisión del bien público de este nivel de gobierno.

\section{Gráfico 2}

Los niveles de provisión de bienes públicos cuando existe imposición distorsionante en el caso de deducibilidad

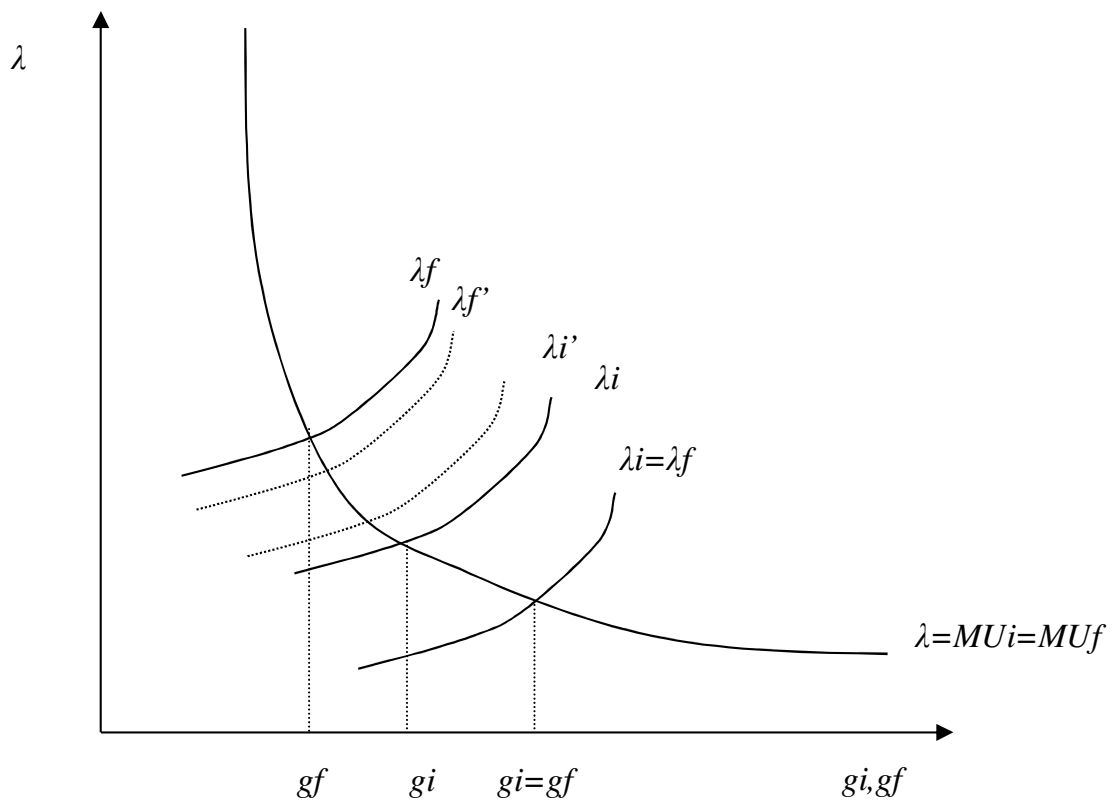

De existir deducibilidad las distorsiones se reducen, aunque en ningún caso se alcanza el óptimo de second best de imposición distorsiva por parte del gobierno unificado (con $n$ finito).

\subsection{Caso en que el gobierno federal considera la restricción presupuestaria del}

\section{gobierno provincial pero no a la inversa}

A diferencia del modelo de Hoyt (2001), y en consonancia con los supuestos del modelo presentado en Dahlby, Mintz y Wilson (2000), se asume a continuación que las provincias ignoran el impacto de sus decisiones sobre alícuotas tributarias propias sobre la restricción presupuestaria del otro gobierno, y el consecuente menor nivel de gasto público que éstos proveen, al no incluir la misma en la función de utilidad indirecta del agente representativo, lo 
que se debe al hecho de que, si existen $n$ gobiernos provinciales idénticos, una provincia soportará sólo una proporción de $1 / n$ del costo de la reducción de la recaudación del gobierno federal causada por sus decisiones fiscales.

En cambio, el gobierno federal considera cómo sus decisiones de impuestos y gastos afectan las restricciones presupuestarias de los gobiernos provinciales. El supuesto subyacente de que el gobierno federal no ignora las externalidades que genera en los gobiernos subnacionales parece, para Dahlby, Mintz y Wilson (2000), razonable en un contexto de un modelo de votante mediano en los que todos los gobiernos subnacionales son idénticos, dado que se espera que, en una elección federal, el votante mediano tendrá en cuenta el efecto de los programas federales en la posición presupuestaria provincial. El gobierno federal, al considerar a todas las provincias, mantiene el rol de internalizador de externalidades generadas por la superposición de bases imponibles. Es decir que el gobierno provincial es "miope", pero el gobierno federal no lo es.

\subsubsection{Políticas impositivas de los gobiernos provinciales}

En este equilibrio de Nash el estado $i$ elige sus alícuotas $\tau_{i}$ dadas las alícuotas federales y las tasas de los otros gobiernos para resolver el siguiente problema, considerando la restricción presupuestaria para el gobierno $i$ y para el gobierno federal, teniendo en cuenta ahora la deducibilidad del impuesto provincial por parte del gobierno federal que lleva a que el precio al consumidor, para el gobierno federal, sea $q_{f}=1+\tau_{i}+\tau_{f} *\left(1-h \tau_{i}\right)$.

El gobierno local maximiza la utilidad y financia bienes públicos locales. El problema del gobierno subnacional es, tomando como dadas las tasas federales para los bienes:

Maximizar $V\left(q_{i}, g_{i}, g_{f}\right)$ s.t. $\tau_{i} x_{i}\left(q_{i}\right)=g_{i}$ $\tau_{i} ; g_{i}$

donde las condiciones de primer orden son:

$$
\begin{aligned}
& \frac{\partial L}{\partial g_{i}}=\frac{\partial V}{\partial g_{i}}-\lambda_{i}=0 \\
& \frac{\partial L}{\partial \tau_{i}}=\frac{\partial V}{\partial q}\left(1-h \tau_{f}\right)+\lambda_{i}\left[x+\tau_{i} \frac{\partial x}{\partial q}\left(1-h t_{f}\right)\right]=0
\end{aligned}
$$

Aplicando la identidad de Roy, reagrupando y despejando el costo marginal de los fondos públicos, resulta 
$\frac{\alpha\left(1-h \tau_{f}\right)}{1+\frac{\tau_{i}}{x} \frac{\partial x}{\partial q_{i}}\left(1-h \tau_{f}\right)}=\lambda_{i}=M U_{i}$

Comparando el valor del $\lambda_{i}$ para el caso de no deducibilidad, este último, colocando un valor de $h=0$ implicaría un menor nivel de gasto público del gobierno subnacional. Valores positivos de $h$ implican niveles de gasto superiores.

\subsubsection{Políticas impositivas del gobierno federal}

El gobierno federal maximiza la utilidad agregada en los estados, aunque sólo financia bienes públicos federales tomando como dadas las tasas impositivas y el nivel de gasto público de los estados. Influye indirectamente en el nivel de provisión de bienes públicos locales a partir de afectar las bases imponibles de los estados.

El gobierno local maximiza la utilidad y financia bienes públicos locales considerando la restricción presupuestaria del gobierno federal. El problema del gobierno subnacional es, tomando como dadas las tasas federales para los bienes:

Maximizar $\sum_{i=1}^{n} V\left(q_{i}, g_{i}, g_{f}\right)$ s.t. $\sum_{i=1}^{n}\left(\tau_{f}\left(1-h \tau_{i}\right) x_{i}\left(q_{i}\right)\right)=n g_{f} \sum_{i=1}^{n} \tau_{i} x_{i}\left(q_{i}\right)=g_{i}$

$\tau_{f} ; g_{f}$

donde las condiciones de primer orden son:

$$
\begin{aligned}
& \frac{\partial L}{\partial g_{f}}=\frac{\partial V}{\partial g_{f}}-\lambda_{f}=0 \\
& \frac{\partial L}{\partial t_{f}}=\frac{\partial V}{\partial q}\left(1-h \tau_{i}\right)+\frac{\partial V}{\partial g_{i}}\left(\tau_{i} \frac{\partial x}{\partial q_{i}}\left(1-h \tau_{i}\right)\right)+\lambda_{f}\left[x_{i}\left(1-h \tau_{i}\right)+\tau_{f} \frac{\partial x}{\partial q}\left(1-h t_{f}\right)^{2}\right]=0
\end{aligned}
$$

Aplicando la identidad de Roy, reagrupando y despejando el costo marginal de los fondos públicos, resulta

$$
\frac{\alpha-\frac{\partial V}{\partial q_{i}} \frac{\tau_{i}}{x} \frac{\partial x_{i}}{\partial q}}{1+\frac{\tau_{f}}{x} \frac{\partial x}{\partial q}\left(1-h \tau_{i}\right)}=\lambda_{f}=M U_{f}
$$

Comparando el valor del $\lambda_{f}$ para el caso de no deducibilidad $(h=0)$, este último, sería inferior que en el caso anterior, con lo cual el nivel de gasto público del gobierno federal aumenta. 
A partir de la comparación entre los costos marginales de los fondos públicos para el gobierno nacional y los estados (11) y (14), puede apreciarse que, para que el gobierno federal pueda incrementar su gasto y reducir el de los estados, el valor de $h$ a aplicar debería ser negativo, es decir, aplicar una sobretasa a la tasa impositiva del gobierno subnacional.

En consecuencia, para aumentar el gasto propio el gobierno federal debe colocar una sobretasa al impuesto del gobierno subnacional. Esto puede apreciarse en el siguiente gráfico, en donde, cuando la tasa de deducción es negativa, el gobierno federal diseña un nivel tal que iguala la pérdida de recaudación que le genera el aumento en la tasa del gobierno subnacional (área e del gráfico) con la recaudación que recupera con la sobretasa (área f).

\section{Gráfico 2}

Deducibilidad en el precio del bien

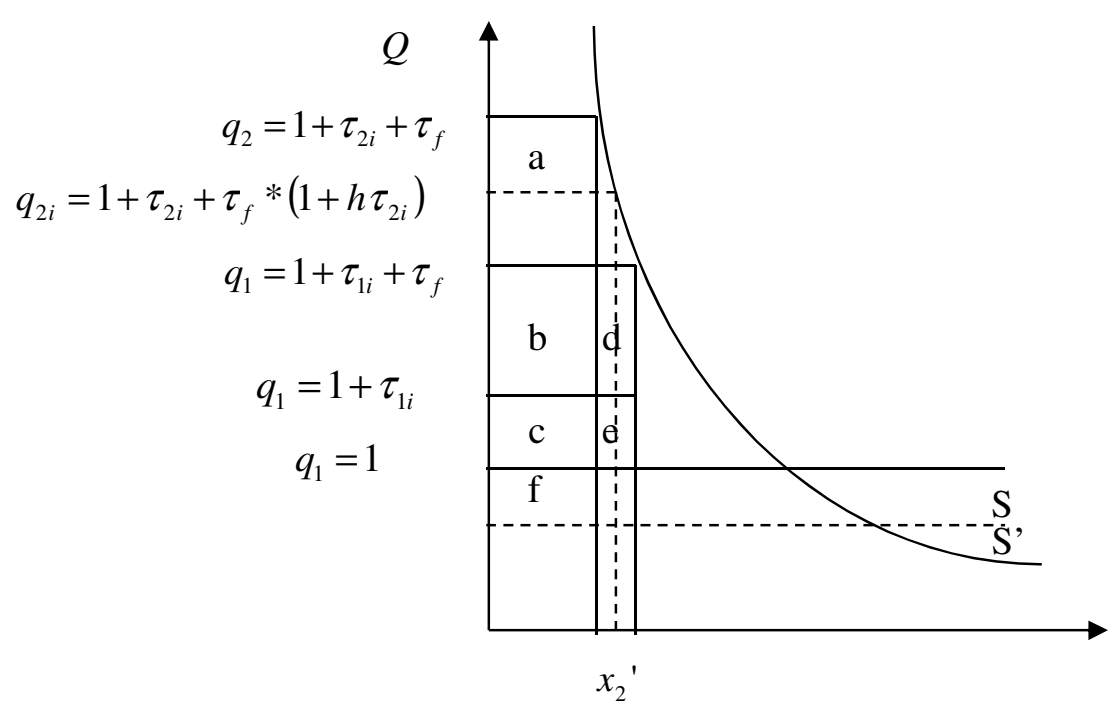

La tasa de deducción óptima es cero si el aumento del la alícuota provincial no tiene efectos en la base imponible del gobierno federal. En este caso, la existencia de externalidad negativa implica que la deducibilidad sea positiva ${ }^{53}$.

\subsection{Caso en que ambos niveles de gobierno ignoran mutuamente la restricción}

\section{presupuestaria del otro nivel.}

Se considera a continuación el caso de los gobiernos "miopes", es decir, las instancias en que los gobiernos ignoran la restricción presupuestaria del otro nivel. Este es el supuesto que presentan Dahlby, Mintz y Wilson (2000) para el caso de los gobiernos provinciales. Se asume que $n$ es lo suficientemente grande como para que una provincia pueda ignorar el impacto de sus decisiones fiscales sobre la restricción presupuestaria del gobierno federal

\footnotetext{
${ }^{53}$ Esto implica que se reduce la remuneración al factor de producción
} 
cuando toma sus decisiones fiscales. Se asumirá un supuesto idéntico para el caso del gobierno federal como marco de referencia.

\subsubsection{Políticas impositivas de los estados}

El gobierno del estado maximiza la utilidad del agente representativo, y sólo financia sus propios bienes públicos. Ignora su impacto en el nivel de provisión de bienes públicos federales en la función de utilidad del agente representativo, a diferencia del modelo de Hoyt (2001); en consecuencia, el problema del gobierno local es, tomando como dadas las tasas de los estados, el siguiente:

Maximizar $V\left(q_{i}, g_{i}, g_{f}\right)$ s.t. $\tau_{i} x_{i}\left(q_{i}\right)=g_{i}$ $\tau_{i}, g_{i,}$

donde las condiciones de primer orden son, con respecto a la tasa del gobierno estadual:

$$
\begin{aligned}
& \frac{\partial L_{i}}{\partial \tau_{i}}=\frac{\partial V}{\partial q}\left(1-h \tau_{f}\right)+\lambda_{i}\left[x+\tau_{i} \frac{\partial x}{\partial q_{i}}\left(1-h \tau_{f}\right)\right]=0, \\
& \frac{\partial L_{i}}{\partial g_{i}}=\frac{\partial V}{\partial g_{i}}-\lambda_{i}=0
\end{aligned}
$$

A partir de la ecuación (15), reordenando, y utilizando la identidad de Roy y la descomposición de Slutzky, se obtiene el nivel de gasto público en el caso del nivel subnacional de gobierno:

$\frac{\alpha\left(1-h \tau_{f}\right)}{1+\frac{\tau_{i}}{x_{i}} \frac{\partial x}{\partial q}\left(1-h \tau_{f}\right)}=\lambda_{i}=M U_{i}$

\subsubsection{Políticas impositivas del gobierno federal}

El gobierno federal maximiza la utilidad agregada en los estados, aunque sólo financia bienes públicos federales. Si el gobierno federal ignora su impacto en el nivel de provisión de bienes públicos locales en la función de utilidad del agente representativo, el problema del gobierno federal es, tomando como dadas las tasas de los estados, el siguiente:

Maximizar $\sum_{i=1}^{n} V\left(q_{i}, g_{i}, g_{f}\right)$ s.t. $\sum_{i=1}^{n}\left(\tau_{f}\left(1-h \tau_{i}\right) x_{i}\left(q_{i}\right)\right)=n g_{f}$

$\tau_{f}, g_{f}$

donde las condiciones de primer orden son, con respecto a la tasa del gobierno federal: 


$$
\begin{aligned}
& \frac{\partial L}{\partial \tau_{f}}=\frac{\partial V}{\partial q_{i}}\left(1-h \tau_{i}\right)+\lambda_{f}\left(x_{i}\left(1-h \tau_{i}\right)+\tau_{f}\left(1-h \tau_{i}\right)^{2} \frac{\partial x_{i}}{\partial q_{i}}\right)=0 \\
& \frac{\partial L}{\partial g_{f}}=\frac{\partial V}{\partial g_{f}}-\lambda_{f}=0
\end{aligned}
$$

A partir de la ecuación (18), y utilizando la identidad de Roy y la descomposición de Slutzky, surge:

$$
\frac{\partial L}{\partial \tau_{f}}=-\alpha x_{i}+\lambda_{f}\left(x_{i}+\tau_{f}\left(1-h \tau_{i}\right) \frac{\partial x_{i}}{\partial q_{i}}\right)=0
$$

En lo que respecta al nivel de gasto público en el caso del nivel federal de gobierno, a partir de las ecuación (20), se obtiene:

$$
\frac{\alpha}{1+\frac{\tau_{f}}{x_{i}}\left(1-h \tau_{i}\right) \frac{\partial x_{i}}{\partial q_{i}}}=\lambda_{f}=M U_{f}(21)
$$

Al igual que en los casos anteriores, la deducción de impuestos le permite al gobierno federal incrementar su gasto y reducir el del nivel subnacional mediante una sobretasa al impuesto provincial. Sin embargo, esta situación no sería óptima, porque el hecho de que ambos gobiernos actúen ignorando el efecto de sus propias políticas respecto a los niveles de gasto del otro gobierno, les llevaba a determinar un nivel de gasto ineficientemente elevado, según lo expuesto en el capítulo anterior. Si el gobierno federal coloca una sobretasa, estaría expandiendo el gasto más allá del socialmente óptimo, y estaría generando un gasto superior al de las provincias, cuando el caso óptimo es que sean iguales.

\subsection{Caso en que ambos gobiernos consideran la restricción presupuestaria del gobierno otro nivel de gobierno}

En este caso, el gobierno federal considera el impacto del aumento de sus tasas en la recaudación tributaria de todos los estados por igual, mientras que cada uno de los estados pondera, en la función de utilidad del individuo representativo, a la disminución del gasto público del gobierno federal en todas las jurisdicciones.

\subsubsection{Políticas impositivas de los estados}


En este equilibrio de Nash el estado $i$ elige sus alícuotas $\tau_{i}$ dadas las alícuotas federales y las tasas de los otros estados para resolver el siguiente problema, considerando la restricción presupuestaria para el gobierno $i$ y para el gobierno federal:

Maximizar $V\left(q_{i}, g_{i}, g_{f}\right)$ s.t. $\tau_{i} x_{i}\left(q_{i}\right)=g_{i}{ }_{\mathrm{y}} \tau_{f} x_{i}\left(q_{i}\right)=g_{f}$ $\tau_{i} ; g_{i}$

Las condiciones de primer orden son, para la alícuota $\tau_{i}$ y para el gasto público propio $g_{i}$, y a partir del lagrangiano $L$ las siguientes:

$$
\begin{aligned}
& \frac{\partial L}{\partial \tau_{i}}=\frac{\partial V}{\partial q}\left(1-h \tau_{f}\right)+\lambda_{i}\left(x_{i}+\tau_{i} \frac{\partial x_{i}}{\partial q_{i}}\left(1-h \tau_{f}\right)\right)+\frac{\partial V_{i}}{\partial g_{f}}\left(1-h \tau_{f}\right)\left(\tau_{f} \frac{\partial x_{i}}{\partial q_{i}}\right)=0 \\
& \frac{\partial L}{\partial g_{i}}=\frac{\partial V}{\partial g_{i}}-\lambda_{i}=0
\end{aligned}
$$

En la condición de primer orden para la determinación de la alícuota del estado $i$ para el bien se aprecia el impacto de la misma sobre el precio del bien y sobre la recaudación necesaria para financiar la provisión del bien público $g_{i}$ además del efecto sobre la recaudación del gobierno federal, lo que reduce el nivel de provisión del bien público federal $g_{f}$.

Los gobiernos estaduales consideran el impacto de las políticas impositivas en la recaudación del gobierno federal. Para determinar el nivel de gasto público de los estados, se iguala el costo marginal con el beneficio marginal de los fondos públicos. A partir de las condiciones de primer orden, se determina el costo marginal de los fondos públicos:

$$
\frac{\left(\alpha-\frac{\partial V}{\partial g_{f}}\left[\frac{\tau_{i}}{x_{i}} \frac{\partial x}{\partial q}\right]\right)\left(1-h \tau_{f}\right)}{1+\frac{\tau_{i}}{x_{i}} \frac{\partial x_{i}}{\partial q_{i}}\left(1-h \tau_{f}\right)}=\lambda_{i}=M U_{i}
$$

\subsubsection{Políticas impositivas del gobierno federal}

El gobierno federal maximiza la utilidad agregada en los estados, aunque sólo financia bienes públicos federales. Influye indirectamente en el nivel de provisión de bienes públicos locales a partir de afectar las bases imponibles de los estados. En consecuencia, el problema del gobierno federal es, tomando como dadas las tasas de los estados:

Maximizar $\sum_{i=1}^{n} V\left(q_{i}, g_{i}, g_{f}\right)$ s.t. $\sum_{i=1}^{n}\left(\tau_{f}\left(1-h \tau_{i}\right) x_{i}\left(q_{i}\right)\right)=n g_{f}$ y $\sum_{i=1}^{n} \tau_{i} x_{i}\left(q_{i}\right)=g_{i}$ 
$\tau_{f}, g_{f}$

donde las condiciones de primer orden son, con respecto a la tasa del gobierno federal:

$$
\begin{aligned}
& \frac{\partial L}{\partial t_{f}}=\left(\frac{\partial V}{\partial q_{i}}\left(1-h \tau_{i}\right)+\frac{\partial V}{\partial g_{i}} \frac{\partial x_{i}}{\partial q_{i}} \tau_{i}\left(1-h \tau_{i}\right)\right)+\lambda_{f}\left(\left(1-h \tau_{i}\right) x_{i}+\tau_{f}\left(1-h \tau_{i}\right) \frac{\partial x_{i}}{\partial q_{i}}\right)=0, \\
& \frac{\partial L}{\partial g_{f}}=\frac{\partial V}{\partial g_{f}}-\lambda_{f}=0
\end{aligned}
$$

Para determinar el nivel de gasto público del gobierno federal, se iguala el costo marginal con el beneficio marginal de los fondos públicos. A partir de las condiciones de primer orden, se determina el costo marginal de los fondos públicos:

$$
\frac{\alpha-\frac{\partial V}{\partial g_{i}}\left[\frac{\tau_{f}}{x_{i}} \frac{\partial x_{i}}{\partial q_{i}}\right]}{1+\frac{\tau_{f}}{x_{i}} \frac{\partial x_{i}}{\partial q_{i}}\left(1-h \tau_{i}\right)}=\lambda_{f}=M U_{f}
$$

A partir de la comparación de ambos costos marginales de los fondos públicos, puede apreciarse ahora que la posibilidad de establecer deducción de impuestos le permite al gobierno federal variar el nivel de gasto propio y de los estados, siendo ambos diferentes en relación con el coeficiente de deducción de impuestos.

\section{Un ejemplo numérico}

Continuando con el ejemplo desarrollado en el capítulo anterior, en impuestos selectivos sobre bienes, el problema para el consumidor representativo es el siguiente

Maximizar $a^{*} \ln (x)+b^{*} \ln l$ s.t. $w T=q x+w l$

$x, l$

De las condiciones de primer orden, resultan las siguientes soluciones

$$
\begin{aligned}
& x=\frac{a}{a+b} \frac{1}{q} \\
& l=\frac{b}{a+b}
\end{aligned}
$$

Se considera el caso de la deducibilidad de impuestos, en donde el gobierno federal deduce la tasa impositiva del gobierno subnacional. Se asume que $h$ es la fracción del impuesto provincial que es deducible en la determinación de la obligación tributaria federal. El 
gobierno federal puede imponer deducibilidad total, con $h=1$, deducibilidad parcial $(0<h$ $<1)$, no deducibilidad, deducibilidad negativa, por medio de la cual impone una sobretasa a la recaudación del gobierno provincial, o aún valores de $h$ superiores a 1 . El precio que enfrenta el consumidor es, en consecuencia, $q=1=\tau_{i}+\tau_{f}\left(1-h \tau_{i}\right)$

\subsection{Caso de gobierno descentralizado con ambos gobiernos "miopes"}

Para el caso del gobierno descentralizado, se presentará inicialmente el caso de ambos gobiernos "miopes", en el sentido de que ignoran la restricción presupuestaria del otro nivel de gobierno. Para el caso de los estados, la función de utilidad del agente representativo a maximizar es

Maximizar $a \ln \left(\frac{a}{a+b} \frac{1}{q}\right)+b \ln \left(\frac{b}{a+b}\right)+c \ln g_{i}+c \ln g_{f}$

$\tau_{i}, g_{i}$

s.t. $\tau_{i} x=g_{i}$

$\tau_{f} x\left(1-h t_{i}\right)=g_{f}$

El lagrangiano correspondiente es el siguiente:

$L=a \ln \left(\frac{a}{a+b} \frac{1}{q}\right)+b \ln \left(\frac{b}{a+b}\right)+c \ln g_{i}+\lambda\left(\tau_{i} x-g_{i}\right)$

Con lo cual, sustituyendo, resulta

$$
L=a \ln \left(\frac{a}{a+b} \frac{1}{1+t_{i}+\tau_{f}-h \tau_{i} \tau_{f}}\right)+b \ln \left(\frac{b}{a+b}\right)+c \ln g_{i}+\lambda\left(\tau_{i} \frac{a}{a+b} \frac{1}{1+t_{i}+\tau_{f}-h \tau_{i} \tau_{f}}-g_{i}\right)
$$

Las siguientes son las condiciones de primer orden

$$
\begin{aligned}
& \frac{\partial L}{\partial \tau_{i}}=\frac{-a\left(1-h \tau_{f}\right)}{1+\tau_{i}+\tau_{f}}+\lambda\left(\frac{a}{a+b} \frac{1}{1+\tau_{i}+\tau_{f}-h \tau_{i} \tau_{f}}+\tau_{i}\left(-\frac{a}{a+b}\right)\left(\frac{1-h \tau_{f}}{\left(1+\tau_{i}+\tau_{f}-h \tau_{i} \tau_{f}\right)^{2}}\right)\right)=0 \\
& \frac{\partial L}{\partial g_{i}}=\frac{c}{g_{i}}-\lambda=0
\end{aligned}
$$

Despejando en las condiciones de primer orden en relación con los gastos, resulta:

$$
\frac{\partial L}{\partial g_{i}}=\frac{c}{\tau_{i} x}-\lambda=0
$$




$$
\frac{\partial L}{\partial g_{i}}=\frac{c(a+b)\left(1+\tau_{i}+\tau_{f}-h \tau_{i} \tau_{f}\right)}{a \tau_{i}}=\lambda
$$

Reemplazando y despejando, en la condición de primer orden, relacionado con el impuesto provincial, resulta:

$$
\left(1-h \tau_{f}\right)=\frac{c}{a \tau_{i}}\left(\frac{1}{(a+b)}-\frac{\tau_{i}}{a+b} \frac{1-h \tau_{f}}{\left(1+\tau_{i}+\tau_{f}-h \tau_{i} \tau_{f}\right)}\right)=0
$$

Luego de varias operaciones algebraicas, resulta,

$\frac{\left(1-h \tau_{f}\right)}{\left(1+\tau_{i}+\tau_{f}-h \tau_{i} \tau_{f}\right)}=\frac{c}{a \tau_{i}}-\frac{1}{a} \frac{c\left(1-h \tau_{f}\right)}{\left(1+\tau_{i}+\tau_{f}-h \tau_{i} \tau_{f}\right)}=0$

Despejando, se llega a que la tasa impositiva de los estados depende de la del gobierno federal, con lo cual, para calcular los niveles de impuestos y gastos debe resolverse el problema del gobierno federal

$$
\tau_{i}=\frac{c+c \tau_{f}}{a\left(1-h \tau_{f}\right)}
$$

Para el caso del gobierno federal, la función de utilidad del agente representativo a maximizar es:

Maximizar $a \ln \left(\frac{a}{a+b} \frac{1}{q}\right)+b \ln \left(\frac{b}{a+b}\right)+c \ln g_{f}$ $\tau_{f}, g_{f}$

s.t. $\tau_{f} x=g_{f}$

El lagrangiano correspondiente es el siguiente:

$$
L=a \ln \left(\frac{a}{a+b} \frac{1}{1+\tau_{i}+\tau_{f}-h \tau_{i} \tau_{f}}\right)+b \ln \left(\frac{b}{a+b}\right)+c \ln g_{f}+\lambda\left(\tau_{f} x-g_{f}\right)
$$

Las siguientes son las condiciones de primer orden

$$
\begin{aligned}
\frac{\partial L}{\partial \tau_{f}} & =\frac{-a\left(1-h \tau_{i}\right)}{1+\tau_{i}+\tau_{f}-h \tau_{i} \tau_{f}}+\lambda\left(\frac{a}{a+b} \frac{1}{1+\tau_{i}+\tau_{f}-h \tau_{i} \tau_{f}}+\tau_{f}\left(-\frac{a}{a+b} \frac{\left(1-h \tau_{i}\right)}{\left(1+\tau_{i}+\tau_{f}-h \tau_{i} \tau_{f}\right)^{2}}\right)\right)=0 \\
\frac{\partial L}{\partial g_{f}} & =\frac{c}{g_{f}}-\lambda=0
\end{aligned}
$$


Despejando en las condiciones de primer orden en relación con los gastos, resulta:

$$
\begin{aligned}
& \frac{\partial L}{\partial g_{f}}=\frac{c}{\tau_{f} x}-\lambda=0 \\
& \frac{\partial L}{\partial g_{f}}=\frac{c(a+b)\left(1+\tau_{i}+\tau_{f}-h \tau_{i} \tau_{f}\right)}{a \tau_{f}}=\lambda
\end{aligned}
$$

Reemplazando y despejando, en la condición de primer orden, relacionado con el impuesto provincial, resulta:

$$
\left(1-h \tau_{i}\right)=\frac{c}{a \tau_{f i}}\left(\frac{1}{(a+b)}-\frac{\tau_{f i}}{a+b} \frac{1-h \tau_{i}}{\left(1+\tau_{i}+\tau_{f}-h \tau_{i} \tau_{f}\right)}\right)=0
$$

Luego de varias operaciones algebraicas, resulta,

$$
\frac{\left(1-h \tau_{i}\right)}{\left(1+\tau_{i}+\tau_{f}-h \tau_{i} \tau_{f}\right)}=\frac{c}{a \tau_{f}}-\frac{1}{a} \frac{c\left(1-h \tau_{i}\right)}{\left(1+\tau_{i}+\tau_{f}-h \tau_{i} \tau_{f}\right)}=0
$$

Despejando, se llega a que la tasa impositiva de los estados depende de la del gobierno federal, con lo cual, para calcular los niveles de impuestos y gastos debe resolverse el problema del gobierno federal

$$
\tau_{f}=\frac{c+c \tau_{i}}{a\left(1-h \tau_{i}\right)}
$$

La determinación de las alícuotas anteriores no tiene solución analítica, por lo cual debe resolverse numéricamente. Los niveles de gasto público se calculan a partir de reemplazar las tasas obtenidas en los cálculos anteriores en la restricción presupuestaria de cada gobierno.

\subsection{Caso de gobierno descentralizado en donde ambos gobiernos consideran la} restricción presupuestaria del otro nivel de gobierno

Se plantea a continuación el caso de los gobiernos no miopes. El nivel provincial percibe la reducción del gasto público federal sólo en su propia jurisdicción, mientras que el nivel federal pondera en su totalidad al gasto público de los gobiernos subnacionales. Por consiguiente, este caso incluye al denominado "caso base". En consecuencia, el problema para los estados es el siguiente,

Maximizar $a \ln \left(\frac{a}{a+b} \frac{1}{q}\right)+b \ln \left(\frac{b}{a+b}\right)+c \ln g_{i}+c \ln g_{f}$ 
$\tau_{i}, g_{i}$

s.t. $\tau_{i}\left(1-h \tau_{f}\right) x=g_{i}$

$\frac{1}{n} \tau_{f} x=g_{f}$

Reemplazando, el lagrangiano resulta:

$$
L=a \ln \left(\frac{a}{a+b} \frac{1}{1+\tau_{i}+\tau_{f}-h \tau_{i} \tau_{f}}\right)+b \ln \left(\frac{b}{a+b}\right)+c \ln g_{i}+c \ln \left(\frac{1}{n} \tau_{f} x\right)+\lambda\left(\tau_{i}\left(1-h \tau_{f}\right) x-g_{i}\right)
$$

Las siguientes son las condiciones de primer orden

$$
\begin{aligned}
& \frac{\partial L}{\partial \tau_{i}}=\frac{-a\left(1-h \tau_{f}\right)}{1+\tau_{f}+\tau_{i}-h \tau_{i} \tau_{f}}-\frac{c\left(1-h \tau_{f}\right)}{n\left(1+\tau_{f}+\tau_{i}-h \tau_{i} \tau_{f}\right)}+ \\
& +\lambda\left(\frac{a}{a+b}\right)\left(\frac{1}{1+\tau_{f}+\tau_{i}-h \tau_{i} \tau_{f}}-\frac{\tau_{i}\left(1-h \tau_{f}\right)}{\left(1+\tau_{f}+\tau_{i}-h \tau_{i} \tau_{f}\right)^{2}}-\frac{h \tau_{f}}{1+\tau_{f}+\tau_{i}-h \tau_{i} \tau_{f}}+\frac{h \tau_{i} \tau_{f}\left(1-h \tau_{f}\right)}{\left(1+\tau_{f}+\tau_{i}-h \tau_{i} \tau_{f}\right)^{2}}\right)=0 \\
& \frac{\partial L}{\partial \tau_{i}}=\frac{-(n a+c)\left(-1+h \tau_{f}\right)}{n\left(1+\tau_{i}+\tau_{f}-h \tau_{i} \tau_{f}\right)}=\lambda\left(\frac{a}{a+b}\right)\left(\frac{1}{1+\tau_{i}+\tau_{f}-h \tau_{i} \tau_{f}}+\frac{\left.h \tau_{f}\right)-\tau_{i}\left(1-h \tau_{f}\right)}{\left(1+\tau_{i}+\tau_{f}-h \tau_{i} \tau_{f}\right)^{2}}\right)=0 \\
& \frac{\partial L}{\partial g_{i}}=\frac{c}{g_{i}}-\lambda=0
\end{aligned}
$$

Despejando en las condiciones de primer orden en relación con los gastos, resulta:

$$
\begin{aligned}
& \frac{\partial L}{\partial g_{i}}=\frac{c}{\tau_{i} x}-\lambda=0 \\
& \frac{\partial L}{\partial g_{i}}=\frac{c(a+b)\left(1+\tau_{i}+\tau_{f}-h \tau_{i} \tau_{f}\right)}{a \tau_{i}\left(1-h \tau_{f}\right)}=\lambda
\end{aligned}
$$

Reemplazando y despejando, en la condición de primer orden, relacionado con el impuesto provincial, resulta:

$$
\frac{-(n a+c)\left(-1+h \tau_{f}\right)}{n}=\lambda\left(\frac{a}{a+b}\right)\left(1-h \tau_{f}+\frac{h \tau_{i} \tau_{f}\left(1-h \tau_{f}\right)-\tau_{i}\left(1-h \tau_{f}\right)}{\left(1+\tau_{i}+\tau_{f}-h \tau_{i} \tau_{f}\right)}\right)=0
$$

Sustituyendo el valor del multiplicador (el costo marginal de los fondos públicos) en la ecuación anterior, y después de reordenar y despejar, queda: 
$-(n a+c)\left(-1+h \tau_{f}\right)=n \frac{c\left(1+\tau_{i}+\tau_{f}-h \tau_{i} \tau_{f}\right)}{\tau_{i}}+n \frac{\operatorname{ch}\left(\tau_{i} \tau_{f}\right)-c \tau_{i}}{\tau_{i}}$

Las tasas impositivas resultan ser las siguientes, teniendo en cuenta que para el caso del gasto público, al depender la tasa de la federal, no existe solución analítica ${ }^{54}$, y se calcula a partir de la restricción presupuestaria del gobierno subnacional. $\tau_{i}\left(1-h \tau_{f}\right) x=g_{i}$

$\tau_{i}=\frac{n c\left(1+\tau_{f}\right)}{(n a+c)\left(1-h \tau_{f}\right)}$

El problema para el gobierno federal es el siguiente,

Maximizar $a \ln \left(\frac{a}{a+b} \frac{1}{q}\right)+b \ln \left(\frac{b}{a+b}\right)+c \ln g_{i}+c \ln g_{f}$

$\tau_{f}, g_{f}$

s.t. $\tau_{i} x=g_{i}$

$\tau_{f}\left(1-h \tau_{i}\right) x=g_{f}$

Reemplazando, el lagrangiano resulta:

$L=a \ln \left(\frac{a}{a+b} \frac{1}{1+\tau_{i}+\tau_{f}-h \tau_{i} \tau_{f}}\right)+b \ln \left(\frac{b}{a+b}\right)+c \ln g_{f}+c \ln \left(\tau_{i} \frac{a}{a+b} \frac{1}{1+\tau_{i}+\tau_{f}-h \tau_{i} \tau_{f}}\right)+\lambda\left(\tau_{f}\left(1-h \tau_{i}\right) x-g_{f}\right)$

Donde

$\lambda\left(\tau_{f}\left(1-h \tau_{i}\right) x-g_{f}\right)=\lambda\left(\tau_{f}\left(1-h \tau_{i}\right) \frac{a}{a+b} \frac{1}{1+\tau_{i}+\tau_{f}-h \tau_{i} \tau_{f}}-g_{f}\right)$

Las siguientes son las condiciones de primer orden

$$
\begin{aligned}
& \frac{\partial L}{\partial \tau_{f}}=\frac{-a\left(1-h \tau_{i}\right)}{1+\tau_{i}+\tau_{f}-h \tau_{i} \tau_{f}}-\frac{c\left(1-h \tau_{i}\right)}{1+\tau_{i}+\tau_{f}-h \tau_{i} \tau_{f}}+\lambda\left(\frac{a}{a+b}\right)\left(\frac{1}{1+\tau_{i}+\tau_{f}-h \tau_{i} \tau_{f}}-\frac{\tau_{f}\left(1-h \tau_{i}\right)}{\left(1+\tau_{i}+\tau_{f}-h \tau_{i} \tau_{f}\right)^{2}}\right)- \\
& -\frac{h \tau_{i}}{1+\tau_{i}+\tau_{f}-h \tau_{i} \tau_{f}}+\frac{h \tau_{i} \tau_{f}\left(1-h \tau_{i}\right)}{\left(1+\tau_{i}+\tau_{f}-h \tau_{i} \tau_{f}\right)^{2}}=0
\end{aligned}
$$

Reagrupando y despejando,

\footnotetext{
${ }^{54}$ Para el cálculo de las tasas y los niveles de gasto público, tanto para el caso del gobierno federal como para el provincial en los casos en que no existe solución analítica se utilizó el programa Matlab 2010.
} 


$$
\frac{\partial L}{\partial \tau_{f}}=-(c+a)\left(-1+h \tau_{i}\right)=\lambda\left(\frac{a}{a+b}\right)\left(1-h \tau_{i}+\frac{\left(1-h \tau_{i}\right)\left(h \tau_{i} \tau_{f}-\tau_{f}\right)}{1+\tau_{i}+\tau_{f}-h \tau_{i} \tau_{f}}\right)
$$

En relación con el gasto federal

$$
\frac{\partial L}{\partial g_{f}}=\frac{c}{g_{f}}-\lambda=0
$$

Despejando en las condiciones de primer orden en relación con los gastos, resulta:

$$
\begin{aligned}
& \frac{\partial L}{\partial g_{f}}=\frac{c}{\tau_{f}\left(1-h \tau_{i}\right) x}-\lambda=0 \\
& \frac{\partial L}{\partial g_{f}}=\frac{c(a+b)\left(1+\tau_{i}+\tau_{f}-h \tau_{i} \tau_{f}\right)}{a \tau_{f}\left(1-h \tau_{i}\right)}=\lambda
\end{aligned}
$$

Reemplazando y despejando, en la condición de primer orden, resulta:

$$
\begin{aligned}
& \frac{\partial L}{\partial \tau_{f}}=-(c+a)\left(-1+h \tau_{i}\right)=\frac{c(a+b)\left(1+\tau_{i}+\tau_{f}-h \tau_{i} \tau_{f}\right)}{a \tau_{f}\left(1-h \tau_{i}\right)}\left(\frac{a}{a+b}\right)\left(1-h \tau_{i}+\frac{\left(1-h \tau_{i}\right)\left(h \tau_{i} \tau_{f}-\tau_{f}\right)}{1+\tau_{i}+\tau_{f}-h \tau_{i} \tau_{f}}\right) \\
& -(c+a)\left(-1+h \tau_{i}\right)=\frac{c\left(1+\tau_{i}+\tau_{f}-h \tau_{i} \tau_{f}\right)}{\tau_{f}}+\frac{c}{\tau_{f}}\left(h \tau_{i} \tau_{f}-\tau_{f}\right)
\end{aligned}
$$

Las tasas impositivas resultan ser las siguientes, teniendo en cuenta que para el caso del gasto público, al depender la tasa de la provincial, no existe solución analítica, y se calcula a partir de la restricción presupuestaria del gobierno federal $\tau_{f}\left(1-h \tau_{i}\right) x=g_{f}$

$$
\tau_{f}=\frac{c\left(1+\tau_{i}\right)}{-(a+c)\left(-1+h \tau_{i}\right)}
$$

\subsection{Caso en que el gobierno federal considera la restricción presupuestaria de las} provincias pero éstas son "miopes"

Se plantea a continuación el caso del gobierno provincial miope con gobierno federal teniendo en cuenta la restricción presupuestaria de los gobiernos subnacionales. El problema para los estados es el siguiente

Maximizar $a \ln \left(\frac{a}{a+b} \frac{1}{q}\right)+b \ln \left(\frac{b}{a+b}\right)+c \ln g_{i}+c \ln g_{f}$ $\tau_{i}, g_{i}$ 
s.t. $\tau_{i} x=g_{i}$

$\tau_{f} x\left(1-h t_{i}\right)=g_{f}$

El lagrangiano correspondiente es el siguiente:

$L=a \ln \left(\frac{a}{a+b} \frac{1}{q}\right)+b \ln \left(\frac{b}{a+b}\right)+c \ln g_{i}+\lambda\left(\tau_{i} x-g_{i}\right)$

Con lo cual, sustituyendo, resulta

$L=a \ln \left(\frac{a}{a+b} \frac{1}{1+t_{i}+\tau_{f}-h \tau_{i} \tau_{f}}\right)+b \ln \left(\frac{b}{a+b}\right)+c \ln g_{i}+\lambda\left(\tau_{i} \frac{a}{a+b} \frac{1}{1+t_{i}+\tau_{f}-h \tau_{i} \tau_{f}}-g_{i}\right)$

Las siguientes son las condiciones de primer orden

$$
\begin{aligned}
& \frac{\partial L}{\partial \tau_{i}}=\frac{-a\left(1-h \tau_{f}\right)}{1+\tau_{i}+\tau_{f}}+\lambda\left(\frac{a}{a+b} \frac{1}{1+\tau_{i}+\tau_{f}-h \tau_{i} \tau_{f}}+\tau_{i}\left(-\frac{a}{a+b}\right)\left(\frac{1-h \tau_{f}}{\left(1+\tau_{i}+\tau_{f}-h \tau_{i} \tau_{f}\right)^{2}}\right)\right)=0 \\
& \frac{\partial L}{\partial g_{i}}=\frac{c}{g_{i}}-\lambda=0
\end{aligned}
$$

Despejando en las condiciones de primer orden en relación con los gastos, resulta:

$$
\begin{aligned}
& \frac{\partial L}{\partial g_{i}}=\frac{c}{\tau_{i} x}-\lambda=0 \\
& \frac{\partial L}{\partial g_{i}}=\frac{c(a+b)\left(1+\tau_{i}+\tau_{f}-h \tau_{i} \tau_{f}\right)}{a \tau_{i}}=\lambda
\end{aligned}
$$

Reemplazando y despejando, en la condición de primer orden, relacionado con el impuesto provincial, resulta:

$$
\left(1-h \tau_{f}\right)=\frac{c}{a \tau_{i}}\left(\frac{1}{(a+b)}-\frac{\tau_{i}}{a+b} \frac{1-h \tau_{f}}{\left(1+\tau_{i}+\tau_{f}-h \tau_{i} \tau_{f}\right)}\right)=0
$$

Luego de varias operaciones algebraicas, resulta,

$\frac{\left(1-h \tau_{f}\right)}{\left(1+\tau_{i}+\tau_{f}-h \tau_{i} \tau_{f}\right)}=\frac{c}{a \tau_{i}}-\frac{1}{a} \frac{c\left(1-h \tau_{f}\right)}{\left(1+\tau_{i}+\tau_{f}-h \tau_{i} \tau_{f}\right)}=0$ 
Despejando, se llega a que la tasa impositiva de los estados depende de la del gobierno federal, con lo cual, para calcular los niveles de impuestos y gastos debe resolverse el problema del gobierno federal

$$
\tau_{i}=\frac{c+c \tau_{f}}{a\left(1-h \tau_{f}\right)}
$$

El problema para el gobierno federal es el siguiente,

Maximizar $a \ln \left(\frac{a}{a+b} \frac{1}{q}\right)+b \ln \left(\frac{b}{a+b}\right)+c \ln g_{i}+c \ln g_{f}$

$\tau_{f}, g_{f}$

s.t. $\tau_{i} x=g_{i}$

$\tau_{f}\left(1-h \tau_{i}\right) x=g_{f}$

Reemplazando, el lagrangiano resulta:

$L=a \ln \left(\frac{a}{a+b} \frac{1}{1+\tau_{i}+\tau_{f}-h \tau_{i} \tau_{f}}\right)+b \ln \left(\frac{b}{a+b}\right)+c \ln g_{f}+c \ln \left(\tau_{i} \frac{a}{a+b} \frac{1}{1+\tau_{i}+\tau_{f}-h \tau_{i} \tau_{f}}\right)+\lambda\left(\tau_{f}\left(1-h \tau_{i}\right) x-g_{f}\right)$

Donde

$$
\lambda\left(\tau_{f}\left(1-h \tau_{i}\right) x-g_{f}\right)=\lambda\left(\tau_{f}\left(1-h \tau_{i}\right) \frac{a}{a+b} \frac{1}{1+\tau_{i}+\tau_{f}-h \tau_{i} \tau_{f}}-g_{f}\right)
$$

Las siguientes son las condiciones de primer orden

$$
\begin{aligned}
& \frac{\partial L}{\partial \tau_{f}}=\frac{-a\left(1-h \tau_{i}\right)}{1+\tau_{i}+\tau_{f}-h \tau_{i} \tau_{f}}-\frac{c\left(1-h \tau_{i}\right)}{1+\tau_{i}+\tau_{f}-h \tau_{i} \tau_{f}}+\lambda\left(\frac{a}{a+b}\right)\left(\frac{1}{1+\tau_{i}+\tau_{f}-h \tau_{i} \tau_{f}}-\frac{\tau_{f}\left(1-h \tau_{i}\right)}{\left(1+\tau_{i}+\tau_{f}-h \tau_{i} \tau_{f}\right)^{2}}\right)- \\
& -\frac{h \tau_{i}}{1+\tau_{i}+\tau_{f}-h \tau_{i} \tau_{f}}+\frac{h \tau_{i} \tau_{f}\left(1-h \tau_{i}\right)}{\left(1+\tau_{i}+\tau_{f}-h \tau_{i} \tau_{f}\right)^{2}}=0
\end{aligned}
$$

Reagrupando y despejando,

$$
\frac{\partial L}{\partial \tau_{f}}=-(c+a)\left(-1+h \tau_{i}\right)=\lambda\left(\frac{a}{a+b}\right)\left(1-h \tau_{i}+\frac{\left(1-h \tau_{i}\right)\left(h \tau_{i} \tau_{f}-\tau_{f}\right)}{1+\tau_{i}+\tau_{f}-h \tau_{i} \tau_{f}}\right)
$$

En relación con el gasto federal 
$\frac{\partial L}{\partial g_{f}}=\frac{c}{g_{f}}-\lambda=0$

Despejando en las condiciones de primer orden en relación con los gastos, resulta:

$$
\begin{aligned}
& \frac{\partial L}{\partial g_{f}}=\frac{c}{\tau_{f}\left(1-h \tau_{i}\right) x}-\lambda=0 \\
& \frac{\partial L}{\partial g_{f}}=\frac{c(a+b)\left(1+\tau_{i}+\tau_{f}-h \tau_{i} \tau_{f}\right)}{a \tau_{f}\left(1-h \tau_{i}\right)}=\lambda
\end{aligned}
$$

Reemplazando y despejando, en la condición de primer orden, relacionado con el impuesto federal, resulta:

$$
\begin{aligned}
& \frac{\partial L}{\partial \tau_{f}}=-(c+a)\left(-1+h \tau_{i}\right)=\frac{c(a+b)\left(1+\tau_{i}+\tau_{f}-h \tau_{i} \tau_{f}\right)}{a \tau_{f}\left(1-h \tau_{i}\right)}\left(\frac{a}{a+b}\right)\left(1-h \tau_{i}+\frac{\left(1-h \tau_{i}\right)\left(h \tau_{i} \tau_{f}-\tau_{f}\right)}{1+\tau_{i}+\tau_{f}-h \tau_{i} \tau_{f}}\right) \\
& -(c+a)\left(-1+h \tau_{i}\right)=\frac{c\left(1+\tau_{i}+\tau_{f}-h \tau_{i} \tau_{f}\right)}{\tau_{f}}+\frac{c}{\tau_{f}}\left(h \tau_{i} \tau_{f}-\tau_{f}\right)
\end{aligned}
$$

Las tasas impositivas resultan ser las siguientes, teniendo en cuenta que para el caso del gasto público, al depender la tasa de la provincial, no existe solución analítica, y se calcula a partir de la restricción presupuestaria del gobierno federal $\tau_{f}\left(1-h \tau_{i}\right) x=g_{f}$

$$
\tau_{f}=\frac{c\left(1+\tau_{i}\right)}{-(a+c)\left(-1+h \tau_{i}\right)}
$$

\subsection{Simulaciones}

Para la simulación numérica, se establecen los siguientes valores de los parámetros en la función de utilidad: $a=0.4 ; b=0.5 ; c=(1-a-b) / 2$. Los resultados que se presentan a continuación presentan las simulaciones sobre distintos valores del parámetro de deducibilidad, fijándolo en $h=-1$ (sobretasa), $h=1$ y $h=2$, y variación de cantidad de estados, los mismos se fijan inicialmente en $n=1$, para luego incrementarlos a $n=10$ y $n=10000000$.

En el cuadro y los gráficos subsiguientes puede apreciarse que la introducción de una sobretasa al impuesto provincial, por parte del gobierno federal, logra el objetivo de reducir la tasa impositiva de los estados e incrementar la propia en relación con la situación inicial, determinando un efecto neto de disminución en la tasa impositiva agregada de ambos niveles 
jurisdiccionales. Esta disminución no es sin embargo compensada pese al incremento en el gasto público subnacional que se genera a través del aumento del número de estados.

\section{Cuadro 1}

Síntesis de resultados caso de valor del parámetro de deducción=-1 (sobretasa)

\begin{tabular}{|c|c|c|c|c|c|c|c|}
\hline & \multicolumn{2}{|c|}{ Centralizado } & \multirow{2}{*}{\multicolumn{5}{|c|}{$\frac{\text { Descentralizado Distorsivo }}{\text { Deducibilidad }}$}} \\
\hline & \multirow[b]{2}{*}{ Lump Sum } & \multirow{2}{*}{$\begin{array}{l}\text { Distorsivo } \\
\text { unificado }\end{array}$} & & & & & \\
\hline & & & Miope & $\begin{array}{c}\text { Miope I y no } \\
\text { miope F }\end{array}$ & \multicolumn{3}{|c|}{ No miopes } \\
\hline $\begin{array}{l}\text { Estados } \\
\text { Deducibilidad }\end{array}$ & $\begin{array}{c}1 \\
-1\end{array}$ & $\begin{array}{c}1 \\
-1\end{array}$ & $\begin{array}{c}1 \\
-1\end{array}$ & $\begin{array}{l}1 \\
-1\end{array}$ & $\begin{array}{c}1 \\
-1\end{array}$ & $\begin{array}{l}10 \\
-1\end{array}$ & $\begin{array}{c}10000000 \\
-1\end{array}$ \\
\hline $\mathbf{x}$ & 0.400 & 0.356 & 0.351 & 0.353 & 0.360 & 0.356 & 0.356 \\
\hline I & 0.500 & 0.556 & 0.556 & 0.556 & 0.556 & 0.556 & 0.556 \\
\hline ti & $10.00 \%$ & $25.00 \%$ & $12.50 \%$ & $11.81 \%$ & $11.11 \%$ & $12.35 \%$ & $12.50 \%$ \\
\hline tF & $0.00 \%$ & $0.00 \%$ & $12.50 \%$ & $12.50 \%$ & $11.11 \%$ & $11.11 \%$ & $11.11 \%$ \\
\hline tFd & $0.00 \%$ & $0.00 \%$ & $14.06 \%$ & $13.98 \%$ & $12.35 \%$ & $12.48 \%$ & $12.50 \%$ \\
\hline ti+tf & $10.00 \%$ & $25.00 \%$ & $26.56 \%$ & $25.78 \%$ & $23.46 \%$ & $24.83 \%$ & $25.00 \%$ \\
\hline gi & 0.050 & 0.044 & 0.044 & 0.042 & 0.040 & 0.044 & 0.044 \\
\hline gF & 0.050 & 0.044 & 0.049 & 0.049 & 0.044 & 0.044 & 0.044 \\
\hline gi+gf & 0.100 & 0.089 & 0.093 & 0.091 & 0.084 & 0.088 & 0.089 \\
\hline U & -1.013 & -1.019 & -1.019 & -1.019 & -1.019 & -1.019 & -1.019 \\
\hline
\end{tabular}

Adicionalmente, la introducción de la mencionada sobretasa reduce el gasto público de los estados, generando una disminución en el gasto total agregado de ambos niveles jurisdiccionales; el aumento en el número de estados y el consecuente incremento en los niveles de gasto público no alcanza a compensar la caída inicial en los niveles de gasto.

\section{Gráfico 2}

Evolución de las tasas impositivas para distintas alternativas y valor del parámetro de deducción=-1

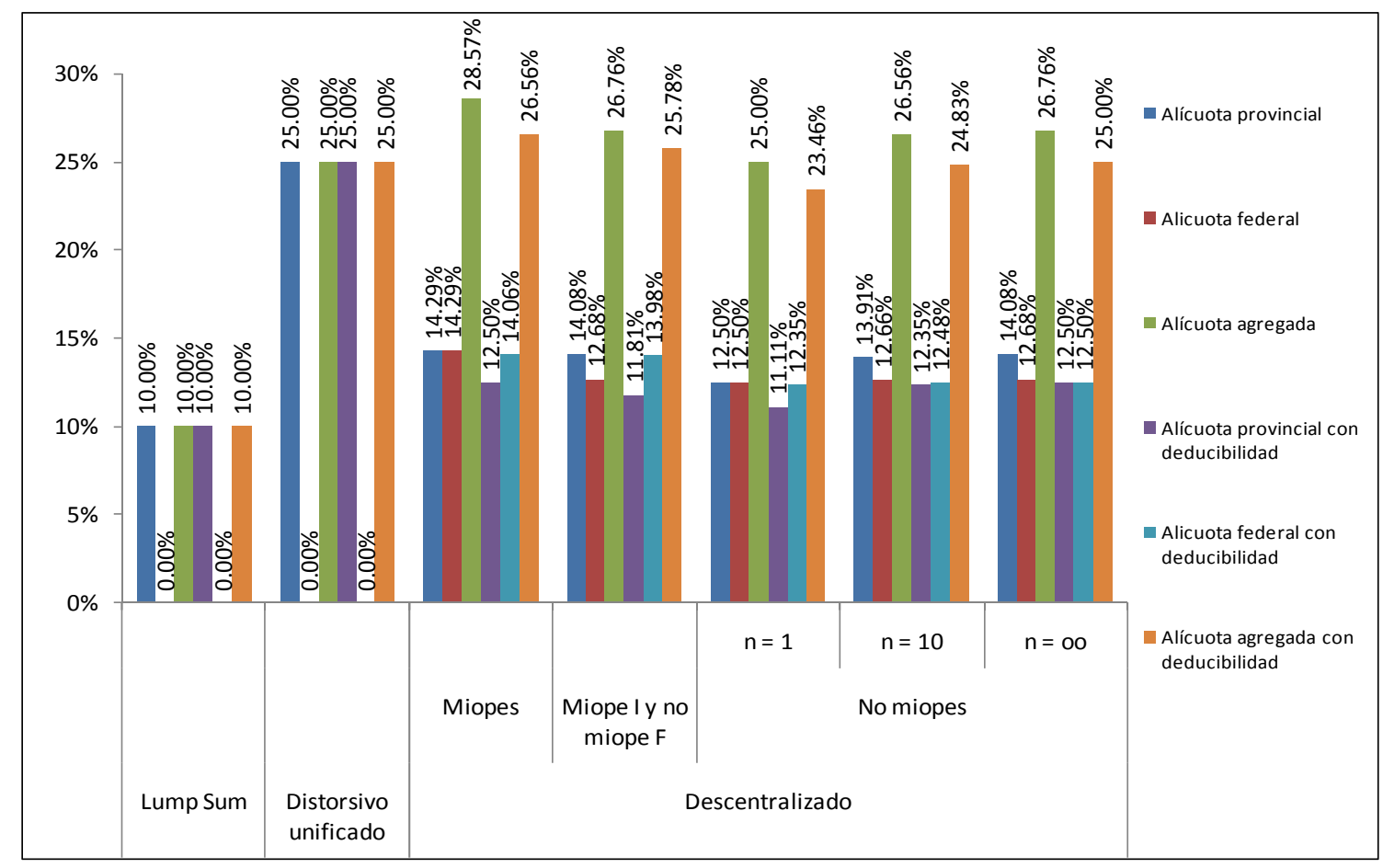




\section{Gráfico 3}

Evolución de los niveles de gasto público para distintas alternativas y valor del parámetro de deducción=-1

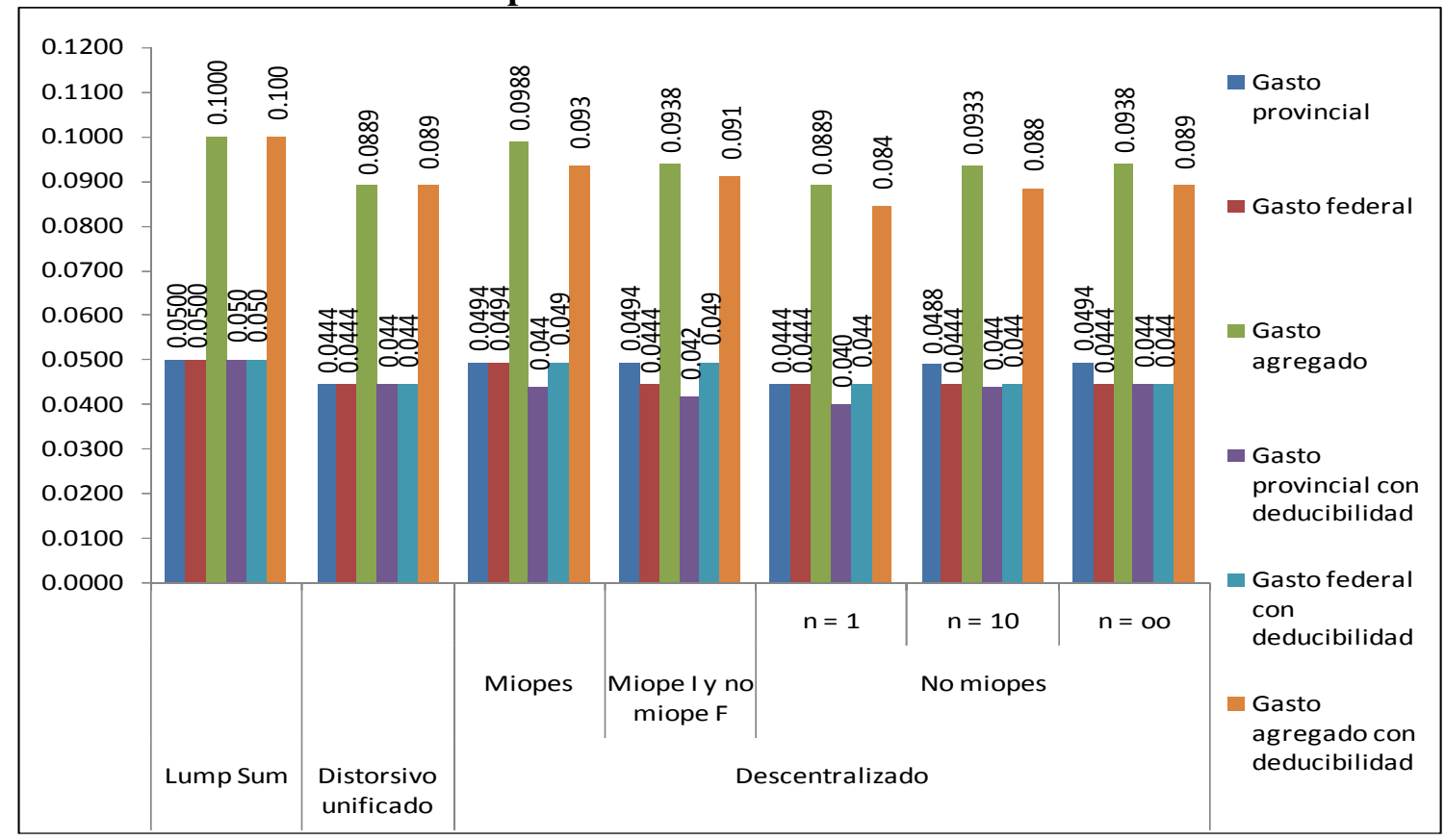

La introducción de una tasa positiva al impuesto provincial, que genere una disminución en la tasa efectiva del gobierno federal, incrementa el gasto agregado a través de aumentar la tasa efectiva de los gobiernos subnacionales y el aumento en el nivel de gasto de éstos, a costa de una disminución del gasto propio y la recaudación impositiva (cuadros 2 y 3, gráficos 4 a 7).

En los cuadros y gráficos subsiguientes puede apreciarse que este efecto es creciente a mayor valor del parámetro de deducibilidad, cuando éste es igual a 2 se aprecian niveles de gastos públicos y tasas impositivas mayores que al considerar valores iguales a 1 .

Cuadro 2

Síntesis de resultados caso de valor del parámetro de deducción=1

\begin{tabular}{|c|c|c|c|c|c|c|c|}
\hline & \multicolumn{2}{|c|}{ Centralizado } & \multirow{2}{*}{\multicolumn{5}{|c|}{$\frac{\text { Descentralizado Distorsivo }}{\text { Deducibilidad }}$}} \\
\hline & \multirow[b]{2}{*}{ Lump Sum } & \multirow[b]{2}{*}{$\begin{array}{l}\text { Distorsivo } \\
\text { unificado }\end{array}$} & & & & & \\
\hline & & & Miope & $\begin{array}{l}\text { Miope I y no } \\
\text { miope F }\end{array}$ & \multicolumn{3}{|c|}{ No miopes } \\
\hline \begin{tabular}{|l} 
Estados \\
Deducibilidad
\end{tabular} & $\begin{array}{l}1 \\
1\end{array}$ & $\begin{array}{l}1 \\
1\end{array}$ & $\begin{array}{l}1 \\
1\end{array}$ & $\begin{array}{l}1 \\
1\end{array}$ & $\begin{array}{l}1 \\
1\end{array}$ & $\begin{array}{c}10 \\
1\end{array}$ & $\begin{array}{c}10000000 \\
1\end{array}$ \\
\hline $\mathbf{x}$ & 0.400 & 0.356 & 0.335 & 0.362 & 0.348 & 0.342 & 0.341 \\
\hline I & 0.500 & 0.556 & 0.556 & 0.556 & 0.556 & 0.556 & 0.556 \\
\hline ti & $10.00 \%$ & $25.00 \%$ & $17.98 \%$ & $15.05 \%$ & $15.05 \%$ & $16.92 \%$ & $17.16 \%$ \\
\hline $\mathrm{tF}$ & $0.00 \%$ & $0.00 \%$ & $17.98 \%$ & $9.25 \%$ & $15.05 \%$ & $15.64 \%$ & $15.72 \%$ \\
\hline$t F d$ & $0.00 \%$ & $0.00 \%$ & $14.75 \%$ & $7.86 \%$ & $12.78 \%$ & $12.99 \%$ & $13.02 \%$ \\
\hline$t i+t f$ & $10.00 \%$ & $25.00 \%$ & $32.73 \%$ & $22.90 \%$ & $27.83 \%$ & $29.91 \%$ & $30.18 \%$ \\
\hline gi & 0.050 & 0.044 & 0.060 & 0.054 & 0.052 & 0.058 & 0.059 \\
\hline gF & 0.050 & 0.044 & 0.049 & 0.028 & 0.044 & 0.044 & 0.044 \\
\hline gi+gf & 0.100 & 0.089 & 0.110 & 0.083 & 0.097 & 0.102 & 0.103 \\
\hline U & -1.013 & -1.019 & -1.022 & -1.024 & -1.020 & -1.021 & -1.021 \\
\hline
\end{tabular}




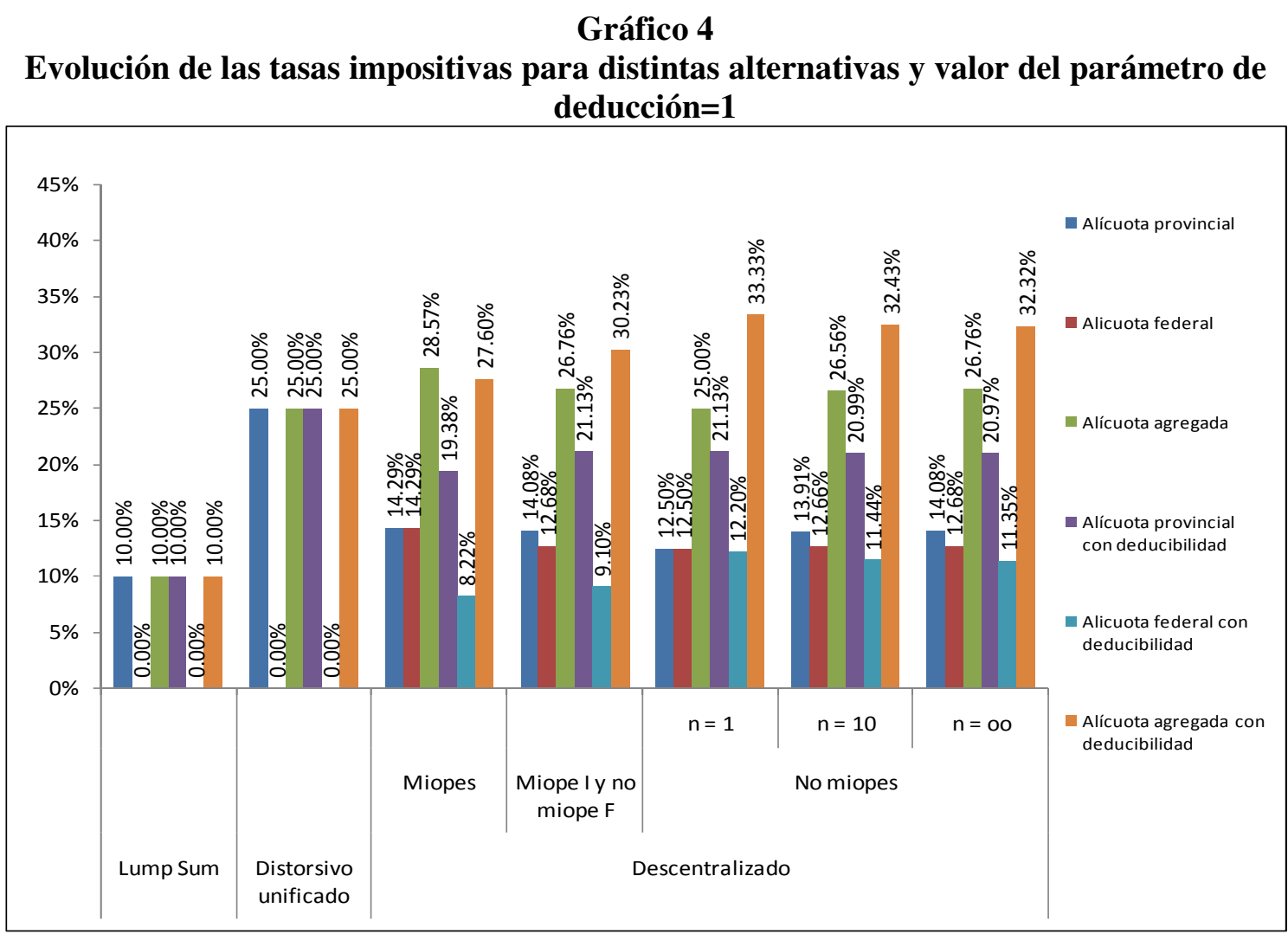

\section{Gráfico 5}

Evolución de los niveles de gasto público para distintas alternativas y valor del parámetro de deducción=1

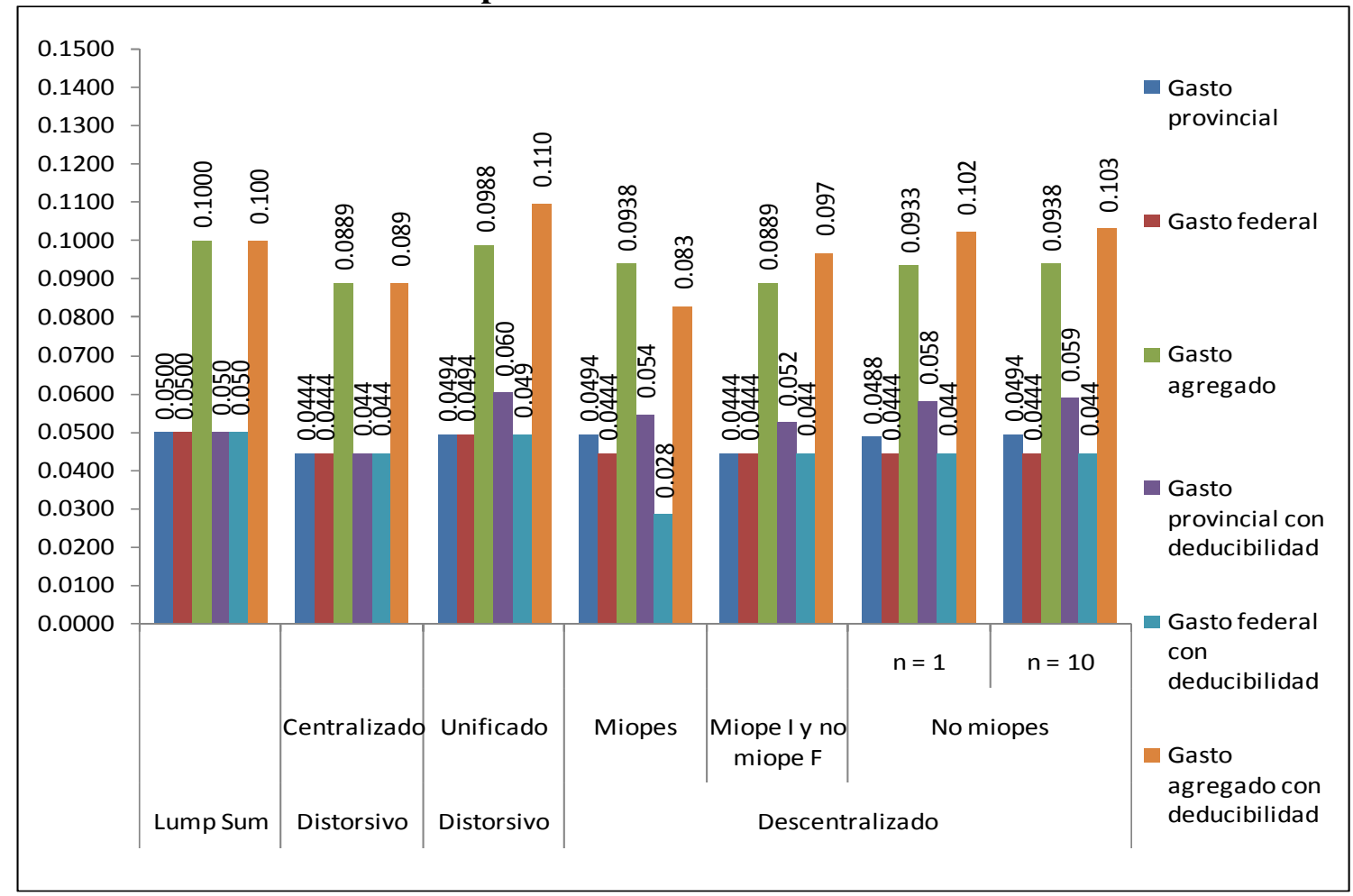




\section{Cuadro 3}

Síntesis de resultados caso de no deducción y valor del parámetro de deducción=2

\begin{tabular}{|c|c|c|c|c|c|c|c|}
\hline & \multicolumn{2}{|c|}{ Centralizado } & \multirow{2}{*}{\multicolumn{5}{|c|}{$\frac{\text { Descentralizado Distorsivo }}{\text { Deducibilidad }}$}} \\
\hline & \multirow[b]{2}{*}{ Lump Sum } & \multirow{2}{*}{$\begin{array}{l}\text { Distorsivo } \\
\text { unificado }\end{array}$} & & & & & \\
\hline & & & Miope & $\begin{array}{c}\text { Miope I y no } \\
\text { miope F }\end{array}$ & \multicolumn{3}{|c|}{ No miopes } \\
\hline \begin{tabular}{|l} 
Estados \\
Deducibilidad
\end{tabular} & $\begin{array}{l}1 \\
2\end{array}$ & $\begin{array}{l}1 \\
2\end{array}$ & $\begin{array}{l}0 \\
2\end{array}$ & $\begin{array}{l}1 \\
2\end{array}$ & $\begin{array}{l}1 \\
2\end{array}$ & $\begin{array}{c}10 \\
2\end{array}$ & $\begin{array}{c}10000000 \\
2\end{array}$ \\
\hline $\mathbf{x}$ & 0.400 & 0.356 & 0.348 & 0.341 & 0.333 & 0.336 & 0.336 \\
\hline I & 0.500 & 0.556 & 0.556 & 0.556 & 0.556 & 0.556 & 0.556 \\
\hline ti & $10.00 \%$ & $25.00 \%$ & $19.38 \%$ & $21.13 \%$ & $21.13 \%$ & $20.99 \%$ & $20.97 \%$ \\
\hline$t F$ & $0.00 \%$ & $0.00 \%$ & $13.42 \%$ & $15.76 \%$ & $21.13 \%$ & $19.72 \%$ & $19.55 \%$ \\
\hline tFd & $0.00 \%$ & $0.00 \%$ & $8.22 \%$ & $9.10 \%$ & $12.20 \%$ & $11.44 \%$ & $11.35 \%$ \\
\hline$t i+t f$ & $10.00 \%$ & $25.00 \%$ & $27.60 \%$ & $30.23 \%$ & $33.33 \%$ & $32.43 \%$ & $32.32 \%$ \\
\hline gi & 0.050 & 0.044 & 0.068 & 0.072 & 0.070 & 0.070 & 0.070 \\
\hline gF & 0.050 & 0.044 & 0.029 & 0.031 & 0.041 & 0.038 & 0.038 \\
\hline gi+gf & 0.100 & 0.089 & 0.096 & 0.103 & 0.111 & 0.109 & 0.109 \\
\hline $\mathbf{U}$ & -1.013 & -1.019 & -1.028 & -1.029 & -1.026 & -1.026 & -1.026 \\
\hline
\end{tabular}

\section{Gráfico 6}

Evolución de las tasas impositivas para distintas alternativas y valor del parámetro de deducción $=2$

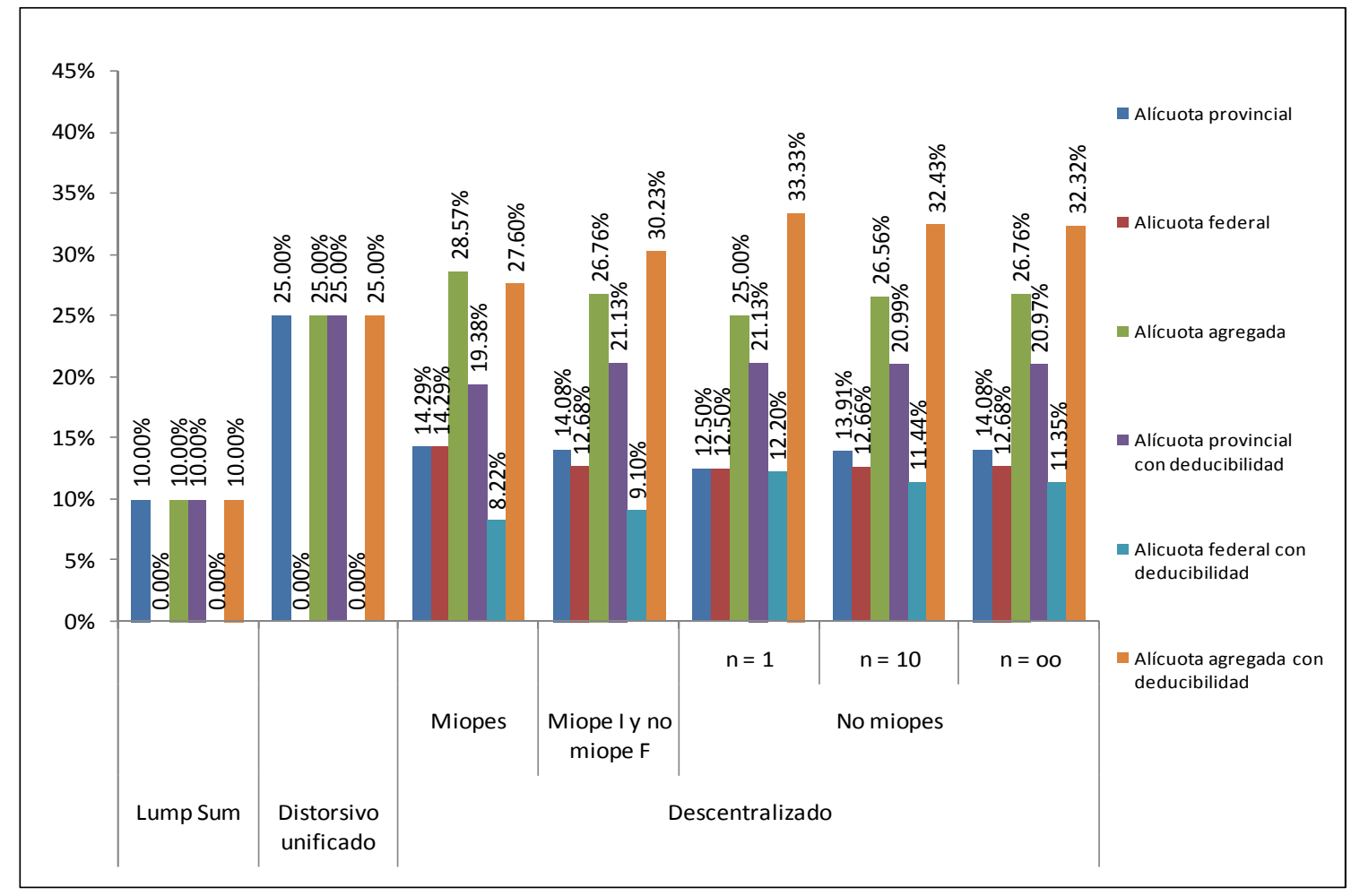




\section{Gráfico 7}

Evolución de los niveles de gasto público para distintas alternativas y valor del parámetro de deducción $=2$

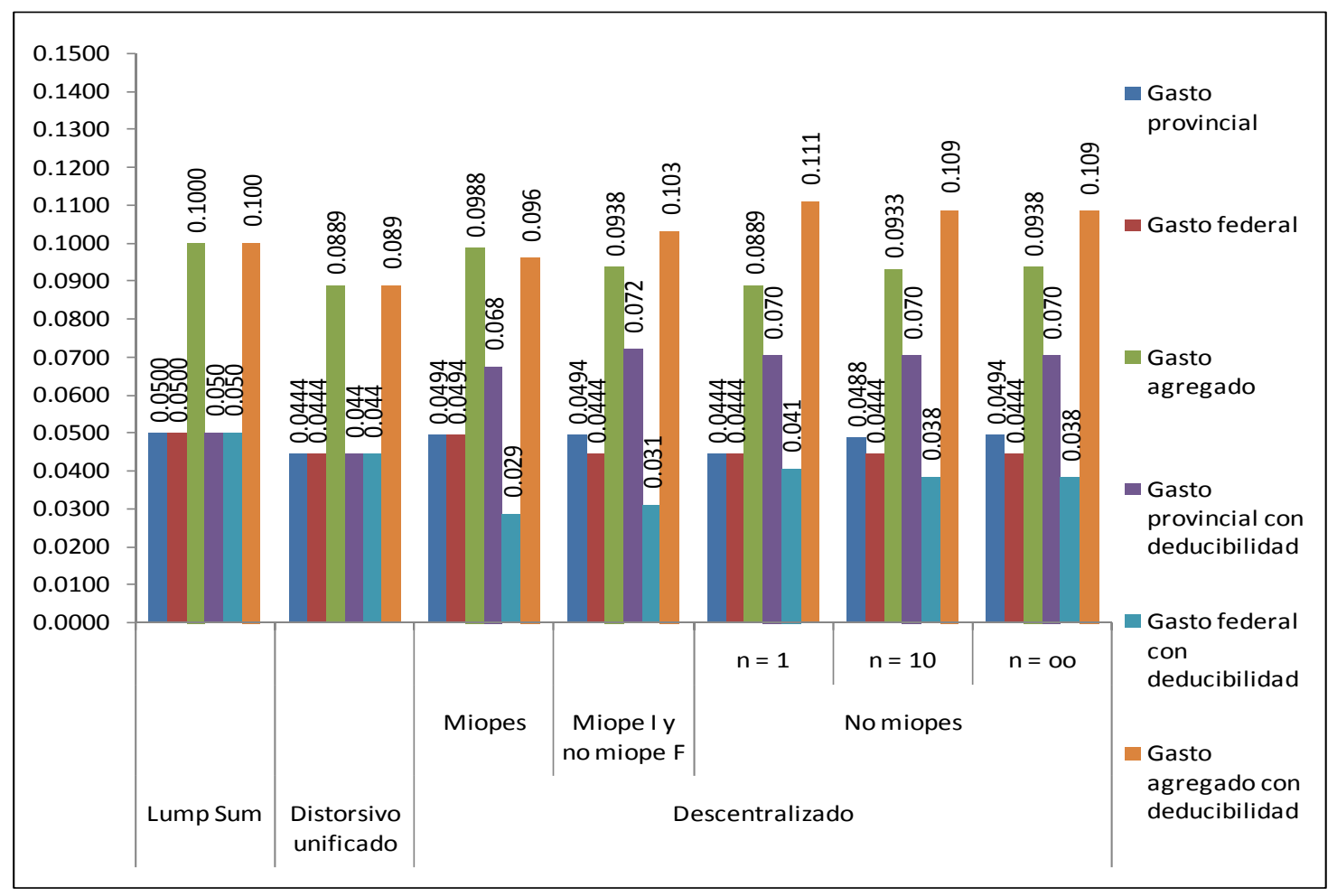

Gráfico 8

Evolución de los niveles de bienestar para distintas alternativas y valores del parámetro de deducción

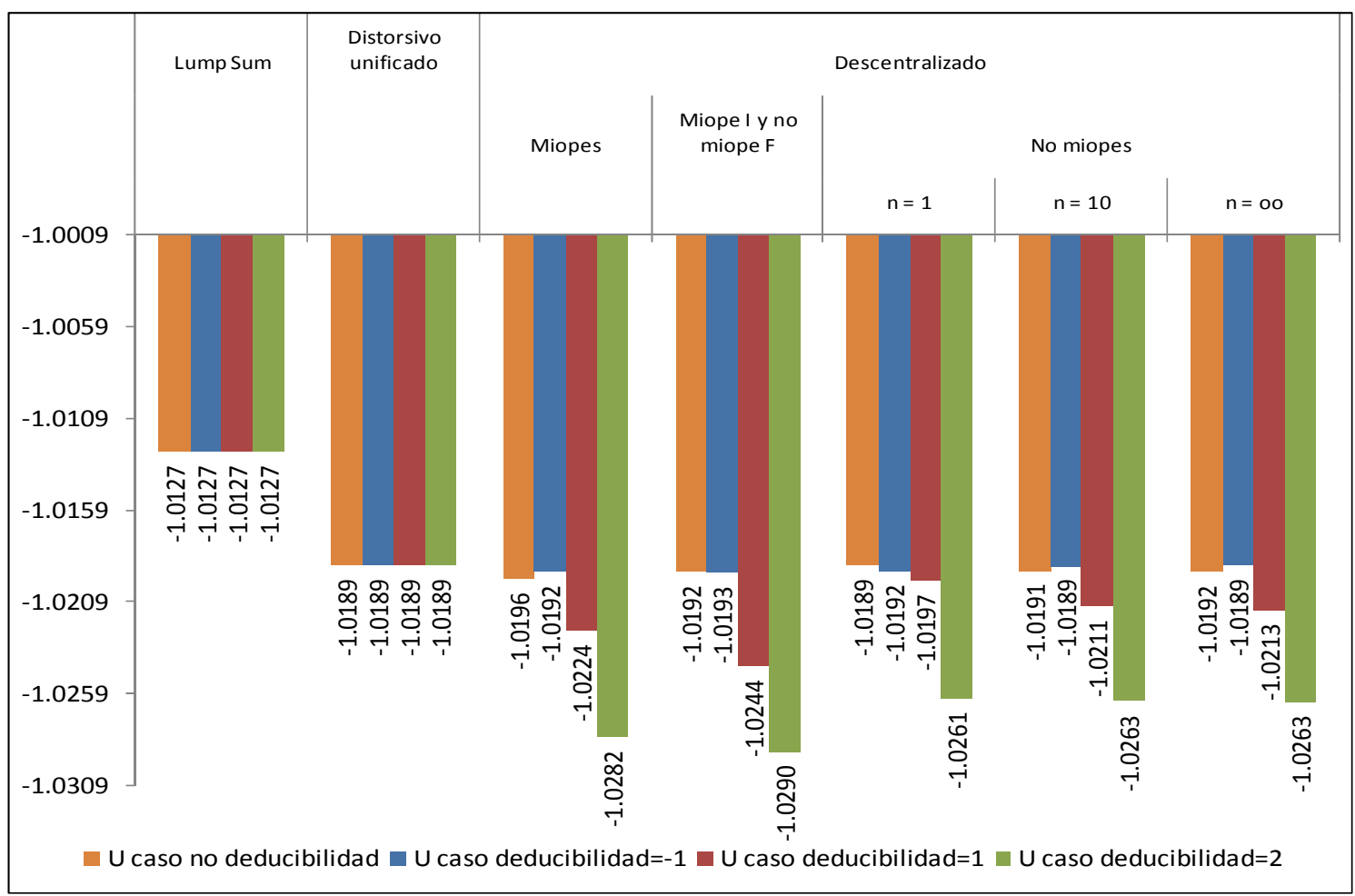


En última instancia se presenta (gráfico 8) la evolución de los niveles de bienestar, en base a los cuadros anteriores, tanto para el caso de no deducción como para los distintos valores de los parámetros de deducción. Allí puede apreciarse que el bienestar decrece a mayor cantidad de estados, y a mayores valores del parámetro de deducibilidad, con lo cual, cuando el valor de éste es de -1 (sobretasa), hay un trade off entre la disminución del bienestar por el aumento de la cantidad de estados y el incremento del mismo debido a la sobretasa que reduce la tasa impositiva agregada.

\section{Conclusiones}

Las externalidades tributarias verticales entre jurisdicciones de distinto nivel surgen a partir de la existencia del solapamiento de las bases tributarias, es decir, de la existencia de concurrencia en las fuentes de imposición.

A partir del análisis del modelo de externalidades tributarias verticales en impuestos sobre los consumos, el efecto de las mismas generaba niveles excesivamente elevados de gastos públicos y de tasas impositivas, considerando ambos niveles de gobierno.

Adicionalmente a lo anterior, el hecho de que ambos niveles de gobierno percibieran de manera diferente al impacto que sus decisiones de política impositiva tienen sobre el otro nivel hace que se generen niveles de gasto público y tasas impositivas diferentes para ambos estratos de gobierno. El resultado general (con $n$, la cantidad de estados, mayor que uno) es que el gobierno provincial genera niveles de gasto y de tasas impositivas más elevado que el gobierno federal.

Una de las posibles alternativas de política tributaria a las que puede apelar el gobierno federal, dado que se asume que su interés radica en el óptimo social global, es la deducción del impuesto subnacional de gobierno. Los mecanismos de deducción de impuestos entre gobiernos de distinto nivel jurisdiccional generan dos efectos: un efecto indirecto dado por la reducción en la recaudación del otro nivel cuando uno de los dos aumenta la alícuota tributaria, y el otro directo, dado por el cambio en la magnitud de impuesto deducible. Se analizan el mecanismo de deducción en el precio; el mismo se relaciona con la base imponible sobre la que se calcula el impuesto (si incluye o no al impuesto de la otra jurisdicción).

El rol del gobierno federal es, dado que tiene en cuenta el óptimo social global, el de minimizar la toma de decisiones erróneas por parte de los gobiernos subnacionales al colocar sus alícuotas teniendo en cuenta solamente al costo marginal de los fondos públicos que 
pueden apreciar, y que difiere del social al llevarles a generar niveles de gasto demasiado elevados.

A partir del análisis realizado, surge, de nuevo en función de los distintos supuestos sobre la función objetivo de cada gobierno, que el gobierno nacional podría aplicar la deducción de impuestos para aproximarse en mayor medida al óptimo social global.

Los valores óptimos colocados por el gobierno federal, para minimizar el efecto de la externalidad, son negativos, implicando la colocación de sobretasas al impuesto subnacional. 


\section{Capítulo 4. Una estimación empírica sobre externalidades verticales en impuestos sobre los consumos en Argentina}

\section{Introducción}

El efecto que generan las externalidades verticales, a partir de gravar la misma fuente de imposición por parte de diferentes niveles de gobierno (financiación concurrente), puede evaluarse desde dos puntos de vista.

En primer lugar, el objetivo es establecer si la alícuota tributaria resultante es óptima o no en función de los bienes públicos que deben proveerse si se pretende maximizar la utilidad social, y en segundo, cuál es la reacción de uno de los niveles de gobierno cuando el otro incrementa su presión tributaria.

Este trabajo se encuentra en la segunda de las alternativas. Siguiendo a los trabajos de Esteller-Moré y Solé-Ollé para Canadá y Estados Unidos (1999 y 2001), Keen (1998), Devereux et al (2007), y Esteller Moré y Rizzo (2011), el propósito es el de sugerir una metodología de análisis empírico con el fin de establecer el grado de reacción de la política impositiva provincial ante un incremento del impuesto nacional que grava la misma base, aunque de una manera ligeramente diferente, que las provincias.

El objeto del análisis será el caso de Argentina, donde conviven dos impuestos generales que afectan a los consumos: el Impuesto al Valor Agregado, de orden nacional, y el Impuesto sobre los Ingresos Brutos, de índole provincial, los que gravan la misma base imponible.

A partir del análisis de la política tributaria llevada a cabo por el gobierno federal y las provincias, en Argentina puede apreciarse un incremento constante de la presión tributaria en general, y de los impuestos sobre los consumos, en particular, en los últimos 20 años. Esto es particularmente relevante para el caso de las provincias, las cuales, después de haber estado inmersas en un proceso de disminución de alícuotas del impuesto sobre los Ingresos Brutos acordada en el Pacto Fiscal de principios de la década de 1990, comenzaron a embarcarse en una reversión ligera de ese proceso a partir de principios de la década de 2000, para luego, hacia fines de esa década, intensificar los incrementos de alícuotas del impuesto.

El propósito de este capítulo es el de evaluar si este proceso llevado a cabo por las provincias puede asociarse a un fenómeno de externalidad vertical, en donde el gobierno federal, a partir del incremento en la carga tributaria, medida de la manera que se explicitará más adelante, esté generando una reacción de las variables tributarias provinciales. 
A diferencia de otros trabajos, en éste se procura desarrollar una metodología que presente diversas variables que aproximen en forma más acabada a la política tributaria de cada nivel jurisdiccional, dado que la existencia de exenciones y alícuotas diferenciales pueden hacer que la tasa nominal no resulte ser la variable de mayor interés.

Otra diferencia con los trabajos existentes en la materia es que, en los antecedentes internacionales, las estimaciones se realizan considerando impuestos específicos sobre consumos (gasolina, cigarrillos), mientras que aquí se procura encontrar una medición que convierta un impuesto general en impuesto específico sobre bienes, para lo cual se construye la variable de "tasa efectiva sobre cadena agroindustrial"

El presente capítulo se configura como sigue: en la sección 2 se resumen algunos de los antecedentes empíricos sobre la temática, mientras que en la tercera se plantean los aspectos normativos referidos al régimen rentístico argentino en función del establecimiento de potestades tributarias, y un somero análisis normativo y cuantitativo de los tributos considerados para el estudio, a saber, el Impuesto al Valor agregado y el Impuesto sobre los ingresos brutos.

La sección 4 especifica el modelo teórico de las externalidades tributarias verticales; entretanto, en la sección 5 se especifica la metodología de estimación, mientras que en la sección 6 se presentan los resultados. En la sección 7 se sintetizan los resultados y en la sección 8 se exponen las conclusiones.

\section{Antecedentes de estudios sobre la temática}

La mayoría de las estimaciones realizadas para los trabajos internacionales, en las que el objetivo es el de estimar la pendiente de la función de reacción del gobierno provincial, se basan en general para los casos de los impuestos específicos sobre consumos de cigarrillos y gasolina en Estados Unidos, y del impuesto a la Renta de Estados Unidos y Canadá. En el cuadro 1 se presentan los resultados, en forma sintética, de los estudios.

Besley y Rosen (1998) estiman la reacción de los impuestos estaduales específicos a los cigarrillos y a la gasolina en Estados Unidos para el período 1975-1989. Como resultado de las estimaciones obtienen una respuesta positiva de los impuestos estaduales ante un incremento de los impuestos específicos nacionales; en el caso de los cigarrillos, un $10 \%$ de aumento en la tasa federal induce un 2,8\% de aumento en la tasa del estado; para la gasolina, un $10 \%$ de aumento en la tasa federal induce un $4,1 \%$ de aumento en la tasa del estado. 
Esteller-Moré y Solé-Ollé (2001), para el caso del impuesto personal a la renta nacional y los impuestos generales a las ventas estaduales en Estados Unidos en el período 1987-1996 eligen como variable dependiente a los impuestos estaduales dado que al existir múltiples estados, el gobierno federal no reacciona ante la variación en la alícuota de impuestos de uno de ellos, sino probablemente de una suma ponderada de ellos, lo que, según plantean los autores, elimina la posible endogeneidad de la tasa federal. Los resultados empíricos muestran que un punto de incremento en los impuestos federales generan una reacción de 0.1 puntos en el impuesto estadual a la renta, y de 0.22 al considerar impuesto a la renta y a las ventas en forma conjunta.

\section{Cuadro 1}

Síntesis de estudios teóricos y empíricos sobre externalidades tributarias verticales

\begin{tabular}{|c|c|c|}
\hline Autores & Impuestos considerados & Resultados \\
\hline $\begin{array}{l}\text { Besley, T.J. y Rosen, H.S. } \\
\text { (1998): Journal of Public } \\
\text { Economics }\end{array}$ & $\begin{array}{l}\text { Gasolina y cigarrillos en } \\
\text { Estados Unidos 1975-1989 }\end{array}$ & $+($ significativo $)$ \\
\hline $\begin{array}{l}\text { Esteller-Moré A. y Solé- } \\
\text { Ollé, A. (2001), Regional } \\
\text { Science and Urban } \\
\text { Economics }\end{array}$ & $\begin{array}{l}\text { Impuestos a las ganancias } \\
\text { personales y generales a } \\
\text { los consumos en Estados } \\
\text { Unidos } 1987-1996\end{array}$ & + (significativo) \\
\hline $\begin{array}{l}\text { Esteller-Moré, A. y Solé- } \\
\text { Ollé, A (2002), } \\
\text { International Tax and } \\
\text { Public Finance }\end{array}$ & $\begin{array}{l}\text { Impuestos a las ganancias } \\
\text { personales en Canadá } \\
\text { 1982-1996 }\end{array}$ & $+($ significativo $)$ \\
\hline $\begin{array}{l}\text { Boadway, R. y M. Hayashi } \\
\text { (2002), Canadian Journal } \\
\text { of Economics }\end{array}$ & $\begin{array}{l}\text { Impuestos a las ganancias } \\
\text { de sociedades en Canadá } \\
1963-1996\end{array}$ & - (significativo) \\
\hline $\begin{array}{l}\text { Devereux, M.P., } \\
\text { Lockwood B. y Redoano } \\
\text { M. (2007), Journal of } \\
\text { Public Economics }\end{array}$ & $\begin{array}{l}\text { Gasolina y cigarrillos en } \\
\text { Estados Unidos 1977-1997 }\end{array}$ & $\begin{array}{l}+ \text { (no significativo) sin competencia } \\
\text { horizontal } \\
+(\text { no significativo }) \text { con competencia } \\
\text { horizontal }\end{array}$ \\
\hline $\begin{array}{l}\text { Fredriksson y Mamun } \\
\text { (2008) Journal of Urban } \\
\text { Economics }\end{array}$ & $\begin{array}{l}\text { Cigarrillos en Estados } \\
\text { Unidos 1975-2001 }\end{array}$ & + (no significativo) \\
\hline $\begin{array}{l}\text { Esteller Moré A. y Rizzo, } \\
\text { L. (2011): National Tax } \\
\text { Journal }\end{array}$ & $\begin{array}{l}\text { Gasolina y cigarrillos en } \\
\text { Estados Unidos 1975-2006 }\end{array}$ & + (no significativo) \\
\hline
\end{tabular}

Fuente: elaboración propia

Devereux (2007) realiza sus estimaciones para el caso de los impuestos específicos sobre cigarrillos y gasolina para Estados Unidos en el período 1977-1997. En relación con el trabajo de Besley y Rosen (1998), encuentran que aquél no incluía las externalidades horizontales en su análisis e incluyen en sus estimaciones variables para considerar el efecto de las mismas.

Los resultados para el caso de los cigarrillos concuerdan con la teoría; dado que la demanda de cigarrillos es relativamente inelástica, un aumento en la tasa federal no tiene efectos significativos en la respuesta de los gobiernos estaduales. En el caso de la gasolina, el 
coeficiente asociado a la tasa federal es significativo, no siéndolo el de las tasas de los otros estados, con lo cual la evidencia asociada a la externalidad horizontal es reducida.

Esteller Moré y Rizzo (2011), para el caso de gasolina y cigarrillos en Estados Unidos en1975-2006 intentan identificar la variación de la tasa federal de ambos impuestos a partir de deflactarla por índices de precios regionales, encontrando reacciones negativas y no significativas en ambos tributos por parte de los gobiernos subnacionales.

Como puede apreciarse en el cuadro, los resultados de las estimaciones son muy sensibles a las metodologías de cálculo empleadas y al universo de información utilizado, no existiendo evidencia concluyente sobre el impacto de los impuestos federales sobre la política tributaria subnacional. Adicionalmente, no existen antecedentes sobre estudios realizados en impuestos generales sobre los consumos, sino que los mismos se relacionan con impuestos específicos, tomando como única variable de análisis la alícuota nominal. En este trabajo se procurará analizar el impacto de impuestos generales sobre consumos, utilizando diferentes definiciones, sobre la variable de decisión tributaria, de los gobiernos nacional y provinciales.

\section{Marco normativo y cuantitativo}

El régimen rentístico de la República Argentina ha sido reglado por la Constitución Nacional, que establece la asignación de potestades tributarias entre la Nación y las Provincias. En este sentido la Ley fundamental dispone:

a) Exclusividad federal en la imposición del comercio exterior

b) Concurrencia de la Nación con las Provincias en la imposición indirecta

c) Facultad por tiempo determinado y en condiciones especiales de la Nación para aplicar imposición directa.

d) Potestad de las Provincias de aplicar imposición directa, sin restricciones.

De lo expuesto se puede colegir que, salvo en materia de tributos que recaigan sobre el comercio exterior, las potestades tributarias de las Provincias resultan más amplias que las de la Nación, no limitando la Constitución Nacional la posibilidad de concurrencia en las fuentes de imposición más allá del caso de los tributos que recaen sobre el comercio exterior.

Se debe entender por concurrencia a la condición en que los distintos niveles de gobierno pueden o deben adoptar tributos iguales, que gravan iguales o similares manifestaciones de capacidad contributiva, mientras que por separación la restricción a que ello ocurra. 
El hecho que se apliquen tributos iguales o similares en los distintos niveles de gobierno, no merece necesariamente un juicio de valor negativo, siempre que se satisfagan determinadas condiciones que permitan que los mismos se ajusten a las reglas de equidad y eficiencia o neutralidad económica.

Una de ellas es que no se manifiesten problemas de "superposición institucional", entendidos como doble imposición distorsiva y discriminatoria, ni de "ausencia de imposición" que también resulta distorsiva y discriminatoria.

Dado que la concurrencia en las fuentes de imposición está definida para los tributos indirectos, en este trabajo se hará referencia al impuesto al Valor Agregado, de jurisdicción nacional, y el impuesto sobre los Ingresos Brutos, principal fuente de recaudación provincial. Ambos son tributos generales sobre los consumos, adicionándole al segundo la característica de afectar la producción por ser un tributo en cascada. A continuación se efectuará un resumido análisis de ambos impuestos.

\subsection{Impuesto al Valor Agregado}

\subsubsection{Síntesis normativa}

El IVA es un impuesto nacional, recaudado en cada jurisdicción provincial, siendo su recaudación transferida a la Nación. El impuesto grava el consumo como resultado de un mecanismo de imposición que actúa en todas las etapas de producción y distribución de bienes y servicios. No es acumulativo y adopta el sistema llamado de "impuesto contra impuesto", en que se confrontan débitos fiscales (por las ventas) y créditos fiscales (por las compras), pagándose mensualmente los saldos entre ambos. Este procedimiento equivale a aplicar el impuesto sobre el valor agregado en cada etapa de elaboración. Grava las importaciones en la misma forma que la producción interna y, en cambio, exime a las exportaciones.

Las exenciones son relativamente numerosas, aunque muchas de ellas tienden a ser eliminadas en las últimas reformas. Por ejemplo, entre las que tenían sensible peso en 1997 desde el punto de vista recaudatorio, deben citarse: el transporte de pasajeros en cualquiera de sus formas, los productos medicinales, la educación, la edición de diarios, revistas y libros.

Dentro de los hechos gravados, prevalece la tasa general de $21 \%$. Las excepciones están constituidas por los casos gravados con tasas del $27 \%$, del 31,5\% y de 10,50\%. El $27 \%$ corresponde esencialmente a la facturación de servicios públicos prestados a empresas que 
son responsables del impuesto (no así las prestaciones domiciliarias a no responsables del impuesto, que pagan la tasa general).

\subsubsection{Evolución histórica}

Argentina implanta el impuesto al Valor Agregado a partir de 1975, con una alícuota general del $13 \%$ y una tasa diferencial para determinados bienes del $21 \%$. Inicialmente el IVA se aplicó como un impuesto general a los consumos sobre bienes, y selectivo sobre algunos servicios. Este concepto se fue modificando a lo largo de los años, eliminándose la casi totalidad de los bienes exentos y generalizándose a la mayor parte de los servicios.

La tendencia en el diseño de este tributo ha sido dominada por sucesivas reformas tendientes a la generalización en su base y aumento de sus alícuotas, lo que ha permitido un importante aumento en su recaudación, tanto en términos absolutos como en relación con los restantes tributos. El nivel de alícuota general se ubica desde el año 1995 en el 21\%, habiendo crecido un $62 \%$ desde 1990.

La evolución de la alícuota general puede apreciarse en el gráfico 1, en donde para el cálculo de las tasas anuales se han promediado proporcionalmente las tasas vigentes en cada período mensual.

En términos de legislación histórica, una de las primeras reformas de importancia fue la reforma de 1986, que sustituyó el texto de la ley del gravamen, aplicando modificaciones sustanciales, como ser la unificación de la tasa general al 18\% para bienes y al $9 \%$ para obras y trabajos sobre inmuebles, la exención para los bienes que antes estaban alcanzados con la alícuota del 5\%, la incorporación en el régimen de imposición selectiva a los bienes y servicios que antes estaban gravados a la tasa del 25\%, la aplicación de un régimen simplificado para los pequeños contribuyentes y la adopción de una serie de medidas tendientes a mejorar la fiscalización y evitar las prácticas elusivas del gravamen.

Una diferencia fundamental en los efectos de este gravamen debe ser puesta de relieve. La misma se refiere a la amplitud de la base imponible del tributo que, según la reforma de 1986, excluye a prácticamente la totalidad de los bienes producidos por el sector agropecuario, así como a los insumos del mismo, a los productos de la industria farmacéutica y a los materiales e insumos de la construcción. 


\section{Gráfico 1}

\section{Evolución de la alícuota general del IVA \\ Promedios anuales}

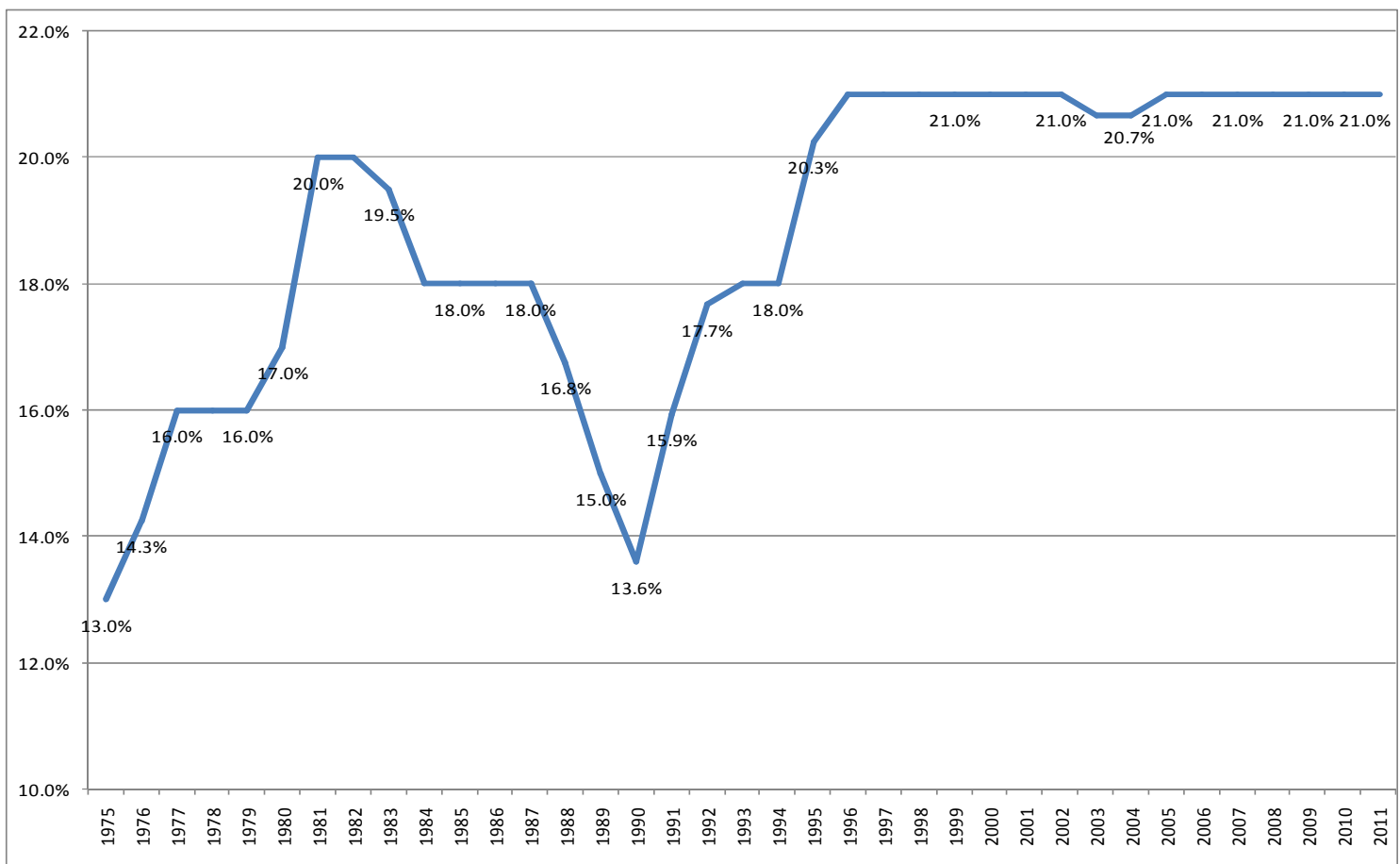

Fuente: elaboración propia en base a legislación

Estas exenciones fueron prácticamente eliminadas en su totalidad a partir de 1990 buscando generalizar la base del tributo a fin de darle al mismo un sesgo más neutral, aunque sin meditar en las consecuencias que el mismo tendría desde el punto de vista distributivo.

En febrero de 1990 se amplía la base de imposición del IVA, incorporándose la mayor parte de los bienes y muchos de los servicios que hasta ese momento se encontraban exentos. Se reduce asimismo la alícuota del tributo del 15\% al 13\%, decisión que se revierte poco tiempo después elevándola primero al 15,60\%, luego al 16\% y después al 18\%. Finalmente se incrementa al $21 \%$ en 1996.

También se modifica el régimen aplicado a los pequeños contribuyentes, estableciéndose nuevamente en 1990 la figura del responsable no inscripto que había estado vigente hasta 1986, cuando la misma se sustituye por un régimen especial de tratamiento simplificado al pequeño contribuyente. Posteriormente en 1998 se vuelve a establecer un sistema semejante, aunque ahora con la coexistencia del régimen de responsable no inscripto para el caso de algunos sujetos especiales.

En cuanto a la base, en 1992 se realizó una nueva reforma que fundamentalmente consistió en retomar el camino hacia la generalización del impuesto. Este proceso continuó en la misma 
dirección a través de sucesivas reformas, la última de las cuales fue efectuada en el año 2006 y consistió en la eliminación de casi todas las exenciones de bienes, quedando exceptuadas la leche fluida o en polvo, y las medicinas para uso humano. También en lo que se refiere a servicios se generalizó a todo tipo de prestaciones, excepto que se trate de las efectuadas por la Nación, provincias, municipalidades, establecimientos educacionales, prestaciones medicas a obras sociales y al PAMI, intereses de préstamos para vivienda, servicios educativos, bolsas de comercio; las efectuadas por bancos y demás entidades financieras; operaciones de seguro; asistencia médica a obras sociales; y espectáculos artísticos, culturales, deportivos y cinematográficos y las prestaciones personales en los mismos, entre los de mayor significación ${ }^{55}$.

Una de las últimas modificaciones de ese período lo constituyó la extensión del IVA al campo de los servicios financieros, transporte de carga, operaciones de seguros y reaseguros, quedando al margen del tributo sólo algunos servicios finales. Con la reforma de diciembre de 1998, se completó la imposición casi total del IVA sobre los servicios eliminándose la exención sobre los servicios de televisión por cable, servicios de medicina prepaga -el que está aún sujeto a discusión jurídica- publicidad, libros y folletos, incorporándose también una tasa diferencial del 10,5\% para las ventas del sector agropecuario.

A su vez el gravamen tiene una serie de tasas diferenciales que afectan a los bienes y servicios que en algunos casos reducen la tasa a la mitad de la tasa general (10,5\%). En 1997 sólo pagaba esa tasa la venta de viviendas residenciales nuevas, mientras que en 2004 se habían incluido, entre otros, como sujetas a la tasa reducida, carnes, frutas y verduras, pan (el cual se encontraba exento hasta noviembre del año 2006), galletas, facturas, galletitas y bizcochos elaborados con harina de trigo sin envasar, granos, fertilizantes, la medicina prepaga, los libros y material impreso similar (desde el año 2001) y el transporte de pasajeros de corta distancia, tal como se indica en el cuadro siguiente.

\footnotetext{
${ }^{55}$ Gómez Sabaini J. C. y Rossignolo D. (2009): “Argentina. Análisis de la situación tributaria y propuestas de reformas impositivas destinadas a mejorar la distribución del ingreso"
} 


\section{Cuadro 2}

Evolución de las alícuotas del IVA para productos seleccionados 2000-2006

\begin{tabular}{lccccccc}
\hline \multicolumn{1}{c}{ Concepto } & 2000 & 2001 & $2002^{1}$ & $2003^{1}$ & 2004 & 2005 & 2006 \\
\hline Tasa General & $21,0 \%$ & $21,0 \%$ & $21,0 \%$ & $21,0 \%$ & $21,0 \%$ & $21,0 \%$ & $21,0 \%$ \\
$\begin{array}{l}\text { Tasas Diferenciales } \\
\quad \text { Servicios Públicos }\end{array}$ & $27,0 \%$ & $27,0 \%$ & $27,0 \%$ & $27,0 \%$ & $27,0 \%$ & $27,0 \%$ & $27,0 \%$ \\
Transporte de pasajeros $^{2}$ & Exento & $10,5 \%$ & $10,5 \%$ & $10,5 \%$ & $10,5 \%$ & $10,5 \%$ & $10,5 \%$ \\
$\begin{array}{l}\text { Pan, galletas, facturas, } \\
\text { galletitas y bizcochos }\end{array}$ & $21,0 \%$ & $21,0 \%$ & $21,0 \%$ & $21,0 \%$ & $21,0 \%$ & $21,0 \%$ & $10,5 \%$ \\
Otros conceptos $^{4}$ & $10,5 \%$ & $10,5 \%$ & $10,5 \%$ & $10,5 \%$ & $10,5 \%$ & $10,5 \%$ & $10,5 \%$ \\
\hline Fue: & & & & & & &
\end{tabular}

Fuente: AFIP (2006) "Estimación del incumplimiento en el IVA

1/ El Decreto 2312/2002 redujo la alícuota para el período comprendido entre el 18 de noviembre de 2002 hasta el 17 de enero de 2003 , del $21 \%$ y $10,5 \%$ al $19 \%$ y $9,5 \%$, respectivamente.

2/ Terrestres, acuáticos o aéreos, cuando el recorrido no supere los $100 \mathrm{~km}$. Excluídos taxis y remises.

3/ Elaborados exclusivamente con harina de trigo y sin envasar

4/ Otros conceptos gravados al 10,5\% en el período analizado, como animales vivos, carnes, frutas, algunos intereses, medicina

prepaga, Transporte de Pasajeros cuando el recorrido supere los $100 \mathrm{Km}$, venta e importación de obras de arte, etc.

\subsection{Impuesto sobre los Ingresos Brutos Provinciales}

\subsubsection{Síntesis normativa}

Es un impuesto de gran importancia dentro de la recaudación, que actualmente aplican las veinticuatro provincias. Sus características económicas son conocidas: es plurietápico, por cuanto recae en todas las etapas de producción y distribución de bienes y servicios. Pertenece al tipo de tributos en cascada, en tanto grava el ingreso bruto sin deducción del impuesto ya pagado y acumulado sobre las compras ${ }^{56}$.

Por cuanto actúa hasta la venta final al consumidor, tiende a gravar relativamente más a los sectores de bajos recursos. Altera la neutralidad, pues fuerza la integración vertical de las empresas y discrimina en favor de las importaciones (que no arrastran impuestos sobre insumos). Al adoptar la forma de impuesto en etapa múltiple acumulativo, presenta grandes restricciones en la aplicación del criterio "país de destino", dado que exime las exportaciones pero no ajusta en frontera reintegrando el impuesto contenido en los precios hasta la etapa anterior

Formalmente, los Códigos Fiscales de cada provincia consagran los principios básicos del impuesto, pero sus alícuotas son fijadas por la Ley Impositiva anual. El impuesto grava el ejercicio habitual de toda actividad a título oneroso. La base imponible es la suma de ingresos brutos generados durante el período fiscal. En casos especiales se grava el ingreso neto (la

\footnotetext{
${ }^{56}$ La descripción normativa sigue a Santiere, J. J., Gómez Sabaini, J. C. y Rossignolo, Darío A. (2000)
} 
diferencia entre compra y venta), cuando el margen de comercialización es muy pequeño; tal el caso de los cigarrillos; otra excepción es la imposición de sumas fijas en función de unidades físicas u otra base. Para determinar el monto imponible se excluye del precio el débito fiscal del IVA y los impuestos internos que gravan la actividad o producto; las normas prevén exenciones subjetivas y objetivas.

Las tasas del impuesto siguen pautas similares en todo el país, a pesar de lo cual se percibe una variabilidad sensible de porcentajes como resultado de la cantidad de actividades y de jurisdicciones. En principio, las alícuotas se alineaban de mayor a menor en Comercio y Servicios, Industria y Sector Primario. A través de los Pactos Fiscales firmados entre la Nación y la Provincia durante la década de 1990, la actividad agropecuaria primero y la industria posteriormente, quedaron desgravadas en casi su totalidad. En el año 1997, por ejemplo, el Comercio mayorista y minorista pagaba entre $2.50 \%$ y 3\%; en los Servicios predominaba la tasa de 3.50\%; y en las escasas ramas gravadas en la actividad agropecuaria y extractiva, regía el 1\%, así como en los casos también excepcionales de la industria y la construcción se tributaba el $1.50 \%$.

Los problemas creados por los hechos imponibles que afectaron a más de una jurisdicción dentro de la misma empresa, fueron armonizados mediante el mecanismo del Convenio Multilateral. A través del mismo, se trató de evitar que dos o más jurisdicciones tuvieran derecho a gravar el mismo hecho imponible, desarrollándose un mecanismo por el cual se distribuye entre las distintas jurisdicciones involucradas el monto de impuesto pagado por el contribuyente.

\subsubsection{Evolución histórica}

El impuesto sobre los Ingresos Brutos aparece en la legislación argentina en 1948 en la Provincia de Buenos Aires, y más tarde se generaliza al resto de las provincias con el nombre de "Impuesto a las Actividades Lucrativas", nombre similar al que mantiene en algunas provincias (por ej., en Salta, como "Impuesto a las Actividades Económicas"). El mismo ha sido abundantemente analizado en los últimos años, como consecuencia del debate abierto acerca de sus deficiencias técnicas y de la necesidad de reemplazarlo por algún tipo de impuesto a las ventas u otras alternativas menos distorsionantes.

A fines de la década de 1970 y principios de 1980 se procuró llevar a cabo modificaciones que redujeran los efectos negativos del impuesto en cascada, lográndose una mayor homogeneidad interprovincial en la definición de hechos y bases imponibles, asegurando 
mayor uniformidad entre jurisdicciones en función de las alícuotas y alivianando el efecto cascada mediante la reducción de las alícuotas sobre sectores primarios.

Debido al relativo éxito alcanzado en las primeras cuestiones, y la falta del mismo en la última, los pactos fiscales de la década del 90 contenían el propósito de la reformulación del impuesto, procurando convertirlo en forma progresiva en uno que gravara las ventas finales. Este objetivo está aún por cumplirse, si bien se han realizado avances en la adecuación legislativa de las provincias, debido al notable peso de las actividades interjurisdiccionales.

Si se realiza un análisis del Impuesto sobre los Ingresos Brutos a partir de la década del 90, es necesario destacar dos períodos:

- El que se origina a partir del Pacto Federal por el Empleo, la Producción y el Crecimiento, firmado entre las máximas autoridades provinciales y el Gobierno Federal, el 12 de Agosto de 1993 (con excepción de la Ciudad Autónoma de Buenos Aires, por cuanto a esa fecha no detentaba el actual status jurídico, y de la Provincia de Córdoba, que lo suscribió tres años después), y fuera ratificado por el Congreso de la Nación por la Ley 24.307 de Presupuesto General para el ejercicio 1994.

- Y el que se origina a partir del año 2006, cuando se dispone prorrogar por el término de cinco años más los plazos establecidos por el Pacto de 1993.

El Pacto Federal tuvo como objetivo, entre otras disposiciones fiscales, modificar en principio, la estructura del Impuesto a los Ingresos Brutos, disponiendo la exención de numerosas actividades, excepto las que refieran a actividades destinadas a consumidores finales -permitiendo compensar la posible falta de ingresos por la eliminación de exenciones, desgravaciones y deducciones, con la adecuación de las alícuotas aplicables a todas las actividades no exentas- pretendiendo que en un plazo no mayor de tres años, a partir de la firma del convenio y una vez superado el período de transición, la imposición del Impuesto a los Ingresos Brutos, sea sustituida por un impuesto general al consumo.

A partir de allí el conjunto de provincias -fundamentalmente las provincias de Santa $\mathrm{Fe}$, Córdoba y Buenos Aires- comenzaron la desgravación paulatina y progresiva de las actividades requeridas, circunscribiéndose la base imponible de Ingresos Brutos a sólo las etapas mayorista y minorista.

Sin embargo, a partir de principios de la década de 2000 comienza a verificarse en algunas provincias una reversión de este proceso, particularmente evidenciado en la limitación de la exenciones a contribuyentes con sede en la provincia respectiva, o con eliminando las mismas 
a la construcción o a la industrias o actividades agropecuarias que vendieran sus productos al consumo final. A partir del año 2006 se advierte una reestructuración en este Impuesto, comenzando a gravarse actividades que estaban desgravadas, lo que es más marcado hacia fines de la mencionada década.

Respecto de la recaudación total, resalta la importancia de la Provincia de Buenos Aires, con más de un tercio del total producido por el impuesto; le sigue la Ciudad de Buenos Aires, y, muy distanciadas, el resto de las provincias.

En relación a los sectores fuente del tributo, se verifica una marcada importancia de "Comercio, restaurantes y hoteles", por estar gravado con una tasa relativamente alta, ya que la materia imponible es el total de sus ventas y no el valor agregado o sus ingresos netos, y porque muchos bienes transitan por dos etapas de distribución, mayorista y minorista. Los sectores primarios están apenas incididos por el impuesto debido a las exenciones que aún lo amparan progresivamente desde hace años. Las actividades manufactureras conservan algún peso, no obstante las sucesivas desgravaciones dispuestas por los pactos fiscales. Finalmente, se debe destacar el aporte de los Servicios Financieros a la recaudación, sobre todo en la Ciudad de Buenos Aires, donde se concentra la mayor parte de las operaciones de esta índole.

\section{3. $\quad$ Análisis cuantitativo}

El IVA es el impuesto de mayor recaudación a nivel nacional. Los ingresos generados por el tributo se fueron incrementando paulatinamente desde el 3,5\% del PBI en 1979 hasta el 6,5\% en 1993, al 8,4\% de 2011.

Mientras tanto, en cuanto a la importancia cuantitativa del impuesto a los Ingresos Brutos en las finanzas públicas provinciales, a lo largo del período analizado el mismo ha representado una proporción nunca inferior al 53\% del total de recursos tributarios de las provincias, alcanzando un nivel de $61 \%$ en 2003 , con un máximo, para 2011, de $75 \%$, y siendo, en promedio, de alrededor del $61 \%$ en todo el tramo bajo estudio.

En los gráficos subsiguientes pueden analizarse las cifras de la recaudación del impuesto al Valor Agregado Nacional y el impuesto a los Ingresos Brutos provinciales. En el primero puede verse la evolución de ambos tributos en términos de presión tributaria por período de análisis; hasta principios de los 90 la presión tributaria del IVA fluctúa entre el 2 y el 3 por ciento del PBI, para crecer a valores de alrededor del 7\% del PBI a partir de 1993, para luego caer a valores próximos al 5\% y volver a crecer hasta niveles superiores al $8 \%$ del PBI. 
Entretanto, a lo largo de toda la serie, los ingresos brutos provinciales varían entre el $1 \%$ y el 3\% del PBI total, aproximándose al 4\% del PBI hacia 2011.

Gráfico 2

Evolución de la presión tributaria de IVA e IIBB En porcentajes del PBI

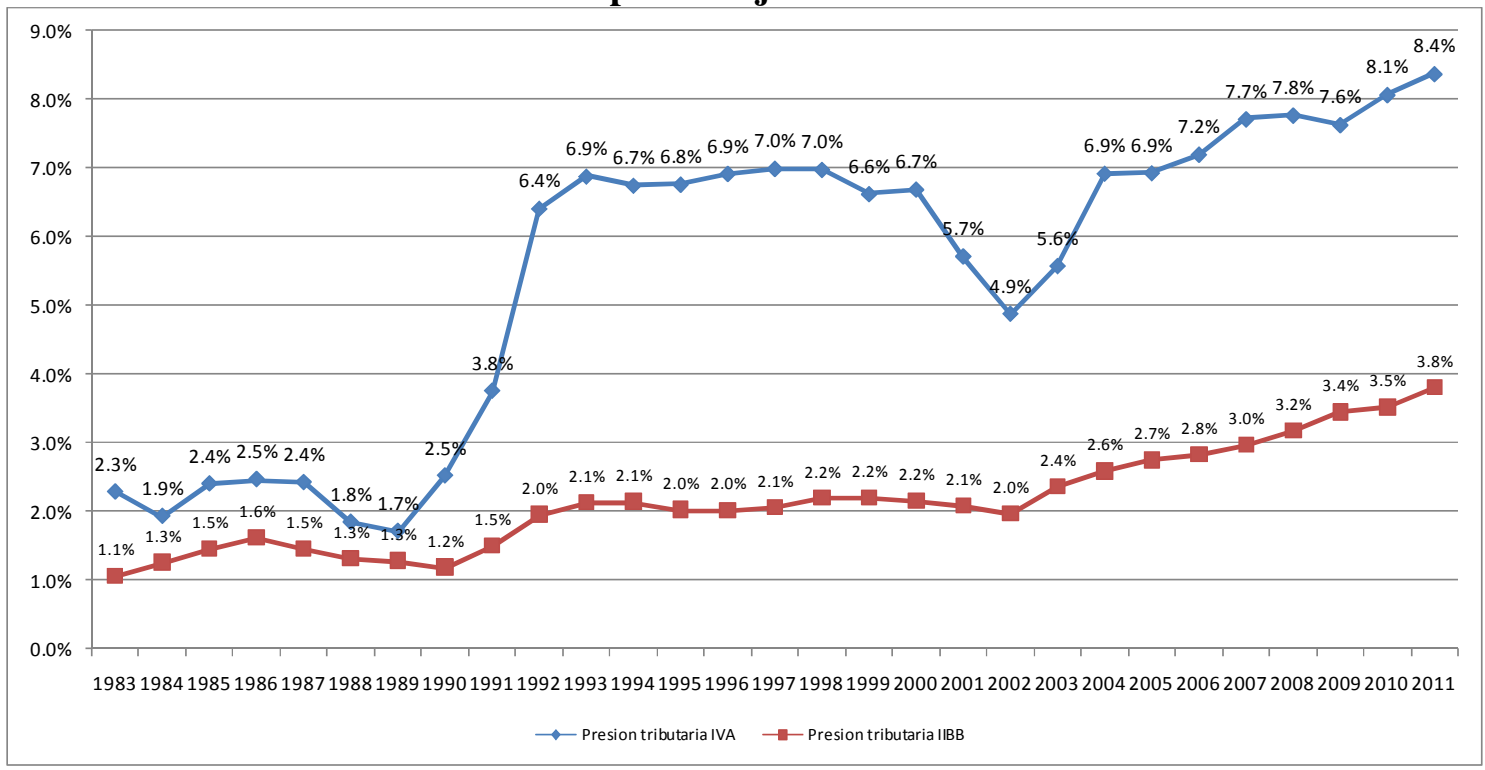

Fuente: elaboración propia en base a datos de MECON

Hacia mediados de la década de 1990, la recaudación por estos impuestos alcanzaba alrededor del 45\% del total de los ingresos tributarios, mientras que hacia 2010-1011 ambos impuestos concentraban aproximadamente el 35\% del total de recaudación nacional y provincial.

\section{Gráfico 3}

Evolución de la participación porcentual de IVA e IIBB en el total de recaudación En porcentajes sobre el total

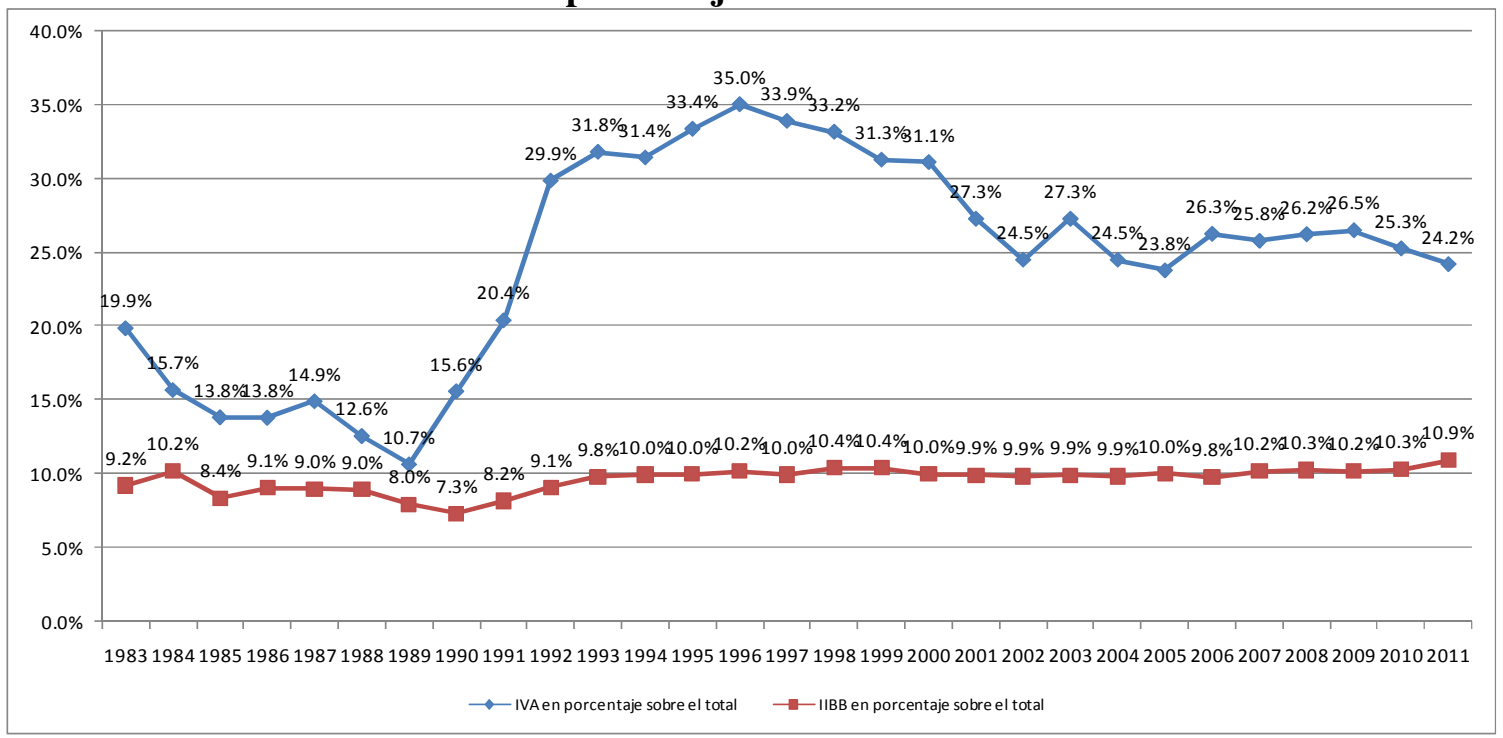

Fuente: elaboración propia en base a datos de MECON 
En el gráfico 4 puede apreciarse la presión tributaria del impuesto sobre los Ingresos Brutos como porcentaje del respectivo PBG de cada provincia, como promedio para todo el período analizado. Las provincias de Neuquén, Río Negro, Salta, Tucumán, Ciudad de Buenos Aires, y Santiago del Estero muestran un coeficiente de presión tributaria superior al promedio, del 2,5\% del PBI para todo el período 1991-2011.

\section{Gráfico 4}

Evolución de la presión tributaria de IIBB

En porcentajes del PBG de cada provincia

Promedio 1991-2011

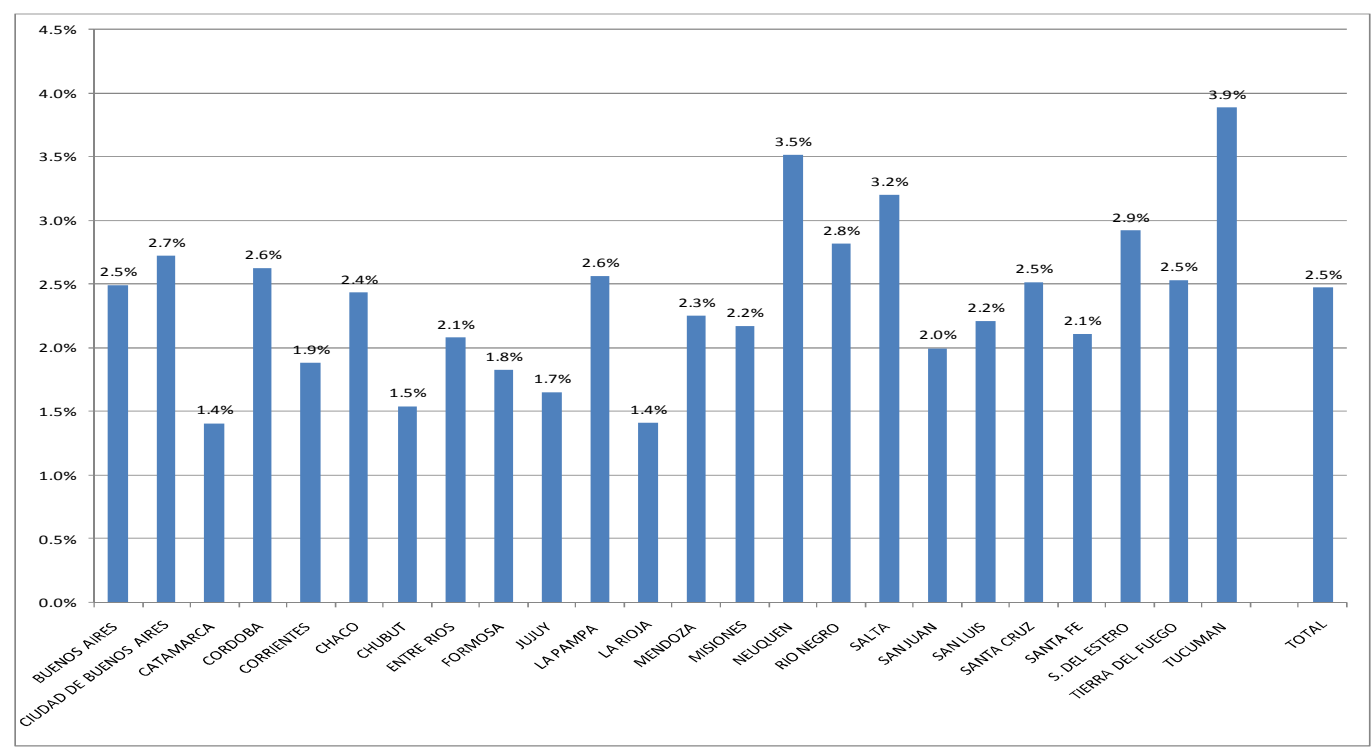

Fuente: elaboración propia en base a datos de MECON

\section{4. $\underline{\text { Aspectos teóricos }}$}

\subsection{Modelo sin competencia horizontal}

La existencia de concurrencia afecta, como quedara expresado, las bases imponibles de los distintos niveles gubernamentales. En equilibrio, la alícuota combinada de ambos niveles gubernamentales tiende a ser más alta que el valor óptimo; la existencia de competencia tributaria horizontal reduce la posibilidad de establecer alícuotas elevadas para las subjurisdicciones dependiendo de la movilidad de la base imponible.

El trabajo se sustenta en una estimación de la reacción de las alícuotas de los gobiernos subnacionales ante una variación en la tasa del gobierno federal. El resto de esta sección presenta el marco teórico de análisis, siguiendo a Keen (1998), Devereux et.al. (2007), Esteller-Moré y Solé-Ollé (2001), y Esteller-Moré y Rizzo (2009 y 2011). 
Se supone inicialmente que ambos niveles de gobierno graven la misma base imponible. Se trata de un solo bien, en donde el impuesto bajo análisis es indirecto, y se supone que los estados son idénticos, que están compuestos por un solo consumidor. Inicialmente se supone que la base imponible es inmóvil. Estos últimos supuestos no permiten la existencia de cuestiones de equidad ni la competencia horizontal entre jurisdicciones.

En segunda instancia se ampliará el modelo, con la introducción de competencia tributaria horizontal, modelada de diferentes maneras para evaluar el grado en que la misma afecta la determinación del nivel de las tasas de los gobiernos subnacionales.

Dado que se supone que ambos niveles de gobierno toman como dados la tasa impositiva y el nivel de gasto de la otra jurisdicción, se comportan como equilibrio de Nash. Ambos niveles maximizan la función de utilidad indirecta del agente representativo, sujeta a sus respectivas restricciones presupuestarias.

El problema para el gobierno regional es el siguiente:

$\operatorname{Max}_{\tau} \mu V(q)+\Gamma(g, G)$ sujeto a $\tau x(q)=g(1)$

donde el precio que enfrenta el consumidor es $q=1+\tau+T$, y siendo $\tau$ la tasa provincial, $T$ la tasa nacional, y el precio para el productor ha sido normalizado a 1. Entretanto, $x(q)$ es la base imponible, $g$ es el bien público regional y $G$ es el bien público nacional, siendo sus utilidades marginales respectivas $\Gamma_{g}$ y $\quad \Gamma_{G}$, ambas cóncavas y siendo $\Gamma_{g} \geq 0 \geq \Gamma_{g g}$ y $\Gamma_{G} \geq 0 \geq \Gamma_{G G}$. El parámetro $\mu$ determina si el gobierno es leviatánico o benevolente; en el primer caso el valor del parámetro es cero, y en el segundo, el valor del mismo es uno.

El lagrangiano es $L=\mu V(p+\tau+T)+\Gamma(\tau x(p+\tau+T), G)(2)$

La condición de primer orden se vuelve

$\mu \frac{\partial V}{\partial q} \frac{\partial q}{\partial \tau}+\Gamma_{g}\left(x+\tau x^{\prime}\right)=0$

Empleando la identidad de Roy y despejando se obtiene la condición para la provisión de bienes públicos en presencia de imposición distorsiva:

$\Gamma_{g}=\frac{\mu}{1+\tau \frac{x^{\prime}}{x}}=R M C P F \geq 1$ 
Definiendo la elasticidad $\varepsilon=-(\partial x / \partial q) /(q / x) \geq 0$, la condición es

$$
\Gamma_{g}=\frac{\mu}{1-\tau \frac{\varepsilon}{q}}=R M C P F \geq 1(5)
$$

En el óptimo, el gobierno regional iguala el beneficio marginal de la provisión del bien público y el costo marginal de los fondos públicos, lo que implica la pérdida del contribuyente ante el aumento de una unidad en la recaudación tributaria. Cada vez que el gobierno federal eleva la presión tributaria (a través de q), el gobierno subnacional actúa para rebalancear la expresión anterior.

En el caso de un gobierno subnacional con comportamiento leviatánico $(\mu=0)$, esto implica tener en cuenta dos efectos: el efecto del lado del gasto (lado izquierdo de (5)), que requiere un aumento de la alícuota regional para mantener constantes los ingresos públicos y consecuentemente los gastos públicos, y el efecto de pérdida de bienestar, que implica que el gobierno eleva las tasas para mantener la presión tributaria (cociente entre alícuota y precio del bien) constante. La ecuación (5) se convierte entonces en $\frac{\tau}{q}=\frac{1}{\varepsilon}(6)$

En definitiva, el efecto final depende de la consideración sobre la elasticidad-precio de la demanda del bien gravado. Si la misma es constante, un aumento en los impuestos nacionales eleva el precio del bien y el gobierno subnacional elevará el impuesto para mantener constante la igualdad anterior. Si la curva de demanda fuera lineal, un aumento de los impuestos federales genera una reducción de los impuestos provinciales (se reduce el cociente $(q / \varepsilon)$. Es condición necesaria y suficiente para un aumento de los impuestos provinciales la log convexidad de la curva de demanda del bien gravado.

Si el gobierno provincial fuera benevolente, es decir, colocando la alícuota optima teniendo en cuenta la valoración marginal de los individuos por los bienes públicos maximizando su bienestar, aunque sin tener en cuenta el impacto de sus decisiones sobre el nivel de provisión del bien público nacional $G$, la ecuación (5) se convierte entonces en $\frac{\tau}{q}=\frac{1}{\varepsilon}\left(1-\frac{\mu}{\Gamma_{g}}\right)$ (7)

Ahora los impuestos provinciales financian la provisión del bien público local, y aparecen dos efectos. En primer lugar, el mayor precio del bien reduce su demanda y la pérdida de bienestar asociada al incremento del impuesto local; mientras que en segunda instancia la contracción de la base genera una caída en la provisión del bien público local; esto hace más 
atractivo el incremento en el impuesto provincial para aumentar la provisión del bien público (Keen, 1998). Ambos efectos van en la dirección de provocar un aumento de los impuestos subnacionales ante un incremento de los nacionales, esto es, los vuelve complementarios.

Lo anterior puede verse a partir de diferenciar totalmente la condición de primer orden, de la siguiente manera:

$-\mu x^{\prime} d T+\Gamma_{g g}\left(x+\tau x^{\prime}\right) \tau x^{\prime} d T+\Gamma_{g}\left(x^{\prime}+\tau x^{\prime \prime}\right) d T-\mu x^{\prime} d \tau+\Gamma_{g g}\left(x+\tau x^{\prime}\right)^{2} d \tau+\Gamma_{g}\left(2 x^{\prime}+\tau x^{\prime \prime}\right) d \tau=0 \quad(8)$

Agrupando, se vuelve:

$$
\left(-\mu x^{\prime}+\Gamma_{g g}\left(x+\tau x^{\prime}\right) \tau x^{\prime}+\Gamma_{g}\left(x^{\prime}+\tau x^{\prime \prime}\right)\right) d T+\left(-\mu x^{\prime}+\Gamma_{g g}\left(x+\tau x^{\prime}\right)^{2}+\Gamma_{g}\left(2 x^{\prime}+\tau x^{\prime \prime}\right)\right) d \tau=0
$$

Despejando:

$$
\frac{d \tau}{d T}=\frac{-\mu x^{\prime}+\Gamma_{g g}\left(x+\tau x^{\prime}\right) \tau x^{\prime}+\Gamma_{g}\left(x^{\prime}+\tau x^{\prime \prime}\right)}{-\left(-\mu x^{\prime}+\Gamma_{g g}\left(x+\tau x^{\prime}\right)^{2}+\Gamma_{g}\left(2 x^{\prime}+\tau x^{\prime \prime}\right)\right)}
$$

Reemplazando y dividiendo por $\Gamma_{g}$

$$
\frac{d \tau}{d T}=\frac{-\mu x^{\prime}+\Gamma_{g g}\left(\frac{\mu x}{\Gamma_{g}}\right) \tau x^{\prime}+\Gamma_{g}\left(x^{\prime}+\tau x^{\prime \prime}\right)}{-\left(-\mu x^{\prime}+\Gamma_{g g}\left(\frac{\mu x}{\Gamma_{g}}\right)^{2}+\Gamma_{g}\left(2 x^{\prime}+\tau x^{\prime \prime}\right)\right)}
$$

Si $\mu=0$ (gobierno leviatánico), el resultado es Devereux et.al. (2007):

$$
\frac{d \tau}{d T}=\frac{x^{\prime}+\tau x^{\prime \prime}}{-\left(2 x^{\prime}+\tau x^{\prime \prime}\right)}(12)
$$

En consecuencia, el resultado depende de la curvatura de la función de demanda y de la consecuente elasticidad precio. Si la demanda fuera lineal, la reacción es negativa, mientras que si la demanda fuera isoelástica, la reacción sería positiva.

Si fuera benevolente $\mu=1$, el resultado es (Keen (1998))

$$
\frac{d \tau}{d T}=\frac{-x^{\prime}+\Gamma_{g g}\left(\frac{x}{\Gamma_{g}}\right) \chi x^{\prime}+\Gamma_{g}\left(x^{\prime}+\tau x^{\prime \prime}\right)}{-\left(-x^{\prime}+\Gamma_{g g}\left(\frac{x}{\Gamma_{g}}\right)^{2}+\Gamma_{g}\left(2 x^{\prime}+\tau x^{\prime \prime}\right)\right)}
$$


Suponiendo elasticidad constante (Esteller-Moré y Solé-Ollé (2001)), el desarrollo sería el siguiente. Diferenciando totalmente la condición de primer orden (5), la misma resulta:

$$
\Gamma_{g g}\left(1-\tau \varepsilon q^{-1}\right) \frac{\partial g}{\partial T} d T+\Gamma_{g}\left(\tau \varepsilon q^{-2}\right) d T+\Gamma_{g g}\left(1-\tau \varepsilon q^{-1}\right) \frac{\partial g}{\partial \tau} d \tau+\Gamma_{g}\left(-\varepsilon q^{-1}+\tau \varepsilon q^{-2}\right) d \tau=0
$$

Reemplazando,

$$
\Gamma_{g g}\left(1-\tau \varepsilon q^{-1}\right) \tau x^{\prime} d T+\Gamma_{g}\left(\tau \varepsilon q^{-2}\right) d T+\Gamma_{g g}\left(1-\tau \varepsilon q^{-1}\right)\left(x+\tau x^{\prime}\right) d \tau+\Gamma_{g}\left(-\varepsilon q^{-1}+\tau \varepsilon q^{-2}\right) d \tau=0
$$

Reagrupando,

$$
\frac{d \tau}{d T}=\frac{-\left[\Gamma_{g g}\left(1-\tau \varepsilon q^{-1}\right) \tau x^{\prime}+\Gamma_{g}\left(\tau \varepsilon q^{-2}\right)\right]}{\left[\Gamma_{g g}\left(1-\tau \varepsilon q^{-1}\right)\left(x+\tau x^{\prime}\right)+\Gamma_{g}\left(\tau \varepsilon q^{-2}\right)-\Gamma_{g} \varepsilon q^{-1}\right]}
$$

Dividiendo por $x$ y reemplazando nuevamente por la condición de primer orden (5),

$$
\frac{d \tau}{d T}=\frac{-\Gamma_{g g}\left(1-\tau \varepsilon q^{-1}\right)\left(-\frac{\tau}{q} \varepsilon\right)-\frac{\Gamma_{g}}{x}\left(\tau \varepsilon q^{-2}\right)}{\left[\Gamma_{g g}\left(1-\tau \varepsilon q^{-1}\right)\left(1-\tau \frac{\varepsilon}{q}\right)-\frac{\Gamma_{g}}{x} \frac{\varepsilon}{q}+\frac{\Gamma_{g}}{x}(\tau \varepsilon) q^{-2}\right]}
$$

Dividiendo por $\Gamma_{g}$ y reemplazando,

$$
\frac{d \tau}{d T}=\frac{-x \frac{\Gamma_{g g}}{\Gamma_{g}}\left(1-\tau \varepsilon q^{-1}\right)\left(-\frac{\tau}{q} \varepsilon\right)-\left(\tau \varepsilon q^{-2}\right)}{\left[x \frac{\Gamma_{g g}}{\Gamma_{g}}\left(1-\tau \varepsilon q^{-1}\right)\left(1-\tau \frac{\varepsilon}{q}\right)^{2}-\frac{\varepsilon}{q}\left(1-\tau q^{-1}\right)\right]}
$$

Reagrupando nuevamente, se llega a la siguiente expresión, que resulta mayor o igual que cero:

$$
\frac{d \tau}{d T}=\frac{-x \frac{\Gamma_{g g}}{\Gamma_{g}}\left(1-\tau \varepsilon q^{-1}\right)\left(\frac{\tau}{q} \varepsilon\right)+\left(\tau \varepsilon q^{-2}\right)}{\left[-x \frac{\Gamma_{g g}}{\Gamma_{g}}\left(1-\tau \varepsilon q^{-1}\right)\left(1-\tau \frac{\varepsilon}{q}\right)^{2}+\frac{\varepsilon}{q}(1+T)\right]}
$$

De esta forma, este modelo estaría determinando, para el caso general de impuestos sobre los consumos, una reacción positiva de los impuestos subnacionales ante incrementos en los federales, asumiendo una curva de demanda de elasticidad constante. 


\subsection{Modelo con competencia tributaria horizontal}

El modelo a presentar agrega la competencia por impuestos entre jurisdicciones del mismo nivel. Esta presentación sigue a Devereux et. al. (2007), y Lucas (2004), aunque con la posibilidad de que los gobiernos sean benevolentes.

Existen dos estados en la federación, $i=1,2$; cada estado determina un impuesto específico de origen en el bien, el cual está también gravado por el gobierno federal con el impuesto $T$; el precio del bien al consumidor en el estado $i$ es $q_{i}=\tau_{i}+T$, normalizando a cero el precio del productor.

Para asumir competencia horizontal, se supone que los consumidores pueden migrar entre jurisdicciones. En consecuencia, aparecen dos reacciones, una vertical, y otra horizontal, ante variaciones en los impuestos de la otra jurisdicción.

Los residentes del estado $i$ están distribuidos a lo largo de una línea de longitud $l_{i . ;}$ la proporción de población del estado que reside a una distancia $d \leq l_{i}$. o menor en relación a la frontera se define como $\phi_{i} d$, donde $\phi_{i}$ es la densidad de población. El consumidor típico de cada estado puede adquirir el bien en su jurisdicción, abonando $q_{i} \mathrm{o}$ viajar hasta la frontera y abonar $q_{j}$ más los costos de transporte asociados. La función de costos de transporte se especifica como $c_{i}(x, d)=c_{i} d$, independiente de la cantidad consumida.

La decisión del típico "cross border shopper" puede ser caracterizada de la siguiente manera. Se define en Devereux et. al. (2007) una función indirecta de utilidad y una función de demanda individual para cada bien gravado para el residente del estado $i$ cuando el precio es $q$, teniendo en cuenta que los costos de transporte no afectan la demanda individual, además de que no existen efectos ingreso porque son abonados en el numerario.

El residente maximiza la función de utilidad indirecta $V(q)=\max \{u(x)-q x\}$, derivando la demanda individual del bien gravado cuando el precio es $q: x(q)=\arg \max \{u(x)-q x\}$. La decisión de adquirir el bien en el otro estado $j$ se determina en función de si el precio es menor $q_{i}>q_{j}$ y la distancia a la que se encuentra de la frontera es $\left(1 / c_{i}\right)\left(v\left(q_{j}\right)-v\left(q_{i}\right)\right)=d_{i}$ o menor. En consecuencia, si el costo de adquirir en el otro estado es prohibitivo, no hay externalidades tributarias horizontales.

La base imponible en el estado $i$ es $X_{i}=x\left(q_{i}\right) s_{i}\left(q_{i}, q_{j}\right)$, donde $s_{i}\left(q_{i}, q_{j}\right)$ es la cantidad de compradores en $\quad i$, y $\quad s_{i}\left(q_{j}, q_{i}\right)=n_{i}-\rho_{i}\left(v\left(q_{j}\right)-v\left(q_{i}\right)\right) \quad$ si $\quad q_{i} \geq q_{j}, \quad$ y 
$s_{i}\left(q_{j}, q_{i}\right)=n_{i}+\rho_{i}\left(v\left(q_{j}\right)-v\left(q_{i}\right)\right)$ si $q_{i} \leq q_{j}$ donde $\rho_{i}=\phi_{i} / c_{i}$ mide la respuesta de los compradores en el otro estado a las diferencias en los impuestos; si $q_{i}=q_{j}$, no hay compras en el otro estado; si $q_{i}>q_{j}$, hay compras en $j$ por parte de los residentes en $i$, mientras que si $q_{i}<q_{j}$, hay compras en $i$ por parte de los residentes de $j$; la base imponible en consecuencia se reduce o se amplía en función de las compras de los residentes de los otros estados.

Se asume que los gobiernos maximizan la función de utilidad del agente representativo, sujeta a generar la recaudación tributaria necesaria para financiar sus propios gastos.

$\operatorname{Max}_{\tau} \mu V\left(\tau_{i}+T, \tau_{j}+T\right)+\Gamma\left(g_{i}, G\right)$ sujeto a $\tau_{i} X_{i}\left(\tau_{i}+T, \tau_{j}+T\right)=g_{i}(20)$

La condición de primer orden es

$\mu \frac{\partial V}{\partial q_{i}} \frac{\partial q_{i}}{\partial \tau_{i}}+\Gamma_{g_{i}}\left(x_{i}\left(\tau_{i}+T, \tau_{j}+T\right)+\tau_{i} \frac{\partial X_{i}\left(\tau_{i}+T, \tau_{j}+T\right)}{\partial \tau_{i}}\right)=0$

Resultando

$$
\Gamma_{g_{i}}=\frac{\mu X_{i}}{X_{i i}+\tau_{i} \frac{\partial X_{i}}{\partial \tau_{i}}}
$$

Para establecer las reacciones de las tasas impositivas, debe diferenciarse totalmente la expresión anterior, de la siguiente manera:

$$
\begin{aligned}
& -\mu X_{i}^{\prime} d \tau_{i}-\mu X_{i}^{\prime} d T-\mu \frac{\partial X_{i}}{\partial q_{j}} \frac{\partial q_{j}}{\partial T} d T+\Gamma_{g_{i} g_{i}}\left(X_{i}+\tau_{i} X_{i}^{\prime}\right)^{2} d \tau_{i}+\Gamma_{g_{i}}\left(2 X_{i}^{\prime} d \tau_{i}+\tau_{i} X_{i}^{\prime \prime} d \tau_{i}\right)+ \\
& +\Gamma_{g_{i} g_{i}} \tau_{i}\left(X_{i}+\tau_{i} X_{i}^{\prime}\right)\left(X_{i}^{\prime}+\frac{\partial X_{i}}{\partial q_{j}} \frac{\partial q_{j}}{\partial T}\right) d T+\Gamma_{g_{i}}\left(X_{i}^{\prime} d T+\tau_{i} X_{i}^{\prime \prime} d T+\frac{\partial X_{i}}{\partial q_{j}} \frac{\partial q_{j}}{\partial T} d T+\tau_{i} \frac{\partial X_{i}^{2}}{\partial q_{i} \partial q_{j}} \frac{\partial q_{j}}{\partial T} d T\right)=0
\end{aligned}
$$

Resultando para el caso de la competencia vertical

$$
\frac{\partial \tau_{i}}{\partial T}=\frac{-\mu X_{i}^{\prime}-\mu \frac{\partial X_{i}}{\partial q_{j}}+\Gamma_{g_{i} g_{i}} \tau_{i}\left(X_{i}+\tau_{i} X_{i}^{\prime}\right)\left(X_{i}{ }^{\prime}+\frac{\partial X_{i}}{\partial q_{j}}\right)+\Gamma_{g_{i}}\left(X_{i}^{\prime}+\tau_{i} X_{i}{ }^{\prime \prime}+\frac{\partial X_{i}}{\partial q_{j}}+\tau_{i} \frac{\partial^{2} X_{i}}{\partial q_{i} \partial q_{j}}\right)}{-\left[-\mu X_{i}^{\prime}+\Gamma_{g_{i} g_{1}}\left(X_{i}+\tau_{i} X_{i}^{\prime}\right)^{2}+\Gamma_{g_{i}}\left(2 X_{i}{ }^{\prime}+\tau_{i} X_{i}{ }^{\prime \prime}\right)\right]}
$$

Para el caso de competencia horizontal, a partir de la condición de primer orden, 


$$
\begin{aligned}
& -\mu X_{i}^{\prime} d \tau_{i}-\mu \frac{\partial X_{i}}{\partial q_{j}} d \tau_{j}+\Gamma_{g_{i} g_{i}}\left(X_{i}+\tau_{i} X_{i}^{\prime}\right)^{2} d \tau_{i}+\Gamma_{g_{i} g_{i}}\left(\tau_{i} \frac{\partial^{2} X_{i}}{\partial q_{i} \partial q_{j}} d \tau_{j}\right)+ \\
& +\Gamma_{g_{i}}\left(X_{i}^{\prime} d \tau_{i}+\frac{\partial X_{i}}{\partial q_{j}} d \tau_{j}+X_{i}^{\prime} d \tau_{i}+\tau_{i} X_{i}^{\prime \prime} d \tau_{i}+\tau_{i} \frac{\partial^{2} X_{i}}{\partial q_{i} \partial q_{j}} d \tau_{j}\right)=0
\end{aligned}
$$

Reagrupando,

$$
\frac{\partial \tau_{i}}{\partial T}=\frac{-\mu X_{i}-\mu \frac{\partial X_{i}}{\partial q_{j}}+}{\Gamma_{g_{i} g_{i}} \tau_{i}\left(\frac{\mu}{\Gamma_{g_{1}}} X_{i}^{\prime}\right)\left(X_{i}^{\prime}+\frac{\partial X_{i}}{\partial q_{j}}\right)+\Gamma_{g_{i}}\left(X_{i}^{\prime}+\tau_{i} X_{i}^{\prime \prime}+\frac{\partial X_{i}}{\partial q_{j}}+\tau_{i} \frac{\partial^{2} X_{i}}{\partial q_{i} \partial q_{j}}\right)}(26)
$$

Reemplazando,

$$
\begin{aligned}
& \frac{\partial \tau_{i}}{\partial \tau_{j}}= \frac{-\mu \frac{\partial X_{i}}{\partial q_{j}}+\Gamma_{g_{i} g_{i}} \tau_{i} \frac{\partial^{2} X_{1}}{\partial q_{i} \partial q_{j}}+\Gamma_{g_{1}} \frac{\partial X_{i}}{\partial q_{j}}+\Gamma_{g_{1}} \tau_{i} \frac{\partial^{2} X_{i}}{\partial q_{i} \partial q_{j}}}{-\left[-\mu X_{i}{ }^{\prime}+\Gamma_{g_{i} g_{1}}\left(X_{i}+\tau_{i} X_{i}^{\prime}\right)^{2}+2 \Gamma_{g_{i}} X_{i}{ }^{\prime}+\Gamma_{g_{i}} \tau_{i} X_{i}{ }^{\prime \prime}\right]} \\
& \frac{\partial \tau_{i}}{\partial \tau_{j}}=\frac{-\mu \frac{\partial X_{i}}{\partial q_{j}}+\Gamma_{g_{i} g_{i}} \tau_{i} \frac{\partial^{2} X_{1}}{\partial q_{i} \partial q_{j}}+\Gamma_{g_{1}} \frac{\partial X_{i}}{\partial q_{j}}+\Gamma_{g_{1}} \tau_{i} \frac{\partial^{2} X_{i}}{\partial q_{i} \partial q_{j}}}{-\left[-\mu X_{i}{ }^{\prime}+\Gamma_{g_{i} g_{i}}\left(\frac{\mu}{\Gamma_{g_{1}}} X_{i}^{\prime}\right)^{2}+2 \Gamma_{g_{i}} X_{i}{ }^{\prime}+\Gamma_{g_{i}} \tau_{i} X_{i}{ }^{\prime \prime}\right]}
\end{aligned}
$$

Si el costo de transporte es prohibitivo $\left(c_{i}=\infty\right)$, con gobiernos leviatánicos $(\mu=0)$, se llega a la ecuación (12) anterior. Es decir, como no existen compras al otro lado de la frontera, entonces las funciones de reacción implican que el impuesto del estado $i$ no reacciona ante variaciones en la tasa del estado $j$, mientras que la reacción de la tasa del estado $i$ ante variaciones en la tasa del impuesto federal puede ser positiva o negativa, dependiendo de la curvatura de la función de demanda del bien (si es lineal la reacción es negativa, mientras que si es isoelástica, la reacción es positiva)

En el caso de gobiernos benevolentes $(\mu=1)$, con curva de demanda lineal, el resultado estaría dado por la siguiente expresión, la que es negativa si la suma de los dos primeros términos es mayor que el tercero. 


$$
\frac{\partial \tau_{i}}{\partial T}=\frac{-1+\Gamma_{g_{i} g_{i}} \tau_{i}\left(\frac{n_{i} x}{\Gamma_{g_{i} i}}\right)+\Gamma_{g_{i}}}{\left[1-\Gamma_{g_{i} g_{1}}\left(\frac{n_{i} x_{i}}{\Gamma_{g_{1}}}\right)^{2}-\Gamma_{g_{i}}\right]}(29),
$$

Si la función de demanda es inelástica, $x_{i}(q)=\bar{x}$, asumiendo la existencia de compras interestaduales, la base imponible es ahora $X_{i}\left(q_{i}, q_{j}\right)=n_{i} \bar{x}+\rho_{i}\left(q_{j}-q_{i}\right) \bar{x}^{2} \cdot(30)$

Las condiciones (26) y (28) anteriores son ahora:

$$
\begin{aligned}
& \frac{\partial \tau_{i}}{\partial T}=\frac{\rho_{i} \bar{x}^{2}-\rho_{i} \bar{x}^{2}+\Gamma_{g_{i} g_{i}} \tau_{i}\left(\bar{x}-\tau_{i} \rho_{i} \bar{x}\right)\left(-\rho_{i} \bar{x}^{2}+\rho_{i} \bar{x}\right)+\Gamma_{g_{i}}\left(-\rho_{i} \bar{x}^{2}+\rho_{i} \bar{x}^{2}\right)}{-\left[\rho_{i} \bar{x}^{2}+\Gamma_{g_{i} g_{1}}\left(\bar{x}-\tau_{i} \rho_{i} \bar{x}_{i}^{2}\right)^{2}+\Gamma_{g_{i}}\left(2 \rho_{i} \bar{x}^{2}\right)\right]}=0 \\
& \frac{\partial \tau_{i}}{\partial \tau_{j}}=\frac{-\rho_{i} \bar{x}+\Gamma_{g_{1}} \rho_{i} \bar{x}^{-2}}{-\left[\rho_{i} \bar{x}^{2}+\Gamma_{g_{i} g_{i}}\left(\bar{x}-\tau_{i} \rho_{i} \bar{x}^{2}\right)^{2}-2 \Gamma_{g_{1}} \rho_{i} \bar{x}^{2}\right]}
\end{aligned}
$$

Reexpresando,

$$
\frac{\partial \tau_{i}}{\partial \tau_{j}}=\frac{\rho_{i} \bar{x}^{2}\left(\Gamma_{g_{1}}-1\right)}{\rho_{i} \bar{x}^{2}\left[2 \Gamma_{g_{1}}-1\right]-\Gamma_{g_{i} g_{i}}\left[\bar{x}\left(1-\tau_{i} \rho_{i} \bar{x}\right)\right]^{2}}
$$

Esta última expresión es positiva si el segundo término del denominador es menor que el primero (el numerador es negativo).

De acuerdo a los supuestos anteriores, el modelo arrojaría, para bienes de demanda inelástica, una reacción vertical nula y una reacción horizontal positiva. Devereux (2007) presenta además el caso general en donde existen compras interestaduales y demanda elástica, en un gobierno leviatánico, si bien no puede predecirse el signo de la reacción vertical, puede establecerse que la reacción horizontal es positiva $\frac{\partial t_{1}}{\partial t_{2}}>0$ y $\frac{\partial t_{2}}{\partial t_{1}}>0$, lo que es robusto aún ante la existencia de potenciales asimetrías entre los estados.

En función de lo comentado, no existe una determinación teórica concluyente sobre la reacción de los impuestos provinciales ante cambios en los impuestos nacionales, con lo cual depende de las estimaciones empíricas. 


\section{Metodología empleada para el análisis}

Para que la externalidad tributaria opere, la base imponible debe responder a los cambios en las alícuotas tributarias; es decir que el impuesto debe ser distorsivo. Si cada nivel de gobierno ignora el efecto sobre la recaudación del otro, las alícuotas tenderán a ser demasiado elevadas.

Sin embargo, no todas las reacciones observadas en la conducta de los gobiernos jurisdiccionales ante incrementos en las tasas de los demás se deben a externalidades tributarias. Por ejemplo, si el gobierno subnacional deduce el monto de impuesto nacional, o lo que es equivalente, percibe el impuesto propio sobre el total de la base excluyendo los impuestos nacionales, tiende a una alícuota más alta que en el caso de no deducibilidad por reducir el costo marginal de los fondos públicos.

Adicionalmente, existe otro tipo de reacción que puede asimilarse a la externalidad fiscal que se relaciona con la denominada ilusión fiscal. Esto hace referencia a que incrementos automáticos en los recursos tributarios de los estados no son compensados con políticas discrecionales por parte de los mismos, sino que se comportan en forma pasiva ${ }^{57}$.

El propósito de esta sección es el de establecer los lineamientos utilizados para el análisis empírico. El objetivo es estimar la reacción del impuesto a los Ingresos Brutos provincial ante cambios en el impuesto al Valor Agregado nacional, la estimación de la pendiente de la función de reacción del gobierno provincial. Las estimaciones a realizar considerarán las variables dependientes que se explicitan a continuación.

\subsection{Variables dependientes relevantes}

Como fuera expuesto con anterioridad, puede apreciarse un crecimiento importante en la recaudación tributaria, medida a partir de la presión tributaria, a lo largo de todo el período analizado. Sin embargo, resulta dificultoso definir una variable de decisión a partir de la cual pueda testearse la "política tributaria" de cada gobierno.

Los estudios sobre estas temáticas utilizan como variable relevante para analizar la política impositiva de cada nivel de gobierno a las alícuotas nominales, deflactadas por algún índice de precios que se juzgue como apropiado. Sin embargo, la recaudación impositiva puede aumentar aunque los gobiernos no incrementen las tasas: una eliminación de una exención implicaría mayores ingresos para el fisco, lo que no estaría contemplado en la alícuota

\footnotetext{
${ }^{57}$ La explicitación sigue a Esteller-Moré y Solé-Ollé (2001) op. cit.
} 
nominal. Este trabajo procurará medir distintas variables que aproximen a la política impositiva de los gobiernos, además de la alícuota nominal, para guardar comparabilidad con los antecedentes de la literatura.

Las variables dependientes cuya evolución se procurará explicar se dividen en dos grupos: el primero corresponde al caso general, en donde el análisis, dado que el IVA e Ingresos Brutos son impuestos generales sobre los consumos, involucra a la evolución de las alícuotas nominales, productividad y tasas efectivas de ambos tributos. En este caso, de acuerdo a la teoría, no existe una determinación teórica a priori sobre el comportamiento de las variables tributarias del nivel subnacional de gobierno cuando el nivel federal varía sus políticas.

El segundo grupo corresponde al caso de los impuestos selectivos sobre consumos. Los estudios sobre externalidades verticales en estos tributos hacen referencia a impuestos específicos sobre cigarrillos o combustibles, en donde existe potestad tributaria de ambos niveles de gobierno. En Argentina, los impuestos específicos sólo existen a nivel nacional ${ }^{58}$, lo que determina la imposibilidad de replicar el análisis sobre los mismos tributos que los empleados en los antecedentes mencionados.

La metodología utilizada en este estudio consistió en construir una variable de tasa efectiva que contemple la estructura productiva de un bien surgido de la cadena agroalimentaria cuya demanda sea inelástica: el pan. De manera similar a lo que ocurre con los tributos sobre los cigarrillos, en este caso también cabría esperar, de acuerdo con la teoría desarrollada en el apartado anterior, ausencia de reacción de las tasas provinciales ante cambios en la política tributaria nacional.

Alícuotas nominales: La primera de las variables empleadas para evaluar la externalidad vertical es la tasa impositiva nominal. De los gráficos presentados con anterioridad puede apreciarse que la misma, en el caso del IVA, es creciente, al pasar de un 15,6\% en 1991 al $21 \%$ en 1995, quedando fija en ese valor desde entonces. Para el caso de Ingresos Brutos, entretanto, a partir del momento en que las provincias comienzan a alejarse de los compromisos del Pacto Fiscal, la tasa promedio también vuelve a crecer, desde el 2,2\% de 1991 al 2,5\% del promedio simple o del promedio ponderado en 2011.

En el gráfico 5 se aprecia la evolución de las alícuotas del impuesto, en promedios totales para todas las provincias, Para realizar este gráfico, se relevaron las tasas vigentes para un grupo de

\footnotetext{
${ }^{58}$ En algunas provincias (Córdoba, por ejemplo), existen intentos incipientes de colocar impuestos provinciales a los combustibles, que coexistirían con el impuesto federal.
} 
11 actividades económicas ${ }^{59}$, , para cada una de las 24 provincias en el período 1991-2011 $1^{61}$ y se elaboró un promedio ponderado de las mismas en relación a la participación de cada grupo de actividad económica en el Producto Bruto Geográfico de cada provincia.

\section{Gráfico 5}

\section{Evolución de las alícuotas nominales de Ingresos Brutos Promedio simple y ponderado por actividad económica En puntos porcentuales}

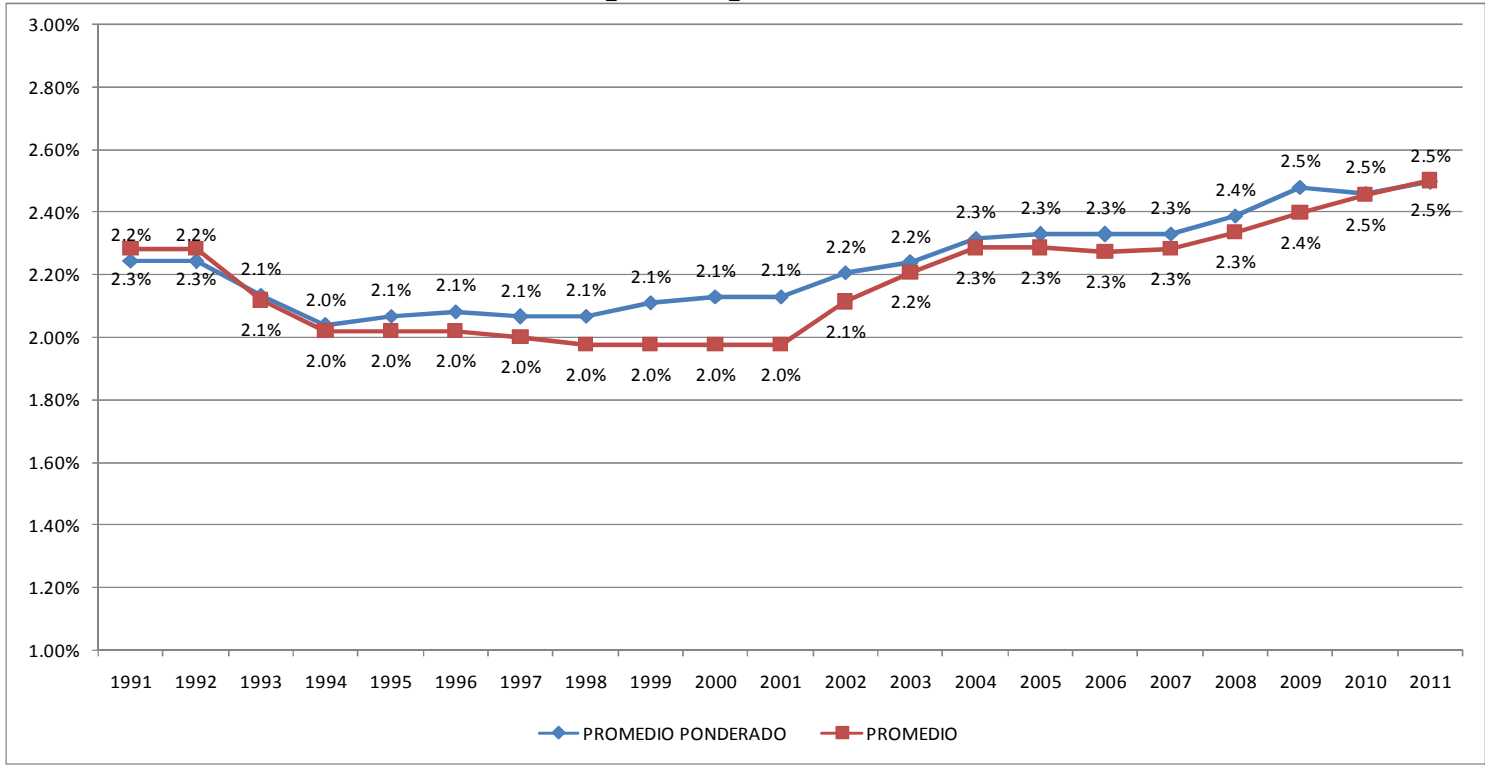

Fuente: elaboración propia en base a datos de legislaciones y Direcciones de Estadística provinciales e INDEC

Cabe consignar que para lo anterior se elaboró una serie de PBG para cada provincia, para todo el período 1991-2011, con agregación en las actividades económicas mencionadas ${ }^{62}$. Las tasas ponderadas fueron las que se tomaron en cuenta para las estimaciones, dado que se considera que aproximan de mejor manera a la evolución de la recaudación, por la importancia de cada sector en el total de las economías provinciales.

En consonancia con los estudios realizados en la materia, y para depurar el comportamiento de las variables la evolución de los precios, se procedió a reexpresar los valores de las alícuotas nominales en valores reales, a partir del deflactor del PBI y ante la ausencia de

\footnotetext{
${ }^{59}$ Agricultura, minería, industria manufacturera, electricidad, gas y agua, construcción, comercio al por mayor, comercio al por menor, restaurantes y hoteles, transporte y comunicaciones, intermediación financiera y resto de actividades económicas.

${ }^{60}$ Las tasas consideradas fueron las generales por actividad económica.

${ }^{61}$ Este período es el objeto del estudio, dado que es el lapso para el cual pudieron recopilarse las distintas fuentes de legislación provincial.

${ }^{62}$ Las fuentes utilizadas para este cálculo fueron las Direcciones de Estadísticas provinciales y Provinfo. En el caso en que la información no estuviera completa para todos los períodos se proyectaron los valores agregados por cada sector por el crecimiento promedio del PBI nacional.
} 
estimaciones consistentes y de una extensión aprovechable para el período de tiempo analizado de índices de precios provinciales (gráfico 6).

Las tasas del IVA también fueron recalculadas a valores reales a partir del deflactor del PBI y evidencian diferencias sustanciales entre los valores nominales y reales (gráfico 7).

\section{Gráfico 6}

Evolución de las alícuotas reales de Ingresos Brutos

Promedio simple y ponderado por actividad económica

En puntos porcentuales

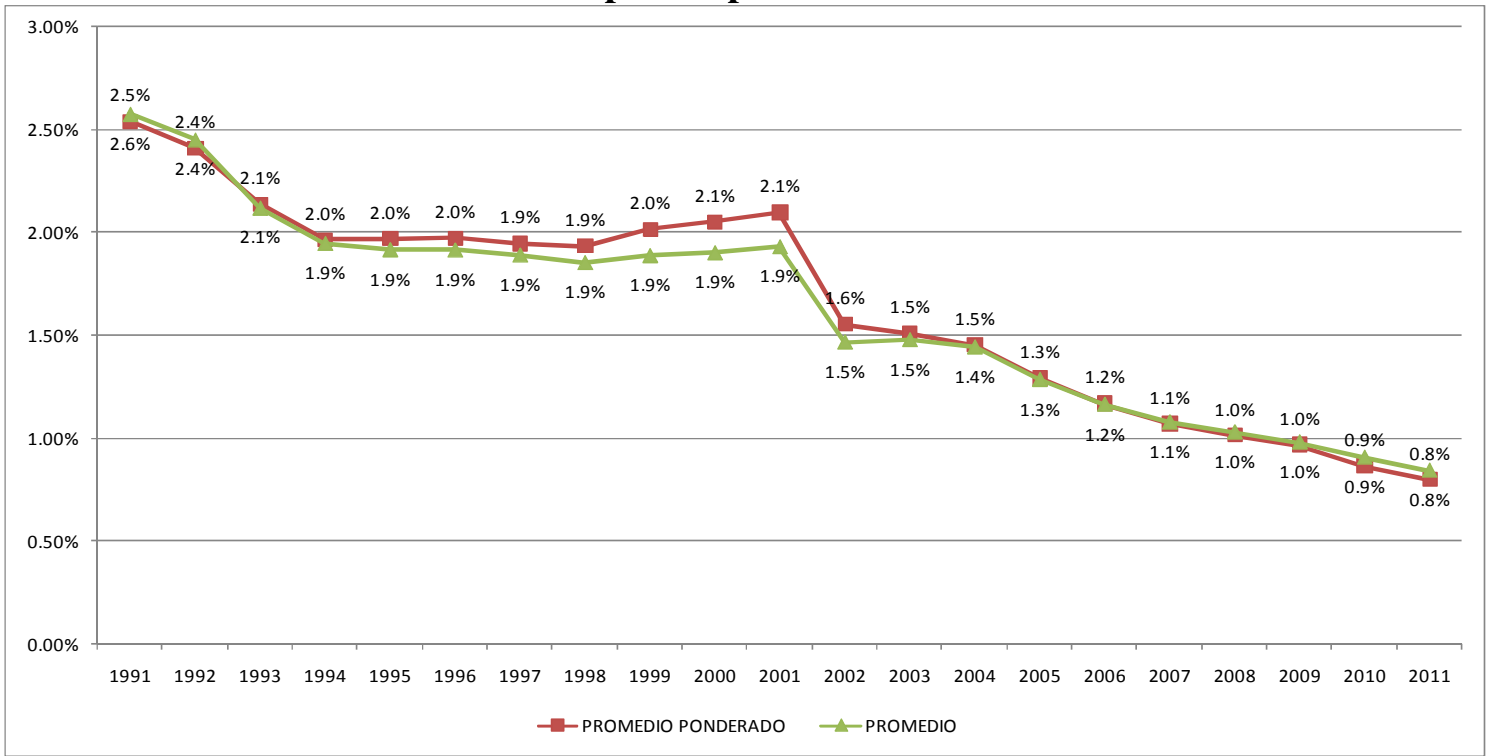

Fuente: elaboración propia en base a datos de legislaciones y Direcciones de Estadística provinciales e INDEC

\section{Gráfico 7}

Evolución de las alícuotas nominales y reales del IVA

En puntos porcentuales

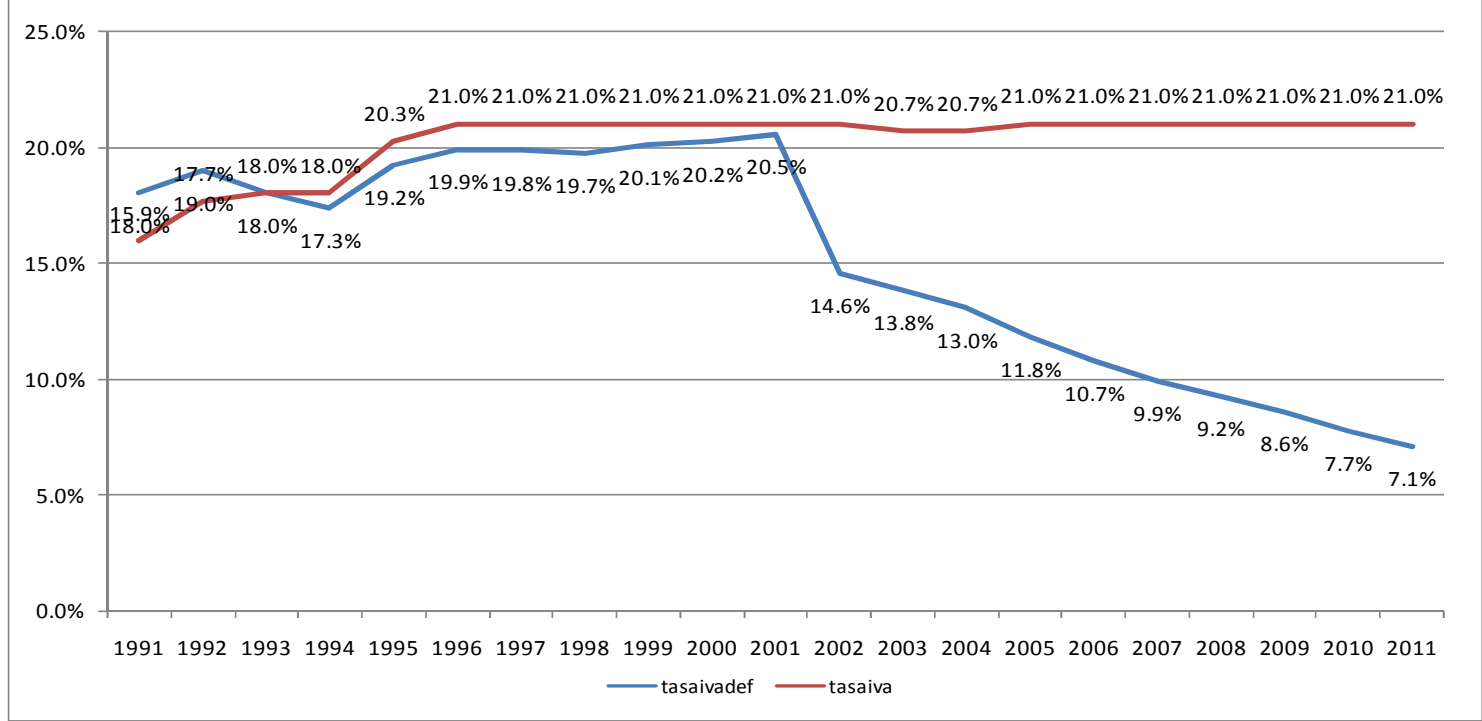

Fuente: elaboración propia en base a datos de legislaciones y Direcciones de Estadística provinciales e INDEC 
Productividad: Una de las formas de calcular el rendimiento de un impuesto es el denominado coeficiente de productividad, que se define como el ratio de la recaudación del impuesto en porcentaje del PBI (presión tributaria) dividida por la tasa impositiva nominal. Un impuesto con alícuota uniforme, sin exenciones, sobre el Valor Agregado, debería, sin evasión, acercarse a un valor de $1^{63}$.

La idea básica es que si la recaudación es el resultado de aplicar una alícuota a una determinada base imponible, la relación entre la misma (medida como porcentaje de un agregado macroeconómico que mejor represente la base imponible del impuesto) debe ser de 1 o muy cercano a 1, por cada punto de alícuota. Esto no debe necesariamente esperarse como una regla, dado que el agregado macroeconómico elegido puede no representar íntegramente la base imponible, o hacerlo en forma parcial ${ }^{64}$.

\section{Gráfico 8}

Evolución de la productividad nominal de IVA e de Ingresos Brutos

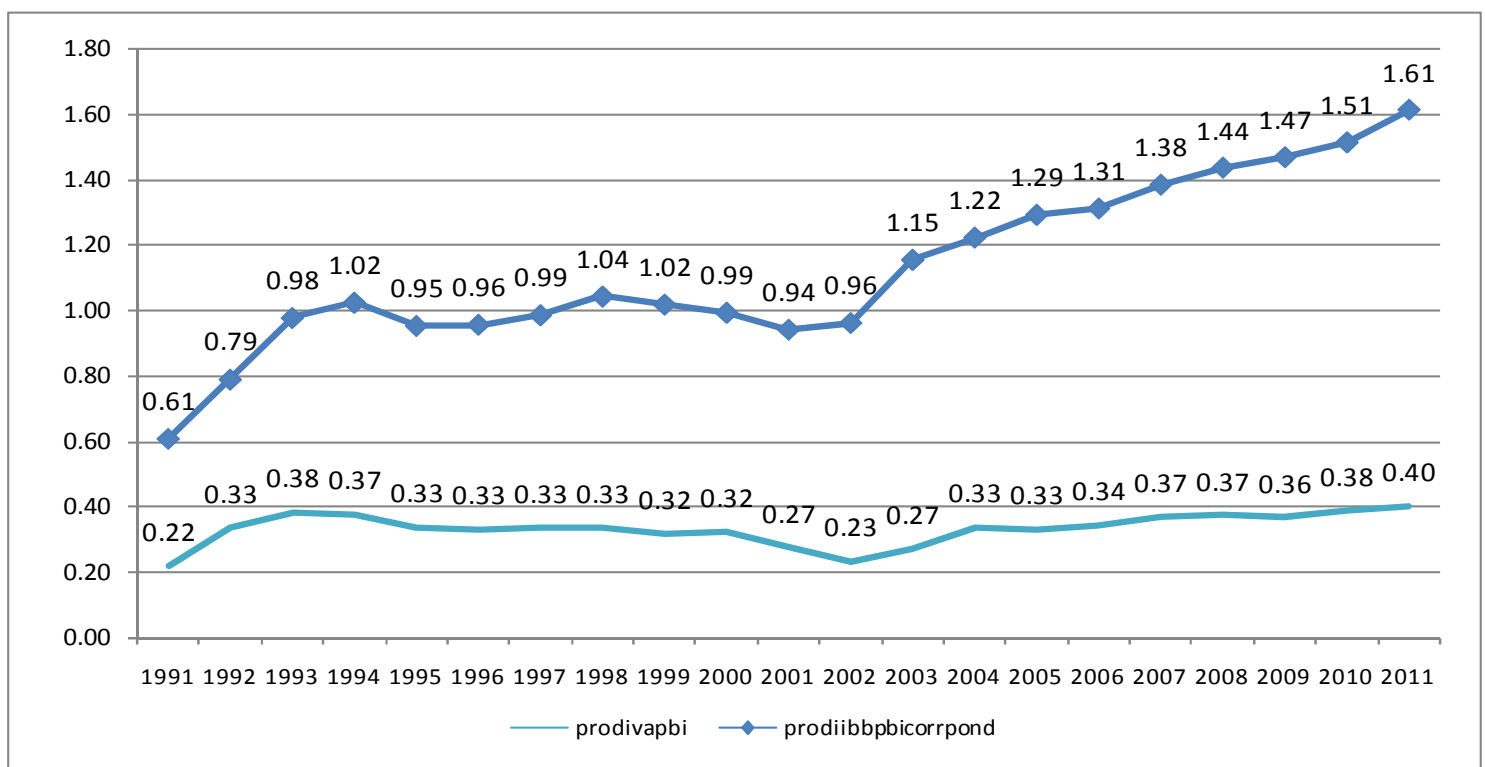

Fuente: elaboración propia en base a datos de MECON, Direcciones de Estadísticas Provinciales y legislación vigente

En el gráfico 8 se muestra la evolución de la productividad del IVA e Ingresos Brutos. Allí puede verse que la productividad del IVA es creciente y oscila entre 0,2 y 0,4 puntos, mientras que la de IIBB es superior a la unidad dado que la base imponible apropiada sería en este caso el Valor Bruto de Producción, mientras que el denominador de la expresión utilizado

\footnotetext{
${ }^{63}$ Otro indicador utilizado el de eficiencia tributaria, que se calcula a partir de dividir la recaudación del impuesto sobre su base imponible más aproximada (en el caso del IVA por ejemplo, sería el consumo privado). Debido a las deficiencias imperantes en la información sobre el Valor Bruto de Producción por provincia, relevante para la estimación del Ingresos Brutos, se decidió dejar de lado esta variable.

${ }^{64}$ Pecho, M., Peláez, F. y Sánchez, J. (2012)
} 
aquí es el PBG de cada provincia; al ser un impuesto en cascada, se está tributando varias veces sobre el mismo valor.

Debido a la evolución de los precios, la variable de productividad también debe sin embargo ser corregida, dado que el cociente representaría ahora a la tasa nominal, de IVA e Ingresos Brutos, deflactadas. La evolución de ambas se presenta en el gráfico 9.

\section{Gráfico 9}

\section{Evolución de la productividad real de IVA e de Ingresos Brutos}

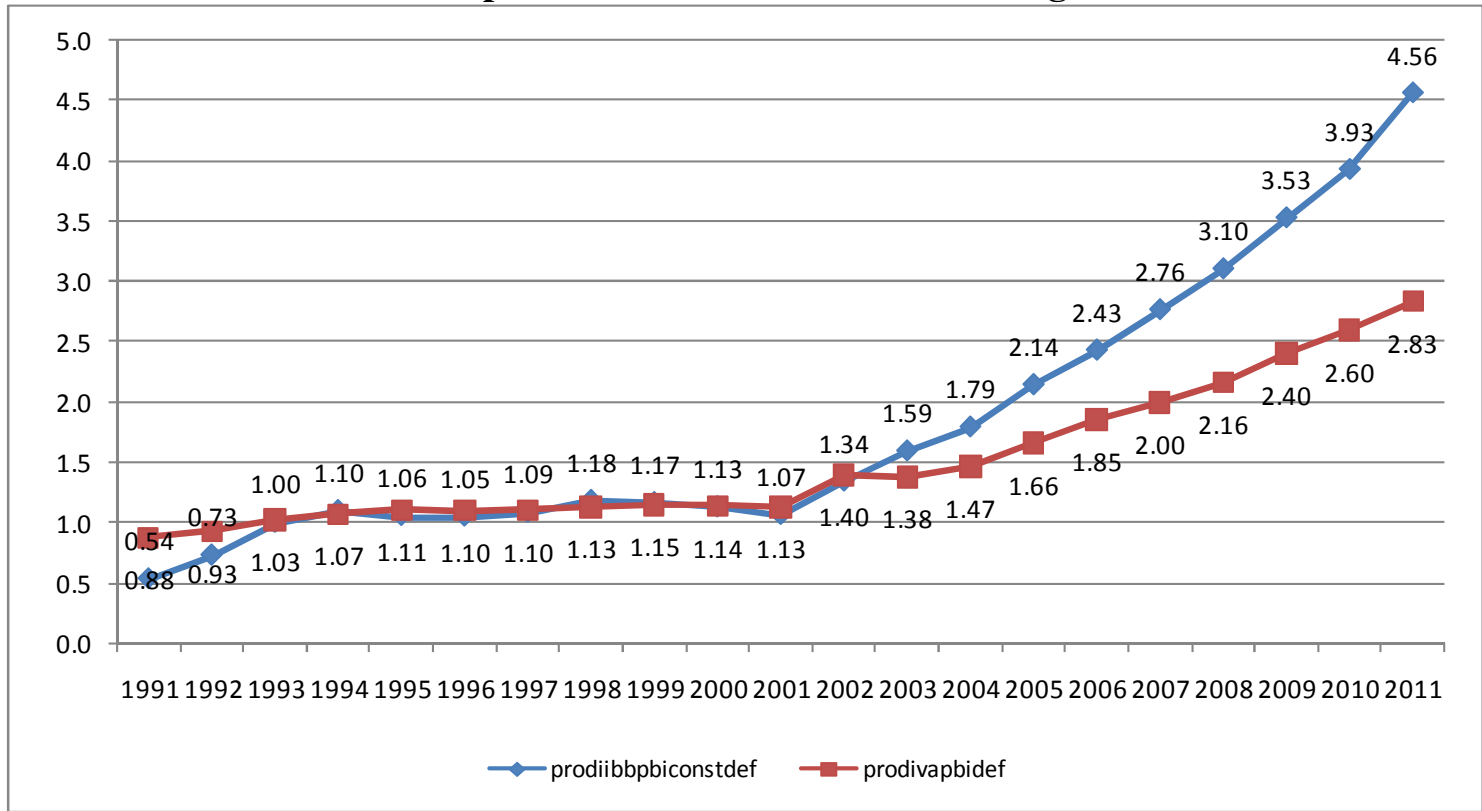

Fuente: elaboración propia en base a datos de MECON, Direcciones de Estadísticas Provinciales y legislación vigente

Tasas efectivas: La existencia de exenciones y alícuotas diferenciales, las que, en el caso del IVA, por ejemplo, interrumpen la cadena de créditos y débitos, hace que la alícuota nominal difiera de la tasa efectiva, la que se calcula como el cociente del impuesto pagado sobre la base imponible. De nuevo, sin exenciones ni tasas diferenciales, un IVA del $21 \%$ nominal sobre el consumo generaría una tasa efectiva del mismo valor.

A continuación se muestran las tasas efectivas (gráficos 10 y 11), calculadas para cada período y cada provincia. En el caso del IVA, el cálculo partió de información de la Matriz Insumo Producto, a la cual se le aplicaron las tasas vigentes por período para los sectores gravados, configurando el impuesto teórico pagado. La tasa efectiva surge de dividir el mismo por el consumo privado.

Para Ingresos Brutos, entretanto, para cada provincia se expandió el valor del PBG a precios básicos calculado como fuera explicitado anteriormente, por el coeficiente de Valor Bruto de Producción (VBP) a Valor Agregado Bruto (VAB) de la Matriz Insumo Producto para cada 
actividad económica. A estos valores se le aplicaron las tasas por actividad económica relevadas $^{65}$, considerando el encadenamiento productivo que implica que la tasa nominal de una actividad debe aplicarse sobre el VBP de sector al que éste le compra más el impuesto pagado por el sector (impuesto en cascada) ${ }^{66} 67$.

En el gráfico 10 puede apreciarse la caída a principios de la década de 2000 de la tasa efectiva del IVA, debido a la introducción de la alícuota nominal del 10,5\%; en 1997 sólo pagaba esa tasa la venta de viviendas residenciales nuevas, mientras que en 2004 se habían incluido, entre otros, los consumos de carne vacuna, frutas y verduras frescas, medicina prepaga y el transporte de pasajeros, para luego evidenciar un leve alza hacia fines de la década.

\section{Gráfico 10 \\ Tasas efectivas teóricas nominales de IVA e Ingresos Brutos En puntos porcentuales}

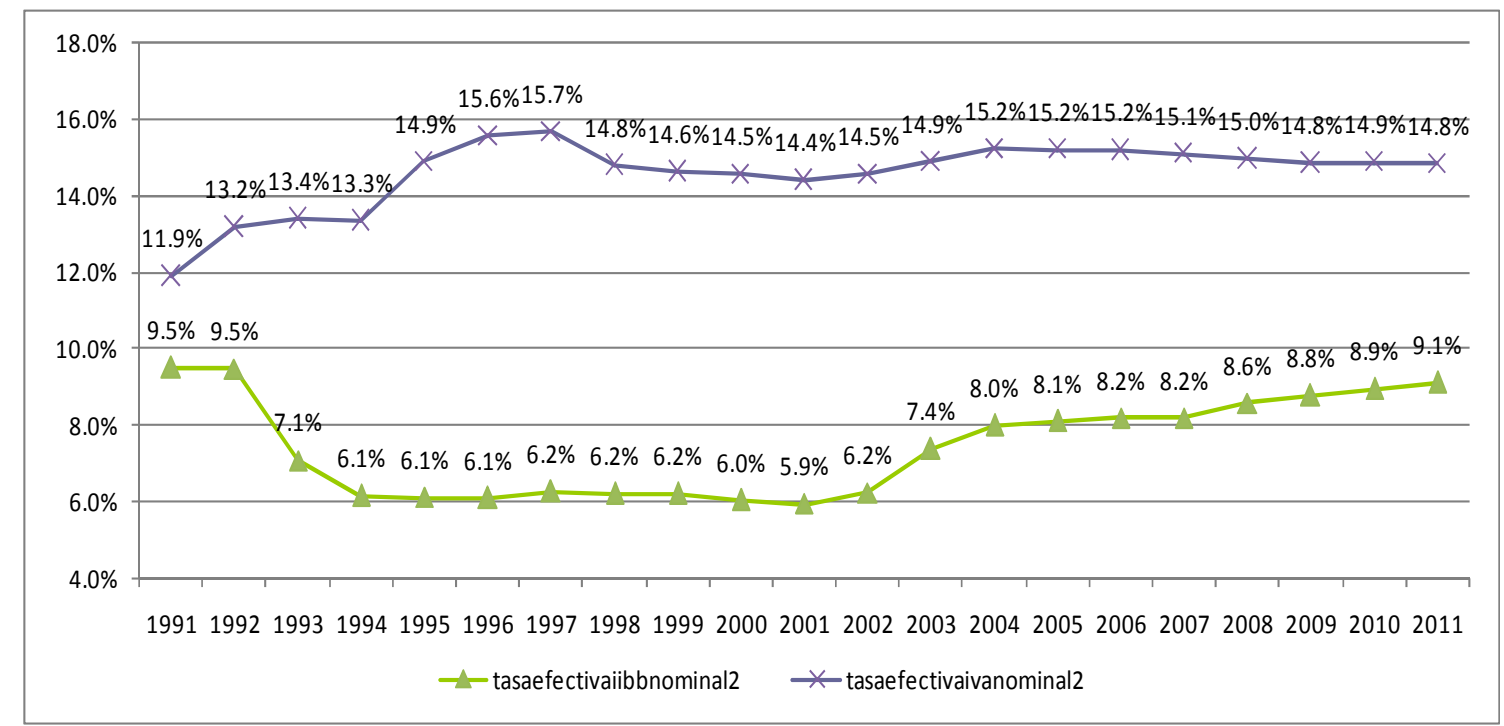

Fuente: elaboración propia en base a datos de MECON, Direcciones de Estadísticas Provinciales y legislación vigente

Las tasas efectivas del IVA y de Ingresos Brutos también fueron recalculadas a valores reales a partir del deflactor del PBI; su evolución se aprecia en el gráfico 11.

\footnotetext{
${ }^{65}$ Agricultura, minería, industria manufacturera, electricidad, gas y agua, construcción, comercio al por mayor, comercio al por menor, restaurantes y hoteles, transporte y comunicaciones, intermediación financiera y resto de actividades

${ }^{66}$ Este procedimiento fue seguido por no disponerse de la recaudación por actividad económica del impuesto, para todas las provincias y todos los años.

${ }^{67}$ Una representación acabada de este dato implicaría establecer, para cada uno de los productos relevantes, los tributos incluidos en el encadenamiento productivo
} 


\section{Gráfico 11}

Tasas efectivas teóricas reales de IVA e Ingresos Brutos

En puntos porcentuales

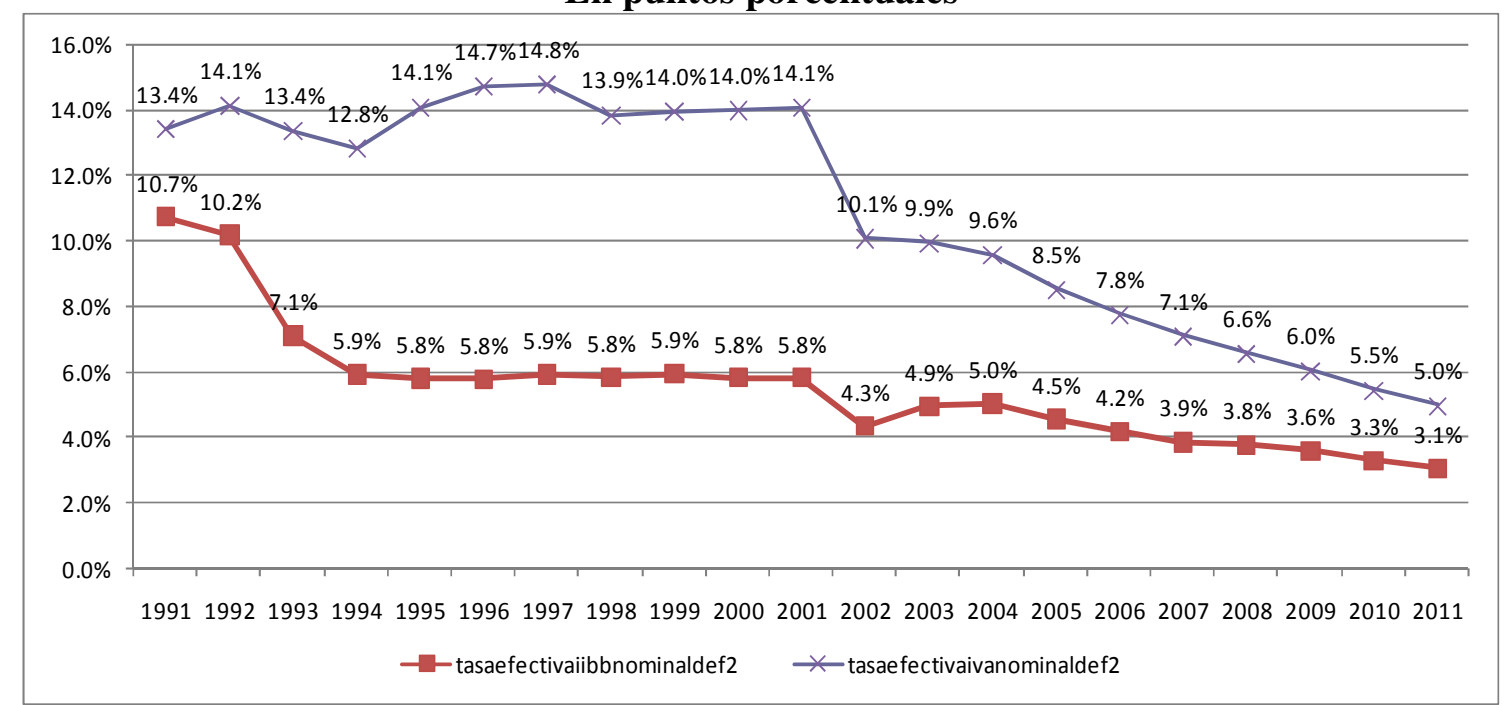

Fuente: elaboración propia en base a datos de MECON, Direcciones de Estadísticas Provinciales y legislación vigente

Tasas efectivas cadena agroalimentaria: Si bien tanto el IVA como Ingresos Brutos son dos impuestos generales que recaen sobre los consumos (aunque por cierto Ingresos Brutos, al ser acumulativo, recae sobre la producción, como fuera explicitado), es interesante evaluar en forma específica cómo inciden estos impuestos sobre determinadas actividades económicas.

Dado que no pudo contarse con información por producto para todos los períodos y provincias de ambos impuestos ${ }^{68}$, se calculó una alícuota efectiva teórica para IVA e Ingresos Brutos de la cadena productiva trigo/harina/pan, con el fin de aproximar al comportamiento de las variables tributarias para un sector cuyos bienes son, en general, de demanda inelástica, asumiendo que los bienes producidos por este sector llegan al consumidor final a partir de atravesar un subconjunto de las actividades económicas mencionadas anteriormente.

Este ejercicio es relevante debido al hecho de que durante el período analizado hubo un cambio en la política del IVA sobre esta cadena productiva; hacia fines de 2006 se dispuso que el trigo, la harina y los productos panificados paguen 10,5\% de IVA. Esto tuvo como objetivo terminar con una disparidad de tasas poco frecuente: el cereal pagaba $10,5 \%$, la harina $21 \%$ y el pan $0 \%$. Debe reconocerse sin embargo que la tasa diferencial indicada, del $10,5 \%$ a diferencia de la general del $21 \%$, ha obedecido básicamente al propósito de reducir los márgenes de evasión del gravamen con motivo de la brecha entre bienes (insumos a tasa general) y bienes elaborados o finales (exentos).

\footnotetext{
${ }^{68}$ Sería menester contar con una Matriz Insumo Producto por provincia y por año.
} 
Si bien este cálculo intentará aproximar al impacto de las tasas efectivas, se reconoce que no se cuenta con estimaciones de evasión en la cadena productiva que podrían presentar evidencia fehaciente respecto del efecto recaudatorio de esta política.

Para realizar los cálculos mencionados, se utilizó la información actualizada a 2005 del trabajo de Nogués y Porto (2007), cuya estructura se presenta al final del Anexo (cuadro 18). Dejando constantes las estructuras productivas de insumos (trigo), sector manufacturero (molienda) y consumo final (panaderías), se calcularon las cargas impositivas correspondientes para cada provincia y período, tomando en cuenta las alícuotas de Ingresos Brutos e IVA que recaen sobre cada etapa productiva. Debe tenerse en cuenta que el IVA incluye, en su base imponible, al impuesto sobre los Ingresos Brutos, con lo cual una variación de la alícuota nominal de éste afecta la tasa efectiva del IVA.

En forma consistente con la existencia de tratamientos diferenciales, la tasa efectiva del IVA es menor que la nominal. Distinto es el caso de Ingresos Brutos, en el que, dado que es un impuesto en cascada, la tasa efectiva es mayor que la nominal.

Adicionalmente, es menester, como en el caso de las variables mencionadas con anterioridad, deflactar las tasas nominales con el fin de transformarlas a valores reales. En los gráficos 12 y 13 se presenta la evolución de ambas tasas efectivas, nominales y reales.

Gráfico 12

Tasas efectivas teóricas nominales de IVA e Ingresos Brutos para cadena agroalimentaria En porcentajes

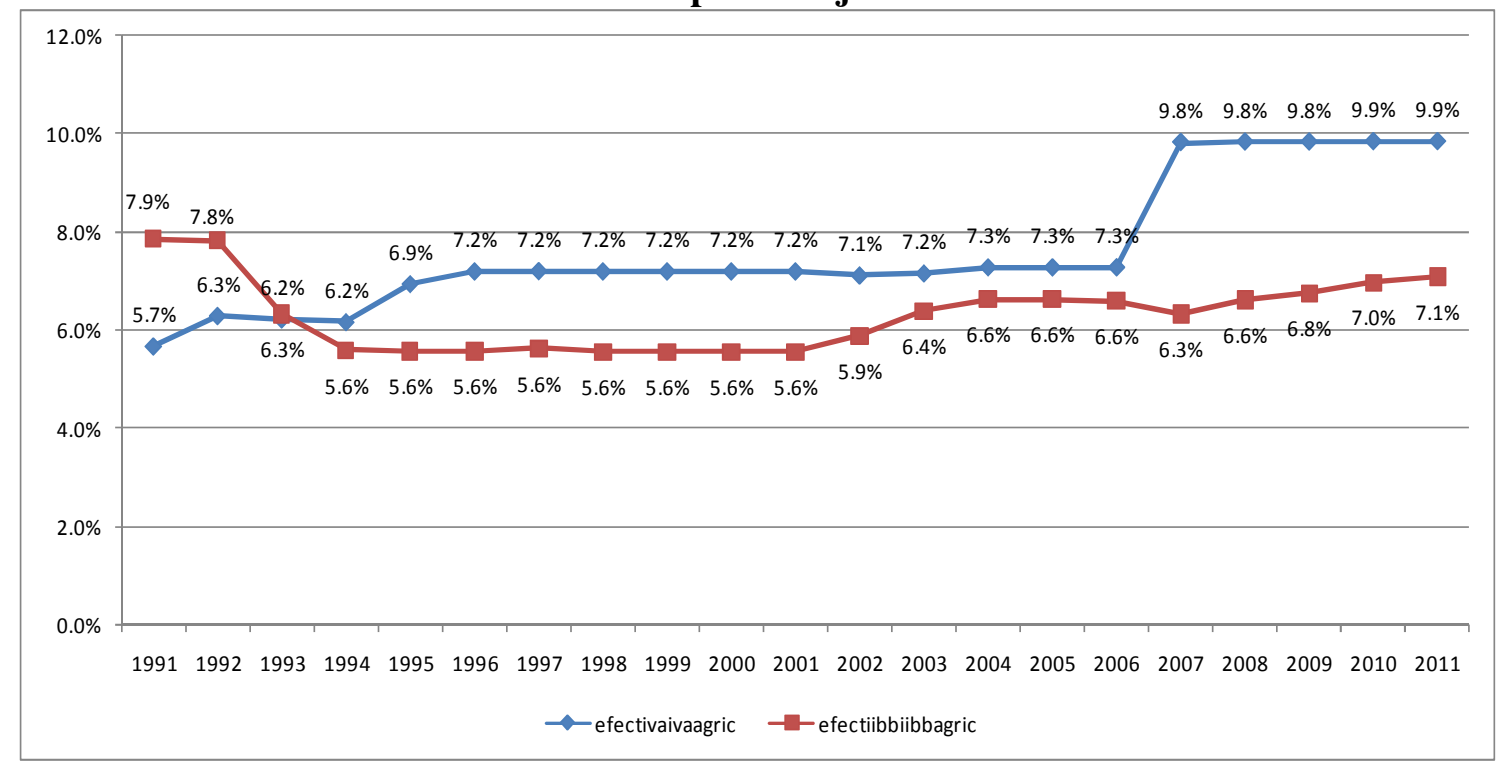

Fuente: elaboración propia en base a datos de MECON, MIP y Direcciones de Estadística provinciales 


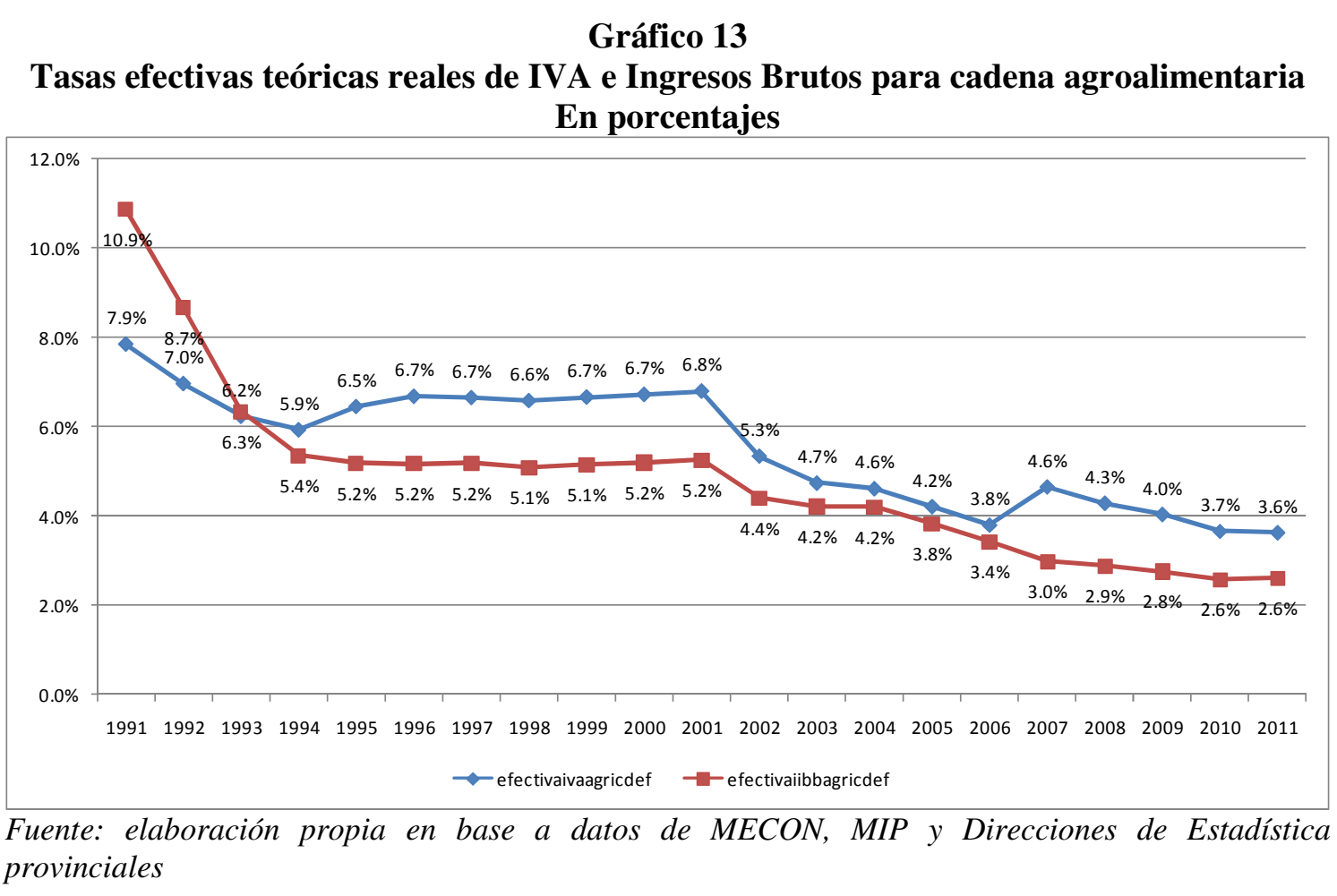

\subsection{Estrategia empírica}

De acuerdo con la teoría, y siguiendo a Devereux (2007), los impuestos provinciales son función de los impuestos federales y de los tributos de los demás estados. En consecuencia, los impuestos a los Ingresos Brutos provinciales, definidos tanto en forma de tasa nominal, como de productividad o de tasa efectiva, dependen de un efecto fijo provincial $\alpha_{i}$, un vector de variables de control específicas y un vector de variables federales.

La ecuación del modelo es $t_{i s}=\alpha_{i}+\sum_{j \neq i} \beta_{i j} t_{j s}+\gamma T_{s}+\delta^{\prime} Y_{i s}+\phi^{\prime} Z_{s}+\varepsilon_{i s}$, donde $Y_{i}$ es un vector de variables de control estaduales y $Z$ es el vector de variables federales, con $i=1, \ldots ., n$ denotando provincias, y $s=1, \ldots . S$, períodos ${ }^{69}$. La agregación de competencia tributaria horizontal implica que se adicionen al modelo las variables tributarias de las otras provincias. Para reducir la cantidad de parámetros $\beta$ a estimar, se introduce una ponderación de las variables impositivas (tasas nominales, productividad y tasas efectivas) de los otros

\footnotetext{
${ }^{69}$ Más adelante se utilizará como variable dependiente la tasa efectiva de los tributos que recaen sobre los bienes producidos por la cadena agroalimentaria (el pan), asumiendo que éstos son de demanda inelástica. En un modelo estructural debería adicionarse al modelo una ecuación que plantee esta relación. La mencionada especificación queda fuera del alcance de este trabajo.
} 
estados, $t_{-i, s}=\sum_{j \neq i} \varpi_{i j} t_{j s}$, con lo cual, la ecuación a estimar es la siguiente: $t_{i s}=\alpha_{i}+\sum_{j \neq i} \beta_{i j} t_{-i, s}+\gamma T_{s}+\delta^{\prime} Y_{i s}+\phi^{\prime} Z_{s}+\varepsilon_{i s}$

De manera similar al procedimiento llevado a cabo en Devereux et. al. (2007), Esteller Moré y Rizzo (2011) y Jacobs et. al (2007) ${ }^{70}$, entre otros, y con el fin de aproximar mejor al comportamiento estimado de la competencia tributaria horizontal, se consideran distintos tipos de ponderación normalizados a uno ${ }^{71}$. En este trabajo se presentan cuatro mecanismos: los tres primeros ponderan a las provincias limítrofes, con los criterios que se exponen a continuación y la formulación subsiguiente: $\omega_{i j}=\left\{\begin{array}{c}\frac{1}{n_{i}}-s i_{-} j \in N_{i} \\ 0_{-} s i_{-} j \notin N_{i}\end{array}\right\}$

- estados limítrofes ponderados por recaudación del impuesto: asigna mayor participación a los estados vecinos que más recaudan, para aproximar a la existencia de economías de escala en la función de recaudación

- estados limítrofes ponderados por distancia geográfica: para aproximar al costo de transporte, se calculó la distancia geográfica en kilómetros entre las capitales provinciales; el ponderador asigna mayor participación a los estados vecinos más cercanos

- estados limítrofes igualmente ponderados (denominado en lo sucesivo "ponderador lineal"): se consideran de igual manera a los estados que limitan con el propio.

Mientras tanto, el cuarto considera a todas las provincias menos la propia, de la siguiente manera:

- ponderador uniforme (denominado en lo sucesivo "ponderador igual”), es decir, aquel en el cual todos los estados tienen la misma relevancia, $\omega_{i j}=\frac{1}{n-1}$

Si el resto de las provincias reacciona a la política impositiva de los demás, la variable impositiva provincial es endógena. Se utilizan como instrumentos a otras variables de control de las demás provincias, ponderadas de acuerdo a los coeficientes anteriormente explicitados:

$$
Z_{i, s}=\sum_{j \neq i} \varpi_{i j} Y_{j s}
$$

\footnotetext{
${ }^{70}$ Jacobs, J., Ligthart, J. y Vrijburg, H. (2007): "Consumption Tax Competition among Governments: Evidence from the United States", mimeo Tilburg University

${ }^{71}$ De acuerdo con Rork (2003), la competencia horizontal se modela en términos nominales
} 
Si se considerara al gobierno federal como líder de Stackelberg $^{72}$ en el modelo teórico, la política impositiva del mismo sería exógena. Sin embargo, dado que se analiza un equilibrio de Nash en el cual se determinan las políticas en forma simultánea, se plantea que existe posible endogeneidad de los impuestos federales y se utilizan variables instrumentales federales, en consonancia con el procedimiento realizado en Besley y Rosen (1998), Devereux et. al. (2007), Esteller Moré y Rizzo (2009, 2011), Rizzo (2006), y Esteller Moré y Solé Ollé (2001, 2002).

Adicionalmente, para permitir la correlación serial de primer orden se incluye la variable dependiente rezagada en un período entre los regresores; de acuerdo al procedimiento de Esteller Moré y Rizzo (2009, 2011) y Devereux et. al. (2007). La ecuación a estimar es: $t_{i s}=\alpha_{i}+\theta t_{i, s-1}+\beta_{i-i, s}+\gamma T_{s}+\delta^{\prime} Y_{i s}+\phi^{\prime} Z_{s}+\varepsilon_{i s}$

Se incluyen, como variables de control, variables económicas federales (tasa de desocupación y el deflactor del $\mathrm{PBI}^{73}$ ), variables económicas provinciales (ingreso per cápita, desocupación, transferencias federales discriminadas por cada concepto y en términos per cápita), variables demográficas de los estados (población, población al cuadrado, para captar no linealidades, proporciones de menores y mayores de edad) y variables de índole política (en los cuadros 1 y 2 del Anexo se presentan las estadísticas básicas y las fuentes de información).

Las provincias con mayor nivel de ingreso tenderán a demandar mayores bienes públicos y tolerarán mayores impuestos; por otro lado, dado que ante un aumento del ingreso el mismo nivel de recaudación puede alcanzarse con una alícuota menor, el efecto del nivel de renta sobre la alícuota es incierto.

Del mismo modo, las transferencias que perciben los gobiernos subnacionales por parte del gobierno central pueden tener alguna influencia sobre el nivel de los impuestos provinciales y su reacción ante un incremento de los nacionales dado que reducen el costo marginal de los fondos públicos.

Como el sistema de coparticipación argentino refiere a transferencias no condicionadas, se incluyen todos los fondos enviados por la Nación a las provincias en concepto de distribución secundaria, regalías, transferencias y otros recursos nacionales y no tributarios, en términos per cápita.

\footnotetext{
${ }^{72}$ Rizzo (2006) evalúa este supuesto.

${ }^{73}$ No existen para toda la serie relevante, y para todas las provincias, datos homogéneos y consistentes sobre precios regionales que permitan utilizar esta variable como control para las tasas impositivas provinciales.
} 
Se incluyen como variables de costos las proporciones de población que utilizan los servicios públicos en forma más intensiva (mayores de 65 y menores de 14, por provincia y por año), además de la cantidad total de habitantes, su cuadrado y la densidad de población, y la tasa de desocupación por provincia ${ }^{74}$.

Adicionalmente, se incluyen tres variables dummy de índole política. La primera refiere a la relación entre la Nación y las provincias en función del partido político gobernante: para la variable presygobel valor es 1 cuando ambos, presidente y gobernador, son del mismo signo político, y cero en caso contrario.

La segunda hace alusión a la representatividad de las provincias en el gobierno nacional: cuando el gobernador de la provincia concuerda con el partido político de los diputados nacionales elegidos por su provincia, el valor de la variable gobydip es igual a 1 , y cero en caso contrario, mientras que la tercera concierne a la concordancia del partido político del presidente y los diputados nacionales.

Para poder captar efectos sobre la recaudación, sería interesante poder adicionar variables relacionadas con incumplimiento tributario o institucionalidad por provincia. Sin embargo, estos datos pudieron relevarse sólo a nivel federal, y los mismos se han adicionado al set de variables de control del modelo.

Se incluyen, como controles adicionales, variables institucionales y de índole política, a fines de intentar captar institucionalidad que pudiera relacionarse con el pago de impuestos ${ }^{75}$, como las que se mencionarán a continuación. El Overall Freedom Index abarca características relacionadas con derechos políticos (1 es libre, 2 es parcialmente libre, y 3 representa no libre), definido por la Freedom House y recopilado por USAID.

El Civil Liberties Index es un índice escalado del Civil Liberties Aggregate Score de forma tal que 1 es el más alto, y 7 es la medida más baja de libertad. Los derechos civiles comprenden a

\footnotetext{
${ }^{74}$ Se analizó la posibilidad de incluir la proporción de personas por debajo de la línea de pobreza, pero no existen series para todas las provincias en todos los períodos analizados. Además, la necesaria inclusión de los precios regionales se vio impedida por la inexistencia de índices homogéneos y completos para todo el período.

${ }^{75}$ En la literatura sobre esfuerzo tributario (Gupta (2007), Davoodi y Grigorian (2007), Pessino et. al. (2010) entre otros), se adiciona la variable de gasto en educación como control de la propensión a pagar impuestos. Si bien se reconoce que la misma puede ser un determinante importante, en este caso le agregaría una variable endógena adicional al depender el gasto de la recaudación de impuestos. Podría haberse adicionado el gasto en educación universitaria, como indicador de mayor "conciencia tributaria" pero adolecería de la misma potencial endogeneidad. Además, el dato sería sólo nacional, al igual que la cantidad de años de educación o nivel educativo máximo alcanzado, el cual no está disponible para todas las provincias, y está sesgado dado que las encuestas no indagan sobre los años de educación para los graduados.
} 
las libertades para desarrollar miradas, instituciones y autonomías individuales aparte de las del Estado (fuente USAID).

El Political Rights Index es un índice escalado del Political Rights Aggregate Score de forma tal que 1 es el más alto, y 7 es la medida más baja de libertad. Los derechos políticos permiten a la población participar libremente en el proceso político; un sistema es genuinamente libre o democrático si la población tiene posibilidad de elegir libremente a sus líderes (fuente USAID). El indicador ICRG de calidad del Gobierno, entretanto, varía entre 0 y 1; valores más altos indican mayor calidad de gobierno (fuente USAID).

La informalidad, expresada en porcentajes sobre el total de la población urbana empleada, mide la población urbana empleada en trabajos caracterizados como inseguros en relación con salarios, duración, seguridad social, etc. La definición utilizada es la informalidad en términos de productividad $^{76}$, la fuente es CEPALSTAT, Labour Overview (ILO) y SEDLAC.

\section{Presentación de los resultados}

En el presente apartado se exponen los resultados del modelo para las cuatro variables dependientes ya explicitadas, que intentan determinar la política tributaria de las provincias en relación con el impuesto a los Ingresos Brutos: la alícuota nominal, la productividad, la tasa efectiva total y la tasa efectiva del subconjunto de actividades relacionadas con la cadena agroindustrial.

Cabe consignar que para las estimaciones, tanto las variables de control como las dependientes fueron transformadas a valores constantes utilizando el deflactor del PBI. De haberse contado con estimaciones confiables y consistentes sobre los índices de precios provinciales, podría haberse utilizado esta información para deflactar los valores de las variables que no varían a nivel provincial pero sí en el tiempo, como la tasa y la productividad del IVA. En todos los casos, los errores estándares son robustos, con cluster a nivel de período.

El hecho de que existan variables que no cambian por provincia, aunque sí en el tiempo, impide, para el caso mencionado, utilizar variables de tiempo (time dummies) que capturen efectos comunes a todos los estados y, en este caso, no permiten identificar el efecto de las variables federales. Como se menciona en Devereux (2007), la existencia de variables federales que no cambian por provincia pero sí en el tiempo excluye la posibilidad de utilizar

\footnotetext{
${ }^{76}$ Ver definición en SEDLAC o IDLA (op. cit.)
} 
variables dummy que capturen el efecto de shocks agregados que generen efectos comunes a lo largo de los estados, generando un problema de identificación ${ }^{77}$.

Sin embargo, la metodología de cálculo de la variable de tasa efectiva del IVA de la cadena agroalimentaria ha permitido, en este trabajo, generar una tasa de IVA que varía por provincia al cambiar de acuerdo a las tasas de Ingresos Brutos de las provincias dado que, como fuera explicitado, el IVA incluye al impuesto a los Ingresos Brutos dentro de su base imponible (ver evolución en los gráficos 12 y 13 anteriores). En consecuencia, en adición al caso general, también se presentarán los resultados de incluir time effects en las estimaciones de la tasa efectiva de la cadena agroalimentaria ${ }^{78}$.

Se presentan inicialmente los resultados de las regresiones por OLS, efectos fijos y aleatorios (cuadros 5 a 8 del Anexo). En todos los casos, el test de significatividad de efectos fijos en las regresiones OLS implica la existencia de los mismos. Adicionalmente, el test de Hausman indica rechazo de la hipótesis de que los errores individuales no estén correlacionados con las variables explicativas (el valor del theta se acerca a uno), reflejando el hecho de que el estimador de efectos aleatorios no es consistente, a la inversa de lo que ocurre con el de efectos fijos, razón por la cual se prefiere esta especificación.

La tasa del IVA genera una reacción positiva en la tasa de Ingresos Brutos, y resulta significativa al $1 \%$ en todas las especificaciones; un aumento del $1 \%$ en la tasa del IVA genera un aumento aproximado del $0,085 \%$ en la tasa de Ingresos Brutos promedio provincial. Si se analiza la productividad, la reacción es también positiva, aunque sólo significativa para OLS; un aumento de la productividad del IVA genera un incremento en la productividad de IIBB.

En cuanto al resto de los modelos y especificaciones, también puede apreciarse que las variables generan una reacción positiva, y significativa, tanto para el caso de la tasa efectiva del IVA, como para el caso de las variables que fueron relacionadas con la cadena agroindustrial; el aumento de la tasa efectiva en el IVA genera un aumento de la tasa efectiva de Ingresos Brutos.

En los cuadros 9 a 17 del Anexo se muestran los resultados de incluir competencia tributaria horizontal en los modelos de efectos fijos y aleatorios. Como puede observarse allí, si bien el

\footnotetext{
${ }^{77}$ Empero, si las variables dependientes pudieran variar por provincia, el problema de identificación podría resolverse. Esto podría lograrse con estimaciones consistentes para toda la serie analizada de índices de precios provinciales (Esteller Moré y Rizzo (2011)).

${ }^{78}$ Se obtiene en consecuencia un efecto similar al de Esteller Moré y Rizzo (2011), que deflactan las alícuotas nominales de los tributos específicos federales con índices de precios diferenciales por estado.
} 
test de Hausman y el valor del theta llevan a preferir efectos fijos, continúa existiendo fuerte evidencia de una reacción de los impuestos provinciales ante variaciones en la tasa del IVA nacional (aunque la fuerte significatividad se reduce ligeramente).

En cuanto a las variables que se relacionan con el impacto de las tasas impositivas del impuesto a los Ingresos Brutos de las provincias limítrofes, si bien afectan positivamente a la tasa propia, como la tasa federal, los resultados que presentan son, en general, no significativos. Para el caso de la tasa del IVA, la reacción es negativa aunque no significativa para todos los casos.

La productividad del IVA impacta positiva, aunque no en todos los casos significativamente, para prácticamente todas las especificaciones, en la de Ingresos Brutos, después de añadir al modelo la competencia horizontal entre provincias. Esta variable, tiene una reacción positiva y significativa para todos los casos de competencia entre provincias, excepto el caso de los ponderadores iguales.

Para los casos de las tasas efectivas, tanto el caso general como la tasa de la cadena agroindustrial, los valores de los coeficientes asociados a la competencia vertical son positivos, mientras que los relacionados con competencia horizontal son no significativos, y negativos en la mayoría de los casos.

Sin embargo, varias consideraciones deben efectuarse en relación a estas especificaciones. Las primeras tienen que ver con la existencia de autocorrelación y heteroscedasticidad. En el Anexo (cuadros 5 a 16) se muestran los resultados de los tests de Wooldridge, de autocorrelación serial de primer orden, y de Wald para heteroscedasticidad, rechazándose, en todos los casos, las hipótesis nulas de ausencia de autocorrelación (en todos los casos se rechaza la hipótesis nula de ausencia de correlación serial al 1\%) y heteroscedasticidad.

Al apreciar los gráficos 5 a 13 anteriores, puede verse que tanto la recaudación del IVA como de Ingresos Brutos medidas en puntos del PBI, como las variables de tasas y productividad, y pese a las diferencias observadas en los niveles, son altamente persistentes a lo largo del tiempo, es decir, que los valores de cada período guardan estrecha correspondencia con los de los períodos previos. Esto guarda estrecha consistencia con los valores de los mencionados tests de Wooldridge, en donde se aprecia que existe evidencia de autocorrelación de primer orden en los residuos.

La literatura sobre datos de panel hace referencia a dos fuentes de persistencia. La primera refiere a la especificación mediante correlación serial en el término de error, mientras que la 
segunda intenta capturar la persistencia a través de incluir la variable dependiente rezagada. En este trabajo se llevarán a cabo las estimaciones relacionadas con ambas especificaciones.

En relación con la primera de las fuentes de persistencia mencionada, asumiendo correlación serial en el error, el modelo empírico es ahora ${ }^{79}$ :

$$
t_{i s}=\alpha_{i}+\theta t_{i, s-1}+\beta_{i-i, s}+\gamma T_{s}+\delta^{\prime} Y_{i s}+\phi^{\prime} Z_{s}+\varepsilon_{i s}
$$

donde

$$
\varepsilon_{i s}=\rho_{i} \varepsilon_{i s-1}+v_{i s}
$$

Se reestiman los modelos mediante Mínimos Cuadrados Generalizados, empleando una estructura de error heteroscedástico entre paneles, y especificando autocorrelación de orden 1 $(A R(1))$ para los errores entre paneles con un coeficiente específico para cada panel $\left(\rho_{i} \neq \rho_{j} \forall i \neq j\right)$.

En los cuadros 3 a 7 se muestran los resultados de las estimaciones para cada una de las variables independientes, adicionando efectos individuales y la competencia tributaria horizontal en función de las ponderaciones mencionadas. Para el caso de la tasa real del IVA, por ejemplo (cuadro 3), se aprecia una relación positiva y significativa al 1\%; la competencia horizontal, la cual también es positiva y significativa, aunque sólo para la ponderación de competencia tributaria en el caso de ponderadores lineales (aquellos que consideran de igual manera a las provincias limítrofes) aunque en este caso la reacción es negativa (un aumento de las tasas de Ingresos Brutos de las provincias limítrofes disminuye la alícuota propia).

Los resultados para las variables de control son significativos y negativos en varios casos, como las variables de ingreso per cápita, población, proporción de mayores de 65 , tasa de desocupación y transferencias (estos casos podrían estar indicando que ante aumentos de estas variables se generan incrementos en la base imponible, que llevan a alcanzar la misma recaudación con una reducción de la tasa impositiva), y la informalidad (en este caso, en forma consistente con los resultados de los modelos de esfuerzo tributario ${ }^{80}$, una reducción en la informalidad implicaría mayor demanda de bienes públicos y mayores impuestos).

En el caso de la productividad (cuadro 4), la reacción vertical es no significativa, a diferencia de la competencia horizontal (los casos de ponderadores de distancias e iguales, siendo ambas reacciones positivas y significativas al $1 \%$ ).

\footnotetext{
${ }^{79}$ Esta explicación sigue a Gupta (2007)

${ }^{80}$ Por ejemplo Davoodi y Grigorian (2007), en donde una reducción en la informalidad se asocia a un incremento en la recaudación tributaria.
} 


\section{Cuadro 3}

Resultados de Mínimos Cuadrados Generalizados con heteroscedasticidad Incorporando Panel Specific Autocorrelation Coefficients

Variable dependiente: tasa de Ingresos Brutos

\begin{tabular}{|c|c|c|c|c|c|}
\hline VARIABLES & $\begin{array}{l}\text { GLS Ind effects } \\
\text { Tasa IIBB real }\end{array}$ & $\begin{array}{l}\text { GLS Ind effects } \\
\text { Tasa IIBB real }\end{array}$ & $\begin{array}{c}\text { GLS Ind effects } \\
\text { Tasa IIBB real }\end{array}$ & $\begin{array}{c}\text { GLS Ind effects } \\
\text { Tasa IIBB real }\end{array}$ & $\begin{array}{c}\text { GLS Ind effects } \\
\text { Tasa IIBB real }\end{array}$ \\
\hline Tasa IVA real & $\begin{array}{l}0.0841853 \\
(10.593)^{* * *}\end{array}$ & $\begin{array}{l}0.0848292 \\
(10.606)^{* \star *}\end{array}$ & $\begin{array}{l}0.0840438 \\
(10.591)^{* * *}\end{array}$ & $\begin{array}{l}0.0867472 \\
(11.094)^{* \star *}\end{array}$ & $\begin{array}{l}0.0859231 \\
(9.867)^{* * *}\end{array}$ \\
\hline gobydip & $\begin{array}{c}-0.0010363 \\
(-0.050)\end{array}$ & $\begin{array}{c}0.0002531 \\
(0.012)\end{array}$ & $\begin{array}{c}0.0001184 \\
(0.006)\end{array}$ & $\begin{array}{c}-0.0011037 \\
(-0.054)\end{array}$ & $\begin{array}{c}-0.0019098 \\
(-0.092)\end{array}$ \\
\hline presygob & $\begin{array}{c}0.0471368 \\
(1.834)^{*}\end{array}$ & $\begin{array}{c}0.0474800 \\
(1.848)^{*}\end{array}$ & $\begin{array}{c}0.0451032 \\
(1.744)^{*}\end{array}$ & $\begin{array}{c}0.0472163 \\
(1.866)^{*}\end{array}$ & $\begin{array}{c}0.0480859 \\
(1.863)^{*}\end{array}$ \\
\hline presydip & $\begin{array}{c}-0.0067138 \\
(-0.349)\end{array}$ & $\begin{array}{c}-0.0067588 \\
(-0.352)\end{array}$ & $\begin{array}{c}-0.0056798 \\
(-0.295)\end{array}$ & $\begin{array}{c}-0.0055866 \\
(-0.297)\end{array}$ & $\begin{array}{c}-0.0052438 \\
(-0.272)\end{array}$ \\
\hline deflactornac & $\begin{array}{l}-0.1981302 \\
(-5.917)^{* * *}\end{array}$ & $\begin{array}{l}-0.1968342 \\
(-5.826)^{* * *}\end{array}$ & $\begin{array}{l}-0.2015416 \\
(-6.000)^{* \star *}\end{array}$ & $\begin{array}{l}-0.1873713 \\
(-5.837)^{* * *}\end{array}$ & $\begin{array}{l}-0.1841534 \\
(-4.091)^{* * *}\end{array}$ \\
\hline tasadesocupacion & $\begin{array}{l}-0.0136022 \\
(-4.107)^{* \star *}\end{array}$ & $\begin{array}{l}-0.0134371 \\
(-4.063)^{\star * *}\end{array}$ & $\begin{array}{l}-0.0134366 \\
(-4.079)^{* * *}\end{array}$ & $\begin{array}{l}-0.0140535 \\
(-4.273)^{* * *}\end{array}$ & $\begin{array}{l}-0.0136537 \\
(-3.863)^{\star * *}\end{array}$ \\
\hline subtotalnacpercapita & $\begin{array}{c}0.0033391 \\
(0.636)\end{array}$ & $\begin{array}{c}0.0032133 \\
(0.616)\end{array}$ & $\begin{array}{c}0.0036640 \\
(0.699)\end{array}$ & $\begin{array}{c}0.0024565 \\
(0.471)\end{array}$ & $\begin{array}{c}0.0032214 \\
(0.619)\end{array}$ \\
\hline regaliaspercapita & $\begin{array}{l}0.0942927 \\
(8.048)^{\star \star \star}\end{array}$ & $\begin{array}{l}0.0952084 \\
(8.197)^{\star * \star}\end{array}$ & $\begin{array}{l}0.0949817 \\
(8.207)^{\star \star \star}\end{array}$ & $\begin{array}{l}0.1054961 \\
(9.358)^{\star * *}\end{array}$ & $\begin{array}{l}0.0947111 \\
(8.078)^{\star * \star}\end{array}$ \\
\hline notribpercapita & $\begin{array}{c}0.0268589 \\
(1.600)\end{array}$ & $\begin{array}{c}0.0260665 \\
(1.547)\end{array}$ & $\begin{array}{c}0.0253784 \\
(1.513)\end{array}$ & $\begin{array}{c}0.0274982 \\
(1.639)\end{array}$ & $\begin{array}{c}0.0268296 \\
(1.589)\end{array}$ \\
\hline transfpercapita & $\begin{array}{l}-0.0397316 \\
(-2.968)^{\star \star \star}\end{array}$ & $\begin{array}{l}-0.0394519 \\
(-2.930)^{\star * *}\end{array}$ & $\begin{array}{l}-0.0402397 \\
(-3.005)^{\star * *}\end{array}$ & $\begin{array}{c}-0.0347365 \\
(-2.452)^{\star \star}\end{array}$ & $\begin{array}{l}-0.0397973 \\
(-2.967)^{\star \star \star}\end{array}$ \\
\hline rentasproppercapita & $\begin{array}{c}-0.0732823 \\
(-0.830)\end{array}$ & $\begin{array}{c}-0.0650274 \\
(-0.739)\end{array}$ & $\begin{array}{c}-0.0715475 \\
(-0.810)\end{array}$ & $\begin{array}{c}-0.0359023 \\
(-0.389)\end{array}$ & $\begin{array}{c}-0.0748306 \\
(-0.843)\end{array}$ \\
\hline deficittotalpercapita & $\begin{array}{c}-0.0075550 \\
(-1.111)\end{array}$ & $\begin{array}{c}-0.0076552 \\
(-1.120)\end{array}$ & $\begin{array}{c}-0.0072294 \\
(-1.053)\end{array}$ & $\begin{array}{c}-0.0065467 \\
(-0.946)\end{array}$ & $\begin{array}{c}-0.0079568 \\
(-1.161)\end{array}$ \\
\hline ingresorealpercapita & $\begin{array}{l}-0.0000216 \\
(-3.412)^{\star \star *}\end{array}$ & $\begin{array}{l}-0.0000216 \\
(-3.400)^{\star * *}\end{array}$ & $\begin{array}{l}-0.0000218 \\
(-3.451)^{\star * \star}\end{array}$ & $\begin{array}{l}-0.0000178 \\
(-2.807)^{\star \star \star}\end{array}$ & $\begin{array}{l}-0.0000221 \\
(-3.519)^{\star \star *}\end{array}$ \\
\hline poblacion & $\begin{array}{l}-0.1124292 \\
(-2.894)^{\star \star \star}\end{array}$ & $\begin{array}{l}-0.1133591 \\
(-2.902)^{\star * *}\end{array}$ & $\begin{array}{l}-0.1148729 \\
(-2.922)^{\star * *}\end{array}$ & $\begin{array}{l}-0.1088935 \\
(-2.659)^{\star \star \star}\end{array}$ & $\begin{array}{l}-0.1123924 \\
(-3.007)^{\star \star \star}\end{array}$ \\
\hline poblacionsq & $\begin{array}{l}0.0143837 \\
(4.707)^{\star * \star}\end{array}$ & $\begin{array}{l}0.0144954 \\
(4.747)^{\star \star \star}\end{array}$ & $\begin{array}{l}0.0147128 \\
(4.746)^{\star * *}\end{array}$ & $\begin{array}{l}0.0145994 \\
(4.563)^{\star * \star}\end{array}$ & $\begin{array}{l}0.0142000 \\
(4.735)^{\star \star \star}\end{array}$ \\
\hline propmenor14 & $\begin{array}{l}0.0468677 \\
(5.378)^{\star * *}\end{array}$ & $\begin{array}{l}0.0462950 \\
(5.315)^{\star \star *}\end{array}$ & $\begin{array}{l}0.0458105 \\
(5.281)^{\star \star \star}\end{array}$ & $\begin{array}{l}0.0453164 \\
\left(5.6588^{\star * \star}\right.\end{array}$ & $\begin{array}{l}0.0466493 \\
(5.339)^{\star \star \star}\end{array}$ \\
\hline propmayor65 & $\begin{array}{l}-0.1823298 \\
(-5.235)^{\star * *}\end{array}$ & $\begin{array}{l}-0.1826065 \\
(-5.325)^{\star * *}\end{array}$ & $\begin{array}{l}-0.1819740 \\
(-5.302)^{* * *}\end{array}$ & $\begin{array}{c}-0.2018285 \\
(-6.039)^{* * *}\end{array}$ & $\begin{array}{c}-0.1884217 \\
(-5.068)^{\star * *}\end{array}$ \\
\hline densidad & $\begin{array}{c}-0.0809133 \\
(-0.509)\end{array}$ & $\begin{array}{c}-0.0841708 \\
(-0.532)\end{array}$ & $\begin{array}{c}-0.0817603 \\
(-0.512)\end{array}$ & $\begin{array}{c}-0.1142571 \\
(-0.762)\end{array}$ & $\begin{array}{c}-0.0992477 \\
(-0.616)\end{array}$ \\
\hline f_overall & $\begin{array}{c}0.0165587 \\
(0.346)\end{array}$ & $\begin{array}{c}0.0131174 \\
(0.273)\end{array}$ & $\begin{array}{c}0.0147446 \\
(0.308)\end{array}$ & $\begin{array}{c}-0.0012540 \\
(-0.027)\end{array}$ & $\begin{array}{c}0.0137543 \\
(0.283)\end{array}$ \\
\hline f_civil & $\begin{array}{l}0.2208195 \\
(5.009)^{* * *}\end{array}$ & $\begin{array}{l}0.2242101 \\
(5.088)^{\star * \star}\end{array}$ & $\begin{array}{l}0.2251303 \\
(5.125)^{\star * *}\end{array}$ & $\begin{array}{l}0.2194892 \\
(5.042)^{* * *}\end{array}$ & $\begin{array}{l}0.2262779 \\
(4.889)^{\star * \star}\end{array}$ \\
\hline f_politic & $\begin{array}{l}-0.1820447 \\
(-9.356)^{\star * *}\end{array}$ & $\begin{array}{l}-0.1825181 \\
(-9.364)^{\star \star *}\end{array}$ & $\begin{array}{l}-0.1826633 \\
(-9.395)^{* * *}\end{array}$ & $\begin{array}{l}-0.1808726 \\
(-9.346)^{\star \star \star}\end{array}$ & $\begin{array}{l}-0.1848534 \\
(-9.143)^{\star \star \star}\end{array}$ \\
\hline icrg_qog & $\begin{array}{c}0.3797782 \\
(1.536)\end{array}$ & $\begin{array}{c}0.3714715 \\
(1.494)\end{array}$ & $\begin{array}{c}0.3639614 \\
(1.469)\end{array}$ & $\begin{array}{c}0.2084558 \\
(0.838)\end{array}$ & $\begin{array}{c}0.4178883 \\
(1.589)\end{array}$ \\
\hline informal & $\begin{array}{l}-0.0724155 \\
(-11.340)^{\star * *}\end{array}$ & $\begin{array}{l}-0.0728578 \\
(-11.121)^{\star * *}\end{array}$ & $\begin{array}{l}-0.0720905 \\
\left(-10.9577^{\star * *}\right.\end{array}$ & $\begin{array}{l}-0.0768791 \\
(-11.955)^{\star * *}\end{array}$ & $\begin{array}{c}-0.0741532 \\
(-9.347)^{\star \star \star}\end{array}$ \\
\hline limitestasaspondrecaudacion & & $\begin{array}{c}-0.0054639 \\
(-0.126)\end{array}$ & & & \\
\hline limitestasasponddistancias & & & $\begin{array}{c}0.0246892 \\
(0.491)\end{array}$ & & \\
\hline limitestasaspondlineales & & & & $\begin{array}{c}-0.2144801 \\
(-2.985)^{* * *}\end{array}$ & \\
\hline limitestasaspondiguales & & & & & $\begin{array}{c}-0.0854818 \\
(-0.414)\end{array}$ \\
\hline Constant & $\begin{array}{l}2.9581926 \\
(4.183)^{\star * \star}\end{array}$ & $\begin{array}{l}2.9842722 \\
(4.219)^{\star * \star}\end{array}$ & $\begin{array}{l}2.8918223 \\
(4.009)^{\star * *}\end{array}$ & $\begin{array}{l}3.8002804 \\
(5.021)^{\star * \star}\end{array}$ & $\begin{array}{l}3.2367402 \\
(3.424)^{\star * \star}\end{array}$ \\
\hline Observations & 504 & 504 & 504 & 504 & 504 \\
\hline
\end{tabular}

Columna I: sin competencia horizontal; columnas II a V: competencia horizontal y vertical. Estadísticos robustos entre paréntesis: “*”: significativo al 10\%; “**”: significativo al 5\%; “***”: significativo al $1 \%$.

No se encuentra evidencia de significatividad en la reacción de las tasas efectivas de IIBB ante cambios en las alícuotas de provincias limítrofes (aunque son negativas), aunque sí en relación con las tasas efectivas del IVA (cuadro 5). La informalidad, la tasa de desocupación, 
la población y la proporción de mayores de 65 años mantienen su significatividad y su relación negativa con la tasa efectiva de Ingresos Brutos provinciales.

\section{Cuadro 4}

Resultados de Mínimos Cuadrados Generalizados con heteroscedasticidad Incorporando Panel Specific Autocorrelation Coefficients

Variable dependiente: productividad ponderada de IIBB

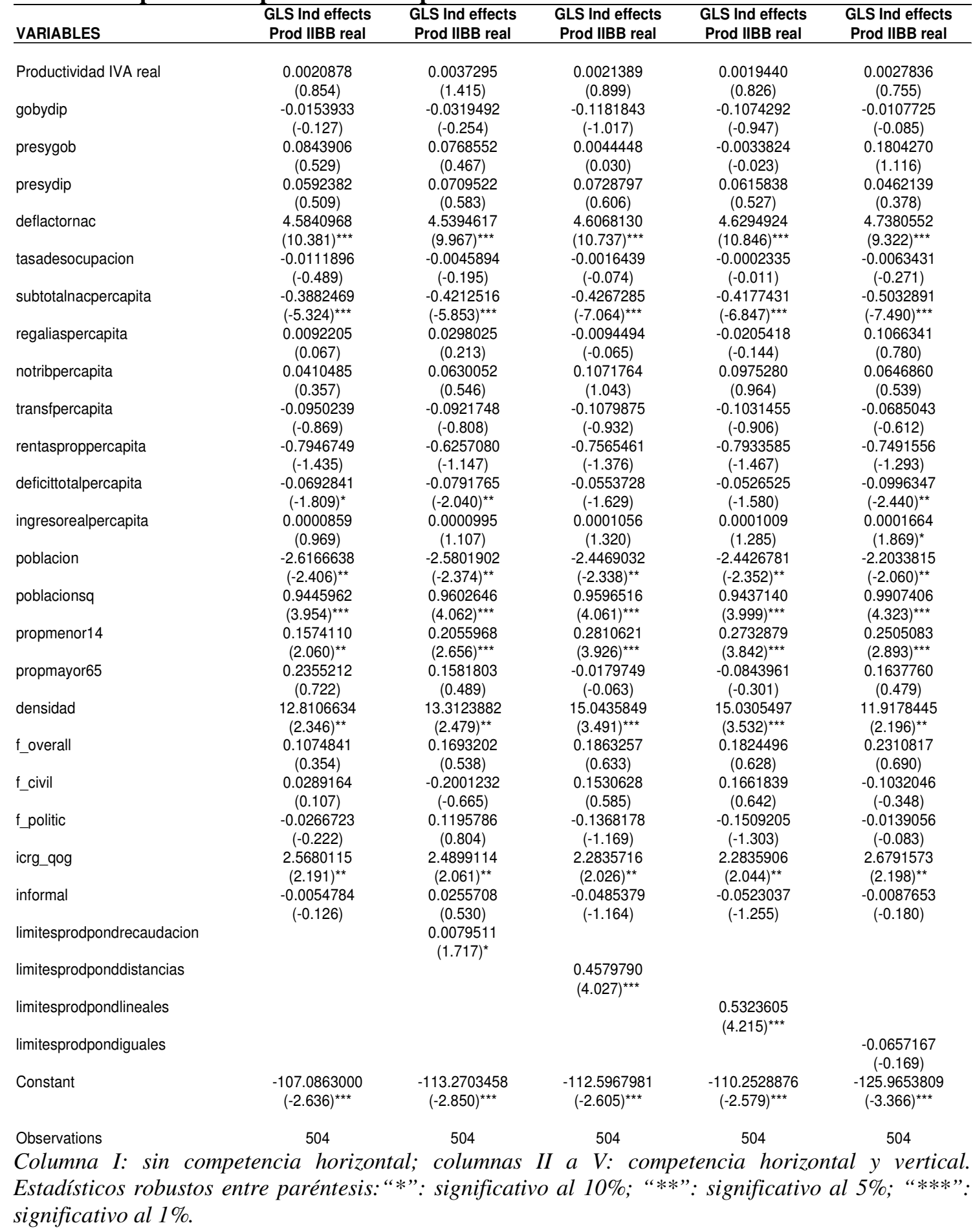




\section{Cuadro 5}

Resultados de Mínimos Cuadrados Generalizados con heteroscedasticidad Incorporando Panel Specific Autocorrelation Coefficients Variable dependiente: tasa efectiva de IIBB

\begin{tabular}{|c|c|c|c|c|c|}
\hline VARIABLES & $\begin{array}{c}\text { GLS Ind effects } \\
\text { Tasa efectiva IIBB } \\
\text { real }\end{array}$ & $\begin{array}{c}\text { GLS Ind effects } \\
\text { Tasa efectiva IIBB } \\
\text { real }\end{array}$ & $\begin{array}{c}\text { GLS Ind effects } \\
\text { Tasa efectiva IIBB } \\
\text { real }\end{array}$ & $\begin{array}{c}\text { GLS Ind effects } \\
\text { Tasa efectiva IIBB } \\
\text { real }\end{array}$ & $\begin{array}{c}\text { GLS Ind effects } \\
\text { Tasa efectiva IIBB } \\
\text { real }\end{array}$ \\
\hline Tasa efectiva IVA real & $\begin{array}{l}0.5233725 \\
(13.292)^{\star * *}\end{array}$ & $\begin{array}{l}0.5284792 \\
(13.314)^{\star * \star}\end{array}$ & $\begin{array}{l}0.5291852 \\
(13.203)^{\star * *}\end{array}$ & $\begin{array}{l}0.5312426 \\
(13.171)^{\star * \star}\end{array}$ & $\begin{array}{l}0.5329178 \\
(13.019)^{\star * *}\end{array}$ \\
\hline gobydip & $\begin{array}{c}-0.0322270 \\
(-0.320)\end{array}$ & $\begin{array}{c}-0.0472612 \\
(-0.464)\end{array}$ & $\begin{array}{c}-0.0668598 \\
(-0.646)\end{array}$ & $\begin{array}{c}-0.0705528 \\
(-0.683)\end{array}$ & $\begin{array}{c}-0.0505344 \\
(-0.486)\end{array}$ \\
\hline presygob & $\begin{array}{c}0.0967796 \\
(0.728)\end{array}$ & $\begin{array}{c}0.0872998 \\
(0.659)\end{array}$ & $\begin{array}{c}0.0994444 \\
(0.745)\end{array}$ & $\begin{array}{c}0.0910930 \\
(0.683)\end{array}$ & $\begin{array}{c}0.0920516 \\
(0.683)\end{array}$ \\
\hline presydip & $\begin{array}{c}-0.0268930 \\
(-0.269)\end{array}$ & $\begin{array}{c}-0.0221996 \\
(-0.222)\end{array}$ & $\begin{array}{c}-0.0215596 \\
(-0.213)\end{array}$ & $\begin{array}{c}-0.0226086 \\
(-0.224)\end{array}$ & $\begin{array}{c}-0.0139206 \\
(-0.138)\end{array}$ \\
\hline deflactornac & $\begin{array}{c}0.0743472 \\
(0.429)\end{array}$ & $\begin{array}{c}0.1102217 \\
(0.613)\end{array}$ & $\begin{array}{c}0.0883865 \\
(0.494)\end{array}$ & $\begin{array}{c}0.0761062 \\
(0.427)\end{array}$ & $\begin{array}{c}0.1155180 \\
(0.637)\end{array}$ \\
\hline tasadesocupacion & $\begin{array}{l}-0.0960941 \\
(-5.608)^{\star * *}\end{array}$ & $\begin{array}{l}-0.0939928 \\
(-5.461)^{\star \star \star}\end{array}$ & $\begin{array}{l}-0.0919816 \\
(-5.307)^{\star \star \star}\end{array}$ & $\begin{array}{l}-0.0920816 \\
(-5.306)^{\star \star \star}\end{array}$ & $\begin{array}{l}-0.0956915 \\
(-5.526)^{\star * *}\end{array}$ \\
\hline subtotalnacpercapita & $\begin{array}{c}0.0108967 \\
(0.406)\end{array}$ & $\begin{array}{c}0.0080634 \\
(0.298)\end{array}$ & $\begin{array}{c}0.0119760 \\
(0.436)\end{array}$ & $\begin{array}{c}0.0137188 \\
(0.502)\end{array}$ & $\begin{array}{c}0.0133242 \\
(0.489)\end{array}$ \\
\hline regaliaspercapita & $\begin{array}{l}0.4486454 \\
(5.267)^{\star \star \star}\end{array}$ & $\begin{array}{l}0.4409676 \\
(5.146)^{\star \star \star}\end{array}$ & $\begin{array}{l}0.4537812 \\
(5.250)^{\star \star *}\end{array}$ & $\begin{array}{l}0.4558288 \\
(5.215)^{\star \star \star}\end{array}$ & $\begin{array}{l}0.4536280 \\
(5.262)^{\star \star \star}\end{array}$ \\
\hline notribpercapita & $\begin{array}{c}-0.1656361 \\
(-2.136)^{\star \star}\end{array}$ & $\begin{array}{c}-0.1661771 \\
(-2.133)^{\star *}\end{array}$ & $\begin{array}{c}-0.1681213 \\
(-2.152)^{* *}\end{array}$ & $\begin{array}{c}-0.1678054 \\
(-2.145)^{* *}\end{array}$ & $\begin{array}{c}-0.1646732 \\
(-2.106)^{\star *}\end{array}$ \\
\hline transfpercapita & $\begin{array}{c}0.0064892 \\
(0.092)\end{array}$ & $\begin{array}{c}0.0075227 \\
(0.106)\end{array}$ & $\begin{array}{c}0.0046177 \\
(0.065)\end{array}$ & $\begin{array}{c}0.0047069 \\
(0.066)\end{array}$ & $\begin{array}{c}0.0102027 \\
(0.143)\end{array}$ \\
\hline rentasproppercapita & $\begin{array}{c}-0.8390430 \\
(-1.453)\end{array}$ & $\begin{array}{c}-0.7948856 \\
(-1.402)\end{array}$ & $\begin{array}{c}-0.8337042 \\
(-1.459)\end{array}$ & $\begin{array}{c}-0.7962287 \\
(-1.400)\end{array}$ & $\begin{array}{c}-0.8049287 \\
(-1.400)\end{array}$ \\
\hline deficittotalpercapita & $\begin{array}{c}-0.0026335 \\
(-0.073)\end{array}$ & $\begin{array}{c}-0.0037526 \\
(-0.104)\end{array}$ & $\begin{array}{c}-0.0037250 \\
(-0.103)\end{array}$ & $\begin{array}{c}-0.0036300 \\
(-0.100)\end{array}$ & $\begin{array}{c}-0.0051278 \\
(-0.143)\end{array}$ \\
\hline ingresorealpercapita & $\begin{array}{c}-0.0000712 \\
(-2.209)^{\star *}\end{array}$ & $\begin{array}{c}-0.0000745 \\
(-2.317)^{\star *}\end{array}$ & $\begin{array}{c}-0.0000680 \\
(-2.142)^{* *}\end{array}$ & $\begin{array}{c}-0.0000682 \\
(-2.175)^{\star *}\end{array}$ & $\begin{array}{c}-0.0000730 \\
(-2.227)^{\star *}\end{array}$ \\
\hline poblacion & $\begin{array}{c}-0.2438171 \\
(-1.625)\end{array}$ & $\begin{array}{c}-0.2875721 \\
(-1.894)^{\star}\end{array}$ & $\begin{array}{c}-0.2631007 \\
(-1.688)^{\star}\end{array}$ & $\begin{array}{c}-0.3011164 \\
(-1.970)^{\star \star}\end{array}$ & $\begin{array}{c}-0.2534171 \\
(-1.665)^{\star}\end{array}$ \\
\hline poblacionsq & $\begin{array}{l}0.0476678 \\
(3.757)^{\star \star \star}\end{array}$ & $\begin{array}{l}0.0484745 \\
(3.842)^{\star * *}\end{array}$ & $\begin{array}{l}0.0472353 \\
(3.704)^{\star * *}\end{array}$ & $\begin{array}{l}0.0493512 \\
(3.938)^{\star \star \star *}\end{array}$ & $\begin{array}{l}0.0473270 \\
(3.748)^{\star \star *}\end{array}$ \\
\hline propmenor14 & $\begin{array}{l}0.3033787 \\
(6.455)^{\star \star \star}\end{array}$ & $\begin{array}{l}0.3012840 \\
(6.335)^{\star \star \star}\end{array}$ & $\begin{array}{l}0.3017832 \\
(6.265)^{\star * \star}\end{array}$ & $\begin{array}{l}0.2996441 \\
(6.216)^{\star \star \star *}\end{array}$ & $\begin{array}{l}0.3111290 \\
(6.480)^{\star * *}\end{array}$ \\
\hline propmayor65 & $\begin{array}{c}-1.4108259 \\
(-8.739)^{\star * *}\end{array}$ & $\begin{array}{c}-1.3780103 \\
(-8.490)^{\star * *}\end{array}$ & $\begin{array}{c}-1.4069155 \\
(-8.519)^{\star \star \star}\end{array}$ & $\begin{array}{c}-1.4071409 \\
(-8.405)^{\star * \star}\end{array}$ & $\begin{array}{c}-1.4393932 \\
(-8.615)^{* * *}\end{array}$ \\
\hline densidad & $\begin{array}{c}-2.0357301 \\
(-2.340)^{* *}\end{array}$ & $\begin{array}{c}-1.9170891 \\
(-2.286)^{* *}\end{array}$ & $\begin{array}{c}-1.8605540 \\
(-2.312)^{\star *}\end{array}$ & $\begin{array}{c}-1.8090760 \\
(-2.298)^{\star *}\end{array}$ & $\begin{array}{c}-2.1132857 \\
(-2.376)^{\star *}\end{array}$ \\
\hline f_overall & $\begin{array}{c}-0.4307422 \\
(-1.710)^{*}\end{array}$ & $\begin{array}{c}-0.4314222 \\
(-1.694)^{*}\end{array}$ & $\begin{array}{c}-0.4120541 \\
(-1.593)\end{array}$ & $\begin{array}{c}-0.4081485 \\
(-1.571)\end{array}$ & $\begin{array}{c}-0.3876999 \\
(-1.502)\end{array}$ \\
\hline f_civil & $\begin{array}{l}1.0596996 \\
(4.545)^{\star * \star}\end{array}$ & $\begin{array}{l}1.0797488 \\
(4.617)^{\star \star \star}\end{array}$ & $\begin{array}{l}1.0819727 \\
(4.612)^{\star * *}\end{array}$ & $\begin{array}{l}1.0908957 \\
(4.644)^{\star * *}\end{array}$ & $\begin{array}{l}1.0669617 \\
(4.499)^{\star * \star}\end{array}$ \\
\hline f_politic & $\begin{array}{c}-0.5485982 \\
(-5.063)^{\star \star *}\end{array}$ & $\begin{array}{l}-0.5632460 \\
(-5.149)^{\star \star \star}\end{array}$ & $\begin{array}{l}-0.5773300 \\
(-5.276)^{\star * \star}\end{array}$ & $\begin{array}{l}-0.5836472 \\
(-5.317)^{\star \star \star}\end{array}$ & $\begin{array}{c}-0.5715383 \\
(-5.010)^{\star * \star}\end{array}$ \\
\hline icrg_qog & $\begin{array}{c}-5.4189593 \\
(-4.641)^{* * *}\end{array}$ & $\begin{array}{r}-5.5004580 \\
(-4.665)^{* * *}\end{array}$ & $\begin{array}{c}-5.4989108 \\
(-4.635)^{\star * \star}\end{array}$ & $\begin{array}{c}-5.5944422 \\
(-4.697)^{\star * *}\end{array}$ & $\begin{array}{l}-5.4452775 \\
(-4.605)^{\star * *}\end{array}$ \\
\hline informal & $\begin{array}{l}-0.4789508 \\
(-15.067)^{\star \star \star}\end{array}$ & $\begin{array}{l}-0.4871498 \\
(-14.939)^{\star * *}\end{array}$ & $\begin{array}{l}-0.4900262 \\
(-14.676)^{\star * *}\end{array}$ & $\begin{array}{l}-0.4941462 \\
(-14.697)^{\star * *}\end{array}$ & $\begin{array}{l}-0.4928054 \\
(-13.218)^{* * *}\end{array}$ \\
\hline limitestasasefnomrecaudacion & & $\begin{array}{c}-0.0794987 \\
(-0.967)\end{array}$ & & & \\
\hline limitestasasefnomdistancias & & & $\begin{array}{c}-0.1507279 \\
(-1.312)\end{array}$ & & \\
\hline limitestasasefnomlineales & & & & $\begin{array}{c}-0.1926314 \\
(-1.543)\end{array}$ & \\
\hline limitestasasefnomiguales & & & & & $\begin{array}{c}-0.2028003 \\
(-0.825)\end{array}$ \\
\hline Constant & $\begin{array}{c}24.6521264 \\
(8.661)^{\star \star \star}\end{array}$ & $\begin{array}{c}25.4014910 \\
(8.612)^{\star \star \star}\end{array}$ & $\begin{array}{c}25.8367626 \\
(8.722)^{\star \star \star}\end{array}$ & $\begin{array}{c}26.3929042 \\
(8.767)^{\star \star \star}\end{array}$ & $\begin{array}{c}26.0202257 \\
(7.571)^{\star \star \star}\end{array}$ \\
\hline Observations & 504 & 504 & 504 & 504 & 504 \\
\hline
\end{tabular}

Columna I: sin competencia horizontal; columnas II a V: competencia horizontal y vertical. Estadísticos robustos entre paréntesis: “*”: significativo al 10\%; “**”: significativo al 5\%; “***”: significativo al $1 \%$.

En relación con las tasas efectivas de la cadena agroindustrial, la reacción vertical es positiva y significativa, mientras que la reacción horizontal es negativa y significativa al 5\% para el caso de los ponderadores de distancias, iguales y lineales (cuadro 6). 


\section{Cuadro 6}

Resultados de Mínimos Cuadrados Generalizados con heteroscedasticidad Incorporando Panel Specific Autocorrelation Coefficients Variable dependiente: tasa efectiva de IIBB cadena agroindustrial

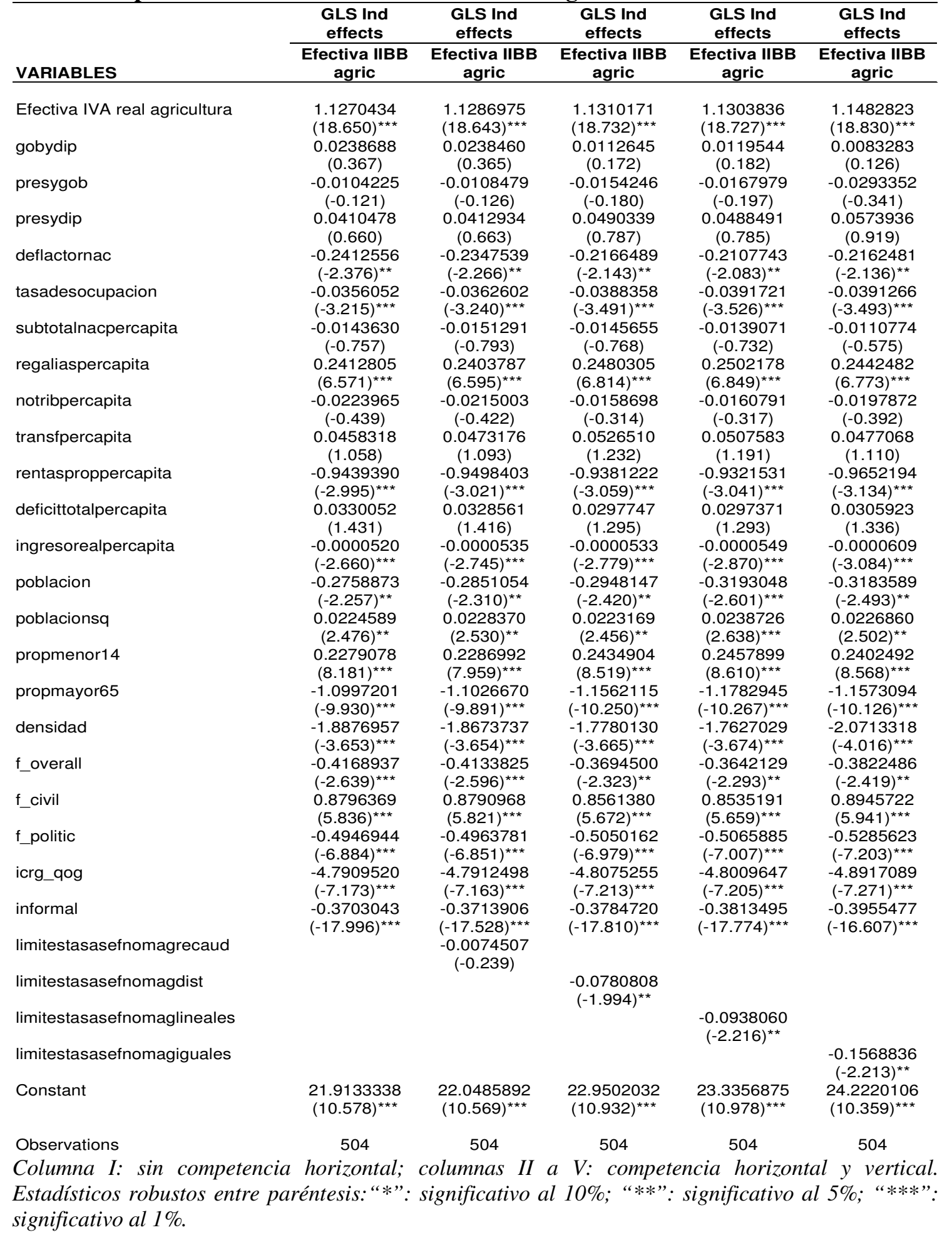




\section{Cuadro 7}

Resultados de Mínimos Cuadrados Generalizados con heteroscedasticidad Incorporando Panel Specific Autocorrelation Coefficients con time effects Variable dependiente: tasa efectiva de IIBB cadena agroindustrial

\begin{tabular}{ccccc}
$\begin{array}{c}\text { GLS Ind y time } \\
\text { effects }\end{array}$ & $\begin{array}{c}\text { GLS Ind y time } \\
\text { effects }\end{array}$ & $\begin{array}{c}\text { GLSInd y time } \\
\text { effects }\end{array}$ & $\begin{array}{c}\text { GLS Ind y time } \\
\text { effects }\end{array}$ & $\begin{array}{c}\text { GLS Ind y time } \\
\text { effects }\end{array}$ \\
\hline
\end{tabular}

VARIABLES

Efectiva IIBB agric Efectiva IIBB agric Efectiva IIBB agric Efectiva IIBB agric Efectiva IIBB agric

\begin{tabular}{|c|c|c|c|c|c|}
\hline Efectiva IVA real agricultura & $\begin{array}{l}4.0731775 \\
(12.491)^{* * *}\end{array}$ & $\begin{array}{l}4.0642452 \\
(12.462)^{* * \star}\end{array}$ & $\begin{array}{l}4.0458495 \\
(12.399)^{\star * \star}\end{array}$ & $\begin{array}{l}4.0295515 \\
(12.350)^{* * *}\end{array}$ & $\begin{array}{l}3.8166752 \\
(11.618)^{\star * \star}\end{array}$ \\
\hline gobydip & $\begin{array}{c}-0.0759301 \\
(-1.561)\end{array}$ & $\begin{array}{c}-0.0766687 \\
(-1.579)\end{array}$ & $\begin{array}{c}-0.0782009 \\
(-1.615)\end{array}$ & $\begin{array}{c}-0.0768993 \\
(-1.588)\end{array}$ & $\begin{array}{c}-0.0965252 \\
(-1.922)^{*}\end{array}$ \\
\hline presygob & $\begin{array}{c}0.0090730 \\
(0.145)\end{array}$ & $\begin{array}{c}0.0097757 \\
(0.156)\end{array}$ & $\begin{array}{c}0.0143397 \\
(0.230)\end{array}$ & $\begin{array}{c}0.0092444 \\
(0.148)\end{array}$ & $\begin{array}{c}0.0126687 \\
(0.197)\end{array}$ \\
\hline presydip & $\begin{array}{c}-0.0192807 \\
(-0.420)\end{array}$ & $\begin{array}{c}-0.0194727 \\
(-0.425)\end{array}$ & $\begin{array}{c}-0.0167557 \\
(-0.368)\end{array}$ & $\begin{array}{c}-0.0190155 \\
(-0.417)\end{array}$ & $\begin{array}{c}-0.0207914 \\
(-0.434)\end{array}$ \\
\hline deflactornac & $\begin{array}{c}-6.4875315 \\
(-5.853)^{\star * *}\end{array}$ & $\begin{array}{c}-6.4371483 \\
(-5.799)^{\star * *}\end{array}$ & $\begin{array}{c}-6.4329802 \\
(-5.769)^{\star * *}\end{array}$ & $\begin{array}{c}-6.3952881 \\
(-5.760)^{* * *}\end{array}$ & $\begin{array}{l}-6.2631563 \\
(-5.411)^{\star * *}\end{array}$ \\
\hline tasadesocupacion & $\begin{array}{c}-0.0192267 \\
(-1.945)^{\star}\end{array}$ & $\begin{array}{c}-0.0200526 \\
(-2.036)^{\star \star}\end{array}$ & $\begin{array}{c}-0.0212171 \\
(-2.137)^{\star *}\end{array}$ & $\begin{array}{c}-0.0205853 \\
(-2.089)^{\star *}\end{array}$ & $\begin{array}{c}-0.0194766 \\
(-1.914)^{*}\end{array}$ \\
\hline subtotalnacpercapita & $\begin{array}{l}-0.0499786 \\
(-3.385)^{\star \star \star}\end{array}$ & $\begin{array}{l}-0.0520379 \\
(-3.507)^{\star \star *}\end{array}$ & $\begin{array}{l}-0.0515808 \\
(-3.522)^{\star \star \star}\end{array}$ & $\begin{array}{l}-0.0509931 \\
(-3.480)^{\star * *}\end{array}$ & $\begin{array}{l}-0.0477075 \\
(-3.212)^{\star * *}\end{array}$ \\
\hline regaliaspercapita & $\begin{array}{l}0.1341908 \\
(3.764)^{\star * *}\end{array}$ & $\begin{array}{l}0.1344441 \\
(3.878)^{\star * *}\end{array}$ & $\begin{array}{l}0.1394422 \\
(4.075)^{\star * \star}\end{array}$ & $\begin{array}{l}0.1409175 \\
(4.127)^{\star * *}\end{array}$ & $\begin{array}{l}0.1258409 \\
(3.697)^{* * *}\end{array}$ \\
\hline notribpercapita & $\begin{array}{c}-0.0301533 \\
(-0.750)\end{array}$ & $\begin{array}{c}-0.0279350 \\
(-0.695)\end{array}$ & $\begin{array}{c}-0.0271462 \\
(-0.675)\end{array}$ & $\begin{array}{c}-0.0279766 \\
(-0.694)\end{array}$ & $\begin{array}{c}-0.0300724 \\
(-0.729)\end{array}$ \\
\hline transfpercapita & $\begin{array}{c}0.0583395 \\
(1.544)\end{array}$ & $\begin{array}{c}0.0584156 \\
(1.554)\end{array}$ & $\begin{array}{c}0.0584062 \\
(1.567)\end{array}$ & $\begin{array}{c}0.0564664 \\
(1.517)\end{array}$ & $\begin{array}{c}0.0672089 \\
(1.777)^{*}\end{array}$ \\
\hline rentasproppercapita & $\begin{array}{c}-0.3588243 \\
(-1.445)\end{array}$ & $\begin{array}{c}-0.3660812 \\
(-1.467)\end{array}$ & $\begin{array}{c}-0.3556886 \\
(-1.433)\end{array}$ & $\begin{array}{c}-0.3535570 \\
(-1.416)\end{array}$ & $\begin{array}{c}-0.3977268 \\
(-1.579)\end{array}$ \\
\hline deficittotalpercapita & $\begin{array}{c}-0.0079232 \\
(-0.500)\end{array}$ & $\begin{array}{c}-0.0082402 \\
(-0.518)\end{array}$ & $\begin{array}{c}-0.0086225 \\
(-0.536)\end{array}$ & $\begin{array}{c}-0.0083686 \\
(-0.525)\end{array}$ & $\begin{array}{c}-0.0044958 \\
(-0.273)\end{array}$ \\
\hline ingresorealpercapita & $\begin{array}{c}-0.0000001 \\
(-0.004)\end{array}$ & $\begin{array}{c}-0.0000004 \\
(-0.026)\end{array}$ & $\begin{array}{c}0.0000014 \\
(0.084)\end{array}$ & $\begin{array}{c}0.0000016 \\
(0.098)\end{array}$ & $\begin{array}{c}-0.0000103 \\
(-0.677)\end{array}$ \\
\hline poblacion & $\begin{array}{c}-0.1127122 \\
(-1.539)\end{array}$ & $\begin{array}{c}-0.1209670 \\
(-1.646)^{\star}\end{array}$ & $\begin{array}{c}-0.1181211 \\
(-1.646)^{\star}\end{array}$ & $\begin{array}{c}-0.1219826 \\
(-1.679)^{\star}\end{array}$ & $\begin{array}{c}-0.1081435 \\
(-1.438)\end{array}$ \\
\hline poblacionsq & $\begin{array}{c}0.0173740 \\
(2.753)^{\star * *}\end{array}$ & $\begin{array}{l}0.0174491 \\
(2.826)^{\star * *}\end{array}$ & $\begin{array}{l}0.0172402 \\
(2.648)^{\star \star *}\end{array}$ & $\begin{array}{l}0.0178602 \\
(2.786)^{\star \star *}\end{array}$ & $\begin{array}{c}0.0121639 \\
(1.859)^{*}\end{array}$ \\
\hline propmenor14 & $\begin{array}{c}0.0622728 \\
(2.296)^{\star *}\end{array}$ & $\begin{array}{c}0.0588778 \\
(2.159)^{\star *}\end{array}$ & $\begin{array}{l}0.0617030 \\
(2.233)^{* *}\end{array}$ & $\begin{array}{c}0.0600545 \\
(2.160)^{\star *}\end{array}$ & $\begin{array}{l}0.0693360 \\
(2.860)^{\star * *}\end{array}$ \\
\hline propmayor65 & $\begin{array}{c}-0.3420844 \\
(-3.255)^{\star \star \star}\end{array}$ & $\begin{array}{l}-0.3315310 \\
(-3.123)^{\star \star *}\end{array}$ & $\begin{array}{c}-0.3430836 \\
(-3.236)^{\star * *}\end{array}$ & $\begin{array}{c}-0.3461158 \\
(-3.239)^{\star \star *}\end{array}$ & $\begin{array}{l}-0.3357697 \\
(-3.551)^{\star \star \star}\end{array}$ \\
\hline densidad & $\begin{array}{c}-0.3732645 \\
(-0.903)\end{array}$ & $\begin{array}{c}-0.3725487 \\
(-0.881)\end{array}$ & $\begin{array}{c}-0.3800227 \\
(-0.902)\end{array}$ & $\begin{array}{c}-0.3962495 \\
(-0.932)\end{array}$ & $\begin{array}{c}-0.3026854 \\
(-0.843)\end{array}$ \\
\hline f_overall & $\begin{array}{c}24.8492911 \\
(3.528)^{* \star *}\end{array}$ & $\begin{array}{c}24.6202725 \\
(3.490)^{\star * *}\end{array}$ & $\begin{array}{c}24.6743223 \\
(3.482)^{\star * *}\end{array}$ & $\begin{array}{c}24.4191019 \\
(3.460)^{\star \star *}\end{array}$ & $\begin{array}{c}26.0474668 \\
(3.493)^{\star * *}\end{array}$ \\
\hline f_civil & $\begin{array}{c}-11.1589247 \\
(-3.396)^{\star * *}\end{array}$ & $\begin{array}{c}-11.0462684 \\
(-3.356)^{\star * *}\end{array}$ & $\begin{array}{c}-11.0509133 \\
(-3.346)^{* * *}\end{array}$ & $\begin{array}{c}-10.9121186 \\
(-3.313)^{\star * *}\end{array}$ & $\begin{array}{c}-10.8341426 \\
(-3.178)^{\star * *}\end{array}$ \\
\hline f_politic & $\begin{array}{c}-13.5905466 \\
(-3.424)^{\star \star \star}\end{array}$ & $\begin{array}{c}-13.4828107 \\
(-3.391)^{\star \star \star}\end{array}$ & $\begin{array}{c}-13.5285497 \\
(-3.387)^{\star \star \star}\end{array}$ & $\begin{array}{c}-13.4081342 \\
(-3.371)^{\star \star \star}\end{array}$ & $\begin{array}{c}-15.8394428 \\
(-3.655)^{\star \star *}\end{array}$ \\
\hline icrg_qog & $\begin{array}{c}-65.5816311 \\
(-3.379)^{\star * *}\end{array}$ & $\begin{array}{c}-65.1553221 \\
(-3.349)^{\star * *}\end{array}$ & $\begin{array}{c}-65.3109607 \\
(-3.346)^{\star * *}\end{array}$ & $\begin{array}{l}-64.6868169 \\
(-3.324)^{\star * *}\end{array}$ & $\begin{array}{c}-79.1157462 \\
(-3.716)^{\star * \star}\end{array}$ \\
\hline informal & $\begin{array}{l}-4.7367224 \\
(-6.999)^{\star * *}\end{array}$ & $\begin{array}{c}-4.7084698 \\
(-6.947)^{\star * *}\end{array}$ & $\begin{array}{l}-4.7002857 \\
(-6.906)^{\star * *}\end{array}$ & $\begin{array}{l}-4.6739901 \\
(-6.892)^{\star * *}\end{array}$ & $\begin{array}{l}-4.6760098 \\
(-6.642)^{\star * *}\end{array}$ \\
\hline limitestasasefnomagrecaud & & $\begin{array}{c}-0.0073373 \\
(-0.267)\end{array}$ & & & \\
\hline limitestasasefnomagdist & & & $\begin{array}{c}-0.0306095 \\
(-0.913)\end{array}$ & & \\
\hline limitestasasefnomaglineales & & & & $\begin{array}{c}-0.0273643 \\
(-0.688)\end{array}$ & \\
\hline limitestasasefnomagiguales & & & & & $\begin{array}{l}-1.6622122 \\
(-3.072)^{\star * \star}\end{array}$ \\
\hline Constant & $\begin{array}{c}236.1824690 \\
(5.410)^{\star \star \star}\end{array}$ & $\begin{array}{c}234.7473557 \\
(5.368)^{\star * *}\end{array}$ & $\begin{array}{c}234.7505786 \\
(5.344)^{\star * *}\end{array}$ & $\begin{array}{c}233.1585662 \\
(5.327)^{\star \star *}\end{array}$ & $\begin{array}{c}250.2918322 \\
(5.384)^{\star * *}\end{array}$ \\
\hline Observations & 504 & 504 & 504 & 504 & 504 \\
\hline
\end{tabular}


La incorporación de efectos fijos por período (time effects) en las tasas efectivas de la cadena agroindustrial, no hace variar el signo ni la significatividad de la reacción vertical, pero reduce ligeramente la reacción horizontal; ahora la misma es negativa y significativa sólo para el caso de los ponderadores iguales (cuadro 7), mientras que el resto no resulta significativo.

Los resultados para las variables de control son significativos en varios casos, como el ingreso per cápita, que es negativo, como así también las variables de población, tasa de desocupación e informalidad, al igual que en los casos anteriores y en forma consistente con los resultados de los modelos de esfuerzo tributario como fuera mencionado anteriormente, y las variables institucionales (negativo para el indicador político).

En todos los casos analizados, se considera como exógena a la tasa impositiva del gobierno federal, asumiendo que el mismo es líder de Stackelberg. Sin embargo, como fuera mencionado en la introducción, dado que se analiza un equilibrio de Nash en el cual se determinan las políticas impositivas en forma simultánea, existe posible endogeneidad de los impuestos federales. Asimismo, si las provincias reaccionan a la política impositiva de las demás, la variable impositiva provincial es endógena.

En el primero de los casos, se utilizan, como instrumentos de las variables de competencia tributaria provincial, a las variables de control de las demás provincias, ponderadas de acuerdo a los coeficientes anteriormente explicitados, de acuerdo con Devereux et. al (2007), Esteller Moré y Rizzo (2009, 2011) y Rizzo (2008). Estas variables se instrumentan, de acuerdo con la literatura, con variables de control provinciales, como la proporción de mayores de 65, la proporción de menores de 14 y la tasa de desocupación provincial, ponderadas de la misma manera que las variables impositivas. A éstas se les adicionaron la población, el déficit fiscal, las transferencias por fuera de la coparticipación y las regalías, todos en términos per cápita.

Dado que las tasas cambian en forma infrecuente, es probable que la existencia de autocorrelación se deba a la omisión de la variable dependiente rezagada (la segunda de las fuentes de persistencia mencionada más arriba) ${ }^{81}$. Para permitir la correlación serial de primer orden y corregir los errores de especificación, se incluye la variable dependiente rezagada en un período entre los regresores; de acuerdo al procedimiento de Esteller Moré y Rizzo (2009, 2011) y Devereux et. al. (2007).

\footnotetext{
${ }^{81}$ Siguiendo la explicación de Esteller Moré y Rizzo (2011), la variable dependiente rezagada sesga todos los coeficientes estimados para muestras con T pequeñas. Sin embargo, el sesgo de Nickell (1981) no sería, de acuerdo a estos autores, un problema debido al tamaño de la muestra (32 años). El mismo razonamiento se emplea aquí para no instrumentar la variable dependiente rezagada.
} 
Además, como fuera explicitado con anterioridad, la variable de política tributaria del gobierno nacional se considera como endógena, siendo los instrumentos utilizados el resultado fiscal per cápita del gobierno nacional, y la tasa de desocupación promedio nacional (siguiendo a Besley y Rosen (1998), Devereux et. al (2007), Esteller Moré y Rizzo (2009, 2011), Rizzo (2006), y Esteller Moré y Solé Ollé (2001, 2002))

De igual manera que en Devereux et. al. (2007), Esteller Moré y $\operatorname{Rizzo}(2009,2011)$, Rizzo (2006) y Durán Cabré, et. al. (2012), se testea la validez de los instrumentos a través del test de Hansen de sobreidentificación, tratando a las variables de control como exógenas, a partir de los test de exogeneidad para las variables de control que no determinan evidencia de endogeneidad. Dada la existencia de heteroscedasticidad, se incluyen los cluster robust errores estándares para permitir correlación serial.

En los cuadros 8 a 12 subsiguientes pueden verse los resultados de aplicar el método de variables instrumentales, mediante Método Generalizado de Momentos en dos etapas (GMMIV) para cada una de las variables, incorporando clusters por período y errores estándares y estadísticos robustos, dada la evidencia de heteroscedasticidad y autocorrelación.

En la columna I de los cuadros 8 a 12 se presentan las estimaciones sin competencia horizontal, mientras que en las columnas subsiguientes se adicionan las variables que refieren a la externalidad tributaria provincial introduciendo el promedio ponderado de las tasas de los otros estados; dado que también se considera endógena, es instrumentada con variables de control provinciales tal cual fuera mencionado con anterioridad. Puede apreciarse que la variable dependiente rezagada resulta en todos los casos positiva y muy significativa, lo que elimina la evidencia de autocorrelación de primer orden, y se supera el test de sobreidentificación.

Analizando el caso de la tasa real del IVA (cuadro 8), el aumento de un 1\% de la tasa de IVA incrementa en un 0,07\% la tasa promedio de Ingresos Brutos para el caso de competencia vertical en el corto plazo, mientras que para el largo plazo el impacto es de 0,19\%. Al agregar competencia horizontal disminuye la significatividad de la reacción de la tasa provincial ante variaciones en la alícuota real nacional, la que no es significativa. Adicionalmente se satisfacen, los tests de Hansen de sobreidentificación y de endogeneidad, arrojando indicios de instrumentos adecuados. 


\section{Cuadro 8}

\section{Resultados de Mínimos Cuadrados Generalizados en dos etapas-Variables}

instrumentales.

Clustered-Robust standard errors por período Variable dependiente: tasa de Ingresos Brutos.

\begin{tabular}{|c|c|c|c|c|c|}
\hline VARIABLES & $\begin{array}{c}\text { IVGMM I } \\
\text { Tasa IIBB real }\end{array}$ & $\begin{array}{c}\text { IVGMM II } \\
\text { Tasa IIBB real } \\
\end{array}$ & $\begin{array}{c}\text { IVGMM III } \\
\text { Tasa IIBB real }\end{array}$ & $\begin{array}{c}\text { IVGMM IV } \\
\text { Tasa IIBB real }\end{array}$ & $\begin{array}{c}\text { IVGMM V } \\
\text { Tasa IIBB real }\end{array}$ \\
\hline Tasa IVA real & $\begin{array}{l}0.0692055 \\
(4.068)^{\star * \star}\end{array}$ & $\begin{array}{c}0.0294347 \\
(0.756)\end{array}$ & $\begin{array}{c}0.0396303 \\
(1.611)\end{array}$ & $\begin{array}{c}0.0645694 \\
(2.067)^{\star *}\end{array}$ & $\begin{array}{l}0.0670940 \\
(3.526)^{\star * *}\end{array}$ \\
\hline gobydip & $\begin{array}{l}-0.0260209 \\
(-2.484)^{\star \star}\end{array}$ & $\begin{array}{c}-0.0422154 \\
(-2.278)^{\star *}\end{array}$ & $\begin{array}{c}-0.0386864 \\
(-2.224)^{\star *}\end{array}$ & $\begin{array}{l}-0.0384267 \\
(-2.961)^{\star * \star}\end{array}$ & $\begin{array}{l}-0.0331369 \\
(-3.524)^{\star \star \star}\end{array}$ \\
\hline presygob & $\begin{array}{c}0.0208087 \\
(1.290)\end{array}$ & $\begin{array}{c}0.0173113 \\
(0.968)\end{array}$ & $\begin{array}{c}0.0202362 \\
(0.956)\end{array}$ & $\begin{array}{c}0.0252636 \\
(1.512)\end{array}$ & $\begin{array}{c}0.0331519 \\
(1.921)^{\star}\end{array}$ \\
\hline presydip & $\begin{array}{c}0.0004750 \\
(0.053)\end{array}$ & & & & \\
\hline Itasaiibbdefprompreal & $\begin{array}{l}0.6416238 \\
(9.507)^{\star * *}\end{array}$ & $\begin{array}{l}0.6409097 \\
(7.795)^{\star * *}\end{array}$ & $\begin{array}{l}0.6166883 \\
(8.724)^{\star * \star}\end{array}$ & $\begin{array}{c}0.6027269 \\
(7.749)^{\star \star \star}\end{array}$ & $\begin{array}{l}0.5830202 \\
(9.805)^{\star \star \star}\end{array}$ \\
\hline deflactornac & $\begin{array}{c}0.0520184 \\
(1.148)\end{array}$ & & & & \\
\hline tasadesocupacion & $\begin{array}{l}-0.0056250 \\
(-2.169)^{\star \star}\end{array}$ & & & & \\
\hline subtotalnacpercapita & $\begin{array}{l}-0.0083273 \\
(-4.189)^{\star * *}\end{array}$ & $\begin{array}{c}-0.0141138 \\
(-1.368)\end{array}$ & $\begin{array}{c}-0.0103617 \\
(-1.736)^{*}\end{array}$ & $\begin{array}{l}-0.0086374 \\
(-2.459)^{\star \star}\end{array}$ & $\begin{array}{l}-0.0085926 \\
(-4.352)^{\star * *}\end{array}$ \\
\hline regaliaspercapita & $\begin{array}{l}0.0296851 \\
(3.128)^{\star \star \star}\end{array}$ & $\begin{array}{c}0.0263906 \\
(2.190)^{\star *}\end{array}$ & $\begin{array}{l}0.0319495 \\
(2.836)^{\star \star \star}\end{array}$ & $\begin{array}{c}0.0229319 \\
(1.608)\end{array}$ & $\begin{array}{l}0.0385916 \\
(4.764)^{\star \star \star}\end{array}$ \\
\hline notribpercapita & $\begin{array}{l}0.0207815 \\
(2.698)^{\star \star \star}\end{array}$ & $\begin{array}{c}0.0191145 \\
(1.959)^{*}\end{array}$ & $\begin{array}{c}0.0222900 \\
(1.601)\end{array}$ & $\begin{array}{l}0.0275276 \\
(3.120)^{\star \star \star}\end{array}$ & $\begin{array}{l}0.0233198 \\
(3.236)^{\star \star \star}\end{array}$ \\
\hline transfpercapita & $\begin{array}{c}0.0005735 \\
(0.106)\end{array}$ & $\begin{array}{c}0.0049968 \\
(0.458)\end{array}$ & $\begin{array}{c}0.0008652 \\
(0.103)\end{array}$ & $\begin{array}{c}-0.0011068 \\
(-0.182)\end{array}$ & $\begin{array}{c}-0.0009470 \\
(-0.178)\end{array}$ \\
\hline rentasproppercapita & $\begin{array}{c}0.0439027 \\
(0.879)\end{array}$ & $\begin{array}{c}0.0294992 \\
(0.519)\end{array}$ & $\begin{array}{c}0.0142867 \\
(0.225)\end{array}$ & $\begin{array}{c}0.0303917 \\
(0.411)\end{array}$ & $\begin{array}{c}0.0194880 \\
(0.373)\end{array}$ \\
\hline deficittotalpercapita & $\begin{array}{c}-0.0062486 \\
(-1.232)\end{array}$ & $\begin{array}{c}-0.0016741 \\
(-0.145)\end{array}$ & $\begin{array}{c}-0.0051957 \\
(-0.529)\end{array}$ & $\begin{array}{c}-0.0069364 \\
(-1.470)\end{array}$ & $\begin{array}{c}-0.0061710 \\
(-1.183)\end{array}$ \\
\hline ingresorealpercapita & $\begin{array}{l}-0.0000094 \\
(-2.196)^{\star \star}\end{array}$ & $\begin{array}{c}-0.0000191 \\
(-1.081)\end{array}$ & $\begin{array}{c}-0.0000144 \\
(-1.082)\end{array}$ & $\begin{array}{l}-0.0000199 \\
(-2.183)^{\star *}\end{array}$ & $\begin{array}{l}-0.0000127 \\
(-4.020)^{\star * *}\end{array}$ \\
\hline poblacion & $\begin{array}{c}-0.0455002 \\
(-1.712)^{*}\end{array}$ & $\begin{array}{c}-0.0594710 \\
(-1.430)\end{array}$ & $\begin{array}{c}-0.0614706 \\
(-0.841)\end{array}$ & $\begin{array}{c}-0.0854122 \\
(-1.919)^{*}\end{array}$ & $\begin{array}{c}-0.0475124 \\
(-1.782)^{*}\end{array}$ \\
\hline poblacionsq & $\begin{array}{c}0.0014814 \\
(0.543)\end{array}$ & $\begin{array}{c}-0.0003903 \\
(-0.159)\end{array}$ & $\begin{array}{c}0.0013570 \\
(0.308)\end{array}$ & $\begin{array}{c}0.0033911 \\
(0.937)\end{array}$ & $\begin{array}{c}0.0025452 \\
(0.962)\end{array}$ \\
\hline propmenor14 & $\begin{array}{c}-0.0023631 \\
(-0.275)\end{array}$ & $\begin{array}{c}-0.0078693 \\
(-0.475)\end{array}$ & $\begin{array}{c}-0.0040361 \\
(-0.203)\end{array}$ & $\begin{array}{c}-0.0177632 \\
(-1.000)\end{array}$ & $\begin{array}{c}0.0009466 \\
(0.116)\end{array}$ \\
\hline propmayor65 & $\begin{array}{c}-0.0370112 \\
(-1.205)\end{array}$ & $\begin{array}{c}-0.0662649 \\
(-1.219)\end{array}$ & $\begin{array}{c}-0.0590183 \\
(-1.913)^{*}\end{array}$ & $\begin{array}{c}-0.0289197 \\
(-0.844)\end{array}$ & $\begin{array}{c}-0.0570123 \\
(-2.219)^{\star \star}\end{array}$ \\
\hline tasadesocupacion & & $\begin{array}{c}-0.0023703 \\
(-0.508)\end{array}$ & $\begin{array}{c}-0.0043623 \\
(-1.163)\end{array}$ & $\begin{array}{c}-0.0065780 \\
(-1.522)\end{array}$ & $\begin{array}{c}-0.0058763 \\
(-2.245)^{\star \star}\end{array}$ \\
\hline limitestasasrecaudacion & & $\begin{array}{c}0.1633209 \\
(0.436)\end{array}$ & & & \\
\hline limitestasasdistancias & & & $\begin{array}{c}0.0529327 \\
(0.136)\end{array}$ & & \\
\hline limitestasaslineales & & & & $\begin{array}{c}0.3589392 \\
(1.019)\end{array}$ & \\
\hline limitestasaspondiguales & & & & & $\begin{array}{c}0.4631415 \\
(0.892)\end{array}$ \\
\hline Observations & 480 & 480 & 480 & 480 & 480 \\
\hline R-squared & 0.790 & 0.759 & 0.781 & 0.757 & 0.785 \\
\hline Underidentification test Kleibergen-Paap & 5.277 & 1.603 & 2.282 & 5.417 & 6.519 \\
\hline$p$ value & 0.0715 & 0.4487 & 0.3196 & 0.0666 & 0.0384 \\
\hline Weak identification test Kleibergen-Paap-Wald & 138.502 & 1.537 & 2.061 & 6.102 & 73.857 \\
\hline Hansen overidentification test & 0.571 & 2.156 & 1.585 & 0.772 & 0.259 \\
\hline$p$ value & 0.4498 & 0.142 & 0.2081 & 0.3797 & 0.6111 \\
\hline Endogeneity test & 0.002 & 0.205 & 0.496 & 2.467 & 5.157 \\
\hline$p$ value & 0.9636 & 0.9028 & 0.7803 & 0.2913 & 0.0759 \\
\hline Arellano-Bond $\mathrm{AR}(1)$ test & -0.29 & 0.36 & 0.01 & 0.72 & 0.45 \\
\hline$p$ value & 0.7699 & 0.7172 & 0.9951 & 0.4713 & 0.6514 \\
\hline Arellano-Bond $\mathrm{AR}(2)$ test & 2.64 & 1.85 & 2.25 & 1.85 & 2.06 \\
\hline$p$ value & 0.0082 & 0.0637 & 0.0242 & 0.064 & 0.0394 \\
\hline
\end{tabular}

Columna I (sin competencia horizontal): se instrumenta la tasa de IVA con el resultado financiero total per cápita y la tasa de desocupación promedio nacional. Resto: se instrumenta la tasa de IVA con el resultado financiero total per cápita y se adiciona la competencia tributaria horizontal; se instrumenta la variable endógena de las tasas ponderadas provinciales por controles provinciales ponderados, como la proporción de mayores de 65, la proporción de menores de 14, la tasa de desocupación provincial, las transferencias por recursos no tributarios y las regalías 


\section{Cuadro 9}

\section{Resultados de Mínimos Cuadrados Generalizados en dos etapas-Variables}

instrumentales

Clustered-Robust standard errors por período Variable dependiente: productividad ponderada de IIBB

\begin{tabular}{|c|c|c|c|c|c|}
\hline VARIABLES & $\begin{array}{c}\text { IVGMM I } \\
\text { Prod IIBB real } \\
\end{array}$ & $\begin{array}{c}\text { IVGMM II } \\
\text { Prod IIBB real } \\
\end{array}$ & $\begin{array}{c}\text { IVGMM III } \\
\text { Prod IIBB real } \\
\end{array}$ & $\begin{array}{c}\text { IVGMM IV } \\
\text { Prod IIBB real } \\
\end{array}$ & $\begin{array}{c}\text { IVGMM V } \\
\text { Prod IIBB real } \\
\end{array}$ \\
\hline Productividad IVA real & $\begin{array}{c}-0.0031174 \\
(-0.948)\end{array}$ & $\begin{array}{c}0.0166576 \\
(1.380)\end{array}$ & $\begin{array}{l}0.0087502 \\
(2.677)^{\star * *}\end{array}$ & $\begin{array}{c}0.0115247 \\
(2.187)^{\star \star}\end{array}$ & $\begin{array}{c}0.0187784 \\
(2.547)^{\star *}\end{array}$ \\
\hline gobydip & $\begin{array}{c}-0.0403473 \\
(-0.271)\end{array}$ & $\begin{array}{c}-0.2577153 \\
(-1.082)\end{array}$ & $\begin{array}{c}-0.1004791 \\
(-0.705)\end{array}$ & $\begin{array}{c}-0.5691042 \\
(-1.039)\end{array}$ & $\begin{array}{c}-0.1089550 \\
(-0.712)\end{array}$ \\
\hline presygob & $\begin{array}{c}0.1868385 \\
(0.784)\end{array}$ & $\begin{array}{c}-0.1832752 \\
(-0.477)\end{array}$ & $\begin{array}{c}-0.0322679 \\
(-0.106)\end{array}$ & $\begin{array}{c}0.7975073 \\
(0.636)\end{array}$ & $\begin{array}{c}0.1854719 \\
(0.827)\end{array}$ \\
\hline presydip & $\begin{array}{c}0.0491348 \\
(0.225)\end{array}$ & & & & \\
\hline deflactornac & $\begin{array}{c}1.2041278 \\
(2.502)^{* *}\end{array}$ & & & & \\
\hline tasadesocupacion & $\begin{array}{l}-0.0623262 \\
(-2.017)^{\star *}\end{array}$ & $\begin{array}{c}0.0261433 \\
(0.352)\end{array}$ & $\begin{array}{c}0.0017776 \\
(0.054)\end{array}$ & $\begin{array}{c}-0.0006789 \\
(-0.013)\end{array}$ & $\begin{array}{c}-0.0079338 \\
(-0.222)\end{array}$ \\
\hline subtotalnacpercapita & $\begin{array}{c}-0.0490582 \\
(-1.349)\end{array}$ & $\begin{array}{c}-0.0601481 \\
(-0.534)\end{array}$ & $\begin{array}{c}-0.0321958 \\
(-0.450)\end{array}$ & $\begin{array}{c}-0.0777102 \\
(-0.686)\end{array}$ & $\begin{array}{c}-0.0439701 \\
(-0.625)\end{array}$ \\
\hline regaliaspercapita & $\begin{array}{c}0.0508287 \\
(0.688)\end{array}$ & $\begin{array}{c}-0.1707548 \\
(-1.025)\end{array}$ & $\begin{array}{c}-0.0005971 \\
(-0.008)\end{array}$ & $\begin{array}{c}-0.0183950 \\
(-0.143)\end{array}$ & $\begin{array}{c}0.0050270 \\
(0.072)\end{array}$ \\
\hline notribpercapita & $\begin{array}{l}-0.1414150 \\
(-3.263)^{\star \star \star}\end{array}$ & $\begin{array}{c}-0.2468740 \\
(-2.217)^{\star \star}\end{array}$ & $\begin{array}{l}-0.1934223 \\
(-3.988)^{\star \star \star}\end{array}$ & $\begin{array}{c}-0.1924208 \\
(-1.372)\end{array}$ & $\begin{array}{l}-0.2353672 \\
(-4.867)^{\star \star \star}\end{array}$ \\
\hline transfpercapita & $\begin{array}{c}0.1196956 \\
(2.098)^{\star \star}\end{array}$ & $\begin{array}{c}-0.0092023 \\
(-0.106)\end{array}$ & $\begin{array}{c}0.0652956 \\
(0.629)\end{array}$ & $\begin{array}{c}0.4196030 \\
(0.788)\end{array}$ & $\begin{array}{c}0.0940233 \\
(1.675)^{*}\end{array}$ \\
\hline rentasproppercapita & $\begin{array}{c}-0.4132674 \\
(-0.774)\end{array}$ & $\begin{array}{c}-0.3700109 \\
(-0.476)\end{array}$ & $\begin{array}{c}-0.1809835 \\
(-0.377)\end{array}$ & $\begin{array}{c}-0.8135291 \\
(-0.735)\end{array}$ & $\begin{array}{c}-0.0248005 \\
(-0.049)\end{array}$ \\
\hline deficittotalpercapita & $\begin{array}{c}-0.0510145 \\
(-1.475)\end{array}$ & $\begin{array}{c}0.0630044 \\
(0.864)\end{array}$ & $\begin{array}{c}-0.0139456 \\
(-0.398)\end{array}$ & $\begin{array}{c}0.0057456 \\
(0.055)\end{array}$ & $\begin{array}{c}-0.0551261 \\
(-1.289)\end{array}$ \\
\hline ingresorealpercapita & $\begin{array}{c}0.0000167 \\
(0.332)\end{array}$ & $\begin{array}{c}0.0001007 \\
(1.367)\end{array}$ & $\begin{array}{c}0.0000214 \\
(0.286)\end{array}$ & $\begin{array}{c}-0.0003231 \\
(-0.883)\end{array}$ & $\begin{array}{c}-0.0000387 \\
(-0.647)\end{array}$ \\
\hline poblacion & $\begin{array}{l}-0.6949749 \\
(-1.977)^{\star \star}\end{array}$ & $\begin{array}{c}0.0351330 \\
(0.052)\end{array}$ & $\begin{array}{l}-0.8158993 \\
(-2.462)^{\star \star}\end{array}$ & $\begin{array}{c}-3.4944766 \\
(-1.081)\end{array}$ & $\begin{array}{l}-1.1082817 \\
(-2.943)^{\star \star \star}\end{array}$ \\
\hline poblacionsq & $\begin{array}{c}0.0905432 \\
(2.115)^{\star *}\end{array}$ & $\begin{array}{c}-0.0634208 \\
(-0.525)\end{array}$ & $\begin{array}{c}0.0864774 \\
(2.497)^{\star \star}\end{array}$ & $\begin{array}{c}0.3640774 \\
(0.957)\end{array}$ & $\begin{array}{c}0.1025978 \\
(2.029)^{\star *}\end{array}$ \\
\hline propmenor 14 & $\begin{array}{l}0.1785503 \\
(3.266)^{\star \star \star}\end{array}$ & $\begin{array}{c}0.1090858 \\
(0.667)\end{array}$ & $\begin{array}{c}0.1991324 \\
(2.477)^{\star \star}\end{array}$ & $\begin{array}{c}0.2989446 \\
(1.097)\end{array}$ & $\begin{array}{c}0.0827649 \\
(0.812)\end{array}$ \\
\hline propmayor65 & $\begin{array}{c}-0.2785805 \\
(-1.050)\end{array}$ & $\begin{array}{c}0.4012682 \\
(0.769)\end{array}$ & & $\begin{array}{c}0.2227826 \\
(0.525)\end{array}$ & $\begin{array}{c}0.2629198 \\
(0.786)\end{array}$ \\
\hline IProd IIBB real & $\begin{array}{l}1.0384531 \\
(28.398)^{\star \star \star}\end{array}$ & $\begin{array}{l}1.1546713 \\
(17.443)^{\star \star \star}\end{array}$ & $\begin{array}{l}1.0835200 \\
(21.871)^{\star \star \star}\end{array}$ & $\begin{array}{c}0.8910532 \\
(2.816)^{\star \star \star}\end{array}$ & $\begin{array}{l}1.0461841 \\
(22.862)^{\star \star *}\end{array}$ \\
\hline limitesprodrecaudacion & & $\begin{array}{c}-1.1267754 \\
(-1.784)^{*}\end{array}$ & & & \\
\hline limitesprodpdistancias & & & $\begin{array}{c}-0.4127490 \\
(-1.277)\end{array}$ & & \\
\hline limitesprodpondlineales & & & & $\begin{array}{c}1.8958514 \\
(0.647)\end{array}$ & \\
\hline limitesprodpondiguales & & & & & $\begin{array}{l}-3.5882108 \\
(-2.627)^{\star \star *}\end{array}$ \\
\hline Observations & 480 & 480 & 480 & 480 & 480 \\
\hline R-squared & 0.954 & 0.907 & 0.953 & 0.912 & 0.954 \\
\hline Underidentification test Kleibergen-Paap & 6.15 & 1.969 & 8.377 & 2.04 & 2.517 \\
\hline$p$ value & 0.0462 & 0.3736 & 0.0388 & 0.3606 & 0.2841 \\
\hline Weak identification test Kleibergen-Paap-Wald & 817.404 & 1.532 & 4.962 & 0.624 & 20.739 \\
\hline Hansen overidentification test & 1.816 & 0.968 & 5.389 & 0.993 & 0.917 \\
\hline$p$ value & 0.1777 & 0.3251 & 0.0676 & 0.3191 & 0.3382 \\
\hline Endogeneity test & 2.136 & 2.72 & 0.263 & 0.982 & 2.73 \\
\hline$p$ value & 0.1439 & 0.2567 & 0.8769 & 0.6121 & 0.2554 \\
\hline Arellano-Bond $\mathrm{AR}(1)$ test & 0.28 & 1.48 & 0.05 & 0.75 & 1.03 \\
\hline$p$ value & 0.7814 & 0.1395 & 0.9579 & 0.4544 & 0.3019 \\
\hline Arellano-Bond $\mathrm{AR}(2)$ test & 1.61 & 1.54 & 0.9 & 1.91 & 0.19 \\
\hline$p$ value & 0.1077 & 0.1244 & 0.3667 & 0.0563 & 0.8462 \\
\hline
\end{tabular}

Columna I (sin competencia horizontal): se instrumenta la tasa de IVA con el resultado financiero total per cápita y la tasa de desocupación promedio nacional. Resto: se instrumenta la tasa de IVA con el resultado financiero total per cápita y se adiciona la competencia tributaria horizontal; se instrumenta la variable endógena de las tasas ponderadas provinciales por controles provinciales ponderados, como la proporción de mayores de 65, la proporción de menores de 14, la tasa de desocupación provincial, las transferencias por recursos no tributarios y las regalías

Para la variable de productividad del IVA (cuadro 9), la introducción de competencia horizontal introduce variaciones en la significatividad de los coeficientes; en el caso del 
ponderador de recaudación, la competencia horizontal es negativa y débilmente significativa, pero no la competencia vertical; el caso del ponderador por distancias muestra una reacción negativa pero no significativa, aunque la reacción vertical es positiva y significativa. Lo propio ocurre con el caso del ponderador lineal, mientras que en el caso del ponderador igual la reacción vertical es positiva y la horizontal negativa, siendo ambas significativas. Este comportamiento podría implicar que las provincias reaccionan ante la política impositiva del resto en forma conjunta, reduciendo la eficiencia recaudatoria en las provincias si el resto ha incrementado su carga impositiva.

En relación con las tasas efectivas, se advierte que, si bien la relación vertical es positiva, lo es en forma significativa para el caso general en los ponderadores de distancias y "lineales" (cuadro 10) pero no resulta significativa para el caso de la tasa para el subconjunto de actividades económicas relacionadas con la cadena agroindustrial (cuadro 11). Esto es consistente con los resultados de la literatura, en donde se concluye que en el caso de los bienes con demanda inelástica (el caso de los cigarrillos, por ejemplo, para las estimaciones más recientes, como las de Devereux (2007), Esteller Moré y Rizzo (2009), o Fredriksson y Mamun (2008)) no se aprecia reacción de las tasas subnacionales ante un incremento de las alícuotas federales ${ }^{82}$.

Al incorporar efectos específicos por período (cuadro 12) la reacción vertical se vuelve positiva y significativa, pero al adicionar competencia horizontal la significatividad estadística se reduce. La competencia horizontal propiamente dicha, entretanto, resulta poco significativa para ambas variables y para todas las especificaciones.

Pueden apreciarse comportamientos disímiles en relación con las variables de control. En cuanto a las variables de transferencia de fondos de la Nación a las provincias, en general los fondos de coparticipación tienen impacto negativo; las regalías (recursos naturales) implican una variación positiva en la presión tributaria provincial, mientras que las transferencias corrientes tienen el efecto opuesto y resultan ser significativas para el caso de la tasa efectiva de la cadena agroindustrial.

\footnotetext{
${ }^{82}$ Puede apreciarse de la lectura de los cuadros que el test de endogeneidad se cumple en prácticamente la totalidad de los casos, y los tests de sobreidentificación y de debilidad de instrumentos se superan.
} 


\section{Cuadro 10}

\section{Resultados de Mínimos Cuadrados Generalizados en dos etapas-Variables}

instrumentales

Clustered-Robust standard errors por período Variable dependiente: tasa efectiva de IIBB

\begin{tabular}{|c|c|c|c|c|c|}
\hline VARIABLES & $\begin{array}{c}\text { IVGMM I } \\
\text { Гasa efectiva IIBB reaTas }\end{array}$ & $\begin{array}{l}\text { IVGMM II } \\
\text { efectiva IIBB reaI }\end{array}$ & $\begin{array}{l}\text { IVGMM III } \\
\text { efectiva IIBB reaI }\end{array}$ & $\begin{array}{l}\text { IVGMM IV } \\
\text { efectiva IIBB reaI }\end{array}$ & $\begin{array}{l}\text { IVGMM V } \\
\text { efectiva IIBB real }\end{array}$ \\
\hline Tasa efectiva IVA real & $\begin{array}{l}0.4045762 \\
(6.051)^{\star \star \star}\end{array}$ & $\begin{array}{c}0.0348368 \\
(0.161)\end{array}$ & $\begin{array}{c}0.3196714 \\
(1.985)^{\star *}\end{array}$ & $\begin{array}{c}0.4565689 \\
(3.607)^{\star \star *}\end{array}$ & $\begin{array}{c}0.0464470 \\
(0.241)\end{array}$ \\
\hline gobydip & $\begin{array}{l}-0.2831732 \\
(-2.975)^{\star * \star}\end{array}$ & $\begin{array}{c}-0.3809231 \\
(-2.309)^{\star *}\end{array}$ & $\begin{array}{l}-0.3089980 \\
(-2.843)^{\star \star \star}\end{array}$ & $\begin{array}{c}-0.2038283 \\
(-1.622)\end{array}$ & $\begin{array}{c}-0.3198934 \\
(-1.922)^{*}\end{array}$ \\
\hline presygob & $\begin{array}{c}0.0755246 \\
(0.910)\end{array}$ & $\begin{array}{c}0.0366532 \\
(0.269)\end{array}$ & $\begin{array}{c}0.1188665 \\
(1.634)\end{array}$ & $\begin{array}{c}0.0521523 \\
(0.269)\end{array}$ & $\begin{array}{c}0.0870812 \\
(1.039)\end{array}$ \\
\hline presydip & $\begin{array}{c}-0.0547809 \\
(-0.419)\end{array}$ & & & & \\
\hline deflactornac & $\begin{array}{c}0.4860884 \\
(2.433)^{\star *}\end{array}$ & & & & \\
\hline tasadesocupacion & $\begin{array}{c}-0.0192248 \\
(-1.038)\end{array}$ & $\begin{array}{c}-0.0267438 \\
(-0.817)\end{array}$ & $\begin{array}{c}-0.0239390 \\
(-1.231)\end{array}$ & $\begin{array}{c}-0.0623307 \\
(-1.180)\end{array}$ & $\begin{array}{c}0.0013395 \\
(0.039)\end{array}$ \\
\hline subtotalnacpercapita & $\begin{array}{c}-0.0158409 \\
(-1.037)\end{array}$ & $\begin{array}{c}-0.0386227 \\
(-0.902)\end{array}$ & $\begin{array}{c}-0.0189626 \\
(-0.622)\end{array}$ & $\begin{array}{c}0.0346670 \\
(0.366)\end{array}$ & $\begin{array}{c}-0.0690945 \\
(-1.194)\end{array}$ \\
\hline regaliaspercapita & $\begin{array}{l}0.2234419 \\
(4.219)^{\star * *}\end{array}$ & $\begin{array}{c}0.0695929 \\
(0.633)\end{array}$ & $\begin{array}{c}0.1768359 \\
(2.332)^{\star \star}\end{array}$ & $\begin{array}{c}0.3960390 \\
(1.407)\end{array}$ & $\begin{array}{c}0.0492245 \\
(0.668)\end{array}$ \\
\hline notribpercapita & $\begin{array}{c}-0.0173180 \\
(-0.373)\end{array}$ & $\begin{array}{c}0.0244449 \\
(0.287)\end{array}$ & $\begin{array}{c}0.0287111 \\
(0.533)\end{array}$ & $\begin{array}{c}0.1042159 \\
(0.357)\end{array}$ & $\begin{array}{c}-0.0120360 \\
(-0.187)\end{array}$ \\
\hline transfpercapita & $\begin{array}{c}0.0920118 \\
(1.712)^{*}\end{array}$ & $\begin{array}{c}0.1054496 \\
(1.563)\end{array}$ & $\begin{array}{c}0.1309920 \\
(2.172)^{\star *}\end{array}$ & $\begin{array}{c}0.0220495 \\
(0.157)\end{array}$ & $\begin{array}{c}0.1018365 \\
(1.419)\end{array}$ \\
\hline rentasproppercapita & $\begin{array}{c}-0.0223127 \\
(-0.060)\end{array}$ & $\begin{array}{c}-0.2511468 \\
(-0.349)\end{array}$ & $\begin{array}{c}-0.2352427 \\
(-0.665)\end{array}$ & $\begin{array}{c}-0.1928538 \\
(-0.280)\end{array}$ & $\begin{array}{c}-0.1221047 \\
(-0.219)\end{array}$ \\
\hline deficittotalpercapita & $\begin{array}{c}-0.0059085 \\
(-0.247)\end{array}$ & $\begin{array}{c}-0.0422420 \\
(-0.827)\end{array}$ & $\begin{array}{c}0.0126818 \\
(0.408)\end{array}$ & $\begin{array}{c}-0.0993505 \\
(-0.612)\end{array}$ & $\begin{array}{c}0.0272930 \\
(0.519)\end{array}$ \\
\hline ingresorealpercapita & $\begin{array}{c}-0.0000355 \\
(-1.500)\end{array}$ & $\begin{array}{c}0.0000514 \\
(0.690)\end{array}$ & $\begin{array}{c}-0.0000467 \\
(-1.426)\end{array}$ & $\begin{array}{c}0.0000752 \\
(0.482)\end{array}$ & $\begin{array}{c}-0.0000444 \\
(-1.550)\end{array}$ \\
\hline poblacion & $\begin{array}{c}-0.2617867 \\
(-1.629)\end{array}$ & $\begin{array}{c}-0.3519883 \\
(-1.359)\end{array}$ & $\begin{array}{c}-0.2331442 \\
(-1.251)\end{array}$ & $\begin{array}{c}0.0638634 \\
(0.117)\end{array}$ & $\begin{array}{c}-0.2146173 \\
(-1.338)\end{array}$ \\
\hline poblacionsq & $\begin{array}{l}0.0330696 \\
(2.641)^{* * *}\end{array}$ & $\begin{array}{l}0.0408935 \\
(2.693)^{* * *}\end{array}$ & $\begin{array}{c}0.0389819 \\
(2.701)^{\star \star *}\end{array}$ & $\begin{array}{c}0.0287961 \\
(1.457)\end{array}$ & $\begin{array}{c}0.0292139 \\
(1.976)^{* *}\end{array}$ \\
\hline propmenor14 & $\begin{array}{l}0.0689839 \\
(2.116)^{\star *}\end{array}$ & $\begin{array}{c}0.2640824 \\
(1.779)^{*}\end{array}$ & & $\begin{array}{c}0.3206357 \\
(0.586)\end{array}$ & $\begin{array}{c}0.0531644 \\
(1.545)\end{array}$ \\
\hline propmayor65 & $\begin{array}{c}-0.3703812 \\
(-2.462)^{\star *}\end{array}$ & $\begin{array}{c}-0.4237346 \\
(-2.250)^{* *}\end{array}$ & $\begin{array}{l}-0.3668452 \\
(-3.205)^{\star * *}\end{array}$ & $\begin{array}{c}-0.8728878 \\
(-0.797)\end{array}$ & $\begin{array}{c}-0.2703690 \\
(-1.475)\end{array}$ \\
\hline I_Tasa efectiva IIBB real & $\begin{array}{c}0.5278152 \\
(6.741)^{\star * *}\end{array}$ & $\begin{array}{l}0.5158921 \\
(4.487)^{\star * \star}\end{array}$ & $\begin{array}{l}0.5192982 \\
(5.541)^{* * *}\end{array}$ & $\begin{array}{c}0.3804812 \\
(2.041)^{\star *}\end{array}$ & $\begin{array}{c}0.6082824 \\
(6.382)^{\star \star *}\end{array}$ \\
\hline limitestasasefrecaud & & $\begin{array}{c}-1.2741626 \\
(-1.385)\end{array}$ & & & \\
\hline limitestasasefdist & & & $\begin{array}{c}0.2627736 \\
(1.011)\end{array}$ & & \\
\hline limitestasaseflineales & & & & $\begin{array}{c}-1.9182037 \\
(-0.503)\end{array}$ & \\
\hline limitestasasefiguales & & & & & $\begin{array}{c}1.2544259 \\
(0.353)\end{array}$ \\
\hline Observations & 480 & 480 & 480 & 480 & 480 \\
\hline R-squared & 0.719 & 0.584 & 0.703 & 0.610 & 0.661 \\
\hline $\begin{array}{l}\text { Underidentification test Kleibergen-Paap } \\
p \text { value }\end{array}$ & $\begin{array}{r}5.112 \\
0.0776\end{array}$ & $\begin{array}{r}1.551 \\
0.4604\end{array}$ & $\begin{array}{r}4.424 \\
0.2192\end{array}$ & $\begin{array}{r}0.537 \\
0.7647\end{array}$ & $\begin{array}{r}0.632 \\
0.7291\end{array}$ \\
\hline Weak identification test Kleibergen-Paap & 62.828 & 0.744 & 5.987 & 0.306 & 3.195 \\
\hline Hansen overidentification test & 0.019 & 2.285 & 4.512 & 0.655 & 2.565 \\
\hline$p$ value & 0.8889 & 0.1306 & 0.1048 & 0.4185 & 0.1092 \\
\hline Endogeneity test & 0.002 & 2.094 & 0.2 & 1.479 & 2.584 \\
\hline$p$ value & 0.9664 & 0.351 & 0.9049 & 0.4773 & 0.2747 \\
\hline Arellano-Bond $\mathrm{AR}(1)$ test & -0.52 & 0.25 & -0.09 & 0.32 & -0.71 \\
\hline$p$ value & 0.6033 & 0.806 & 0.9254 & 0.7506 & 0.478 \\
\hline Arellano-Bond $\mathrm{AR}(2)$ test & 1.56 & 1.11 & 1.54 & 0.9 & 1.02 \\
\hline$p$ value & 0.1199 & 0.2682 & 0.1236 & 0.3686 & 0.3081 \\
\hline
\end{tabular}

Columna I (sin competencia horizontal): se instrumenta la tasa de IVA con el resultado financiero total per cápita y la tasa de desocupación promedio nacional. Resto: se instrumenta la tasa de IVA con el resultado financiero total per cápita y se adiciona la competencia tributaria horizontal; se instrumenta la variable endógena de las tasas ponderadas provinciales por controles provinciales ponderados, como la proporción de mayores de 65, la proporción de menores de 14, la tasa de desocupación provincial, las transferencias por recursos no tributarios y las regalías 


\section{Cuadro 11}

\section{Resultados de Mínimos Cuadrados Generalizados en dos etapas-Variables}

instrumentales

Clustered-Robust standard errors por período Variable dependiente: tasa efectiva de IIBB cadena agroindustrial

\begin{tabular}{|c|c|c|c|c|c|}
\hline & IVGMM I & IVGMM II & IVGMM III & IVGMM IV & IVGMM V \\
\hline VARIABLES & $\begin{array}{c}\text { Efectiva IIBB } \\
\text { agric }\end{array}$ & $\begin{array}{c}\text { Efectiva IIBB } \\
\text { agric }\end{array}$ & $\begin{array}{c}\text { Efectiva IIBB } \\
\text { agric }\end{array}$ & $\begin{array}{c}\text { Efectiva IIBB } \\
\text { agric }\end{array}$ & $\begin{array}{c}\text { Efectiva IIBB } \\
\text { agric }\end{array}$ \\
\hline Efectiva IVA real agricultura & $\begin{array}{c}0.7693418 \\
(1.409)\end{array}$ & $\begin{array}{c}0.6056510 \\
(0.869)\end{array}$ & $\begin{array}{c}0.6417747 \\
(1.005)\end{array}$ & $\begin{array}{c}0.7241940 \\
(1.147)\end{array}$ & $\begin{array}{c}0.0953274 \\
(0.295)\end{array}$ \\
\hline gobydip & $\begin{array}{c}-0.1144372 \\
(-1.272)\end{array}$ & $\begin{array}{c}-0.0941032 \\
(-0.644)\end{array}$ & $\begin{array}{c}-0.0690279 \\
(-0.663)\end{array}$ & $\begin{array}{c}-0.0592687 \\
(-0.542)\end{array}$ & $\begin{array}{l}-0.1647690 \\
(-2.644)^{\star \star \star \star}\end{array}$ \\
\hline presygob & $\begin{array}{c}-0.0143766 \\
(-0.328)\end{array}$ & $\begin{array}{c}-0.0099277 \\
(-0.124)\end{array}$ & $\begin{array}{c}-0.0141869 \\
(-0.318)\end{array}$ & $\begin{array}{c}-0.0151146 \\
(-0.315)\end{array}$ & $\begin{array}{c}-0.0086229 \\
(-0.202)\end{array}$ \\
\hline presydip & $\begin{array}{c}0.0632546 \\
(0.642)\end{array}$ & & & & \\
\hline deflactornac & $\begin{array}{c}0.1470478 \\
(0.767)\end{array}$ & & & & \\
\hline tasadesocupacion & $\begin{array}{c}-0.0129396 \\
(-0.863)\end{array}$ & $\begin{array}{c}-0.0092846 \\
(-0.430)\end{array}$ & $\begin{array}{c}0.0020867 \\
(0.085)\end{array}$ & $\begin{array}{c}0.0018071 \\
(0.076)\end{array}$ & $\begin{array}{c}0.0069953 \\
(0.481)\end{array}$ \\
\hline subtotalnacpercapita & $\begin{array}{l}-0.0583628 \\
(-3.247)^{\star \star \star}\end{array}$ & $\begin{array}{c}-0.0620359 \\
(-3.808)^{\star \star \star}\end{array}$ & $\begin{array}{c}-0.0559429 \\
(-4.874)^{\star \star \star}\end{array}$ & $\begin{array}{l}-0.0590977 \\
(-5.022)^{\star \star \star}\end{array}$ & $\begin{array}{c}-0.0545608 \\
(-1.879)^{*}\end{array}$ \\
\hline regaliaspercapita & $\begin{array}{c}0.0595360 \\
(1.868)^{*}\end{array}$ & $\begin{array}{c}0.0424169 \\
(1.359)\end{array}$ & $\begin{array}{c}0.0251407 \\
(0.853)\end{array}$ & $\begin{array}{c}0.0251140 \\
(0.889)\end{array}$ & $\begin{array}{c}0.0160067 \\
(0.564)\end{array}$ \\
\hline notribpercapita & $\begin{array}{c}-0.0084181 \\
(-0.285)\end{array}$ & $\begin{array}{c}0.0493260 \\
(0.908)\end{array}$ & $\begin{array}{c}-0.0186934 \\
(-0.528)\end{array}$ & $\begin{array}{c}-0.0136022 \\
(-0.354)\end{array}$ & $\begin{array}{c}0.0001032 \\
(0.004)\end{array}$ \\
\hline transfpercapita & $\begin{array}{c}0.1221423 \\
(2.367)^{\star *}\end{array}$ & $\begin{array}{l}0.1368904 \\
(2.913)^{\star * \star}\end{array}$ & $\begin{array}{l}0.1299375 \\
(3.013)^{\star * *}\end{array}$ & $\begin{array}{l}0.1383445 \\
(3.084)^{\star * *}\end{array}$ & $\begin{array}{c}0.1382073 \\
(2.571)^{\star *}\end{array}$ \\
\hline rentasproppercapita & $\begin{array}{c}-0.1629645 \\
(-0.641)\end{array}$ & $\begin{array}{c}-0.2606858 \\
(-0.794)\end{array}$ & $\begin{array}{c}-0.1284210 \\
(-0.538)\end{array}$ & $\begin{array}{c}-0.1599941 \\
(-0.668)\end{array}$ & $\begin{array}{c}-0.0607747 \\
(-0.330)\end{array}$ \\
\hline deficittotalpercapita & $\begin{array}{c}0.0210546 \\
(0.777)\end{array}$ & $\begin{array}{c}0.0214285 \\
(0.596)\end{array}$ & $\begin{array}{c}0.0288374 \\
(1.171)\end{array}$ & $\begin{array}{c}0.0319299 \\
(1.280)\end{array}$ & $\begin{array}{c}0.0162671 \\
(0.656)\end{array}$ \\
\hline ingresorealpercapita & $\begin{array}{c}-0.0000108 \\
(-0.673)\end{array}$ & $\begin{array}{c}-0.0000085 \\
(-0.210)\end{array}$ & $\begin{array}{c}-0.0000076 \\
(-0.275)\end{array}$ & $\begin{array}{c}-0.0000086 \\
(-0.315)\end{array}$ & $\begin{array}{c}-0.0000172 \\
(-1.146)\end{array}$ \\
\hline poblacion & $\begin{array}{c}-0.1168510 \\
(-1.522)\end{array}$ & $\begin{array}{c}-0.1752708 \\
(-1.749)^{\star}\end{array}$ & $\begin{array}{c}-0.0894283 \\
(-0.880)\end{array}$ & $\begin{array}{c}-0.0870152 \\
(-0.969)\end{array}$ & $\begin{array}{c}-0.1318216 \\
(-1.673)^{*}\end{array}$ \\
\hline poblacionsq & $\begin{array}{c}0.0138074 \\
(2.598)^{\star \star \star}\end{array}$ & $\begin{array}{c}0.0188928 \\
(2.343)^{\star *}\end{array}$ & $\begin{array}{c}0.0147324 \\
(2.402)^{\star \star}\end{array}$ & $\begin{array}{c}0.0139614 \\
(2.558)^{\star \star}\end{array}$ & $\begin{array}{c}0.0112870 \\
(2.037)^{\star \star}\end{array}$ \\
\hline propmayor65 & $\begin{array}{c}-0.2353735 \\
(-1.985)^{\star *}\end{array}$ & $\begin{array}{c}-0.2401370 \\
(-1.543)\end{array}$ & & & $\begin{array}{c}-0.1251194 \\
(-1.555)\end{array}$ \\
\hline IEfectiva IIBB agric & $\begin{array}{l}0.4720952 \\
(4.622)^{\star * \star}\end{array}$ & $\begin{array}{l}0.5100337 \\
(3.212)^{\star \star \star}\end{array}$ & $\begin{array}{l}0.5317070 \\
(5.293)^{\star \star \star}\end{array}$ & $\begin{array}{l}0.5141581 \\
(5.016)^{\star \star \star}\end{array}$ & $\begin{array}{l}0.6221565 \\
(3.898)^{\star \star \star}\end{array}$ \\
\hline limitestasaefnomagrec & & $\begin{array}{c}-0.1427607 \\
(-0.570)\end{array}$ & & & \\
\hline limitestasasefnomagdist & & & $\begin{array}{c}0.0339767 \\
(0.281)\end{array}$ & & \\
\hline limitestasefaglineales & & & & $\begin{array}{c}0.0378879 \\
(0.272)\end{array}$ & \\
\hline limitestasasefagiguales & & & & & $\begin{array}{c}-0.1351280 \\
(-0.284)\end{array}$ \\
\hline $\begin{array}{l}\text { Observations } \\
\text { R-squared }\end{array}$ & $\begin{array}{c}480 \\
0.777\end{array}$ & $\begin{array}{c}480 \\
0.780\end{array}$ & $\begin{array}{c}480 \\
0.779\end{array}$ & $\begin{array}{c}480 \\
0.776\end{array}$ & $\begin{array}{c}480 \\
0.781\end{array}$ \\
\hline Underidentification test Kleibergen-Paap & 2.933 & 3.899 & 6.613 & 7.025 & 4.845 \\
\hline$p$ value & 0.2307 & 0.1423 & 0.0853 & 0.0711 & 0.0887 \\
\hline Weak identification test Kleibergen-Paap-Wald & 18.249 & 1.928 & 6.95 & 7.649 & 18.473 \\
\hline Hansen overidentification test & 1.922 & 2.466 & 1.382 & 1.304 & 4.449 \\
\hline$p$ value & 0.1656 & 0.1163 & 0.5011 & 0.5211 & 0.0349 \\
\hline Endogeneity test & 0.011 & 0.654 & 0.382 & 0.598 & 1.174 \\
\hline$p$ value & 0.9154 & 0.7209 & 0.8263 & 0.7416 & 0.556 \\
\hline Arellano-Bond $\mathrm{AR}(1)$ test & 0.43 & 0.08 & 0.06 & 0.16 & -0.48 \\
\hline$p$ value & 0.6656 & 0.9361 & 0.9501 & 0.875 & 0.6289 \\
\hline Arellano-Bond $\mathrm{AR}(2)$ test & 0.82 & 0.35 & 0.41 & 0.43 & 0.14 \\
\hline$p$ value & 0.4119 & 0.7282 & 0.6807 & 0.6702 & 0.8856 \\
\hline
\end{tabular}

Columna I (sin competencia horizontal): se instrumenta la tasa de IVA con el resultado financiero total per cápita y la tasa de desocupación promedio nacional. Resto: se instrumenta la tasa de IVA con el resultado financiero total per cápita y se adiciona la competencia tributaria horizontal; se instrumenta la variable endógena de las tasas ponderadas provinciales por controles provinciales ponderados, como la proporción de mayores de 65, la proporción de menores de 14, la tasa de desocupación provincial, las transferencias por recursos no tributarios y las regalías 


\section{Cuadro 12}

\section{Resultados de Mínimos Cuadrados Generalizados en dos etapas-Variables}

instrumentales

Clustered-Robust standard errors por periodo con time effects

Variable dependiente: tasa efectiva de IIBB cadena agroindustrial

\begin{tabular}{|c|c|c|c|c|c|}
\hline VARIABLES & $\begin{array}{c}\text { IVGMM I } \\
\text { Efectiva IIBB } \\
\text { agric } \\
\end{array}$ & $\begin{array}{c}\text { IVGMM II } \\
\text { Efectiva IIBB } \\
\text { agric } \\
\end{array}$ & $\begin{array}{c}\text { IVGMM III } \\
\text { Efectiva IIBB } \\
\text { agric } \\
\end{array}$ & $\begin{array}{c}\text { IVGMM IV } \\
\text { Efectiva IIBB } \\
\text { agric } \\
\end{array}$ & $\begin{array}{c}\text { IVGMM V } \\
\text { Efectiva IIBB } \\
\text { agric } \\
\end{array}$ \\
\hline Efectiva IVA real agricultura & $\begin{array}{c}0.9375843 \\
(2.603)^{\star \star *}\end{array}$ & $\begin{array}{c}-3.1133918 \\
(-0.789)\end{array}$ & $\begin{array}{c}-2.6018517 \\
(-1.179)\end{array}$ & $\begin{array}{c}0.6561623 \\
(1.362)\end{array}$ & $\begin{array}{c}0.2487143 \\
(0.247)\end{array}$ \\
\hline gobydip & $\begin{array}{l}-0.1941761 \\
(-2.595)^{\star \star \star}\end{array}$ & & $\begin{array}{c}-0.1210166 \\
(-1.280)\end{array}$ & $\begin{array}{c}-0.1742112 \\
(-2.335)^{\star *}\end{array}$ & $\begin{array}{c}-0.0749658 \\
(-1.160)\end{array}$ \\
\hline tasadesocupacion & $\begin{array}{c}-0.0146731 \\
(-1.436)\end{array}$ & $\begin{array}{c}-0.0196310 \\
(-0.772)\end{array}$ & $\begin{array}{c}0.0075724 \\
(0.524)\end{array}$ & $\begin{array}{c}-0.0175233 \\
(-1.009)\end{array}$ & $\begin{array}{c}-0.0143568 \\
(-1.725)^{*}\end{array}$ \\
\hline subtotalnacpercapita & $\begin{array}{c}-0.0465089 \\
(-2.529)^{* *}\end{array}$ & $\begin{array}{c}-0.0325353 \\
(-1.833)^{*}\end{array}$ & $\begin{array}{c}-0.0188676 \\
(-0.994)\end{array}$ & $\begin{array}{c}-0.0181563 \\
(-1.249)\end{array}$ & $\begin{array}{c}-0.0330359 \\
(-2.271)^{* *}\end{array}$ \\
\hline regaliaspercapita & $\begin{array}{c}0.0415795 \\
(1.843)^{*}\end{array}$ & $\begin{array}{c}0.0496179 \\
(1.327)\end{array}$ & $\begin{array}{c}0.0197480 \\
(0.723)\end{array}$ & $\begin{array}{c}0.0336953 \\
(0.825)\end{array}$ & $\begin{array}{c}0.0195793 \\
(1.084)\end{array}$ \\
\hline notribpercapita & $\begin{array}{c}-0.0022696 \\
(-0.107)\end{array}$ & $\begin{array}{c}-0.0315429 \\
(-0.938)\end{array}$ & $\begin{array}{c}-0.0387493 \\
(-1.314)\end{array}$ & $\begin{array}{c}-0.0338653 \\
(-0.935)\end{array}$ & $\begin{array}{c}-0.0004542 \\
(-0.026)\end{array}$ \\
\hline transfpercapita & $\begin{array}{c}0.0870030 \\
(1.889)^{*}\end{array}$ & $\begin{array}{c}0.1014834 \\
(1.720)^{*}\end{array}$ & $\begin{array}{c}0.0980414 \\
(1.422)\end{array}$ & $\begin{array}{c}0.0437634 \\
(0.909)\end{array}$ & $\begin{array}{c}0.0800767 \\
(2.159)^{* *}\end{array}$ \\
\hline rentasproppercapita & $\begin{array}{c}0.0242082 \\
(0.140)\end{array}$ & $\begin{array}{c}0.0113766 \\
(0.022)\end{array}$ & $\begin{array}{c}0.0553231 \\
(0.230)\end{array}$ & $\begin{array}{c}-0.2032850 \\
(-0.529)\end{array}$ & $\begin{array}{c}-0.0493193 \\
(-0.529)\end{array}$ \\
\hline deficittotalpercapita & $\begin{array}{c}-0.0064404 \\
(-0.391)\end{array}$ & $\begin{array}{c}0.0043173 \\
(0.167)\end{array}$ & $\begin{array}{c}0.0372356 \\
(1.261)\end{array}$ & $\begin{array}{c}0.0033673 \\
(0.168)\end{array}$ & $\begin{array}{c}-0.0017433 \\
(-0.124)\end{array}$ \\
\hline ingresorealpercapita & $\begin{array}{c}-0.0000088 \\
(-0.617)\end{array}$ & $\begin{array}{c}-0.0000130 \\
(-0.596)\end{array}$ & $\begin{array}{c}-0.0000376 \\
(-1.628)\end{array}$ & $\begin{array}{c}-0.0000221 \\
(-1.129)\end{array}$ & $\begin{array}{c}-0.0000090 \\
(-0.640)\end{array}$ \\
\hline poblacion & $\begin{array}{c}-0.1102296 \\
(-1.261)\end{array}$ & $\begin{array}{c}-0.2400378 \\
(-1.123)\end{array}$ & $\begin{array}{c}-0.2965211 \\
(-1.722)^{*}\end{array}$ & $\begin{array}{c}-0.1090285 \\
(-1.081)\end{array}$ & $\begin{array}{c}-0.0835564 \\
(-0.951)\end{array}$ \\
\hline poblacionsq & $\begin{array}{c}0.0124479 \\
(2.173)^{* *}\end{array}$ & $\begin{array}{c}0.0184745 \\
(1.595)\end{array}$ & $\begin{array}{c}0.0233996 \\
(2.292)^{* *}\end{array}$ & $\begin{array}{c}0.0119730 \\
(2.074)^{* *}\end{array}$ & $\begin{array}{c}0.0082616 \\
(1.333)\end{array}$ \\
\hline propmenor14 & & & & $\begin{array}{c}-0.0196665 \\
(-0.509)\end{array}$ & \\
\hline propmayor65 & $\begin{array}{c}-0.1623711 \\
(-2.197)^{\star *}\end{array}$ & $\begin{array}{c}-0.3032358 \\
(-1.205)\end{array}$ & $\begin{array}{c}-0.3036630 \\
(-2.050)^{\star *}\end{array}$ & $\begin{array}{c}-0.0746402 \\
(-0.615)\end{array}$ & $\begin{array}{c}-0.1105725 \\
(-1.510)\end{array}$ \\
\hline IEfectiva IIBB agric & $\begin{array}{l}0.5962964 \\
(4.552)^{\star * \star}\end{array}$ & $\begin{array}{c}0.7192268 \\
(5.898)^{\star * *}\end{array}$ & $\begin{array}{l}0.8433548 \\
(9.334)^{* * *}\end{array}$ & $\begin{array}{l}0.7078557 \\
(11.250)^{* * *}\end{array}$ & $\begin{array}{l}0.7447121 \\
(9.986)^{\star * *}\end{array}$ \\
\hline limitestasaefnomagrec & & $\begin{array}{c}0.0513487 \\
(0.990)\end{array}$ & & & \\
\hline limitestasasefnomagdist & & & $\begin{array}{c}0.1932863 \\
(1.762)^{*}\end{array}$ & & \\
\hline limitestasefaglineales & & & & $\begin{array}{c}0.2147677 \\
(1.730)^{*}\end{array}$ & \\
\hline limitestasasefagiguales & & & & & $\begin{array}{c}-0.2911173 \\
(-0.313)\end{array}$ \\
\hline Observations & 480 & 480 & 480 & 480 & 480 \\
\hline R-squared & 0.581 & 0.248 & 0.258 & 0.513 & 0.528 \\
\hline Underidentification test Kleibergen-Paap & 2.473 & 4.523 & 7.601 & 21.729 & 7.351 \\
\hline$p$ value & 0.2904 & 0.3399 & 0.055 & 0.0002 & 0.1958 \\
\hline Weak identification test Kleibergen-Paap-Wald & 38.897 & 0.455 & 2.442 & 7.451 & 1.745 \\
\hline Hansen overidentification test & 1.809 & 6.211 & 3.343 & 10.895 & 5.617 \\
\hline$p$ value & 0.1786 & 0.1018 & 0.1879 & 0.0123 & 0.2296 \\
\hline Endogeneity test & 0.596 & 1.825 & 1.833 & 2.097 & 0.263 \\
\hline$p$ value & 0.4401 & 0.1767 & 0.1758 & 0.1476 & 0.6083 \\
\hline Arellano-Bond $\mathrm{AR}(1)$ test & -0.59 & -1.19 & -1.39 & -0.86 & -2.13 \\
\hline$p$ value & 0.5583 & 0.2351 & 0.1657 & 0.3893 & 0.0329 \\
\hline Arellano-Bond $\mathrm{AR}(2)$ test & 0.78 & 1.71 & 1.29 & 1.17 & 0.07 \\
\hline$p$ value & 0.4375 & 0.0867 & 0.1977 & 0.2425 & 0.947 \\
\hline
\end{tabular}

Columna I (sin competencia horizontal): se instrumenta la tasa de IVA con el resultado financiero total per cápita y la tasa de desocupación promedio nacional. Resto: se instrumenta la tasa de IVA con el resultado financiero total per cápita y se adiciona la competencia tributaria horizontal; se instrumenta la variable endógena de las tasas ponderadas provinciales por controles provinciales ponderados, como la proporción de mayores de 65, la proporción de menores de 14, la tasa de desocupación provincial, las transferencias por recursos no tributarios y las regalías 
El coeficiente del ingreso per cápita influye en general con signo negativo (y significativo para el caso de la tasa real de Ingresos Brutos, ver Cuadro 5); si el mismo fuera significativo en todos los casos podría indicarse que prima la hipótesis de que un incremento del producto genera caída en el nivel de recursos provinciales dado que el mismo nivel de gasto puede alcanzarse con una alícuota inferior.

Sin embargo, al no verificarse significatividad ni homogeneidad en el signo para todos los casos (se aprecian variaciones positivas en algunos casos), no puede descartarse la hipótesis de ilusión fiscal (reacciones pasivas a positivas ante aumentos en la base imponible). Las variables poblacionales resultan, entretanto, significativas en general, en especial el caso de la población al cuadrado.

Entre las variables de índole política, si bien algunas debieron descartarse por existir colinealidad, la variable de mayor significatividad es la de coincidencia política entre el gobernador provincial y los diputados nacionales, evidenciando una relación negativa. En general, puede advertirse que pierden significatividad a medida que se alejan de la variable de tasa nominal, haciendo referencia a que la fijación de tasas nominales parece estar más relacionada con un proceso político.

Del análisis realizado puede concluirse que se encuentra, en el caso general y en la mayoría de las especificaciones, evidencia de una relación entre las variables tributarias del gobierno federal y de las provincias, en relación con el IVA e Ingresos Brutos. La misma es positiva, y en general significativa, para el caso de las tasas legales en ausencia de competencia horizontal, aunque al adicionarle competencia entre gobiernos del mismo nivel la significatividad se reduce sobre todo para el caso de las tasas legales reales (el caso de ponderadores lineales e iguales para las tasas legales y el caso de ponderadores lineales y distancias para las tasas efectivas continúan resultando significativos).

La variable de productividad, sin embargo, refleja una reacción positiva y una significatividad aún mayor, al adicionar la competencia horizontal. Sin embargo, la evidencia encontrada para las tasas relacionadas con la cadena agroindustrial no resulta significativa.

Las variables relacionadas con competencia horizontal muestran que, en general, y a excepción de los casos de ponderadores iguales y de recaudación, para la productividad (en ambos casos las reacciones horizontales son negativas), no puede apreciarse una reacción significativa de los impuestos provinciales ante variaciones en las variables impositivas de las provincias limítrofes o el resto de los niveles subnacionales de gobierno. 


\section{Síntesis de los resultados de las estimaciones}

En la presente sección se presentan, a modo de resumen, los resultados de las estimaciones realizadas, separadamente para cada una de las variables dependientes. En los cuadros que se exponen a continuación puede apreciarse el signo y la significatividad estadística de los coeficientes asociados a las variables que se pretende explicar.

La tasa del IVA genera una reacción positiva y significativa al $1 \%$ en la tasa de Ingresos Brutos provinciales para los modelos de Mínimos Cuadrados Ordinarios, Efectos Fijos y Mínimos Cuadrados Generalizados (en todos los casos, previamente a introducir la variable endógena rezagada entre las variables explicativas), resultado que se mantiene en la estimación por el método de Variables Instrumentales.

Al introducir competencia tributaria horizontal para el modelo dinámico, esta reacción vertical deja de ser significativa, prácticamente en todos los casos, a excepción del caso de la variable que pondera a las tasas de todas las provincias por igual, en el cual es significativa al $1 \%$ y al ponderador lineal, en donde es significativa al $5 \%$.

\section{Cuadro 13}

Síntesis de resultados de las estimaciones Variable dependiente: Tasa IIIBB real

\begin{tabular}{|c|c|c|c|c|c|c|}
\hline \multirow[b]{2}{*}{ Modelo } & \multirow[b]{2}{*}{ Variable independiente } & \multicolumn{2}{|c|}{ Competencia horizontal } & \multirow{2}{*}{$\begin{array}{l}\text { Variable } \\
\text { endógena } \\
\text { rezagada }\end{array}$} & \multirow{2}{*}{$\begin{array}{c}\text { Time } \\
\text { dummies }\end{array}$} & \multirow[b]{2}{*}{ Signo de la reacción } \\
\hline & & Se modela & Ponderador & & & \\
\hline POLS & Tasa IVA real & No & - & No & No & $+($ significativa al $1 \%)$ \\
\hline Efectos fijos & Tasa IVA real & No & - & No & No & $+($ significativa al $1 \%)$ \\
\hline GLS & Tasa IVA real & No & - & No & No & $+($ significativa al $1 \%)$ \\
\hline GMM IV & Tasa IVA real & No & - & $\mathrm{Si}$ & No & $+($ significativa al $1 \%)$ \\
\hline Efectos fijos & Tasa IVA real & $\mathrm{Si}$ & Recaudación & No & No & $+($ significativa al $1 \%)$ \\
\hline GLS & Tasa IVA real & $\mathrm{Si}$ & Recaudación & No & No & $+($ significativa al $1 \%$ ) \\
\hline GMM IV & Tasa IVA real & $\mathrm{Si}$ & Recaudación & $\mathrm{Si}$ & No & + (no significativa) \\
\hline Efectos fijos & Tasa IVA real & $\mathrm{Si}$ & Distancias & No & No & $+($ significativa al $1 \%)$ \\
\hline GLS & Tasa IVA real & $\mathrm{Si}$ & Distancias & No & No & $+($ significativa al $1 \%)$ \\
\hline GMM IV & Tasa IVA real & $\mathrm{Si}$ & Distancias & $\mathrm{Si}$ & No & $+($ no significativa) \\
\hline Efectos fijos & Tasa IVA real & $\mathrm{Si}$ & Lineal & No & No & $+($ significativa al $1 \%)$ \\
\hline GLS & Tasa IVA real & $\mathrm{Si}$ & Lineal & No & No & $+($ significativa al $1 \%)$ \\
\hline GMM IV & Tasa IVA real & $\mathrm{Si}$ & Lineal & $\mathrm{Si}$ & No & $+($ significativa al $5 \%)$ \\
\hline Efectos fijos & Tasa IVA real & $\mathrm{Si}$ & Igual & No & No & $+($ significativa al $1 \%)$ \\
\hline GLS & Tasa IVA real & $\mathrm{Si}$ & Igual & No & No & $+($ significativa al $1 \%)$ \\
\hline GMM IV & Tasa IVA real & $\mathrm{Si}$ & Igual & $\mathrm{Si}$ & No & $+($ significativa al $1 \%)$ \\
\hline
\end{tabular}

Fuente: cuadros anteriores. Para referencias, ver texto

La productividad del IVA genera una reacción positiva y significativa al $5 \%$ en la productividad de Ingresos Brutos provinciales para los modelos de Mínimos Cuadrados Ordinarios, pero no mantiene su relevancia estadística en las especificaciones de Efectos Fijos, Mínimos Cuadrados Generalizados y Variables Instrumentales, adicionando además la variable endógena rezagada en un período y antes de introducir la competencia por impuestos entre provincias entre las variables explicativas. 
La introducción de competencia tributaria horizontal genera resultados disímiles de acuerdo al ponderador que se trate; para el ponderador por recaudación la reacción de la tasa provincial es no significativa; para el que considera a todas las provincias por igual y para el caso de ponderadores lineales (considera de igual manera a las provincias limítrofes) la reacción es significativa al 5\%, y para el ponderador por distancias, la reacción es significativa al 1\%, en ambos casos experimentando reacciones positivas.

Una posible explicación a este fenómeno puede radicar en el hecho de que la variable de productividad puede evidenciar un efecto de impacto recaudatorio de las administraciones tributarias, existiendo algún grado de economías de escala y complementariedad en la función de recaudación tributaria entre el gobierno nacional y los subnacionales.

\section{Cuadro 14}

Síntesis de resultados de las estimaciones Variable dependiente: Productividad IIBB real

\begin{tabular}{|c|c|c|c|c|c|c|}
\hline \multirow[b]{2}{*}{ Modelo } & \multirow[b]{2}{*}{ Variable independiente } & \multicolumn{2}{|c|}{ Competencia horizontal } & \multirow{2}{*}{$\begin{array}{l}\text { Variable } \\
\text { endógena } \\
\text { rezagada }\end{array}$} & \multirow{2}{*}{$\begin{array}{c}\text { Time } \\
\text { dummies }\end{array}$} & \multirow[b]{2}{*}{ Signo de la reacción } \\
\hline & & Se modela & Ponderador & & & \\
\hline POLS & Productividad IVA real & No & - & No & No & $+($ significativa al $5 \%)$ \\
\hline Efectos fijos & Productividad IVA real & No & - & No & No & + (no significativa) \\
\hline GLS & Productividad IVA real & No & - & No & No & + (no significativa) \\
\hline GMM IV & Productividad IVA real & No & - & $\mathrm{Si}$ & No & - (no significativa) \\
\hline Efectos fijos & Productividad IVA real & $\mathrm{Si}$ & Recaudación & No & No & $+($ significativa al $10 \%)$ \\
\hline GLS & Productividad IVA real & $\mathrm{Si}$ & Recaudación & No & No & + (no significativa) \\
\hline GMM IV & Productividad IVA real & $\mathrm{Si}$ & Recaudación & $\mathrm{Si}$ & No & + (no significativa) \\
\hline Efectos fijos & Productividad IVA real & $\mathrm{Si}$ & Distancias & No & No & - (significativa al 5\%) \\
\hline GLS & Productividad IVA real & $\mathrm{Si}$ & Distancias & No & No & + (no significativa) \\
\hline GMM IV & Productividad IVA real & $\mathrm{Si}$ & Distancias & $\mathrm{Si}$ & No & $+($ significativa al $1 \%)$ \\
\hline Efectos fijos & Productividad IVA real & Si & Lineal & No & No & + (no significativa) \\
\hline GLS & Productividad IVA real & $\mathrm{Si}$ & Lineal & No & No & + (no significativa) \\
\hline GMM IV & Productividad IVA real & $\mathrm{Si}$ & Lineal & $\mathrm{Si}$ & No & $+($ significativa al $5 \%)$ \\
\hline Efectos fijos & Productividad IVA real & $\mathrm{Si}$ & Igual & No & No & + (no significativa) \\
\hline GLS & Productividad IVA real & $\mathrm{Si}$ & Igual & No & No & + (no significativa) \\
\hline GMM IV & Productividad IVA real & $\mathrm{Si}$ & Igual & $\mathrm{Si}$ & No & $+($ significativa al $5 \%)$ \\
\hline
\end{tabular}

Fuente: cuadros anteriores. Para referencias, ver texto

La tasa efectiva del IVA genera una reacción positiva y significativa al $1 \%$ en la tasa de Ingresos Brutos provinciales (cuadro 15) para los modelos de Mínimos Cuadrados Ordinarios, Efectos Fijos y Mínimos Cuadrados Generalizados (en todos los casos, sin introducir la variable endógena rezagada entre las variables explicativas), al igual que en la estimación por Variables Instrumentales (con la variable endógena rezagada en un período).

La competencia tributaria horizontal genera, en general, una disminución en la significatividad estadística de los coeficientes asociados a la reacción vertical, a excepción del caso del ponderador por distancia geográfica, en el cual, si bien el signo se mantiene, la significatividad se reduce al 5\%, y del caso del ponderador lineal, en donde la reacción preserva su significatividad. 
La tasa efectiva del IVA para la cadena agroalimentaria genera una reacción positiva y significativa al $1 \%$ en la tasa de Ingresos Brutos provinciales para los modelos de Mínimos Cuadrados Ordinarios, Efectos Fijos y Mínimos Cuadrados Generalizados si no se adiciona la variable endógena rezagada en un período al set de variables explicativas. Este resultado no se conserva en la estimación por el método de Variables Instrumentales (cuadro 16).

\section{Cuadro 15}

Síntesis de resultados de las estimaciones Variable dependiente: Tasa efectiva IIBB real

\begin{tabular}{|c|c|c|c|c|c|c|}
\hline \multirow[b]{2}{*}{ Modelo } & \multirow[b]{2}{*}{ Variable independiente } & \multicolumn{2}{|c|}{ Competencia horizontal } & \multirow{2}{*}{$\begin{array}{c}\text { Variable } \\
\text { endógena } \\
\text { rezagada }\end{array}$} & \multirow{2}{*}{$\begin{array}{c}\text { Time } \\
\text { dummies }\end{array}$} & \multirow[b]{2}{*}{ Signo de la reacción } \\
\hline & & Se modela & Ponderador & & & \\
\hline POLS & Tasa efectiva IVA real & No & - & No & No & $+($ significativa al $1 \%)$ \\
\hline Efectos fijos & Tasa efectiva IVA real & No & - & No & No & $+($ significativa al $1 \%)$ \\
\hline GLS & Tasa efectiva IVA real & No & - & No & No & $+($ significativa al $1 \%)$ \\
\hline GMM IV & Tasa efectiva IVA real & No & - & $\mathrm{Si}$ & No & $+($ significativa al $1 \%)$ \\
\hline Efectos fijos & Tasa efectiva IVA real & $\mathrm{Si}$ & Recaudación & No & No & $+($ significativa al $1 \%)$ \\
\hline GLS & Tasa efectiva IVA real & $\mathrm{Si}$ & Recaudación & No & No & + (significativa al $1 \%$ ) \\
\hline GMM IV & Tasa efectiva IVA real & $\mathrm{Si}$ & Recaudación & $\mathrm{Si}$ & No & $+($ no significativa) \\
\hline Efectos fijos & Tasa efectiva IVA real & $\mathrm{Si}$ & Distancias & No & No & $+($ significativa al $1 \%)$ \\
\hline GLS & Tasa efectiva IVA real & $\mathrm{Si}$ & Distancias & No & No & $+($ significativa al $1 \%)$ \\
\hline GMM IV & Tasa efectiva IVA real & $\mathrm{Si}$ & Distancias & $\mathrm{Si}$ & No & $+($ significativa al $5 \%)$ \\
\hline Efectos fijos & Tasa efectiva IVA real & $\mathrm{Si}$ & Lineal & No & No & $+($ significativa al $1 \%)$ \\
\hline GLS & Tasa efectiva IVA real & $\mathrm{Si}$ & Lineal & No & No & $+($ significativa al $1 \%)$ \\
\hline GMM IV & Tasa efectiva IVA real & $\mathrm{Si}$ & Lineal & $\mathrm{Si}$ & No & $+($ significativa al $1 \%)$ \\
\hline Efectos fijos & Tasa efectiva IVA real & $\mathrm{Si}$ & Igual & No & No & $+($ significativa al $1 \%)$ \\
\hline GLS & Tasa efectiva IVA real & $\mathrm{Si}$ & Igual & No & No & $+($ significativa al $1 \%)$ \\
\hline GMM IV & Tasa efectiva IVA real & $\mathrm{Si}$ & Igual & $\mathrm{Si}$ & No & + (no significativa) \\
\hline
\end{tabular}

Fuente: cuadros anteriores. Para referencias, ver texto

Al introducir competencia tributaria horizontal esta reacción vertical continúa siendo no significativa, generando evidencias de ausencia de reacción vertical de manera consistente con los resultados presentados en Devereux et. al. (2007) ${ }^{\mathbf{8 3}}$, Esteller Moré y Rizzo (2009, 2011), o Fredriksson y Mamun (2008) en el caso de los impuestos sobre cigarrillos.

\section{Cuadro 16}

Síntesis de resultados de las estimaciones Variable dependiente: Tasa efectiva IIBB cadena agroalimentaria

\begin{tabular}{|c|c|c|c|c|c|c|}
\hline \multirow[b]{2}{*}{ Modelo } & \multirow[b]{2}{*}{ Variable independiente } & \multicolumn{2}{|c|}{ Competencia horizontal } & \multirow{2}{*}{$\begin{array}{l}\text { Variable } \\
\text { endógena } \\
\text { rezagada }\end{array}$} & \multirow{2}{*}{$\begin{array}{c}\text { Time } \\
\text { dummies }\end{array}$} & \multirow[b]{2}{*}{ Signo de la reacción } \\
\hline & & Se modela & Ponderador & & & \\
\hline POLS & Tasa efectiva IVA cadena agroalimentaria & No & - & No & No & $+($ significativa al $1 \%)$ \\
\hline Efectos fijos & Tasa efectiva IVA cadena agroalimentaria & No & - & No & No & $+($ significativa al $1 \%)$ \\
\hline GLS & Tasa efectiva IVA cadena agroalimentaria & No & - & No & No & $+($ significativa al $1 \%)$ \\
\hline GMM IV & Tasa efectiva IVA cadena agroalimentaria & No & - & $\mathrm{Si}$ & No & $+($ no significativa $)$ \\
\hline Efectos fijos & Tasa efectiva IVA cadena agroalimentaria & $\mathrm{Si}$ & Recaudación & No & No & $+($ significativa al $1 \%)$ \\
\hline GLS & Tasa efectiva IVA cadena agroalimentaria & $\mathrm{Si}$ & Recaudación & No & No & $+($ significativa al $1 \%)$ \\
\hline GMM IV & Tasa efectiva IVA cadena agroalimentaria & $\mathrm{Si}$ & Recaudación & $\mathrm{Si}$ & No & $+($ no significativa $)$ \\
\hline Efectos fijos & Tasa efectiva IVA cadena agroalimentaria & $\mathrm{Si}$ & Distancias & No & No & $+($ significativa al $1 \%)$ \\
\hline GLS & Tasa efectiva IVA cadena agroalimentaria & $\mathrm{Si}$ & Distancias & No & No & $+($ significativa al $1 \%)$ \\
\hline GMM IV & Tasa efectiva IVA cadena agroalimentaria & $\mathrm{Si}$ & Distancias & $\mathrm{Si}$ & No & $+($ no significativa $)$ \\
\hline Efectos fijos & Tasa efectiva IVA cadena agroalimentaria & $\mathrm{Si}$ & Lineal & No & No & $+($ significativa al $1 \%)$ \\
\hline GLS & Tasa efectiva IVA cadena agroalimentaria & $\mathrm{Si}$ & Lineal & No & No & $+($ significativa al $1 \%)$ \\
\hline GMM IV & Tasa efectiva IVA cadena agroalimentaria & $\mathrm{Si}$ & Lineal & $\mathrm{Si}$ & No & $+($ no significativa) \\
\hline Efectos fijos & Tasa efectiva IVA cadena agroalimentaria & $\mathrm{Si}$ & Igual & No & No & $+($ significativa al $1 \%)$ \\
\hline GLS & Tasa efectiva IVA cadena agroalimentaria & $\mathrm{Si}$ & Igual & No & No & $+($ significativa al $1 \%)$ \\
\hline GMM IV & Tasa efectiva IVA cadena agroalimentaria & $\mathrm{Si}$ & Igual & $\mathrm{Si}$ & No & + (no significativa) \\
\hline
\end{tabular}

Fuente: cuadros anteriores. Para referencias, ver texto

\footnotetext{
${ }^{83}$ Devereux et. al. (2007), presenta, en relación con la competencia horizontal, una reacción significativa al 5\% en el caso de los ponderadores aquí denominados "iguales"; una reacción significativa al 10\% en el caso de los ponderadores por población y distancia geográfica, y una variación no significativa en el caso de los ponderadores "lineales", todos positivos.
} 
La incorporación de efectos por período en la estimación de la tasa efectiva para la cadena agroalimentaria muestra que se mantiene la una reacción positiva y significativa al $1 \%$ en la tasa de Ingresos Brutos provinciales para los modelos de Efectos Fijos y Mínimos Cuadrados Generalizados. En la estimación por el método de Variables Instrumentales, la reacción vertical no es significativa, al igual que lo que ocurre con competencia tributaria horizontal (cuadro 17).

\section{Cuadro 17}

Síntesis de resultados de las estimaciones Variable dependiente: Tasa efectiva IIBB cadena agroalimentaria con time effects

\begin{tabular}{|c|c|c|c|c|c|c|}
\hline \multirow[b]{2}{*}{ Modelo } & \multirow[b]{2}{*}{ Variable independiente } & \multicolumn{2}{|c|}{ Competencia horizontal } & \multirow{2}{*}{$\begin{array}{l}\text { Variable } \\
\text { endógena } \\
\text { rezagada }\end{array}$} & \multirow{2}{*}{$\begin{array}{c}\text { Time } \\
\text { dummies }\end{array}$} & \multirow[b]{2}{*}{ Signo de la reacción } \\
\hline & & Se modela & Ponderador & & & \\
\hline POLS & Tasa efectiva IVA cadena agroalimentaria & No & - & No & $\mathrm{Si}$ & - \\
\hline Efectos fijos & Tasa efectiva IVA cadena agroalimentaria & No & - & No & Si & + (no significativa) \\
\hline GLS & Tasa efectiva IVA cadena agroalimentaria & No & - & No & Si & + (significativa al 1\%) \\
\hline GMM IV & Tasa efectiva IVA cadena agroalimentaria & No & - & $\mathrm{Si}$ & $\mathrm{Si}$ & $+($ significativa al $1 \%)$ \\
\hline Efectos fijos & Tasa efectiva IVA cadena agroalimentaria & $\mathrm{Si}$ & Recaudación & No & $\mathrm{Si}$ & $+($ no significativa $)$ \\
\hline GLS & Tasa efectiva IVA cadena agroalimentaria & $\mathrm{Si}$ & Recaudación & No & $\mathrm{Si}$ & + (significativa al 1\%) \\
\hline GMM IV & Tasa efectiva IVA cadena agroalimentaria & $\mathrm{Si}$ & Recaudación & $\mathrm{Si}$ & $\mathrm{Si}$ & + (no significativa) \\
\hline Efectos fijos & Tasa efectiva IVA cadena agroalimentaria & $\mathrm{Si}$ & Distancias & No & $\mathrm{Si}$ & + (no significativa) \\
\hline GLS & Tasa efectiva IVA cadena agroalimentaria & $\mathrm{Si}$ & Distancias & No & $\mathrm{Si}$ & + (significativa al 1\%) \\
\hline GMM IV & Tasa efectiva IVA cadena agroalimentaria & $\mathrm{Si}$ & Distancias & $\mathrm{Si}$ & $\mathrm{Si}$ & + (no significativa) \\
\hline Efectos fijos & Tasa efectiva IVA cadena agroalimentaria & $\mathrm{Si}$ & Lineal & No & Si & + (no significativa) \\
\hline GLS & Tasa efectiva IVA cadena agroalimentaria & $\mathrm{Si}$ & Lineal & No & $\mathrm{Si}$ & $+($ significativa al $1 \%)$ \\
\hline GMM IV & Tasa efectiva IVA cadena agroalimentaria & $\mathrm{Si}$ & Lineal & $\mathrm{Si}$ & $\mathrm{Si}$ & + (no significativa) \\
\hline Efectos fijos & Tasa efectiva IVA cadena agroalimentaria & Si & Igual & No & Si & + (no significativa) \\
\hline GLS & Tasa efectiva IVA cadena agroalimentaria & $\mathrm{Si}$ & Igual & No & $\mathrm{Si}$ & $+($ significativa al $1 \%)$ \\
\hline GMM IV & Tasa efectiva IVA cadena agroalimentaria & $\mathrm{Si}$ & Igual & $\mathrm{Si}$ & $\mathrm{Si}$ & + (no significativa) \\
\hline
\end{tabular}

Fuente: cuadros anteriores. Para referencias, ver texto

\section{Conclusiones}

Los estudios sobre externalidades tributarias verticales entre jurisdicciones de distinto nivel surgen a partir de la existencia del solapamiento de las bases tributarias, es decir, de la concurrencia en las fuentes de imposición. Esta es una característica de los sistemas federales, los que, en mayor o menor medida, plantean esta problemática desde las atribuciones de potestades jurisdiccionales.

En el caso de Canadá y Estados Unidos, por ejemplo, la superposición está dada por los impuestos sobre la renta, en donde los estados difieren entre sí en función de la concordancia total o no en la definición de la base imponible, la existencia de deducibilidad del impuesto federal y de deducibilildad recíproca de los impuestos estaduales, y aún la posibilidad de establecer sobretasas sobre las alícuotas nacionales en sus propios estados. Otro de los antecedentes analizados en forma exhaustiva por la literatura radica en los impuestos sobre combustibles y cigarrillos en los Estados Unidos. 
En el caso de la Argentina, si bien la concurrencia está dada por el mandato constitucional, no existe un grado de concordancia entre los tributos que gravan la misma base imponible, con lo cual ésta se encuentra gravada de manera diferente.

En este trabajo se procuran establecer algunos lineamientos orientativos para el análisis de las externalidades tributarias tomando el caso del impuesto al Valor Agregado nacional y el impuesto a los Ingresos Brutos provinciales, que gravan bases imponibles asimilables, y si puede encontrarse evidencia de que la política impositiva provincial responda ante una variación en las variables de política impositiva por parte del gobierno federal.

Se presentan cuatro indicadores diferentes a fines de intentar aproximar de la manera más precisa a la competencia tributaria. Las mismas son: la tasas legales de Ingresos Brutos provinciales (ponderada por la participación de las actividades económicas que gravan en el PBG provincial), a valores reales; la productividad de Ingresos Brutos (cociente entre presión tributaria y tasa); la tasa "efectiva" de Ingresos Brutos; y la tasa "efectiva" de Ingresos Brutos que recae sobre la cadena productiva del trigo, harina y pan (denominada "cadena agroindustrial").

Como variables explicativas, a nivel federal, fueron incorporadas: la alícuota legal promedio, expresada en términos reales, del IVA; la productividad del IVA; la tasa efectiva del IVA y la tasa efectiva del IVA relacionada con la cadena productiva mencionada con anterioridad.

Se incorporan como controles a variables de índole política (coincidencia en el signo político entre gobernador y diputados, presidente y gobernador, y presidente y diputados), ingreso per cápita, transferencias de Nación a provincias por mecanismos de coparticipación y otros, tasa de desocupación, población, proporciones de población superiores a 65 e inferiores a 14, y variables institucionales, que apuntan a evaluar la calidad de la gestión política, como índices de libertades individuales o de gobernabilidad democrática.

La evidencia encontrada sugiere que existe una reacción positiva y en general significativa de los impuestos provinciales ante cambios en tasas legales del IVA, al igual de lo que ocurre ante cambios en las tasas efectivas. La reacción vertical es también positiva en el caso de la productividad y de la tasa efectiva de la cadena agroalimentaria, aunque ésta, a diferencia de la anterior, no resulta ser significativa.

Las relaciones encontradas disminuyen su significatividad al incorporar competencia tributaria horizontal para la mayoría de las especificaciones; para las tasas legales reales de 
IVA la reacción vertical es no significativa (a excepción del ponderador igual), mientras que para la productividad y la tasa efectiva la relevancia estadística se mantiene en pocos casos.

Lo anterior implica que el incremento verificado en las variables impositivas de las provincias, medidas tanto a partir de las tasas nominales, como de la productividad y las tasas efectivas, que se traduce en un crecimiento de la presión tributaria subnacional, si bien puede relacionarse en principio con un efecto de externalidad vertical, no deben excluirse otras causas con que el mencionado crecimiento se relacionaría, como la ilusión fiscal antes mencionada (incrementos exógenos de la base imponible ante la cual los gobiernos reaccionan en forma pasiva), o la necesidad de incrementar los tributos subnacionales ante déficit presupuestarios crecientes.

Para las tasas efectivas de la cadena agroalimentaria, entretanto, en consonancia con la literatura (Devereux et. al. (2007), Esteller Moré y Rizzo (2009, 2011)), no se encuentra evidencia de externalidad vertical aún excluyendo la competencia tributaria horizontal, si bien la misma es ligeramente mayor en este caso. No se encuentra evidencia significativa sobre la competencia por impuestos entre jurisdicciones del mismo nivel para la mayoría de las especificaciones planteadas.

Estos resultados están, sin embargo, sujetos a la disponibilidad y calidad de la información existente, como variables a nivel de provincia (precios, cuestiones institucionales, informalidad, desigualdad, etc.), estructuras productivas, datos sobre gastos e ingresos, etc. podrían ayudar a aportar mayor evidencia al respecto. 


\section{Anexo estadístico}

\section{Cuadro 1}

\section{Resumen de estadísticas básicas de variables utilizadas}

Variable

Gobernador y diputados

Presidente y gobernador

Presidente y diputados

Tasa nominal IVA

Deflactor PBI nacional

Indice de precios al consumidor nacional

Tasa desocupación provinciales

Coparticipación y leyes especiales per cápita

Otros recursos nacionales per cápita

Subtotal recursos nacionales per cápita

Regalías per cápita

Recursos no tributarios per cápita

Transferencias corrientes per cápita

Rentas de la propiedad per cápita

Déficit total per cápita

Resultado económico per cápita

PBG nominal per cápita

Población

Población al cuadrado

Proporción de menores de 14

Proporción de mayores de 65

Densidad de población

Tasa desocupación nacional

Overall Freedom Index

The Civil Liberties Index

The Political Rights Index

ICRG indicator of Quality of Government

Informalidad

Tasa efectiva IVA nominal

Tasa efectiva IIBB nominal

Productividad de IIIBB en relación con el PBI corriente

Tasa efectiva IVA nominal agricultura

Tasa efectiva IIBB nominal agricultura

Tasa IIBB promedio ponderada

Productividad del IVA en relación al PBI

PBG real per cápita
Obs

Unidad




$\times 10^{\wedge} 3$
$\times 10^{\wedge} 3$
$\times 10^{\wedge} 3$
$\times 10^{\wedge} 3$
$\times 10^{\wedge} 3$
$\times 10^{\wedge} 3$
$\times 10^{\wedge} 3$
$\times 10^{\wedge} 3$
$\times 10^{\wedge} 3$
$\times 10^{\wedge} 3$
$\times 10^{\wedge} 3$
$\times 10^{\wedge} 3$

Cuadro 2

\section{Fuentes de información}

\section{Variable}

Gobernador y diputados

Presidente y gobernador

Presidente y diputados

Tasa nominal IVA

Deflactor PBI nacional

Indice de precios al consumidor naciona

Tasa desocupación provinciales

Coparticipación y leyes especiales per cápita

Otros recursos nacionales per cápita

Subtotal recursos nacionales per cápita

Regalías per cápita

Recursos no tributarios per cápita

Transferencias corrientes per cápita

Rentas de la propiedad per cápita

Déficit total per cápita

Resultado económico per cápita

PBG nominal per cápita

Población

Población al cuadrado

Proporción de menores de 14

Proporción de mayores de 65

Densidad de población

Tasa desocupación nacional

Overall Freedom Index

The Civil Liberties Index

The Political Rights In

ICRG indicator of Quality of Government

Informalidad

Tasa efectiva IVA nominal

Tasa efectiva IIBB nominal

Productividad de IIBB en relación con el PBI corriente

Tasa efectiva IVA nominal agricultura

Tasa efectiva IIBB nominal agricultura

Tasa IIBB promedio ponderada

Productividad del IVA en relación al PB

PBG real per cápita

INDEC USAID

USAID

USAID

USAID

CEDLAS

\begin{tabular}{rrrr}
\multicolumn{1}{l}{ Mean } & \multicolumn{1}{l}{ Std. Dev } & \multicolumn{1}{l}{ Min } \\
& & \multicolumn{1}{l}{ Max } \\
0.6388889 & 0.4807999 & 0 & 1 \\
0.6170635 & 0.486586 & 0 & 1 \\
0.6448413 & 0.4790369 & 0 & 1 \\
20.24686 & 0.0144326 & 15.933 & 21 \\
1.651293 & 0.8881019 & 0.8863563 & 4.008133 \\
1.503439 & 0.6082471 & 0.7238312 & 2.719851 \\
10.00978 & 4.50038 & 1.3 & 23 \\
618.5773 & 466.4686 & 0 & 3226.5 \\
94.73331 & 256.1663 & 0 & 2321.577 \\
2.569909 & 3.757552 & 0 & 29.24431 \\
0.5037508 & 1.568021 & 0 & 11.00203 \\
0.2744867 & 0.7567551 & 0.0009577 & 8.650852 \\
0.5143656 & 1.087853 & 0 & 11.8219 \\
0.039748 & 0.1107631 & 0 & 1.035633 \\
-0.0561542 & 0.9466194 & -7.689862 & 5.766806 \\
820.542 & 1799.711 & -6815.351 & 15702.58 \\
13232.88 & 16342.22 & 831.8752 & 142286.7 \\
1.546964 & 2.779497 & 0.075 & 15.444 \\
10.10338 & 40.29682 & 0.0055915 & 238.5266 \\
30.99982 & 4.889898 & 15.717 & 40.25 \\
7.749069 & 2.828604 & 1.896775 & 17.77462 \\
0.6337215 & 2.994376 & 0.0006552 & 15.25364 \\
9.609524 & 2.990065 & 5.26 & 15.76 \\
1.095238 & 0.2938352 & 1 & 2 \\
2.52381 & 0.499929 & 2 & 3 \\
2.047619 & 0.4861034 & 1 & 3 \\
0.5703263 & 0.0565656 & 0.4675926 & 0.6944444 \\
40.15223 & 3.598249 & 34.10236 & 45.8 \\
14.5291 & 0.0080663 & 12.34771 & 16.23256 \\
7.31295 & 0.0299944 & 1.3963 & 18.25677 \\
4.43053 & 0.0786848 & 0.17399 & 43.70862 \\
7.61484 & 0.0132791 & 4.89864 & 10.0597 \\
6.27449 & 0.0169483 & 3.01443 & 12.14678 \\
2.06505 & 0.0050954 & 0.57784 & 3.99757 \\
33.0166 & 0.0471166 & 21.63432 & 39.87255 \\
7843.739 & 6149.827 & 657.1769 & 34525.67 \\
& & & 3
\end{tabular}

Cálculos propios a partir de datos del Ministerio del Interior Cálculos propios a partir de datos del Ministerio del Interior Cálculos propios a partir de datos del Ministerio del Interior Elaboración propia a partir de legislación

Elaboración propia a partir de datos de MECON

Elaboración propia a partir de datos de MECON

Estimaciones propias a partir de datos de DNCPF e INDEC Estimaciones propias a partir de datos de DNCPF e INDEC Estimaciones propias a partir de datos de DNCPF e INDEC Estimaciones propias a partir de datos de DNCPF e INDEC Estimaciones propias a partir de datos de DNCPF e INDEC Estimaciones propias a partir de datos de DNCPF e INDEC Estimaciones propias a partir de datos de DNCPF e INDEC Estimaciones propias a partir de datos de DNCPF e INDEC Estimaciones propias a partir de datos de DNCPF e INDEC

Estimaciones propias a partir de datos de Direcciones de Estadística provinciales Estimaciones propias a partir de datos de INDEC Estimaciones propias a partir de datos de INDEC Estimaciones propias a partir de datos de INDEC

Estimaciones propias a partir de datos de INDEC Estimaciones propias a partir de datos de INDEC

Estimaciones propias a partir de datos de INDEC

Estimaciones propias a partir de datos de DNCPF, Matriz Insumo Producto y legislación provincial Estimaciones propias a partir de datos de DNCPF, Matriz Insumo Producto y legislación provincia Estimaciones propias a partir de datos de DNIAF e INDEC

Estimaciones propias a partir de datos de DNCPF, Matriz Insumo Producto y legislación provincial Estimaciones propias a partir de datos de DNCPF, Matriz Insumo Producto y legislación provincial Elaboración propia a partir de legislación provincial

Estimaciones propias a partir de datos de DNIAF e INDEC

Estimaciones propias a partir de datos de Direcciones de Estadística provinciales 


\section{Cuadro 3}

Correlaciones entre variables

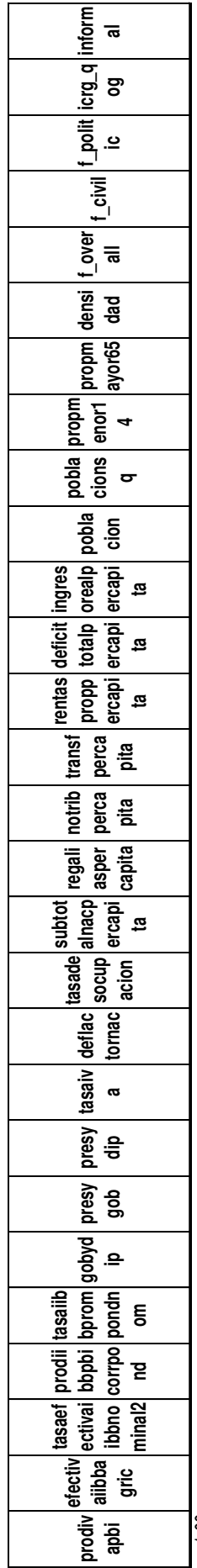

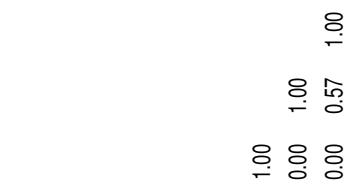

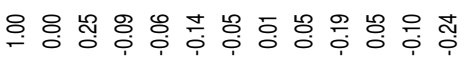

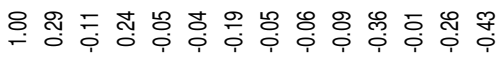

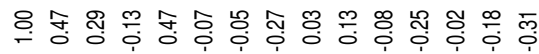

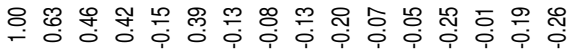

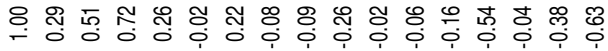

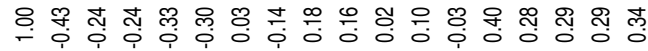

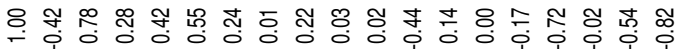

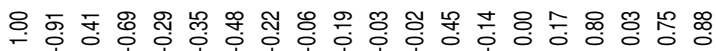

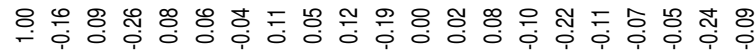

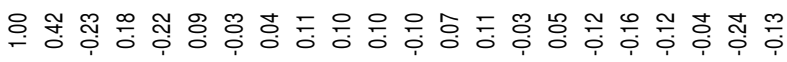

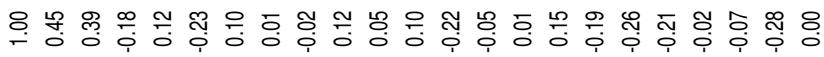

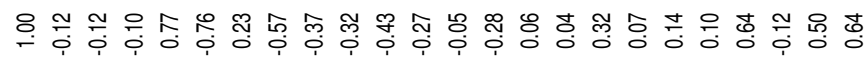

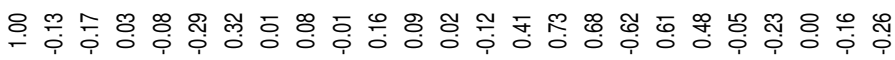

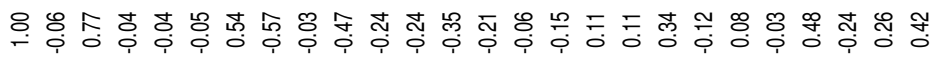

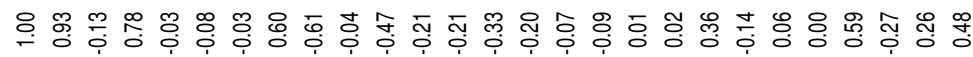

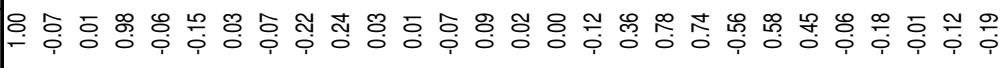

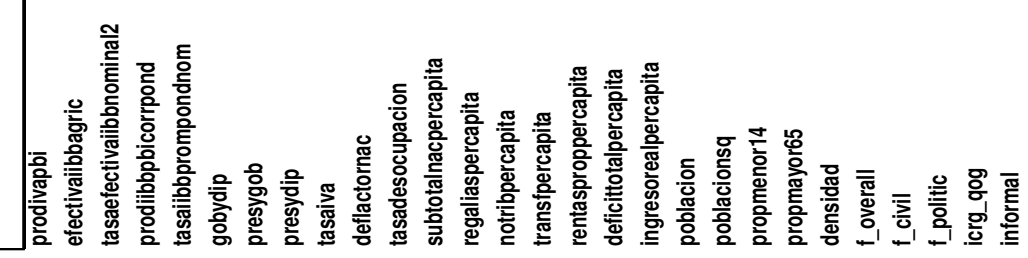




\section{Cuadro 4}

\section{Correlaciones entre variables endógenas y exógenas}

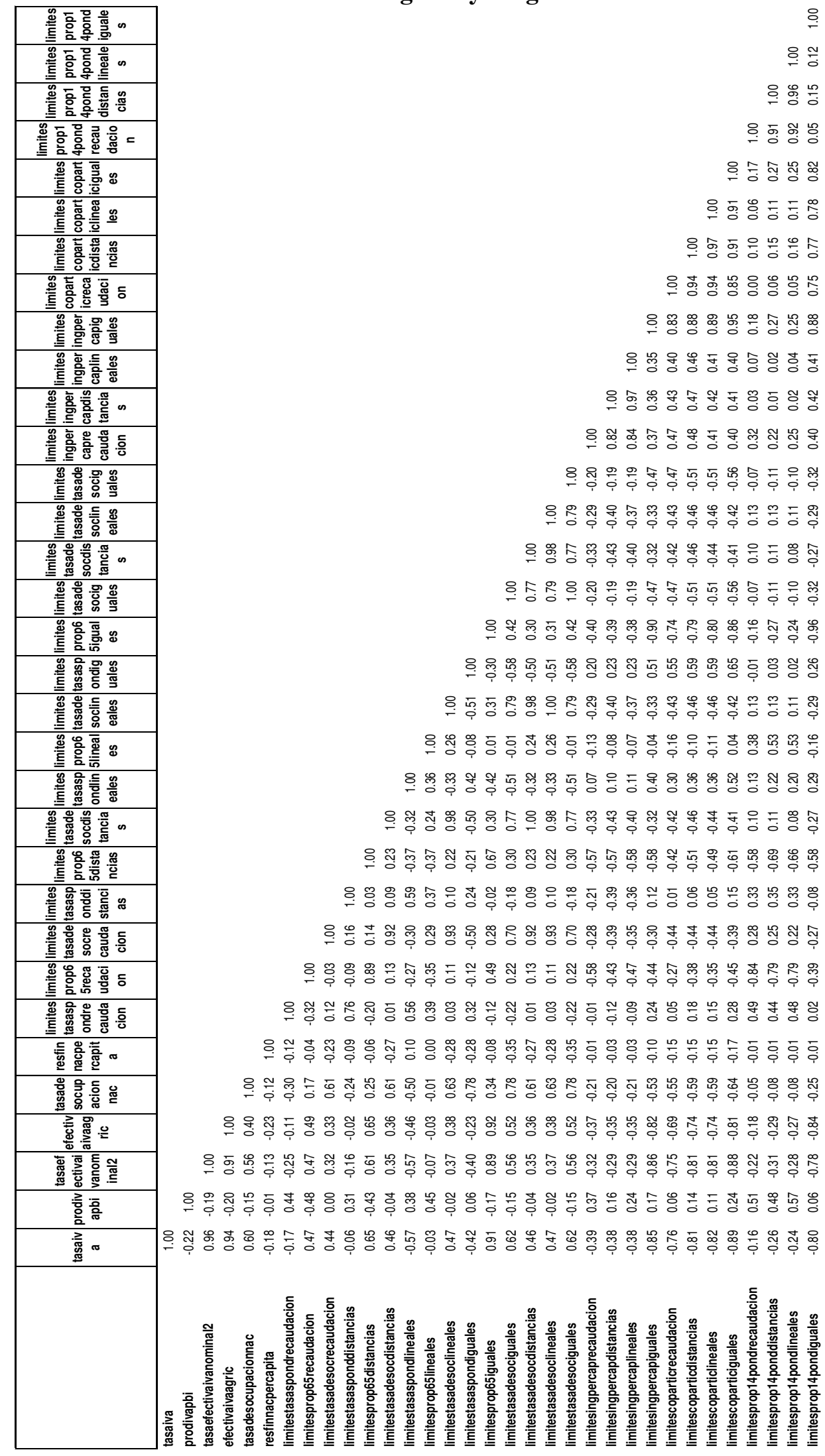




\section{Cuadro 5}

Resultados de las regresiones de base

OLS, efectos fijos y aleatorios, Clustered robust standard errors por período Variable dependiente: tasa de Ingresos Brutos

\begin{tabular}{|c|c|c|c|c|}
\hline VARIABLES & $\begin{array}{c}\text { POLS } \\
\text { Tasa IIBB real } \\
\end{array}$ & $\begin{array}{c}\text { POLS LSDV } \\
\text { Tasa IIBB real }\end{array}$ & $\begin{array}{l}\text { Fixed Effects } \\
\text { Tasa IIBB real }\end{array}$ & $\begin{array}{c}\text { Random Effects } \\
\text { Tasa IIBB real }\end{array}$ \\
\hline Tasa IVA real & $\begin{array}{l}0.0844013 \\
(4.281)^{\star \star \star}\end{array}$ & $\begin{array}{l}0.0847826 \\
(4.910)^{\star \star \star}\end{array}$ & $\begin{array}{l}0.0847826 \\
(7.685)^{\star \star \star}\end{array}$ & $\begin{array}{l}0.0844985 \\
(8.007)^{\star \star \star}\end{array}$ \\
\hline gobydip & $\begin{array}{c}0.0015939 \\
(0.044)\end{array}$ & $\begin{array}{c}-0.0292377 \\
(-1.399)\end{array}$ & $\begin{array}{c}-0.0292377 \\
(-0.988)\end{array}$ & $\begin{array}{c}-0.0350026 \\
(-0.999)\end{array}$ \\
\hline presygob & $\begin{array}{c}0.0129651 \\
(0.321)\end{array}$ & $\begin{array}{c}0.0471531 \\
(2.081)^{*}\end{array}$ & $\begin{array}{c}0.0471531 \\
(1.055)\end{array}$ & $\begin{array}{c}0.0360103 \\
(0.709)\end{array}$ \\
\hline presydip & $\begin{array}{c}-0.0361060 \\
(-0.741)\end{array}$ & $\begin{array}{c}-0.0021752 \\
(-0.106)\end{array}$ & $\begin{array}{c}-0.0021752 \\
(-0.065)\end{array}$ & $\begin{array}{c}0.0031181 \\
(0.087)\end{array}$ \\
\hline deflactornac & $\begin{array}{c}-0.3664947 \\
(-5.526)^{\star \star \star}\end{array}$ & $\begin{array}{c}-0.1992789 \\
(-3.567)^{\star \star \star}\end{array}$ & $\begin{array}{c}-0.1992789 \\
(-4.821)^{\star \star \star}\end{array}$ & $\begin{array}{l}-0.2441770 \\
(-5.975)^{\star \star \star}\end{array}$ \\
\hline tasadesocupacion & $\begin{array}{c}-0.0133560 \\
(-2.711)^{\star *}\end{array}$ & $\begin{array}{c}-0.0101125 \\
(-1.720)\end{array}$ & $\begin{array}{c}-0.0101125 \\
(-1.664)\end{array}$ & $\begin{array}{c}-0.0100165 \\
(-1.534)\end{array}$ \\
\hline subtotalnacpercapita & $\begin{array}{c}0.0168240 \\
(2.338)^{\star \star}\end{array}$ & $\begin{array}{c}-0.0034729 \\
(-0.747)\end{array}$ & $\begin{array}{c}-0.0034729 \\
(-0.313)\end{array}$ & $\begin{array}{c}-0.0070415 \\
(-0.689)\end{array}$ \\
\hline regaliaspercapita & $\begin{array}{c}-0.0239889 \\
(-2.306)^{\star \star}\end{array}$ & $\begin{array}{l}0.0674989 \\
(4.724)^{\star \star \star}\end{array}$ & $\begin{array}{c}0.0674989 \\
(2.641)^{\star *}\end{array}$ & $\begin{array}{c}0.0431164 \\
(2.356)^{\star \star}\end{array}$ \\
\hline notribpercapita & $\begin{array}{l}0.0733529 \\
(4.252)^{\star \star \star}\end{array}$ & $\begin{array}{l}0.0479774 \\
(3.698)^{\star \star \star *}\end{array}$ & $\begin{array}{c}0.0479774 \\
(2.086)^{\star *}\end{array}$ & $\begin{array}{c}0.0510101 \\
(2.172)^{\star \star}\end{array}$ \\
\hline transfpercapita & $\begin{array}{c}-0.0013642 \\
(-0.198)\end{array}$ & $\begin{array}{c}-0.0039700 \\
(-0.316)\end{array}$ & $\begin{array}{c}-0.0039700 \\
(-0.132)\end{array}$ & $\begin{array}{c}0.0016311 \\
(0.067)\end{array}$ \\
\hline rentasproppercapita & $\begin{array}{c}-0.2272226 \\
(-1.399)\end{array}$ & $\begin{array}{c}-0.0581376 \\
(-0.545)\end{array}$ & $\begin{array}{c}-0.0581376 \\
(-0.490)\end{array}$ & $\begin{array}{c}-0.0790385 \\
(-0.525)\end{array}$ \\
\hline deficittotalpercapita & $\begin{array}{c}-0.0169948 \\
(-2.042)^{\star}\end{array}$ & $\begin{array}{c}-0.0134394 \\
(-1.899)^{\star}\end{array}$ & $\begin{array}{c}-0.0134394 \\
(-1.324)\end{array}$ & $\begin{array}{c}-0.0150798 \\
(-1.500)\end{array}$ \\
\hline ingresorealpercapita & $\begin{array}{l}-0.0000232 \\
(-3.983)^{\star \star \star}\end{array}$ & $\begin{array}{c}-0.0000375 \\
(-6.023)^{\star \star \star}\end{array}$ & $\begin{array}{c}-0.0000375 \\
(-3.135)^{\star \star \star}\end{array}$ & $\begin{array}{c}-0.0000323 \\
(-3.379)^{\star * \star}\end{array}$ \\
\hline poblacion & $\begin{array}{c}-0.0236304 \\
(-1.212)\end{array}$ & $\begin{array}{l}-0.2049918 \\
(-4.224)^{\star \star \star}\end{array}$ & $\begin{array}{l}-0.2049918 \\
(-2.654)^{\star \star}\end{array}$ & $\begin{array}{l}-0.1517008 \\
(-3.162)^{\star \star \star}\end{array}$ \\
\hline poblacionsq & $\begin{array}{c}0.0023252 \\
(1.723)\end{array}$ & $\begin{array}{l}0.0165219 \\
(3.564)^{\star \star \star}\end{array}$ & $\begin{array}{l}0.0165219 \\
(6.447)^{\star \star \star}\end{array}$ & $\begin{array}{l}0.0128226 \\
(4.231)^{\star \star \star}\end{array}$ \\
\hline propmenor14 & $\begin{array}{c}0.0242011 \\
(2.758)^{\star *}\end{array}$ & $\begin{array}{c}0.0347953 \\
(2.841)^{\star *}\end{array}$ & $\begin{array}{c}0.0347953 \\
(2.000)^{\star}\end{array}$ & $\begin{array}{c}0.0295228 \\
(1.858)^{*}\end{array}$ \\
\hline propmayor65 & $\begin{array}{l}0.0709023 \\
(6.454)^{\star \star \star}\end{array}$ & $\begin{array}{c}-0.1457937 \\
(-2.694)^{\star \star}\end{array}$ & $\begin{array}{c}-0.1457937 \\
(-2.536)^{\star \star}\end{array}$ & $\begin{array}{c}-0.0117332 \\
(-0.232)\end{array}$ \\
\hline densidad & $\begin{array}{l}0.0332606 \\
(8.382)^{\star \star \star}\end{array}$ & $\begin{array}{c}-0.0090282 \\
(-0.052)\end{array}$ & $\begin{array}{c}-0.0090282 \\
(-0.094)\end{array}$ & $\begin{array}{l}0.1164455 \\
(2.902)^{\star \star *}\end{array}$ \\
\hline f_overall & $\begin{array}{c}-0.0385171 \\
(-0.311)\end{array}$ & $\begin{array}{c}-0.0003206 \\
(-0.003)\end{array}$ & $\begin{array}{l}0.2720917 \\
(3.171)^{\star \star \star}\end{array}$ & $\begin{array}{l}0.3771877 \\
(4.622)^{\star \star \star}\end{array}$ \\
\hline f_civil & $\begin{array}{l}0.4015572 \\
(4.009)^{\star \star \star}\end{array}$ & $\begin{array}{c}0.2720917 \\
(2.275)^{\star \star}\end{array}$ & $\begin{array}{l}-0.2128341 \\
(-5.754)^{\star \star \star}\end{array}$ & $\begin{array}{l}-0.2553488 \\
(-6.959)^{\star \star \star}\end{array}$ \\
\hline f_politic & $\begin{array}{c}-0.2691353 \\
(-7.206)^{\star \star \star}\end{array}$ & $\begin{array}{l}-0.2128341 \\
(-4.417)^{\star \star \star}\end{array}$ & $\begin{array}{l}-0.0745085 \\
(-5.584)^{\star \star \star}\end{array}$ & $\begin{array}{c}-0.0781936 \\
(-5.756)^{\star \star \star}\end{array}$ \\
\hline icrg_qog & $\begin{array}{c}-0.5505406 \\
(-1.083)\end{array}$ & $\begin{array}{c}-0.0072130 \\
(-0.017)\end{array}$ & $\begin{array}{c}-0.0003206 \\
(-0.007)\end{array}$ & $\begin{array}{c}-0.0435112 \\
(-0.848)\end{array}$ \\
\hline informal & $\begin{array}{c}-0.0799808 \\
(-4.209)^{\star \star \star}\end{array}$ & $\begin{array}{c}-0.0745085 \\
(-4.384)^{\star * *}\end{array}$ & $\begin{array}{c}-0.0072130 \\
(-0.016)\end{array}$ & $\begin{array}{c}-0.2640263 \\
(-0.581)\end{array}$ \\
\hline Constant & $\begin{array}{l}3.0353557 \\
(4.430)^{\star \star \star}\end{array}$ & $\begin{array}{l}4.0947545 \\
(4.460)^{\star \star \star}\end{array}$ & $\begin{array}{l}3.9720271 \\
(4.610)^{\star \star \star}\end{array}$ & $\begin{array}{l}3.1985268 \\
(3.580)^{\star \star \star}\end{array}$ \\
\hline Observations & 504 & 504 & 504 & 504 \\
\hline $\begin{array}{l}\text { R-squared } \\
\text { Testparm } \\
\text { p value }\end{array}$ & 0.765 & $\begin{array}{rr}0.894 \\
& 1261.9 \\
& 0\end{array}$ & 0.869 & \\
\hline Theta & & & & 0.839 \\
\hline Wald for groupwise heteroskedasticity & & & 1462.87 & \\
\hline $\begin{array}{l}\text { Hausman (Sargan-Hansen) } \\
\text { p value }\end{array}$ & & & & 9434.918 \\
\hline Breusch and Pagan & & & & 881.9 \\
\hline $\begin{array}{l}\text { Wooldridge test } \\
\mathrm{p} \text { value }\end{array}$ & & & & $\begin{array}{r}212.921 \\
0\end{array}$ \\
\hline
\end{tabular}

Columna I: estimación OLS. Columna II: estimación OLS con efectos individuales. Columna III: estimación por modelo de efectos fijos. Columna IV: estimación por modelo de efectos aleatorios. Estadísticos robustos entre paréntesis: “*”: significativo al 10\%; “**”: significativo al 5\%; “***”: significativo al $1 \%$. 


\section{Cuadro 6}

Resultados de las regresiones de base

OLS, efectos fijos y aleatorios, Clustered robust standard errors por período Variable dependiente: productividad ponderada de IIBB

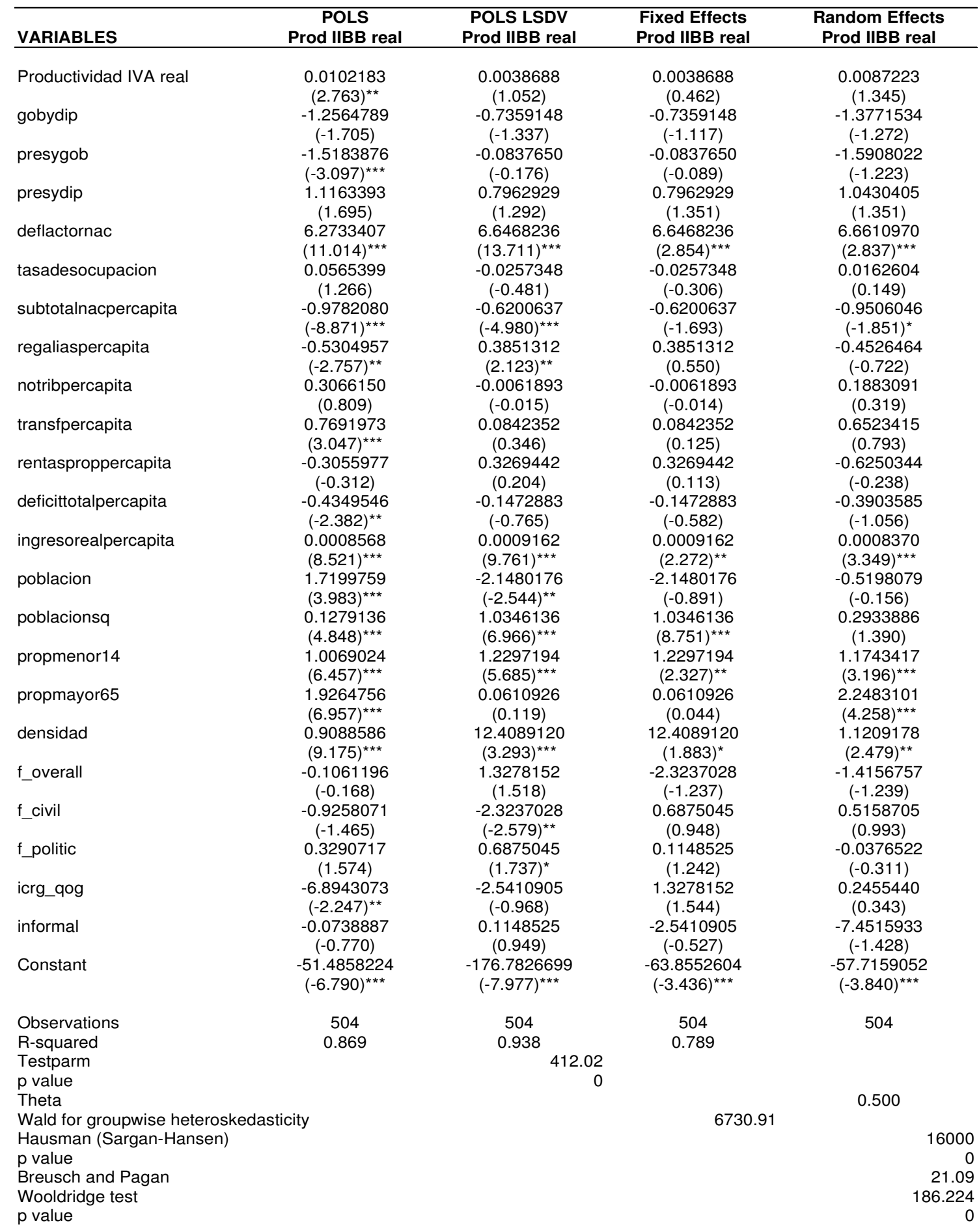

Columna I: estimación OLS. Columna II: estimación OLS con efectos individuales. Columna III: estimación por modelo de efectos fijos. Columna IV: estimación por modelo de efectos aleatorios. Estadísticos robustos entre paréntesis: “*”: significativo al 10\%; “**”: significativo al 5\%; “***”: significativo al $1 \%$. 


\section{Cuadro 7}

Resultados de las regresiones de base

OLS, efectos fijos y aleatorios. Clustered robust standard errors por período Variable dependiente: tasa efectiva de IIBB

\begin{tabular}{|c|c|c|c|c|}
\hline VARIABLES & $\begin{array}{c}\text { POLS } \\
\text { Tasa efectiva IIBB real }\end{array}$ & $\begin{array}{c}\text { POLS LSDV } \\
\text { Tasa efectiva IIBB real }\end{array}$ & $\begin{array}{c}\text { Fixed Effects } \\
\text { Tasa efectiva IIBB real }\end{array}$ & $\begin{array}{c}\text { Random Effects } \\
\text { Tasa efectiva IIBB real }\end{array}$ \\
\hline Tasa efectiva IVA real & $\begin{array}{l}0.5538679 \\
(7.284)^{* * *}\end{array}$ & $\begin{array}{l}0.5406678 \\
(7.815)^{\star \star \star}\end{array}$ & $\begin{array}{l}0.5406678 \\
(6.658)^{\star * \star}\end{array}$ & $\begin{array}{l}0.5496420 \\
(6.043)^{\star * \star}\end{array}$ \\
\hline gobydip & $\begin{array}{c}0.0908275 \\
(0.451)\end{array}$ & $\begin{array}{c}-0.1766985 \\
(-1.292)\end{array}$ & $\begin{array}{c}-0.1766985 \\
(-1.185)\end{array}$ & $\begin{array}{c}-0.2103344 \\
(-1.241)\end{array}$ \\
\hline presygob & $\begin{array}{c}0.3857212 \\
(1.886)^{*}\end{array}$ & $\begin{array}{c}0.1899256 \\
(1.592)\end{array}$ & $\begin{array}{c}0.1899256 \\
(0.675)\end{array}$ & $\begin{array}{c}0.1842052 \\
(0.602)\end{array}$ \\
\hline presydip & $\begin{array}{c}-0.5002757 \\
(-2.049)^{*}\end{array}$ & $\begin{array}{c}-0.0958822 \\
(-0.850)\end{array}$ & $\begin{array}{c}-0.0958822 \\
(-0.593)\end{array}$ & $\begin{array}{c}-0.0785334 \\
(-0.436)\end{array}$ \\
\hline deflactornac & $\begin{array}{l}-0.6517574 \\
(-2.742)^{\star *}\end{array}$ & $\begin{array}{c}-0.1852213 \\
(-0.698)\end{array}$ & $\begin{array}{c}-0.1852213 \\
(-0.712)\end{array}$ & $\begin{array}{l}-0.4384740 \\
(-1.756)^{*}\end{array}$ \\
\hline tasadesocupacion & $\begin{array}{l}-0.1342241 \\
(-4.414)^{* \star *}\end{array}$ & $\begin{array}{l}-0.0914213 \\
(-2.485)^{\star *}\end{array}$ & $\begin{array}{l}-0.0914213 \\
(-3.909)^{* * *}\end{array}$ & $\begin{array}{l}-0.0922638 \\
(-3.519)^{* * *}\end{array}$ \\
\hline subtotalnacpercapita & $\begin{array}{l}-0.0613838 \\
(-4.492)^{* \star *}\end{array}$ & $\begin{array}{c}-0.0154261 \\
(-0.734)\end{array}$ & $\begin{array}{c}-0.0154261 \\
(-0.264)\end{array}$ & $\begin{array}{c}-0.0404315 \\
(-0.753)\end{array}$ \\
\hline regaliaspercapita & $\begin{array}{l}-0.1424099 \\
(-2.737)^{\star *}\end{array}$ & $\begin{array}{l}0.3653337 \\
(5.331)^{\star * *}\end{array}$ & $\begin{array}{l}0.3653337 \\
(2.806)^{\star *}\end{array}$ & $\begin{array}{c}0.2242736 \\
(1.827)^{*}\end{array}$ \\
\hline notribpercapita & $\begin{array}{l}0.3534160 \\
(3.335)^{\star * \star}\end{array}$ & $\begin{array}{c}-0.0520981 \\
(-0.706)\end{array}$ & $\begin{array}{c}-0.0520981 \\
(-0.317)\end{array}$ & $\begin{array}{c}-0.0290124 \\
(-0.171)\end{array}$ \\
\hline transfpercapita & $\begin{array}{c}0.0654041 \\
(1.285)\end{array}$ & $\begin{array}{l}0.1860717 \\
(2.443)^{\star \star}\end{array}$ & $\begin{array}{c}0.1860717 \\
(1.216)\end{array}$ & $\begin{array}{c}0.2134005 \\
(1.776)^{*}\end{array}$ \\
\hline rentasproppercapita & $\begin{array}{c}-2.3475544 \\
(-1.960)^{*}\end{array}$ & $\begin{array}{c}-1.1551703 \\
(-1.485)\end{array}$ & $\begin{array}{c}-1.1551703 \\
(-2.017)^{\star}\end{array}$ & $\begin{array}{l}-1.2919985 \\
(-1.667)^{*}\end{array}$ \\
\hline deficittotalpercapita & $\begin{array}{c}-0.0957094 \\
(-2.037)^{\star}\end{array}$ & $\begin{array}{c}-0.0232830 \\
(-0.492)\end{array}$ & $\begin{array}{c}-0.0232830 \\
(-0.536)\end{array}$ & $\begin{array}{c}-0.0340016 \\
(-0.746)\end{array}$ \\
\hline ingresorealpercapita & $\begin{array}{c}-0.0000491 \\
(-1.998)^{*}\end{array}$ & $\begin{array}{l}-0.0000976 \\
(-2.856)^{* \star *}\end{array}$ & $\begin{array}{c}-0.0000976 \\
(-1.862)^{*}\end{array}$ & $\begin{array}{c}-0.0000708 \\
(-1.599)\end{array}$ \\
\hline poblacion & $\begin{array}{l}0.3548798 \\
(3.287)^{\star \star \star}\end{array}$ & $\begin{array}{l}-0.5737454 \\
(-2.617)^{\star *}\end{array}$ & $\begin{array}{c}-0.5737454 \\
(-1.792)^{\star}\end{array}$ & $\begin{array}{c}-0.2816520 \\
(-1.195)\end{array}$ \\
\hline poblacionsq & $\begin{array}{c}-0.0100071 \\
(-1.246)\end{array}$ & $\begin{array}{l}0.0569316 \\
(4.481)^{\star \star \star}\end{array}$ & $\begin{array}{l}0.0569316 \\
(4.195)^{\star * \star}\end{array}$ & $\begin{array}{l}0.0412989 \\
(2.830)^{\star * \star}\end{array}$ \\
\hline propmenor14 & $\begin{array}{l}0.1027355 \\
(2.855)^{* * *}\end{array}$ & $\begin{array}{l}0.2374387 \\
(4.246)^{\star \star \star}\end{array}$ & $\begin{array}{l}0.2374387 \\
(3.170)^{* \star *}\end{array}$ & $\begin{array}{l}0.1921487 \\
(2.572)^{* \star}\end{array}$ \\
\hline propmayor65 & $\begin{array}{c}-0.0865644 \\
(-1.434)\end{array}$ & $\begin{array}{l}-1.1975056 \\
(-4.582)^{\star * *}\end{array}$ & $\begin{array}{l}-1.1975056 \\
(-3.886)^{* * *}\end{array}$ & $\begin{array}{c}-0.3688614 \\
(-1.621)\end{array}$ \\
\hline densidad & $\begin{array}{l}0.2133681 \\
(7.140)^{\star * \star}\end{array}$ & $\begin{array}{l}-1.3227140 \\
(-1.841)^{*}\end{array}$ & $\begin{array}{l}-1.3227140 \\
(-2.109)^{* *}\end{array}$ & $\begin{array}{l}0.5908912 \\
(3.650)^{\star * \star}\end{array}$ \\
\hline f_overall & $\begin{array}{c}-1.0421818 \\
(-1.373)\end{array}$ & $\begin{array}{c}-0.9337114 \\
(-1.500)\end{array}$ & $\begin{array}{l}1.6771476 \\
(5.082)^{* * *}\end{array}$ & $\begin{array}{l}2.3428018 \\
(7.173)^{\star * \star}\end{array}$ \\
\hline f_civil & $\begin{array}{l}2.3735005 \\
(4.000)^{\star \star \star}\end{array}$ & $\begin{array}{l}1.6771476 \\
(2.445)^{\star *}\end{array}$ & $\begin{array}{l}-0.8420665 \\
(-6.840)^{* * \star}\end{array}$ & $\begin{array}{l}-1.1164142 \\
(-8.006)^{* \star \star}\end{array}$ \\
\hline f_politic & $\begin{array}{l}-1.1687017 \\
(-5.814)^{\star * *}\end{array}$ & $\begin{array}{l}-0.8420665 \\
(-3.092)^{\star * *}\end{array}$ & $\begin{array}{l}-0.5565516 \\
(-12.330)^{\star \star \star}\end{array}$ & $\begin{array}{l}-0.5753068 \\
(-12.663)^{* * *}\end{array}$ \\
\hline icrg_qog & $\begin{array}{l}-11.7645889 \\
(-3.953)^{\star \star \star}\end{array}$ & $\begin{array}{l}-9.5353774 \\
(-4.597)^{\star * *}\end{array}$ & $\begin{array}{l}-0.9337114 \\
(-4.116)^{\star * \star}\end{array}$ & $\begin{array}{l}-1.1998860 \\
(-5.892)^{\star * *}\end{array}$ \\
\hline informal & $\begin{array}{l}-0.5734792 \\
(-5.294)^{\star \star \star}\end{array}$ & $\begin{array}{l}-0.5565516 \\
(-6.207)^{\star * \star}\end{array}$ & $\begin{array}{l}-9.5353774 \\
(-4.064)^{\star \star \star}\end{array}$ & $\begin{array}{l}-11.3233773 \\
(-4.958)^{\star \star \star}\end{array}$ \\
\hline Constant & $\begin{array}{l}26.4504929 \\
(7.220)^{\star \star \star}\end{array}$ & $\begin{array}{l}32.3747386 \\
(11.493)^{\star \star \star}\end{array}$ & $\begin{array}{c}30.6258768 \\
(8.531)^{\star \star \star}\end{array}$ & $\begin{array}{c}25.2994744 \\
(6.610)^{\star \star \star}\end{array}$ \\
\hline Observations & 504 & 504 & 504 & 504 \\
\hline R-squared & 0.670 & 0.838 & 0.790 & \\
\hline $\begin{array}{l}\text { Testparm } \\
\text { p value }\end{array}$ & & $\begin{array}{r}623.14 \\
0\end{array}$ & & \\
\hline Theta & & & & 0.827 \\
\hline Wald for groupwise het & skedasticity & & 646.25 & \\
\hline $\begin{array}{l}\text { Hausman (Sargan-Han } \\
\text { p value }\end{array}$ & & & & $\begin{array}{r}2600.00 \\
0\end{array}$ \\
\hline $\begin{array}{l}\text { p value } \\
\text { Breusch and Pagan }\end{array}$ & & & & 621.63 \\
\hline $\begin{array}{l}\text { Wooldridge test } \\
\mathrm{p} \text { value }\end{array}$ & & & & $\begin{array}{r}201.465 \\
0\end{array}$ \\
\hline
\end{tabular}

Columna I: estimación OLS. Columna II: estimación OLS con efectos individuales. Columna III: estimación por modelo de efectos fijos. Columna IV: estimación por modelo de efectos aleatorios. Estadísticos robustos entre paréntesis: “*”: significativo al 10\%; “**”: significativo al 5\%; “***”: significativo al $1 \%$. 


\section{Cuadro 8}

Resultados de las regresiones de base

OLS, efectos fijos y aleatorios. Clustered robust standard errors por período Variable dependiente: tasa efectiva de IIBB cadena agroindustrial

\begin{tabular}{|c|c|c|c|c|c|}
\hline VARIABLES & $\begin{array}{c}\text { POLS } \\
\begin{array}{c}\text { Efectiva IIBB } \\
\text { agric }\end{array} \\
\end{array}$ & $\begin{array}{l}\text { POLS LSDV } \\
\text { Efectiva IIBB } \\
\text { agric } \\
\end{array}$ & $\begin{array}{c}\text { Fixed Effects } \\
\text { Efectiva IIBB } \\
\text { agric } \\
\end{array}$ & $\begin{array}{c}\text { Random Effects } \\
\text { Efectiva IIBB } \\
\text { agric } \\
\end{array}$ & $\begin{array}{c}\text { FE with time } \\
\text { dummies } \\
\text { Efectiva IIBB } \\
\text { agric } \\
\end{array}$ \\
\hline Efectiva IVA real agricultura & $\begin{array}{l}1.2718655 \\
(5.282)^{\star \star \star}\end{array}$ & $\begin{array}{l}1.1723776 \\
(5.742)^{\star \star \star}\end{array}$ & $\begin{array}{l}1.1723776 \\
(14.842)^{\star \star \star}\end{array}$ & $\begin{array}{l}1.2265201 \\
(15.244)^{\star \star \star}\end{array}$ & $\begin{array}{c}2.5098533 \\
(1.688)\end{array}$ \\
\hline gobydip & $\begin{array}{c}0.1319185 \\
(1.078)\end{array}$ & $\begin{array}{c}-0.0410214 \\
(-0.540)\end{array}$ & $\begin{array}{c}-0.0410214 \\
(-0.443)\end{array}$ & $\begin{array}{c}-0.0530516 \\
(-0.564)\end{array}$ & $\begin{array}{c}-0.1410342 \\
(-1.651)\end{array}$ \\
\hline presygob & $\begin{array}{l}0.0660165 \\
(0.728)\end{array}$ & $\begin{array}{c}-0.0031550 \\
(-0.051)\end{array}$ & $\begin{array}{l}-0.0031550 \\
(-0.015)\end{array}$ & $\begin{array}{c}-0.0175720 \\
(-0.081)\end{array}$ & $\begin{array}{c}0.0526293 \\
(1.096)\end{array}$ \\
\hline presydip & $\begin{array}{l}-0.1994820 \\
(-1.365)\end{array}$ & $\begin{array}{c}0.0631489 \\
(0.621)\end{array}$ & $\begin{array}{l}0.0631489 \\
(0.643)\end{array}$ & $\begin{array}{c}0.0722313 \\
(0.704)\end{array}$ & $\begin{array}{l}-0.0351537 \\
(-0.386)\end{array}$ \\
\hline deflactornac & $\begin{array}{l}-0.8664471 \\
(-3.203)^{\star \star *}\end{array}$ & $\begin{array}{c}-0.3430771 \\
(-1.616)\end{array}$ & $\begin{array}{l}-0.3430771 \\
(-2.842)^{\star \star \star}\end{array}$ & $\begin{array}{c}-0.6052682 \\
(-5.057)^{\star \star *}\end{array}$ & $\begin{array}{c}1.9575736 \\
(0.759)\end{array}$ \\
\hline tasadesocupacion & $\begin{array}{l}-0.1002505 \\
(-4.335)^{\star \star *}\end{array}$ & $\begin{array}{c}-0.0511918 \\
(-2.033)^{*}\end{array}$ & $\begin{array}{l}-0.0511918 \\
(-3.626)^{\star \star *}\end{array}$ & $\begin{array}{l}-0.0542002 \\
(-3.802)^{\star * *}\end{array}$ & $\begin{array}{c}-0.0490456 \\
(-2.602)^{\star *}\end{array}$ \\
\hline subtotalnacpercapita & $\begin{array}{l}-0.0657695 \\
(-4.624)^{\star * *}\end{array}$ & $\begin{array}{c}-0.0525419 \\
(-2.157)^{\star \star}\end{array}$ & $\begin{array}{c}-0.0525419 \\
(-1.153)\end{array}$ & $\begin{array}{c}-0.0736747 \\
(-1.910)^{*}\end{array}$ & $\begin{array}{l}-0.0748500 \\
(-3.482)^{\star \star \star}\end{array}$ \\
\hline regaliaspercapita & $\begin{array}{c}-0.1156322 \\
(-4.133)^{* * *}\end{array}$ & $\begin{array}{l}0.1285788 \\
(3.628)^{\star * \star}\end{array}$ & $\begin{array}{c}0.1285788 \\
(1.526)\end{array}$ & $\begin{array}{c}0.0546565 \\
(0.862)\end{array}$ & $\begin{array}{l}0.0888885 \\
(3.102)^{\star * \star}\end{array}$ \\
\hline notribpercapita & $\begin{array}{l}0.2146076 \\
(3.141)^{\star \star \star}\end{array}$ & $\begin{array}{c}-0.0282679 \\
(-0.766)\end{array}$ & $\begin{array}{c}-0.0282679 \\
(-0.424)\end{array}$ & $\begin{array}{c}-0.0071730 \\
(-0.101)\end{array}$ & $\begin{array}{c}-0.0383051 \\
(-1.249)\end{array}$ \\
\hline transfpercapita & $\begin{array}{c}0.0430741 \\
(1.307)\end{array}$ & $\begin{array}{l}0.2187181 \\
(3.072)^{\star * \star}\end{array}$ & $\begin{array}{c}0.2187181 \\
(1.862)^{*}\end{array}$ & $\begin{array}{c}0.2147544 \\
(2.396)^{\star *}\end{array}$ & $\begin{array}{l}0.2138627 \\
(3.369)^{* \star *}\end{array}$ \\
\hline rentasproppercapita & $\begin{array}{c}-1.4692316 \\
(-1.937)^{*}\end{array}$ & $\begin{array}{c}-0.8156263 \\
(-2.108)^{\star *}\end{array}$ & $\begin{array}{l}-0.8156263 \\
(-3.146)^{\star * \star}\end{array}$ & $\begin{array}{c}-0.8967867 \\
(-2.450)^{\star \star}\end{array}$ & $\begin{array}{c}-0.2824729 \\
(-0.797)\end{array}$ \\
\hline deficittotalpercapita & $\begin{array}{c}0.0147173 \\
(0.592)\end{array}$ & $\begin{array}{c}0.0418344 \\
(1.584)\end{array}$ & $\begin{array}{c}0.0418344 \\
(1.696)\end{array}$ & $\begin{array}{c}0.0386939 \\
(1.537)\end{array}$ & $\begin{array}{c}-0.0008046 \\
(-0.034)\end{array}$ \\
\hline ingresorealpercapita & $\begin{array}{l}0.0000347 \\
(3.343)^{\star \star \star}\end{array}$ & $\begin{array}{l}-0.0000745 \\
(-3.102)^{\star \star \star}\end{array}$ & $\begin{array}{c}-0.0000745 \\
(-1.908)^{*}\end{array}$ & $\begin{array}{c}-0.0000212 \\
(-0.768)\end{array}$ & $\begin{array}{c}-0.0000429 \\
(-2.410)^{\star \star}\end{array}$ \\
\hline poblacion & $\begin{array}{l}0.3307080 \\
(3.684)^{\star \star \star}\end{array}$ & $\begin{array}{l}-0.5191328 \\
(-3.826)^{\star \star \star}\end{array}$ & $\begin{array}{c}-0.5191328 \\
(-2.204)^{\star \star}\end{array}$ & $\begin{array}{c}-0.1398045 \\
(-0.754)\end{array}$ & $\begin{array}{c}-0.3332334 \\
(-2.566)^{\star *}\end{array}$ \\
\hline poblacionsq & $\begin{array}{c}-0.0166909 \\
(-2.775)^{\star \star}\end{array}$ & $\begin{array}{l}0.0279585 \\
(3.062)^{\star \star \star}\end{array}$ & $\begin{array}{c}0.0279585 \\
(2.596)^{\star *}\end{array}$ & $\begin{array}{c}0.0179668 \\
(1.533)\end{array}$ & $\begin{array}{c}0.0232704 \\
(2.680)^{\star \star}\end{array}$ \\
\hline propmenor14 & $\begin{array}{c}0.0333424 \\
(1.877)^{*}\end{array}$ & $\begin{array}{l}0.1883078 \\
(4.025)^{\star \star \star}\end{array}$ & $\begin{array}{l}0.1883078 \\
(4.465)^{\star \star \star}\end{array}$ & $\begin{array}{l}0.1208307 \\
(2.668)^{\star \star \star}\end{array}$ & $\begin{array}{l}0.0924233 \\
(5.079)^{\star * *}\end{array}$ \\
\hline propmayor65 & $\begin{array}{c}-0.0854798 \\
(-2.910)^{\star \star \star}\end{array}$ & $\begin{array}{l}-0.8445953 \\
(-4.478)^{\star \star \star}\end{array}$ & $\begin{array}{l}-0.8445953 \\
(-3.327)^{\star \star \star}\end{array}$ & $\begin{array}{c}-0.2549079 \\
(-1.833)^{\star}\end{array}$ & $\begin{array}{l}-0.4477374 \\
(-4.456)^{\star \star \star}\end{array}$ \\
\hline densidad & $\begin{array}{c}0.0372099 \\
(2.014)^{*}\end{array}$ & $\begin{array}{c}-1.1369987 \\
(-2.169)^{\star *}\end{array}$ & $\begin{array}{c}-1.1369987 \\
(-2.652)^{\star \star}\end{array}$ & $\begin{array}{l}0.3436314 \\
(3.082)^{\star \star \star}\end{array}$ & $\begin{array}{c}0.0257158 \\
(0.071)\end{array}$ \\
\hline f_overall & $\begin{array}{c}-0.6042943 \\
(-1.172)\end{array}$ & $\begin{array}{c}-0.5786380 \\
(-1.250)\end{array}$ & $\begin{array}{l}1.1992095 \\
(4.723)^{\star * \star}\end{array}$ & $\begin{array}{l}1.7405079 \\
(6.952)^{\star * \star}\end{array}$ & \\
\hline f_civil & $\begin{array}{l}1.7225073 \\
(2.251)^{\star *}\end{array}$ & $\begin{array}{l}1.1992095 \\
(1.765)^{*}\end{array}$ & $\begin{array}{l}-0.6399074 \\
(-6.604)^{\star \star \star}\end{array}$ & $\begin{array}{l}-0.8598940 \\
(-9.545)^{\star \star \star}\end{array}$ & $\begin{array}{c}-1.0288003 \\
(-1.380)\end{array}$ \\
\hline f_politic & $\begin{array}{c}-0.8890748 \\
(-3.949)^{* * *}\end{array}$ & $\begin{array}{c}-0.6399074 \\
(-3.113)^{\star \star *}\end{array}$ & $\begin{array}{l}-0.3881297 \\
(-14.491)^{\star * \star}\end{array}$ & $\begin{array}{l}-0.3973818 \\
(-14.742)^{\star \star \star}\end{array}$ & $\begin{array}{c}0.1136115 \\
(0.290)\end{array}$ \\
\hline icrg_qog & $\begin{array}{l}-9.9261347 \\
(-3.642)^{\star * \star}\end{array}$ & $\begin{array}{c}-7.6909305 \\
(-4.351)^{\star * *}\end{array}$ & $\begin{array}{l}-0.5786380 \\
(-3.328)^{\star \star *}\end{array}$ & $\begin{array}{c}-0.8085604 \\
(-5.282)^{\star \star \star}\end{array}$ & \\
\hline informal & $\begin{array}{l}-0.3754005 \\
(-4.338)^{\star * *}\end{array}$ & $\begin{array}{l}-0.3881297 \\
(-5.682)^{\star * *}\end{array}$ & $\begin{array}{c}-7.6909305 \\
(-6.537)^{\star \star *}\end{array}$ & $\begin{array}{l}-9.2801806 \\
(-8.143)^{\star * *}\end{array}$ & \\
\hline Constant & $\begin{array}{c}18.2577564 \\
(6.613)^{\star * \star}\end{array}$ & $\begin{array}{l}24.9100665 \\
(10.130)^{\star \star \star}\end{array}$ & $\begin{array}{c}20.7941352 \\
(8.056)^{\star * \star}\end{array}$ & $\begin{array}{c}17.3531708 \\
(7.919)^{* * \star}\end{array}$ & $\begin{array}{c}-13.3352832 \\
(-0.436)\end{array}$ \\
\hline Observations & 504 & 504 & 504 & 504 & 504 \\
\hline $\begin{array}{l}\text { R-squared } \\
\text { Testparm }\end{array}$ & 0.781 & $\begin{array}{l}0.904 \\
4151.84\end{array}$ & 0.889 & & 0.915 \\
\hline $\begin{array}{l}\text { p value } \\
\text { Theta }\end{array}$ & & 0 & & 0.820 & \\
\hline Wald for groupwise heteroske & & & 224.09 & & \\
\hline $\begin{array}{l}\text { Hausman (Sargan-Hansen) } \\
\text { p value }\end{array}$ & & & & $\begin{array}{r}2600.00 \\
0\end{array}$ & \\
\hline Breusch and Pagan & & & & 716.09 & \\
\hline $\begin{array}{l}\text { Wooldridge test } \\
\text { p value }\end{array}$ & & & & $\begin{array}{r}720.839 \\
0\end{array}$ & \\
\hline
\end{tabular}

Columna I: estimación OLS. Columna II: estimación OLS con efectos individuales. Columna III: estimación por modelo de efectos fijos. Columna IV: estimación por modelo de efectos aleatorios. Estadísticos robustos entre paréntesis: “*”: significativo al 10\%; “**”: significativo al 5\%; “***”: significativo al $1 \%$. 


\section{Cuadro 9}

Resultados de las regresiones de efectos fijos y aleatorios incorporando competencia tributaria horizontal. Clustered robust standard errors por período Variable dependiente: tasa de Ingresos Brutos (parte 1)

\begin{tabular}{|c|c|c|c|c|}
\hline VARIABLES & $\begin{array}{l}\text { Fixed Effects } \\
\text { Tasa IIBB real }\end{array}$ & $\begin{array}{c}\text { Random Effects } \\
\text { Tasa IIBB real }\end{array}$ & $\begin{array}{l}\text { Fixed Effects } \\
\text { Tasa IIBB real } \\
\end{array}$ & $\begin{array}{c}\text { Random Effects } \\
\text { Tasa IIBB real }\end{array}$ \\
\hline Tasa IVA real & $\begin{array}{l}0.0846501 \\
(4.833)^{\star \star \star}\end{array}$ & $\begin{array}{l}0.0842701 \\
(4.226)^{\star \star \star}\end{array}$ & $\begin{array}{l}0.0844588 \\
(4.847)^{* * *}\end{array}$ & $\begin{array}{l}0.0845714 \\
(4.338)^{\star \star \star}\end{array}$ \\
\hline gobydip & $\begin{array}{c}-0.0311675 \\
(-1.439)\end{array}$ & $\begin{array}{c}-0.0362612 \\
(-1.361)\end{array}$ & $\begin{array}{c}-0.0293877 \\
(-1.390)\end{array}$ & $\begin{array}{c}-0.0348114 \\
(-1.360)\end{array}$ \\
\hline presygob & $\begin{array}{c}0.0501605 \\
(2.130)^{\star *}\end{array}$ & $\begin{array}{c}0.0347625 \\
(1.348)\end{array}$ & $\begin{array}{l}0.0498338 \\
(2.139)^{* *}\end{array}$ & $\begin{array}{c}0.0368670 \\
(1.531)\end{array}$ \\
\hline presydip & $\begin{array}{l}-0.0044095 \\
(-0.208)\end{array}$ & $\begin{array}{c}0.0026676 \\
(0.097)\end{array}$ & $\begin{array}{l}-0.0041735 \\
(-0.198)\end{array}$ & $\begin{array}{c}0.0030198 \\
(0.114)\end{array}$ \\
\hline deflactornac & $\begin{array}{l}-0.1863861 \\
(-3.139)^{* \star *}\end{array}$ & $\begin{array}{l}-0.2427527 \\
(-4.518)^{\star * *}\end{array}$ & $\begin{array}{l}-0.1941869 \\
(-3.395)^{* \star *}\end{array}$ & $\begin{array}{l}-0.2424928 \\
(-4.488)^{* * *}\end{array}$ \\
\hline tasadesocupacion & $\begin{array}{c}-0.0097492 \\
(-1.670)\end{array}$ & $\begin{array}{c}-0.0097776 \\
(-1.670)^{*}\end{array}$ & $\begin{array}{c}-0.0098559 \\
(-1.670)\end{array}$ & $\begin{array}{c}-0.0100411 \\
(-1.711)^{*}\end{array}$ \\
\hline subtotalnacpercapita & $\begin{array}{c}-0.0025776 \\
(-0.590)\end{array}$ & $\begin{array}{c}-0.0069392 \\
(-1.721)^{*}\end{array}$ & $\begin{array}{c}-0.0031109 \\
(-0.680)\end{array}$ & $\begin{array}{c}-0.0069269 \\
(-1.668)^{*}\end{array}$ \\
\hline regaliaspercapita & $\begin{array}{l}0.0694072 \\
(4.782)^{* \star \star}\end{array}$ & $\begin{array}{l}0.0407573 \\
(4.379)^{* \star \star}\end{array}$ & $\begin{array}{l}0.0692420 \\
(5.053)^{* \star *}\end{array}$ & $\begin{array}{l}0.0443524 \\
(4.985)^{* \star *}\end{array}$ \\
\hline notribpercapita & $\begin{array}{l}0.0485288 \\
(3.724)^{* * *}\end{array}$ & $\begin{array}{l}0.0518629 \\
(3.845)^{* \star *}\end{array}$ & $\begin{array}{l}0.0494265 \\
(3.665)^{* \star *}\end{array}$ & $\begin{array}{l}0.0507007 \\
(3.902)^{\star \star \star}\end{array}$ \\
\hline transfpercapita & $\begin{array}{c}-0.0056705 \\
(-0.480)\end{array}$ & $\begin{array}{l}0.0015605 \\
(0.153)\end{array}$ & $\begin{array}{l}-0.0049420 \\
(-0.416)\end{array}$ & $\begin{array}{l}0.0013953 \\
(0.135)\end{array}$ \\
\hline rentasproppercapita & $\begin{array}{c}-0.0677692 \\
(-0.701)\end{array}$ & $\begin{array}{c}-0.0871817 \\
(-0.646)\end{array}$ & $\begin{array}{c}-0.0607647 \\
(-0.589)\end{array}$ & $\begin{array}{c}-0.0773707 \\
(-0.573)\end{array}$ \\
\hline deficittotalpercapita & $\begin{array}{c}-0.0147894 \\
(-2.015)^{*}\end{array}$ & $\begin{array}{c}-0.0159520 \\
(-2.415)^{\star \star}\end{array}$ & $\begin{array}{c}-0.0143021 \\
(-1.925)^{\star}\end{array}$ & $\begin{array}{c}-0.0149298 \\
(-2.324)^{* *}\end{array}$ \\
\hline ingresorealpercapita & $\begin{array}{l}-0.0000357 \\
(-6.470)^{\star * *}\end{array}$ & $\begin{array}{l}-0.0000311 \\
(-5.157)^{\star \star \star}\end{array}$ & $\begin{array}{l}-0.0000366 \\
(-6.341)^{\star * *}\end{array}$ & $\begin{array}{l}-0.0000326 \\
(-5.499)^{\star * \star}\end{array}$ \\
\hline poblacion & $\begin{array}{l}-0.2048280 \\
(-4.057)^{\star * *}\end{array}$ & $\begin{array}{l}-0.1455023 \\
(-2.859)^{* \star *}\end{array}$ & $\begin{array}{l}-0.1987526 \\
(-4.164)^{* \star *}\end{array}$ & $\begin{array}{l}-0.1547846 \\
(-2.975)^{* * *}\end{array}$ \\
\hline poblacionsq & $\begin{array}{l}0.0167180 \\
(3.646)^{\star * *}\end{array}$ & $\begin{array}{l}0.0122896 \\
(3.737)^{\star * \star}\end{array}$ & $\begin{array}{l}0.0161477 \\
(3.360)^{\star * *}\end{array}$ & $\begin{array}{l}0.0131180 \\
(3.880)^{\star * \star}\end{array}$ \\
\hline propmenor14 & $\begin{array}{c}0.0399787 \\
(2.824)^{\star *}\end{array}$ & $\begin{array}{c}0.0317356 \\
(2.409)^{\star *}\end{array}$ & $\begin{array}{c}0.0379670 \\
(2.647)^{\star *}\end{array}$ & $\begin{array}{c}0.0294459 \\
(2.097)^{\star *}\end{array}$ \\
\hline propmayor65 & $\begin{array}{l}-0.1423664 \\
(-2.586)^{* *}\end{array}$ & $\begin{array}{c}0.0039412 \\
(0.142)\end{array}$ & $\begin{array}{l}-0.1474057 \\
(-2.711)^{* *}\end{array}$ & $\begin{array}{c}-0.0176731 \\
(-0.644)\end{array}$ \\
\hline densidad & $\begin{array}{c}0.0116140 \\
(0.066)\end{array}$ & $\begin{array}{l}0.1073168 \\
(5.872)^{\star * *}\end{array}$ & $\begin{array}{c}0.0057268 \\
(0.032)\end{array}$ & $\begin{array}{l}0.1207059 \\
(5.959)^{\star * *}\end{array}$ \\
\hline f_civil & $\begin{array}{c}0.2833605 \\
(2.387)^{\star *}\end{array}$ & $\begin{array}{l}0.3922830 \\
(3.698)^{* \star *}\end{array}$ & $\begin{array}{c}0.2751363 \\
(2.290)^{\star *}\end{array}$ & $\begin{array}{l}0.3728309 \\
(3.548)^{\star \star \star}\end{array}$ \\
\hline f_politic & $\begin{array}{l}-0.2172980 \\
(-4.711)^{\star * *}\end{array}$ & $\begin{array}{l}-0.2611323 \\
(-7.575)^{\star \star *}\end{array}$ & $\begin{array}{l}-0.2144137 \\
(-4.525)^{\star \star \star}\end{array}$ & $\begin{array}{l}-0.2536422 \\
(-7.246)^{\star * \star}\end{array}$ \\
\hline informal & $\begin{array}{l}-0.0767412 \\
(-4.631)^{* \star *}\end{array}$ & $\begin{array}{l}-0.0797538 \\
(-4.107)^{\star \star \star}\end{array}$ & $\begin{array}{l}-0.0755847 \\
(-4.497)^{\star \star \star}\end{array}$ & $\begin{array}{l}-0.0779324 \\
(-4.074)^{* \star *}\end{array}$ \\
\hline f_overall & $\begin{array}{c}-0.0095424 \\
(-0.080)\end{array}$ & $\begin{array}{l}-0.0523768 \\
(-0.391)\end{array}$ & $\begin{array}{c}-0.0044334 \\
(-0.037)\end{array}$ & $\begin{array}{c}-0.0414520 \\
(-0.318)\end{array}$ \\
\hline icrg_qog & $\begin{array}{c}0.0655930 \\
(0.146)\end{array}$ & $\begin{array}{c}-0.2536818 \\
(-0.490)\end{array}$ & $\begin{array}{c}0.0366468 \\
(0.084)\end{array}$ & $\begin{array}{c}-0.2559293 \\
(-0.520)\end{array}$ \\
\hline limitestasaspondrecaudacion & $\begin{array}{c}-0.0772421 \\
(-1.034)\end{array}$ & $\begin{array}{c}-0.0354359 \\
(-0.603)\end{array}$ & & \\
\hline limitestasasponddistancias & & & $\begin{array}{c}-0.0502884 \\
(-0.714)\end{array}$ & $\begin{array}{c}0.0026503 \\
(0.039)\end{array}$ \\
\hline Constant & $\begin{array}{l}3.9381204 \\
(5.670)^{\star \star \star}\end{array}$ & $\begin{array}{l}3.1188421 \\
(4.171)^{\star \star \star}\end{array}$ & $\begin{array}{l}3.9794826 \\
(5.825)^{* * *}\end{array}$ & $\begin{array}{l}3.2277675 \\
(4.457)^{\star \star \star}\end{array}$ \\
\hline $\begin{array}{l}\text { Observations } \\
\text { R-squared } \\
\text { Testparm } \\
\text { p value }\end{array}$ & $\begin{array}{c}504 \\
0.869\end{array}$ & 504 & $\begin{array}{c}504 \\
0.869\end{array}$ & 504 \\
\hline Theta & & 0.820 & & 0.847 \\
\hline $\begin{array}{l}\text { Hausman (Sargan-Hansen) } \\
\text { p value }\end{array}$ & & 9474 & & $\begin{array}{r}8200.00 \\
0\end{array}$ \\
\hline $\begin{array}{l}\text { Wooldridge test } \\
\mathrm{p} \text { value }\end{array}$ & & 355.5 & & $\begin{array}{r}346.495 \\
0\end{array}$ \\
\hline
\end{tabular}

Columnas I y IV: estimación por modelo de efectos fijos. Columnas II y IV: estimación por efectos aleatorios. Estadísticos robustos entre paréntesis: “*”: significativo al 10\%; “**”: significativo al 5\%; “***”: significativo al $1 \%$. 


\section{Cuadro 10}

Resultados de las regresiones de efectos fijos y aleatorios incorporando competencia tributaria horizontal. Clustered robust standard errors por período Variable dependiente: tasa de Ingresos Brutos (parte 2)

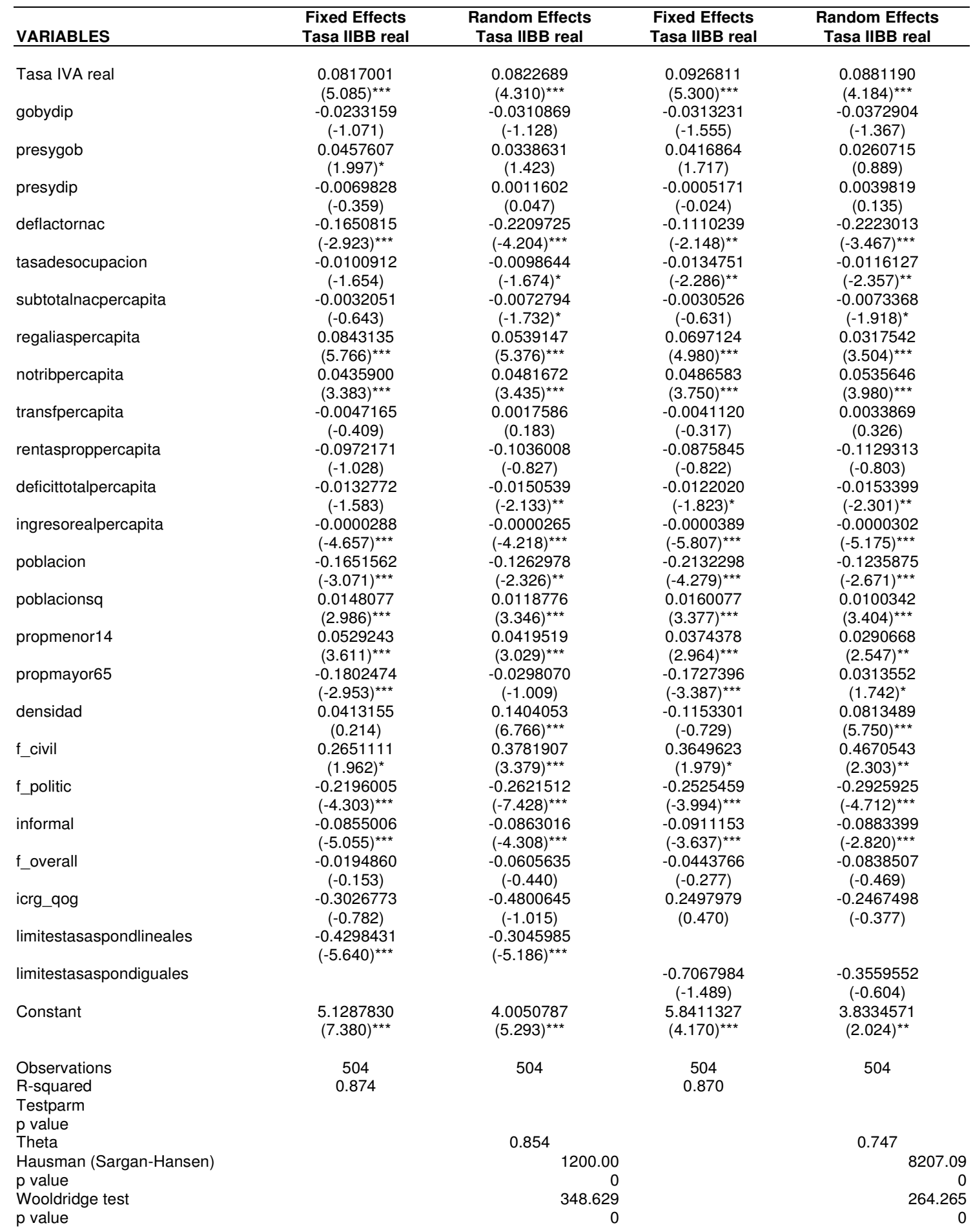

Columnas I y IV: estimación por modelo de efectos fijos. Columnas II y IV: estimación por efectos aleatorios. Estadísticos robustos entre paréntesis: “*”: significativo al 10\%; “**”: significativo al $5 \%$; “***”: significativo al $1 \%$. 


\section{Cuadro 11}

Resultados de las regresiones de efectos fijos y aleatorios incorporando competencia tributaria horizontal. Clustered robust standard errors por período Variable dependiente: productividad ponderada de IIBB (parte 1)

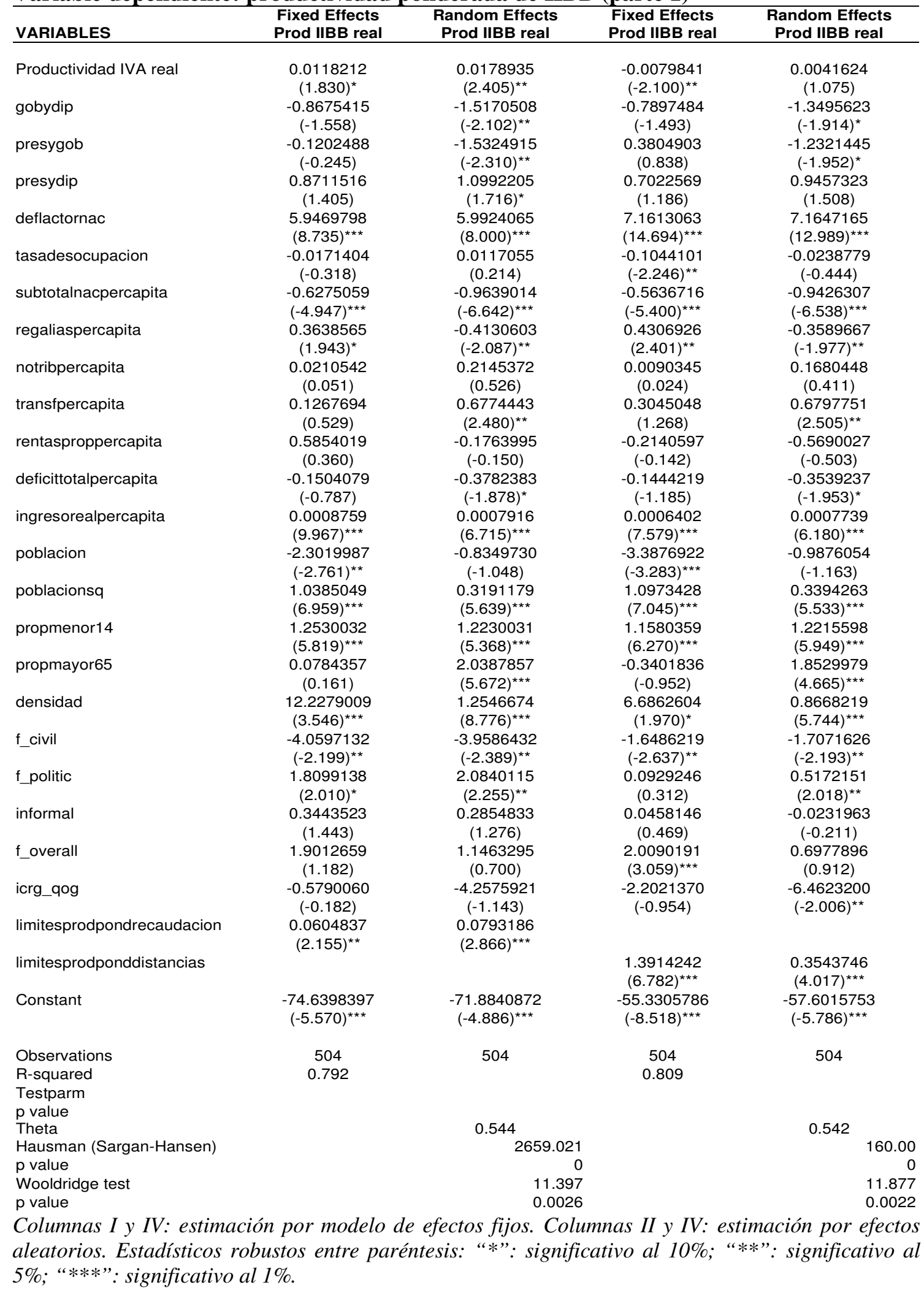




\section{Cuadro 12}

Resultados de las regresiones de efectos fijos y aleatorios incorporando competencia tributaria horizontal. Clustered robust standard errors por período Variable dependiente: productividad ponderada de IIBB (parte 2)

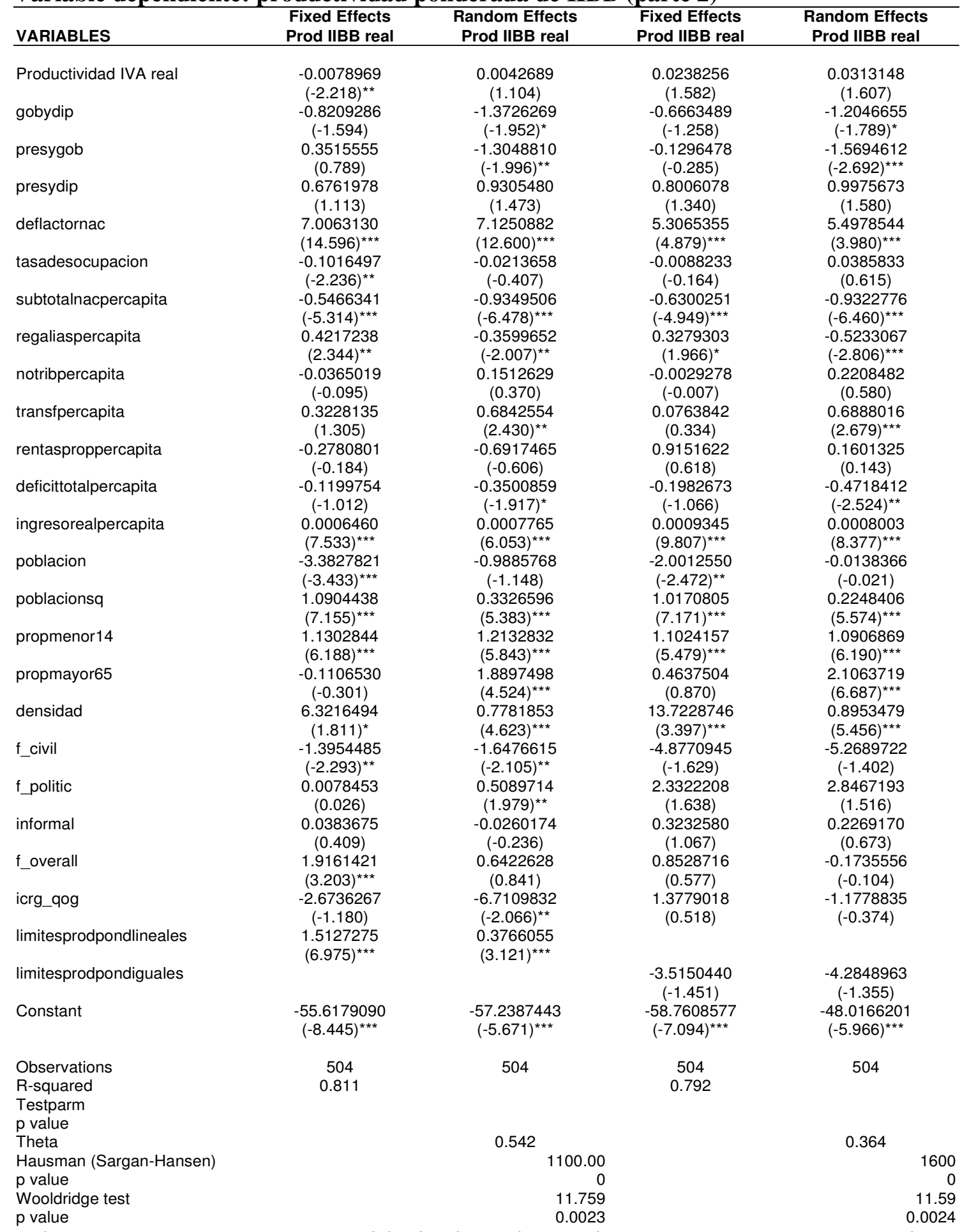

Columnas I y IV: estimación por modelo de efectos fijos. Columnas II y IV: estimación por efectos aleatorios. Estadísticos robustos entre paréntesis: “*”: significativo al 10\%; “**”: significativo al $5 \%$; “***”: significativo al $1 \%$. 


\section{Cuadro 13}

Resultados de las regresiones de efectos fijos y aleatorios incorporando competencia tributaria horizontal. Clustered robust standard errors por período Variable dependiente: tasa efectiva de IIBB (parte 1)

\begin{tabular}{|c|c|c|c|c|}
\hline VARIABLES & $\begin{array}{c}\text { Fixed Effects } \\
\text { Tasa efectiva IIBB real }\end{array}$ & $\begin{array}{c}\text { Random Effects } \\
\text { Tasa efectiva IIBB real }\end{array}$ & $\begin{array}{c}\text { Fixed Effects } \\
\text { Tasa efectiva IIBB real }\end{array}$ & $\begin{array}{c}\text { Random Effects } \\
\text { Tasa efectiva IIBB real }\end{array}$ \\
\hline Tasa efectiva IVA real & $\begin{array}{l}0.5375711 \\
(7.525)^{\star \star \star}\end{array}$ & $\begin{array}{l}0.5482486 \\
(7.060)^{\star * \star}\end{array}$ & $\begin{array}{l}0.5395311 \\
(7.644)^{\star \star \star}\end{array}$ & $\begin{array}{l}0.5480894 \\
(7.294)^{* * \star}\end{array}$ \\
\hline gobydip & $\begin{array}{c}-0.1944470 \\
(-1.381)\end{array}$ & $\begin{array}{c}-0.2107249 \\
(-1.200)\end{array}$ & $\begin{array}{c}-0.1920652 \\
(-1.372)\end{array}$ & $\begin{array}{c}-0.2174714 \\
(-1.306)\end{array}$ \\
\hline presygob & $\begin{array}{c}0.1949287 \\
(1.677)\end{array}$ & $\begin{array}{c}0.1633887 \\
(1.043)\end{array}$ & $\begin{array}{c}0.2093223 \\
(1.764)^{*}\end{array}$ & $\begin{array}{c}0.1877600 \\
(1.404)\end{array}$ \\
\hline presydip & $\begin{array}{c}-0.0968506 \\
(-0.876)\end{array}$ & $\begin{array}{c}-0.0882435 \\
(-0.566)\end{array}$ & $\begin{array}{c}-0.0968230 \\
(-0.865)\end{array}$ & $\begin{array}{c}-0.0755934 \\
(-0.539)\end{array}$ \\
\hline deflactornac & $\begin{array}{c}-0.1358109 \\
(-0.483)\end{array}$ & $\begin{array}{c}-0.4738374 \\
(-1.911)^{*}\end{array}$ & $\begin{array}{c}-0.1266363 \\
(-0.451)\end{array}$ & $\begin{array}{c}-0.4027152 \\
(-1.635)\end{array}$ \\
\hline tasadesocupacion & $\begin{array}{l}-0.0921639 \\
(-2.556)^{\star *}\end{array}$ & $\begin{array}{l}-0.0929194 \\
(-2.498)^{\star *}\end{array}$ & $\begin{array}{l}-0.0929117 \\
(-2.623)^{\star *}\end{array}$ & $\begin{array}{l}-0.0926795 \\
(-2.551)^{\star *}\end{array}$ \\
\hline subtotalnacpercapita & $\begin{array}{c}-0.0145886 \\
(-0.728)\end{array}$ & $\begin{array}{c}-0.0499824 \\
(-2.137)^{\star *}\end{array}$ & $\begin{array}{c}-0.0139121 \\
(-0.710)\end{array}$ & $\begin{array}{c}-0.0398515 \\
(-1.833)^{\star}\end{array}$ \\
\hline regaliaspercapita & $\begin{array}{l}0.3589012 \\
(5.201)^{\star \star \star}\end{array}$ & $\begin{array}{l}0.1658205 \\
(2.913)^{\star * *}\end{array}$ & $\begin{array}{l}0.3757246 \\
(5.351)^{\star \star \star}\end{array}$ & $\begin{array}{l}0.2330359 \\
(3.864)^{\star * \star}\end{array}$ \\
\hline notribpercapita & $\begin{array}{c}-0.0455191 \\
(-0.667)\end{array}$ & $\begin{array}{c}-0.0003877 \\
(-0.006)\end{array}$ & $\begin{array}{c}-0.0340600 \\
(-0.501)\end{array}$ & $\begin{array}{c}-0.0181818 \\
(-0.269)\end{array}$ \\
\hline transfpercapita & $\begin{array}{l}0.1852623 \\
(2.437)^{\star *}\end{array}$ & $\begin{array}{l}0.2153173 \\
(2.238)^{\star *}\end{array}$ & $\begin{array}{c}0.1807962 \\
(2.494)^{\star *}\end{array}$ & $\begin{array}{c}0.2099159 \\
(2.290)^{\star *}\end{array}$ \\
\hline rentasproppercapita & $\begin{array}{c}-1.2027084 \\
(-1.624)\end{array}$ & $\begin{array}{c}-1.4085110 \\
(-1.416)\end{array}$ & $\begin{array}{c}-1.1734382 \\
(-1.533)\end{array}$ & $\begin{array}{c}-1.2915557 \\
(-1.354)\end{array}$ \\
\hline deficittotalpercapita & $\begin{array}{c}-0.0298437 \\
(-0.610)\end{array}$ & $\begin{array}{c}-0.0432503 \\
(-0.957)\end{array}$ & $\begin{array}{c}-0.0355039 \\
(-0.736)\end{array}$ & $\begin{array}{c}-0.0410820 \\
(-0.897)\end{array}$ \\
\hline ingresorealpercapita & $\begin{array}{c}-0.0000896 \\
(-2.646)^{* *}\end{array}$ & $\begin{array}{l}-0.0000588 \\
(-2.176)^{* *}\end{array}$ & $\begin{array}{l}-0.0000856 \\
(-2.453)^{\star *}\end{array}$ & $\begin{array}{c}-0.0000621 \\
(-2.050)^{\star *}\end{array}$ \\
\hline poblacion & $\begin{array}{l}-0.6055787 \\
(-2.620)^{\star *}\end{array}$ & $\begin{array}{c}-0.1767600 \\
(-1.034)\end{array}$ & $\begin{array}{c}-0.5157093 \\
(-2.424)^{\star *}\end{array}$ & $\begin{array}{c}-0.2410082 \\
(-1.566)\end{array}$ \\
\hline poblacionsq & $\begin{array}{l}0.0584697 \\
(4.392)^{\star * \star}\end{array}$ & $\begin{array}{l}0.0312395 \\
(2.501)^{\star *}\end{array}$ & $\begin{array}{l}0.0530805 \\
(4.681)^{\star * *}\end{array}$ & $\begin{array}{l}0.0396493 \\
(3.433)^{\star * *}\end{array}$ \\
\hline propmenor14 & $\begin{array}{l}0.2639675 \\
(4.589)^{\star * \star}\end{array}$ & $\begin{array}{l}0.1947263 \\
(5.215)^{\star * *}\end{array}$ & $\begin{array}{l}0.2829390 \\
(4.931)^{\star \star \star}\end{array}$ & $\begin{array}{l}0.2208249 \\
(5.233)^{\star * \star}\end{array}$ \\
\hline propmayor65 & $\begin{array}{l}-1.1775791 \\
(-4.461)^{\star * \star}\end{array}$ & $\begin{array}{c}-0.1526936 \\
(-1.417)\end{array}$ & $\begin{array}{l}-1.2271626 \\
(-4.453)^{\star * \star}\end{array}$ & $\begin{array}{l}-0.3959775 \\
(-2.873)^{\star \star \star}\end{array}$ \\
\hline densidad & $\begin{array}{c}-1.0711131 \\
(-1.482)\end{array}$ & $\begin{array}{l}0.4383690 \\
(4.066)^{* * *}\end{array}$ & $\begin{array}{c}-0.8629622 \\
(-1.074)\end{array}$ & $\begin{array}{l}0.6391705 \\
(4.011)^{* * *}\end{array}$ \\
\hline f_civil & $\begin{array}{l}1.7033253 \\
(2.441)^{\star *}\end{array}$ & $\begin{array}{l}2.5044238 \\
(3.688)^{\star * \star}\end{array}$ & $\begin{array}{c}1.6705302 \\
(2.370)^{\star *}\end{array}$ & $\begin{array}{l}2.3376358 \\
(3.448)^{\star * \star}\end{array}$ \\
\hline f_politic & $\begin{array}{l}-0.8850003 \\
(-3.272)^{\star * *}\end{array}$ & $\begin{array}{l}-1.1939785 \\
(-4.831)^{\star * \star}\end{array}$ & $\begin{array}{l}-0.8947669 \\
(-3.338)^{\star * *}\end{array}$ & $\begin{array}{l}-1.1470932 \\
(-4.696)^{\star * *}\end{array}$ \\
\hline informal & $\begin{array}{l}-0.5685425 \\
(-6.496)^{\star * \star}\end{array}$ & $\begin{array}{l}-0.5888225 \\
(-5.422)^{\star * *}\end{array}$ & $\begin{array}{l}-0.5744942 \\
(-6.492)^{\star * \star}\end{array}$ & $\begin{array}{l}-0.5872105 \\
(-5.610)^{\star * \star}\end{array}$ \\
\hline f_overall & $\begin{array}{c}-0.8656803 \\
(-1.328)\end{array}$ & $\begin{array}{c}-1.2366975 \\
(-1.603)\end{array}$ & $\begin{array}{c}-0.8063159 \\
(-1.243)\end{array}$ & $\begin{array}{c}-1.1235479 \\
(-1.519)\end{array}$ \\
\hline icrg_qog & $\begin{array}{l}-9.4494201 \\
(-4.352)^{\star * \star}\end{array}$ & $\begin{array}{c}-11.6604530 \\
(-3.963)^{\star \star \star}\end{array}$ & $\begin{array}{l}-9.3603757 \\
(-4.254)^{\star * \star}\end{array}$ & $\begin{array}{c}-11.1755487 \\
(-4.043)^{\star \star \star}\end{array}$ \\
\hline limitestasasefnomrecaudacion & $\begin{array}{c}-0.1775529 \\
(-0.978)\end{array}$ & $\begin{array}{c}-0.0768976 \\
(-0.399)\end{array}$ & & \\
\hline limitestasasefnomdistancias & & & $\begin{array}{c}-0.3166262 \\
(-1.341)\end{array}$ & $\begin{array}{c}-0.1936454 \\
(-0.844)\end{array}$ \\
\hline Constant & $\begin{array}{l}30.4505702 \\
(13.698)^{\star \star \star}\end{array}$ & $\begin{array}{c}24.4388025 \\
(6.494)^{\star \star \star}\end{array}$ & $\begin{array}{l}30.6124899 \\
(13.838)^{\star \star \star}\end{array}$ & $\begin{array}{c}25.4773129 \\
(6.884)^{\star \star \star}\end{array}$ \\
\hline $\begin{array}{l}\text { Observations } \\
\text { R-squared } \\
\text { Testparm } \\
\text { p value }\end{array}$ & $\begin{array}{c}504 \\
0.792\end{array}$ & 504 & $\begin{array}{c}504 \\
0.792\end{array}$ & 504 \\
\hline Theta & & 0.743 & & 0.836 \\
\hline Hausman (Sargan-Hansen) & & 5100.00 & & 1500.00 \\
\hline$p$ value & & 0 & & $\begin{array}{r}0 \\
193.795\end{array}$ \\
\hline $\begin{array}{l}\text { Wooldridge test } \\
\text { p value }\end{array}$ & & $\begin{array}{r}196.428 \\
0\end{array}$ & & $\begin{array}{r}193.795 \\
0\end{array}$ \\
\hline
\end{tabular}

Columnas I y IV: estimación por modelo de efectos fijos. Columnas II y IV: estimación por efectos aleatorios. Estadísticos robustos entre paréntesis: “*”: significativo al 10\%; “**”: significativo al 5\%; “***”: significativo al $1 \%$. 


\section{Cuadro 14}

Resultados de las regresiones de efectos fijos y aleatorios incorporando competencia tributaria horizontal. Clustered robust standard errors por período Variable dependiente: tasa efectiva de IIBB (parte 2)

\begin{tabular}{|c|c|c|c|c|}
\hline VARIABLES & $\begin{array}{c}\text { Fixed Effects } \\
\text { Tasa efectiva IIBB real }\end{array}$ & $\begin{array}{c}\text { Random Effects } \\
\text { Tasa efectiva IIBB real }\end{array}$ & $\begin{array}{c}\text { Fixed Effects } \\
\text { Tasa efectiva IIBB real }\end{array}$ & $\begin{array}{c}\text { Random Effects } \\
\text { Tasa efectiva IIBB real }\end{array}$ \\
\hline Tasa efectiva IVA real & $\begin{array}{l}0.5465069 \\
(7.761)^{\star \star \star}\end{array}$ & $\begin{array}{l}0.5518688 \\
(7.393)^{\star \star \star}\end{array}$ & $\begin{array}{l}0.5495654 \\
(7.389)^{\star \star \star}\end{array}$ & $\begin{array}{l}0.5525478 \\
(7.199)^{\star \star \star}\end{array}$ \\
\hline gobydip & $\begin{array}{c}-0.1928819 \\
(-1.391)\end{array}$ & $\begin{array}{c}-0.2166212 \\
(-1.270)\end{array}$ & $\begin{array}{c}-0.2031277 \\
(-1.346)\end{array}$ & $\begin{array}{c}-0.0907974 \\
(-0.441)\end{array}$ \\
\hline presygob & $\begin{array}{c}0.2066243 \\
(1.754)^{*}\end{array}$ & $\begin{array}{c}0.1733085 \\
(1.255)\end{array}$ & $\begin{array}{l}0.1754989 \\
(1.343)\end{array}$ & $\begin{array}{c}0.2418922 \\
(1.166)\end{array}$ \\
\hline presydip & $\begin{array}{c}-0.0885701 \\
(-0.785)\end{array}$ & $\begin{array}{c}-0.0691998 \\
(-0.478)\end{array}$ & $\begin{array}{c}-0.0905809 \\
(-0.744)\end{array}$ & $\begin{array}{c}-0.2658773 \\
(-1.258)\end{array}$ \\
\hline deflactornac & $\begin{array}{c}-0.0801829 \\
(-0.278)\end{array}$ & $\begin{array}{c}-0.4013006 \\
(-1.617)\end{array}$ & $\begin{array}{c}-0.1156057 \\
(-0.374)\end{array}$ & $\begin{array}{l}-0.5729523 \\
(-2.279)^{\star \star}\end{array}$ \\
\hline tasadesocupacion & $\begin{array}{l}-0.0936976 \\
(-2.698)^{\star *}\end{array}$ & $\begin{array}{l}-0.0928272 \\
(-2.567)^{\star \star}\end{array}$ & $\begin{array}{l}-0.0954030 \\
(-2.787)^{\star \star}\end{array}$ & $\begin{array}{l}-0.1084133 \\
(-3.433)^{\star \star *}\end{array}$ \\
\hline subtotalnacpercapita & $\begin{array}{c}-0.0103159 \\
(-0.555)\end{array}$ & $\begin{array}{l}-0.0416491 \\
(-1.962)^{\star *}\end{array}$ & $\begin{array}{c}-0.0128491 \\
(-0.614)\end{array}$ & $\begin{array}{l}-0.0594360 \\
(-3.200)^{\star * *}\end{array}$ \\
\hline regaliaspercapita & $\begin{array}{l}0.3918282 \\
(5.471)^{\star \star \star}\end{array}$ & $\begin{array}{l}0.2236216 \\
(3.809)^{* * *}\end{array}$ & $\begin{array}{l}0.3686233 \\
(5.170)^{* * \star}\end{array}$ & $\begin{array}{c}0.0071552 \\
(0.163)\end{array}$ \\
\hline notribpercapita & $\begin{array}{c}-0.0274914 \\
(-0.412)\end{array}$ & $\begin{array}{c}-0.0093088 \\
(-0.139)\end{array}$ & $\begin{array}{c}-0.0471140 \\
(-0.666)\end{array}$ & $\begin{array}{l}0.1590157 \\
(2.396)^{\star \star}\end{array}$ \\
\hline transfpercapita & $\begin{array}{c}0.1685191 \\
(2.460)^{\star \star}\end{array}$ & $\begin{array}{c}0.2057869 \\
(2.268)^{\star \star}\end{array}$ & $\begin{array}{c}0.1871124 \\
(2.430)^{\star *}\end{array}$ & $\begin{array}{c}0.1559802 \\
(2.115)^{\star \star}\end{array}$ \\
\hline rentasproppercapita & $\begin{array}{c}-1.1900590 \\
(-1.577)\end{array}$ & $\begin{array}{c}-1.3190691 \\
(-1.369)\end{array}$ & $\begin{array}{c}-1.2084187 \\
(-1.649)\end{array}$ & $\begin{array}{c}-1.9289469 \\
(-1.705)^{*}\end{array}$ \\
\hline deficittotalpercapita & $\begin{array}{c}-0.0410966 \\
(-0.839)\end{array}$ & $\begin{array}{c}-0.0453473 \\
(-0.998)\end{array}$ & $\begin{array}{c}-0.0250402 \\
(-0.512)\end{array}$ & $\begin{array}{c}-0.0669946 \\
(-1.525)\end{array}$ \\
\hline ingresorealpercapita & $\begin{array}{l}-0.0000837 \\
(-2.380)^{\star *}\end{array}$ & $\begin{array}{c}-0.0000583 \\
(-1.914)^{*}\end{array}$ & $\begin{array}{l}-0.0001043 \\
(-3.065)^{\star * *}\end{array}$ & $\begin{array}{l}-0.0000520 \\
(-2.150)^{\star *}\end{array}$ \\
\hline poblacion & $\begin{array}{l}-0.5481768 \\
(-2.550)^{\star *}\end{array}$ & $\begin{array}{c}-0.2228667 \\
(-1.431)\end{array}$ & $\begin{array}{l}-0.6060562 \\
(-2.396)^{* *}\end{array}$ & $\begin{array}{l}0.1587226 \\
(1.125)\end{array}$ \\
\hline poblacionsq & $\begin{array}{l}0.0555343 \\
(4.586)^{\star * *}\end{array}$ & $\begin{array}{l}0.0381903 \\
(3.251)^{* * *}\end{array}$ & $\begin{array}{l}0.0560582 \\
(4.843)^{* \star *}\end{array}$ & $\begin{array}{l}0.0037733 \\
(0.368)\end{array}$ \\
\hline propmenor14 & $\begin{array}{l}0.3031732 \\
(5.065)^{\star \star \star}\end{array}$ & $\begin{array}{l}0.2274494 \\
(5.271)^{\star \star \star}\end{array}$ & $\begin{array}{l}0.2498962 \\
(5.519)^{\star \star \star}\end{array}$ & $\begin{array}{l}0.1505587 \\
(4.479)^{\star \star \star}\end{array}$ \\
\hline propmayor65 & $\begin{array}{l}-1.2693231 \\
(-4.481)^{\star * *}\end{array}$ & $\begin{array}{l}-0.3377608 \\
(-2.651)^{* * *}\end{array}$ & $\begin{array}{l}-1.2438551 \\
(-4.573)^{\star \star \star}\end{array}$ & $\begin{array}{c}-0.0190265 \\
(-0.295)\end{array}$ \\
\hline densidad & $\begin{array}{c}-0.6286137 \\
(-0.748)\end{array}$ & $\begin{array}{l}0.6116089 \\
(4.254)^{\star \star \star}\end{array}$ & $\begin{array}{c}-1.5069003 \\
(-2.251)^{\star *}\end{array}$ & $\begin{array}{l}0.2502891 \\
(5.398)^{\star \star \star}\end{array}$ \\
\hline f_civil & $\begin{array}{l}1.6509109 \\
(2.343)^{\star *}\end{array}$ & $\begin{array}{l}2.3873518 \\
(3.518)^{\star \star *}\end{array}$ & $\begin{array}{l}1.7850772 \\
(2.373)^{\star *}\end{array}$ & $\begin{array}{l}2.5923491 \\
(3.195)^{\star \star \star}\end{array}$ \\
\hline f_politic & $\begin{array}{l}-0.9116185 \\
(-3.481)^{\star \star *}\end{array}$ & $\begin{array}{l}-1.1773139 \\
(-4.872)^{\star \star \star}\end{array}$ & $\begin{array}{l}-0.9384675 \\
(-2.499)^{* *}\end{array}$ & $\begin{array}{l}-1.2500048 \\
(-3.243)^{* * *}\end{array}$ \\
\hline informal & $\begin{array}{l}-0.5870361 \\
(-6.607)^{\star \star *}\end{array}$ & $\begin{array}{l}-0.5967535 \\
(-5.551)^{\star * *}\end{array}$ & $\begin{array}{l}-0.5930110 \\
(-4.711)^{\star \star \star}\end{array}$ & $\begin{array}{l}-0.5992315 \\
(-3.947)^{\star * *}\end{array}$ \\
\hline f_overall & $\begin{array}{c}-0.7396400 \\
(-1.146)\end{array}$ & $\begin{array}{c}-1.1198257 \\
(-1.503)\end{array}$ & $\begin{array}{c}-0.8282624 \\
(-1.253)\end{array}$ & $\begin{array}{c}-1.1951924 \\
(-1.532)\end{array}$ \\
\hline icrg_qog & $\begin{array}{l}-9.3585451 \\
(-4.192)^{\star * *}\end{array}$ & $\begin{array}{l}-11.3220640 \\
(-3.999)^{* * *}\end{array}$ & $\begin{array}{l}-9.4015021 \\
(-4.464)^{* * *}\end{array}$ & $\begin{array}{l}-11.9049019 \\
(-3.822)^{* * *}\end{array}$ \\
\hline limitestasasefnomlineales & $\begin{array}{c}-0.4868742 \\
(-1.891)^{*}\end{array}$ & $\begin{array}{c}-0.2737700 \\
(-1.094)\end{array}$ & & \\
\hline limitestasasefnomiguales & & & $\begin{array}{c}-0.4647577 \\
(-0.450)\end{array}$ & $\begin{array}{c}-0.1628815 \\
(-0.153)\end{array}$ \\
\hline Constant & $\begin{array}{l}31.1009133 \\
(13.691)^{\star \star \star}\end{array}$ & $\begin{array}{c}25.4356570 \\
(6.789)^{\star \star \star}\end{array}$ & $\begin{array}{c}33.4399251 \\
(4.699)^{\star \star \star}\end{array}$ & $\begin{array}{c}25.6471854 \\
(3.303)^{\star \star \star}\end{array}$ \\
\hline Observations & 504 & 504 & 504 & 504 \\
\hline $\begin{array}{l}\text { R-squared } \\
\text { Testparm } \\
\text { p value }\end{array}$ & 0.795 & & 0.791 & \\
\hline $\begin{array}{l}\text { Theta } \\
\text { Wald for groupwise hetero }\end{array}$ & & 0.818 & & 0.363 \\
\hline Hausman (Sargan-Hansen) & & 1600.00 & & 4800.00 \\
\hline$p$ value & & 0 & & 0 \\
\hline $\begin{array}{l}\text { Wooldridge test } \\
\text { p value }\end{array}$ & & $\begin{array}{r}195.551 \\
0\end{array}$ & & $\begin{array}{r}197.795 \\
0\end{array}$ \\
\hline
\end{tabular}

Columnas I y IV: estimación por modelo de efectos fijos. Columnas II y IV: estimación por efectos aleatorios. Estadísticos robustos entre paréntesis: “*”: significativo al 10\%; “**”: significativo al $5 \%$; “***”: significativo al $1 \%$. 


\section{Cuadro 15}

Resultados de las regresiones de efectos fijos y aleatorios incorporando competencia tributaria horizontal. Clustered robust standard errors por período Variable dependiente: tasa efectiva de IIBB cadena agroindustrial (parte 1)

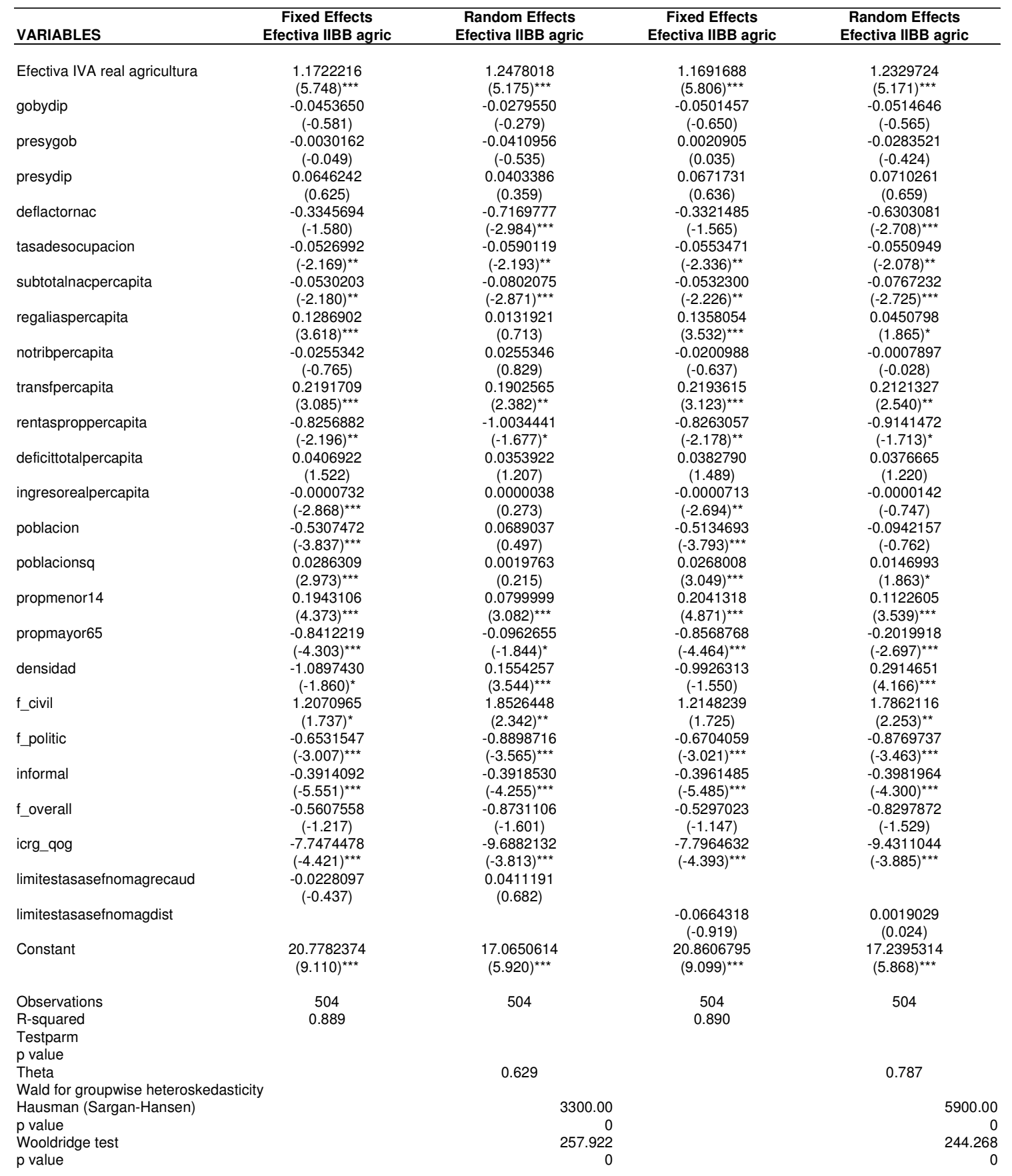

Columnas I y IV: estimación por modelo de efectos fijos. Columnas II y IV: estimación por efectos aleatorios. Estadísticos robustos entre paréntesis: “*”: significativo al 10\%; “**”: significativo al $5 \%$; “***”: significativo al $1 \%$. 


\section{Cuadro 16}

Resultados de las regresiones de efectos fijos y aleatorios incorporando competencia tributaria horizontal. Clustered robust standard errors por período Variable dependiente: tasa efectiva de IIBB cadena agroindustrial (parte 2)

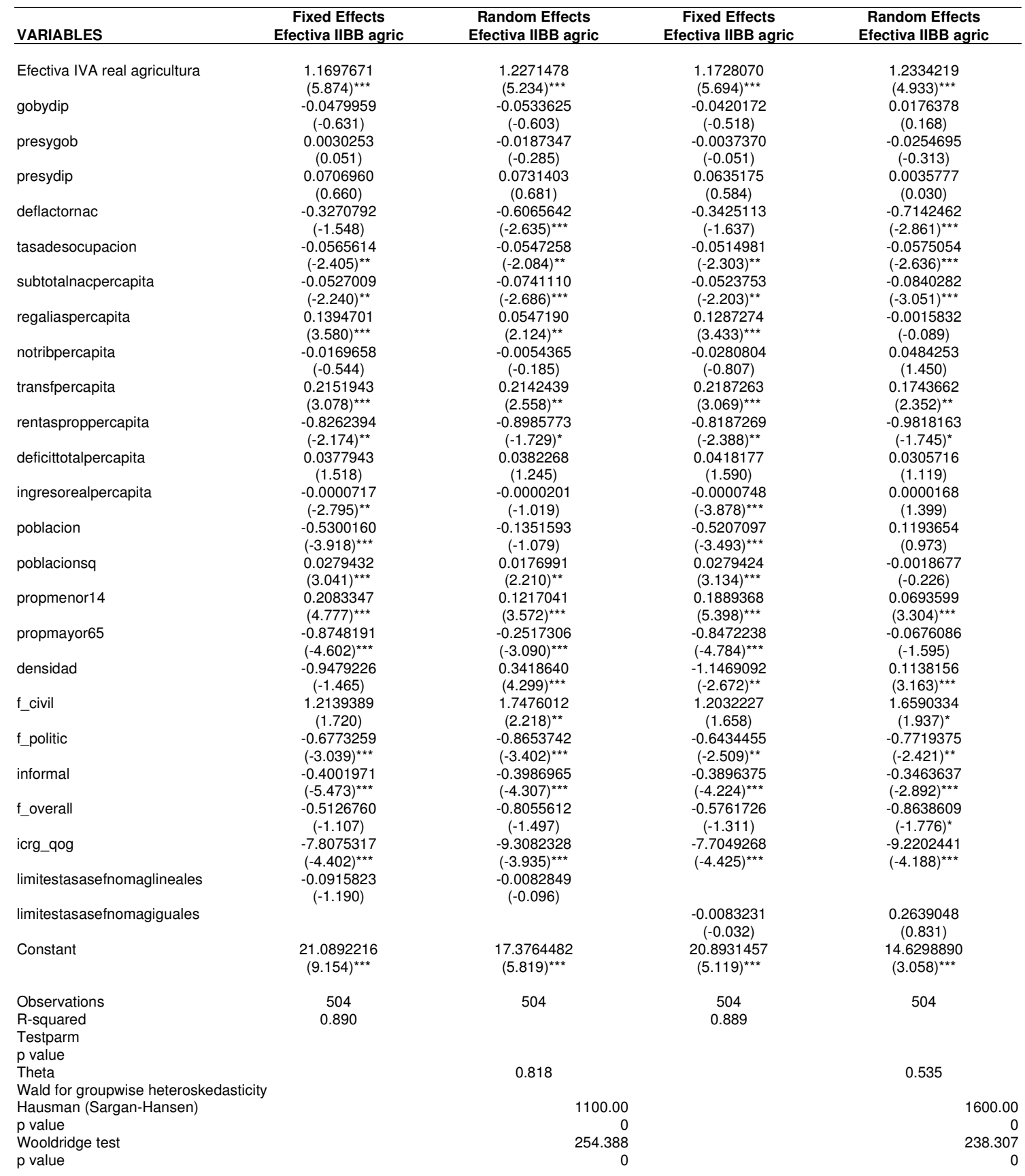

Columnas I y IV: estimación por modelo de efectos fijos. Columnas II y IV: estimación por efectos aleatorios. Estadísticos robustos entre paréntesis: “*”: significativo al 10\%; “**”: significativo al 5\%; “***”: significativo al $1 \%$. 


\section{Cuadro 17}

Resultados de las regresiones de efectos fijos y aleatorios incorporando competencia tributaria horizontal. Clustered robust standard errors por período con time effects Variable dependiente: tasa efectiva de IIBB cadena agroindustrial

\begin{tabular}{|c|c|c|c|c|}
\hline VARIABLES & $\begin{array}{c}\text { FE time effects } \\
\text { Efectiva IIBB agric }\end{array}$ & $\begin{array}{c}\text { FE time effects } \\
\text { Efectiva IIBB agric }\end{array}$ & $\begin{array}{c}\text { FE time effects } \\
\text { Efectiva IIBB agric }\end{array}$ & $\begin{array}{c}\text { FE time effects } \\
\text { Efectiva IIBB agric }\end{array}$ \\
\hline Efectiva IVA real agricultura & $\begin{array}{c}2.5099763 \\
(1.696)\end{array}$ & $\begin{array}{c}2.4999754 \\
(1.710)\end{array}$ & $\begin{array}{c}2.4832404 \\
(1.700)\end{array}$ & $\begin{array}{c}2.0022396 \\
(1.361)\end{array}$ \\
\hline gobydip & $\begin{array}{c}-0.1464864 \\
(-1.731)^{*}\end{array}$ & $\begin{array}{c}-0.1455724 \\
(-1.742)^{*}\end{array}$ & $\begin{array}{c}-0.1356113 \\
(-1.640)\end{array}$ & $\begin{array}{c}-0.1107929 \\
(-1.058)\end{array}$ \\
\hline presygob & $\begin{array}{c}0.0576675 \\
(1.271)\end{array}$ & $\begin{array}{c}0.0717131 \\
(1.598)\end{array}$ & $\begin{array}{c}0.0720085 \\
(1.632)\end{array}$ & $\begin{array}{c}0.0608919 \\
(1.111)\end{array}$ \\
\hline presydip & $\begin{array}{c}-0.0326337 \\
(-0.359)\end{array}$ & $\begin{array}{c}-0.0312327 \\
(-0.338)\end{array}$ & $\begin{array}{c}-0.0266760 \\
(-0.288)\end{array}$ & $\begin{array}{c}-0.0088960 \\
(-0.099)\end{array}$ \\
\hline deflactornac & $\begin{array}{c}1.9386689 \\
(0.756)\end{array}$ & $\begin{array}{c}1.8907727 \\
(0.746)\end{array}$ & $\begin{array}{c}1.8552867 \\
(0.732)\end{array}$ & $\begin{array}{c}-2.4617064 \\
(-0.892)\end{array}$ \\
\hline tasadesocupacion & $\begin{array}{c}-0.0500260 \\
(-2.721)^{\star \star}\end{array}$ & $\begin{array}{l}-0.0522024 \\
(-2.846)^{\star \star \star}\end{array}$ & $\begin{array}{c}-0.0523879 \\
(-2.831)^{* \star}\end{array}$ & $\begin{array}{c}-0.0353892 \\
(-2.048)^{*}\end{array}$ \\
\hline subtotalnacpercapita & $\begin{array}{l}-0.0767030 \\
(-3.554)^{\star \star *}\end{array}$ & $\begin{array}{c}-0.0776296 \\
(-3.721)^{\star \star *}\end{array}$ & $\begin{array}{c}-0.0765332 \\
(-3.694)^{\star \star *}\end{array}$ & $\begin{array}{c}-0.0473650 \\
(-1.946)^{*}\end{array}$ \\
\hline regaliaspercapita & $\begin{array}{l}0.0875877 \\
(3.010)^{\star \star \star}\end{array}$ & $\begin{array}{l}0.1003887 \\
(3.328)^{\star * \star}\end{array}$ & $\begin{array}{l}0.1041595 \\
(3.431)^{\star * \star}\end{array}$ & $\begin{array}{l}0.0861064 \\
(3.051)^{\star \star \star}\end{array}$ \\
\hline notribpercapita & $\begin{array}{c}-0.0340984 \\
(-1.217)\end{array}$ & $\begin{array}{c}-0.0272282 \\
(-1.034)\end{array}$ & $\begin{array}{c}-0.0254434 \\
(-0.959)\end{array}$ & $\begin{array}{c}-0.0776367 \\
(-1.741)^{*}\end{array}$ \\
\hline transfpercapita & $\begin{array}{l}0.2137894 \\
(3.356)^{\star \star \star}\end{array}$ & $\begin{array}{l}0.2130579 \\
(3.437)^{\star * \star}\end{array}$ & $\begin{array}{l}0.2054309 \\
(3.334)^{\star * \star}\end{array}$ & $\begin{array}{l}0.1828078 \\
(3.209)^{\star \star \star}\end{array}$ \\
\hline rentasproppercapita & $\begin{array}{c}-0.2821075 \\
(-0.793)\end{array}$ & $\begin{array}{c}-0.2499410 \\
(-0.693)\end{array}$ & $\begin{array}{c}-0.2431481 \\
(-0.677)\end{array}$ & $\begin{array}{c}-0.3530543 \\
(-0.957)\end{array}$ \\
\hline deficittotalpercapita & $\begin{array}{c}-0.0033868 \\
(-0.149)\end{array}$ & $\begin{array}{c}-0.0076803 \\
(-0.358)\end{array}$ & $\begin{array}{c}-0.0075673 \\
(-0.359)\end{array}$ & $\begin{array}{c}0.0127055 \\
(0.484)\end{array}$ \\
\hline ingresorealpercapita & $\begin{array}{c}-0.0000366 \\
(-2.057)^{\star}\end{array}$ & $\begin{array}{c}-0.0000315 \\
(-1.694)\end{array}$ & $\begin{array}{c}-0.0000328 \\
(-1.779)^{\star}\end{array}$ & $\begin{array}{l}-0.0000442 \\
(-2.255)^{\star *}\end{array}$ \\
\hline poblacion & $\begin{array}{c}-0.3502480 \\
(-2.770)^{\star *}\end{array}$ & $\begin{array}{c}-0.2940878 \\
(-2.425)^{\star *}\end{array}$ & $\begin{array}{c}-0.3214581 \\
(-2.640)^{* \star}\end{array}$ & $\begin{array}{c}-0.2889955 \\
(-2.080)^{*}\end{array}$ \\
\hline poblacionsq & $\begin{array}{l}0.0251188 \\
(3.033)^{* * *}\end{array}$ & $\begin{array}{c}0.0208671 \\
(2.431)^{\star *}\end{array}$ & $\begin{array}{c}0.0231658 \\
(2.694)^{* *}\end{array}$ & $\begin{array}{c}0.0087327 \\
(0.960)\end{array}$ \\
\hline propmenor14 & $\begin{array}{l}0.1031695 \\
(4.904)^{\star * \star}\end{array}$ & $\begin{array}{l}0.1131750 \\
(5.390)^{\star \star \star}\end{array}$ & $\begin{array}{l}0.1140500 \\
(4.964)^{\star * \star}\end{array}$ & $\begin{array}{l}0.0713353 \\
(3.816)^{\star \star \star}\end{array}$ \\
\hline propmayor65 & $\begin{array}{c}-0.4085805 \\
(-3.681)^{\star * \star}\end{array}$ & $\begin{array}{l}-0.4213810 \\
(-4.218)^{\star \star \star}\end{array}$ & $\begin{array}{c}-0.4459446 \\
(-4.560)^{\star \star \star}\end{array}$ & $\begin{array}{c}-0.4496091 \\
(-4.423)^{\star \star \star}\end{array}$ \\
\hline densidad & $\begin{array}{c}0.2569369 \\
(0.677)\end{array}$ & $\begin{array}{c}0.4863944 \\
(1.126)\end{array}$ & $\begin{array}{c}0.5147848 \\
(1.183)\end{array}$ & $\begin{array}{c}-0.5895853 \\
(-1.460)\end{array}$ \\
\hline f_politic & $\begin{array}{c}-1.0684846 \\
(-1.455)\end{array}$ & $\begin{array}{c}-1.0827979 \\
(-1.481)\end{array}$ & $\begin{array}{c}-1.0844783 \\
(-1.480)\end{array}$ & $\begin{array}{c}-4.3248441 \\
(-3.163)^{* * *}\end{array}$ \\
\hline informal & $\begin{array}{c}0.1028521 \\
(0.265)\end{array}$ & $\begin{array}{c}0.0888191 \\
(0.232)\end{array}$ & $\begin{array}{c}0.0772672 \\
(0.202)\end{array}$ & $\begin{array}{l}-1.6744092 \\
(-3.285)^{\star \star \star}\end{array}$ \\
\hline limitestasasefnomagrecaud & $\begin{array}{c}-0.0633374 \\
(-1.931)^{*}\end{array}$ & & & \\
\hline limitestasasefnomagdist & & $\begin{array}{l}-0.1324481 \\
(-4.333)^{\star \star \star}\end{array}$ & & \\
\hline limitestasasefnomaglineales & & & $\begin{array}{l}-0.1508917 \\
(-4.833)^{\star \star \star}\end{array}$ & \\
\hline limitestasasefnomagiguales & & & & $\begin{array}{l}-5.4521995 \\
(-3.481)^{\star \star *}\end{array}$ \\
\hline Constant & $\begin{array}{c}-13.3871226 \\
(-0.439)\end{array}$ & $\begin{array}{c}-12.8988303 \\
(-0.429)\end{array}$ & $\begin{array}{c}-12.0550068 \\
(-0.402)\end{array}$ & $\begin{array}{c}93.0584222 \\
(2.263)^{\star *}\end{array}$ \\
\hline Observations & 504 & 504 & 504 & 504 \\
\hline R-squared & 0.915 & 0.916 & 0.916 & 0.923 \\
\hline $\begin{array}{l}\text { Testparm } \\
\text { p value }\end{array}$ & $\begin{array}{r}42411.5 \\
0\end{array}$ & $\begin{array}{r}89943.39 \\
0\end{array}$ & $\begin{array}{r}28940.35 \\
0\end{array}$ & $\begin{array}{r}36569.92 \\
0\end{array}$ \\
\hline
\end{tabular}

Estadísticos robustos entre paréntesis: “*”: significativo al 10\%; “**”: significativo al 5\%; “***”: significativo al $1 \%$. 


\section{Cuadro 18}

Transacciones económicas involucradas en la cadena trigo/harina/pan en base a matriz insumo-producto 1997 actualizada al año 2005 (Millones de \$ corrientes)

\begin{tabular}{|c|l|r|}
\hline \multirow{5}{*}{} & Componentes del valor de producción del bien CEREALES & \multicolumn{1}{|c|}{ Valor } \\
\cline { 2 - 3 } & Actividad CULTIVO DE CEREALES & 10,351 \\
& Otras actividades e importaciones & 1,459 \\
& Retenciones a la exportación & 1,405 \\
& Impuestos indirectos y aranceles & 215 \\
\cline { 2 - 3 } CEREA & Total oferta del bien CEREALES & $\mathbf{1 3 , 4 3 0}$ \\
\cline { 2 - 3 } LES & Destino de la producción del bien CEREALES & \multicolumn{1}{|c|}{ Valor } \\
\cline { 2 - 3 } & Insumo para actividad MOLIENDA DE TRIGO & 2,396 \\
& Insumo para otras actividades & 2,669 \\
& Exportaciones & 8,158 \\
& Consumo final & 0 \\
& Otros destinos (stocks) & 207 \\
\cline { 2 - 3 } & Total demanda del bien CEREALES & $\mathbf{1 3 , 4 3 0}$ \\
\hline
\end{tabular}

\begin{tabular}{|c|c|c|}
\hline & Estructura de costos de la actividad MOLIENDA DE TRIGO & Valor \\
\hline & Consumo intermedio del bien CEREALES & 2,396 \\
\hline & Consumo intermedio de otros bienes & 1,804 \\
\hline & Remuneración de factores productivos & 785 \\
\hline & Total costos de actividad MOLIENDA DE TRIGO & 4,985 \\
\hline & Actividad MOLIENDA DE TRIGO produce PRODUCTOS DE MOLINERIA & 4,286 \\
\hline & Actividad MOLIENDA DE TRIGO produce otros bienes & 699 \\
\hline & Componentes del valor de producción del bien PRODUCTOS DE MOLINERIA & Valor \\
\hline & Actividad MOLIENDA DE TRIGO & 4,286 \\
\hline MOLIE & Otras actividades e importaciones & 501 \\
\hline NDA & Retenciones a la exportación & 12 \\
\hline & Impuestos indirectos y aranceles & 374 \\
\hline & Total oferta de PRODUCTOS DE MOLINERIA & 5,173 \\
\hline & Destino de la producción del bien PRODUCTOS DE MOLINERIA & Valor \\
\hline & Insumo para actividad PANADERIAS & 2,194 \\
\hline & Insumo para otras actividades & 1,510 \\
\hline & Exportaciones & 283 \\
\hline & Consumo final & 1,108 \\
\hline & Otros destinos (stocks) & 78 \\
\hline & Total demanda del bien PRODUCTOS DE MOLINERIA & 5,173 \\
\hline
\end{tabular}

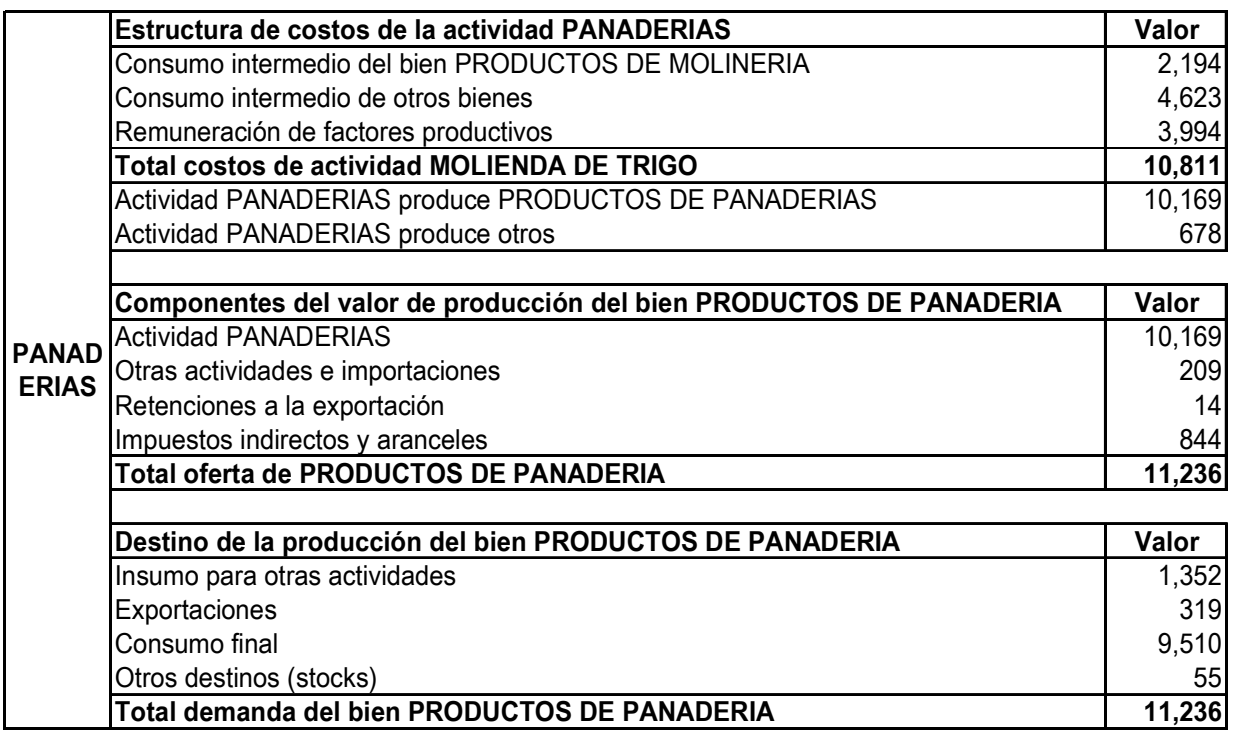

Fuente: Nogués, J. y Porto, A., (2007) en base a MIP 1997 actualizada al 2005 (Porto, Piffano y Di Gresia, 2007). 


\section{Referencias bibliográficas}

AFIP (2005): “Estimación del incumplimiento en el IVA. Años 2000 a 2004" AFIP, Dirección de Estudios

AFIP (2006): "Estimación del incumplimiento en el IVA. Año 2005” AFIP, Dirección de Estudios

AFIP (2007): "Estimación del incumplimiento en el IVA. Año 2006” AFIP, Dirección de Estudios

AFIP (2008): “Estimación del incumplimiento en el IVA. Año 2007” AFIP, Dirección de Estudios

Aghón, G. y Krause-Junk, G. (1996): “Descentralización Fiscal en América Latina. Balance y principales desafíos”. Proyecto de Descentralización Fiscal CEPAL-GTZ

Ahmad, E., Hewitt, D. y Ruggiero, E. (1997): “Assigning Expenditure Responsibilities”, en Ter Minassian, T. (ed.) "Fiscal Federalism in Theory and Practice", International Monetary Fund

Atkinson, A., y Stern N. H. (1974): "Pigou, Taxation and Public Goods" The Review of Economic Studies, Vol. 41, No. 1.

Atkinson, A. y Stiglitz, J. (1980): “'Lectures on Public Economics,” McGraw-Hill, New York Baca-Campodónico, J., de Mello, L. y Kirilenko, A. (2006): “The Rates and Revenue of Bank Transaction Taxes", Economics Department Working Papers No. 494, OECD

Besley, T.J., y Rosen, H.S. (1998): "Vertical Externalities in Tax Setting: Evidence from Gasoline and Cigarettes". Journal of Public Economics 70

Boadway, R. y Hayashi, M. (2002): “An Empirical Analysis of Intergovernmental Tax Interaction: the Case of Business Income Taxes in Canada" Canadian Journal of Economics, 34

Boadway, R. y Keen, M., (1996): "Efficiency and the Optimal Direction for Federal-State Transfers".International Tax and Public Finance 3.

Boadway, R., Marchand, M. y Vigneault, M. (1998): “The Consequences of Overlapping Tax Bases for Redistribution and Public Spending In A Federation” Journal of Public Economics 68 (1998) 453-478 
Brennan, G. y Buchanan, J. (1980): “The Power to Tax: Analytical Foundations to a Fiscal Constitution", Cambridge University Press

Brulhart, M. y Jametti, M. (2006): "Vertical versus Horizontal Tax Externalities: an Empirical Test", Journal of Public Economics, 90

Cameron, C., Gelbach, J. y Miller, D. (2011): "Robust Inference with Multi-way Clustering", Journal of Business and Economic Statistics

Cameron, C. y Trivedi, P. (2005): "Microeconometrics. Methods and Applications" Cambridge University Press

Cameron, C. y Trivedi, P. (2009): “Microeconometrics Using Stata” Stata Press Publication

Cont, W. (2004): "Evasión en el Impuesto al Valor Agregado en Argentina en el año 2004", en FIEL, "La presión tributaria sobre el sector formal en la Argentina"

Cullen, J. y Gordon, R. (2008): "Deductibility of State and Local Taxes: Is There a Case for Continuing this Tax Expenditure? mimeo UCLA

Dahlby, B. (2001): “The Incentive Effects of Fiscal Equalization Grants", paper presented at the AIMS/MEI/FCPP Conference on "Equalization: Welfare Trap or Helping Hand?" Montreal, Canada.

Dahlby, B. Mintz, J. y Wilson, S. (2000): “The Deductibility of Provincial Business Taxes in a Federation with Vertical Fiscal Externalities" Canadian Journal of Economics 0 Revue Canadienne D'economique, Vol. 33, No. 3

Dahlby, B., y Wilson, L. (2003): "Vertical Fiscal Externalities in a Federation", Journal of Public Economics 87

Davoodi, H. y G. Grigorian (2007): “Tax Potential vs. Tax Effort: A Cross-Country Analysis of Armenia's Stubbornly Low Tax Collection”. IMF Working Paper No. 106

Devereux, M., Lockwood B., y Redoano M. (2007): "Horizontal and Vertical Indirect Tax Competition: Theory and Some Evidence from the USA”, Journal of Public Economics, 91

Diamond, P. y Mirrlees, J. (1971): “Optimal Taxation and Public Production, I. Production efficiency, II. Tax Rules, American Economic Review, 61, 8_27 \& 261_278

Durán Cabré, J., Esteller Moré A. y Salvadori, L. (2012): “Empirical Evidence on Horizontal Competition in Tax Enforcement", Documento de trabajo 2012/5, Instituto d'Economia de Barcelona 
Esteller-Moré, A. y Solé-Ollé, A. (2000): "Vertical Income Tax Externalities and Fiscal Interdependence: Evidence From The U.S”. Departament d'Hisenda Pública, Universitat de Barcelona.

Esteller-Moré, A. y Solé-Ollé, A. (2001): "An Empirical Analysis of Vertical Tax Externalities: The Case of Personal Income Taxation In Canada". Departament d'Hisenda Pública, Universitat de Barcelona.

Esteller-Moré, A., y Solé-Ollé, A (2002): "Tax Setting in a Federal System: The Case of Personal Income Taxation in Canada". International Tax and Public Finance 9

Esteller Moré A. y Rizzo, L. (2009): "Identification of Vertical Tax Externalities in Consumption: An Application to the US Case", mimeo

Esteller Moré A. y Rizzo, L. (2011): “(Uncontrolled) Aggregate Shocks or Vertical Tax Interdependence? Evidence From Gasoline And Cigarettes” National Tax Journal 64, 2

Feldstein M. y Metcalf G. (1986): “The Effect of Federal Tax Deductibility on State and Local Taxes and Spending” NBER Working Paper Series Working Paper No. 1791

Fenge, R. y Wrede, M. (2004): "EU Regional Policy: Vertical Fiscal Externalities and Matching Grants" Cesifo Working Paper No. 1146 Category 1: Public Finance

Fernández, G. (2004): “Tax Increment Financing: Interaction between Two Overlapping Jurisdictions" Journal of Urban Economics 55 151-164

Flochel, L., y Madiès, T. (2002): "Interjurisdictional Tax Competition in a Federal System of Overlapping Revenue Maximizing Governments, International Tax and Public Finance 9 121141.

Fredriksson, P.G., y Mamun, K. (2008): "Vertical externalities in cigarette taxation: Do tax revenues go up in smoke?", Journal of Urban Economics, 64, 35-48.

Goodspeed, T J. (2000): “Tax Structure in a Federation”, Journal of Public Economics, 75

Gordon, R. (1982): “An Optimal Taxation Approach to Fiscal Federalism” NBER Working Paper Series Working Paper No. 10014

Gómez Sabaini, J. y Rossignolo, D. (2009): “Argentina. Análisis de la situación tributaria y propuestas de reformas impositivas destinadas a mejorar la distribución del ingreso", en S. Keifman: "Reflexiones y propuestas para mejorar la distribución del ingreso en Argentina", Oficina de la Organización Internacional del Trabajo en Buenos Aires 
Gupta, A. (2007): "Determinants of Tax Revenue Efforts in Developing Countries" IMF Working Paper WP/07/184

Hayashi, M. y Boadway, R. (2001): “An Empirical Analysis of Intergovernmental Tax Interaction: The Case of Business Income Taxes in Canada" Canadian Journal of Economics Vol 34 Nro. 2

Holtz-Eakin, D. y Rosen, H. (1987): "Tax Deductibility And Municipal Budget Structure" Working Paper No. 2224, National Bureau Of Economic Research

Hoyt, W. (2001): “Tax Policy Coordination, Vertical Externalities, and Optimal Taxation in a System of Hierarchical Governments" Journal of Urban Economics 50

Jacobs, J., Ligthart, J. y Vrijburg, H. (2007): “Consumption Tax Competition among Governments: Evidence from the United States", mimeo Tilburg University

Janeba, E. y Wilson, J. (2009): "Optimal Fiscal Federalism in the Presence of Tax Competition”, mimeo University of Mannheim and Michigan State University

Karakosta, O., y Kotsogiannis, C. (2006): "Imperfect Competition, Principles of Commodity Taxation and Tax Inefficiencies in Federal Systems" mimeo Athens University and University of Exeter

Kanbur, R. y M. Keen (1991): “Jeux sans Frontiers: Tax Competition and Tax Coordination When Provinces Differ in Size”, University of Essex Discussion Paper No. 385

Kanbur, R. y M. Keen (1993): "Jeux sans Frontiers: Tax Competition and Tax Coordination When Provinces Differ in Size", American Economic Review, Vol. 83 No. 4.

Keen, M. (1998): "Vertical Tax Externalities in the Theory of Fiscal Federalism" IMF Staff Papers Vol. 45, No. 3

Keen, M. y Kotsogiannis C. (2002 a): "Does Federalism Lead to Excessively High Taxes?" American Economic Review Vol. 92 No. 1

Keen, M. y Kotsogiannis, C. (2002 b): "Tax Competition in Federations and the Welfare Consequences of Decentralization" mimeo International Monetary Fund and University of Exeter

Keen, M. y Kotsogiannis C. (2003): "Leviathan and Tax Competition in Federations” Journal of Public Economic Theory, 5 
Kelders, C. y Koethenbuerger, M. (2009): “Tax Incentives in Fiscal Federalism: an Integrated Perspective" Mimeo University of Copenhagen

Kothenburger, M. (2002): "Tax Competition and Fiscal Equalization" International Tax and Public Finance; Aug 2002; 9, 4; Abi/Inform Global

Kotsogiannis, Ch. (2010): "Federal Tax Competition and the Efficiency Consequences for Local Taxation of Revenue Equalization" International Tax Public Finance 17

Libonatti, O. (1998): “La imposición sobre los Ingresos Brutos” en FIEL (comp.) "La reforma tributaria en la Argentina"

Lockwood, B. (2001): “Tax Competition and Tax Co-ordination under Destination and Origin Principles: a Synthesis” Journal of Public Economics 81

Lockwood, B. (2004): “Competition in Unit vs. Ad Valorem Taxes" International Tax and Public Finance, Volume 11

Lucas, V., (2004): “Cross-border Shopping in a Federal Country", Regional Science and Urban Economics 34 (4)

Macón, J. (1998): “Armonización fiscal en el Cono Sur”, Consejo Federal de Inversiones.

Madiès, T. (2004): "Interjurisdictional Tax Competition and Vertical Externalities When States Provide Industrial Public Goods: A Note" Paper prepared for the $60^{\text {th }}$ Conference of International Institute of Public Finance, Milan.

Madiès, T. (2008): "Do Vertical Tax Externalities Lead To Tax Rates Being Too High? A Note" Annals of Regional Science 42

Martínez-López, D. (2005): "Fiscal Federalism and Public Inputs Provision Vertical Externalities Matter” Working Paper Series No. 484 / May 2005 European Central Bank

Martorano, B. y Cornia, G. (2011): “The IDLA Dataset: a Tool to Analyze Recent Changes in Income Inequality in L.A.” UNU - WIDER's Research Project on “The New Policy Model, Inequality and Poverty in Latin America: Evidence from the Last Decade and Prospects for the Future"

Murray, M. (2006): "Avoiding Invalid Instruments and Coping with Weak Instruments", Journal of Economic Perspectives-Volume 20, Number 4-Fall 2006-Pages 111-132

Nogués, J. y Porto, A., (2007): "Evaluación de impactos económicos y sociales de políticas públicas en la Cadena Agroindustrial” Foro de la Cadena Agroindustrial Argentina 
Oates, W. (1972): “Fiscal Federalism”, Harcourt Brace Jovanovich, New York.

Oates, W. (1985): "Searching for Leviathan: An Empirical Study", The American Economic Review, Vol. 75, No. 4. pp. 748-757.

Oates, W. (1999): “An Essay on Fiscal Federalism”, Journal of Economic Literature Vol. XXXVII (September 1999) pp. 1120-1149

Oates, W. (2002): "Fiscal Competition or Harmonization? Some Reflections" National Tax Journal Vol. LIV, No. 3

Pecho, M., Peláez, F. y Sánchez, J. (2012): “Estimación del incumplimiento tributario en América Latina 2000-2010”, Documento de trabajo No. 3, Dirección de Estudios e Investigaciones Tributarias, Centro Interamericano de Administraciones Tributarias.

Pessino, C. y Fenocchietto, R. (2010): “Determining Countries' Tax Effort” Revista de Economía Pública 195-4/2010, Instituto de Estudios Fiscales Hacienda Pública Española

Petersen, M. (2009): "Estimating standard errors in finance panel data sets: Comparing approaches" Review of Financial Studies 22(1): 435-480

Piffano, H. (2005): "Fiscal Decentralization, Tax Competition, and Federal Tax Administration: A Note from the Argentine Experience" Revista de Economía y Estadística Vol. XLIII, Instituto de Economía y Finanzas-Facultad de Ciencias Económicas, Universidad Nacional de Córdoba - Argentina

Porto, A. (2004): "La teoría económica del federalismo fiscal y las finanzas federales", en Porto, A. (ed.) “Disparidades Regionales y Federalismo Fiscal”. Ed. Universitaria de La Plata. Porto, A. y Di Gresia, L. (2007): "El Resultado Fiscal de las Provincias: ¿Exógeno o Endógeno? Una Mirada de Mediano Plazo" Documento de Trabajo Nro. 73, Departamento de Economía, Facultad de Ciencias Económicas, Universidad Nacional de La Plata

Rizzo, L. (2008): “Interaction between Vertical and Horizontal Tax Competition: Evidence and Some Theory". MPRA Paper No. 8632

Rork, Jonathan C., 2003. “Coveting Thy Neighbors' Taxation.” National Tax Journal 56 (4), $775-787$.

Santiere, J. J., Gómez Sabaini, J. C. y Rossignolo, D. (2000): “Impacto de los impuestos sobre la distribución del ingreso en Argentina en 1997”, Banco Mundial, SPEyR, Ministerio de Economía. 
Stock, J., Wright, J. y Yogo, M. (2002): “A Survey of Weak Instruments and Weak Identification in Generalized Method of Moments" Journal of Business \& Economic Statistics October 2002, Vol. 20, No. 4

Stotsky, J. y WoldeMariam, A. (1997): “Tax Effort in the Sub-Saharan Africa”, International Monetary Fund, Working Paper WP/97/107

Touya, F. (2009): "Tax Interactions with Asymmetric Information and Nonlinear Instruments" CATT WP No. 9. Centre d'Analyse Théorique et de Traitement des données économiques, Université de Pau et des Pays de l'Adour

Vigneault, M. y Boadway, R. (1996): “The Interaction of Federal and Provincial Taxes on Businesses” Working Paper 96-11, Paper Prepared for the Technical Committee on Business Taxation

Wang, Y. (1999): “Commodity Taxes Under Fiscal Competition: Stackelberg Equilibrium and Optimality" American Economic Review, Vol. 89 No. 4

Wigger, B. y Wartha, U. (2004): "Vertical Tax Externalities and the Composition of Public Spending in a Federation" Economics Letters 84

Wildasin, D. (2005): “Fiscal Competition” IFIR Working Paper No. 2005-05

Wilson, J. (1986): “A Theory of Interregional Tax Competition”, Journal of Urban Economics 19.

Wilson, J. (1999): “Theories of Tax Competition”, National Tax Journal 52, Vol. 2.

Wilson, J. (2005): "Tax Competition in a Federal Setting", revised version of the paper prepared for the conference, "Fiscal Decentralization: Analysis and Perspectives," Bocconi University, 2003.

Wooldridge, J.M. (2002): "Econometric Analysis of Cross-Section and Panel Data", MIT Press

Wrede, M. (1996): "Vertical and Horizontal Tax Competition: Will Uncoordinated Leviathans End Up on the Wrong Side of the Laffer Curve? Finanzarchiv NF 53

Wrede, M. (2000): "Shared Tax Sources and Public Expenditure", International Tax and Public Finance, Volume 7, Number 2

Zodrow, G., y Mieszkowski (1986): "Pigou, Tiebout, Property Taxation, and the Underprovision of Local Public Goods", Journal of Urban Economics 19. 